\title{
LOS TRABAJOS
}

PREPARATORIOS DE LA DECLARACIÓN AMERICANA DE LOS DERECHOS Y DEBERES DEL HOMBRE Y DEL ORIGEN REMOTO DE LA CORTE INTERAMERICANA

\section{ÂlVAro PAÚl}


LOS TRABAJOS PREPARATORIOS DE LA DEGLARAGIÓN AMERICANA DE LOS DERECHOS Y DEBERES DEL HOMBRE Y EL ORIGEN REMOTO DE LA CORTE INTERAMERICANA 


\section{INSTITUTO DE INVESTIGACIONES JURÍDICAS}

Serie DoGTRINA JuRÍDiCA, núm. 810

\section{COORDINAGIÓN EDITORIAL}

Lic. Raúl Márquez Romero

Secretario Técnico

Lic. Wendy Vanesa Rocha Cacho

Jefa del Departamento de Publicaciones

Diana Luján Verón

Gilda Bautista Ravelo

Cuidado de la edición

Hector Arias Escamilla

Apoyo editorial

Gilda Bautista Ravelo

Diana Luján Verón

Formación en computadora

Carlos Martín Aguilera Ortiz

Elaboración de portada 
ÁLVARO PAÚL

\section{LOS TRABAJOS PREPARATORIOS DE LA DEGLARAGIÓN AMERICANA DE LOS DEREGHOS Y DEBERES DEL HOMBRE Y EL ORIGEN REMOTO DE LA CORTE INTERAMERICANA}
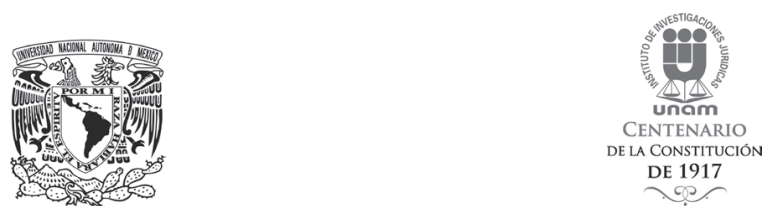

UNIVERSIDAD NACIONAL AUTÓNOMA DE MÉXICO INSTITUTO DE INVESTIGACIONES JURÍDICAS 
Primera edición: 24 de octubre de 2017

DR (C) 2017. Universidad Nacional Autónoma de México

\section{INSTITUTO DE INVESTIGACIONES JURÍDICAS}

Circuito Maestro Mario de la Cueva s/n

Ciudad de la Investigación en Humanidades

Ciudad Universitaria, 04510 Ciudad de México

Impreso y hecho en México

ISBN 978-607-02-9613-0 
A la causa de nuestra alegría 


\section{CONTENIDO}

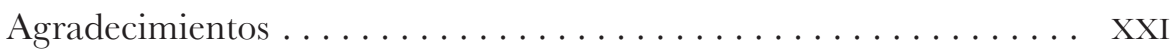
Abreviaturas ............................. XXII

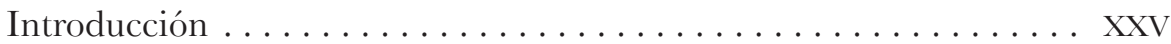

\section{CAPÍTULO PRIMERO \\ RELEVANCIA HISTÓRICA Y JURÍDICA DE LA DEGLARAGIÓN}

I. Cuestiones preliminares $\ldots \ldots \ldots \ldots \ldots \ldots \ldots \ldots \ldots \ldots$

II. Relación entre las declaraciones americana y universal. . . . . . . 2

III. Valor jurídico de la Declaración. . . . . . . . . . . . . . . 5

1. Percepciones sobre el valor jurídico de la Declaración ...... 5

2. La Declaración y el artículo 29 de la Convención Americana. . 15

IV. Uso que los órganos del sistema interamericano le dan a la Decla-

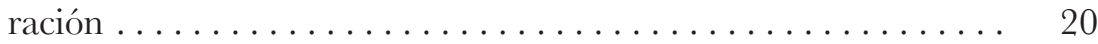

1. Uso por parte de la Comisión . . . . . . . . . . . . . 20

2. Uso por parte de la Corte $\ldots \ldots \ldots \ldots \ldots \ldots \ldots \ldots .24$

3. Ejemplo de uso de los trabajos preparatorios de la Declaración . 27

\section{Gapítulo SEgundo \\ CONTEXTO HISTÓRICO AL ELABORAR LA DECLARACIÓN}

I. Contexto mundial y latinoamericano. . . . . . . . . . 33

II. El Bogotazo . . . . . . . . . . . . . . . . . . . . . 39 
III. Novena Conferencia y la Declaración Americana. . . . . . . . . . 41

1. Antecedentes del acercamiento americano ........... 41

2. La Novena Conferencia y su organización ............ 43

\section{CAPÍtUlo TERCERO}

\section{TRABAJOS PREPARATORIOS DE LA DECLARACIÓN Y DEL GERMEN DE LA CORTE INTERAMERICANA}

I. Algunas cuestiones relevantes que se aprecian en los trabajos preparatorios......................... 47

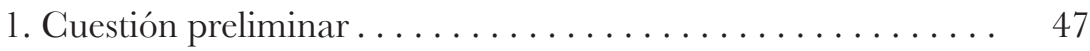

2. La dignidad como fuente de los derechos . . . . . . . . 47

3. A modo de control de convencionalidad .............. 50

4. La Comisión Consultiva Interamericana de los Derechos del

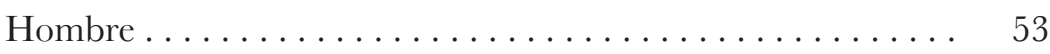

5. Otras discusiones . . . . . . . . . . . . . . 55

II. Origen remoto de la Corte Interamericana . . . . . . . . . . 56

Conclusiones .......................... 63

Bibliografía ................................. 65

\section{AnEXOs $^{*}$}

I. Notas formales sobre este anexo . . . . . . . . . . . . 75

II. Conferencias Internacionales Americanas (Segundo Suplemento) 79

1. Conferencia Interamericana sobre Problemas de la Guerra y

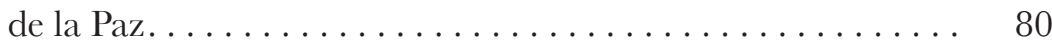

1.1. Nota preliminar. . . . . . . . . . . . . . 80

1.2. Conferencia Interamericana sobre Problemas de la Guerra

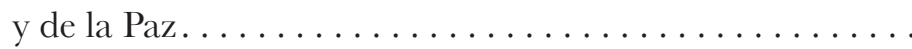

* La numeración de los títulos de este índice no se encuentra en los anexos. Ella se incluye para efectos de entregar una mayor claridad. Por su parte, los títulos del tercer nivel del punto 4 están con paréntesis cuadrados en los anexos, para indicar que ellos no forman parte de los documentos originales, sino que fueron agregados en esta edición. 
1.3. Programa de la Conferencia Interamericana sobre Problemas de la Guerra y de la Paz . . . . . . . . . . . . . . . 82

1.4. Acta final. . . . . . . . . . . . . . . . . . . . 82

1.5. Texto de las Resoluciones . . . . . . . . . . . . . . 83

1.5.1. IX: Reorganización, Consolidación y Fortalecimiento del Sistema Interamericano. . . . . . . . . . . . .

1.5.2. XL: Protección Internacional de los Derechos Esenciales del Hombre.......................... 87

2. Novena Conferencia Internacional Americana . . . . . . . . . . 89

2.1. Introducción . . . . . . . . . . . . . . . . . . 90

2.2. Programa de la Novena Conferencia Internacional Ameri-

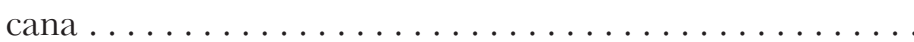

III. Anteproyecto de Declaración de los Derechos y Deberes Internacionales del Hombre e Informe Anexo . . . . . . . . . . . . . .

1. Anteproyecto de Declaración de los Derechos y Deberes Internacionales del Hombre . . . . . . . . . . . . . . . . .

2. Informe anexo al Anteproyecto de Declaración de los Derechos y Deberes Internacionales del Hombre. . . . . . . . . . . . . . . . 104

2.1. Razones por las cuales el Comité Jurídico presenta una Declaración de los Derechos y Deberes Internacionales del Hombre .

2.2. Antecedentes de la aspiración a una Declaración de los Derechos y Deberes Internacionales del Hombre . . . . . . . . . 105

2.3. Medidas especiales encaminadas a promover el respeto a los derechos fundamentales del hombre . . . . . . . . 107

2.4. Proyectos anteriormente elaborados por asociaciones privadas. . . . . ..................... 109

2.5. Alcance de una declaración internacional de derechos . . 110

2.6. Análisis detallado de derechos y deberes ........... 112

2.6.1. Artículo I: Derecho a la vida . . . . . . . . . . . . 112

2.6.2. Artículo II: Derecho a la libertad individual . . . . . . . 113

2.6.3. Artículo III: Derecho de libertad de palabra y de expresión ........................... 114

2.6.4. Artículo IV: Derecho de libertad religiosa......... 118

2.6.5. Artículo V: Derecho de libertad de reunión ....... 119 
2.6.6. Artículo VI: Derecho de libertad de asociación . . . . 120

2.6.7. Artículo VII: Derecho de petición. . . . . . . . . . . 121

2.6.8. Artículo VIII: Derecho de propiedad . . . . . . . . . . 122

2.6.9. Artículo IX: Derecho de nacionalidad .......... 124

2.6.10. Artículo X: Derecho de libertad de relaciones familiares. . . . . . . . . . . . . . . . . . . . . . 125

2.6.11. Artículo XI: Derecho de protección contra la prisión arbitraria . . . . . . . . . . . . . . . . . . . . . 127

2.6.12. Artículo XII: Derecho a proceso regular. . . . . . . . 128

2.6.13. Artículo XIII: Derecho de sufragio . . . . . . . . . . 128

2.6.14. Artículo XIV: Derecho al trabajo ............. 130

2.6.15. Artículo XV: Derecho de participar en los beneficios de la ciencia......................... 132

2.6.16. Artículo XVI: Derecho de seguro social . . . . . . . 133

2.6.17. Artículo XVII: Derecho a la educación ......... 135

2.6.18. Artículo XVIII: Derecho de igualdad ante la ley . . 136

2.6.19. Artículo XIX: Derechos y deberes correlativos. . . . 139

2.6.20. Artículo XX: Incorporación de la declaración en las leyes nacionales . . . . . . . . . . . . . . . . . . . 139

2.6.21. Artículo XXI: Procedimiento en casos concernientes a extranjeros . . . ................... 139

2.7. Ideales políticos y posibilidades prácticas . . . . . . . . . . 140

2.8. Una norma internacional para la protección de los derechos fundamentales..................... 141

IV. Novena Conferencia Internacional Americana. Actas y Documentos. Volumen $1 \ldots \ldots \ldots \ldots \ldots \ldots \ldots$. . . . . . . . . . . . . 147

1. Antecedentes de la Conferencia..................... 149

1.1. Invitaciones y aceptaciones . . . . . . . . . . . . . . 149

1.1.1. Mensaje del Canciller de Colombia a los Ministros de Relaciones Exteriores de las Repúblicas Americanas. . . 149

1.1.2. Mensaje del Canciller de Colombia al Director General de la Unión Panamericana. . . . . . . . . . . . . . . . . 149

1.1.3. Mensaje del Canciller de Colombia al Secretario General de las Naciones Unidas .................. 150 
2. Reunión Preliminar ....................... 151

2.1. Acta de la primera parte de la reunión preliminar ..... 151

V. Novena Conferencia Internacional Americana. Actas y Documentos. Volumen $\mathrm{V} \ldots \ldots \ldots \ldots \ldots \ldots \ldots \ldots \ldots \ldots \ldots$

1. Sumario general. . . . . . . . . . . . . . . . . 162

2. Programa de la Comisión Sexta. Asuntos Jurídico-Políticos . . 163

3. Documentos correspondientes a la Comisión ........... 164

3.1. Comité Jurídico Interamericano: Proyecto de Declaración de los Derechos y Deberes Internacionales del Hombre.... 3.1.1. Informe anexo al Proyecto Definitivo de Declaración de los Derechos y Deberes Internacionales del Hombre .

3.2. México: Propuesta para que durante las discusiones sobre derechos y deberes internacionales del hombre se tenga a la vista el proyecto de las Naciones Unidas sobre esta materia.

3.3. Uruguay: Propuesta sobre la organización de la competencia internacional para la garantía de los derechos de la persona humana..................................

3.4. Brasil: Proyecto de resolución sobre la creación de una corte interamericana destinada a garantizar los derechos del hom-

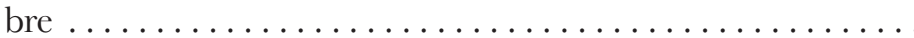

3.5. Brasil: Propuesta de enmiendas al proyecto de Declaración de los Derechos y Deberes Internacionales del Hombre. . . .

3.6. Bolivia: Propuesta de enmiendas al Proyecto de Declaración de los Derechos y Deberes Internacionales del Hombre. . . . . .

3.7. Panamá: Proyecto de Declaración de los Derechos y Libertades Fundamentales del Hombre. . . . . . . . . . . . . . .

3.8. Informe del Relator del Grupo de Trabajo sobre Derechos del Hombre . . . . . . . . . . . . . . . . . . . . . . . . . . .

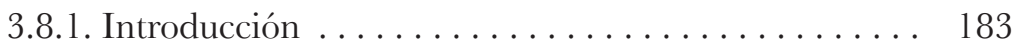

3.8.2. Labor del Grupo de Trabajo . . . . . . . . . . . . . . . . . 184

3.8.3. Proyecto de texto . . . . . . . . . . . . . . . . . . . 187

3.9. Perú: Proyecto de resolución sobre los deberes internacionales del hombre . . . . . . . . . . . . . . . . .

3.10. Haití: Propuesta de enmienda al artículo I del Proyecto de Declaración de los Derechos y Deberes Internacionales del Hombre, sobre la pena de muerte.............. 
3.11. Proyecto de resolución sobre la creación de una corte interamericana destinada a garantizar los derechos del hombre ... 194

3.12. Proyecto de resolución sobre creación de una corte interamericana destinada a garantizar los derechos del hombre...

3.13. Declaración Americana de los Derechos y Deberes Esenciales del Hombre . . . . . . . . . . . . . . . . . . . . . . . . .

3.14. Informe del Relator del Grupo de Trabajo sobre derecho de resistencia ......................... 201

3.15. Informe del Secretario de la Comisión Sexta sobre los documentos aprobados por ella .................. 202

3.16. Declaración Americana de los Derechos y Deberes Esenciales del Hombre . . . . . . . . . . . . . . . . . . . . . 203

3.17. Informe del Relator de la Comisión Sexta . . . . . . . . . 208

4. Sesiones de la Comisión Sexta . . . . . . . . . . . . 215

4.1. Acta de la sesión de instalación de la Comisión Sexta . . . 215

4.1.1. Instalación de la Comisión Sexta. . . . . . . . . . . . 215

4.1.2. Elección del Presidente de la Comisión. . . . . . . . . 216

4.1.3. Elección del Vicepresidente de la Comisión Sexta . . . 220

4.1.4. Elección del Relator de la Comisión Sexta . . . . . . . 221

4.2. Acta de la primera sesión de la Comisión Sexta. . . . . . . 224

4.2.1. Renuncia del Relator y nueva elección ......... . 225

4.2.2. Creación de subcomisiones . . . . . . . . . . . . . . 227

4.3. Acta resumida de la segunda sesión de la Comisión Sexta. 233

4.3.1. Sobre los trabajos de las subcomisiones......... . 234

4.3.2. La Comisión absorbe el trabajo de las subcomisiones. 235

4.3.3. Sobre si la Comisión discutiría el articulado del PDADDH 236

4.4. Acta de la tercera sesión de la Comisión Sexta. . . . . . . . 237

4.4.1. Recapitulación de la sesión anterior ........... 238

4.4.2. Referencia al cuestionario presentado por Uruguay . . 238

4.4.3. Cuba presenta cuatro documentos . . . . . . . . . . 239

4.4.4. Propuestas cubanas de modificaciones al PDADDH . 239

4.4.5. Uruguay comenta la necesidad de una protección internacional de derechos . . . . . . . . . . . . . . . . . . 240 
4.4.6. Observación uruguaya sobre un sistema judicial internacional de protección de derechos ............

4.4.7. Observaciones frente a las propuestas de la Delegación de Uruguay. . . . . . . . . . . . . . . . . . . . . . 244

4.4.8. Discusión sobre la naturaleza jurídica del PDADDH . 247

4.4.9. Se rechaza que el instrumento sea parte del Pacto Constitutivo ............................... 249

4.4.10. Se rechaza la elaboración un tratado . . . . . . . . 249

4.4.11. Se decide elaborar una simple declaración ....... 250

4.4.12. Sobre si el PDADDH debe incluir derechos sociales. 251

4.4.13. Sobre la creación de una competencia judicial internacional........................ 251

4.4.14. Sobre la creación de un tribunal moral . . . . . . . . 253

4.4.15. Designación de un grupo de trabajo para la elaboración de un proyecto definitivo . . . . . . . . . . . . . 254

4.4.16. Observaciones del Relator. . . . . . . . . . . . . . 259

4.5. Acta de la cuarta sesión de la Comisión Sexta ... . . . . 260

4.5.1. Proyecto de recomendación de crear una corte interamericana..................... 261

4.5.2. Otras observaciones sobre una corte interamericana . 263

4.5.3. Se propone declarar que incumbe al Estado hacer respetar los derechos en su jurisdicción ............. 264

4.5.4. Organización de la discusión del PDADDH preparado por el Grupo de Trabajo ..................... 265

4.5.5. Consideraciones generales sobre el PDADDH . . . . 265

4.5.6. Observación uruguaya sobre el fortalecimiento internacional de las garantías humanas. . . . . . . . . 266

4.5.7. Observación uruguaya sobre la gratuidad de la educación ............................. 266

4.5.8. Observación uruguaya sobre la frase "prestar servicio de armas" ....................... 267

4.5.9. Sobre el deber de abstenerse de actividades políticas en el extranjero ............................ 267

4.5.10. Observación estadounidense sobre el desequilibrio entre derechos y deberes ..................... 269 
4.6. Acta resumida de la quinta sesión de la Comisión Sexta . . 270 4.6.1. Apertura del debate sobre el articulado del PDADDH 270 4.6.2. Sobre los considerandos. . . . . . . . . . . . . . . 270

4.6.3. Sobre el Preámbulo . . . . . . . . . . . . . . . . 271

4.6.4. Aprobación sin observaciones de los derechos a la vida, libertad, seguridad e integridad, a la igualdad ante la ley y a la libertad religiosa y de culto (Arts. I-III) . . . . . . . . 271

4.6.5. Aprobación del derecho de libertad de investigación, opinión, expresión y difusión (Art. IV). . . . . . . . . .

4.6.6. Aprobación del derecho de protección a la honra, la reputación personal y la vida privada y familiar (Art. V) .

4.6.7. Aprobación sin observaciones de los derechos a la familia y su protección, a la protección de la maternidad y la infancia, y al derecho de residencia y tránsito (Arts. VI-VIII) .

4.6.8. Aprobación del derecho de inviolabilidad del domicilio (Art. IX) ...........................

4.6.9. Aprobación del derecho a la inviolabilidad y circulación de la correspondencia (Art. X) . . . . . . . .

4.6.10. Aprobación del derecho a la preservación de la salud y al bienestar (Art. XI) . . . . . . . . . . . . . . . . . 272

4.6.11. Aprobación del derecho a la educación (Art. XII) . . 273

4.6.12. Aprobación del derecho a los beneficios de la cultura (Art. XIII) . . . . . . . . . . . . . . . .

4.6.13. Aprobación sin observaciones del derecho al trabajo y a una justa retribución y al descanso y su aprovechamiento $($ Arts. XIV-XV) . . . . . . . . . . . . . . .

4.7. Acta resumida de la sexta sesión de la Comisión Sexta ...

4.7.1. Cuba se reserva el derecho de presentar un artículo sobre el derecho de resistencia. . . . . . . . . . . . . . . . 277

4.7.2. Aprobación del derecho a la seguridad social (Art. XVI) 278

4.7.3. Aprobación del derecho de reconocimiento de la personalidad jurídica y de los derechos civiles (Art. XVII). . . 279

4.7.4. Aprobación del derecho de justicia (Art. XVIII) . . . . 280

4.7.5. Aprobación del derecho de nacionalidad (Art. XIX) . 281

4.7.6. Aprobación del derecho de sufragio y participación en el gobierno $($ Art. XX) . . . . . . . . . . . . . 
4.7.7. Aprobación del derecho de reunión (Art. XXI) . . . . .

4.7.8. Aprobación sin observaciones del derecho de asociación

(Art. XXII) . . . . . . . . . . . . . . . . . . . . . 285

4.7.9. Aprobación del derecho de propiedad (Art. XXIII) . . 285

4.8. Acta resumida de la séptima sesión de la Comisión Sexta . 286

4.8.1. Rechazo de propuesta haitiana de reconsiderar artícu-

los ya aprobados . . . . . . . . . . . . . . . 286

4.8.2. Aprobación sin modificaciones de los derechos de petición y de protección contra la detención (Arts. XXIV-XXV) . . . . 287

4.8.3. Aprobación del derecho a proceso regular (Art. XXVI) 287

4.8.4. Aprobación del derecho de asilo (Art. XXVII) . . . . . 287

4.8.5. Discusión y aprobación de la propuesta de agregar el "Derecho de Resistencia" ... . . . . . . . . . . . . . . . . 288

4.8.6. Aprobación del artículo sobre el alcance de los derechos del hombre (Art. XXIX, ex XXVIII) . . . . . . . . . . . . . . 289

4.8.7. Aprobación del proyecto de resolución sobre una corte

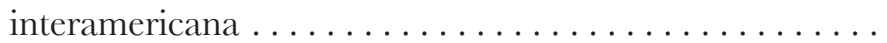

4.8.8. Propuesta dominicana de señalar que el listado de derechos no es taxativo . . . . . . . . . . . . . . . . 290

4.8.9. Aprobación de la propuesta estadounidense de reconsiderar un artículo ya aprobado . . . . . . . . . . . . 290

4.9. Acta resumida de la octava sesión de la Comisión Sexta .. 291

4.9.1. Modificación del derecho a la preservación de la salud y al bienestar (Art. XI) . . . . . . . . . . . . .

4.9.2. Rechazo de la propuesta de redacción del derecho de resistencia y aplazamiento de su discusión . . . . . . . . 292

4.9.3. Apertura de la discusión sobre los deberes del hombre . 294

4.9.4. Aprobación de tres nuevos deberes y de un preámbulo adicional ............................ 294

4.9.5. Aprobación de los deberes ante la sociedad (Art. XXIX) 295

4.9.6. Aprobación de los deberes para con los hijos y los padres (Art. XXX) . . . . . . . . . . . . . . . . . . . 295

4.9.7. Aprobación sin observaciones de los deberes de instruc-

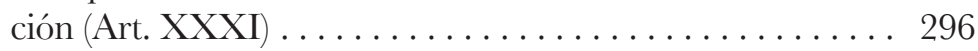

4.9.8. Aprobación del deber de sufragio (Art. XXXII) . . . . 296 
4.9.9. Aprobación sin observaciones del deber de obediencia a la ley (Art. XXXIII) . . . . . . . . . . . . . .

4.9.10. Aprobación del deber de servir a la comunidad y a la Nación (Art. XXXIV) . . . . . . . . . . . . . . . . . 297

4.9.11. Aprobación de los deberes de asistencia y seguridad sociales (Art. XXXV) . . . . . . . . . . . . . . . . . . 298

4.9.12. Aprobación del deber de pagar impuestos (Art. XXXVI) 298

4.9.13. Aprobación del deber de trabajo (Art. XXXVII) . . 299

4.9.14. Aprobación del deber de abstenerse de actividades políticas en país extranjero (Art. XXXVIII) . . . . . . . . . . 299

4.9.15. Traslado de los tres artículos nuevos al preámbulo del PDADDH . . . . . . . . . . . . . . . . . . 300

4.10. Acta resumida de la novena sesión de la Comisión Sexta. 301

4.10.1. Sobre los nuevos artículos y agradecimientos al Presidente y Relator ........................ 301

4.11. Minuta de la sesión de instalación de la Subcomisión A . 303

4.11.1. Elección del Presidente de la Subcomisión . . . . . . . 303

4.11.2. Elección del Relator de la Subcomisión ....... . . 304

4.12. Minuta de la primera sesión de la Subcomisión A . . . . . 304

4.12.1. Propuesta uruguaya de discutir un cuestionario . . . 305

4.12.2. Breve discusión sobre la propuesta de Uruguay ... . 305

4.12.3. Se abre el debate general. . . . . . . . . . . . 306

4.13. Minuta de la segunda sesión de la Subcomisión A . . . . . 307

4.13.1. Respuesta de Guatemala al cuestionario uruguayo. . 307

4.13.2. Respuesta de Bolivia al cuestionario uruguayo . . . . 308

4.13.3. Respuesta del Brasil al cuestionario uruguayo. ... . . 310

4.13.4. Respuesta de Haití al cuestionario uruguayo ..... . 311

4.13.5. Respuesta de Venezuela al cuestionario uruguayo . . 312

4.13.6. Respuesta de República Dominicana al cuestionario uruguayo ........................ 314

4.13.7. Respuesta de México al cuestionario uruguayo. . . . 315

4.13.8. Respuesta de Chile al cuestionario uruguayo .... . . 317

4.13.9. Respuesta de Ecuador al cuestionario uruguayo . . . 318

4.13.10. Respuesta de Panamá al cuestionario uruguayo . . . 318 
VI. Novena Conferencia Internacional Americana. Actas y Documentos. Volumen VI . . . . . . . . . . . . . . . . . . . . . . . . . 321

1. Declaración Americana de los Derechos y Deberes del Hombre 322

2. Corte interamericana para proteger los derechos del hombre . 327

3. American Declaration of the Rights and Duties of Man . . . . 329

4. Inter-American court to protect the rights of man ........ 334

Índice temático . . . . . . . . . . . . . . . . . . . . . . . . . . . . . 337 


\section{AGRADEGIMIENTOS}

A la Organización de los Estados Americanos, por haberme permitido usar su biblioteca, y haberme confirmado la posibilidad de republicar sus documentos oficiales en los anexos de este libro. En este trabajo se transcribe la publicación llamada "Conferencias Internacionales Americanas, Segundo Suplemento 1945-1954", a partir de la cual se obtuvieron las secciones referidas a la Conferencia Interamericana sobre Problemas de la Guerra y de la Paz. También se republica el documento llamado "Anteproyecto de Declaración de los Derechos y Deberes Internacionales del Hombre e Informe Anexo", formulado por el Comité Jurídico Interamericano de acuerdo con las Resoluciones IX y XL de la Conferencia Interamericana sobre Problemas de la Guerra y de la Paz, y publicado por la Unión de Repúblicas Americanas, en 1946.

Al Ministerio de Relaciones Exteriores de la República de Colombia, por haberme confirmado la posibilidad de republicar extractos de la compilación de 1953 llamada "Novena Conferencia Internacional Americana, Bogotá, Actas y Documentos". La presente publicación se realiza con plena consciencia de los derechos morales que el Ministerio de Relaciones Exteriores de la República de Colombia tiene sobre los documentos señalados.

Agradezco también a Christian Perrone, Clara Cecilia López, Diego Reyes Urbina, Francisco Javier Urbina Molfino, Jean Menanteau Monnier, Laura Alicia Camarillo Govea, Marcelo Moreno Faundez, Milenko Bertrand-Galindo Arriagada, Mirentxu Alberdi Soto, Natalia Cox Lyon, Pier Pigozzi, Paolo Carozza, Sandra Concha Díaz y Sebastián Rioseco Sullivan. Sin su ayuda, me habría resultado imposible completar este trabajo. 
Este libro forma parte del acervo de la Biblioteca Jurídica Virtual del Instituto de Investigaciones Jurídicas de la UNAM

\section{ABREVIATURAS}

AD Anteproyecto de Declaración de los Derechos y Deberes Internacionales del Hombre e Informe Anexo.

APDADDH Anteproyecto de Declaración de los Derechos y Deberes Internacionales del Hombre (elaborado por el Comité Jurídico Interamericano).

CA Conferencias Internacionales Americanas, Segundo Suplemento 1945-1954.

Corte IDH Corte Interamericana de Derechos Humanos.

DADDH Declaración Americana de los Derechos y Deberes del Hombre.

NCI Novena Conferencia Internacional Americana, Bogotá, Actas y Documentos, vol. I.

NGV Novena Conferencia Internacional Americana, Bogotá, Actas y Documentos, vol. V.

NGVI Novena Conferencia Internacional Americana, Bogotá, Actas y Documentos, vol. VI.

OEA Organización de los Estados Americanos.

PDDADH Proyecto de Declaración Americana de los Derechos y Deberes del Hombre. 


\section{INTRODUGGIÓN}

Estando ya próximos a celebrar los setenta años de la Declaración Americana sobre Derechos y Deberes del Hombre (DADDH), corresponde poner de relieve su importancia. No fue el primer instrumento en reconocer derechos humanos en América, pues varias resoluciones internacionales de esta región consagraron algunos derechos humanos en forma previa, en particular, algunas redactadas durante la Octava Conferencia Internacional Americana de 1938, celebrada en Lima, ${ }^{1}$ y en la Conferencia Interamericana sobre Problemas de la Guerra y de la Paz. ${ }^{2}$ No obstante ello, la DADDH es reconocida como un instrumento pionero. En efecto, fue el primer catálogo internacional contemporáneo de derechos humanos, pues su aprobación precedió en algunos meses a la Declaración Universal de Derechos Humanos, y comprende un amplio conjunto de derechos y deberes de las personas.

Este libro busca realzar los trabajos preparatorios de la DADDH de dos formas: en primer lugar, su sección principal comenta la relevancia actual de la DADDH y sus travaux préparatoires. En segundo lugar, su anexo republica las fuentes donde ellos se encuentran. Esto último se justifica porque los trabajos preparatorios de la DADDH son de difícil acceso. En efecto, al momento de comenzar a escribir este libro, ellos podían obtenerse solo en unas pocas bibliotecas especializadas. Además, son difíciles de acceder porque gran parte de ellos se encuentran dispersos entre los diversos antecedentes de la Novena Conferencia Internacional Americana. Por otro lado, las discusiones de tal conferencia no cuentan con títulos que indiquen su contenido, por lo que era dificil navegar entre ellos. Para solucionar este

1 Tales como la resolución sobre la libre asociación y libertad de expresión de los obreros, la declaración en favor de los derechos de la mujer y la "Declaración en Defensa de los Derechos Humanos", referida al respeto a los derechos humanos (sin entrar a detallarlos) y otros bienes durante los conflictos armados que podían observarse en otros continentes. Corte Interamericana de Derechos Humanos, Documentos básicos en Materia de Derechos Humanos en el Sistema Interamericano: Actualizado a Febrero de 2012, Corte Interamericana de Derechos Humanos, San José, 2012, pp. 4 y 5. Los instrumentos de las Conferencias Internacionales Americanas se encuentran disponibles en http://biblio2.colmex.mx/coinam/Default.htm (visitado el 5 de enero de 2016).

2 Por ejemplo, la resolución referida a la discriminación racial, CA 53. 
último inconveniente, los anexos de este libro incluyen encabezados, que individualizan tales discusiones, así como un índice temático.

La expresión trabajos preparatorios es bastante abierta. Esto explica que la Convención de Viena del Derecho de los Tratados, no obstante que hace referencia a este concepto, no lo defina. La Comisión de Derecho Internacional, que redactó tal tratado, tomó esta decisión por considerar que definir este concepto llevaría sólo a excluir pruebas relevantes. ${ }^{3}$ Podría decirse que los trabajos preparatorios consisten en los materiales usados en la preparación de la forma definitiva de un acuerdo, ley o tratado. ${ }^{4}$ Estos antecedentes pueden ser usados para la interpretación de instrumentos por parte de cortes internacionales y nacionales. ${ }^{5}$ En materia de tratados internacionales, generalmente se entiende que los trabajos preparatorios incluyen material escrito, tales como diversos proyectos del tratado, registros de conferencias, declaraciones explicativas por parte de expertos durante la conferencia que lo redacta y declaraciones de los presidentes de las comisiones redactoras. ${ }^{6}$

La Convención de Viena sobre el Derecho de los Tratados se refiere a los trabajos preparatorios sólo como un medio de interpretación auxiliar de tratados, no de instrumentos de otra naturaleza. ${ }^{7}$ Sin embargo, la norma respectiva de la Convención de Viena no hace más que recoger un criterio de sentido común para interpretar la voluntad de quienes redactan una norma. Por ello, los trabajos preparatorios de la DADDH serían igual de útiles para determinar el contenido de este instrumento, que los trabajos preparatorios de un tratado.

La DADDH no es un tratado internacional, por lo que es pertinente preguntarse cuál podría ser la importancia de referirse a sus trabajos preparatorios. Por ello, en este libro desarrollamos primero la relevancia de este instrumento internacional; consideramos si la $\mathrm{DADDH}$, aparte de su carácter de manifiesto político, ${ }^{8}$ tiene un valor jurídico. Al hacerlo, determinamos el uso que le da a la DADDH la Comisión Interamericana de Derechos Humanos

3 Gardiner, R., Treaty Interpretation, Oxford, Oxford University Press, 2008, p. 24.

4 Garner, B. A. (ed.), Black's Law Dictionary, 10a. ed., Minnesota, Thomson Reuters, 2014, p. 1729.

5 Gardiner, R., Treaty Interpretation, cit., p. 24.

6 Aust, A., Modern Treaty Law and Practice, 3a. ed., Cambridge, Cambridge University Press, 2014, p. 218.

7 Pues la Convención de Viena busca normar solo determinado tipo de tratados. La referencia a los trabajos preparatorios en esta convención se encuentra en su artículo 32, Convención de Viena sobre el Derecho de los Tratados, 23 de mayo de 1969.

8 Buergenthal, T., "La relación conceptual y normativa entre la Declaración Americana y la Convención Americana sobre Derechos Humanos", cit., p. 111. 
(Comisión IDH), el valor que le da la Corte Interamericana de Derechos Humanos (Corte IDH), y la importancia de la referencia que la Convención Americana sobre Derechos Humanos $(\mathrm{CADH})^{9}$ hace a la DADDH en su artículo 29, entre otros asuntos similares. A modo de adelanto, basta con decir que tanto la Comisión como la Corte interamericanas se han referido a la DADDH, y que ambas se han remitido también a sus trabajos preparatorios.

Este trabajo también se refiere a la resolución que recomienda crear una corte interamericana para proteger los derechos del hombre. Ello, por cuanto ésta se aprobó también en la Novena Conferencia, y porque esta resolución fue motivada por la discusión sobre la DADDH. Además, ambas resoluciones buscan proteger la generalidad de los derechos humanos en América, por lo que es adecuado tratarlas en forma conjunta.

Según se afirmó, el anexo de este libro recoge los trabajos preparatorios de la DADDH. La fuente material de estos trabajos son obras que recopilan antecedentes de dos conferencias internacionales y otros documentos del organismo regional de las Américas. El anexo también contiene las referencias que se hizo en tales conferencias a la futura creación de una corte interamericana. El anexo republica los siguientes antecedentes:

1) Algunos documentos emanados de la Conferencia sobre Problemas de la Guerra y de la Paz, celebrada en la Ciudad de México, entre febrero y marzo de 1945, también conocida como Conferencia de Chapultepec (en atención al hecho de haberse celebrado en el castillo de dicho nombre).

2) El Anteproyecto de Declaración de los Derechos y Deberes Internacionales del Hombre (APDADDH), así como el informe donde el Comité Jurídico Interamericano explica su propuesta.

3) Ciertas actas y documentos emanados de la Novena Conferencia Internacional Americana, celebrada entre marzo y mayo de 1948. Aquí se encuentra la mayor parte de los trabajos preparatorios; esta conferencia fue fundamental para todo el desarrollo del sistema de la Organización de los Estados Americanos (OEA), ya que en ella se aprobaron textos como la Carta de la OEA, el Tratado Americano de Soluciones Pacíficas o Pacto de Bogotá, y las dos convenciones sobre concesión de derechos políticos y civiles a la mujer. ${ }^{10}$

La disposición en la que aparecen los textos en el anexo de este libro no indica necesariamente un orden cronológico. Los anexos se ordenan según los libros a partir de los cuales se extraen, los que se disponen según las

9 Convención Americana sobre Derechos Humanos, "Pacto de San José", 22 de noviembre de 1969 (en adelante $\mathrm{CADH}$ ).

10 NCVI, conclusiones. 
Este libro forma parte del acervo de la Biblioteca Jurídica Virtual del Instituto de Investigaciones Jurídicas de la UNAM

fechas de los primeros antecedentes que contienen. Así, unos pocos instrumentos de la Novena Conferencia se encuentran en el primer libro extractado. Por otro lado, dentro de la misma colección de actas y documentos de la Novena Conferencia Internacional hay varios tomos, el primero de los cuales contiene sesiones plenarias, algunas de las cuales se realizaron con posterioridad a muchas sesiones de las comisiones que se encuentran recogidas en el tomo $\mathrm{V}$. Incluso más, en el mismo tomo $\mathrm{V}$, las actas de las subcomisiones se recogen después del trabajo general de la Comisión, cuestión que no coincide con su orden cronológico. Es por ello que, según ya afirmamos, hemos incluido títulos e índices que ayuden a que el lector no se pierda entre los debates que se observan en estos trabajos. 


\section{CAPÍTULO PRIMERO}

\section{RELEVANCIA HISTÓRICA Y JURÍDICA DE LA DEGLARAGIÓN}

\section{GUESTIONES PRELIMINARES}

Antes de comenzar a hablar sobre el tema de este trabajo, es importante hacer una breve relación sobre qué es la DADDH, el instrumento que ha sido llamado la "Carta Magna del Sistema Interamericano". ${ }^{11}$ Esta declaración fue aprobada el 30 de abril de 1948, por una resolución de la Novena Conferencia Internacional Americana, fue concebida como un instrumento no vinculante. En ese sentido, surgió como un manifiesto político, pero se afirma que hoy sería también un instrumento normativo, ${ }^{12}$ porque la situación jurídica interamericana ha cambiado mucho durante los casi setenta años desde que se aprobó la DADDH. Estos cambios normativos podrían incidir en el valor jurídico de este instrumento, por lo que nos referimos a ellos en este trabajo.

La relevancia de la DADDH consiste en indicar, en términos generales, qué se considera que son los derechos humanos para los Estados integrantes de la OEA; porque la Carta de la OEA hace referencia a los derechos humanos, pero no los define. ${ }^{13}$ Algunos sostienen que, como la Carta de la OEA fue aprobada en la misma conferencia que la DADDH, debe entenderse que ésta expresa el concepto de derechos humanos que compartían quienes aprobaron la Carta. Se suele afirmar que esto se habría reflejado, de algún modo, en lo dispuesto en el artículo 2o. del antiguo Estatuto de la Comisión IDH, adoptado en 1960, que disponía: "Para los fines de este

11 Buergenthal, T., "La relación conceptual y normativa entre la Declaración Americana y la Convención Americana sobre Derechos Humanos", Revista Instituto Interamericano de Derechos Humanos, número especial en conmemoración del cuadragésimo aniversario de la Declaración Americana de Derechos y Deberes del Hombre, 1989, p. 111.

12 Idem.

13 Carta de la OEA, reformada por el "Protocolo de Buenos Aires", suscrito el 27 de febrero de 1967, por el "Protocolo de Cartagena de Indias", aprobado el 5 de diciembre de 1985, por el "Protocolo de Washington", aprobado el 14 de diciembre de 1992, y por el "Protocolo de Managua", adoptado el 10 de junio de 1993 (en adelante "Carta de la OEA"). 
Este libro forma parte del acervo de la Biblioteca Jurídica Virtual del Instituto de Investigaciones Jurídicas de la UNAM

Estatuto, por derechos humanos se entienden los consagrados en la Declaración Americana de los Derechos y Deberes del Hombre". ${ }^{14}$

Hoy en día, la Comisión IDH aplica frecuentemente la DADDH en virtud de una norma similar del Estatuto vigente, según se describe más abajo.

\section{RELACIÓN ENTRE LAS DECLARACIONES AMERICANA Y UNIVERSAL}

La temprana aprobación de la DADDH con relación a la Declaración Universal sobre Derechos Humanos no se debió a un simple apuro por adelantarse al instrumento de Naciones Unidas; muy por el contrario, según afirma Mary Ann Glendon, los trabajos realizados en América habrían sido usados por la Comisión de Derechos Humanos de las Naciones Unidas, como base para la preparación del documento universal. ${ }^{15}$ En efecto, cuando se le solicitó al director de la División de Derechos Humanos de las Naciones Unidas, el canadiense John Humphrey, la preparación de un primer proyecto de Declaración Universal de Derechos Humanos, éste comenzó por realizar un estudio de las diversas declaraciones de derechos existentes en el mundo. ${ }^{16}$ En ese momento tuvo a la vista variados documentos, y él se habría basado principalmente en dos, uno entregado por el representante de Panamá y otro por el delegado chileno. ${ }^{17} \mathrm{El}$ documento presentado por el representante de Chile fue el APDADDH, elaborado por el Comité Jurídico Interamericano como insumo para la discusión en la Novena Conferencia, un par de años antes de la celebración de ésta. ${ }^{18}$ Cuatro fueron los redactores de tal documento, uno de los cuales fue Félix Nieto del Río, quien representó a Chile en la primera

14 Estatuto de la Comisión IDH (original de 1960), disponible en: García Bauer, C., Los derechos humanos preocupación universal, Guatemala, Editorial Universitaria, 1960, pp. 417 y ss. Tal disposición se mantuvo vigente hasta 1979, y no fue afectado por las modificaciones y enmiendas introducidas por la Resolución XXII de la Segunda Conferencia Interamericana Extraordinaria y por el Consejo de la OEA en 1968. Comisión Interamericana de Derechos Humanos, Diez años de actividades, 1971-1981, Washington D.C., Secretaría General, Organización de Estados Americanos, 1982, p. 41.

15 Glendon, M. A., "The Forgotten Grucible: The Latin American Influence on the Universal Human Rights Idea", Harvard Human Rights fournal, vol. 16, 2003, pp. 30 y 31. Para una relación de todo el proceso de elaboración de la Declaración Universal, con particular énfasis en el trabajo de Eleanor Roosevelt, véase Glendon, M. A., A World Made New: Eleanor Roosevelt and the Universal Declaration of Human Rights, Nueva York, Random House, 2002.

16 Glendon, M. A., "The Forgotten Crucible...", ibidem., p. 30.

17 Ibidem, pp. 30 y 31.

18 Ibidem, p. 31. 
Este libro forma parte del acervo de la Biblioteca Jurídica Virtual del Instituto de Investigaciones Jurídicas de la UNAM

reunión de la Comisión de Derechos Humanos de las Naciones Unidas. ${ }^{19}$ Esto podría revelar una cierta promoción del APDADDH al interior de dicho organismo.

Glendon también demuestra que el pensamiento latinoamericano sirvió como una suerte de bisagra entre las diversas visiones mundiales sobre los derechos humanos: la visión individualista liberal, más propia del mundo anglosajón occidental, y la visión más comunitaria, que hacía resonar concepciones de otras geografias. ${ }^{20}$ En parte, esta postura intermedia latinoamericana se habría debido a la influencia de la doctrina social católica, pues ésta no sólo reconoce la importancia del contenido de los derechos civiles y políticos (fundamentales para el bloque occidental), sino también de la función social de la propiedad y de la solidaridad que debe existir hacia los menos favorecidos en una sociedad (proclamadas por el bloque soviético). ${ }^{21}$ Paolo Carozza se refiere a algunas normas en las que se habría producido esta influencia. ${ }^{22}$ Él también desarrolla la historia de esta tradición latinoamericana, tan particular, de reconocimiento normativo de los derechos humanos. ${ }^{23}$ Según él, ella tendría su origen en Bartolomé de las Casas, y habría recibido diversas influencias a través del tiempo, hasta terminar plasmándose en las Constituciones de la América hispana. ${ }^{24}$ Carozza afirma que esta tradición influyó no solo en la aprobación de la Declaración Universal de los Derechos Humanos, sino que también, varios años antes, en la inclusión de referencias a los derechos humanos en la Carta de las Naciones Unidas. ${ }^{25}$

La influencia de la DADDH en la Declaración Universal de Derechos Humanos hizo que el alcance de la primera se expandiera a otras latitudes. En efecto, según afirma Burgorgue-Larsen, el artículo 13 del Convenio Europeo de Derechos Humanos se habría basado en el artículo 80. de la Declaración Universal. Ésta, a su vez, habría sido influenciada por la DADDH, pues el delegado de México solicitó que se incorporara en la Declaración Universal la disposición de la DADDH que recogía el amparo, recurso que existe en muchos sistemas jurídicos latinoamericanos. ${ }^{26}$

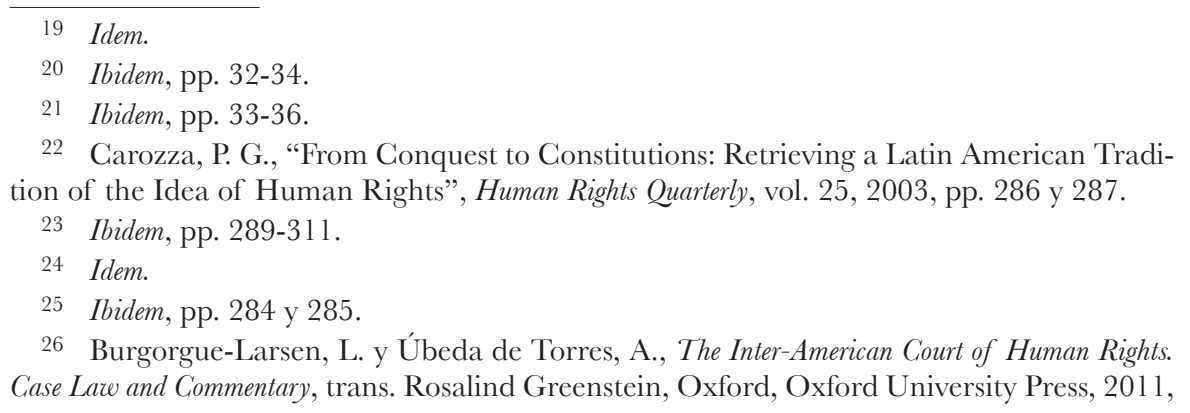


Los redactores del APDADDH de 1945 tenían conciencia de su importancia no solo regional, sino que también universal. Es por ello que el Comité Jurídico Interamericano señala, en su informe anexo al APDADDH, que la DADDH "podrá servir de antecedente para la declaración universal facilitando de esa manera un mayor estímulo al respeto de "los derechos humanos y libertades fundamentales", de acuerdo con las disposiciones de la Carta" ${ }^{27}$ Esta conciencia se mantuvo durante la Novena Conferencia Internacional Americana, en 1948, según se observa en la siguiente afirmación de la delegación de Venezuela:

La Declaración de los Derechos y Deberes del Hombre debe hacerse con criterio universalista, a fin de que en un próximo futuro puedan estar esos derechos al alcance mundial y a fin de concretar el límite común de derechos individuales aceptables por los Estados. ${ }^{28}$

A esto puede agregarse lo señalado por el Relator de la Comisión, el delegado de Colombia, que reconoce "la oportunidad de que América se presente culturalmente como una aportación universal". ${ }^{29}$

Lo anterior no significa que los redactores de la DADDH no hayan, a su vez, tomado una cierta inspiración del trabajo realizado en Naciones Unidas. En efecto, durante la Novena Conferencia, mientras los delegados discutían las reformas al APDADDH, ellos reconocen que tuvieron delante el proyecto de Declaración Universal. ${ }^{30}$ Además, el grupo de trabajo sobre derechos del hombre tomó tal proyecto como uno de los documentos base para realizar su trabajo. ${ }^{31}$ Por ello, algunas disposiciones de la DADDH fueron influenciadas fuertemente por el proyecto de Declaración Universal. Así, por ejemplo, el primer párrafo del Preámbulo fue tomado del Proyecto de Naciones Unidas, "variándolo apenas". ${ }^{32}$

p. 677. Esta relación sería aún más notoria si se compara el artículo XVIII de la DADDH con el artículo 25 de la $\mathrm{CADH}$, idem.

27 AD, p. 54.

28 NCV, p. 621.

29 NCV, p. 567.

30 Por ejemplo, lo hace el delegado de Cuba en NGV, pp. 544 y 562. Por su parte, durante el trabajo de la Subcomisión, Panamá propuso tener presente el proyecto elaborado por el Consejo Económico y Social de las Naciones Unidas. NCV, p. 627.

31 NCV, p. 475.

32 Esas son palabras del informe del relator de la Comisión Sexta, NCV, p. 513; lo mismo se observa en NCV, p. 477. La redacción actual del primer párrafo del preámbulo dispone: "Todos los hombres nacen libres e iguales en dignidad y derechos, y dotados como están por naturaleza de razón y conciencia, deben conducirse fraternalmente los unos con los otros". 
Este libro forma parte del acervo de la Biblioteca Jurídica Virtual del Instituto de Investigaciones Jurídicas de la UNAM

\section{VALOR JURÍDICO DE LA DECLARACIÓN}

\section{Percepciones sobre el valor jurídico de la Declaración}

\section{A. Algunas percepciones doctrinales}

Según se afirmó en la introducción, el valor normativo de la DADDH sería el primer punto a analizar en un estudio sobre sus trabajos preparatorios. A continuación trataremos el punto, pero haciendo la prevención de que no buscamos afirmar o negar el valor jurídico de la DADDH, sino que sólo pretendemos revisar algunas ideas en torno a las percepciones sobre su valor jurídico.

En la Conferencia Interamericana sobre Problemas de la Guerra y de la Paz, los delegados de los Estados buscaban que la "Declaración de los Derechos y Deberes Internacionales del Hombre" y la "Declaración de los Derechos y Deberes Internacionales de los Estados" fueran anexadas al pacto constitutivo, destinado a mejorar y fortalecer el sistema panamericano, de modo que, "sin necesidad de modificar éste, puedan ser revisadas de tiempo en tiempo, con el objeto de que correspondan a las necesidades y aspiraciones de la convivencia internacional". ${ }^{33}$ Este asunto volvió a ser discutido durante la Novena Conferencia, ${ }^{34}$ donde se analizó si se le daría o no una forma de tratado a la DADDH, si sería incorporada a la Carta de la OEA, o si se le daría alguna otra naturaleza jurídica. Fue ahí donde se resolvió no darle a la DADDH la forma de un tratado, ${ }^{35}$ sino la de una simple declaración no obligatoria. ${ }^{36}$ Una vez tomada la decisión, la delegación de Venezuela propuso que el Pacto de la OEA hiciera una referencia a la DADDH, de modo que le diera "un vínculo más concreto con el Pacto mismo". ${ }^{37}$ Sin embargo, ello no se hizo; por su parte, la delegación de Uruguay planteó que en el futuro se podría acordar dar un valor vinculante a la DADDH. ${ }^{38}$ De este modo, la

\footnotetext{
Dentro de las diferencias que tienen ambas disposiciones se encuentra la inclusión de la expresión "por naturaleza". Ella muestra que la DADH buscó declarar que la igual dignidad del ser humano no se desprende del hecho de tener razón y conciencia, sino que del pertenecer a una naturaleza que posee tales atributos.

33 CA, p. 23.

34 NCV, pp. 552 y ss.

35 NGV, p. 555.

36 NCV, pp. 555 y 556. No obstante ello, el delegado de Argentina afirmó "que las declaraciones en todos los casos tienen una obligatoriedad jurídica", NCV, p. 560. Sin embargo, las afirmaciones de este delegado tienen un cariz retórico más que jurídico.

37 NGV, p. 556. En NGV, p. 565, se solicitó que se dejara expresa constancia de esta solicitud que había hecho.

38 NCV, p. 558.
} 
Este libro forma parte del acervo de la Biblioteca Jurídica Virtual del Instituto de Investigaciones Jurídicas de la UNAM

DADDH surgió como un instrumento no vinculante. Esto fue posteriormente ratificado por el Comité Jurídico Interamericano, el que consideró "obvio" que la Declaración de Bogotá no creaba obligaciones contractuales. ${ }^{39}$

Hoy la situación es distinta, es difícil discutir que muchos de los derechos consagrados en la DADDH tienen un valor jurídico superior a los consagrados en una simple declaración. Por una parte, sería posible afirmar que algunos de ellos forman parte de la costumbre internacional. Además, hay un elemento jurídico adicional que da pie para afirmaciones más audaces. En efecto, ya en 1975 Thomas Buergenthal afirmaba que la entrada en vigor del Protocolo de Buenos Aires en 1970 "fortalecía el carácter normativo de la DADDH" ${ }^{40} \mathrm{El}$ proceso argumentativo que él siguió se describe a continuación.

El Protocolo de Buenos Aires reformó la Carta de la OEA, estableciendo a la Comisión IDH como uno de los órganos principales del organismo regional de América. La Comisión ya se encontraba en funcionamiento, pues fue creada en 1959 por una resolución de la Quinta Reunión de Consulta de Ministros de Relaciones Exteriores. El Estatuto de la Comisión IDH se promulgó en 1960 por el Consejo de la OEA, ${ }^{41}$ y establecía que para efectos de dicho estatuto, se entendía que los derechos humanos serían aquellos definidos en la DADDH. El Protocolo de Buenos Aires también definió, en una nueva disposición transitoria a la Carta de la OEA, que mientras no se aprobara la CADH, "la actual Comisión Interamericana de Derechos $\mathrm{Hu}$ manos velaría por la observancia de tales derechos". ${ }^{42}$ Buergenthal consideró que la referencia a "la actual Comisión" incluía su Estatuto, con lo que lo incorporaba a la Carta de la OEA, por referencia. ${ }^{43}$ Más aún, él afirmó que todas las disposiciones del Estatuto, que no estuvieran en conflicto con la Carta se incorporaba como parte integral de la misma. ${ }^{44}$ Con ello, atendido que el Estatuto se refiere a la DADDH, ésta habría adquirido un valor normativo según Buergenthal.

39 Buergenthal, V., "The Revised OAS Charter and the Protection of Human Rights", The American Fournal of International Law, vol. 69, 1975, p. 829 (la traducción es del autor). Véase también, Interpretación de la Declaración Americana de los Derechos y Deberes del Hombre en el marco del artículo 64 de la Convención Americana sobre Derechos Humanos (1989): Corte Interamericana de DD.HH., Opinión Consultiva OC-10/89, Serie A, núm. 10, párr. 34.

40 Ibidem, p. 828 (la traducción es del autor).

41 Ibidem, pp. 829 y 830.

42 Artículo XXIII, Protocolo de Reformas a la Carta de la Organización de los Estados Americanos, "Protocolo de Buenos Aires", 27 de febrero de 1967 (que creó las disposiciones transitorias 149 y 150).

43 Buergenthal, T., "The Revised OAS Charter and the Protection of Human Rights", cit., p. 834 .

44 Ibidem, p. 835. 
Héctor Faúndez coincide en que la DADDH tendría valor vinculante. ${ }^{45}$ Lo mismo opina la Comisión IDH, que en el famoso caso Baby Boy señaló que la vigencia de los artículos - entonces enumerados - 3.j, 16, 51.e, 112 y 150 de la Carta de la OEA, ${ }^{46}$ le daban fuerza vinculante a tres instrumentos: la DADDH, el Estatuto de la Comisión IDH y el Reglamento de la misma. ${ }^{47}$ La Comisión ha dicho claramente que la DADDH "constituye una fuente de obligaciones internacionales", ${ }^{48}$ en ello coincide con la afirmación que hace la Corte IDH, según se describe más abajo, y que es aceptada por autores como Medina y Nash, quienes reiteran el razonamiento de tal tribunal. ${ }^{49}$ Por su parte, Salvioli considera que el valor vinculante se habría consolidado a través de diferentes vías. ${ }^{50}$ Como vemos, Buergenthal no se encuentra solo entre

45 Faúndez Ledesma, H., El Sistema Interamericano de Protección de los Derechos Humanos: aspectos institucionales y procesales, 3a. ed., Instituto Interamericano de Derechos Humanos, San José, 2004, pp. 50 y 51.

46 En ese entonces se hallaba vigente la Carta de la OEA modificada solo por el Protocolo de Buenos Aires, por lo que la numeración de esos artículos no coinciden con los artículos actuales. A continuación se copia el contenido de tales artículos y su equivalencia con la Carta en su estado actual. El artículo 3.j disponía: "Los Estados Americanos proclaman los derechos fundamentales de la persona humana sin hacer distinción de raza, nacionalidad, credo o sexo" (es equivalente al actual artículo 3.l); el artículo 16: "Cada Estado tiene el derecho a desenvolver libre y espontáneamente su vida cultural, política y económica. En este libre desenvolvimiento el Estado respetará los derechos de la persona humana y los principios de la moral universal" (equivale al actual 17); el artículo 51.e: "La Organización de los Estados Americanos realiza sus fines por medio de: e) La Comisión Interamericana de Derechos Humanos" (equivale al actual 53.e); el artículo 112: "Habrá una Comisión Interamericana de Derechos Humanos que tendrá, como función principal, la de promover la observancia y la defensa de los derechos humanos y de servir como órgano consultivo de la Organización en esta materia. Una convención interamericana sobre derechos humanos determinará la estructura, competencia y procedimiento de dicha Comisión, así como los de los otros órganos encargados de esa materia" (equivale al actual 106), y el artículo 150: "Mientras no entre en vigor la convención interamericana sobre derechos humanos a que se refiere el capítulo XVIII, la actual Comisión Interamericana de Derechos Humanos velará por la observancia de tales derechos" (equivale a la actual disposición transitoria que se encuentra en el artículo 145; la referencia que se hace al capítulo XVIII se refiere al actual capítulo XV). Carta de la Organización de los Estados Americanos, reformada por el "Protocolo de Buenos Aires", suscrito el 27 de febrero de 1967, con relación a la Carta de la OEA actual.

47 Caso 2141, Estados Unidos (1981): Comisión Interamericana de DD.HH., Resolución, núm. 23/81, párr. 16. Esto fue reiterado en el Caso 9647, Estados Unidos (1987): Comisión Interamericana de DD.HH., Informe, núm. 3/87, párr. 48.

48 Caso 9903, Rafael Ferrer-Mazorra y otros, Estados Unidos (2001): Comisión Interamericana de DD.HH., Informe, núm. 51/01, párr. 178.

49 Medina Quiroga, C. y Nash Rojas, C., Sistema Interamericano de Derechos Humanos: introducción a sus mecanismos de protección, edición actualizada, Santiago, Universidad de Chile, Facultad de Derecho, Centro de Derechos Humanos, 2011, p. 32.

50 Salvioli, F. O., "El aporte de la Declaración Americana de 1948, para la Protección Internacional de los Derechos Humanos", en El Sistema Interamericano de Protección de los Dere- 
Este libro forma parte del acervo de la Biblioteca Jurídica Virtual del Instituto de Investigaciones Jurídicas de la UNAM

quienes consideran que la DADDH tendría valor vinculante. Sin embargo, aún se cuestiona la obligatoriedad de la DADDH; $; 1$ en este sentido, Christina Cerna sostiene que afirmar que la DADDH es vinculante, es un mecanismo útil, pero una ficción en la ausencia de ratificación de la CADH o de accesión a la misma. ${ }^{52}$

Se debería realizar un análisis detallado sobre este punto en un trabajo más especializado; sin embargo, nos referiremos a un par de reparos a los razonamientos recién descritos. Por una parte, es difícil pensar que, al hacer las reformas a la Carta de la OEA, los Estados no hubieran querido dejar explícito algo, tan importante, como la concesión de la fuerza vinculada a un instrumento al que, expresamente, se concibió como no vinculante. Por otro lado, el artículo 106 de la carta dispone que la Comisión se regirá por una futura convención interamericana sobre derechos humanos, no por la DADDH, por lo que pone en duda que se haya querido dar un valor vinculante a un instrumento, que no fue concebido así por sus redactores. Es cierto, que el artículo 145 - una disposición transitoria- dispone que: "[m]ientras no entre en vigor la convención interamericana sobre derechos humanos a que se refiere el capítulo XV, la actual Comisión Interamericana de Derechos Humanos velará por la observancia de tales derechos". Sin embargo, la CADH ya entró en vigor, aunque no lo haya hecho respecto de todos los Estados de América. Por último, en el entendido de que la DADDH deviniera en vinculante, en virtud de lo dispuesto en el Estatuto de la Comisión, convendría saber cuál es el efecto que tendría, en este valor, el que el Estatuto disponga que la Comisión debe prestar particular atención a unos determinados derechos humanos por sobre otros ${ }^{53}$ debido a que, sería extraño sostener que algunas normas, dentro de un instrumento que es vinculante como un todo, tengan mayor obligatoriedad que otras.

Otro autor que tiene un desarrollo interesante sobre este asunto es Pedro Nikken, si bien está en conocimiento de la postura de Buergenthal, afirma que "las circunstancias señaladas no conducen necesaria o exclusivamente a la conclusión de que la Declaración Americana de los Derechos y Deberes

chos Humanos en el Umbral del Siglo XXI, San José de Costa Rica, vol. I, Corte Interamericana de Derechos Humanos, 2003, pp. 685-691.

51 Faúndez Ledesma, H., El Sistema Interamericano de Protección de los Derechos Humanos: aspectos institucionales y procesales, cit., p. 51.

52 Cerna, C. M., "Reflections on the Normative Status of the American Declaration of the Rights and Duties of Man", University of Pennsylvania Fournal of International Law, vol. 30, núm. 4, 2009, p. 1213.

53 En efecto, el artículo 20.a del Estatuto dispone que la Comisión debe prestar, respecto de aquellos Estados que no hayan ratificado la CADH, especial atención a la observancia de los artículos I, II, III, IV, XVIII, XXV y XXVI de la DADDH. 
del Hombre ha adquirido el rango de derecho convencional por haber quedado, de alguna forma, incorporada a la Carta de la OEA". ${ }^{44}$ No obstante, él sí considera, después de comparar "el tratamiento que la Comisión da a las comunicaciones referentes a la observancia del Pacto de San José con las relativas a la Declaración Americana", ${ }^{55}$ así como, de analizar el elemento material y espiritual de la costumbre, que normas de la DADDH adquirieron un valor consuetudinario. ${ }^{56}$ Nikken también hace un pormenorizado análisis que compara el valor de la DADDH con el de la Declaración Universal, y estudia el posible valor convencional o consuetudinario de ambas. Por este motivo, aun si no se está de acuerdo con sus conclusiones, vale la pena leer su artículo.

La antigua comisionada Dinah Shelton también aporta al debate, considera que la DADDH constituiría una interpretación auténtica de la Carta de la OEA $;{ }^{57}$ probablemente esa afirmación se funda en el hecho de que la Carta se refiere en varias ocasiones a los derechos humanos, concepto que no se encuentra definido en la Carta misma. Frente a esta afirmación, habría que notar que las interpretaciones auténticas, según desarrollamos en la próxima sección, deben ser realizadas siguiendo mecanismos que puedan reformar el documento que se interpreta. Puede contribuir a la conclusión de Shelton el que algunas referencias a los derechos fundamentales de la Carta de la OEA fueron incorporadas en reformas posteriores a la aprobación de la DADDH; sin embargo, gran parte de esas referencias son hechas en el contexto de la Comisión IDH, por lo que conviene preguntarse si tales reformas no buscaron delimitar las competencias de la Comisión, más que dar una definición auténtica y vinculante de los derechos humanos para efectos de la carta.

\section{B. Opinión consultiva de la Corte}

Un importante elemento que se debe tener en consideración en este debate es la Opinión Consultiva número 10 de la Corte IDH..$^{58}$ Esta opinión

54 Nikken, P., "La Declaración Universal y la Declaración Americana. La Formación del Moderno Derecho Internacional de los Derechos Humanos", Revista Instituto Interamericano de Derechos Humanos, Número especial en conmemoración del cuadragésimo aniversario de la Declaración Americana de Derechos y Deberes del Hombre, 1989, p. 86.

55 Ibidem, p. 87.

56 No nos queda absolutamente claro que se haya referido a toda la DADDH y no solo a algunos artículos. Esta falta de claridad se genera por la referencia que él hace a algunas de sus normas. Ibidem, pp. 98 y 99.

57 Shelton, D., "International Law and «Relative Normativity»", en Malcolm D. Evans (ed.), International Law, 2a. ed., Oxford, Oxford University Press, 2006, p. 182.

58 Interpretación de la Declaración Americana de los Derechos y Deberes del Hombre en el marco del artículo 64 de la Convención Americana sobre Derechos Humanos, cit. 
Este libro forma parte del acervo de la Biblioteca Jurídica Virtual del Instituto de Investigaciones Jurídicas de la UNAM

fue solicitada por Colombia, y buscaba dilucidar si la Corte IDH podía o no interpretar la DADDH en el marco de su competencia consultiva. En ella, no sólo es posible apreciar la opinión de la Corte IDH, sino también, la de varios Estados, los cuales presentaron sus observaciones sobre esta solicitud de opinión consultiva en 1988, tanto en forma escrita, como en la audiencia pública celebrada al efecto. En ellas se apreciaron diversas posturas frente a la pregunta planteada por Colombia. Costa Rica recalcó que la DADDH no era un tratado internacional, pero que ello no significaba que la Corte IDH no pudiera usarla para interpretar otros instrumentos jurídicos relacionados, tampoco menoscababa la idea de que muchos de los derechos allí establecidos hubieran sido "elevados a la categoría indiscutible de costumbre internacional". ${ }^{59}$ Estados Unidos, por su parte, dijo que la DADDH no fue redactada como un instrumento jurídico, por lo que carecía de la precisión necesaria para resolver dudas legales; ${ }^{60}$ por lo cual, afirmó que "su valor normativo estriba en ser una declaración de principios básicos de carácter moral y de carácter político, y en ser la base para velar por el cumplimiento general de los derechos humanos por parte de los Estados miembros; no en ser un conjunto de obligaciones vinculantes". ${ }^{61}$ Este mismo Estado dijo reconocer las buenas intenciones de quienes buscaban transformar la DADDH en un instrumento jurídico, pero recalcó que "las buenas intenciones no crean derecho". ${ }^{62}$ En definitiva, Estados Unidos manifestó que la DADDH "continúa siendo para todos los Estados Miembros de la OEA lo que era cuando fue adoptada: una enunciación de principios generales de derechos humanos no vinculantes". ${ }^{63}$ Venezuela manifestó una postura similar a la de Estados Unidos. ${ }^{64}$

Perú, en cambio, se manifestó en sentido opuesto, afirmando que el artículo 29 de la CADH le habría "dado a la citada Declaración una jerarquía similar a la que tiene la propia Convención para los Estados partes". ${ }^{65}$ Uruguay fue más allá, afirmando que "la naturaleza jurídica de la Declaración es la de un instrumento multilateral vinculante que enuncia, define y concreta, principios fundamentales reconocidos por los Estados Americanos y que cristaliza normas de derecho consuetudinario generalmente aceptadas por dichos Estados". ${ }^{66}$ Como puede observarse, los gobiernos expresaron

\footnotetext{
59 Ibidem, párr. 11 y párr. 18.

60 Ibidem, párr. 12.

61 Idem.

62 Idem.

63 Ibidem, párr. 17.

64 Ibidem, párr. 15.

65 Ibidem, párr. 13.

66 Ibidem, párr. 14.
} 
Este libro forma parte del acervo de la Biblioteca Jurídica Virtual del Instituto de Investigaciones Jurídicas de la UNAM

posiciones bastante disímiles en este punto. Los pareceres vertidos en esta opinión consultiva pueden ser también complementados con otros que los Estados han manifestado en otras ocasiones. ${ }^{67}$

Enfrentada con las posiciones presentadas en la opinión consultiva número 10, la Corte IDH emitió su dictamen, donde afirmó que el valor de la DADDH en la actualidad no es el mismo que el que tuvo al momento de ser aprobada en 1948;68 ello, por cuanto se habría producido una cierta evolución en el valor de la DADDH. ${ }^{69}$ La opinión de la Corte continúa su argumentación, pero antes de describirla, debemos hacer una precisión: la Corte afirma que se habría producido una evolución en el valor de la DADDH, pero tal transformación no puede producirse por el mero paso del tiempo, pues éste no cambia la naturaleza de los instrumentos internacionales; entonces, para que la afirmación de la Corte sea válida, es necesario que se den algunos elementos adicionales. En el caso de la DADDH, la Corte parece relacionar esta evolución con la aprobación de nuevos instrumentos, ${ }^{70}$ así como con modificaciones en el orden jurídico global. ${ }^{71}$ Por ello, podría alegarse que la Corte IDH basa esta evolución, principalmente, sobre las reformas a la Carta de la OEA, ya referidas al analizar el debate sobre el valor jurídico de la DADDH.72

La Corte también afirma que las normas de la Carta de la OEA "atribuyen a la Comisión Interamericana la competencia de velar por los derechos humanos y estos derechos no son otros que los enunciados y definidos en la Declaración Americana". ${ }^{73}$ Esto se deduciría del artículo 1o. del Estatuto de la Comisión IDH, que nos dice qué se entiende por derechos humanos para efectos de dicho Estatuto. ${ }^{74}$ Este artículo dispone actualmente lo siguiente:

67 Por ejemplo, en la opinión consultiva número 16, México y República Dominicana expresaron ideas interesantes. El derecho a la información sobre la asistencia consular en el marco de las garantías del debido proceso legal, Corte Interamericana de DD.HH., Opinión consultiva OC16/99, serie A, núm. 16, 1999, párrs. 26 y 27.

68 Interpretación de la Declaración Americana de los Derechos y Deberes del Hombre en el marco del artículo 64 de la Convención Americana sobre Derechos Humanos, cit., párr. 37.

69 Idem.

70 Idem.

71 Ibidem, párr. 38.

72 La Corte también hace una referencia al artículo 29 de la CADH, aunque no parece darle la misma interpretación que le da hoy en día, y no aporta mayores antecedentes a este argumento (ibidem, párr. 46), por lo que no requiere ahondar en este asunto en este momento. Sin embargo, la interpretación actual del artículo 29 de la CADH es muy relevante, por lo que será analizado en detalle más abajo.

73 Ibidem, párr. 41.

74 Idem. 
1. La Comisión Interamericana de Derechos Humanos es un órgano de la Organización de los Estados Americanos creado para promover la observancia y la defensa de los derechos humanos y servir como órgano consultivo de la Organización en esta materia.

2. Para los fines del presente Estatuto, por derechos humanos se entiende:

a. Los derechos definidos en la Convención Americana sobre Derechos Humanos en relación con los Estados partes en la misma;

b. Los derechos consagrados en la Declaración Americana de Derechos y Deberes del Hombre, en relación con los demás Estados miembros. ${ }^{75}$

La Corte IDH se basó, además, en otras resoluciones de la OEA, donde se habrían reafirmado los compromisos contraídos en la DADDH. ${ }^{76}$ Según la Corte, esto permitiría afirmar:

que, a manera de interpretación autorizada, los Estados Miembros han entendido que la Declaración contiene y define aquellos derechos humanos esenciales a los que la Carta se refiere, de manera que no se puede interpretar y aplicar la Carta de la Organización en materia de derechos humanos, sin integrar las normas pertinentes de ella con las correspondientes disposiciones de la Declaración, como resulta de la práctica seguida por los órganos de la OEA. ${ }^{77}$

La Corte concluye entonces, que para los Estados miembros de la OEA "la Declaración Americana constituye, en lo pertinente y en relación con la Carta de la Organización, una fuente de obligaciones internacionales".78 Es importante recalcar que no puede afirmarse que la opinión de la Corte IDH haya zanjado el debate sobre si la DADDH es o no obligatoria. Afirmar lo contrario implicaría pensar que la Corte IDH es la intérprete auténtica de todo instrumento del sistema interamericano, cuestión que sería errada. ${ }^{79}$

75 Además, el artículo 20 dispone que la Comisión debe prestar "particular" atención a la observancia de los artículos I, II, III, IV, XVIII, XXV y XXVI de la DADDH. En virtud de estas disposiciones, la Comisión ha afirmado que "para efectos del Estatuto se entiende por derechos humanos los derechos consagrados en la Declaración Americana en relación con los Estados que no son Parte de la Convención Americana sobre Derechos Humanos”. Caso 9647 - Estados Unidos (1987): Comisión Interamericana de DD.HH., Informe, núm. 3/87, párr. 49. En este mismo sentido, Gros Espiell, H., "La Declaración Americana: raíces conceptuales y políticas en la historia, la filosofia y el derecho americano", Revista Instituto Interamericano de Derechos Humanos, núm. especial, 1989, pp. 59 y 60. Este asunto es tratado en detalle más abajo.

76 Interpretación de la Declaración Americana de los Derechos y Deberes del Hombre en el marco del artículo 64 de la Convención Americana sobre Derechos Humanos, cit., párr. 42.

77 Ibidem, párr. 43.

78 Ibidem, párr. 45.

79 Ello, sin perjuicio de que las opiniones consultivas de la Corte IDH sean relevantes jurídicamente para los demás Estados de América, como lo ha afirmado la Corte en un par 
Esto queda patente al considerar que no todos los Estados miembros de la OEA han ratificado el instrumento que da vida a la Corte IDH, y que ni siquiera todos los Estados que lo han ratificado le han dado jurisdicción a dicho tribunal. Más aún, las opiniones consultivas no son vinculantes ni siquiera para los Estados que se encuentran bajo la jurisdicción de la Corte, ${ }^{80}$ no obstante que ella esté acuñando la idea de un control de convencionalidad preventive ${ }^{81}$ Por lo demás, la interpretación auténtica es aquella que se rige por el principio eius est legem interpretare, cuius est condere, es decir, que "[c]orresponde interpretar la ley a quien la establece" ${ }^{82}$ Esto fue reconocido por la Corte Permanente de Justicia Internacional en el asunto Jaworzina, donde afirmó que era un principio establecido el que sólo corresponde interpretar, autorizadamente, una norma al órgano que tiene el poder de modificarla o suprimirla. ${ }^{83}$ Según este concepto, la Corte IDH no es, ni siquiera, la intérprete auténtica de la CADH. Ello, con independencia de que sí tiene la última palabra en los casos contenciosos que se le plantean. ${ }^{84}$ Por lo tanto, la conclusión de la Corte IDH debe juzgarse a la luz de sus méritos, pesando los argumentos que ella esgrime, lo que deja mucho espacio para el debate.

Sin pretensiones de agotar el tema, presentamos algunas reflexiones. En primer lugar, la Corte IDH afirma que ciertas resoluciones de la OEA

de opiniones consultivas. Véase Derechos y garantías de niñas y niños en el contexto de la migración y /o necesidad de protección internacional, Corte Interamericana de DD.HH., Opinión consultiva OC21/14, Serie A, núm. 21, párr. 32, y Titularidad de derechos de las personas jurídicas en el Sistema Interamericano de Derechos Humanos (interpretación y alcance del artículo 1.2, con relación a los artículos 1.1, 8, 11.2, 13, 16, 21, 24, 25, 29, 30, 44, 46 y 62.3 de la Convención Americana sobre Derechos Humanos, así como del artículo 8.1. a y b del Protocolo de San Salvador), Corte Interamericana de DD.HH., Opinión Consultiva OC-22/16, Serie A núm. 22, 2016, párr. 25. Sin embargo, el que una interpretación sea relevante, no significa que sea ni auténtica ni vinculante.

80 Esta afirmación sería contraria al entendimiento que tiene actualmente la Corte IDH sobre la doctrina del control de convencionalidad, que se describe en el último capítulo de este libro.

81 Titularidad de derechos de las personas jurídicas en el Sistema Interamericano de Derechos Humanos (interpretación y alcance del artículo 1.2, en relación con los artículos 1.1, 8, 11.2, 13, 16, 21, 24, 25, 29, 30, 44, 46 Y 62.3 de la Convención Americana sobre Derechos Humanos, Asi Como del Artículo 8.1.a y b del Protocolo de San Salvador), Corte Interamericana de Derechos Humanos, Opinión Consultiva, OC-22/16, Serie A núm. 22, 2016, párr. 26. El concepto del control de convencionalidad será tratado más adelante.

82 Domingo, R. y Rodríguez-Antolín, B., Reglas jurídicas y aforismos (con jurisprudencia actualizada y remisiones a la legislación vigente), Aranzadi, Pamplona, 2000, pp. 47 y 48.

83 Asunto Faworzina (frontera polaco-checoslovaca), Corte Permanente de Justicia Internacional, Opinión Consultiva núm. 8, 1923, p. 37. El texto original afirma: "it is an established principle that the right of giving an authoritative interpretation of a legal rule belongs solely to the person or body who has the power to modify or suppress it".

84 Artículos 62, 63, 67 y 68 de la CADH. 
habrían actuado a manera de una interpretación autorizada; en este punto, si bien los Estados pueden interpretar autorizadamente la Carta de la OEA, deben hacerlo del mismo modo en que se aprueba dicho instrumento, mediante un tratado internacional. Si no se hace así, no se podría hablar de un verdadero acuerdo interpretativo de los Estados, sino del parecer de la Asamblea General de la OEA, la que no es el órgano autorizado para interpretar auténticamente el tratado internacional, pues no puede ni derogarlo ni modificarlo. Una resolución de la OEA solo podría reflejar la opinión de la mayoría de los representantes de los distintos Estados.

También notamos que la Carta de la OEA hizo siempre referencia a derechos fundamentales o esenciales. Ello no fue un agregado de reformas posteriores, en otras palabras, la referencia a los derechos humanos en la Carta de la OEA no impidió que los Estados reiteraran expresamente sus deseos de que la DADDH fuera una simple declaración no vinculante. Por tanto, agregar algunas nuevas referencias a los derechos humanos o a la Comisión IDH difícilmente podría manifestar una voluntad de modificar el poder vinculante de la DADDH. Ello es reforzado al notar que algunos Estados que ratificaron los tratados modificatorios de la Carta han afirmado claramente que la DADDH no los vincula, según se vio más arriba; así, mal podría decirse que los Estados han dado implícitamente valor vinculante a la DADDH, si algunos afirmaron explícitamente que no lo tiene.

Por último, el que se le haya dado a la Comisión IDH la potestad de "promover la observancia y la defensa de los derechos humanos y de servir como órgano consultivo de la Organización en esta materia", ${ }^{85}$ no significa que un Estado incurra en responsabilidad internacional, propiamente tal, al incumplir con uno de los artículos de la DADDH, pues podría incurrir en una responsabilidad meramente política.

Las antedichas afirmaciones no buscan desmerecer, en ningún caso, el valor moral y político que tiene la DADDH, así como su carácter de referente obligado para el actuar de la Comisión Interamericana. Tampoco buscan afirmar o negar el valor jurídico de la $\mathrm{DADDH}$, sino que sólo pretenden agregar algunas ideas a las consideraciones sobre su fuerza vinculante.

\section{G. Valor innegable}

Con independencia de si se considera o no que la DADDH sea vinculante, es innegable que ella debe ser utilizada por la Comisión IDH para saber cuáles son los derechos humanos que le compete promover y defender.

85 Artículo 106, Carta de la OEA. 
Esto fue dispuesto por la OEA en el Estatuto de la Comisión. Según vimos, ya el Estatuto original disponía, que para los propósitos de dicho estatuto, los derechos humanos serían aquellos reconocidos en la DADDH. Hoy en día el Estatuto de la Comisión, aprobado mediante la Resolución 447 en 1979, ${ }^{86}$ tiene una norma similar, transcrita más arriba, cuya única diferencia es incluir una referencia a la CADH.

Incluso Estados Unidos, que ha reiterado que la DADDH es sólo "una manifestación acordada de principios generales sobre derechos humanos, no obligatorios", ${ }^{87}$ reconoce que la Comisión puede utilizar la DADDH para ejercer su labor de promoción y defensa de los derechos humanos. ${ }^{88}$

Por último, es indiscutible que la Comisión y la Corte interamericanas - especialmente la primera - dan importancia a la DADDH. Al final de este capítulo nos referiremos al modo como la DADDH es utilizada por ambos órganos, antes de hacerlo, haremos referencia a una cuestión importante: la mención explícita de la DADDH en el artículo 29 de la CADH.

\section{La Declaración y el artículo 29 de la Convención Americana}

La CADH, un instrumento internacional vinculante, se refiere a la DADDH en un par de ocasiones; lo hace, en primer lugar, en su preámbulo,

86 Corte Interamericana de Derechos Humanos, Documentos básicos en materia de derechos humanos en el Sistema Interamericano: actualizado a febrero de 2012, cit., p. 135.

87 Caso 10.573 - Estados Unidos (1993): Comisión Interamericana de DD.HH., Informe, núm. 31/93, párr. 21. Entre las consecuencias que EE.UU. le asignaría a dicha falta de valor vinculante se encontraría el hecho de que no se debiera "apelar a la Convención de Viena para interpretar la Declaración Americana", por lo que la Comisión debiera "tener cuidado especial en no rechazar el significado explícito cuando la intención de los autores está manifiesta en un artículo determinado". Caso 9647 - Estados Unidos (1987): Comisión Interamericana de DD.HH., Informe, núm. 3/87, párr. 38. d.

88 El hecho de que la Comisión debe aplicar los estándares de la DADDH no es discutido por EE.UU., por ejemplo, Ibidem, párr. 38, y Caso 12.626, Jessica Lenahan (Gonzales) y otros, Estados Unidos (2011): Comisión Interamericana de DD.HH., Informe, núm. 80/11, párr. 3. En efecto, EE.UU. muestra aceptar que la Comisión se refiera a la DADDH en el conocimiento de peticiones individuales; por ejemplo, Caso 10.573, Estados Unidos, cit., párr. 24, donde EE.UU. afirma que excedería de la competencia de la Comisión el conocer de cuestiones relativas al uso de la fuerza y las leyes del conflicto armado; en el caso 9903, Rafael Ferrer-Mazorra y otros, Estados Unidos (2001): Comisión Interamericana de DD.HH., Informe, núm. 51/01, donde reclama que determinada cuestión exigida por la Comisión no estaría regida por la DADDH, y en el Caso 12.626, Jessica Lenahan (Gonzales) y otros, Estados Unidos (2011): Comisión Interamericana de DD.HH., Informe, núm. 80/11, párr. 55, donde afirma que la Comisión no puede incorporar a la DADDH otros derechos que estén establecidos en tratados no ratificados por EE.UU. 
al afirmar que determinados principios que enuncia la CADH se encuentran consagrados en otros instrumentos internacionales, tales como la DADDH. Uno de esos principios es el que dice que: "los derechos esenciales del hombre no nacen del hecho de ser nacional de determinado Estado, sino que tienen como fundamento los atributos de la persona humana". Esta mención del preámbulo no tiene relevancia para los efectos de este trabajo.

En cambio, es de gran importancia la referencia que la letra "d)" del artículo 29 de la CADH hace a la DADDH en la sección que trata sobre el uso que la Corte IDH ha hecho de la DADDH, nos referiremos al modo como este tribunal aplica actualmente el artículo 29; ahora analizaremos el artículo 29 de la CADH en sí mismo. Tal artículo dispone:

Normas de Interpretación

Ninguna disposición de la presente Convención puede ser interpretada en el sentido de:

a) permitir a alguno de los Estados Partes, grupo o persona, suprimir el goce y ejercicio de los derechos y libertades reconocidos en la Convención o limitarlos en mayor medida que la prevista en ella;

b) limitar el goce y ejercicio de cualquier derecho o libertad que pueda estar reconocido de acuerdo con las leyes de cualquiera de los Estados Partes o de acuerdo con otra convención en que sea parte uno de dichos Estados;

c) excluir otros derechos y garantías que son inherentes al ser humano o que se derivan de la forma democrática representativa de gobierno, y

d) excluir o limitar el efecto que puedan producir la Declaración Americana de Derechos y Deberes del Hombre y otros actos internacionales de la misma naturaleza.

Algunos autores han afirmado que el artículo 29 indicaría que el sistema interamericano acepta que la DADDH produce efectos jurídicos. ${ }^{89}$ Dentro de ellos, cierta doctrina ha considerado que el artículo 29 sería una "norma de reenvío", que haría que la competencia ratione materiae de la Corte IDH se extienda a otros instrumentos. ${ }^{90}$ Ello significaría, en otras pala-

89 Por ejemplo, Monroy Cabra, M. G., "Aplicación de la Declaración Americana de Derechos y Deberes del Hombre por la Comisión Interamericana de Derechos Humanos", Revista Instituto Interamericano de Derechos Humanos, número especial en conmemoración del cuadragésimo aniversario de la Declaración Americana de Derechos y Deberes del Hombre, 1989, p. 134, y Salvioli, F. O., "El aporte de la Declaración Americana de 1948, para la Protección Internacional de los Derechos Humanos", cit., p. 686.

90 Medina Quiroga, C. y Nash Rojas, C., Sistema Interamericano de Derechos Humanos: introducción a sus mecanismos de protección, cit., p. 46. Más aún, hace ya un par de décadas se pensaba que la referencia que hace el artículo 29 de la CADH a la DADDH podría hacer que la Corte se tuviera que referir a esta última. Gros Espiell, H., "La Declaración Americana: raíces conceptuales y políticas en la historia, la filosofia y el derecho americano", cit., p. 60. 
bras, que la Corte IDH podría conocer no solo de las violaciones de derechos contenidos en la CADH, sino además, de las otras clases de normas señaladas en el artículo 29. Esto constituiría algo que se puede llamar una jurisdicción extra-Convención, ${ }^{91}$ y daría un valor prácticamente vinculante a lo dispuesto en la DADDH para aquellos Estados que hubieran ratificado la CADH. Sin embargo, no es adecuado interpretar el artículo 29 como una norma de reenvío. La determinación de este asunto no es la tarea principal de este trabajo, por lo que solo se hará una explicación somera de por qué dicha disposición no es una norma de reenvío.

El artículo 29 no es único en su especie en el derecho internacional, su letra "a" alude a una proscripción del abuso del derecho, presente en otras declaraciones o instrumentos de derechos humanos, tales como el artículo 30 de la Declaración Universal de los Derechos Humanos, ${ }^{92}$ el artículo 17 del Convenio Europeo de Derechos Humanos, ${ }^{93}$ el artículo 54 de la Carta de los Derechos Humanos de la Unión Europea ${ }^{94}$ (estos dos últimos instrumentos explícitamente llaman "Prohibición del abuso de derecho" a sus respectivas normas análogas al artículo 29). Existen también normas sobre abuso del derecho en otros instrumentos internacionales, que presentan disposiciones similares, no solo a la de la letra "a", sino que también a la letra "b" del artículo 29 de la CADH. Algunas de ellas son el artículo 5o. del Pacto Internacional de Derechos Civiles y Políticos, ${ }^{95}$ el artículo 5o. del Pacto Internacional de Derechos Económicos, Sociales y Culturales, ${ }^{96}$ y el artículo 40 de la Declaración de Derechos Humanos de la Asociación de Naciones del Sudeste Asiático. ${ }^{97}$ Existen más instrumentos en este mismo sentido, pero no es necesario detallarlos todos..$^{98}$

91 Paúl Díaz, Á., "La Corte Interamericana in vitro: comentarios sobre su proceso de toma de decisiones a propósito del caso Artavia", Derecho Público Iberoamericano, vol. 2, 2013, pp. 310-314.

92 Declaración Universal de Derechos Humanos, Adoptada y proclamada por la Asamblea General en su Resolución 217 A, el 10 de diciembre de 1948.

93 Convenio Europeo para la Protección de los Derechos Humanos y de las Libertades Fundamentales, del 4 de noviembre de 1950.

94 Carta de los Derechos Fundamentales de la Unión Europea, del 7 de diciembre de 2000y del 4 de noviembre de 1950.

95 Pacto Internacional de Derechos Civiles y Políticos, del 16 de diciembre de 1966. Normas similares en este mismo tratado pueden observarse en los artículos 22.3 (con relación a un derecho específico), y el artículo 46 (con relación a atribuciones de determinados organismos).

96 Pacto Internacional de Derechos Económicos, Sociales y Culturales, del 16 de diciembre de 1966.

97 Declaración de Derechos Humanos de la Asociación de Naciones del Sudeste Asiático, Adoptada por los Miembros de ASEAN, Phnom Penh, Camboya, 18 de noviembre de 2012.

98 Por ejemplo, artículo 5o. de la Convención sobre el Estatuto de los Apátridas, del 28 de septiembre de 1954; artículo 5o. de la Convención sobre el Estatuto de los Refugiados, del 28 
Las letras "c" y "d" del artículo 29 son particulares del sistema interamericano, pero buscarían, igualmente, evitar un abuso del derecho. Su redacción se justifica por realidades propias americanas. La primera busca extender la norma de abuso a los "derechos y garantías que son inherentes al ser humano", y a los derechos y garantías "que se derivan de la forma democrática representativa de gobierno". La primera parte de esta norma parece desprenderse de la tradición iusnaturalista, que ha estado tan presente en el pensamiento jurídico hispanoamericano, reafirmando la existencia de derechos que derivan del derecho natural, y que pueden no estar consagrados en el derecho positivo. ${ }^{99}$ Así, se busca evitar que se use como excusa la falta de consagración de derechos en la CADH, para dejar de cumplir con obligaciones emanadas del derecho natural. La segunda sección de esta norma haría lo suyo con los derechos necesarios para llevar adelante la democracia, en cuanto ideal de organización política moderna, consagrado ya en la carta original de la OEA como principio organizativo de las naciones americanas, ${ }^{100} \mathrm{y}$ añorado por los países del continente, a quienes les ha resultado bastante esquiva.

Por su parte, la letra "d)" se hace cargo de la existencia de la DADDH, así como de la discusión sobre su valor jurídico. Se debe recordar que el Estatuto de la Comisión IDH, que se refiere a los derechos de la DADDH, se aprobó en 1960, lo que posiblemente generaría una cierta discusión sobre si la referencia a la DADDH modificaba de algún modo su valor jurídico. Además, podía alegarse que algunas de sus normas forman parte de la costumbre internacional; por este motivo, es razonable pensar que la norma del artículo 29 buscó una formulación que, sin reconocer ni negar el valor vinculante de la DADDH (efecto que puedan producir), ${ }^{101}$ se pusiera en el caso de que algún Estado quisiera alegar la CADH para dejar de cumplir con la DADDH.

de julio de 1951; artículo 23 de la Convención sobre la Eliminación de Todas las Formas de Discriminación contra la Mujer, del 18 de diciembre de 1979; artículo 41 de la Convención sobre los Derechos del Niño, del 20 de noviembre de 1989, y artículo 4o. del Protocolo Adicional a la Convención Americana sobre Derechos Humanos en Materia de Derechos Económicos, Sociales y Culturales, "Protocolo de San Salvador", del 17 de noviembre de 1988.

99 Esta presencia del derecho natural en el ambiente jurídico latinoamericano se aprecia en la misma DADDH. R. K. Goldman, "History and Action: The Inter-American Human Rights System and the Role of the Inter-American Commission on Human Rights", Human Rights Quarterly, vol. 31, 2009, pp. 859 y 860.

100 Se encontraba ya en el preámbulo y en el artículo 5.d de la Carta Original de la OEA, Carta de la Organización de los Estados Americanos, del 30 de abril de 1948.

101 Cerna coincide en que el artículo 29 dispone que el valor de la DADDH no puede ser disminuido, pero sin que este artículo determine cuál sería ese valor. Cerna, C. M., "Reflections on the Normative Status of the American Declaration of the Rights and Duties of Man", cit., p. 1230. 
La decisión de incluir esta norma fue adecuada, pues se podría haber afirmado que la aprobación y ratificación de la $\mathrm{CADH}$ estaría, de algún modo, "derogando" la DADDH. Algún Estado podría haber simplificado la realidad, y haber argumentado que si un tratado que es lex posterior puede derogar otro tratado, con mayor razón podría poner fin a los efectos de una simple declaración. Por tanto, era de suma relevancia dejar claro este asunto, ya que la DADDH contiene derechos que no están consagrados en la CADH.

Esa es la razón por la cual se incluyó una referencia a DADDH en el artículo 29 de la $\mathrm{CADH}$, no porque se quisiera crear una norma de reenvío. Si se hubiese querido hacer lo contrario, lo lógico habría sido incluir, dentro de la enumeración de derechos consagrados en la CADH, todos los derechos y obligaciones consagrados en la DADDH, incluyendo los derechos sociales. Éstos, en cambio, solo volvieron a ser formulados jurídicamente en el Protocolo Adicional a la CADH en Materia de Derechos Económicos, Sociales y Culturales, o "Protocolo de San Salvador", el cual no ha sido ratificado por todos los Estados que han ratificado la CADH.

Según dijimos, éste no es el momento para demostrar la finalidad del artículo 29; sin embargo, haremos referencia a un último argumento para mostrar que el artículo 29 no es una norma de reenvío. Este razonamiento se basa en la consideración de si dicha norma buscaba ser aplicada por la Corte IDH o por los Estados parte. Si ella estuviera destinada a ser aplicada por el Estado, no podría constituir una norma de reenvío. Debemos recordar, que toda la CADH busca convertirse en una obligación estatal, aunque el Estado haya o no concedido jurisdicción de la Corte IDH, pues es posible ratificar la CADH y no quedar sujeto a la competencia de su tribunal. Esto se afirma respecto de todos los derechos de la CADH, pero también de su artículo 29 y de otras normas. El hecho de que el artículo 29 buscaba ser aplicado por el Estado se reafirma al notar que varias declaraciones y convenciones de derechos, que no establecen ningún mecanismo de supervisión, contemplan normas como las del artículo 29, a pesar de que no serían aplicadas por una corte internacional. ${ }^{102}$

Otro motivo que hace pensar que esta norma buscaba ser aplicada por el Estado, es el hecho de su amplitud. Si se pensara que el artículo 29 es una norma de reenvío, se estaría concediendo un poder casi omnímodo a la Corte IDH, esto, en cuanto a que dicha norma hace referencia a todos los tratados de derechos humanos, a las leyes nacionales, e incluso, al derecho natural. Por último, es interesante notar, que la versión inglesa de

102 Por ejemplo, la Declaración Universal de Derechos Humanos y la Declaración de los Estados del Sudeste Asiático, referidas más arriba. 
Este libro forma parte del acervo de la Biblioteca Jurídica Virtual del Instituto de Investigaciones Jurídicas de la UNAM

la CADH llama a este artículo "Restrictions Regarding Interpretation" (Restricciones con Relación a la Interpretación), y si el artículo 29 se leyera como una norma que diera una competencia extra-Convención a la Corte, tal norma no estaría restringiendo el alcance de la interpretación, sino que lo estaría ampliando al permitir interpretar también otras normas mediante un reenvío.

En conclusión, si bien el artículo 29 de la CADH hace una referencia expresa a la DADDH, dicha referencia no busca darle valor vinculante. Esta norma pretende principalmente: afirmar que los Estados no podrán considerar que la CADH habría tenido el efecto de derogar la DADDH; por otro lado, apunta a lograr que los Estados, que consideren que la DADDH tiene un valor vinculante - así como aquellos que buscan ceñirse al contenido de la DADDH, aunque no la consideren vinculante - no dejen de aplicar los derechos consagrados en dicha declaración, bajo la excusa de que ellos no están contenidos en la CADH. Así, por ejemplo, un Estado que estuviera procurando hacer efectivo el derecho a la educación, en virtud del artículo XII de la DADDH, no podría dejar de hacerlo motivado sólo por el hecho de que la CADH no establece tal derecho. ${ }^{103}$

\section{USO QUE LOS ÓRGANOS DEL SISTEMA INTERAMERICANO LE DAN A LA DECLARACIÓN}

\section{Uso por parte de la Comisión}

La Comisión y la Corte interamericana han sido fundamentales para la protección y el restablecimiento de los derechos fundamentales de miles de habitantes de América, uno de los mecanismos que utilizan para ello es el procesamiento de peticiones individuales, en el que revisan denuncias de violaciones específicas a los derechos humanos cometidas por algún Estado americano. La Comisión IDH puede recibir peticiones presentadas en contra de cualquier Estado parte de la OEA. Algunos de ellos no han ratificado la $\mathrm{CADH}$, por lo que el único catálogo de derechos humanos que reconocen a nivel americano es la DADDH. También recibe peticiones en contra de Esta-

103 Este segundo efecto fue, en su momento, recogido por la Corte IDH en su opinión consultiva número diez, de 1989, aunque partiendo del supuesto de que la DADDH genera obligaciones internacionales. En ella, la Corte IDH dispuso que, a la luz del artículo 29.d, "no obstante que el instrumento principal que rige para los Estados Partes en la Convención es esta misma, no por ello se liberan de las obligaciones que derivan para ellos de la Declaración por el hecho de ser miembros de la OEA". Interpretación de la Declaración Americana de los Derechos y Deberes del Hombre en el marco del artículo 64 de la Convención Americana sobre Derechos Humanos, cit., párr. 46. 
Este libro forma parte del acervo de la Biblioteca Jurídica Virtual del Instituto de Investigaciones Jurídicas de la UNAM

dos que sí han ratificado la CADH. ${ }^{104}$ Dentro de éstos, la mayoría de los Estados le han concedido jurisdicción a la Corte (según se aprecia en la tabla).

\section{TABla Comparativa de la Estados AMERICANOS SEGÚN SU RATIFICACIÓN DE LA CADH}

\begin{tabular}{|l|l|}
\hline \multicolumn{1}{|c|}{ Estados no parte de la CADH } & Estados bajo la jurisdicción de la Corte \\
\hline Antigua y Barbuda & Argentina \\
Bahamas (Mancomunidad de las) & Barbados \\
Belice & Bolivia (Estado Plurinacional de) \\
Canadá & Brasil \\
Cuba & Chile \\
Estados Unidos de América & Colombia \\
Guyana & Costa Rica \\
San Cristóbal y Nieves & República Dominicana \\
San Vicente y las Granadinas & Ecuador \\
Santa Lucía & El Salvador \\
Trinidad y Tobago & Guatemala \\
Venezuela (Rep. Bolivariana de) & Haití \\
& Honduras \\
\hline Estados parte de la CADH, pero que no & México \\
están bajo la jurisdicción la Corte & Nicaragua \\
\hline Dominica (Mancomunidad de) & Panamá \\
Granada & Paraguay \\
Jamaica & Perú \\
& Surinam \\
\hline
\end{tabular}

En este punto conviene preguntarse si la Comisión mantiene el poder de aplicar la DADDH en contra de los Estados que están sujetos a la CADH. Originalmente la Comisión no lo hacía. ${ }^{105}$ Ello era consistente con lo dispuesto en el artículo 1.2 de su Estatuto, que no establece que la Comisión pueda aplicar también la DADDH respecto de los Estados parte de la CADH. En efecto, según ya vimos, tal norma dispone lo siguiente:

Para los fines del presente Estatuto, por derechos humanos se entiende:

a. los derechos definidos en la Convención Americana sobre Derechos Humanos en relación con los Estados partes en la misma;

104 Este trabajo no se pronunciará sobre el fundamento jurídico de dichas peticiones.

105 Cerna, C. M., "Reflections on the Normative Status of the American Declaration of the Rights and Duties of Man", cit., pp. 1226-1228. 
Este libro forma parte del acervo de la Biblioteca Jurídica Virtual del Instituto de Investigaciones Jurídicas de la UNAM

b. los derechos consagrados en la Declaración Americana de Derechos y Deberes del Hombre, en relación con los demás Estados miembros. ${ }^{106}$

Hoy en día, en cambio, la práctica de la Comisión es que también puede aplicar la DADDH a Estados que han ratificado la CADH, según Christina Cerna, este cambio habría ocurrido después de emitida la opinión consultiva número 10 de la Corte IDH. ${ }^{107}$ Actualmente, si se alega contra un Estado que ha ratificado la CADH la violación de un derecho establecido en la DADDH, pero que no está establecido en la CADH, la Comisión se considera autorizada para declarar su violación. Lo mismo se podría decir respecto de derechos consagrados en ambos instrumentos, cuando los hechos violatorios comenzaron antes de que el Estado ratificara la $\mathrm{CADH}$, y continuaron después de dicha ratificación o adhesión. Nosotros, no nos pronunciaremos sobre este cambio de práctica, que es criticado por Christina Cerna. ${ }^{108}$

Los efectos que pueden tener las peticiones presentadas ante la Comisión variarán según la relación que tenga el Estado con los instrumentos recién nombrados; las peticiones presentadas ante la Comisión IDH en contra de Estados miembros de la OEA, pero que no han ratificado la $\mathrm{CADH}$, pueden resultar solo en la emisión de un informe de fondo, donde la Comisión efectuará recomendaciones al Estado. Este informe podrá referirse solamente a eventuales violaciones de la DADDH. ${ }^{109}$ Las peticiones en contra de Estados que sí han ratificado la $\mathrm{CADH}$, pero que no le han concedido jurisdicción a la Corte IDH tienen una tramitación muy similar a la anterior, pero la Comisión podrá acusarlos de violaciones de la CADH. Si el Estado le ha concedido jurisdicción a la Corte IDH, el asunto remitido a la Comisión podrá ser presentado ante dicho tribunal, una vez que la Comisión IDH se haya pronunciado sobre el fondo del asunto. ${ }^{10}$ Por su parte, la Corte IDH puede ordenar al Estado - ya no solo recomendar-, que adopte determinadas medidas para reparar la violación.

106 Artículo 1.2.

107 Cerna, C. M., "Reflections on the Normative Status of the American Declaration of the Rights and Duties of Man", cit., pp. 1232-1234.

108 Ibidem, pp. 1232-1237.

109 Faúndez Ledesma, H., El Sistema Interamericano de Protección de los Derechos Humanos: Aspectos Institucionales y Procesales, cit., p. 38.

110 La Corte Interamericana ha afirmado que la Comisión funciona "a manera de ministerio público del Sistema Interamericano, llamado a comparecer en todos los casos ante el tribunal", y que "la Comisión tiene una función investigadora de los hechos denunciados..., que es necesario cumplir en todas las hipótesis, a menos que se trate de un caso de mero derecho". Gallardo y otros (asunto de Viviana, 1981): Corte Interamericana de DD.HH., Decisión, Serie A, núm. G 101/81 (13 de noviembre), párr. 22. El proceso ante la Comisión está regulado en los artículos 44-51, CADH. 
Este libro forma parte del acervo de la Biblioteca Jurídica Virtual del Instituto de Investigaciones Jurídicas de la UNAM

En virtud de lo anterior, la DADDH sigue siendo un instrumento fundamental, pues más de un tercio de los Estados del Continente sólo pueden ser denunciados por violaciones de este catálogo de derechos humanos, en efecto, según se observó en la tabla más arriba, 12 Estados, de un total de 35 Estados miembros de la OEA, no han ratificado la CADH. Frente a esta afirmación, alguien podría replicar que hablar de un tercio de los Estados americanos es engañoso, pues varios de ellos tienen una población muy reducida, por lo que no pueden ser comparados con el resto de los Estados de América. Sin embargo, según se aprecia en la tabla que se presenta a continuación, el tercio de los Estados de América que no han ratificado la $\mathrm{CADH}$, cuenta también con un tercio de la población de América.

TABLA COMPARATIVA DE LA POBLACIÓN AMERICANA SEGÚN SI SU ESTADO HA RATIFICADO LA CADH (DE UNA POBLACIÓN TOTAL DE 1.163.284.978). ${ }^{111}$

\begin{tabular}{|c|c|c|c|}
\hline \multicolumn{2}{|c|}{ Estados no miembros de la CADH } & \multicolumn{2}{|c|}{ Estados bajo la jurisdicción de la Corte } \\
\hline Antig. y Bar:: & 91.295 & Argentina: & 43.024 .374 \\
\hline Bahamas: & 321.834 & Barbados: & 289.680 \\
\hline Belice: & 340.844 & Bolivia: & 10.631 .486 \\
\hline Canadá: & 34.834 .841 & Brasil: & 202.656 .788 \\
\hline Cuba: & 11.047 .251 & Chile: & 17.363 .894 \\
\hline EE.UU.: & 318.892 .103 & Colombia: & 46.245 .297 \\
\hline Guyana: & 735.554 & Costa Rica: & 4.755 .234 \\
\hline Sn. Cbl. y N.: & 51.538 & Rep. Dom.: & 10.349 .741 \\
\hline Sta. Lucía: & 163.362 & Ecuador: & 15.654 .411 \\
\hline S. Vc. y las G.: & 102.918 & El Salvador: & 6.125 .512 \\
\hline Trin. y Tob.: & 1.223 .916 & Guatemala: & 14.647 .083 \\
\hline \multirow[t]{2}{*}{ Venezuela: } & 28.868.486 & Haití: & 9.996 .731 \\
\hline & & Honduras: & 8.598 .561 \\
\hline \multirow[t]{2}{*}{ Total: } & $396.673 .942(34,09 \%)$ & México: & 120.286.655 \\
\hline & & Nicaragua: & 5.848 .641 \\
\hline \multirow{2}{*}{\multicolumn{2}{|c|}{$\begin{array}{l}\text { Estados miembros de la CADH, pero que no } \\
\text { están bajo la jurisdicción la Corte }\end{array}$}} & Panamá: & 3.608 .431 \\
\hline & & Paraguay: & 6.703 .860 \\
\hline Dominica: & 73.449 & $\begin{array}{l}\text { Perú: } \\
\text { Suringm. }\end{array}$ & 30.147 .935 \\
\hline Granada: & 110.152 & $\begin{array}{l}\text { Surmam: } \\
\text { Uruouav: }\end{array}$ & $\begin{array}{l}3 / 3.311 \\
3.332972\end{array}$ \\
\hline Jamaica: & 2.930 .050 & oruguay. & 3.332 .912 \\
\hline \multicolumn{2}{|c|}{ Total: $3.113 .651(0,26 \%)$} & Total: & $763.497 .385(65,63 \%)$ \\
\hline
\end{tabular}

111 Datos obtenidos el 28 de enero de 2015 a partir de Central Intelligence Agency, The World Factbook, disponible en https://wrere.cia.gov/library/publications/the-world-factbook/, fecha de última consulta, 23 de diciembre de 2015 . 
Este libro forma parte del acervo de la Biblioteca Jurídica Virtual del Instituto de Investigaciones Jurídicas de la UNAM

\section{Uso por parte de la Corte}

La Corte IDH también utiliza la DADDH, aunque de un modo mucho menos relevante que la Comisión IDH. La razón de este menor uso es que la Corte encuentra la base de su jurisdicción en la CADH, y dicta sentencias sólo en contra de Estados, que habiendo ratificado tal tratado, violan alguno de los derechos allí consagrados. Antes de referirnos al uso que la Corte IDH hace de la DADDH en casos contenciosos, recordamos que ya hemos analizado la opinión consultiva donde tocó el tema de la DADDH en detalle. ${ }^{112}$ Además, hacemos presente que la Corte IDH ha mencionado incidentalmente la DADDH en algunas otras opiniones consultivas. ${ }^{113}$

El uso que le ha dado la Corte IDH a la DADDH en casos contenciosos es muy relevante. Ella ha utilizado la DADDH para efectos interpretativos. Por ejemplo, en el Caso de la Comunidad Moiwana vs. Surinam la Corte afirmó que ella "generalmente considera las disposiciones de la Declaración Americana en su interpretación de la Convención Americana". ${ }^{114}$ La Corte también ha explicitado su uso en la interpretación de normas específicas de la CADH, como sucedió en Bámaca Velásquez vs. Guatemala. ${ }^{115}$ En dicho caso sostuvo que la norma que dispone que toda persona tiene derecho al reconocimiento de su personalidad jurídica, ${ }^{116}$ debía ser interpretada a la luz de lo dispuesto en el artículo XVII de la DADDH, afirmando que reconocer la personalidad jurídica implica reconocer la capacidad de ser titular de derechos y deberes. ${ }^{117}$ Otro caso en el que lo hizo fue en Artavia Murillo y otros vs. Costa Rica, ${ }^{118}$ al que nos referiremos brevemente en el ejemplo donde la Corte hizo expresa referencia a los trabajos preparatorios de la DADDH. Además de lo anterior, la Corte IDH ha aludido a la DADDH a modo argumentativo, como se obser-

112 Interpretación de la Declaración Americana de los Derechos y Deberes del Hombre en el Marco del Artículo 64 de la Convención Americana sobre Derechos Humanos, cit.

113 Por ejemplo, Derechos y garantías de niñas y niños en el contexto de la migración y/o necesidad de protección internacional, cit., párr. 32, y Titularidad de derechos de las personas jurídicas en el Sistema Interamericano de Derechos Humanos (interpretación y alcance del artículo 1.2, con relación a los artículos 1.1, 8, 11.2, 13, 16, 21, 24, 25, 29, 30, 44, 46 y 62.3 de la Convención Americana sobre Derechos Humanos, así como del artículo 8.1. a y b del Protocolo de San Salvador), cit., párrs. 18 y 25.

114 Comunidad Moiwana vs. Surinam (caso de la, 2005): Corte Interamericana de DD.HH., Excepciones preliminares, fondo, reparaciones y costas, serie C, núm. 124, párr. 63.

115 Bámaca Velásquez vs. Guatemala (2000): Corte Interamericana de DD.HH., Fondo, serie C, núm. 70 .

116 Artículo 3o., CADH.

117 Bámaca Velásquez vs. Guatemala, cit., párrs. 178 y 179.

118 Artavia Murillo y otros (fecundación in vitro) vs. Costa Rica, 2012: Corte Interamericana de DD.HH., Excepciones preliminares, fondo, reparaciones y costas, serie C, núm. 257, párrs. 194-223. 
Este libro forma parte del acervo de la Biblioteca Jurídica Virtual del Instituto de Investigaciones Jurídicas de la UNAM

va en el caso Suárez Peralta vs. Ecuador. ${ }^{119}$ En dicho caso, la DADDH fue citada en conjunto con otros instrumentos, incluido uno de soft law emanado de la OEA $^{120}$ Algo similar ha ocurrido en los recientes casos Pueblos Kalina y Lokono vs. Surinam, respecto del derecho de petición, y Ángel Duque vs. Colombia, respecto del derecho a la preservación de la salud. ${ }^{121}$ Por último, debe notarse que la DADDH ha sido citada por algunos jueces en sus votos separados. ${ }^{122}$

Más interesante aún, es considerar la actitud de la Corte IDH frente a casos en los que la Comisión o las víctimas le han solicitado expresamente declarar la violación directa de derechos reconocidos en la DADDH. Comentaremos cuatro sentencias que revelan diversas aproximaciones a la aplicación de la DADDH, los casos Cantos vs. Argentina, ${ }^{123}$ Bueno Alves vs. Argentina, ${ }^{124}$ Argüelles y otros vs. Argentina ${ }^{125}$ y Ruano Torres y otros vs. El Salvador, ${ }^{126}$ fallados en los años 2002, 2007, 2014 y 2015, respectivamente. En el primer caso la Corte afirmó que los hechos que darían lugar a eventuales violaciones a artículos de la DADDH habían ocurrido antes de la aceptación de la competencia contenciosa de la Corte, por parte de Argentina, por lo que no se referiría a tal alegato. ${ }^{127}$ En este caso, la Corte no se pronuncia sobre si puede o no declarar la violación de artículos de la DADDH, sino que, solo afirma ser incompetente en el caso en particular; en cambio, en el asunto Bueno Alves, la Corte sostiene que podría usar la DADDH, en caso de considerarlo oportuno, para la interpretación de los artículos "concordantes" de la CADH. ${ }^{128}$

119 Suárez Rosero vs. Ecuador (1997): Corte Interamericana de DD.HH., Fondo, serie C, núm. 25, párr. 131.

120 Ibidem, algo similar ocurrió en el caso Artavia Murillo, donde también se citó a modo argumentativo en conjunto con un instrumento no vinculante. Artavia Murillo y otros (Fecundación in vitro) vs. Costa Rica, cit., párr. 150.

121 Pueblos Kaliña y Lokono vs. Surinam (2015): Corte Interamericana de DD.HH., Fondo, reparaciones y costas, serie C núm. 309, párrs. 246 y 265, y Duque vs. Colombia (2016): Corte Interamericana de DD.HH., Excepciones preliminares, fondo, reparaciones y costas, serie C, núm. 310, párr. 172.

122 Salvioli, F. O., "El aporte de la Declaración Americana de 1948, para la protección internacional de los derechos humanos", cit., p. 691.

123 Cantos vs. Argentina (2002): Corte Interamericana de DD.HH., Fondo, reparaciones y costas, serie C, núm. 97, párr. 8 .

124 Bueno Alves vs. Argentina (2007): Corte Interamericana de DD.HH., Fondo, reparaciones y costas, serie $\mathrm{C}$, núm. 164, párr. 7.

125 Argüelles y otros vs. Argentina (2014): Corte Interamericana de DD.HH., Excepciones preliminares, fondo, reparaciones y costas, serie C, núm. 288.

126 Ruano Torres y otros vs. El Salvador (2015): Corte Interamericana de DD.HH., Fondo, reparaciones y costas, serie C, núm. 303, párrs. 6 y 28.

127 Cantos vs. Argentina, cit., párr. 48.

128 Bueno Alves vs. Argentina, cit., párr. 60. La expresión "concordantes" es usada en ibidem, párr. 32 . 
Este libro forma parte del acervo de la Biblioteca Jurídica Virtual del Instituto de Investigaciones Jurídicas de la UNAM

En los recientes casos Argüelles y Ruano Torres, en cambio, la Corte IDH afirmó que, según el artículo 29.d, le corresponde considerar las disposiciones de la DADDH al ejercer su competencia contenciosa de interpretar y aplicar la Convención Americana. ${ }^{129}$ Reiteró que la fuente concreta de las obligaciones de los Estados parte de la CADH es la misma convención, pero que eso no significa que los Estados se liberan de "las obligaciones que derivan para ellos" de la DADDH, por el hecho de ser miembros de la OEA (la Corte IDH parafrasea el artículo 29 de la CADH, pero omite la expresión "que puedan").130 En ambos casos la Corte IDH notó que los representantes no formularon sus alegatos respecto a la DADDH en virtud del artículo 29.d de la CADH. ${ }^{131}$ En el caso Argüelles, esto la llevó a acoger una excepción preliminar del Estado ${ }^{132}$ y en el caso Ruano, a afirmar que, como la parte había alegado la violación de los artículos de la DADDH "en correspondencia" con los derechos y libertades de la $\mathrm{CADH}$, no correspondía pronunciarse sobre estas alegadas violaciones. ${ }^{133}$

Quizá, lo más interesante de estas afirmaciones de los casos Argüello y Ruano, es que la Corte IDH dio a entender que su decisión habría sido distinta si los peticionarios hubiesen formulado su petición sobre la base del artículo 29.d de la CADH, en otras palabras, parece afirmar que sería posible declarar la violación del artículo 29.d de la CADH cuando un Estado viole la DADDH. Esta conclusión no es adecuada; en primer lugar, por lo que afirmamos precedentemente sobre el correcto significado del artículo 29.d; en segundo lugar, porque si bien los Estados que le otorgan competencia a la Corte le permiten conocer cualquier caso relativo a la interpretación o aplicación de la $\mathrm{CADH}$, en general, ${ }^{134}$ según el artículo 63 de la $\mathrm{CADH}$ solo le otorgan competencia para declarar y reparar la violación "de un derecho o libertad protegidos en esta Convención". ${ }^{135}$ En consecuencia, la Corte no podría declarar y reparar una violación del artículo 29.d, pues ese artículo no forma parte de las libertades y derechos consagrados en la CADH. Frente a esta última aseveración, se podría reclamar que la CADH (en su artículo 29.d) igualmente protege los derechos de la DADDH, por lo que sí podría declararse su violación. Sin embargo, dicha afirmación parece errada por dos motivos; en primer lugar, por lo ya afirmado sobre el artículo 29; en segundo lugar, porque tal interpretación permitiría que la Corte IDH tuviera una competencia,

\footnotetext{
129 Argüelles y otros vs. Argentina, cit., párr. 38, y Ruano Torres y otros vs. El Salvador, cit., párr. 29.

130 Ibidem, párr. 37 e Idem.

131 Ibidem, párr. 32 e Idem.

132 Argüelles y otros vs. Argentina, cit., párr. 38.

133 Ruano Torres y otros vs. El Salvador, cit., párr. 29.

134 Artículo 62.3, GADH.

135 Artículo 63.1, CADH, el destacado es nuestro.
} 
Este libro forma parte del acervo de la Biblioteca Jurídica Virtual del Instituto de Investigaciones Jurídicas de la UNAM

que prácticamente se extendería a la universalidad del Derecho. Incluso si no se aceptara nuestra lectura del artículo 29; si se considerara que los derechos de la DADDH están protegidos por la $\mathrm{CADH}$, sería una interpretación errada declarar su violación, porque tales derechos no estarían protegidos en la CADH, lo que es exigido por el artículo 63 de la CADH.

\section{Ejemplo de uso de los trabajos preparatorios de la Declaración}

No obstante que la Comisión y la Corte utilicen la DADDH, podría haber sido el caso que ellas nunca hubiesen recurrido a los trabajos preparatorios de dicho instrumento. Sin embargo, ello no ha sido así, pues ambas lo han hecho, los ejemplos más conocidos son dos casos que buscaban determinar la extensión de la protección de la vida en su etapa de desarrollo prenatal. Se trata de los casos Baby Boy, presentado contra Estados Unidos ante la Comisión IDH, ${ }^{136}$ y Artavia Murillo y otros vs. Costa Rica, analizado por la Corte IDH. En el primer caso, fueron los propios peticionarios quienes invocaron los trabajos preparatorios de la DADDH para interpretar el derecho a la vida. ${ }^{137}$ La Comisión se hizo cargo de este argumento, pero, desafortunadamente, su análisis de los trabajos preparatorios fue superficial y poco ajustado a lo que podía observarse en los travaux préparatoires, según se describirá a continuación.

Los hechos del caso Baby Boy son: en 1973 un médico de Massachusetts efectuó un aborto consentido, pero que no se consideró dentro de los casos permitidos legalmente, por lo que fue condenado por homicidio sin premeditación. ${ }^{138}$ Esta decisión fue anulada por la Corte Suprema de Massachusetts, en virtud de la insuficiencia de pruebas y de un error de procedimiento. ${ }^{139} \mathrm{Los}$ peticionarios alegaron ante la Comisión IDH que Estados Unidos había infringido varios derechos de Baby Boy - el nasciturus - consagrados en la DADDH. Esto habría ocurrido porque la dictación de dos sentencias de la Corte Suprema de dicha nación (Roe vs. Wade y Doe vs. Bolton) habría pavimentado el camino para la realización de este aborto. ${ }^{140}$ Los peticionarios no alegaron infracciones a la $\mathrm{CADH}$, pues Estados Unidos no ha ratificado este último tratado, no hubo controversia respecto a los hechos del caso. ${ }^{141}$

\footnotetext{
136 Caso 2141 - Estados Unidos, cit. (en adelante caso 2141).

137 Caso 2141, considerando párr. 18.

138 Ibidem, párr. 3.d.

139 Idem.

140 Ibidem, párrs. 3.b y 3.c.

141 Ibidem, "Considerando", párr. 7.
} 
En el caso Baby Boy la Comisión afirmó su jurisdicción, para la aplicación de la DADDH, como derecho sustantivo a todos los Estados miembros de la OEA, ${ }^{142}$ y concluyó que la decisión de la Corte Suprema de Massachusetts no violó la DADDH. ${ }^{143}$ Ello, en cuanto consideró que la DADDH habría dejado a cada Estado la facultad de determinar el modo como protegería la vida prenatal. $\mathrm{Al}$ hacerlo, la Comisión analizó tanto la $\mathrm{DADDH}$ como la $\mathrm{CADH}$ a la luz de sus trabajos preparatorios. ${ }^{144}$ Estudió la CADH sólo como un elemento que debía ser tenido a la vista al momento de interpretar la DADDH. Para efectos de nuestra ilustración sobre el uso de los trabajos preparatorios de la DADDH, no nos es pertinente el análisis de la $\mathrm{CADH}$, por lo que no nos referiremos a él. ${ }^{145}$ Aquí analizaremos solo los comentarios que hizo la Comisión respecto de los trabajos preparatorios de la DADDH. Dicho organismo reconoce que el artículo 1o. del PDADDH elaborado por el Comité Jurídico Interamericano se refería al no nacido. ${ }^{146}$ El PDADDH disponía:

Toda persona tiene derecho a la vida, inclusive los que están por nacer así como también los incurables, dementes y débiles mentales.

La pena capital sólo puede aplicarse en los casos en que una ley preexistente la haya establecido para crímenes de excepcional gravedad. ${ }^{147}$

La Comisión IDH se preguntó por qué, una vez sometida esta redacción al estudio del grupo de trabajo formado por la Comisión Sexta, este grupo elaboró un nuevo texto del artículo I (que fundió dos artículos y agregó la referencia a la integridad personal), que disponía: "Todo ser humano tiene derecho a la vida, a la libertad y a la seguridad y a la integridad de su persona". ${ }^{148}$

142 Shelton, D., "Abortion and the Right to Life in the Inter-American System: The Case of «Baby Boy»", Human Rights Law Journal, vol. 2-4, 1981, p. 313.

143 Para mayores detalles consultar: Paúl Díaz, Á., "Estatus del no nacido en la Convención Americana: un ejercicio de interpretación", Ius et Praxis, vol. 18, 1, 2012, pp. 86-89.

144 Según Dinah Shelton, la Comisión no dio mayor importancia a otros métodos de interpretación para apreciar el sentido de estos instrumentos, en particular de la CADH. D. Shelton, "Abortion and the Right to Life in the Inter-American System: The Case of «Baby Boy»", cit., pp. 312 y 313 .

145 Para un desarrollo sobre el punto, puede verse Paúl Díaz, Á., "Estatus del no nacido en la Convención Americana: un ejercicio de interpretación”, cit., pp. 88 y 89 y 75-77.

146 Caso 2141, considerando párr. 19.b.

147 NCV, p. 449. La redacción que usa la Comisión no coincide con la del PDADDH. La que usa la Comisión es la siguiente: "Toda persona tiene derecho a la vida. Este derecho se extiende al derecho a la vida desde el momento de la concepción; al derecho a la vida de los incurables, imbéciles y dementes. La pena capital puede aplicarse únicamente en casos en que se haya prescrito por leyes pre-existentes por delitos de extrema gravedad". Caso 2141, considerando párr. 19.b, citando NCV, p. 449.

148 NCV, p. 479. 
Este libro forma parte del acervo de la Biblioteca Jurídica Virtual del Instituto de Investigaciones Jurídicas de la UNAM

\section{La Comisión IDH explica este cambio afirmando que sería:}

un arreglo al que se llegó para resolver los problemas suscitados por las delegaciones de Argentina, Brasil, Cuba, Estados Unidos, México, Perú, Uruguay y Venezuela, principalmente como consecuencia del conflicto entre las leyes de esos Estados y el texto preliminar del Comité Jurídico (actas y documentos, vol. 5, pp. 474-484, 513-514). ${ }^{149}$

Sin embargo, si se analizan las páginas de los trabajos preparatorios citadas por la Comisión, no se observa el acuerdo aludido, sólo se lee, que diversos Estados presentaron observaciones al proyecto en general. ${ }^{150}$ Más aún, la única documentación que se posee respecto a la opinión de los Estados con relación a la norma sobre el derecho a la vida, es la opinión que éstos emitieron previamente ante el Comité Jurídico Interamericano, cuando éste dio la oportunidad de presentar observaciones a su APDADDH, antes de elaborar el proyecto definitivo que sería enviado a la Novena Conferencia. ${ }^{151}$ En materia del derecho a la vida, fueron muy pocas las modificaciones que se hicieron sobre la base de las observaciones de los Estados, y ninguna de ellas afectó a la vida prenatal. ${ }^{152}$ En efecto, la única discusión o la única disparidad legislativa que es reconocida por el Comité Jurídico Interamericano es respecto de la pena de muerte, frente a la cual "reconoce la facultad de cada Estado de regular esta cuestión", pero anota también que "varias constituciones de América, fundadas en generosas concepciones humanitarias, prohiben [sic] al legislador imponer la mencionada pena". ${ }^{153}$

La Comisión IDH también afirma que, en relación con el derecho a la vida, la definición del PDADDH del Comité "era incompatible con

149 Caso 2141, considerando párr. 19.d.

150 NGV, p. 475.

151 NGV, p. 456.

152 El APDADDH disponía, según se observa en AD, p. 1, lo siguiente:

"Toda persona tiene el derecho a la vida. Este derecho lo tiene el que está por nacer y lo tienen también los incurables, los débiles mentales y los dementes. Los incapaces de sostenerse por su propio esfuerzo tienen derecho a la manutención y amparo; y a este derecho corresponde el deber del Estado de velar por la efectividad de ese amparo. Unicamente [sic] a base de una condena por crímenes graves, a los cuales se aplique la pena capital, puede el Estado abrogar el derecho a la vida".

Como se puede observar, el mayor cambio se refirió al tema de los incapaces de sostenerse por su propio esfuerzo, disposición que fue solo cambiada de artículo. NCV, p. 456.

No está de más notar que el Comité Jurídico Interamericano afirmó que la disposición del APDADDH que reconocía el derecho a la vida de "los incurables, los débiles mentales y los dementes", "implícitamente condena el procedimiento llamado destrucción humanitaria de la vida", AD, p. 21.

153 NCV, pp. 456 y 457. 
las leyes que rigen la pena capital y aborto en la mayoría de los Estados americanos". ${ }^{154}$ Más en lo particular, con relación a la vida prenatal, la Comisión IDH afirmó que en 1948 varios Estados excluían la sanción penal del aborto, en uno o más casos excepcionales; ${ }^{155}$ sin embargo, el que los Estados tuvieran algunas excepciones a la protección del derecho a la vida prenatal parece haber sido considerado, en la época, una excepción que confirmaba la regla general de protección del no nacido, pues el informe anexo del Comité Jurídico Interamericano afirmó expresamente que el APDADDH "garantizaba el derecho a la vida a los seres humanos que están por nacer, en concordancia con la ley civil de la mayoría de los países". ${ }^{156}$

En este punto, lo lógico sería coincidir con el voto disidente del comisionado Luis Demetrio Tinoco Castro, quien sostuvo que la única razón visible para modificar la norma sobre la protección de la vida prenatal sería lo expresado por el relator de la Comisión Sexta, quien afirmó que "se dispuso redactar (los derechos) en su mera esencia, sin enumeraciones ejemplares o taxativas, que llevan consigo el riesgo de la difusión inútil y de la confusión peligrosa de sus límites". ${ }^{157}$ Esta idea de consagrar la redacción de los derechos del modo más simple y claro, manteniendo la fuerza de expresión que proviene de la enunciación de la esencia de los derechos, se observa también en otros pasajes de los trabajos preparatorios. ${ }^{158}$

Existen otros dos elementos que denotan un análisis superficial de los trabajos preparatorios. En primer lugar, la afirmación de la Comisión IDH no explica por qué se habría eliminado también la referencia a los "incurables, dementes y débiles mentales", pues ninguna de las legislaciones domésticas permitía privarlos del derecho a la vida. ${ }^{159}$ Además, su derecho a la vida tam-

154 Caso 2141, considerando párr. 19.e.

155 Ibidem, considerando párr. 19.e y 19.f.

156 AD, p. 21.

157 NCV, p. 513, Caso 2141, voto negativo del doctor Luis Demetrio Tinoco Castro, tercer párrafo.

158 Por ejemplo, el grupo de trabajo afirmó que cada artículo tenía una segunda parte referida a deberes que se tenían para efectos de garantizar los derechos, y que se optó por no incluirlos, considerando que lo apartarían de su mandato, y "que le restaría fuerza de expresión y claridad a la Declaración”. NCV, p. 476. Asimismo, Venezuela sostiene que uno de sus objetivos principales al intervenir en la subcomisión respectiva, "es que las cláusulas del documento que se va a discutir sean redactadas con la mayor amplitud posible y que se sostengan aquellas excepciones a estas reglas generales que se consideren indispensables, o sean, las que exigen al Estado el sostenimiento de la moral pública o que tienden al mantenimiento de la paz”. NCV, p. 621.

159 Shelton, D., "Abortion and the Right to Life in the Inter-American System: The Case of «Baby Boy»", cit., pp. 313 y 314. 
Este libro forma parte del acervo de la Biblioteca Jurídica Virtual del Instituto de Investigaciones Jurídicas de la UNAM

bién se había visto gravemente vulnerado por acciones del régimen Nazi, por lo que también era necesario protegerlos especialmente. En segundo lugar, si los redactores de la DADDH querían hacer compatible este instrumento con la pena de muerte existente en algunos países, llama la atención que ellos hayan modificado el artículo para dejarlo con una redacción que parece no permitir excepciones. En efecto, ellos no borraron de la redacción original una prohibición de esta pena, sino que una frase que permitía hacer excepciones a la protección de la vida. En otras palabras, esta acción iría, justamente, en contra de la idea planteada por la Comisión IDH. Esto demuestra que las razones para la reformulación del artículo I de la DADDH no fueron analizadas concienzudamente por la Comisión IDH. ${ }^{160}$

Por su parte, el uso que hizo la Corte IDH de los trabajos preparatorios de la DADDH en el caso Artavia Murillo y Otros vs. Costa Rica no merece mayores observaciones, pues la Corte solo reprodujo e hizo suyos los argumentos vertidos por la Comisión IDH en el caso Baby Boy ${ }^{161}$. Sin embargo, vale la pena notar que este caso es de finales de 2012, fecha en la que la Corte IDH ya había adoptado la interpretación evolutiva de la CADH, por lo que muestra que el uso de los trabajos preparatorios de la DADDH no es incompatible con esta forma de interpretación.

160 La decisión de la Comisión IDH que recién se comenta, fue tomada por cinco comisionados en contra de otros dos. Las opiniones disidentes manifestaron que la DADDH sí buscaba proteger la vida desde el momento de la concepción. La opinión disidente de Tinoco muestra varias dificultades en la interpretación efectuada por la Comisión IDH.

161 Artavia Murillo y otros (fecundación in vitro) vs. Costa Rica, cit., párrs. 193-200. 


\section{Capítulo SEGUndo \\ CONTEXTO HISTÓRICO AL ELABORAR LA DEGLARAGIÓN}

\section{CONTEXTO MUNDIAL Y LATINOAMERICANO}

El contexto histórico al momento de redactar la DADDH puede servir para entender mejor el contenido de ésta. Para hacer esta contextualización, nos referiremos a algunos hechos que ocurrieron cerca de 1948, tanto a nivel mundial, como americano y colombiano.

El contexto universal seguía marcado por el reciente término de la Segunda Guerra Mundial, que causó una mortandad sin precedentes y se caracterizó por violaciones a los derechos humanos que escandalizaron al mundo. Los abusos más recordados son aquellos cometidos por el régimen Nazi en contra de sus propios ciudadanos: sus prácticas discriminatorias, eugenésicas, eutanásicas, sus campos de concentración y, finalmente, sus campos de exterminio, que culminaron en el llamado Holocausto. Estos hechos generaron la condenación universal y contribuyeron al resurgimiento de la noción del derecho natural y a un interés mayor por los derechos humanos. ${ }^{162}$ Éstos y otros hechos, tales como la privación de la nacionalidad a personas pertenecientes a diversas minorías, o el uso de la energía atómica con fines de destrucción, tuvieron resonancia en las disposiciones que fueron discutidas durante la Novena Conferencia. ${ }^{163}$

Otros hechos que causaron impacto en la Novena Conferencia fueron la expansión del comunismo en la Europa del Este, así como la naciente formación de alianzas en Occidente (que tuvo manifestaciones como la Doctrina Truman y el funcionamiento del llamado Plan Marshall). ${ }^{164}$ Ello impactó

162 Samuel Moyn muestra que estos abusos no habrían sido, sin embargo, el factor determinante en el desarrollo de la idea de los derechos humanos. Véase en general Moyn, S., Christian Human Rights, Philadelphia, University of Pennsylvania Press, 2015. En particular, véanse pp. 13 y 14.

163 Por ejemplo, AD, p. 44.

164 Alape, A., El Bogotazo: memorias del olvido, 2a. ed., La Habana, Casa de las Américas, 1984, pp. 206 y 207. Es interesante también notar que el Secretario de Estado Marshall participó en la Novena Conferencia. Ibidem, p. 208. 
en la DADDH, la que tuvo la intención de proteger derechos que podrían ser afectados por ideologías foráneas. Incluso, se ha afirmado, que el propósito fundamental de la Novena Conferencia era declarar al comunismo como "una amenaza para el continente americano". ${ }^{165} \mathrm{El}$ impacto referido se nota en diversas intervenciones; por ejemplo, al discutir el propuesto derecho de justicia y de resistencia, el delegado de Perú afirmó que la misión de la Conferencia era defender la democracia; ${ }^{166}$ algo similar se observa cuando el delegado de Nicaragua señaló, al momento de discutir sobre el derecho de propiedad, que dicho artículo buscaba "declarar que la propiedad debe ser defendida, para colocar[se] en contraposición a ideologías o sistemas políticos que niegan el amparo a la propiedad privada". ${ }^{167}$

Por último, fue de gran relevancia el establecimiento, a nivel mundial, de una organización internacional destinada a la conservación de la paz y la seguridad, así como a la cooperación universal. En efecto, durante la Novena Conferencia se hicieron numerosas referencias a las Naciones Unidas y a diversos órganos de esta institución. Además, su pacto constitutivo - la Carta de las Naciones Unidas - hacía referencia a los derechos humanos en varias de sus normas, cuestión que tuvo cierta influencia en las intervenciones de algunos delegados en la Novena Conferencia (aunque, según ya hemos afirmado, la insistencia latinoamericana motivó, en gran medida, las normas sobre derechos humanos en la Carta de Naciones Unidas). Finalmente, según se vio más arriba, durante la Novena Conferencia existía una clara consciencia de que se estaba estudiando una Declaración Universal de Derechos Humanos.

Con relación a la situación en América, es necesario recordar, que la cantidad de Estados independientes era bastante inferior a la que existe hoy en día. En efecto, aproximadamente un tercio de los Estados que hoy forman parte de la OEA seguían siendo colonias inglesas. Los países angloparlantes del Caribe alcanzaron su independencia en las siguientes fechas: Jamaica, así como, Trinidad y Tobago, en 1962; Barbados y Guyana en 1966; Las Bahamas en 1973; Granada en 1974; Dominica en 1978; Santa Lucía, en 1979, al igual que San Vicente y las Granadinas; Belice, así como Antigua y Barbuda en 1981, y Saint Kitts y Nevis en 1983. ${ }^{168}$ Algo similar

${ }^{165}$ Arias Trujillo, R., Historia de Colombia contemporánea (1920-2010), Universidad de los Andes, Ediciones Uniandes, Bogotá, 2011, p. 104.

166 NCV, p. 600.

167 Ibidem, p. 593.

${ }^{168}$ Fraser, A., "From Forgotten Through Friction to the Future: The Evolving Relationship of the Anglophone Caribbean and the Inter-American System of Human Rights", Caribbean Law Review, vol. 15, 2, 2005, p. 102, nota al pie núm. 5. 
Este libro forma parte del acervo de la Biblioteca Jurídica Virtual del Instituto de Investigaciones Jurídicas de la UNAM

se puede decir sobre Surinam respecto de Holanda. Lo anterior explica por qué estos Estados se encuentran ausentes de las discusiones de la Novena Conferencia.

Por su parte, durante la época que rodea la redacción de la DADDH, varias naciones latinoamericanas se veían sumidas en la inestabilidad política que ha caracterizado a muchos Estados de la región. Esta inestabilidad se observa, por ejemplo, en países como Paraguay, que tuvo tres presidentes en 1948 - y cuyo presidente electo, Juan Natalicio González, fue derrocado a comienzos del año siguiente - ${ }^{169}$ Algo similar se puede decir de Panamá, que tuvo una seguidilla de Presidentes provisionales. ${ }^{170}$ Bolivia, si bien era gobernada en 1948 por Enrique Hertzog, un presidente electo, había sufrido el asesinato de su presidente Gualberto Villarroel en 1946. ${ }^{171}$ Además, se vería pronto sumida en una guerra civil en 1949.172 La inestabilidad también afectó a Perú, que en octubre de 1948 vio a su general Manuel Odría Amoretti liderar un golpe de Estado que depuso al presidente José Bustamante y Rivero - quien sería posteriormente presidente de la Corte Internacional de Justicia-. ${ }^{173}$

El desorden de la región afectaba incluso a Estados, que hoy se pueden ver como naciones con una democracia estable, como sucedió con Costa Rica, que el mismo año 1948 sufrió la que es conocida como la Guerra Civil de 1948. ${ }^{174}$ Por el contrario, naciones que han tenido una historia política agitada, se encontraban con cierta calma en su historia en 1948. En este supuesto se encontró Ecuador, pues su presidente Carlos Julio Arosemena, quien gobernó durante la Novena Conferencia, fue sucedido en 1948 por un presidente electo que llegaría al término de su mandato. Esto, que suena como algo muy cotidiano, constituía un hecho poco común para un país

${ }^{169}$ Díaz de Arce, O., "El Paraguay Contemporáneo (1925-1975)”, en González Casanova, Pablo (ed.), América Latina: Historia de Medio Siglo, 8a. ed., México, Siglo XXI Editores, vol. I (América del Sur), 1979, pp. 356-360.

170 Soler, R., "Panamá: nación y oligarquía (1925-1975)", en González Casanova, Pablo (ed.) América latina: historia de medio siglo, 7a. ed., México, Siglo XXI Editores, 1979, vol. II (México, Centroamérica y el Caribe), pp. 435-437.

171 Zavaleta Mercado, R., "Consideraciones generales sobre la historia de Bolivia (19321971 )", en González Casanova, Pablo (ed.), América latina: historia de medio siglo, 8a. ed., vol. I, cit., pp. 94-98.

172 Idem.

173 Cotler, J., "Perú: Estado oligárquico y reformismo militar", en González Casanova, Pablo (ed.) América latina: historia de medio siglo, 8a. ed., vol. I, cit., pp. 386-390.

174 Vega Carballo, J. L., "Costa Rica: coyunturas, clases sociales y Estado en su desarrollo reciente”, en González Casanova, Pablo (ed.) América latina: historia de medio siglo, 7a. ed., vol. II, cit., pp. 6-18, y Crawley, E., Dictators Never Die: A Portrait of Nicaragua and the Somoza Dynasty, Nueva York, St. Martin's Press, 1979, pp. 109 y 110. 
Este libro forma parte del acervo de la Biblioteca Jurídica Virtual del Instituto de Investigaciones Jurídicas de la UNAM

que en los 23 años anteriores a 1948 tuvo igual número de presidentes. ${ }^{175}$ El presidente electo en 1948 fue Galo Plaza - un futuro Secretario General de la OEA-, que aseguró una gobernabilidad sin recurrir a constantes represiones. ${ }^{176}$ Algo similar se puede decir de Cuba, que se encontraba en un tiempo de calma antes del golpe de Estado de Fulgencio Batista en 1952. ${ }^{177}$

Por su parte, México se encontraba en un clima de optimismo, pues su situación política y económica daba la sensación de que "estaba en la senda de la paz y la prosperidad". ${ }^{178}$ Por un lado, su economía "se transformó asombrosamente desde la década de 1940", ${ }^{179}$ por otro, si bien la campaña electoral de 1940 estuvo marcada por la violencia y el fraude, ${ }^{180}$ el presidente electo en dicho año, Ávila Camacho, sentó las bases para una estabilidad política. ${ }^{181}$ De este modo, en 1946 Miguel Alemán pudo asumir la presidencia "en medio de la tranquilidad general", ${ }^{182}$ como miembro del Partido Revolucionario Institucional (PRI). ${ }^{183}$ Se pensó que se iniciaba un período en el que México comenzaría a cosechar los frutos de la estabilidad. ${ }^{184}$ Sin embargo, las décadas de gobierno del PRI, con su estabilidad política, fueron controversiales. ${ }^{185}$ Mientras algunos las elogiaron, ${ }^{186}$ otros las calificaron como un ejemplo de gobierno de un partido único con aspectos autoritarios, ${ }^{187} \mathrm{e}$ incluso, como "una monarquía absoluta sexenal". ${ }^{188}$

175 Cueva, A., "Ecuador: 1925-1975", en González Casanova, Pablo (ed.) América latina: historia de medio siglo, 8a. ed., vol. I, cit., pp. 307-310.

176 Idem.

177 El presidente en 1948 era Carlos Prío Socarrás. Le Riverend, J., "Cuba: Del Semicolonialismo al Socialismo (1933-1975)", en González Casanova, Pablo (ed.) América latina: historia de medio siglo, 7a. ed., vol. II, cit.

178 Hamnett, B., Historia de México, Madrid, Cambridge University Press, 2001, p. 270.

179 Idem.

180 Ibidem, p. 272.

181 Ibidem, pp. 273-274.

182 Anna, T. et al., Historia de México, Barcelona, Editorial Crítica, 2001, p. 335.

183 Hamnett, B., Historia de México, cit., pp. 272 y 276.

184 Michaels, A. L. y Bernstein, M., "The Modernization of the Old Order: Organization and Periodization of Twentieth-Century Mexican History", en James W. Wilkie et al. (eds.), Contemporary Mexico. Papers of the IV International Congress of Mexican History, Berkeley-Mexico, University of California Press-El Colegio de México, 1976, p. 705.

185 Ibidem, p. 348, y Needler, M. C., "Problems in the Evaluation of the Mexican Political System", en James W. Wilkie et al. (eds.), ibidem, p. 339.

186 Véase Purcell, J. F. H. y Purcell, S. K., "Machine Politics and Socio-Economic Change in Mexico", en James W. Wilkie et al. (eds.), ibidem, p. 348, y Needler, M. G., "Problems in the Evaluation of the Mexican Political System", cit., p. 339.

187 Anna, T. et al., Historia de México, cit., p. 330.

188 Según el historiador Cosío Villegas, citado en Hamnett, B., Historia de México, cit., p. 275. 
En el Continente, varias naciones se encontraban regidas por dictaduras. Así, por ejemplo, Honduras era gobernada por el general Tiburcio Carías Andino. Este régimen terminó pronto, pero la elección realizada en octubre de 1948 se llevó a cabo a pesar de que el Partido Liberal llamó a abstenerse de votar, por considerar que no cumplía con los estándares mínimos para considerarla una elección libre. ${ }^{189}$ La frecuente presencia de dictaduras en la región explica que algunos presidentes electos democráticamente comenzaran su carrera política ejerciendo importantes cargos en dictaduras anteriores, como fue el caso de Juan Domingo Perón, Presidente argentino que gobernó durante la Novena Conferencia. ${ }^{190}$ Finalmente, las credenciales democráticas de algunos gobiernos elegidos por medio de elecciones populares son en varios casos muy discutibles. Así, por ejemplo, durante el régimen de Rafael Leonidas Trujillo en República Dominicana, se celebraban elecciones cada cuatro años, pero sin oposición. ${ }^{191}$

La delicada situación de las naciones americanas amenazó, incluso, con excluir a uno de estos Estados de la Novena Conferencia. En efecto, los países de América se preguntaron si convenía que Nicaragua participara en dicho evento, pues su gobierno no había sido reconocido por una mayoría de las repúblicas del Continente. ${ }^{192}$ Sin embargo, en atención a diversos factores, entre los que figuraba la importancia de los temas que se discutirían en la Novena Conferencia, se acordó autorizar su participación. ${ }^{193}$ Durante la Conferencia, sería imposible que los demás asistentes olvidaran la tendencia del gobierno de Nicaragua, pues varios delegados de este país se encontraban emparentados, ya fuera directamente o en forma política, con Anastasio Somoza García, el hombre fuerte detrás del gobierno de Román y Reyes. ${ }^{194}$

189 Molina Chocano, G., "Honduras: De la Guerra Civil al Reformismo Militar", en González Casanova, Pablo (ed.) América Latina: Historia de Medio Siglo, 7a. ed., vol. II, cit., pp. 242 y 243.

190 Romero, J. L., Breve historia de la Argentina, Fondo de Cultura Económica, 2001, pp. 153-155.

191 Vega, B., "La Era de Trujillo, 1930-1961", en Frank Moya Pons (ed.) Historia de las Antillas, Ediciones Doce Calles, s.l., 2010, vol. II., Historia de la República Dominicana, p. 449.

192 Woerner, F. F. Jr., "A History of the Ninth Inter-American Conference. Bogotá, Colombia”, Arizona, The University of Arizona, 1965, p. 27. Véase también Fenwick, C. G., "The Ninth International Conference of American States", The American Fournal of International Law, vol. 42, 3, 1948, p. 554.

193 Woerner, F. F. Jr., ibidem, p. 27.

194 Algunos de estos parientes serían Anastasio Somoza (hijo), Luis Manuel Debayle y Antíoco Sacasa. NCI, p. 62. Sobre la influencia de Somoza, véase Crawley, E., Dictators Never Die: A Portrait of Nicaragua and the Somoza Dynasty, cit., pp. 105-108. 
Este libro forma parte del acervo de la Biblioteca Jurídica Virtual del Instituto de Investigaciones Jurídicas de la UNAM

Otra nota interesante, propia de la Guerra Fría, es el modo como se manifestó en la región el temor que producía la idea de que el marxismo llegara al poder. Éste puede observarse en el ánimo y acciones anticomunistas - de diversa envergadura - que desplegaron algunos gobiernos, tales como el colombiano de Mariano Ospina Pérez, ${ }^{195}$ el dominicano de Rafael Leonidas Trujillo, ${ }^{196}$ o el nicaragüense de Víctor Manuel Román y Reyes. ${ }^{197}$ El ambiente anticomunista se manifestó asimismo en la adopción de medidas legales destinadas a proscribir el Partido Comunista, como hicieron los presidentes Eurico Gaspar Dutra en Brasil, y Gabriel González Videla en Chile. ${ }^{198}$ También hubo medidas menos directas, como la adopción de nuevos requisitos para la inscripción de partidos políticos en México, que "impidió que los comunistas permanecieran en la legalidad". ${ }^{199}$ Sin embargo, hubo excepciones, como el gobierno haitiano de Dumarsais Estimé, quien tuvo una política de apertura a las ideas comunistas y socialistas durante estos años. ${ }^{200}$

La época en la que se inserta la Novena Conferencia no solo estuvo marcada por violaciones a los derechos humanos derivadas de golpes de Estado y revoluciones. En efecto, existían muchos abusos que convivían con sistemas más o menos democráticos; por ejemplo, en Estados Unidos aún existía discriminación racial, no solo de facto, sino que también de jure; ${ }^{201}$ otro ejemplo es la falta de voto secreto en El Salvador, cuestión que dicho Estado reconocía sin complejos, llegando incluso a solicitar que no se incluyera en la DADDH la obligación de que el voto poseyera tal característica. ${ }^{202}$ Con relación al sufragio, aún subsistían Estados donde la mujer no contaba con un derecho al voto en elecciones nacionales. Además de lo anterior, las realidades de falta de

195 García, A., "Colombia: medio siglo de historia contemporánea", en González Casanova, Pablo (ed.), América latina: historia de medio siglo, 8a. ed., vol. I, cit., pp. 197-205.

196 Cuello, J. I. et al., "50 años de historia dominicana”, en González Casanova, Pablo (ed.), América Latina: Historia de Medio Siglo, 7a. ed., vol. II, cit., pp. 472-478.

197 Barahona Portocarrero, A., "Breve estudio sobre la historia contemporánea de Nicaragua", en González Casanova, Pablo (ed.) América latina: historia de medio siglo, 7a. ed., vol. II, cit., pp. 392-394.

198 Bambirra, V. y Dos Santos, T., "Brasil: nacionalismo, populismo y dictadura. 50 años de crisis social”, en González Casanova, Pablo (ed.) América latina: historia de medio siglo, 8a. ed., vol. I, cit., pp. 143-146. y Elgueta, B. y Chelén, A., "Breve historia de medio siglo en Chile", América latina: historia de medio siglo, 8a. ed., vol. I, cit., pp. 242 y 243.

199 Anna, T. et al., Historia de México, cit., p. 338.

200 Pierre-Charles, G., "Haití (1930-1975): la crisis ininterrumpida", en González Casanova, Pablo (ed.) América latina: historia de medio siglo, 7a. ed., vol. II, cit., pp. 174-189.

201 Buergenthal, T. et al., International Human Rights in a Nutshell, 4a. ed., Saint Paul, Minnesota, West Publishing Co., 2009, p. 30.

202 NGV, p. 588. 
Este libro forma parte del acervo de la Biblioteca Jurídica Virtual del Instituto de Investigaciones Jurídicas de la UNAM

oportunidades, discriminación y pobreza eran aún más aceptadas de lo que son actualmente. En definitiva, los tiempos en los que se celebró la Novena Conferencia no eran tiempos fáciles para los derechos humanos.

\section{EL BOGOTAZO}

El asesinato del político Jorge Eliecer Gaitán, ocurrido en Bogotá durante los días de la Novena Conferencia, así como los hechos violentos que siguieron a dicho crimen, son conocidos como "El Bogotazo"; éste tiene particular relevancia en toda descripción del contexto histórico de la Novena Conferencia Internacional Americana. Nuestro trabajo no puede hacer una relación detallada del Bogotazo, pero se referirá someramente a estos hechos que afectaron a la Conferencia de diversos modos.

Los años previos a la Novena Conferencia Internacional Americana no fueron tranquilos en Colombia. Entre 1945 y 1947 hubo no menos de cuatro gobiernos; ${ }^{203}$ en 1946, el presidente habría sido obligado a renunciar por su propio partido, ${ }^{204}$ y en 1947, durante el llamado Gobierno de la Unidad Nacional, se afirma que hubo miles de víctimas de la violencia política. ${ }^{205}$ En este contexto, la organización de la Novena Conferencia ha sido vista como una forma en la que los dirigentes colombianos buscaban dejar atrás los problemas de la política nacional, y volver a insertar a Colombia en las grandes discusiones internacionales. ${ }^{206}$ Ello habría motivado la inversión de grandes sumas y esfuerzos en esta Conferencia, los que algunos calificaron de desproporcionados.

Es interesante notar, que en forma paralela a la Novena Conferencia se realizaría el Congreso Latinoamericano de Estudiantes, ${ }^{207}$ ideado por Fidel Castro cuando éste era un dirigente estudiantil - según relata él mismo en una entrevista - ${ }^{208}$ Según Castro, este congreso se ideó ex profeso en forma paralela a la Novena Conferencia, pues buscaba referirse a ciertos objetivos políticos considerados "antimperialistas", como la lucha contra Trujillo, la independencia de Puerto Rico, la devolución del Canal de Panamá

203 Vervaele, J., "Criminal Law and the Protection of Human Rights in Colombia", Netherlands Quarterly of Human Rights, vol. 6, 1988, p. 7.

204 Idem.

205 Idem.

206 Braun, H., The Assassination of Gaitán. Public Life and Urban Violence in Colombia, Wisconsin, The University of Wisconsin Press, 1985, pp. 129-131.

207 Alape, A., El Bogotazo: memorias del olvido, cit., p. 638.

208 Ibidem, p. 640. 
y otros. ${ }^{209}$ El plan de realizar este congreso es relevante por varios motivos; por una parte, aparentemente causó algunos incidentes que fueron percibidos por los participantes en la Conferencia. ${ }^{210}$ Por otra, Gaitán tenía planeado exponer en dicho congreso, luego de haberse reunido el 7 de abril con Fidel Castro. ${ }^{211}$ Por último, algunos de sus asistentes se vieron de uno u otro modo implicados en los desórdenes de El Bogotazo. ${ }^{212}$

En medio de estos eventos ocurre el asesinato de Jorge Eliecer Gaitán el 9 de abril de 1948, a manos de un hombre llamado Juan Roa Sierra. ${ }^{213}$ Gaitán era jefe de la bancada liberal del Parlamento, líder del movimiento popular y ex candidato a la presidencia. ${ }^{214}$ Por ello, Gaitán era un posible candidato para participar en la Novena Conferencia, pero fue excluido de dicho evento. ${ }^{215}$ Él era un líder de masas, de la facción más de izquierda del Partido Liberal, ${ }^{216}$ y su personalidad atraía a grandes multitudes, ${ }^{217}$ por lo cual, su asesinato fue seguido de violentas protestas, desórdenes, incendios, destrozos, disparos, muertes, sublevaciones y represión. ${ }^{218}$ Algunos han afirmado que el Bogotazo habría sido el detonante de la guerra civil conocida como La Violencia, ${ }^{219}$ que causó una enormidad de muertes en Colombia.

209 Idem.

210 Por ejemplo, Ibidem, p. 648.

211 Ibidem, pp. 196 y 197.

212 Por ejemplo, Fidel Castro, según relata él mismo. Ibidem, pp. 655-669.

213 Ésta es la versión que se acepta generalmente. La descripción de la aprehensión de Roa y algunos hechos posteriores puede verse en Ibidem, pp. 253 y 254. Roa Sierra era un hombre pobre de Bogotá, generalmente desempleado, sin convicciones políticas serias. Braun, H., The Assassination of Gaitán. Public Life and Urban Violence in Colombia, cit., p. 249, nota 57. Roa fue tomado por la turba, desnudado, golpeado hasta la muerte y dejado irreconocible. Ibidem. Este hecho impidió interrogarlo y realizar mayores investigaciones.

214 García, A., "Colombia: Medio Siglo de Historia Contemporánea”, cit., pp. 197-205.

215 El gobierno conservador de la época había invitado a personalidades de los partidos conservadores y liberales a este evento. La exclusión de Gaitán habría sido vista como una afrenta por parte de los muchos seguidores de Gaitán. Braun, H., The Assassination of Gaitán. Public Life and Urban Violence in Colombia, cit., pp. 129-131.

216 Jaramillo Salgado, D., "Legado Socialista de Gaitán”, en Ayala Diago, César Augusto et al (eds.), Mataron a Gaitán: 60 años, Bogotá, Universidad Nacional de Colombia, 2009, pp. 359-361.

217 Para más detalles sobre Gaitán, véase Arias Trujillo, R., Historia de Colombia contemporánea (1920-2010), cit., pp. 94-106.

218 García, A., "Colombia: medio siglo de historia contemporánea", cit., pp. 197-205, Vervaele, J., "Criminal Law and the Protection of Human Rights in Colombia", cit., p. 7, y Alape, A., El Bogotazo: memorias del olvido, cit., p. 658.

219 Vervaele, J., "Criminal Law and the Protection of Human Rights in Colombia", cit., p. 7. Otros consideran que no sería posible afirmar esto, en virtud de la multiplicidad de factores relevantes. Arias Trujillo, R., Historia de Colombia contemporánea (1920-2010), cit., pp. 89 y 90. 
El Bogotazo afectó la Conferencia de diversos modos; en primer lugar, motivó ciertos cambios en la forma como ella estaba funcionando administrativamente; ${ }^{220}$ por ejemplo, se tuvo que suspender y volver a sesionar el día 14 de abril, en las afueras de la ciudad.221 Por otra parte, influyó en el aumento de la importancia del ítem de la agenda llamado "Defensa y preservación de la democracia en América frente a la eventual instalación de regímenes antidemocráticos en el continente". ${ }^{222}$ Esto muestra la creencia de algunos, y que el Gobierno habría incentivado, de la influencia de comunistas en el asesinato de Gaitán y en los desórdenes. ${ }^{223}$ También se afirma que El Bogotazo habría sido usado de excusa para apurar las discusiones de la Conferencia, de modo que el trabajo terminara dentro de tiempos razonables. ${ }^{224}$

\section{NOVENA CONFERENCIA Y LA DEGLARACIÓN AMERICANA}

\section{Antecedentes del acercamiento americano}

Los deseos de acercamiento americano vieron su primer fruto en el Congreso Anfictiónico de Panamá de 1826. Este congreso tenía una misión confedera-

220 Woerner, F. F. Jr., "A History of the Ninth Inter-American Conference. Bogotá, Colombia", cit., p. 23.

221 Braun, H., The Assassination of Gaitán. Public Life and Urban Violence in Colombia, cit., p. 188.

222 Woerner, F. F. Jr., "A History of the Ninth Inter-American Conference. Bogotá, Colombia", cit., p. 23. La Conferencia elaboró un documento llamado "Preservación y Defensa de la Democracia en América", donde considera que "para salvaguardar la paz y mantener el mutuo respeto entre los Estados, la situación actual del mundo exige que se tomen medidas urgentes que proscriban las tácticas de hegemonía totalitaria, inconciliables con la tradición de los países de América, y que eviten que agentes al servicio del comunismo internacional o de cualquier totalitarismo pretendan desvirtuar la auténtica y libre voluntad de los pueblos de este Continente". También declara que "por su naturaleza antidemocrática y por su tendencia intervencionista, la acción política del comunismo internacional o de cualquier totalitarismo es incompatible con la concepción de la libertad americana, la cual descansa en dos postulados incontestables: la dignidad del hombre como persona y la soberanía de la nación como Estado." CA, p. 210. Este documento no se encuentra dentro de los recopilados en el anexo de este trabajo. Sin embargo, puede encontrarse en el siguiente sitio web: $h t t p: / /$ biblio2.colmex.mx/coinam/coinam_2_suplemento_1945_1954/base2.htm (fecha de consulta: 28 de octubre de 2015).

223 Braun, H., The Assassination of Gaitán. Public Life and Urban Violence in Colombia, cit., pp. 185 y 186.

224 Woerner, F. F. Jr., "A History of the Ninth Inter-American Conference. Bogotá, Colombia", cit., p. 25. 
Este libro forma parte del acervo de la Biblioteca Jurídica Virtual del Instituto de Investigaciones Jurídicas de la UNAM

tiva que abarcaba a las repúblicas surgidas de la "América antes española".225 Simón Bolívar invitó a participar en forma plena en esta conferencia a Centroamérica, ${ }^{226}$ Chile, Colombia, México, Perú y las Provincias Unidas del Río de la Plata. ${ }^{227}$ Este congreso no buscaba extenderse a naciones como Brasil, Estados Unidos, Gran Bretaña y los Países Bajos, pero se les invitó de diversos modos. ${ }^{228}$ Finalmente, los únicos países que enviaron sus representantes a Panamá fueron Centroamérica, Colombia, México y Perú, además de los Estados observadores de Gran Bretaña y los Países Bajos. ${ }^{229}$ La finalidad de este congreso era constituir una defensa frente a peligros comunes, establecer un sistema de arbitraje, contar con un ejército confederado y establecer un sistema de preferencia comercial hispanoamericana. ${ }^{230}$ No obstante estos intereses acotados, ya es posible encontrar en el Congreso Anfictiónico algunas manifestaciones de un interés en proteger los derechos humanos. ${ }^{231}$

Después de este primer acercamiento continental, el encuentro más importante lo constituyó la Primera Conferencia Internacional Americana, celebrada en Washington entre 1889 y $1890 .{ }^{232}$ Ésta fue la primera de una serie de conferencias interamericanas. ${ }^{233}$ Entre otras cosas, en ella se acordó crear una asociación llamada "Unión Internacional de las Repúblicas americanas para la pronta compilación y distribución de datos sobre el comercio". ${ }^{234}$ Esta unión internacional estaría representada por una oficina que se establecería en Washington, llamada "Oficina Comercial de las Repúblicas Americanas", y que estaría encargada de publicar un boletín que contendría diversa información relevante para el comercio. ${ }^{235}$ En la Segunda Conferencia, esta oficina se reorganizó y pasó a llamarse "Oficina Internacional de las Repúblicas Americanas". ${ }^{236}$ En la Tercera Conferencia Internacional de las Re-

225 De la Reza, G. A. (ed.), Documentos sobre el Congreso Anfictiónico de Panamá, Fundación Biblioteca Ayacucho-Banco Central de Venezuela, Caracas, 2010, p. IX.

226 Entonces se trataba de una unidad política.

227 De la Reza, G. A. (ed.), Documentos sobre el Congreso Anfictiónico de Panamá, cit., p. XII y XIII.

228 Ibidem, p. XIII, XIV y XVII.

229 Ibidem, p. XIV.

230 Ibidem, p. L, LI y LII.

231 Buergenthal, T. y Shelton, D., Protecting Human Rights in the Americas. Cases and Materials, 4a. ed. rev., Kehl-Strasbourg-Arlington, N. P. Engel, 1995, p. 38.

232 CA, p. 109.

233 Gran parte de los textos relevantes de tales conferencias se pueden consultar en: $h t t p: / /$ biblio2.colmex.mx/coinam/Default.htm (fecha de consulta 28 de octubre de 2015).

234 Conferencias Internacionales Americanas 1889-1936. Recopilación de Tratados y Otros Documentos,

2a. reimpresión, México, Secretaría de Relaciones Exteriores, 1990, p. 36.

235 Idem.

236 Ibidem, pp. 94-96. 
Este libro forma parte del acervo de la Biblioteca Jurídica Virtual del Instituto de Investigaciones Jurídicas de la UNAM

públicas Americanas se ampliaron considerablemente los fines de la Oficina Internacional, la que ya no solo tendría funciones de un corte marcadamente comercial y de archivo, sino que también de información sobre asuntos de educación, de compilación de tratados entre Estados americanos y Estados no americanos, y de contribución a la ratificación de las resoluciones y convenciones adoptadas por las diversas Conferencias Internacionales Americanas. ${ }^{237}$

En la Cuarta Conferencia Internacional Americana, celebrada entre julio y agosto de 1910, en Buenos Aires, se decidió que la Unión Internacional creada por la Primera Conferencia pasara a llamarse "Unión de las Repúblicas Americanas". ${ }^{238}$ En esta misma Conferencia se decidió que la Oficina Internacional pasara a llamarse "Unión Pan-Americana", ${ }^{239}$ lo que resulta un poco confuso, en atención a la similitud entre estos nombres. En la Séptima Conferencia, celebrada en Montevideo en 1933, se declara que en la siguiente conferencia se debía estudiar las posibles reformas al Estatuto de la Unión Panamericana, en vistas a hacer más eficaz su funcionamiento. ${ }^{240}$ Sin embargo, aunque la Octava Conferencia hizo algunas recomendaciones en materia de la Unión Panamericana, ${ }^{241}$ no fue sino hasta la Novena Conferencia que se adoptaron las reformas de envergadura que la Unión requería.

\section{La Novena Conferencia y su organización}

Como puede verse, la Novena Conferencia siguió la senda de una serie de conferencias internacionales americanas iniciadas a finales del siglo XIX. ${ }^{242}$ Esta Conferencia debía celebrarse en 1943, cinco años después de la Octava Conferencia, pero fue aplazada hasta 1948, principalmente, en atención a la Segunda Guerra Mundial. ${ }^{243}$ Este mismo evento bélico hizo que se realizaran tres reuniones de consulta entre los ministros de relaciones exteriores de las Repúblicas americanas, en los años 1939, 1940 y 1942, respectivamente,

\footnotetext{
237 Ibidem, p. 132.

238 Ibidem, p. 181.

239 Ibidem, p. 181.

240 Ibidem, p. 535.

241 Conferencias Internacionales Americanas. Primer Suplemento 1938-1942. Recopilación de Tratados y Otros Documentos, México, Secretaría de Relaciones Exteriores, 1990,

242 La Carta de la OEA, elaborada en la Novena Conferencia, modificó el nombre de la Conferencia Internacional Americana al de la Conferencia Interamericana, y precisó las funciones que ésta debía desempeñar en cuanto órgano supremo de la Organización. CA, p. 109. Esta institución sería luego reemplazada por la Asamblea General.
} p. 93.

243 CA, p. 109. 
además de la Conferencia Interamericana sobre Problemas de la Guerra y de la Paz, celebrada en 1945. ${ }^{244}$ Las tres primeras conferencias, se refirieron a temas como la neutralidad en el conflicto, la defensa mutua en caso de ataques por parte de Estados no americanos, la adopción de medidas para evitar que un Estado no americano transfiriera territorio del Continente a otro Estado no americano y, una vez que Estados Unidos entró a la guerra, se llamó a romper relaciones diplomáticas con los Estados del Eje. ${ }^{245}$ En la reunión de 1945 se trató de consolidar medidas defensivas, además de hacer planes para anticiparse a la Conferencia de San Francisco. ${ }^{246}$ Esta Conferencia Interamericana sobre Problemas de la Guerra y de la Paz fue también importante porque resolvió que la Novena Conferencia tratara diversos temas, tales como la reorganización y el fortalecimiento del sistema interamericano. ${ }^{247}$ Además, en la materia que nos interesa, la Resolución XL determinó que la Novena Conferencia redactara una declaración sobre derechos humanos. ${ }^{248}$

La resolución CVIII de la Octava Conferencia Internacional Americana dispuso que la ciudad de Bogotá sería la sede de la Novena Conferencia. ${ }^{249}$ Esta "Conferencia de Bogotá" se llevó a cabo entre el 30 de marzo y el 2 de mayo de 1948. ${ }^{250}$ En ella estuvieron representadas las 21 naciones americanas, y las delegaciones sumaron 545 personas. ${ }^{251}$ El programa de la Novena Conferencia había sido preparado por el Consejo Directivo de la Unión Panamericana, y fue acompañado de numerosos proyectos de tratados, declaraciones y otros documentos preparados por el mismo Consejo Directivo, así como por el Comité Jurídico Interamericano, en respuesta a varias

244 G. G. Fenwick, "The Ninth International Conference of American States", cit., p. 553.

245 Idem.

246 Idem.

247 CA, p. 109.

248 Esta resolución puede verse en CA, p. 52. Se ha afirmado que el texto de esta resolución buscaba afirmar la doctrina de la no intervención en forma absoluta. Goldman, R. K., "History and Action: The Inter-American Human Rights System and the Role of the Inter-American Commission on Human Rights", cit., p. 858. Una relación del contexto e importancia de esta conferencia, contemporánea a su realización, puede verse en Kunz,J. L., "The Inter-American Conference on Problems of War and Peace at Mexico City and the Problem of the Reorganization of the Inter-American System", The American fournal of International Law, vol. 39, 3, 1945.

249 Conferencias internacionales americanas, recopilación de tratados y otros documentos, Primer Suplemento 1938-1942, cit., p. 96.

250 Siguiendo una decisión del Consejo Directivo de la Unión Panamericana, tomada el 5 de diciembre de 1947, que hacía votos para que el aplazamiento efectuado para el 30 de marzo de 1948 fuera considerado improrrogable. NGI, p. 3. La serie de aplazamientos previos se puede observar en Ibidem, nota al pie 1.

251 CA, p. 109. 
resoluciones de conferencias anteriores y de reuniones de consulta entre los ministros de relaciones exteriores. ${ }^{252}$ Según puede observarse en la sección respectiva, ${ }^{253}$ el programa dividió los temas a tratar en cinco partes, cada una de las cuales se llamó capítulo. Los dos primeros lidiaron con la reorganización, consolidación y fortalecimiento del sistema interamericano; el tercero con asuntos económicos; el cuarto con asuntos jurídico-políticos, y el quinto con asuntos sociales.

Según el artículo 14 del Reglamento de la Novena Conferencia Internacional Americana, se organizarían comisiones para analizar cada capítulo en que se dividiera el programa de la Conferencia, ${ }^{254}$ además de las comisiones reglamentarias de iniciativas, de credenciales, de coordinación y de estilo. ${ }^{255}$ Sin embargo, la delegación de Colombia sugirió otro modo de organización en seis comisiones de trabajo (lo que agregaba una comisión), además de las comisiones reglamentarias. ${ }^{256}$ Este asunto fue discutido y se concluyó crear una subcomisión dedicada a discutir cómo se organizarían las comisiones. ${ }^{257}$ Finalmente se decidió aceptar la propuesta de Colombia con ciertas modificaciones. ${ }^{258}$ Las seis comisiones de trabajo adicionales a las reglamentarias quedaron organizadas de este modo: las dos primeras trataron la reorganización, consolidación y fortalecimiento del sistema interamericano, el Pacto Constitutivo del mismo, además de las relaciones de este sistema con el de las Naciones Unidas; la tercera comisión de trabajo se refirió a la solución de controversias y a la seguridad colectiva; la cuarta a asuntos económicos; la quinta a asuntos sociales, y la sexta a asuntos jurídico-políticos. ${ }^{259}$

La comisión que nos interesa para efectos de este estudio es la sexta. Ella, a su vez, se subdividió en tres subcomisiones. En principio, la Subcomisión A analizaría el tema de los derechos y deberes internacionales del hombre; la Subcomisión "B" analizaría el reconocimiento de gobiernos de facto y la defensa y preservación de la democracia en América, y la Subcomisión "C" se referiría a las colonias europeas en el Continente. ${ }^{260}$ La Subcomisión "A" tuvo solo dos sesiones, pues después fue la misma Comisión Sexta la que se

${ }^{252}$ Fenwick, G. G., "The Ninth International Conference of American States", cit., p. 554.

253 CA, pp. 109 y ss.

254 CA, p. 114.

255 Artículo 12 del Reglamento de la Novena Conferencia Internacional Americana, CA, p. 114.

256 NCI, pp. 86 y 87.

257 Esta propuesta fue hecha por Uruguay. NCI, p. 92, la aprobación de esta decisión se observa en NCI, p. 94.

258 NCI, pp. 106 y 107.

$259 \mathrm{NCV}$, p. s/n (página que sigue al título del vol. V en nuestra recopilación).

260 NCV, p. 437. 
Este libro forma parte del acervo de la Biblioteca Jurídica Virtual del Instituto de Investigaciones Jurídicas de la UNAM

dedicó a analizar el PDADDH. ${ }^{261}$ Además del trabajo de la Comisión Sexta y la Subcomisión A, es relevante para efectos de la DADDH el trabajo que fue llevado a cabo por el Grupo de Trabajo sobre Derechos del Hombre.262

$\mathrm{Si}$ se revisan las sesiones donde pueden encontrarse antecedentes relativos a la DADDH y al origen remoto de la Corte IDH en la Novena Conferencia, según el orden en el que aparecen en los trabajos preparatorios, ellas pueden ser confusas. Esto se produce porque tales libros se ordenan según la naturaleza de la sesión (plenaria, de comisión o de subcomisión), y no según un orden cronológico. Si se quisieran leer los trabajos preparatorios en forma lineal, siguiendo la fecha de realización de las sesiones, habría que leerlos en el siguiente orden (se anotan entre paréntesis las páginas de la NGV donde se encuentran las secciones relevantes):

30.03.1948: Plenaria, sesión de inauguración

01.04.1948: Comisión Sexta, sesión de instalación

02.04.1948: Comisión Sexta, primera sesión

05.04.1948: Subcomisión A, sesión de instalación

06.04.1948: Subcomisión A, primera sesión

07.04.1948:Plenaria, quinta sesión

08.04.1948: Subcomisión A, segunda sesión

16.04.1948: Comisión Sexta, segunda sesión

17.04.1948: Comisión Sexta, tercera sesión

21.04.1948: Comisión Sexta, cuarta sesión

22.04.1948: Comisión Sexta, quinta sesión

23.04.1948: Comisión Sexta, sexta sesión

24.04.1948: Comisión Sexta, séptima sesión

24.04.1948: Comisión Sexta, octava sesión

26.04.1948: Comisión Sexta, novena sesión

30.04.1948: Plenaria, séptima sesión (pp. 123, 127-129)

(pp. 517-527)

(pp. 527-538)

(pp. 611-612)

(pp. 613-614)

(pp. 199-202, 231)

(pp. 615-628)

(pp. 538-542)

(pp. 542-567)

(pp. 567-576)

(pp. 577-584)

(pp. 584-593)

(pp. 593-598)

(pp. 598-608)

(pp. 609-610)

(pp. 231, 234-236)

En cuanto al trabajo de la Novena Conferencia en materia de la DADDH, es importante recordar que ella se basó en el PDADDH elaborado por el Comité Jurídico Interamericano. Éste, a su vez, fue un desarrollo del APDADDH, el que fue enviado a los gobiernos americanos para que presentaran observaciones, las que fueron tomadas en cuenta por el Comité Jurídico Interamericano al preparar su proyecto. ${ }^{263}$

261 NCV, pp. 611-628.

$262 \mathrm{El}$ informe de su trabajo puede observarse en NCV, pp. 474-484.

263 Monroy Cabra, M. G., "Aplicación de la Declaración Americana de Derechos y Deberes del Hombre por la Comisión Interamericana de Derechos Humanos", cit., pp. 131 y 132. 
Este libro forma parte del acervo de la Biblioteca Jurídica Virtual del Instituto de Investigaciones Jurídicas de la UNAM

\title{
CapÍtulo TerGero
}

\section{TRABAJOS PREPARATORIOS DE LA DEGLARAGIÓN Y DEL GERMEN DE LA GORTE INTERAMERICANA}

\author{
I. AlgunAS GUESTIONES RELEVANTES QUE SE APRECIAN \\ EN LOS TRABAJOS PREPARATORIOS
}

\section{Cuestión preliminar}

Este trabajo no busca resumir las discusiones relevantes que se pueden observar en los trabajos preparatorios de la DADDH, dichas discusiones se pueden leer directamente en los anexos de este libro, lo que se facilita con los títulos que identifican diversas discusiones, particularmente en el documento NCV. Además, el índice temático de esta edición permite revisar fácilmente distintos asuntos que puedan ser de interés. Por ello, solo nombraremos algunas discusiones que parecen particularmente interesantes, y que podrían despertar en el lector el interés de adentrarse en el estudio de estos trabajos. Antes de hacerlo, hacemos presente que, desgraciadamente, no todas las sesiones relevantes fueron transcritas con actas literales. Existen algunas de mucho interés, referidas a derechos sustantivos, en los que se cuenta solo con versiones resumidas de la sesión. En éstas, las actas suelen dejar constancia, en una nota al pie de página de que "[p] or dificultades insalvables, no hubo servicios taquigráficos para esta sesión". 265 Uno se pregunta si los disturbios ocurridos en Bogotá en las semanas previas a estas sesiones habrán influido en estas dificultades. En cambio, hay otras sesiones que están transcritas completamente, pero cuyo contenido es accesorio, como sucede con las discusiones de nombramiento de presidente y secretario.

\section{La dignidad como fuente de los derechos}

En los trabajos preparatorios y en la redacción final de la DADDH se aprecia que los derechos humanos encuentran su base en la noción de dignidad de la

${ }^{265}$ Por ejemplo, NCV, p. 577. 
persona, en el "reconocimiento del valor moral del ser humano individual";266 sin embargo, los redactores de la DADDH estaban lejos de compartir la visión individualista que algunos tienen sobre los derechos humanos. Ellos consideraban que la realidad habría dejado en claro que las doctrinas individualistas extremas eran inaplicables, ${ }^{267}$ que "el hombre es, sin duda, por su naturaleza, un ser social", ${ }^{268}$ y concebían al Estado como una "comunidad cooperativa". ${ }^{269}$ Sin embargo, no caían en colectivismos, pues reconocen que "el Estado existe para el hombre, no el hombre para el Estado". 270 Su concepción se observa en algunas afirmaciones del Comité Jurídico Interamericano, como cuando sostiene:

El Estado no es un mero conjunto de individuos; es la expresión histórica de los varios grupos sociales dentro de los cuales el hombre ha encontrado la oportunidad para el desenvolvimiento de sus mejores facultades. Comprende una herencia cultural de la cual el individuo se aprovecha profundamente para satisfacer sus necesidades morales y materiales. El hombre no puede disfrutar de los beneficios de la civilización, proporcionados por una vida social organizada, a menos que, dentro del límite de sus fuerzas, también él coopere lo más posible al desenvolvimiento de los grandes objetivos del Estado y a los de la ley, del orden, de la justicia y del bienestar general. ${ }^{271}$

La idea de que la dignidad humana se asienta en la naturaleza, excluye otras teorías sobre sus fundamentaciones, tales como la que la basan en el concepto de autonomía. ${ }^{272}$ En efecto, muchos opinan que los derechos humanos se basan "en la afirmación de que el hombre no está sometido a ninguna otra ley que las de su propia voluntad y su propia libertad". ${ }^{273}$ El hecho

${ }^{266}$ AD, p. 15. También se afirma que "toda la Declaración de Derechos y Deberes se inspira en el concepto de que el ser humano posee una dignidad y valor inherentes". AD, p. 32. Por su parte, algunos delegados dan visiones en sentidos similares, como cuando el delegado de Cuba afirmó que "los derechos del individuo... tienen por base la ley natural", NCV, p. 544.

${ }^{267}$ Idem.

${ }^{268} \mathrm{AD}$, p. 19.

${ }^{269}$ AD, p. 14. Véase también AD, p. 43.

${ }^{270}$ AD, p. 35. Esto se veía reforzado en el PDADDH del Comité Jurídico Interamericano, el que disponía: "La Constitución proveerá a la formación de un gobierno representativo al servicio del bien común". NGV, p. 452.

${ }^{271} \mathrm{AD}$, p. 40. En este pasaje se puede entrever la idea del principio de subsidiariedad.

${ }^{272}$ Esta distinción es importante, porque el concepto de dignidad y su fundamento son bastante controversiales. En esta materia, véase Carozza, P. G., "Human Dignity", en Shelton, Dinah (ed.), The Oxford Handbook of International Human Rights Law, Oxford, Oxford University Press, 2013.

${ }^{273}$ Maritain, J., El hombre y el Estado, Madrid, Fundación humanismo y democracia, Ediciones Encuentro, 1983, p. 100. Maritain no se encuentra entre ellos, sino que sólo constata esta realidad. 
Este libro forma parte del acervo de la Biblioteca Jurídica Virtual del Instituto de Investigaciones Jurídicas de la UNAM

de que la autonomía no es el fundamento de la dignidad ni, por tanto, de los derechos humanos, se observa al leer ciertos deberes que encontraron lugar en la DADDH. Por ejemplo, el deber de trabajo, que nos da a entender que una persona no podría - al menos en justicia - decidir autónomamente no trabajar, a pesar de que tuviera medios de subsistencia suficientes.

En efecto, este deber de trabajo existe no solo para que la persona subsista, sino que también "en beneficio de la comunidad".274 Algo similar se nota en el deber de los hijos de "honrar siempre a sus padres", el que da más la impresión de ser un mandamiento del Decálogo que una norma legal. Estas disposiciones muestran que los redactores de la DADDH consideraban que los derechos no están establecidos solo para el goce de sus beneficiarios. Así, por ejemplo, el Comité Jurídico Interamericano afirma que existen derechos que deben ser ejercidos no solo respetando los derechos de los otros, sino que "para el bien general de la comunidad y la conservación del orden y seguridad públicos". ${ }^{275}$ Ello también se observa al leer el informe anexo al APDADDH, que hace varias referencias a la idea de que el hombre debe tener "conciencia de su responsabilidad". ${ }^{276}$

Es por lo anterior que el Comité Jurídico Interamericano se refiere al "principio de reciprocidad de derechos y deberes". ${ }^{277}$ Este principio es confirmado por el grupo de trabajo creado por la Comisión Sexta, cuando afirma que el proyecto de Río declara "con mucho acierto que «Los derechos y los deberes son correlativos»". ${ }^{278}$ Este principio también se manifiesta en afirmaciones más particulares; por ejemplo, cuando el Comité Jurídico Interamericano afirma que el derecho al sufragio implica una obligación, la que no solo incluye la de emitir el voto, sino que la de hacerlo "con la convicción de que se está cumpliendo un deber cívico al contribuir directa o indirectamente a la orientación de la política general del Gobierno y a la consecución de los medios de mejorar las condiciones de vida del pueblo en general". ${ }^{279}$ En otras palabras, se entiende que el ciudadano debe usar su voluntad autónoma en pos del bien común.

Lo anterior podría hacer que el lector se pregunte si la inclusión de deberes en la DADDH busca limitar los derechos, de modo que quienes

274 Artículo XXXVII, DADDH. Con relación al derecho correlativo, es interesante notar la concepción subsidiaria que éste tiene, $\mathrm{AD}$, p. 41.

275 Ibidem, p. 25.

276 Ibidem, p. 14.

277 Ibidem, p. 25.

278 NCV, p. 477.

279 AD, p. 40. 
Este libro forma parte del acervo de la Biblioteca Jurídica Virtual del Instituto de Investigaciones Jurídicas de la UNAM

incumplen sus deberes podrían perder sus derechos, como si éstos emanaran del cumplimiento los deberes correlativos y no de la misma dignidad humana; tal lectura sería inadecuada. Lo que entendían los redactores de la DADDH es que, al vivir en comunidad, los derechos conllevan necesariamente los deberes. Por eso se afirma que "el derecho de uno implica el deber correlativo de parte de otros de respetarlo". ${ }^{280}$ Se trata más bien de una observación de la realidad, asimilable a decir que si existe un "arriba" habrá también un "abajo". Esto se observa también en la CADH; en efecto, el capítulo "Deberes de las personas", cuyo único artículo es el número 32, llamado "Correlación entre deberes y derechos", fue propuesto por el delegado brasileño Dunshee de Abranches para reconocer "la regla jurídica de que no hay derechos sin deberes", contemplada en la DADDH y en la DUDH; ${ }^{281}$ además, vale la pena notar que algunos delegados consideraban que la sección de los deberes no tenía "la importancia y dignidad" de la sección de los derechos. ${ }^{282}$

\section{A modo de control de convencionalidad}

El Comité Jurídico Interamericano pensaba que la DADDH sería incluida como anexo a la carta organizativa del sistema panamericano. ${ }^{283}$ Por ello, en el entendido de que la DADDH tendría forma de convención, ${ }^{284}$ dicho comité plasmó en el APDADDH una norma según la cual las disposiciones de la DADDH formarían "parte de la ley de cada Estado, para ser respetadas y puestas en vigor por las autoridades administrativas y judiciales de la misma manera que todas las demás leyes del Estado". ${ }^{285}$ Ello, porque el Comité estaba consciente de que, aunque las reglas del Derecho Internacional constituyen una obligación para los Estados, "la relación de estas disposiciones con las leyes nacionales es una cuestión que debe ser resuelta por cada Nación de acuerdo con su propia constitución". ${ }^{286}$ Por

\footnotetext{
280 Ibidem, p. 50.

281 Secretaría General de la Organización de los Estados Americanos, Conferencia Especializada Interamericana sobre Derechos Humanos: Actas y Documentos, OEA/Ser.K/XVI/1.2, San Fosé, Costa Rica, 7-22 de Noviembre de 1969, disponible en http://wrerr.corteidh.or.cr/tablas/15388.pdf, fecha de última consulta: 6 de enero de 2017, pp. 125, 126, 278 y 306.
}

282 NCV, p. 601.

283 AD, p. 13.

284 Ibidem, p. 53.

285 Ibidem, p. 10.

286 Ibidem, pp. 52 y 53. 
eso este proyecto contemplaba un artículo exigiendo la incorporación de la DADDH. Finalmente, al no ser la DADDH aprobada con la naturaleza de un tratado, no tuvo mayor sentido insistir en la propuesta de que formara parte de la ley de cada Estado.

Esta idea del Comité Jurídico Interamericano es interesante, pues se parece a la doctrina del control de convencionalidad que ha formulado la Corte IDH. ${ }^{287}$ Esta doctrina se encuentra en desarrollo actualmente, por lo que es imposible saber cuál será su contenido definitivo. De acuerdo a su formulación actual según la Corte IDH, un Estado no sólo tendría que cumplir con lo que dispone la $\mathrm{CADH}$, sino que también con las interpretaciones que de ésta hace la Corte IDH en sus decisiones, sea que ellas se emitan o no en contra de tal Estado. Más aún, la Corte afirma que cada órgano que tome decisiones al interior de un Estado debe aplicar, directamente, tanto la CADH como la jurisprudencia de la Corte IDH, con independencia de lo que dispongan las leyes nacionales, incluida la Constitución. ${ }^{288}$

287 Para una descripción general de esta doctrina, hecha por un ex Secretario Ejecutivo de la Comisión IDH, véase Dulitzky, A. E., "An Inter-American Constitutional Court? The Invention of the Conventionality Control by the Inter-American Court of Human Rights", Texas International Law Fournal, vol. 50, 2015, pp. 49-52. En sentido favorable a esta doctrina, véase Ruiz-Chiriboga, O. R., "The Conventionality Control: Examples of (Un)Successful Experiences in Latin America", Inter-American and European Human Rights fournal / Revista Interamericana y Europea de Derechos Humanos, vol. 3, 1-2, 2010. En un sentido crítico a esta doctrina véase Castilla Juárez, K. A., “¿Control interno o difuso de convencionalidad? una mejor idea: la garantía de tratados", Anuario Mexicano de Derecho International, vol. XIII, 2013, y Malarino, E., "Acerca de la pretendida obligatoriedad de la jurisprudencia de los órganos interamericanos de protección de derechos humanos para los tribunales judiciales nacionales", en Christian Steiner (ed.) Sistema interamericano de protección de los derechos humanos y derecho penal internacional, vol. II, Konrad-Adenauer-Stiftung e. V., Montevideo, 2011.

288 La Corte hizo, en forma más o menos reciente, la siguiente formulación del control de convencionalidad: "en situaciones y casos en que el Estado concernido no ha sido parte en el proceso internacional en que fue establecida determinada jurisprudencia, por el solo hecho de ser Parte en la Convención Americana, todas sus autoridades públicas y todos sus órganos, incluidas las instancias democráticas, jueces y demás órganos vinculados a la administración de justicia en todos los niveles, están obligados por el tratado, por lo cual deben ejercer, en el marco de sus respectivas competencias y de las regulaciones procesales correspondientes, un control de convencionalidad tanto en la emisión y aplicación de normas, en cuanto a su validez y compatibilidad con la Convención, como en la determinación, juzgamiento y resolución de situaciones particulares y casos concretos, teniendo en cuenta el propio tratado y, según corresponda, los precedentes o lineamientos jurisprudenciales de la Corte Interamericana". Gelman vs. Uruguay (2013): Corte Interamericana de DD.HH., Resolución de Supervisión de Cumplimiento de Sentencia, 20 de marzo, párr. 69. 
Tal interpretación ha sido adoptada por parte de la doctrina, pero otra parte considera que es errada. ${ }^{289}$ Incluso un juez de la Corte parece no aceptarla del todo, pues señala, en su voto disidente al caso Wong Ho Wing vs. Perú, que la jurisprudencia de la Corte IDH es vinculante para el Estado solamente en los casos en los que sea parte, y que para los demás Estados constituye sólo un medio auxiliar para la determinación de las reglas del Derecho. ${ }^{290}$

El control de convencionalidad, según el modo como es entendido por la Corte IDH, se basa en algunas cuestiones que son indiscutibles, como el hecho de que el Estado se encuentra obligado por las sentencias que dicte la Corte en un caso concreto, dentro de su competencia. También se basa en el hecho de que sería una buena práctica que los jueces, al aplicar la normativa nacional, tuvieran en consideración lo que dispone la CADH. Sin embargo, si esta doctrina se entiende con todos los elementos que le asigna actualmente la Corte IDH, ella terminaría siendo contraria al Derecho Internacional general. Además, implicaría un quiebre en el Estado de derecho (a menos que la Constitución nacional le conceda tal poder a las decisiones de la Corte IDH).

Sería contraria al Derecho Internacional general porque, según éste, es prerrogativa del Estado determinar cómo se incorporan los tratados al Derecho interno, según reconoció el mismo Comité Jurídico Interamericano, como se afirmó más arriba. Además, la doctrina del control de convencionalidad sería muy difícil de aplicar en la práctica, en parte, porque la Corte IDH no funciona con un sistema de precedentes. En efecto, ella ha cambiado su postura de un modo radical en más de algún asunto, ${ }^{291}$ incluso

289 Los altos tribunales de los Estados han adoptado distintas posiciones frente a esta doctrina. Por ejemplo, la Corte Suprema de Uruguay ha hecho una importante crítica a esta doctrina. M. L., J. F. F., O. - denuncia- excepción de inconstitucionalidad artículos 1, 2 y 3 de la Ley núm. 18.831 (2013): Sentencia de la Suprema Corte de Justicia (Uruguay), IUE 2-109971/2011. Disponible en: http://medios.elpais.com.uy/downloads/2013/sentenciascj.pdf, fecha de última consulta el 11 de enero de 2016, pp. 12-24 (la paginación es la del documento alojado en internet). Para ver un listado de algunos países a favor y en contra de la aplicación de precedentes de la Corte IDH, véase también Dulitzky, A. E., "An Inter-American Constitutional Court? The Invention of the Conventionality Control by the Inter-American Court of Human Rights", cit., p. 80.

290 Voto disidente del juez Eduardo Vio Grossi en el caso Wong Ho Wing vs. Perú (2015): Corte Interamericana de DD.HH., Excepción Preliminar, fondo, reparaciones y costas, serie C, núm. 297, sección "Conclusión”.

291 Por ejemplo, veáse Paúl Díaz, Á., "La Corte Interamericana in vitro: comentarios sobre su proceso de toma de decisiones a propósito del caso Artavia", cit., p. 307, y Paúl Díaz, Á., "Giro en materia de recurso de revisión ante la Corte Interamericana", Revista Chilena de Derecho y Ciencia Política, vol. 4, núm. 2, 2013. 
en materia de control de convencionalidad. Es más, en una de sus primeras opiniones consultivas dispuso que no podía pronunciarse sobre la aplicación directa de una norma de la CADH dentro de un Estado parte, dando a entender que ello era materia propia de las normas internas del Estado. ${ }^{292}$ Esta falta de precedentes hace que sea dificil utilizar sentencias previas para predecir cómo resolverá la Corte IDH. ${ }^{293}$

Es bastante interesante que el Comité Jurídico Interamericano haya sugerido que la DADDH contara con una norma que tendría efectos similares a los que propone la Corte IDH para su doctrina del control de convencionalidad. Además, hace que estos trabajos preparatorios sean de una relevancia aún más actual. En particular, porque en las afirmaciones del Comité constan elementos que hoy constituyen detalles de la doctrina del control de convencionalidad según la Corte IDH. Por ejemplo, el Comité Jurídico buscaba que las disposiciones de la DADDH fueran aplicadas "por las autoridades administrativas y judiciales del Estado", ${ }^{294}$ cual es uno de los elementos más discutibles de la doctrina propuesta por la Corte IDH. Sin embargo, es del caso señalar que el Comité Jurídico notó que, para contar con estos efectos, era necesario que un tratado vinculante lo prescribiera expresamente, pues estos efectos no se derivan automáticamente de un tratado internacional, a diferencia de lo que opina actualmente la Corte IDH.

\section{La Comisión Consultiva Interamericana de los Derechos del Hombre}

El Comité Jurídico Interamericano se hizo cargo del pronunciamiento de la Resolución XL en favor de la protección internacional de los derechos humanos. Por ello, y considerando que cada Estado debiera ser el principal responsable por la protección de tales derechos, propuso la norma según la

292 Exigibilidad del derecho de rectificación o respuesta (artículos 14.1, 1.1 y 2 Convención Americana sobre Derechos Humanos) Corte Interamericana de DD.HH., Opinión Consultiva OC-7/86, Serie A núm. 7, 1986, párrs. 13 y 14; así como, la opinión disidente conjunta de los jueces Nieto y Nikken, párrs. 12-15. Véase también X. Fuentes Torrijo, "International and Domestic Law: Definitely an Odd Couple", Revista Furídica de la Universidad de Puerto Rico, vol. 77, 2008, pp. 485487.

293 Por ejemplo, en el caso Artavia, el voto disidente del juez chileno Eduardo Vio Grossi afirma que Costa Rica, al prohibir la fecundación in vitro para proteger la vida del embrión, habría estado haciendo "lo que hoy se denomina "control de convencionalidad»", pues habría dado una interpretación amplia al derecho a la vida, cuestión exigida por la jurisprudencia de la Corte. Voto disidente del juez Eduardo Vio Grossi en Artavia Murillo y otros (fecundación in vitro) vs. Costa Rica, cit.

294 AD, p. 54. 
cual las disposiciones de la DADDH entrarían a formar parte directamente de la legislación de los Estados, a la que nos acabamos de referir; sin embargo, consideró que no bastaba con eso, por lo que también propuso que se creara un órgano interamericano con funciones de carácter consultivo para la protección de los derechos humanos. ${ }^{295}$

El Comité Jurídico Interamericano propuso llamar a este órgano "Comisión Consultiva Interamericana de los Derechos del Hombre", el cual sería "un órgano subsidiario del Consejo Económico y Social Interamericano, creado por la Conferencia sobre Problemas de la Guerra y de la Paz". ${ }^{296}$ La relación entre ambos órganos, similar a la existente en el ámbito de Naciones Unidas, nos muestra que la idea del Comité Jurídico Interamericano puede haber estado basada en la Comisión de Derechos Humanos de Naciones Unidas. Las atribuciones de esta Comisión Consultiva americana "serían las de fomentar el respeto a los derechos humanos y las libertades fundamentales de acuerdo con las disposiciones de la Declaración respectiva que adopten los Estados Americanos". ${ }^{297}$ La Comisión Consultiva no tendría la capacidad para actuar cuando un Estado se dedicara a violar sistemáticamente los derechos humanos, pues entonces serían los demás Estados americanos los que deberían adoptar las acciones necesarias. ${ }^{298}$ Esta comisión consultiva debería mantener contacto con la Comisión de los Derechos Humanos de las Naciones Unidas. ${ }^{299}$

Como puede apreciarse, las similitudes de la actual Comisión IDH con esta propuesta de comisión consultiva son bastantes. Curiosamente, esta idea del Comité Jurídico Interamericano no fue objeto de discusiones relevantes en la Novena Conferencia. ${ }^{300}$ Fue necesario el transcurso de unos trece años desde la elaboración de esta propuesta, para que se creara la

295 AD, p. 53. En la primera ocasión en que el Comité Jurídico Interamericano hace referencia a esta Comisión, la redacción del Comité podría dar a entender que se formaría una comisión en cada Estado. Sin embargo, esa no parece ser la intención del Comité Jurídico, y se debería únicamente a la disposición poco clara de las comas en esa oración.

296 Ibidem, p. 53.

297 Ibidem, p. 54.

298 Idem.

299 Idem.

300 Se podría decir que la delegación de Guatemala sí la tuvo en cuenta, pero con fines diversos. En primer lugar, con motivo de la propuesta de Uruguay sobre la creación de una corte interamericana, Guatemala afirmó que, una vez elaborada la DADDH, el juzgar sobre la protección de los derechos humanos debiera quedar encomendado a un ente jurídico y no a un ente político. NCV, pp. 615 y 616. En segundo lugar, sometió a consideración la idea de crear una "Comisión Interna de Divulgación de los Derechos del Hombre", la que también tendría labores de promoción de los derechos humanos,. NCV, pp. 616 y 617. 
Este libro forma parte del acervo de la Biblioteca Jurídica Virtual del Instituto de Investigaciones Jurídicas de la UNAM

Comisión IDH, cuestión que se hizo mediante una simple resolución. ${ }^{301}$ No fue sino hasta 1970 que este organismo logró ser incluido en un tratado internacional, mediante la entrada en vigor del Protocolo de Buenos Aires a la Carta de la OEA.

\section{Otras discusiones}

Son varios los derechos que están discutidos en profundidad en los trabajos preparatorios de la DADDH. Ello sucede, por ejemplo, con el derecho de reunión y de asociación. Con relación a este derecho, el Comité Jurídico Interamericano puso énfasis en el "derecho del Estado de reglamentar las grandes asociaciones, que llegan a rivalizar con el propio Estado, por la grandeza de su poder y la fidelidad de sus miembros". 302 Es interesante que lo haya hecho en una época en que las transnacionales no tenían toda la relevancia que tienen actualmente. Esta inquietud del Comité va muy en línea con la preocupación actual de la relación entre los derechos humanos y las empresas. ${ }^{303}$ Los trabajos preparatorios muestran también discusiones sobre un derecho que no encontró un lugar en la DADDH. Se trata del derecho de resistencia, que fue propuesto por Cuba, y bastante discutido.

Las delegaciones de la Novena Conferencia buscaron redactar los derechos "en su mera esencia, sin enumeraciones ejemplares o taxativas, que llevan consigo el riesgo de la difusión inútil y de la confusión peligrosa de sus límites". ${ }^{304} \mathrm{El}$ problema de dicho enfoque es que impide conocer cuál habría sido, según ellos, el contenido de ciertos derechos. Esta falta solo puede ser suplida con los trabajos preparatorios. Así, por ejemplo, el APDADDH nos muestra que el Comité Jurídico, al redactar el derecho a la libertad, no buscaba referirse solo a la libertad entendida como la ausencia de detenciones arbitrarias, sino que también al libre tránsito, a la inviolabilidad del domicilio, de la correspondencia, y a la salvaguarda de derechos frente a los servicios que el Estado exigiera de los individuos. ${ }^{305}$ La versión actual separó algunos de esos derechos. Desafortunadamente, los trabajos preparatorios

301 Buergenthal, T., "The Revised OAS Charter and the Protection of Human Rights", cit., p. 829 .

302 AD, p. 30.

303 Por ejemplo, Ruggie, J. G., Fust Business: Multinational Corporations and Human Rights, W. W. Norton \& Company, Nueva York, 2013.

304 NGV, p. 513.

305 AD, pp. 1 y 2. 
Este libro forma parte del acervo de la Biblioteca Jurídica Virtual del Instituto de Investigaciones Jurídicas de la UNAM

no son siempre suficientemente completos, por lo que no aclaran todas las dudas que surgen de la lectura de la DADDH.

También es interesante que el Comité Jurídico Interamericano buscó establecer el derecho a la vida en un sentido amplio, no solo relacionado con la prohibición estatal de privar de la vida al inocente, además incluiría el deber del Estado de mantener y amparar a los "incapaces de sostenerse por su propio esfuerzo". ${ }^{306}$ En otras palabras, concebía este derecho (que se podría clasificar dentro de los civiles y políticos) como incluyendo obligaciones positivas y yendo más allá de la simple vida biológica. Algo similar puede decirse respecto de la idea de libertad, ya mencionada, puesto que el Comité Jurídico Interamericano, siguiendo a las Naciones Unidas, se refiere a la idea de que la promoción del "progreso social y el mejoramiento de las condiciones de vida" se encontrarían "dentro de un concepto más amplio de libertad". ${ }^{307}$

Otra discusión interesante, aunque más por un carácter de anécdota histórica que por una importancia actual, es el hecho de que El Salvador propuso que se eliminara la expresión que hacía referencia a la característica de "secreto" del voto. ${ }^{308}$ Lo hace porque, según afirma, el voto no era secreto ni en su país ni en otros Estados. ${ }^{309}$ Esta solicitud de El Salvador fue opuesta fuertemente por los Estados de Uruguay y Cuba. Finalmente, la idea de El Salvador fue rechazada con 6 votos a favor y 12 en contra. ${ }^{310}$ Esta discusión es relevante porque muestra que los delegados estaban dispuestos a tomar decisiones que pudieran ser contrarias al ordenamiento jurídico de diversos países, con tal de que dichas normas fueran vistas como una exigencia de los derechos humanos. En una materia similar, y también de modo anecdótico, es interesante leer que el Comité Jurídico Interamericano tomó nota de que uno de los Estados americanos había hecho la proposición de establecer el "sufragio familiar". 311

\section{ORIGEN REMOTO DE LA CORTE INTERAMERICANA}

A continuación nos referiremos a lo que hemos llamado el origen remoto o germen de la Corte IDH. Éste sería el primer acto oficial de la OEA en el que se observa la preocupación por crear una corte regional de derechos humanos.

\footnotetext{
306 Ibidem, p. 1.

307 Ibidem, p. 20.

308 NCV, p. 588.

309 Idem.

310 Ibidem, p. 590.

311 AD, p. 36.
} 
A través de los años, los Estados de América propusieron crear algunos tribunales internacionales que no tienen mayor relación con la actual Corte IDH. Así, por ejemplo, en la Conferencia de Lima de 1938 se aprobó la "Declaración sobre la Corte de Justicia Internacional Interamericana". ${ }^{312}$ Tal declaración apuntaba a la creación de un tribunal más parecido a la Corte Internacional de Justicia, por lo que difícilmente se podría considerar un antecedente de la Corte IDH. ${ }^{313}$ El APDADDH, elaborado por el Comité Jurídico Interamericano, también hacía una referencia a una corte o tribunal internacional. Éste conocería de casos en que se violaran los derechos de extranjeros ubicados en el territorio de otro Estado. ${ }^{314}$ Según se puede apreciar, este tribunal buscaba dar una respuesta interesante a la antigua

312 A continuación se copia el texto íntegro de la Declaración sobre la Corte de fusticia Internacional Americana:

XXV DEGLARAGIÓN SOBRE LA GORTE DE JUSTICIA INTERNAGIONAL INTERAMERICANA Considerando:

Que la creación de un Tribunal Interamericano de Justicia Internacional está hondamente vinculada a los problemas de la paz en América por ser la justicia uno de los elementos que asegura el libre ejercicio de los derechos y mantiene una conciencia continental de armonía entre los Estados Americanos, basada en el predominio de las normas jurídicas.

Que por el carácter de universalidad de los principios de derecho y por la natural aspiración de que un Tribunal de Justicia pueda resolver las dificultades que se susciten, de acuerdo con los distintos sistemas jurídicos del Continente Americano, la erección de ese organismo judicial cuenta con la simpatía de casi todos los Estados de este hemisferio, sin perjuicio de que la mayoría de estos Estados continúen adscritos al Tribunal Permanente de Justicia Internacional de La Haya que tiene una jurisdicción más amplia,

Que si en el momento presente no se encuentran realizadas las condiciones necesarias para el establecimiento de esta institución administradora de la Justicia en América, no debe abandonarse la idea y el propósito de crearla cuando esas condiciones imperativamente reclamen su instauración sino, por el contrario, deben reafirmarse los Estados Americanos en la idea y en el propósito de llegar a ese anhelo infundiendo en la conciencia continental la aspiración unánime de crear un Tribunal Interamericano de Justicia Internacional, en que se hallen representados todos los Estados del Continente y todos sus sistemas jurídicos,

La Octava Conferencia Internacional Americana, declara:

Que es propósito firme de los Estados del Continente Americano llegar a constituir un Tribunal Interamericano de Justicia Internacional, cuando los mismos Estados reconozcan la oportunidad de hacerlo con seguridad de feliz éxito; y que, entretanto, debe propenderse al estudio de un Estatuto adecuado sobre el que deba descansar la justicia internacional en América. (Aprobada el 22 de diciembre de 1938.)

Esta declaración fue tomada de: Secretaría de Relaciones Exteriores, Conferencias Internacionales Americanas. Primer Suplemento 1938-1942, cit., p. 41, disponible en http://biblio2.colmex. mx/coinam/coinam_1_suplemento_1938_1942/base2.htm (fecha de última consulta, el 26 de enero de 2015).

313 A pesar de ello, durante la Novena Conferencia la delegación de Guatemala enlaza esta idea con la de una corte que proteja los derechos del hombre. NGV, p. 616.

314 AD, pp. 11 y 56. 
Este libro forma parte del acervo de la Biblioteca Jurídica Virtual del Instituto de Investigaciones Jurídicas de la UNAM

institución de la protección diplomática. Por ello, la naturaleza acotada de este tribunal impide que se le considere un antecedente de la Corte IDH.

El primer antecedente directo de la Corte IDH habría surgido en un cuestionario que Uruguay presentó a las demás delegaciones, y que fue discutido en la Subcomisión A. El tercer punto de dicho cuestionario buscaba averiguar si la protección de los derechos del hombre "había de confiarse a la competencia interna de los respectivos regímenes constitucionales de cada país, o si había de crearse una competencia internacional de tipo jurisdiccional". ${ }^{315}$ La idea de crear un tribunal fue apoyada por Guatemala en los trabajos de la subcomisión. ${ }^{316}$ Sin embargo, en esta misma subcomisión recibió críticas de los delegados de Argentina, Brasil, Bolivia, Chile, Ecuador, Estados Unidos, México, Panamá y República Dominicana. ${ }^{317}$ Tal rechazo se basó en distintos motivos, tales como que el órgano que tomara decisiones estaría fallando sobre el régimen interno de los Estados (cuestión que podría afectar el principio de no intervención), y que las reclamaciones internacionales se multiplicarían. ${ }^{318}$

Posteriormente, ya en los trabajos de la Comisión Sexta, Uruguay volvió a poner sobre la mesa el establecimiento de un "poder jurisdiccional" que garantizara los derechos del hombre, los cuales debían ser reconocidos en el mismo "pacto de las naciones americanas". ${ }^{319} \mathrm{Al}$ hacer esta recomendación, Uruguay enuncia de un modo muy elocuente por qué debiera poder recurrirse a una instancia jurisdiccional internacional. ${ }^{320}$ El sistema propuesto para el establecimiento de esta instancia fue bastante distinto al que conocemos hoy en día. Uruguay partió de la base de que el Consejo Económico y Social de las Naciones Unidas ya tenía una misión de protección internacional de los derechos humanos, aunque fuera solo de carácter político y no judicial. Por ello, Uruguay consideró que faltaba instaurar un sistema judicial de protección de los derechos humanos al nivel de las Naciones Unidas. ${ }^{321}$ Su propuesta buscaba que los Estados americanos le dieran una competencia especial a la Corte Internacional de Justicia, ésta funcionaría en una primera etapa como un "Tribunal de Calificación", como una especie de filtro de admisibilidad en que se controlaría si los casos presentados cabían dentro de aquellos previstos en el convenio que le diera

\footnotetext{
315 NGV, p. 613.

316 Ibidem, p. 549 y 550. El trabajo de esta subcomisión puede verse en Ibidem, pp. 615-628.

317 Ibidem, p. 550.

318 Ibidem, p. 550.

319 Ibidem, p. 545.

320 Ibidem, pp. 546-548.

321 Ibidem, pp. 547 y 548.
} 
Este libro forma parte del acervo de la Biblioteca Jurídica Virtual del Instituto de Investigaciones Jurídicas de la UNAM

competencia. ${ }^{322}$ Si ello era así, el asunto podría pasar a un "tribunal especial americano", ${ }^{323}$ que sería nada más que una "Sala Especial Americana en la Corte Internacional de Justicia", ${ }^{324}$ ésta fallaría solo en forma declarativa, aunque la Corte Internacional de Justicia podría fijar una indemnización pecuniaria. ${ }^{325}$ Esta Corte no podría intervenir dentro del ámbito de la soberanía nacional para restituir el derecho agraviado. ${ }^{326}$

La propuesta original de Uruguay fue apoyada abiertamente por el delegado de Haití, ${ }^{327}$ y recibió un guiño conciliador por parte de la delegación de Bolivia. ${ }^{328}$ Honduras, por su parte, preguntó cómo podría acudir un individuo a la Corte Internacional de Justicia, puesto que su estatuto establece que solo los Estados pueden presentar demandas. ${ }^{329}$ Frente a esto, Uruguay aclaró que el mismo proyecto proponía reformar el artículo respectivo del Estatuto de la Corte de La Haya. ${ }^{330}$ Luego de esta aclaración, la delegación de Cuba propuso seguir un orden, contestando el cuestionario presentado por Uruguay, pero comenzando por su primer punto, es decir, la determinación de cuál sería la naturaleza jurídica de la DADDH. Una vez que en esa misma sesión se decidió que la DADDH no sería un instrumento vinculante, el presidente de la Comisión afirmó que "crear una competencia internacional de tipo jurisdiccional equivaldría a darle juridicidad a lo [...] que va a ser una simple declaración". ${ }^{331}$ En atención a la adopción de esta decisión, el delegado de Uruguay se resignó a que no se crearía la instancia jurisdiccional que había propuesto. ${ }^{332}$

En este estado de cosas, el delegado de Brasil señaló que la aprobación de una simple declaración no impedía que en el futuro se constituyera "una institución internacional para la garantía de los derechos del hombre". ${ }^{333}$ Por ello, presentó un proyecto de resolución para que fuera remitido al Comité Jurídico Interamericano el "Estudio del Estatuto de un tribunal intera-

\footnotetext{
322 Ibidem, pp. 463, 547 y 548.

323 Ibidem, 548.

324 NGV, p. 463.

325 NGV, p. 463.

326 NCV, p. 548. Esta propuesta también se detalla en un discurso hecho por el representante de Uruguay al Plenario de la Conferencia. NCI, pp. 201 y 202.

327 NGV, p. 552.

328 Ibidem, p. 551.

329 Ibidem, p. 551.

330 Ibidem, p. 552.

331 Ibidem, p. 556.

332 Ibidem, p. 557.

333 Ibidem, p. 557.
} 
Este libro forma parte del acervo de la Biblioteca Jurídica Virtual del Instituto de Investigaciones Jurídicas de la UNAM

mericano para la defensa de los derechos y deberes del hombre". ${ }^{334}$ El delegado de Uruguay apoyó la propuesta de Brasil. ${ }^{335}$ Cuba también se mostró partidaria de la creación de un órgano jurídico encargado de la protección de los derechos del hombre. ${ }^{336}$ Sin embargo, el presidente de la Comisión insistió en que, si la DADDH no tenía valor vinculante, mal podría haber un tribunal que juzgara sobre si la actuación de los Estados se ceñía a tales derechos. ${ }^{337} \mathrm{El}$ delegado de Chile trató de ordenar el debate, afirmando que la aprobación de la DADDH y la proposición de encomendar al Comité Jurídico Interamericano el estudio de la formación de un tribunal eran dos temas distintos. ${ }^{338}$ Señaló que esta segunda propuesta contaría con el apoyo de todas las delegaciones, pues todos tenían "la intención y la seguridad de que ese tribunal [iba] a funcionar a la perfección". 339

Siguiendo con esta misma discusión, Colombia propuso crear un tribunal moral, que dictara resoluciones morales. Esta entidad podría ser un comité jurídico o el mismo Consejo Directivo de la Unión Panamericana, que debería hacer una investigación informativa cuando se violaran los derechos humanos en un Estado, sin que esta institución o los demás Estados intervinieran en los asuntos internos de otro, pues el tribunal moral haría una simple declaración moral. ${ }^{340}$

A los pocos días se volvió a estudiar la propuesta de Brasil, y Uruguay propuso modificarla. ${ }^{341}$ También sugirió que este asunto fuera discutido no solo por el Comité Jurídico, sino que también por representantes de cada país. ${ }^{342}$ Perú consideró que este asunto debía ser discutido por un grupo de trabajo, ${ }^{343}$ y finalmente se postergó esta discusión algunos días, hasta que el 24 de abril la Comisión Sexta aprobó el Proyecto de Resolución sobre la Creación de una Corte Interamericana Destinada a Garantizar los Derechos del Hombre. ${ }^{344}$ Lamentablemente, ese día no se contó con una transcripción taquigráfica, sino que solo con un resumen de la sesión, donde se hace referencia a ciertas aclaraciones solicitadas por algunos Estados sobre

\footnotetext{
334 Ibidem, p. 557.

335 Ibidem, p. 558.

336 Idem.

337 Idem.

338 NCV, p. 559.

339 Idem.

340 Ibidem, pp. 559 y 560.

341 Ibidem, pp. 568 y 569.

342 Idem.

343 Ibidem, pp. 569 y 570.

344 Ibidem, pp. 596 y 597.
} 
Este libro forma parte del acervo de la Biblioteca Jurídica Virtual del Instituto de Investigaciones Jurídicas de la UNAM

los alcances de esta resolución. ${ }^{345}$ Fue Brasil quien procedió a hacer las clarificaciones debidas, ${ }^{346}$ puesto que la resolución definitiva fue muy similar a la propuesta de dicho Estado.

La sesión plenaria del 30 de abril de 1948 aprobó esta resolución, la XXXI. ${ }^{347}$ En ella se recomienda:

Que el Comité Jurídico Interamericano elabore un proyecto de estatuto para la creación y funcionamiento de una Corte Interamericana destinada a garantizar los derechos del hombre. Este proyecto, después de ser sometido al examen y a las observaciones de los Gobiernos de todos los Estados Americanos, deberá ser remitido a la Décima Conferencia Interamericana para que ésta lo estudie, si considera que ha llegado el momento para una decisión sobre la materia. ${ }^{348}$

Esta recomendación fue bastante innovadora para su época. Se debe tener presente que aún no existía ningún tribunal regional sobre derechos humanos, incluso más, no se había siquiera comenzado a trabajar en el Convenio para la Protección de los Derechos Humanos y de las Libertades Fundamentales en Europa, el tratado que crearía el primer tribunal regional de derechos humanos. En efecto, se afirma que las primeras propuestas de proteger a nivel europeo las garantías fundamentales, y de crear un tribunal al efecto, comenzaron recién en mayo de 1948, y se habrían basado en la idea de una cierta unidad europea, ${ }^{349}$ sólo en 1949 el European Movement presentó su propuesta de convención europea de derechos humanos, ${ }^{350}$ la que sería posteriormente trabajada por el Consejo de Europa. ${ }^{351}$

\footnotetext{
345 Ibidem, p. 597.

346 Idem.

347 NGI, p. 236.

348 NCVI, p. 253.
}

349 Bates, E., "The Birth of the European Convention on Human Rights and the European Court of Human Rights", en Jonas Christoffersen, Mikael Rask Madsen (eds.) The European Court of Human Rights between Law and Politics, Oxford, Oxford University Press, 2011, pp. 17-19.

350 Ibidem, p. 20.

351 Ibidem, pp. 22 y ss. Los trabajos preparatorios del Convenio Europeo para la Protección de los Derechos Humanos y de las Libertades Fundamentales pueden encontrarse en Council of Europe / Conseil de l'Europe, Collected Edition of the "Travaux Préparatoires» of the European Convention on Human Rights / Recueil des Travaux Préparatoires de la Convention Européenne des Droits de l'Homme, Martinus Nijhoff, The Hague-Boston-London, 1975. Una versión digital se puede encontrar en http://echr.coe.int/Documents/Library_TravPrep_Table_ENG.pdf(fecha de última consulta el 6 de enero de 2016). 
Este libro forma parte del acervo de la Biblioteca Jurídica Virtual del Instituto de Investigaciones Jurídicas de la UNAM

Es posible que el carácter precursor de la propuesta interamericana de estudiar la creación de una corte le haya jugado en contra, pues tal recomendación no fue seguida por el Comité Jurídico Interamericano. Más aún, el Comité habría afirmado que sería prematuro aceptar esta invitación efectuada por la Conferencia, pues implicaría la transformación de los sistemas jurídicos de los Estados de América, y aconsejó que primero se preparara un acuerdo vinculante en materia de derechos humanos. ${ }^{352}$

La demora en la puesta en práctica de esta recomendación no crea una solución de continuidad radical entre ella y el origen de la Corte IDH. No obstante ello, este origen remoto se discutió mucho antes de la convención que creó la Corte IDH. Por ello, si se quiere acceder a las discusiones de fondo sobre la creación de la Corte IDH, debe acudirse a los trabajos preparatorios de la $\mathrm{CADH},{ }^{353}$ no a los del origen remoto que acabamos de tratar. Tales trabajos pueden complementarse con otros instrumentos, como las discusiones de los proyectos de convención presentados por algunos Estados. ${ }^{354}$ Los anexos de este trabajo no contienen ningún antecedente de la CADH.

352 Nikken, P., "La Declaración Universal y la Declaración Americana. la formación del moderno derecho internacional de los derechos humanos", cit., p. 82, y Goldman, R. K., "History and Action: The Inter-American Human Rights System and the Role of the InterAmerican Commission on Human Rights", cit., p. 860.

353 Véanse: Secretaría General de la Organización de los Estados Americanos, Conferencia Especializada Interamericana sobre Derechos Humanos: Actas y Documentos, OEA/Ser.K/XVI/1.2, San Fosé, Costa Rica, 7-22 de Noviembre de 1969, disponible en: http://wrere.corteidh.or.cr/tablas/15388.pdf (fecha de última consulta el 6 de enero de 2017), y General Secretariat of the Organization of American States, Anuario Interamericano de Derechos Humanos 1968 / InterAmerican Yearbook on Human Rights 1968, Secretariat of the Inter-American Commission on Human Rights, Washington, D. C., 1973.

354 Por ejemplo, Universidad de la República (Uruguay), Facultad de Derecho, Simposio sobre el Proyecto de Convención de Derechos Humanos de Santiago de Chile, Montevideo, Facultad de Derecho, 1959. 


\section{GONCLUSIONES}

Las circunstancias históricas en las que se elaboró la DADDH fueron bastante convulsionadas, no solo a nivel mundial, sino que también en el ámbito interamericano y, particularmente, a nivel colombiano; esto último, en atención a los violentos hechos que se registraron producto del llamado El Bogotazo. Estas circunstancias no impidieron que los Estados americanos aprobaran la DADDH, la que explicitó el contenido de los derechos fundamentales. La DADDH constituyó un paso fundamental para el desarrollo del sistema interamericano de derechos humanos, el que ha sido un importante mecanismo para reparar las violaciones de derechos humanos de multitudes de personas.

En este libro pusimos de relieve la importancia de los trabajos preparatorios de la DADDH. Su relevancia estriba en el valor que tiene la que ha sido llamada la "Carta Magna del sistema interamericano". Si bien la DADDH no es un tratado, y la extensión y fundamento de su valor jurídico es algo controvertido, no puede negarse el valor moral y político de este documento. Tampoco se puede negar su importancia para el actuar de los órganos encargados de la protección regional de los derechos humanos en América. Ello es especialmente cierto para la Comisión IDH, que aplica este instrumento en sus procedimientos de peticiones individuales en contra de los Estados que no han ratificado la $\mathrm{CADH}$, los que agrupan a un tercio de la población del continente americano. En este libro hicimos un breve análisis de las discusiones sobre el valor jurídico de la DADDH, y pusimos énfasis en interpretar el artículo 29 de la CADH, pues éste hace una referencia expresa a la DADDH, y ha sido incorrectamente interpretado por cierta doctrina y jurisprudencia sobre la materia.

El hecho de que la aprobación de la DADDH, con sus nobles intenciones, no haya logrado impedir la violación masiva de derechos humanos que se siguieron produciendo en el Continente en las décadas posteriores a su aprobación, no anula la importancia de la DADDH. En efecto, sería una muestra de inocencia pensar que un instrumento internacional por sí mismo puede acabar con problemas que existen desde que el hombre es hombre. Lo importante es notar los avances que permitió la Declaración. Entre ellos, logró sentar un contenido consensuado de los derechos humanos, sobre los 
Este libro forma parte del acervo de la Biblioteca Jurídica Virtual del Instituto de Investigaciones Jurídicas de la UNAM

cuales podría actuar la Comisión IDH. Además, allanó el camino para la ratificación de la CADH. Más aún, es notable pensar que, junto con este primer paso para el desarrollo de nuestro sistema regional de protección de los derechos humanos, el estudio de la DADDH haya servido también para la elaboración de la Declaración Universal de los Derechos Humanos.

En este libro nos referimos también al instrumento que constituye el origen remoto de la Corte IDH. Ello, en razón de la estrecha relación que tiene con los con los trabajos preparatorios de la DADDH, tanto por haberse aprobado ambos durante la Novena Conferencia, como por su objetivo común de protección de los derechos humanos en el continente. Este germen del tribunal de las Américas no fue más que una declaración de buenas intenciones, pero no le resta mérito, pues la idea de crear una corte de derechos humanos fue bastante innovadora para un mundo en el que aún no operaba ningún tribunal regional de protección de garantías fundamentales. Ni siquiera el Consejo de Europa había comenzado a discutir sobre el Tribunal Europeo de Derechos Humanos.

Hoy en día, en que estamos ad portas del aniversario número setenta de la aprobación de la DADDH, es importante recordar los orígenes de este instrumento. Ello no solo tiene relevancia desde un punto de vista histórico, sino que también desde uno jurídico; en efecto, los trabajos preparatorios sirven para determinar el real alcance que los redactores de la DADDH quisieron darle a este instrumento, cuestión de gran relevancia al interpretar una norma. Por ello, la importancia de los travaux préparatoires es actual; por una parte, ellos han sido usados tanto por la Comisión como la Corte interamericanas, esta última en una fecha bastante reciente. Por otra parte, algunos asuntos tratados en estos trabajos están de algún modo relacionados con problemáticas actuales y en desarrollo, como el control de convencionalidad o el tema de las empresas y los derechos humanos. Es por ello que este libro contribuirá a un debate que permita perfeccionar nuestro modo de entender los derechos humanos y a fortalecer la institucionalidad americana en esta materia. 
Este libro forma parte del acervo de la Biblioteca Jurídica Virtual del Instituto de Investigaciones Jurídicas de la UNAM

\section{BIBLIOGRAFÍA}

AlaPe, Arturo, El Bogotazo: memorias del olvido, 2a. ed., La Habana, Casa de las Américas, 1984.

ARias TrujILLO, Ricardo, Historia de Colombia contemporánea (1920-2010), Bogotá, Universidad de los Andes, Ediciones Uniandes, 2011.

Aust, Anthony, Modern Treaty Law and Practice, 3a. ed., Cambridge, Cambridge University Press, 2014.

BAMBIRRA, Vania y Dos SANTOS, Theotonio, "Brasil: nacionalismo, populismo y dictadura. 50 años de crisis social", en GonzÁlez CASANOva, Pablo (ed.), América Latina: Historia de Medio Siglo, 8a. ed., Siglo XXI Editores, México, 1979, vol. I (América del Sur).

Barahona Portocarrero, Amaru, "Breve estudio sobre la historia contemporánea de Nicaragua", en GonZÁlez CaSanova, Pablo (ed.), América Latina: Historia de Medio Siglo, 7a. ed., Siglo XXI Editores, México, 1979, vol. II (México, Centroamérica y el Caribe).

BATES, Ed, "The Birth of the European Convention on Human Rights and the European Court of Human Rights", en Christoffersen, Jonas y Rask MADSEn, Mikael (eds.), The European Court of Human Rights between Law and Politics, Oxford, Oxford University Press, 2011.

BRAUn, Herbert, The Assassination of Gaitán. Public Life and Urban Violence in Colombia, Wisconsin, The University of Wisconsin Press, 1985.

Buergenthal, Thomas, "La relación conceptual y normativa entre la Declaración Americana y la Convención Americana sobre Derechos Humanos", Revista Instituto Interamericano de Derechos Humanos, número especial en conmemoración del cuadragésimo aniversario de la Declaración Americana de Derechos y Deberes del Hombre, 1989.

, "The Revised OAS Charter and the Protection of Human Rights", The American Fournal of International Law, vol. 69, 1975.

y Shelton, D., Protecting Human Rights in the Americas. Cases and Materials, 4a. ed., N.P. Engel, Kehl-Strasbourg-Arlington, 1995.

et al., International Human Rights in a Nutshell, 4a. ed., Saint Paul, Minnesota, West Publishing Co., 2009. 
Este libro forma parte del acervo de la Biblioteca Jurídica Virtual del Instituto de Investigaciones Jurídicas de la UNAM

BURgOrgue-Larsen, Laurence y ÚbedA DE TORRES, Amaya, The InterAmerican Court of Human Rights. Case Law and Commentary, trad. de Rosalind Greenstein, Oxford, Oxford University Press, 2011.

Carozza, Paolo G., "From Conquest to Constitutions: Retrieving a Latin American Tradition of the Idea of Human Rights", Human Rights Quarterly, vol. 25, 2003.

, "Human Dignity", en Dinah Shelton (ed.) The Oxford Handbook of International Human Rights Law, Oxford University Press, Oxford, 2013.

Castilla Juárez, Karlos A., “¿Control interno o difuso de convencionalidad? una mejor idea: la garantía de tratados", Anuario Mexicano de Derecho International, vol. XIII, 2013.

Central InTelLigence Agency, The World Factbook, disponible en https:// wrere.cia.gov/library/publications/the-world-factbook/.

Cerna, Christina M., "Reflections on the Normative Status of the American Declaration of the Rights and Duties of Man", University of Pennsylvania Fournal of International Law, vol. 30, núm. 4, 2009.

Comisión Interamericana de Derechos Humanos, Diez años de actividades 1971-1981, Washington D.G., Secretaría General, Organización de Estados Americanos, 1982.

Corte Interamericana de Dereghos Humanos, Documentos básicos en materia de derechos humanos en el Sistema Interamericano: actualizado a febrero de 2012, San José, Corte Interamericana de Derechos Humanos, 2012.

Cotler, Julio, "Perú: Estado Oligárquico y Reformismo Militar", en GONZÁlez Casanova, Pablo (ed.) América latina: historia de medio siglo, 8a. ed., México, Siglo XXI Editores, 1979, vol. I (América del Sur).

Council of Europe / CONSEIL DE L'EuROPE, Collected Edition of the "Travaux Préparatoires» of the European Convention on Human Rights / Recueil des Travaux Préparatoires de la Convention Européenne des Droits de l'Homme, Martinus Nijhoff, The Hague-Boston-London, 1975.

Crawley, Eduardo, Dictators Never Die: A Portrait of Nicaragua and the Somoza Dynasty, Nueva York, St. Martin's Press, 1979.

Cuello, José Israel, et al., "50 años de historia dominicana”, en GONZÁLez Casanova, Pablo (ed.), América latina: historia de medio siglo, 7a. ed., México, Siglo XXI Editores, 1979, vol. II (México, Centroamérica y el Caribe).

Cueva, Agustín, "Ecuador: 1925-1975", en GonzÁlez Casanova, Pablo (ed.), América latina: historia de medio siglo, 8a. ed., México, Siglo XXI Editores, 1979, vol. I (América del Sur). 
Este libro forma parte del acervo de la Biblioteca Jurídica Virtual del Instituto de Investigaciones Jurídicas de la UNAM

De la RezA, Germán A. (ed.), Documentos sobre el Congreso Anfictiónico de Panamá, Caracas, Fundación Biblioteca Ayacucho-Banco Central de Venezuela, 2010.

DÍAZ DE ARCE, Omar, "El Paraguay contemporáneo (1925-1975)", en GONZÁlez Casanova, Pablo (ed.), América latina: historia de medio siglo, 8a. ed., México, Siglo XXI Editores, 1979, vol. I (América del Sur).

DOMINGO, Rafael y RODRÍGUEZ-ANTOLín, Beatriz, Reglas jurídicas y aforismos (con jurisprudencia actualizada y remisiones a la legislación vigente), Pamplona, Aranzadi, 2000.

DuliTZKY, Ariel E., "An Inter-American Constitutional Court? The Invention of the Conventionality Control by the Inter-American Court of Human Rights", Texas International Law Fournal, vol. 50, 2015.

Elgueta B., Belarmino y Chelén R., Alejandro, "Breve historia de medio siglo en Chile", en GonzÁlez Casanova, Pablo (ed.), América latina: historia de medio siglo, 8a. ed., México, Siglo XXI Editores, 1979, vol. I (América del Sur).

FaÚNDEZ LeDesma, Héctor, El Sistema Interamericano de Protección de los Derechos Humanos: aspectos institucionales y procesales, 3a. ed. revisada y puesta al día, San José, Instituto Interamericano de Derechos Humanos, 2004.

Fenwick, Charles G., "The Ninth International Conference of American States", The American Fournal of International Law, vol. 42, núm. 3, 1948.

FrASER, Auro, "From Forgotten Through Friction to the Future: The Evolving Relationship of the Anglophone Caribbean and the Inter-American System of Human Rights", Caribbean Law Review, vol. 15, núm. 2, 2005.

Fuentes Torrijo, Ximena, "International and Domestic Law: Definitely an Odd Couple", Revista Jurídica de la Universidad de Puerto Rico, vol. 77, 2008.

García, Antonio, "Colombia: medio siglo de historia contemporánea", en González Casanova, Pablo (ed.), América latina: historia de medio siglo, 8a. ed., México, Siglo XXI Editores, 1979, vol. I (América del Sur).

GARCía BAUER, Carlos, Los derechos humanos preocupación universal, Guatemala, Editorial Universitaria, 1960.

GARDINER, Richard, Treaty Interpretation, Oxford, Oxford University Press, 2008.

Garner, Bryan A. (ed.), Black's Law Dictionary, 10a. ed., Minnesota, Thomson Reuters, 2014.

General Secretariat of the Organization of American States, Anuario Interamericano de Derechos Humanos 1968 / Inter-American Yearbook on Human Rights 1968, Washington, D.C., Secretariat of the Inter-American Commission on Human Rights, 1973. 
Este libro forma parte del acervo de la Biblioteca Jurídica Virtual del Instituto de Investigaciones Jurídicas de la UNAM

Glendon, Mary Ann, A World Made New: Eleanor Roosevelt and the Universal Declaration of Human Rights, Nueva York, Random House, 2002.

versal Human Rights Idea”, Harvard Human Rights fournal, vol. 16, 2003.

Goldman, Robert K., "History and Action: The Inter-American Human Rights System and the Role of the Inter-American Commission on Human Rights", Human Rights Quarterly, vol. 31, 2009.

Gros EsPIELL, Héctor, "La Declaración Americana: raíces conceptuales y políticas en la historia, la filosofía y el derecho americano", Revista Instituto Interamericano de Derechos Humanos, número especial en conmemoración del cuadragésimo aniversario de la Declaración Americana de Derechos y Deberes del Hombre, 1989.

JARAMILlO SALGADO, Diego, "Legado socialista de Gaitán”, en AYALA DiAGO, César Augusto et al. (eds.), Mataron a Gaitán: 60 años, Bogotá, Universidad Nacional de Colombia, 2009.

Kunz, Josef L., "The Inter-American Conference on Problems of War and Peace at Mexico City and the Problem of the Reorganization of the InterAmerican System", The American Journal of International Law, vol. 39, núm. 3, 1945.

LE Riverend, Julio, "Cuba: del semicolonialismo al socialismo (19331975)", en Pablo González Casanova (ed.), América Latina: Historia de Medio Siglo, 7a. ed., México, Siglo XXI Editores, 1979, vol. II (México, Centroamérica y el Caribe).

MALARINO, Ezequiel, "Acerca de la pretendida obligatoriedad de la jurisprudencia de los órganos interamericanos de protección de derechos humanos para los tribunales judiciales nacionales", en SteIner, Christian (ed.), Sistema interamericano de protección de los derechos humanos y derecho penal internacional, Montevideo, vol. II, Konrad-Adenauer-Stiftung e. V., 2011.

Maritain, Jaques, El hombre y el Estado, Madrid, Fundación Humanismo y Democracia - Ediciones Encuentro, 1983.

Medina Quiroga, Cecilia y NAsh Rojas, Claudio, Sistema Interamericano de Derechos Humanos: introducción a sus mecanismos de protección, Santiago, Universidad de Chile, Facultad de Derecho, Centro de Derechos Humanos, 2011.

Molina Chocano, Guillermo, "Honduras: de la guerra civil al reformismo militar", en González Casanova, Pablo (ed.), América Latina: Historia de Medio Siglo, 7a. ed., México, Siglo XXI Editores, 1979, vol. II (México, Centroamérica y el Caribe). 
Este libro forma parte del acervo de la Biblioteca Jurídica Virtual del Instituto de Investigaciones Jurídicas de la UNAM

Monroy Cabra, Marco G., "Aplicación de la Declaración Americana de Derechos y Deberes del Hombre por la Comisión Interamericana de Derechos Humanos", Revista Instituto Interamericano de Derechos Humanos, número especial en conmemoración del cuadragésimo aniversario de la Declaración Americana de Derechos y Deberes del Hombre, 1989.

Moyn, Samuel, Christian Human Rights, Philadelphia, University of Pennsylvania Press, 2015.

NikKen, Pedro, "La Declaración Universal y la Declaración Americana. La formación del moderno derecho internacional de los derechos humanos", Revista Instituto Interamericano de Derechos Humanos, número especial en conmemoración del cuadragésimo aniversario de la Declaración Americana de Derechos y Deberes del Hombre, 1989.

PAÚl DíAZ, Álvaro, "Estatus del no nacido en la Convención Americana: un ejercicio de interpretación", Ius et Praxis, vol. 18, núm. 1, 2012.

_- "Giro en materia de recurso de revisión ante la Corte Interamericana", Revista Chilena de Derecho y Ciencia Política, vol. 4, núm. 2, 2013.

, "La Corte Interamericana in vitro: comentarios sobre su proceso de toma de decisiones a propósito del caso Artavia", Derecho Público Iberoamericano, vol. 2, 2013.

PIERRE-CHARLES, Gerard, "Haití (1930-1975): La crisis ininterrumpida", en González Casanova, Pablo (ed.), América Latina: Historia de Medio Siglo, 7a. ed., México, Siglo XXI Editores, 1979, vol. II (México, Centroamérica y el Caribe).

Romero, José L., Breve historia de la Argentina, Fondo de Cultura Económica, 2001.

RugGie, John G., Fust Business: Multinational Corporations and Human Rights, Nueva York, W. W. Norton \& Company, 2013.

Ruiz-Chiriboga, Oswaldo R., "The Conventionality Control: Examples of (Un)Successful Experiences in Latin America", Inter-American and European Human Rights fournal/Revista Interamericana y Europea de Derechos Humanos, vol. 3, núms. 1-2, 2010.

SAlviOLI, Fabián O., "El aporte de la Declaración Americana de 1948, para la protección internacional de los derechos humanos", El Sistema Interamericano de Protección de los Derechos Humanos en el Umbral del Siglo XXI, San José de Costa Rica, vol. I, Corte Interamericana de Derechos Humanos, 2003.

SEGRETARÍA General DE LA ORGANIZACión DE LOS ESTAdos AMERICANOS, Conferencia especializada interamericana sobre derechos humanos: actas y documentos, OEA/Ser.K/XVI/1.2, San Fosé, Costa Rica, 7-22 de Noviembre de 1969, Secretariat of the Inter-American Commission on Human Rights, Washington, D.C., 1973, http://wrere.corteidh.or.cr/tablas/15388.pdf. 
Este libro forma parte del acervo de la Biblioteca Jurídica Virtual del Instituto de Investigaciones Jurídicas de la UNAM

Shelton, Dinah, "Abortion and the Right to Life in the Inter-American System: The Case of «Baby Boy»", Human Rights Law fournal, vol. 2, núms. 3 y $4,1981$.

_- "International Law and Relative Normativity", en Evans, Malcolm D. (ed.). International Law, 2a. ed., Oxford, Oxford University Press, 2006.

SOLER, Ricaurte, "Panamá: nación y oligarquía (1925-1975)", en GONZÁLez Casanova, Pablo (ed.), América Latina: Historia de Medio Siglo, 7a. ed., México, Siglo XXI Editores, 1979, vol. II (México, Centroamérica y el Caribe).

Universidad De la República (URUGUaY), Simposio sobre el proyecto de Convención de Derechos Humanos de Santiago de Chile, Montevideo, Facultad de Derecho, 1959.

VEGA, Bernardo, "La Era de Trujillo, 1930-1961", en Frank Moya Pons (ed.) Historia de las Antillas, vol. II. Historia de la República Dominicana, Ediciones Doce Calles, s.l., 2010.

Vega Carballo, José Luis, "Costa Rica: coyunturas, clases sociales y estado en su desarrollo reciente", en GonzÁlez Casanova, Pablo (ed.), América Latina: Historia de Medio Siglo, 7a. ed., México, Siglo XXI Editores, 1979, vol. II (México, Centroamérica y el Caribe).

Vervaele, John, "Criminal Law and the Protection of Human Rights in Colombia", Netherlands Quarterly of Human Rights, vol. 6, 1988.

WOERNER,JR., Frederick Frank, "A History of the Ninth Inter-American Conference. Bogotá, Colombia", 1965, The University of Arizona, Arizona.

Zavaleta Mercado, René, "Consideraciones Generales sobre la Historia de Bolivia (1932-1971)", en González Casanova, Pablo (ed.), América latina: historia de medio siglo, 8a. ed., México, Siglo XXI Editores, 1979, vol. I (América del Sur).

\section{JURISPRUDENCIA}

Argüelles y otros vs. Argentina (2014): Corte Interamericana de DD.HH., Excepciones preliminares, fondo, reparaciones y costas, serie C, núm. 288.

Artavia Murillo y otros (fecundación in vitro) vs. Costa Rica (2012): Corte Interamericana de DD.HH., Excepciones preliminares, fondo, reparaciones y costas, serie $\mathrm{C}$, núm. 257.

Asunto Faworzina (Frontera Polaco-Checoslovaca) (1923): Corte Permanente de Justicia Internacional, Opinión Consultiva núm. 8. 
Este libro forma parte del acervo de la Biblioteca Jurídica Virtual del Instituto de Investigaciones Jurídicas de la UNAM

Bámaca Velásquez vs. Guatemala (2000): Corte Interamericana de DD.HH., Fondo, serie C, núm. 70 .

Bueno Alves vs. Argentina (2007): Corte Interamericana de DD.HH., Fondo, reparaciones y costas, serie $\mathrm{C}$, núm. 164.

Cantos vs. Argentina (2002): Corte Interamericana de DD.HH., Fondo, reparaciones y costas, serie C, núm. 97.

Caso 2141 - Estados Unidos (1981): Comisión Interamericana de DD.HH., resolución, núm. 23/81.

Caso 9647 - Estados Unidos (1987): Comisión Interamericana de DD.HH., Informe, núm. 3/87.

Caso 9903 - Rafael Ferrer-Mazorra y Otros - Estados Unidos (2001): Comisión Interamericana de DD.HH., Informe, núm. 51/01.

Caso 10.573 - Estados Unidos (1993): Comisión Interamericana de DD.HH., informe, núm. 31/93.

Caso 12.626 - Jessica Lenahan (Gonzales) y otros - Estados Unidos (2011): Comisión Interamericana de DD.HH., informe, núm. 80/11.

Comunidad Moiwana vs. Surinam (2005): Corte Interamericana de DD.HH., excepciones preliminares, fondo, reparaciones y costas, serie $\mathrm{C}$, núm. 124.

Derechos y Garantías de Niñas y Niños en el Contexto de la Migración y/o Necesidad de Protección Internacional (2014): Corte Interamericana de DD.HH., opinión consultiva OG-21/14, Serie A, núm. 21.

Duque vs. Colombia (2016): Corte Interamericana de DD.HH., excepciones preliminares, fondo, reparaciones y costas, serie $\mathrm{C}$, núm. 310.

Exigibilidad del Derecho de Rectificación o Respuesta (artículos 14.1, 1.1 y 2 Convención Americana sobre Derechos Humanos), 1986: Corte Interamericana de DD.HH., opinión consultiva OG-7/86, serie A, núm. 7.

Gallardo y otras (Asunto de Viviana), 1981: Corte Interamericana de DD.HH., decisión, Serie A, núm. G 101/81 (13 de noviembre).

Gelman vs. Uruguay (2013): Corte Interamericana de DD.HH., resolución de supervisión de cumplimiento de sentencia, 20 de marzo.

Interpretación de la Declaración Americana de los Derechos y Deberes del Hombre en el Marco del artículo 64 de la Convención Americana sobre Derechos Humanos (1989): Corte Interamericana de DD.HH., opinión consultiva OC-10/89, serie A, núm. 10.

Pueblos Kalina y Lokono vs. Surinam (2015): Corte Interamericana de DD.HH., Fondo, reparaciones y costas, serie C, núm. 309. 
Este libro forma parte del acervo de la Biblioteca Jurídica Virtual del Instituto de Investigaciones Jurídicas de la UNAM

M. L., J.. F. F., O. - Denuncia - Excepción de Inconstitucionalidad Arts. 1, 2 y 3 de la Ley núm. 18.831 (2013): Sentencia de la Suprema Corte de Justicia (Uruguay), IUE 2-109971/2011. Disponible en: http://medios.elpais.com.uy/ downloads/2013/sentenciascj.pdf.

Ruano Torres y otros vs. El Salvador (2015): Corte Interamericana de DD.HH., Fondo, reparaciones y costas, serie C, núm.303.

Suárez Rosero vs. Ecuador (1997): Corte Interamericana de DD.HH., Fondo, serie $\mathrm{C}$, núm.25.

Tabacalera Boquerón, S.A. - Paraguay (1997): Comisión Interamericana de DD.HH., informe de inadmisibilidad, núm. 47/97.

Titularidad de Derechos de las Personas Jurídicas en el Sistema Interamericano de Derechos Humanos (Interpretación y Alcance del Artículo 1.2, con relación a los artículos 1.1, 8, 11.2, 13, 16, 21, 24, 25, 29, 30, 44, 46 y 62.3 de la Convención Americana sobre Derechos Humanos, Así como del Artículo 8.1.a y b del Protocolo de San Salvador) (2016): Corte Interamericana de DD.HH., Opinión Consultiva OC-22/16, serie A, núm. 22.

Wong Ho Wing vs. Perú (2015): Corte Interamericana de DD.HH., Excepción Preliminar, Fondo, Reparaciones y Costas, Serie C, núm. 297.

\section{TRATADOS Y OTROS INSTUMENTOS}

Anteproyecto de Declaración de los Derechos y Deberes Internacionales del Hombre e Informe Anexo. Formulados por el Comité Jurídico Interamericano, Unión de Repúblicas Americanas, Unión Panamericana, abril de 1946.

Canada Act (Reino Unido), 29 de marzo de 1982.

Carta de la Organización de los Estados Americanos, 30 de abril de 1948.

Carta de la Organización de los Estados Americanos, reformada por el "Protocolo de Buenos Aires", suscrito el 27 de febrero de 1967.

Carta de la Organización de los Estados Americanos, reformada por el "Protocolo de Buenos Aires", suscrito el 27 de febrero de 1967, por el "Protocolo de Cartagena de Indias", aprobado el 5 de diciembre de 1985, por el "Protocolo de Washington", aprobado el 14 de diciembre de 1992, y por el "Protocolo de Managua", adoptado el 10 de junio de 1993.

Carta de los Derechos Fundamentales de la Unión Europea, 7 de diciembre de 2000, 4 de Noviembre de 1950.

Conferencias Internacionales Americanas 1889-1936. Recopilación de Tratados y Otros Documentos, Secretaría de Relaciones Exteriores, 2a. reimpresión, 1990, México. 
Este libro forma parte del acervo de la Biblioteca Jurídica Virtual del Instituto de Investigaciones Jurídicas de la UNAM

Conferencias Internacionales Americanas. Primer Suplemento 1938-1942. Recopilación de Tratados y Otros Documentos, México, Secretaría de Relaciones Exteriores, 2a. reimpresión, 1990.

Conferencias Internacionales Americanas. Segundo Suplemento 1945-1954. Recopilación de Tratados y Otros Documentos, Departamento Jurídico, Unión Panamericana, 1956, Washington D.C.

Convención Americana sobre Derechos Humanos, "Pacto de San José", 22 de noviembre de 1969.

Convención de Viena sobre el Derecho de los Tratados, 23 de mayo de 1969. Convención sobre el Estatuto de los Apátridas, 28 de septiembre de 1954.

Convención sobre el Estatuto de los Refugiados, 28 de julio de 1951.

Convención sobre la Eliminación de Todas las Formas de Discriminación contra la Mujer, 18 de diciembre de 1979.

Convención sobre los Derechos del Niño, 20 de noviembre de 1989.

Convenio Europeo para la Protección de los Derechos Humanos y de las Libertades Fundamentales, 4 de Noviembre de 1950.

Declaración Americana de los Derechos y Deberes del Hombre, Aprobada en la Novena Conferencia Internacional Americana, Bogotá, Colombia, 1948.

Declaración de Derechos Humanos de la Asociación de Naciones del Sudeste Asiático, Adoptada por los Miembros de ASEAN, Phnom Penh, Camboya, 18 de noviembre de 2012.

Declaración Universal de Derechos Humanos, Adoptada y proclamada por la Asamblea General en su Resolución 217 A, 10 de diciembre de 1948.

Estatuto de la Comisión Interamericana de Derechos Humanos, aprobado mediante Resolución núm. 447 adoptada por la Asamblea General de la Organización de Estados Americanos en su noveno período ordinario de sesiones, celebrado en La Paz, Bolivia, en octubre de 1979.

Novena Conferencia Internacional Americana, Actas y Documentos, Ministerio de Relaciones Exteriores de Colombia, 1953, Bogotá, vols. I, V y VI.

Pacto Internacional de Derechos Civiles y Políticos, 16 de diciembre de 1966.

Pacto Internacional de Derechos Económicos, Sociales y Culturales, 16 de diciembre de 1966.

Protocolo Adicional a la Convención Americana sobre Derechos Humanos en Materia de Derechos Económicos, Sociales y Culturales, "Protocolo de San Salvador", 17 de noviembre de 1988.

Protocolo de Reformas a la Carta de la Organización de los Estados Americanos, "Protocolo de Buenos Aires", 27 de febrero de 1967. 


\section{ANEXOS}

\section{NOTAS FORMALES SOBRE ESTE ANEXO}

Según hacemos presente en la introducción, extrajimos los trabajos preparatorios de la DADDH a partir de tres libros. El primero es el llamado Segundo Suplemento de la obra "Conferencias Internacionales Americanas", que recopila tratados, convenciones, declaraciones, recomendaciones y mociones. De estos antecedentes, utilizamos algunos adoptados por la Conferencia Interamericana sobre Problemas de la Guerra y de la Paz y por la Novena Conferencia Internacional Americana. El segundo libro es el Anteproyecto de Declaración de los Derechos y Deberes Internacionales del Hombre e Informe Anexo. El tercero es uno que reúne exclusivamente las actas y documentos de la Novena Conferencia Internacional Americana.

$\mathrm{El}$ anexo de nuestro libro busca reproducir lo más fielmente posible a los documentos originales. Sin perjuicio de ello, ha sido necesario realizar una extensa labor de edición, incluyendo la adición de títulos que orienten al lector en la revisión de secciones que pueden ser bastante extensas y áridas. Hemos sujetado el trabajo de edición de este anexo a las reglas que se pasan a exponer.

Los documentos de este anexo siguen el orden de los tres libros que nos sirven de fuente. Primero, pusimos aquel que contiene los antecedentes de la Conferencia sobre Problemas de la Guerra y la Paz, por ser la más antigua. Como este libro es una recopilación de varias conferencias, incluida la Novena, sucede que inmediatamente antes de la sección donde se recoge el libro que contiene el APDADDH, se verán algunas páginas referidas a la Novena Conferencia Internacional Americana, no obstante que tal conferencia es cronológicamente posterior al APDADDH, y de que ella se encuentra recopilada principalmente en el tercer libro que se republica en esta obra. Asimismo, el tercer libro que se recopila no ordena sus documentos siguiendo un modo cronológico, sino que según su naturaleza. Así, la primera parte contiene las sesiones plenarias, la segunda contiene sesiones de 
la Comisión Sexta, y la tercera unos trabajos de la Subcomisión A. Si se quisiera ver el orden cronológico de estos documentos, puede recurrirse al listado que se hace en la sección principal de este libro, en el punto llamado "La Novena Conferencia Interamericana y su Organización".

Originalmente pensamos en no transcribir algunas discusiones más procedimentales, tales como la designación de presidente de la Comisión Sexta, pero optamos finalmente por incluir la gran mayoría de tales discusiones, porque en ocasiones pueden contener algunas ideas sutiles que podrían ser de interés.

Para representar lo más fielmente los libros a partir de los cuales se extrajeron los documentos y actas que aquí se republican, dejamos claramente establecidos los números de páginas de los documentos originales. Ellos se encuentran encerrados en paréntesis cuadrados (corchetes), los que se insertan antes del comienzo del contenido de la página correspondiente. En ocasiones el número estará al costado izquierdo, al comienzo de una página, como sucede cuando ésta comienza con un título, y en otras se encontrará al inicio o en la mitad de algún párrafo. A veces pareciera que algunas páginas son muy cortas, como sucede cuando se transcribe un documento que comenzaba al final de una página, y se omite el resto de lo que se encontraba en dicha página. Esto sucede frecuentemente cuando se copian documentos emanados de la Conferencia de Guerra y Paz.

Se advierte que quienes quieran buscar o citar el contenido de este documento, deben recurrir siempre al número entre corchetes que se encuentra antes del pasaje que les interese, no al que aparece después. Ello, porque este anexo puede haber considerado innecesario incluir la página que antecede a un número entre corchetes, por lo que éste podría no estar precedido por lo que se encuentra en la página anterior en el original. Por ello, reiteramos que si el lector quiere estar seguro sobre cuál es el número de página en el que se encuentra un texto en el original, debe revisar el número que antecede el texto relevante. Algunas páginas, como las que contienen solamente un título, no están enumeradas en el original, por lo que este trabajo tampoco les puso número de página entre paréntesis cuadrados.

En relación con las notillas, se mantuvo la numeración de las notas al pie de los documentos transcritos. En los originales, esta numeración se interrumpe al final de cada página, y vuelve a comenzar con el número uno en la siguiente. Por ello, para saber en qué página de la fuente original se encuentra una nota, debe entenderse que ellas están en la misma página donde se encuentra el número de la notilla en el texto principal. Si las notas están en dos páginas en los originales, lo hemos aclarado intercalando el número de página entre paréntesis cuadrados, dentro de la misma notilla. 
En nuestro empeño por ser fieles a los documentos transcritos, mantuvimos su redacción y ortografía, incluyendo sus errores, pero advirtiendo de este hecho con el adverbio "sic" en una nota al pie. No obstante ello, no se hizo esta advertencia respecto de las palabras que solían escribirse de un modo diferente al momento de la redacción de los originales. Esto suele suceder con monosílabos como "fé", "dió", "nó". También ocurre con la acentuación de diptongos o hiatos, como sucede con "atribuída", "constituído", "prohibe" o "recluídos". Lo mismo con pronombres que aparecen acentuados, tales como "ése" o "aquéllas". Algo similar hicimos con algunas palabras que se escribían con letras diversas, como sucede con el uso de la "j" en palabras como "protejer". También mantuvimos sin advertencia otras costumbres de la época, como el omitir acentuar las letras mayúsculas, o escribir los meses del año con mayúscula. Existen otros casos que podrán notarse al leer estos documentos.

La fidelidad a los originales se conjugó con cuestiones estilísticas y prácticas. Así, por ejemplo, no se mantuvieron elementos que no serían reflejados en una cita que el lector haga de los trabajos preparatorios. Por ello, no fuimos fieles a la cantidad de renglones en cada página ni a las palabras con las que comienza y termina cada renglón, ni a si un título estaba o no centrado. Asimismo, no se mantuvo la división de palabras con un guion al final de un renglón (cuestión que hoy en día suele evitarse en los documentos "justificados"), a menos que el guion se encontrara al final de una página, en cuyo caso la palabra quedó dividida por el guion y el paréntesis cuadrado con el número de la página original.

Tampoco mantuvimos deficiencias formales que no serían incluidas al citar el texto, como los dobles espacios. En este punto, es necesario decir unas palabras sobre la transcripción de Anteproyecto del Comité Jurídico. La fuente que usamos es una reproducción de un texto escrito con máquina de escribir (método bastante común para la publicación de copias de documentos oficiales en la época). En este tipo de documentos era relativamente frecuente encontrar errores formales, como palabras que aparecen juntas o que pueden verse muy separadas en el original. También pueden observarse, en ocasiones, errores tipográficos arreglados en el original, o que incorporaban palabras faltantes en la parte superior de un renglón o en los espacios en que ello fuera posible, pero que no daban lugar a dudas sobre su autenticidad. En la transcripción de este documento nos dimos la libertad de no hacer mención a estas cuestiones formales.

Debido a criterios editoriales, este trabajo cuenta con unas modificaciones menores que podrían notarse al realizar una cita textual; por ejemplo, se borraron las negritas y se intercambian algunas versalitas, mayúsculas y minúsculas. 
Este libro forma parte del acervo de la Biblioteca Jurídica Virtual del Instituto de Investigaciones Jurídicas de la UNAM

Evitamos agregar notas entre paréntesis cuadrados en la parte principal del texto, para que no se generen dudas sobre quién es el autor de tales comentarios. Nuestras notas se encuentran siempre firmadas con las iniciales A. P. D. Cuando afirmamos que algo se encontraba "en el original", nos referimos a los libros a partir de los cuales se recopilaron los documentos, no a las fuentes más primarias. Las únicas adiciones entre paréntesis cuadrados, sin dejar constancia de nuestra autoría, son los títulos que intercalamos para identificar algunas discusiones. 
Este libro forma parte del acervo de la Biblioteca Jurídica Virtual del Instituto de Investigaciones Jurídicas de la UNAM www.juridicas.unam.mx

http://biblio.juridicas.unam.mx/bjv

\title{
ANEXOS
}

\section{CONFERENCIAS INTERNACIONALES AMERICANAS}

\section{SEGUNDO SUPLEMENTO}

1945-1954

Recopilación de los Tratados, Convenciones, Declaraciones, Resoluciones, Recomendaciones y mociones, adoptados por la Conferencia Interamericana Sobre Problemas de la Guerra y de la Paz; la Conferencia Interamericana para el Mantenimiento de la Paz y la Seguridad del Continente; la Novena Conferencia Internacional Americana; la Cuarta Reunión de Consulta de los Ministros de Relaciones Exteriores y la Décima Conferencia Interamericana.

\section{DEPARTAMENTO JURÍDICO \\ UNIÓN PANAMERICANA}

\author{
WASHINGTON, D.C. \\ 1956
}




\title{
CONFERENCIA INTERAMERICANA SOBRE PROBLEMAS DE LA GUERRA Y DE LA PAZ
}

\author{
México, D.F., febrero 21-marzo 8, 1945
}

\section{NOTA PRELIMINAR}

Durante las sesiones de la Décima Conferencia Interamericana, celebrada en Caracas el año de 1954, el Gobierno de Venezuela distribuyó la reedición que, debidamente autorizado por la Dotación Carnegie para la Paz Internacional, había llevado a cabo, con la asistencia de la Unión Panamericana, de los dos volúmenes publicados por aquella importante Institución, titulados "Conferencias Internacionales Americanas", los cuales, dados su utilidad y considerable interés, se hallaban agotados.

En la misma oportunidad, con el deseo de continuar colaborando en lo que considera un valioso servicio a la comunidad americana, el Gobierno de Venezuela, dignamente presidido por el General Marcos Pérez Jiménez, ofreció proseguir en la tarea iniciada por la Dotación Carnegie para la Paz Internacional, llevando a cabo la edición de un tercer volumen, que es el que ahora se ofrece, en el mismo formato y con las mismas características tipográficas de los dos primeros.

La materia contenida en la presente publicación puede considerarse de singular importancia, por cuanto ella comprende un período durante el cual el sistema interamericano ha recibido un notable impulso en su desarrollo y se ha acercado a una etapa de madurez y perfeccionamiento. Ese período, que abarca los años de 1945 a 1954, ha sido particularmente fecundo en la concertación de trascendentales compromisos interamericanos, como son la Carta de la Organización de los Estados Americanos, el Tratado Interamericano de Asistencia Recíproca y las Actas Finales y otros documentos emanados de la Conferencia de Chapultepec, de la Conferencia de Petrópolis, de la Cuarta Reunión de Consulta de Washington y, sobre todo, de las Conferencias Interamericanas de Bogotá y Caracas.

En nombre del Gobierno de Venezuela, quiero agradecer sinceramente a la Unión Panamericana la valiosa colaboración que ha prestado para la preparación y edición de esta obra y, al propio tiempo, reiterar el firme deseo que lo anima de servir a la comunidad de países a la que el mío se honra en pertenecer y de cooperar por todos los medios en el perfeccionamiento del sistema que los vincula y en la realización de los grandes y legítimos ideales americanos. 
Este libro forma parte del acervo de la Biblioteca Jurídica Virtual del Instituto de Investigaciones Jurídicas de la UNAM

$[3]$

\author{
CONFERENCIA INTERAMERICANA \\ SOBRE PROBLEMAS DE LA GUERRA Y DE LA PAZ
}

Ciudad de México, Febrero 21-Marzo 8, 1945

La Conferencia Interamericana sobre Problemas de la Guerra y de la Paz se reunió en la Ciudad de México del 21 de febrero al 8 de marzo de 1945, a invitación del Gobierno de México. Esta Conferencia no correspondió a ninguna de las series de Conferencias Interamericanas, sino que fue más bien una reunión especial convocada por el Gobierno de México, con el objeto de proporcionar a los Gobiernos de las Repúblicas Americanas la oportunidad de considerar conjuntamente "la forma de intensificar su colaboración, así como la participación de América en la futura organización mundial y el impulso que debería darse tanto al sistema interamericano como a la solidaridad económica del continente".

Estuvieron representados todos los países, a excepción de la República Argentina. Mediante su Resolución LIX, la Conferencia invitó al Gobierno de la República Argentina a adherirse a los principios y declaraciones que fueron adoptados, y para estos efectos el Acta Final quedó abierta a la firma de ese país. El Gobierno de la República Argentina aceptó la invitación que le había sido formulada por las veinte Repúblicas Americanas y se adhirió al Acta Final de la Conferencia el día 4 de abril de 1945. 


\section{ACTA FINAL ${ }^{1 E}$}

\section{CONFERENCIA INTERAMERICANA SOBRE PROBLEMAS DE LA GUERRA Y DE LA PAZ}

En virtud de la invitación hecha el 10 de enero de 1945, por el Gobierno de los Estados Unidos Mexicanos, se reunieron en la ciudad de México, el 21 de febrero del mismo año, las Delegaciones de los países que en seguida se enumeran de acuerdo con el orden de precedencia que resultó del sorteo verificado - el mismo día 21 - conforme al inciso g) del artículo 5o. del Reglamento de la Conferencia:

(Aquí siguen los nombres de los Delegados)2E

A las 11 de la mañana del 21 de febrero se celebró, en el Castillo de Chapultepec, de la ciudad de México, la Sesión Preparatoria de acuerdo con el siguiente Orden del Día:

a. Elección del Presidente de la Conferencia;

b. Designación de la Comisión de Verificación de Poderes;

c. Aprobación del Reglamento;

d. Aprobación del Temario;

e. Designación de Comisiones;

f. Distribución de los diversos puntos del Temario entre las Comisiones;

g. Establecimiento, mediante sorteo, de la precedencia de las Delegaciones;

h. Informe de la Comisión de Credenciales;

i. Asuntos varios.

Elección del Presidente de la Conferencia. El Excelentísimo señor Licenciado Ezequiel Padilla, Secretario de Relaciones Exteriores de México, fue electo por aclamación Presidente de la Conferencia.

Designación de la Comisión de Verificación de Poderes. La Comisión de Verificación de Poderes quedó integrada por el Excelentísimo señor Licenciado Gustavo Julio Henríquez (Presidente), de la Delegación de la República Dominicana; por el Excelentísimo señor Marcos A. Kohly, de la Delegación de Cuba; y por el Excelentísimo señor Guillermo Sevilla Sacasa, de la Delegación de Nicaragua.

Esta Comisión sometió a la consideración de la reunión preparatoria el siguiente proyecto de Resolución que fue aprobado por unanimidad:

La Conferencia Interamericana sobre Problemas de la Guerra y de la Paz, basándose en el informe de su Comisión de Verificación de Poderes, estima que [13] han quedado debidamente acreditados 110 Delegados, 106 Asesores y Consejeros, 44 Secretarios y 49 Auxiliares Técnicos. ${ }^{1}$

IE En general, este anexo sólo recoge los antecedentes referidos a la DADDH y a la resolución sobre una creación de una Corte Interamericana. Sin embargo, estas primeras páginas contienen el Acta Final y la Resolución IX. Lo hacen por su importancia para entender esta Conferencia, los motivos para llamar a la Novena, y porque la Resolución IX hace ciertas referencias a la DADDH. Nota del editor A.P.D.

2E Paréntesis en el original. Nota del editor A.P.D.

1 Posteriormente se acreditaron nuevos Delegados y algunos de los funcionarios que lo habían sido con una categoría pasaron a otra distinta, por lo que el total entre Delegados, Asesores, Consejeros, Secretarios y Auxiliares Técnicos ascendió a 330. 
El Excmo. Sr. General de División, Manuel Avila Camacho, Presidente de los Estados Unidos Mexicanos, designó al Excmo. Sr. Manuel Tello, Subsecretario de Relaciones Exteriores, como Secretario General de la Conferencia y al Excmo. Sr. Rafael de la Colina, Enviado Extraordinario y Ministro Plenipotenciario, adscrito a la Embajada de México en Washington, D. C., como Secretario General Adjunto.

El día 21 de febrero, a las 18 horas, el Excmo. Sr. General de División Manuel Avila Camacho, Presidente de los Estados Unidos Mexicanos, declaró solemnemente inaugurada la Conferencia Interamericana sobre Problemas de la Guerra y de la Paz.

\title{
TEXTO DE LAS RESOLUCIONES3E
}

IX

\author{
REORGANIZAGION, CONSOLIDACION Y FORTALECIMENTO \\ DEL SISTEMA INTERAMERICANO
}

\section{La CONFEREncia InTERAMERICANa SOBRE PROBlemas DE LA GUERRA Y DE LA PAZ}

\section{CONSIDERANDO:}

Que el sistema interamericano y los principios, instrumentos, organismos y procedimientos que le dan substancia constituyen la manifestación viva de la determinación de las Repúblicas soberanas de América de actuar unidas para el logro de sus propósitos comunes en el mantenimiento de la paz, la seguridad y el fomento del bienestar de sus pueblos;

[21] Que el sistema interamericano se inspira y tradicionalmente se ha inspirado en un profundo sentimiento de cooperación universal;

Que el sistema interamericano, como expresión de los ideales, las necesidades y la voluntad comunes de la colectividad de Repúblicas americanas, debe mejorarse y fortalecerse aun más ahora para realizar el ajuste y la solución de los problemas interamericanos;

Que el sistema interamericano debe, además, mantener las más amplias relaciones con el organismo internacional general propuesto y asumir las responsabilidades pertinentes en armonía con los principios y propósitos de dicho organismo internacional general,

\section{RESUELVE:}

1o. Las Conferencias Internacionales Americanas se celebrarán ordinariamente cada cuatro años y serán el órgano interamericano que se encargue de formular la política general interamericana y de determinar la estructura y las funciones de los instrumentos y organismos interamericanos. La próxima Conferencia se reunirá en Bogotá en 1946.

3E A continuación se transcribe una serie de resoluciones. Sólo se copian aquellas relevantes. Nota del editor A. P. D. 
2o. Las Reuniones Ordinarias de Consulta entre los Ministros de Relaciones Exteriores se celebrarán anualmente, previa convocatoria especial del Consejo de la Unión Panamericana, salvo el caso de que en el mismo año hubiere de celebrarse la Conferencia Internacional Americana prevista en el artículo anterior. La próxima reunión ordinaria de Ministros de Relaciones Exteriores se efectuará en 1947.

Corresponderá a las Reuniones de Consulta tomar decisiones concernientes a los problemas de mayor urgencia e importancia dentro del sistema interamericano y a las situaciones y disputas de todo género que puedan turbar la paz de las Repúblicas del Hemisferio.

Si excepcionalmente los Ministros de Relaciones Exteriores no pudieren concurrir, se harán representar por un Delegado especial.

3o. El Consejo Directivo de la Unión Panamericana se compondrá de sendos Delegados ad hoc, designados por las Repúblicas americanas, los cuales tendrán categoría de Embajadores y gozarán de los privilegios e inmunidades que como a tales les correspondan; pero no podrán formar parte de la misión diplomática acreditada ante el Gobierno en cuyo territorio se halle la sede de la Unión Panamericana. Esta norma regirá cuando termine el actual período de sesiones del presente Consejo.

4o. Además de sus funciones actuales, el Consejo Directivo de la Unión Panamericana

a) Conocerá, dentro de los límites que le tracen las Conferencias Internacionales Americanas, o por encargo especial de las Reuniones de los Ministros de Relaciones Exteriores, de cualquier asunto que afecte al funcionamiento efectivo del sistema interamericano y a la solidaridad y bienestar general de las Repúblicas americanas;

b) Convocará a las Reuniones Ordinarias de Consulta entre los [22] Ministros de Relaciones Exteriores, previstas en el inciso primero del Artículo 2, o a reuniones extraordinarias, cuando ellas sean solicitadas, para tratar exclusivamente cuestiones de emergencia. En este último caso, la convocatoria se determinará por mayoría absoluta de votos de los miembros del Consejo;

c) Supervisará los organismos interamericanos que estén relacionados con la Unión Panamericana, o que pasen a estar relacionados con ella, y recibirá y aprobará los informes anuales o especiales de esos organismos.

5o. La Presidencia del Consejo Directivo de la Unión Panamericana se designará por elecciones anuales y el Presidente no podrá ser reelecto para el período inmediato.

El Consejo Directivo de la Unión Panamericana se reunirá cuando menos una vez por semana.

La sede de la Unión Panamericana y del Consejo Directivo continuará en Wáshington. ${ }^{4 \mathrm{E}}$

El Director de la Unión Panamericana será designado por el Consejo para un periodo de diez años; no podrá ser reelecto ni ser sucedido por una persona de su misma nacionalidad.

Cuando se produzca vacante en el cargo de Director de la Unión Panamericana, se elegirá libremente su reemplazo hasta el término del período, y dicho reemplazo podrá ser reelecto si la vacante se hubiere producido en la segunda mitad del período.

El primer período comenzará a contarse desde el 1o. de enero de 1955.

La designación y reemplazo del Subdirector se regirá por las mismas normas anteriores, pero el primer período comenzará a contarse desde el 1o. de enero de 1960.

Queda entendido que en cualquier tiempo el Consejo Directivo podrá, con el voto de 15 de sus miembros, acordar la remoción del Director o del Subdirector por razones relacionadas con la eficacia del organismo.

4E Con acento en el original. Nota del editor A.P.D. 
6o. Mientras la Novena Conferencia Internacional Americana, de acuerdo con el procedimiento que se establece adelante, crea o confirma los diversos organismos del sistema americano, continuarán en sus funciones los siguientes organismos creados por las Reuniones de Consulta entre los Ministros de Relaciones Exteriores: el Comité Jurídico Interamericano, el Comité Consultivo de Emergencia para la Defensa Política y la Junta Interamericana de Defensa.

7o. En sustitución del organismo de emergencia que actualmente funciona con el nombre de Comité Consultivo Económico-Financiero Interamericano, créase un Consejo Interamericano Económico y Social, de carácter permanente que dependerá del Consejo Directivo de la Unión Panamericana, los miembros del cual serán designados por los respectivos Gobiernos y que tendrá facultades para:

a) Procurar el cumplimiento de las recomendaciones de las Conferencias Internacionales Americanas;

[23] b) Actuar como organismo coordinador de todas las actividades oficiales interamericanas de carácter económico y social;

c) Promover el progreso social y la elevación del nivel de vida para todos los pueblos americanos;

d) Emprender estudios y otras actividades por iniciativa propia o a petición de cualquier gobierno americano;

e) Recabar y preparar informes sobre asuntos económicos y sociales para uso de las Repúblicas americanas;

f) Mantener contacto con la entidad correspondiente del organismo internacional, cuando se establezca, y con los organismos internacionales de carácter económico y social existentes o proyectados.

El Consejo Directivo de la Unión Panamericana tendrá facultad para organizar provisionalmente el Consejo Interamericano Económico y Social. La organización definitiva corresponderá a la Novena Conferencia Internacional Americana.

8o. Será mantenida la Oficina de Cooperación Intelectual con el objeto de intensificar, por todos los medios a su alcance, las relaciones espirituales entre los países americanos.

9o. Se encarga al Consejo Directivo de la Unión Panamericana de preparar, a partir del 1o. de mayo de 1945 y asesorándose de todos aquellos organismos panamericanos que estime convenientes, un anteproyecto de pacto constitutivo destinado a mejorar y fortalecer el sistema panamericano. El Consejo Directivo deberá someter a todos los Gobiernos del Continente dicho anteproyecto antes del 31 de diciembre de 1945.

$\mathrm{El}$ anteproyecto de Pacto proclamará en primer término:

El reconocimiento, por parte de todas las Repúblicas americanas, del Derecho Internacional como regla efectiva de su conducta y el compromiso de las mismas de observar las normas enunciadas en una "Declaración de Derechos y Deberes de los Estados" y en una "Declaración de Derechos y Deberes Internacionales del Hombre," que sirvan para precisar los principios fundamentales del Derecho Internacional y que deberán figurar como anexos al Pacto, a fin de que, sin necesidad de modificar éste, puedan ser revisadas de tiempo en tiempo con objeto de que correspondan a las necesidades y aspiraciones de la convivencia internacional.

Para la elaboración de la Primera Declaración, deberán coordinarse los principios ya incorporados al patrimonio jurídico del sistema interamericano, especialmente los contenidos en la "Convención sobre Derechos y Deberes de los Estados," aprobada en la Séptima Conferencia Internacional Americana; en la "Declaración de Principios sobre Solidaridad 
y Cooperación Interamericanas," adoptada en la Conferencia Interamericana de Consolidación de la Paz; en la "Declaración de los Principios de Solidaridad de América" y la "Declaración de Principios Americanos," frutos de la Octava Conferencia Internacional Americana; en la "Declaración sobre Mantenimiento de las Actividades Internacionales dentro de la Moral Cristiana" y la Declaración [24] relativa a "Asistencia Recíproca y Cooperación Defensiva de las Naciones Americanas," sancionadas respectivamente en la Primera y Segunda Reuniones de Consulta; y en las Declaraciones acerca de "Solidaridad Continental" en la "Observancia de los Tratados Internacionales" 5E y "Política del Buen Vecino," y que adoptó la Tercera Reunión de Consulta. Se tomará también en cuenta el proyecto de "Reafirmación de Principios Fundamentales de Derecho Internacional," preparado por el Comité Jurídico Interamericano y cualquiera Declaración de Principios que pudiera adoptar esta Conferencia.

En cuanto a la segunda Declaración antes mencionada, el texto será el que, en cumplimiento de la misión que se la confía en otra resolución de la presente Conferencia, formulará el Comité Jurídico Interamericano.

Es el deseo de la Conferencia Interamericana sobre Problemas de la Guerra y de la Paz que se tome en cuenta la Comisión Interamericana de Mujeres, que por 16 años ha prestado eminentes servicios a la causa americana y a la humanidad y que se la incluya entre las instituciones que integran la Unión Panamericana, con las mismas prerrogativas e igual tratamiento de que gozan las otras instituciones interamericanas que han trabajado dentro y fuera de la Unión Panamericana con carácter permanente o de emergencia.

10o. El anteproyecto de Pacto deberá proveer al fortalecimiento del sistema americano sobre las bases de esta resolución y con la creación de nuevos órganos o la eliminación y adaptación de los actuales, precisando sus funciones y su coordinación entre sí y con la organización mundial.

El mismo anteproyecto atenderá a la necesidad de acelerar la consolidación y extensión de los instrumentos interamericanos de paz ya existentes y a la simplificación y mejoramiento del organismo de paz interamericano; a este fin, el Consejo Directivo de la Unión Panamericana deberá utilizar los servicios del Comité Jurídico Interamericano. Asimismo, el anteproyecto procurará la consolidación y simplificación de todos los demás instrumentos interamericanos, con el propósito de que su acción sea más efectiva.

11o. Los Gobiernos americanos enviarán al Consejo Directivo de la Unión Panamericana, antes del 1o. de septiembre de 1945, todas las iniciativas que se relacionen con los artículos anteriores.

12o. El anteproyecto contendrá asimismo el establecimiento de un sistema equitativo de financiación para el sostenimiento de la Unión Panamericana y de todos los organismos conexos.

(Aprobada en la sesión plenaria del día 6 de marzo de 1945)

5E Aparecen como dos documentos separados en el original, pero se referirían a un documento único. Nota del editor A.P.D. 
XL

\section{PROTEGCION INTERNACIONAL DE LOS DERECHOS ESENCIALES DEL HOMBRE}

La Conferencia Interamericana sobre Problemas de la Guerra y de la Paz, CONSIDERANDO:

Que la Declaración de las Naciones Unidas ha consagrado la necesidad de establecer la protección internacional de los Derechos Esenciales del Hombre;

Que para que esa protección sea llevada a la práctica se requiere precisar tales derechos — así como los deberes correlativos - en una Declaración adoptada en forma de Convención por los Estados;

Que la protección internacional de los derechos esenciales del hombre eliminaría el uso indebido de la protección diplomática de los ciudadanos en el exterior, cuyo ejercicio ha determinado más de una vez la violación del principio de no intervención, y también el de igualdad, entre nacionales y extranjeros, en cuanto a los derechos esenciales del hombre,

RESUELVE:

1o. Proclamar la adhesión de las Repúblicas Americanas a los principios consagrados en el Derecho Internacional para la salvaguardia de los derechos esenciales del hombre y pronunciarse en favor de un sistema de protección internacional de los mismos.

2o. Encomendar al Comité Jurídico Interamericano la redacción de un anteproyecto de Declaración de los Derechos y Deberes Internacionales del [53] Hombre que será sometido por conducto de la Unión Panamericana a todos los Gobiernos del Continente, a fin de que éstos formulen las observaciones que estimen pertinentes en el plazo máximo de seis meses para que dicho Comité esté en posibilidad de redactar un proyecto definitivo del instrumento interamericano en cuestión.

3o. Encargar al Consejo Directivo de la Unión Panamericana de la convocatoria de la Conferencia Internacional de Jurisconsultos Americanos una vez que el Comité haya elaborado dicho proyecto así como los demás cuya preparación le confie la presente Conferencia, a fin de que la declaración sea adoptada en forma de convención por los Estados del Continente. 
Este libro forma parte del acervo de la Biblioteca Jurídica Virtual del Instituto de Investigaciones Jurídicas de la UNAM www.juridicas.unam.mx

http://biblio.juridicas.unam.mx/bjv

\section{NOVENA GONFERENGIA INTERNAGIONAL AMERICANA}

\section{BOGOTÁ}

MARZO 30-MAYO 2, $1948^{1 \mathrm{E}}$

1 E Esta página y las cuatro siguientes se obtuvieron del libro Conferencias Internacionales Americanas. Segundo Suplemento. Por ello, para mantener el orden de los libros de donde se obtuvieron estos documentos, se dejan en este sitio, antes del Anteproyecto de Declaración de los Derechos y Deberes Internacionales del Hombre, a pesar de que se refiere a documentos elaborados con posterioridad. Nota del editor A. P. D.

DR @ 2017.

Instituto de Investigaciones Jurídicas - Universidad Nacional Autónoma de México. 
Este libro forma parte del acervo de la Biblioteca Jurídica Virtual del Instituto de Investigaciones Jurídicas de la UNAM

\section{NOVENA GONFERENGIA INTERNAGIONAL AMERICANA}

Bogotá, marzo 30-mayo 2, 1948

Esta Conferencia fue la Novena de la serie iniciada en 1889-1890 en Washington. Debía celebrarse en 1943, es decir, cinco años después de la Octava celebrada en Lima en 1938, pero debido principalmente a la Segunda Guerra Mundial, se aplazó hasta 1948.

Esta Conferencia fue especialmente notable e importante porque en ella se reorganizó, consolidó y fortaleció el Sistema Interamericano, dentro de lo previsto en la Resolución IX, aprobada en la Conferencia Interamericana sobre Problemas de la Guerra y de la Paz, que tuvo lugar en México en 1945. Estos propósitos se cumplieron particularmente mediante la adopción de la Carta de la Organización de los Estados Americanos y el Tratado Americano de Soluciones Pacíficas (Pacto de Bogotá).

La Carta modificó el nombre de la Conferencia Internacional Americana al de "La Conferencia Interamericana", y al mismo tiempo precisó el papel y las funciones que había de desempeñar dentro de la nueva estructura creada en Bogotá, en la cual figura como órgano supremo.

Estuvieron representadas las 21 naciones americanas en la Novena Conferencia. Las delegaciones, incluyendo a sus asesores, secretarios y ayudantes sumaron 545 personas. 


\title{
PROGRAMA DE LA NOVENA CONFERENCIA INTERNACIONAL AMERICANA ${ }^{1}$
}

\author{
CAPITULO PRIMERO \\ Reorganización, Consolidación y Fortalecimiento \\ del Sistema Interamericano
}

I. Pacto Constitutivo del Sistema Interamericano:
A. Preámbulo
B. Propósitos y Principios Generales del Sistema

[110]

\author{
Referencias
}

Anteproyecto de Pacto Constitutivo del Consejo Directivo Proyecto del Brasil

Anteproyecto del Consejo Directivo.

Derechos y deberes de los Estados

(Anteproyecto del Consejo Directivo);

Derechos y deberes internacionales del Hombre (Anteproyecto del Comité Jurídico Interamericano);

Seguridades económicas (Propuesta de Bolivia; propuesta de Cuba);

Garantías Sociales (Anteproyecto del Comité Jurídico Interamericano)

C. Miembros del Sistema

D. Organización del Sistema

1. Asambleas Interamericanas:

a. Conferencias Internacionales Americanas

b. Reuniones de Consulta de Ministros de

Constitutivo

Anteproyecto de Pacto

Relaciones Exteriores

c. Conferencias Especiales

2. Unión Panamericana:

a. Consejo Directivo

b. Dirección General

c. Organos dependientes del Consejo Directivo

3. Organismos Especializados

\begin{abstract}
Anteproyecto de Pacto Constitutivo Anteproyecto de Pacto Constitutivo Propuesta de Honduras relativa a los Delegados Ad Hoc

Anteproyecto de Pacto Constitutivo de Mujeres.

Anteproyecto de Pacto Constitutivo

Propuesta de Chile

Propuesta de los Estados Unidos
\end{abstract} Proyectos del Consejo Directivo, de la Junta Interamericana de Defensa, y los basados en los anteproyectos del Consejo Interamericano Económico y Social, y de la Comisión Interamericana

${ }^{1}$ Aprobado por el Consejo Directivo de la Unión Panamericana en la sesión del 23 de julio de 1947. 
Este libro forma parte del acervo de la Biblioteca Jurídica Virtual del Instituto de Investigaciones Jurídicas de la UNAM www.juridicas.unam.mx

http://biblio.juridicas.unam.mx/bjv

E. Financiación del Sistema

F. Solución pacífica de las controversias

G. Defensa Colectiva

H. Relaciones con las Naciones Unidas y sus organismos especializados

I. Ratificación y Vigencia Anteproyecto de Pacto Constitutivo y Proyecto
del Consejo Directivo

(1) Negociación Directa;

(2) Consulta;

(3) Investigación;

(4) Buenos oficios;

(5) Mediación;

(6) Conciliación;

(7) Arbitraje;

(8) Arreglo Judicial;

(Proyecto del Comité Jurídico Interamericano)

Acta de Chapultepec o Acuerdos de Río de Janeiro

Indicación de varios gobiernos (Chile, México, Venezuela)

Anteproyecto de Pacto Constitutivo

Proyecto del Brasil

Propuesta del Ecuador

Propuesta del Perú

Anteproyecto de Pacto Constitutivo

Proyecto del Brasil

Proyectos del Consejo Directivo

Proyecto del Brasil zados interamericanos y regulación de estos organismos. ${ }^{2 \mathrm{E}}$

\section{CAPITULO TERCERO}

Asuntos ECONÓMICOS

III. Cooperación Económica Interamericana

Proyecto de Colombia

Propuesta de Haití

Indicación de México

\section{CAPITULO CUARTO}

Asuntos Jurídico-Políticos

IV. Reconocimiento de Gobiernos de Facto

2E Con punto final en el original (a diferencia de la mayoría de los demás enunciados). Nota del editor A. P. D. 
V. Defensa y Preservación ${ }^{3 \mathrm{E}}$ de la democracia en América frente a la eventual instalación de regímenes antidemocráticos en el continente. ${ }^{4 \mathrm{E}}$

VI. Colonias Europeas en América

\section{CAPITULO QUINTO}

Asuntos Sociales

VII. Desarrollo y mejoramiento del servicio social interamericano

\section{Propuesta de Guatemala}

Informe del Comité Jurídico Interamericano

Propuesta de Guatemala

[Este Segundo Suplemento del libro Conferencias Internacionales Americanas no contiene más antecedentes relevantes, salvo la transcripción de la Declaración Americana de los Derechos y Deberes del Hombre. Atendido que dicho documento se encuentra al final de esta republicación, al transcribir las secciones relevantes del volumen VI del libro Actas y Documentos de Novena Conferencia Internacional Americana, no se considera necesario insertarlo en este punto. Nota del editor A. P. D.]

3E Con mayúscula en el original. Nota del editor A. P. D.

$4 \mathrm{E}$ Con punto final en el original (a diferencia de la mayoría de los demás enunciados). Nota del editor A. P. D. 
Este libro forma parte del acervo de la Biblioteca Jurídica Virtual del Instituto de Investigaciones Jurídicas de la UNAM www.juridicas.unam.mx

http://biblio.juridicas.unam.mx/bjv

\author{
ANTEPROYEGTO DE DECLARACIÓN \\ DE LOS DERECHOS Y DEBERES INTERNACIONALES \\ DEL HOMBRE \\ $\mathrm{E}$ \\ INFORME ANEXO
}

Formulados por el

\title{
COMITÉ JURÍDICO INTERAMERICANO
}

De acuerdo con las Resoluciones IX y XL de la Conferencia Interamericana sobre Problemas de la Guerra y de la Paz celebrada en la Ciudad de México, del 21 de febrero al 8 de marzo de 1945.

Unión de Repúblicas Americanas ${ }^{1 \mathrm{E}}$

Unión Panamericana

Washington, D. C.

Abril de 1946

IE Este nombre no estaba escrito horizontalmente, sino que dentro de un símbolo análogo al actual de la Organización de Estados Americanos, pero con sólo 21 banderas en vez de las 35 actuales. Nota del editor A. P. D. 


\section{ANTEPROYECTO DE DECLARACIÓN \\ DE LOS DERECHOS Y DEBERES \\ INTERNAGIONALES DEL HOMBRE}

\section{ARTículos de la Declaración}

I.

Derecho a la vida

II.

Derecho de libertad individual

III.

Derecho de libertad de palabra y de expresión

IV.

Derecho de libertad religiosa

V.

Derecho de libertad de reunión

VI.

Derecho de libertad de asociación

VII.

Derecho de petición

VIII.

Derecho de propiedad

IX.

Derecho de nacionalidad

$\mathrm{X}$.

Derecho de libertad de relaciones familiares

XI.

Derecho de protección contra la prisión arbitraria

XII.

Derecho a proceso regular

XIII.

Derecho de sufragio

XIV.

Derecho al trabajo

$\mathrm{XV}$.

Derecho de participar en los beneficios de la ciencia

XVI.

Derecho de seguro social

XVII.

Derecho a la educación

XVIII.

Derecho de igualdad ante la ley

XIX.

Derechos y deberes correlativos

$\mathrm{XX}$.

Incorporación de la declaración en las leyes nacionales

XXI.

Procedimiento en casos concernientes a extranjeros 


\title{
ANTEPROYECTO DE DEGLARAGIÓN \\ DE LOS DERECHOS Y DEBERES \\ INTERNACIONALES DEL HOMBRE
}

\author{
Artículo I \\ DERECHO A LA VIDA
}

Toda persona tiene el derecho a la vida. Este derecho lo tiene el que está por nacer y lo tienen también los incurables, los débiles mentales y los dementes. Los incapaces de sostenerse por su propio esfuerzo tienen derecho a la manutención y amparo; y a este derecho corresponde el deber del Estado de velar por la efectividad de ese amparo.

Unicamente a base de una condena por crímenes graves, a los cuales se aplique la pena capital, puede el Estado abrogar el derecho a la vida.

\section{Artículo II \\ DERECHO DE LIBERTAD INDIVIDUAL}

Toda persona tiene el derecho a su libertad individual.

El derecho de libertad individual incluye el derecho de libre tránsito de una parte del territorio del Estado a otra, y el derecho de salir de ese territorio. Comprende también la libertad de fijar residencia en cualquier parte del territorio, si bien sujeta a las restricciones que puedan ser impuestas por las leyes generales, en consideración al orden público y a la seguridad del Estado.

El derecho de libertad individual incluye la inviolabilidad del domicilio del individuo y de su correspondencia personal.

El Estado puede restringir este derecho solamente en cuanto sea necesario para proteger la salud pública, la seguridad, la moral y bienestar generales, de conformidad con las subsiguientes estipulaciones de esta Declaración.

[2] El derecho del Estado de exigir los servicios del individuo en época de emergencia o para hacer frente a las necesidades de la defensa nacional, no podrá ser considerado como una limitación al derecho fundamental de libertad individual, sino simplemente como una restricción temporaria durante la existencia de la necesidad nacional.

Ninguna persona puede ser detenida o mantenida en prisión por la mera inobservancia de obligaciones contractuales.

Artículo III

\section{DERECHO DE LIBERTAD DE PALABRA Y DE EXPRESIÓN}

Toda persona tiene el derecho de libertad de palabra y de expresión.

Este derecho incluye la libertad de emitir y sostener opiniones y de darles expresión, en privado y en público, y de publicarlas en forma escrita o impresa.

El derecho de libertad de palabra y de expresión se extiende al uso de cualquier medio de comunicación disponible: libertad de usar los servicios de correos, telégrafos, radio y teléfonos; libertad de usar las artes gráficas, el teatro, el cinematógrafo y otros medios para la propagación de ideas. 
El derecho de libertad de palabra y de expresión comprende la libertad de acceso a las fuentes de información, tanto nacionales como extranjeras.

El derecho de libertad de palabra y de expresión incluye el especial y altamente privilegiado derecho de libertad de prensa.

Las únicas limitaciones que el Estado puede imponer a esta libertad son aquellas prescritas por leyes generales, para la protección de la paz pública contra libelos difamatorios y calumniosos de las personas; contra lenguaje o publicaciones obscenas, y lenguaje o publicaciones que inciten directamente a la violencia.

[3] La censura de la prensa está prohibida, ya sea por medios directos o indirectos, y todas las limitaciones impuestas en interés del orden público serán aplicadas únicamente después de la publicación del escrito considerado de carácter ofensivo, definido por la ley. La censura del cinematógrafo puede anticiparse a la exhibición pública, teniendo en cuenta la forma especial de publicidad y la necesidad de proteger al público contra materias consideradas ofensivas para las normas de conducta generalmente admitidas. El Estado no puede reservarse el monopolio de la radiodifusión con el propósito de negar al individuo la oportunidad de libre expresión de su opinión a través de ese vehículo de publicidad.

\section{Artículo IV \\ DERECHO DE LIBERTAD RELIGIOSA}

Toda persona tiene el derecho de libertad de creencia y de culto religiosos.

Este derecho comprende la libertad de culto tanto en público como en privado, la libertad de culto por grupos o por individuos; la libertad de sostener iglesias y otros lugares de culto público y de reunirse en ellos sin restricciones; la libertad de los padres de educar a los hijos en su creencia religiosa y la libertad de propaganda religiosa en forma escrita o hablada.

Las únicas restricciones que el Estado puede imponer a la libertad de culto son aquellas exigidas por los requisitos de salud pública, seguridad y sana moral; pero dichas restricciones deben conformarse con las leyes generales y serán fijadas sin discriminaciones.

Existe una diferencia entre las actividades estrictamente religiosas y otras actividades de carácter económico y financiero, asociadas al sostenimiento del culto, pero que forman parte esencial del mismo. Estas actividades económicas o financieras pueden ser reglamentadas por el Estado, de conformidad con las leyes generales que rigen tales actividades. $[4]$

\section{Artículo $\mathrm{V}$ \\ DEREGHO DE LIBERTAD DE REUNIÓN}

Toda persona tiene el derecho de reunirse pacíficamente, con otras, para tratar asuntos de interés común.

El Estado está obligado a permitir el uso de los sitios públicos para esas reuniones; pero tiene el derecho a ser informado de las reuniones que deban efetuarse ${ }^{2 \mathrm{E}}$ en lugares públicos, a designar localidades y a imponer condiciones para el uso de tales sitios, en interés de la seguridad y orden públicos. Condiciones parecidas pueden ser impuestas a las asambleas celebradas en recintos públicos o particulares. Pero las condiciones impuestas por el Estado para la realición ${ }^{3 \mathrm{E}}$ de reuniones públicas no deben ser tales que sacrifiquen fundamentalmente dicho

2E Sic. Nota del editor A. P. D.

3E Sic. Nota del editor A. P. D. 
derecho. Ninguna condición será necesaria para la reunión de pequeños grupos de personas en sitios públicos o privados. El derecho de reunión incluye el derecho de realizar desfiles públicos, sujetos a las mismas restricciones a que está ${ }^{4 \mathrm{E}}$ sujetas las asambleas.

\section{Artículo VI \\ DERECHO DE LIBERTAD DE ASOGIACIÓN}

Toda persona tiene el derecho de asociarse con otras personas para proteger y promover intereses legítimos.

El Estado tiene el derecho de adoptar medidas que reglamenten las actividades de las asociaciones, siempre que sean aplicadas sin distinción contra cualquier grupo particular, y siempre que no perjudiquen fundamentalmente el derecho de asociación.

\section{Artículo VII DEREGHO DE PETICIÓN}

Toda persona tiene el derecho, ejercido por acción individual o colectiva, de presentar peticiones al gobierno para la reparación de agravios o sobre [5] cualquier otro asunto de interés público o particular.

La publicación de dichas peticiones no puede tomarse como base para castigar de ningún modo, directa o indirectamente, a la persona o personas que formulen la petición.

\section{Artículo VIII \\ DEREGHO DE PROPIEDAD}

Toda persona goza del derecho de propiedad.

El Estado tiene el deber de cooperar con el individuo para que éste consiga un mínimo de propiedad privada correspondiente a las necesidades esenciales de una vida decorosa, y que contribuya a mantener la dignidad de la persona humana y la santidad de su hogar.

El Estado puede determinar por ley las limitaciones susceptibles de ser impuestas a la propiedad, para el mantenimiento de la justicia social y para promover el interés de la comunidad.

El derecho de propiedad privada comprende el derecho de la libre disposición de la propiedad, sujeta sin embargo a las limitaciones impuestas por el Estado en beneficio de la permanencia del patrimonio familiar.

La propiedad privada está subordinada al derecho del Estado de expropiarla de conformidad con las normas públicas, mediante justa indemnización.

\section{Artículo IX \\ DEREGHO DE NACIONALIDAD}

Toda persona tiene derecho a una nacionalidad.

Ningún Estado puede negar su nacionalidad a las personas nacidas en su territorio, de padres legalmente presentes en el país.

Ninguna persona puede ser privada de su nacionalidad de nacimiento, salvo que por su propia y libre voluntad adquiera otra.

4E Sic. Nota del editor A. P. D. 
[6] Toda persona tiene el derecho de renunciar a su nacionalidad de nacimiento, o a la que haya adquirido, en el momento de adquirir una nueva nacionalidad en otro Estado.

\section{Artículo X \\ DEREGHO DE LIBERTAD \\ DE RELACIONES FAMILIARES}

Toda persona tiene el derecho de estar libre de intervención en sus relaciones familiares.

Es deber del Estado respetar y proteger los derechos recíprocos de marido y mujer, en sus relaciones mutuas.

Los padres tienen el derecho de patria potestad sobre sus hijos durante su minoridad, y la obligación de mantenerlos y ampararlos.

Es deber del Estado ayudar a los padres en su esfuerzo para mantener normas adecuadas al binestar ${ }^{5 \mathrm{E}}$ de la niñez en el núcleo de la familia y de promover en lo posible, la propiedad de hogares como un medio de fortalecer las relaciones familiares.

El Estado puede restringir la autoridad de los padres sobre sus hijos únicamente en cuanto los padres sean incapaces de cumplir sus deberes para con ellos o fracasen en su cumplimiento. Cuando sea necesario, el Estado debe proveer a la protección y amparo de tales hijos.

\section{Artículo XI \\ DERECHO DE PROTECGIÓN CONTRA LA PRISIÓN ARBITRARIA}

Toda persona acusada de delito tiene el derecho de no ser arrestada sino por mandato debidamente expedido de acuerdo con la ley, a menos que la persona sea sorprendida in fraganti. Tendrá derecho a un juicio rápido, y a un tratamiento adecuado durante el tiempo que permanezca detenida.

[7]

\section{Artículo XII}

\section{DERECHO A PROGESO REGULAR}

Toda persona acusada de un delito tendrá derecho a que su causa sea ventilada en audiencia imparcial y pública, a ser careada con testigos, y a ser juzgada por tribunales establecidos de acuerdo con la ley vigente en el momento en que fué cometido el acto. No podrá imponerse multa alguna sino de acuerdo con las especificaciones de las leyes generales, ni imponerse castigos corporales crueles y extraordinarios.

Artículo XIII

\section{DERECHO DE SUFRAGIO}

Toda persona, nacional del Estado, tiene el derecho de participar en las elecciones para la formación de los poderes legislativo y ejecutivo del gobierno, de acuerdo con las disposiciones de la Constitución nacional. El ejercicio de este derecho puede, sin embargo, ser condicionado al deber de la persona de probar que es competente para comprender los

5E Sic. Nota del editor A. P. D. 
principios en que se funda la Constitución. La Constitución del Estado proveerá para la formación de un gobierno del pueblo, por el pueblo y para el pueblo.

Este derecho presupone el derecho de organizar partidos políticos.

A ninguna persona le será negado el derecho a desempeñar una función pública, o a ser designada para cualquiera de los servicios públicos del Estado del cual es nacional, por motivo de raza, religión o sexo, o cualquiera otra distinción arbitraria; y la administración de los servicios públicos del Estado se llevará también sin distinciones arbitrarias, en lo concerniente a nombramientos, períodos y condiciones de servicio.

\section{Artículo XIV \\ DERECHO AL TRABAJO}

Toda persona tiene el derecho a trabajar, como medio de mantenerse a sí [8] misma y de contribuir al sostenimiento de su familia.

Este derecho comprende el de seguir libremente una vocación en cuanto lo permitan las oportunidades de trabajo existentes. Tiene también el derecho de cambiar de empleo y de mudarse del lugar de un empleo para otro. Asociado al derecho de trabajar se encuentra el de formar uniones obreras y profesionales.

Toda persona tiene el deber de trabajar para contribuir al bienestar general del Estado.

El Estado tiene el deber de ayudar al individuo en el ejercicio de su derecho de trabajar cuando sus propios esfuerzos no son suficientes para la obtención de un empleo; debe hacer todo esfuerzo para promover la estabilidad de los empleos y para asegurar condiciones apropiadas de trabajo, debiendo fijar normas mínimas de justa compensación.

El Estado tiene el derecho, en casos de emergencia, de exigir los servicios del individuo, cuando dicho ${ }^{6 \mathrm{E}}$ servicios sean requeridos para hacer frente a una necesidad pública urgente.

\section{Artículo XV \\ DERECHO DE PARTICIPAR EN LOS BENEFICIOS DE LA CIENCIA}

Toda persona tiene el derecho de participar en los beneficios resultantes de descubrimientos e invenciones de la ciencia, bajo condiciones que permitan una compensación razonable a la industria y a la capacidad de los autores del descubrimiento o invención.

El Estado tiene el deber de fomentar el desarrollo de las artes y ciencia; pero debe tomar medidas para que las leyes de protección de la propiedad literaria y artística, patentes de invención y marcas de fábrica y comercio no sean usadas para el establecimiento de monopolios que puedan impedir que todas las personas participen de los beneficios de la ciencia. Es el deber del Estado proteger al ciudadano contra el empleo de descubrimientos cintíficos $^{7 \mathrm{E}}$ que puedan [9] crear la intranquilidad o atemorizar al pueblo.

Artículo XVI

\section{DERECHO DE SEGURO SOCIAL}

Toda persona tiene derecho al seguro social.

El Estado tiene el deber de ayudar a las personas a alcanzar el seguro social. Con este fin el Estado debe promover las medidas de salud y seguridad públicas y debe establecer siste-

$6 \mathrm{E}$ Sic. Nota del editor A. P. D.

7 Sic. Nota del editor A. P. D. 
mas de seguro social y agencias de cooperación; por medio de las cuales a todas las personas se les pueda asegurar un nivel de vida adecuado, y la protección contra las contingencias del desempleo, de accidentes, incapacidad, enfermedad y vejez.

Toda persona tiene el deber de cooperar con el Estado, de acuerdo con sus medios, en la manutención y administración de medidas tomadas para promover su propia seguridad social.

\section{Artículo XVII \\ DERECHO A LA EDUCACIÓN}

Toda persona tiene el derecho a la educación.

El derecho de los niños a la educación es primordial.

El Estado tiene el deber de ayudar al individuo en el ejercicio de este derecho a la educación, en conformidad con sus recursos. Las oportunidades de educación deben ser franqueadas a todos en iguales condiciones, de acuerdo con las capacidades naturales y el deseo de aprovechar las facilidades proporcionadas.

El Estado tiene el derecho de fijar normas generales a las cuales las instituciones educacionales deben ajustarse, siempre que estas normas se hallen de acuerdo con otros principios fundamentales y sean las mismas para las escuelas públicas o particulares.

[10] El derecho a la educación comprende el derecho de enseñar, sujeto a las restricciones inherentes al ejercicio de aquel derecho.

\section{Artículo XVIII \\ DERECHO DE IGUALDAD ANTE LA LEY}

Todas las personas son iguales ante la ley en lo que concierne al goce de sus derechos fundamentales. No habrá clases privilegiadas de ninguna índole.

Es deber del Estado respetar los derechos fundamentales de todas las personas dentro de su jurisdicción y de protegerlas en el goce de ellos contra la intervención de terceros.

En todos los procedimientos relacionados con los derechos fundamentales, el Estado debe actuar de acuerdo con las normas legales, y debe asegurar a cada persona la igual protección de la ley.

Las restricciones impuestas a los derechos fundamentales deben ser únicamente aquellas que sean necesarias para la conservación del orden público; y deben ser de carácter general y aplicables a todas las personas, dentro de una misma categoría.

\section{Artículo XIX \\ DERECHOS Y DEBERES CORRELATIVOS}

Los derechos y los deberes son correlativos; y el deber de respetar los derechos de los otros será, en todo tiempo, una restricción al ejercicio arbitrario de los derechos.

\section{Artículo XX \\ INGORPORAGIÓN DE LA DEGLARAGIÓN \\ EN LAS LEYES NACIONALES}

Las disposiciones de esta Declaración formarán parte de la ley de cada Estado, para ser respetadas y puestas en vigor por las autoridades administrativas y judiciales de la misma manera que todas las demás leyes del Estado. 
Este libro forma parte del acervo de la Biblioteca Jurídica Virtual del Instituto de Investigaciones Jurídicas de la UNAM

[11] Las disposiciones de esta Declaración no pueden ser revocadas o modificadas, salvo que sea de conformidad con un acuerdo Inter-Americano o un acuerdo de las Naciones Unidas que vincule a los Estados Americanos.

\section{Artículo XXI \\ PROCEDIMIENTO EN CASOS CONCERNIENTES \\ A EXTRANJEROS}

En los casos en que individuos de nacionalidad extranjera aleguen violación de los precedentes derechos fundamentales por el Estado en el cual residen, la reclamación será decidida, en primer término, por los tribunales de dicho Estado. En caso que el Estado del cual es nacional el reclamante alegue denegación de justicia por el otro Estado, y de no llegarse a un acuerdo por la vía diplomática, el caso será sometido a una Corte Internacional, cuyo estatuto será incluído como parte integrante del instrumento por el cual sea adoptada la presente Declaración.

Río de Janeiro, 31 de diciembre de 1945

(Fdo.) Francisco Campos

(Fdo.) F. Nieto del Río

(Fdo.) Charles G. Fenwick

(Fdo.) A. Gómez Robledo 


\title{
INFORME ANEXO AL ANTEPROYEGTO \\ DE DEGLARAGIÓN DE LOS DEREGHOS Y DEBERES INTERNACIONALES DEL HOMBRE
}

\author{
I. RAZONES POR LAS CUALES EL COMITÉ JURÍDICO PRESENTA \\ UNA DECLARACIÓN DE LOS DERECHOS Y DEBERES INTERNACIONALES \\ DEL HOMBRE
}

1. La conferencia Interamericana sobre Problemas de la Paz y de la Guerra, en su Resolución XL, proclamó la adhesión de las Repúblicas Americanas [13] a los principios consagrados por el derecho internacional, para la salvaguardia de los derechos fundamentales del hombre, y se pronunció en favor de un sistema de protección internacional de los mismos. La Conferencia, por la citada Resolución, encomendó al Comité Jurídico Interamericano la preparación de un anteproyecto de Declaración de los Derechos y Deberes Internacionales del Hombre, que sería sometido, por conducto de la Unión Panamericana, a todos los gobiernos Americanos, a fin de que éstos formulen las observaciones que juzguen convenientes, y pongan al Comité en aptitud de preparar un proyecto definitivo destinado a adoptarse en forma de Convención Interamericana.

2. Por la Resolución IX de la misma Conferencia, que trata de la reorganización del sistema interamericano, el Consejo Directivo de la Unión Panamericana fué encargado de preparar un anteproyecto de Pacto constitutivo destinado a mejorar y fortalecer el sistema Panamericano. El proyecto de pacto deberá proclamar la adhesión de las Repúblicas Americanas a algunos principios fundamentales de derecho internacional establecidos en una Declaración de los Derechos y Deberes de los Estados y en otra Declaración de los Derechos y Deberes Internacionales del Hombre, declaraciones ambas que serán incluidas como anexo a la Carta. Además, fué estipulado que el texto de la Segunda Declaración sería el texto preparado por el Comité Jurídico Interamericano, en cumplimiento del encargo contenido en la Resolución XL. Se fijó la fecha del 31 de Diciembre para presentar a los Gobiernos Americanos el anteproyecto de Pacto constitutivo.

\footnotetext{
*El texto de la Resolución XL, es el siguiente:
}

\section{PROTEGCION INTERNACIONAL DE LOS DERECHOS ESENCIALES DEL HOMBRE}

La Conferencia Interamericana sobre Problemas de la Guerra y de la Paz, Considerando:

Que la Declaración de las Naciones Unidas ha consagrado la necesidad de establecer la protección internacional de los Derechos Esenciales del Hombre; Que para que esa protección sea llevada a la práctica se requiere precisar tales derechos - así como los deberes correlativos - en una Declaración adoptada en forma de Convención por los Estados; Que la protección internacional de los derechos esenciales del hombre eliminaría el uso indebido de la protección diplomática de los ciudadanos en el exterior, cuyo ejercicio ha determinado más de una vez la violación del principio de no intervención, y también el de igualdad, entre nacionales y extranjeros, en cuanto a los derechos esenciales del hombre. 


\section{ANTECEDENTES DE LA ASPIRACIÓN A UNA DECLARACIÓN DE LOS DERECHOS Y DEBERES INTERNACIONALES DEL HOMBRE}

1. Antes de la reciente guerra el derecho internacional dejaba a cargo exclusivo de cada Estado el manejo de las relaciones entre el Estado y la comunidad regida por él. El derecho de intervención humanitaria era reconocido por el derecho internacional en términos generales; pero estaba limitado a los casos extremos en que un Gobierno tratara a una minoría religiosa o racial con tal crueldad que repugnase a la conciencia del mundo. Tales intervenciones, realizadas muy raras veces, se fundaban en la vindicación de las obligaciones morales de un pueblo civilizado, y no envolvían ninguna relación entre los actos ofensivos y la paz del mundo.

2. Con el estallido de la reciente guerra se llegó, sin embargo, a la conclusión que los gobiernos totalitarios que negaban a sus pueblos los derechos tradicionales de libertad de palabra y de reunión, constituían una amenaza a la paz de las Naciones. La negación de dichos derechos hizo posible que un gobierno inculcase a su pueblo ideas falsas sobre la política de otros Estados, y que crease sentimientos de odio que constituyen la base psicológica de futuras agresiones. En su Recomendación Preliminar de Problemas de la Post-Guerra, sometida a los Gobiernos Americanos el 6 de Septiembre de 1942, el Comité Jurídico, tratando de los factores que contribuyeron a la violación de la ley y el orden internacionales en 1939, señaló cómo un espíritu de fanático nacionalismo fué capaz de hacer eficaz su propaganda de supremacía racial, clausurando las fuentes de información pública por medio de la censura rigurosa de la prensa y el monopolio gubernamental de las radiodifusoras. "De esta manera las propias fuentes del pensamiento fueron envenenadas", dijo el Comité, "y los hombres de Estado que propugnaban las falsas teorías del nacionalismo consiguieron fortalecer su dominio sobre el pueblo así engañado en cuanto a la verdadera actitud de otros países." En relación a los factores sociales que contribuyeron a [14] la ruptura del orden y de la ley, el Comité señaló la relación, que existe entre la inseguridad económica y la susceptibilidad de un pueblo a la propaganda en favor del empleo de la fuerza como procedimiento para remediar una situación desesperada, cuando otras medidas menos violentas parecieron inadecuadas.

3. La Carta del Atlántico, proclamada el 14 de Agosto de 1941, por el Presidente Roosevelt y el Primer Ministro Churchill, se refirió (únicamente) al aspecto económico del problema de los derechos humanos. El quinto principio proclamado en la Carta expresa el deseo

Resuelve:

$1^{\circ}$ Proclamar la adhesión de las Repúblicas Americanas a los principios consagrados en el Derecho Internacional para la salvaguardia de los derechos esenciales del hombre y pronunciarse en favor de un sistema de protección internacional de los mismos.

$2^{\circ}$ Encomendar al Comité Jurídico Interamericano de la redacción de un anteproyecto de Declaración de los Derechos y Deberes Internacionales del Hombre que será sometido por conducto de la Unión Panamericana a todos los Gobiernos del Continente, a fin de que éstos formulen las observaciones que estimen pertinentes en el plazo máximo de seis meses para que dicho Comité esté en posibilidad de redactar un proyecto definitivo del instrumento interamericano en cuestión.

$3^{\circ}$ Encargar al Consejo Directivo de la Unión Panamericana de la convocatoria de la Conferencia Internacional de Jurisconsultos Americanos una vez que el Comité haya elaborado dicho proyecto así como los demás cuya preparación le confie la presente Conferencia, a fin de que la declaración sea adoptada en forma de convención por los Estados del Continente. 
de "conseguir la mayor colaboración entre todas las Naciones en el campo económico, con el objeto de asegurar para todos mejores condiciones de trabajo, adelanto económico y seguridad social". El Sexto principio prevé el establecimiento de una paz que asegure a todos los hombres de todos los países una vida "exenta de temor y de privaciones".

4. La Declaración de las Naciones Unidas, de 1o. de Enero de 1942, proclamó que los Gobiernos signatarios habían adherido a la Carta del Atlántico como un "programa común de propósitos y principios", y que estaban convencidos de que la victoria sobre sus enemigos era esencial para defender la vida y la libertad de conciencia, "y preservar los derechos humanos y la justicia tanto en sus propios países como en los otros". De este modo la Declaración proclamó que la protección a los derechos del hombre en todos los países era uno de los resultados que se esperaba alcanzar con la victoria sobre los países del Eje.

5. La protección de los derechos fundamentales del hombre en todos los países puede, por lo tanto, ser considerada desde dos puntos de vista diferentes. En primer lugar, es una condición esencial de cooperación amistosa entre las naciones. Un pueblo al cual se le niegue el derecho fundamental de libertad de palabra y de prensa, y de acceso a las fuentes de información, no puede cooperar eficientemente con los ciudadanos de otros Estados, porque no tiene contacto directo con ellos, no dispone de medios para alcanzar una comprensión imparcial de sus puntos de vista, ni seguridad de que la política que se les atribuye represente las genuinas actitudes de esos otros Estados.

En segundo lugar, la protección de los derechos fundamentales del hombre por la acción de cada Estado, forma parte del objetivo más amplio de facilitar el desenvolvimiento del ser humano como libre miembro de la comunidad internacional, con fé en sí mismo, y con la conciencia de su responsabilidad. La concepción del Estado como una comunidad cooperativa, en que los recursos de la misma deben ser empleados para elevar el nivel de vida y para proveer a una subsistencia decorosa de todos sus miembros, domina el pensamiento político moderno. Hasta hace pocos años se creía que el Estado democrático realizaba debidamente su propósito si dejaba a sus ciudadanos la libertad necesaria de aprovechar cada uno ${ }^{8 \mathrm{E}}$ de las oportunidades que parecían presentarse a todos para ganar su sustento, allí donde el Estado no ponía trabas. Pero el desarrollo del industrialismo moderno, acompañado de concepciones más elevadas de obligación social, ha hecho inaplicables las doctrinas del individualismo extremo. Al mismo tiempo se impuso como una necesidad la organización de la vida económica del Estado para ofrecer a todos la igualdad de posibilidad y para conceder al trabajo una retribución más de acuerdo con la contribución de éste al bienestar nacional.

[15] Además de reconocer el cambio de condiciones de la vida económica y social moderna, la concepción de la democracia se ha ampliado al reconocimiento del valor moral del ser humano individual, y a la conclusión de que el hombre no puede alcanzar su verdadera personalidad moral bajo condiciones de desnutrición, enfermedad, malas viviendas, falta de higiene y otros ambientes aflictivos. El respeto por el hombre a los derechos de los otros hombres siempre es más posible cuando el individuo posee las condiciones esenciales de una vida decorosa. La cooperación mutua entre los pueblos del mundo para la consecución de la paz y la justicia en el futuro, dependerá grandemente de que, dentro de cada comunidad nacional,

${ }_{8 \mathrm{E}} \quad$ Sic. Nota del editor A. P. D. 
el conjunto de ciudadanos se caracterice por la dignidad personal y la responsabilidad moral de cada individuo miembro de ese conjunto.

\section{MEDIDAS ESPECIALES ENCAMINADAS A PROMOVER EL RESPETO A LOS DERECHOS FUNDAMENTALES DEL HOMBRE}

1. En el otoño de 1944, los delegados de los Estados Unidos, Gran Bretaña, la Unión Soviética y China, reunidos en Washington con el propósito de cumplir los acuerdos de la Conferencia de $\mathrm{Moscou}^{9 \mathrm{E}}$, de Noviembre de 1943, formularon las Proposiciones de Dumbarton Oaks para el establecimiento de una Organización Internacional destinada a la conservación de la paz y la seguridad. En el Capítulo IX del Plan de Dumbarton Oaks se incluyeron disposiciones relativas a entendimientos de la cooperación internacional en lo económico y social, para lo cual la Organización "debería facilitar las soluciones de los problemas internacionales de carácter económico y social, así como de los de carácter humanitario, y promover el respeto a los derechos humanos y a las libertades fundamentales".

2. La presentación del Plan de Dumbarton Oaks a los Gobiernos Americanos para su estudio, dió lugar a numerosas indicaciones concernientes a la formulación de una declaración especial de derechos y deberes del hombre, conforme a las garantías tradicionales contenidas en las Constituciones. El Gobierno de México recomendó que el Plan fuese enmendado de modo que "incorporase los derechos humanos fundamentales en una Declaración de los Derechos y Deberes Internacionales del Hombre, los cuales, junto con una declaración semejante a la de los derechos y deberes de los Estados, debería figurar como anexo a la Carta”. El Comité Jurídico, en sus Comentarios al Plan de Dumbarton Oaks, sugirió que cada Estado asumiese la obligación de mantener expeditos los medios internacionales de información, con el fin de fomentar el entendimiento recíproco, Esa obligación sería uno de los elementos de la "declaración internacional de derechos" que el Comité sugería.

3. La Conferencia sobre Problemas de la Guerra y de la Paz, que se inauguró en la Ciudad de México el 21 de Febrero de 1945, dió un nuevo impulso a las indicaciones para la protección internacional de los derechos del hombre y a la idea de preparar una declaración especial de los derechos que deben ser protegidos y de los deberes correspondientes. Diversas delegaciones formularon proyectos. El proyecto $\left(\mathrm{N}^{\circ} 24\right)$ presentado por la delegación Cubana recapituló los principios en que debe basarse la declaración de los derechos del hombre, seguida de una enumeración de los derechos substantivos de la persona y de la propiedad, tanto de ciudadanos como de extranjeros, que deberían ser reconocidos, así como de los derechos del orden procesal en los casos ventilados ante los tribunales nacionales. Un proyecto separado ( $\left.\mathrm{N}^{\circ} 27\right)$, presentado por la misma delegación, tenía por objeto la protección especial que debería concederse a los Judíos, y proponía la creación de un Estado judío, libre y democrático, [16] con fronteras debidamente fijadas.

El proyecto ( $\left.\mathrm{N}^{\mathrm{o}} 30\right)$ presentado por la Delegación Mexicana, iba precedido de una erudita exposición de motivos, con los fundamentos filosóficos e históricos del problema y contenía una parte resolutiva en que se solicitaba del Comité Jurídico Interamericano que formule un proyecto de declaración de Derechos y Deberes Internacionales del Hombre, para ser

9E Sic. Nota del editor A. P. D. 
sometido a la consideración de los Gobiernos Americanos. Una característica del proyecto Mexicano es el concepto de que la declaración, "al establecer un padrón mínimo de justicia civilizada", eliminaría la necesidad de la protección diplomática de nacionales residentes en el extranjero, que ha provocado frecuentemente la violación del principio de no intervención. Con ese propósito el proyecto recomendaba la creación de un organismo Interamericano encargado de supervisar la reglamentación y aplicación práctica de los principios proclamados en la declaración.

La Delegación Uruguaya presentó un proyecto $\left(\mathrm{N}^{\circ}\right.$ 83) que se caracteriza por la prominencia concedida a los derechos económicos y a la seguridad social. El proyecto de la Delegación Brasileña ( $\left.N^{\circ} 136\right)$, titulado "Valorización del Hombre", sin hacer referencia especial a la declaración de los derechos humanos, recalca la necesidad de elevar el nivel de vida y el mejoramiento de las condiciones económicas y sociales del pueblo.

Como quedó señalado más arriba, la Resolución XL adoptada por la Conferencia a base de los diversos proyectos, dejó a cargo del Comité Jurídico la elaboración del anteproyecto de la declaración propuesta.

4. Las disposiciones de la Carta de las Naciones Unidas al contemplar la promoción del respeto a los derechos fundamentales, amplía los términos de las Proposiciones de Dumbarton Oaks, reflejando la convicción generalizada de la estrecha relación que existe entre la protección de los derechos fundamentales y la paz y justicia internacionales. El Preámbulo, que es parte integrante de la Carta, proclama la determinación "de reafirmar la fé en los derechos fundamentales del hombre, en la dignidad y el valor de la persona humana, en la igualdad de derechos de hombres y mujeres y de las naciones grandes y pequeñas". El Capítulo I incluye, entre los "Propósitos" de la Organización, el de realizar la cooperación internacional "en el desarrollo y estímulo del respeto a los derechos humanos y a las libertades fundamentales de todos, sin hacer distinción por motivos de raza, sexo, idioma o religión”. El Capítulo IV concede a la Asamblea General, entre otros poderes, el de hacer recomendaciones con el fín de "ayudar a hacer efectivos los derechos humanos y las libertades fundamentales de todos, sin hacer distinción por motivos de raza, sexo, idioma o religión". El Capítulo IX, que trata de la cooperación económica y social, proclama la obligación de las Naciones Unidas de promover "el respeto universal a los derechos humanos y libertades fundamentales de todos, sin hacer distinción por motivos de raza, sexo, idioma o religión, y la efectividad de tales derechos y libertades". El Capítulo X, que trata del Consejo Económico y Social, establece que el Consejo "podrá hacer recomendaciones con el objeto de promover el respeto a los derechos humanos y a las libertades fundamentales de todos, y la efectividad de tales derechos y libertades", y con este fín, entre otros, podrá formular proyectos de convención para someterlos a la Asamblea General, y podrá convocar conferencias internacionales. A este Consejo se le dieron instrucciones para establecer "comisiones de orden económico y social y para la promoción de los derechos humanos".

[17] Estas diversas enmiendas hechas a las Proposiciones de Dumbarton Oaks fueron en mucha parte el resultado de los esfuerzos de las delegaciones de los Estados Americanos. Las delegaciones de Brasil, República Dominicana, Ecuador y México presentaron una enmienda conjunta al Capítulo de los "Propósitos" de la Organización. Las delegaciones de Cuba y Panamá propusieron cada una la adopción inmediata de una declaración formal de los Derechos y Deberes del Individuo. La Delegación Uruguaya propuso que las liberta- 
des humanas fundamentales y los derechos fuesen definidos en una "Carta de la Humanidad", que debe ser elaborada por una Comisión Técnica y Jurídica, y sometida a la consideración de la Asamblea, dentro del plazo de seis meses. El jefe de la Delegación de los Estados Unidos, a pesar de sostener que no era factible formular una enumeración de los derechos humanos en la Conferencia, expresó la opinión de que la Comisión de derechos humanos, del Consejo Económico y Social, debería iniciar prontamente la preparación de una declaración internacional de derechos, que pudiera ser adoptada por todas las naciones miembros, como parte integrante de sus propios sistemas jurídicos.

El reiterado énfasis dado en la Carta a la promoción del respeto a los derechos fundamentales del hombre, claramente indica la intención, por parte de las potencias signatarias, de no satisfacerse con la simple proclamación de principios generales, sino que desean llevar a la práctica la aplicación de esos principios en las relaciones de los Estados. El informe de la sexta sesión del Comité técnico encargado de los asuntos relativos a la cooperación social y económica, revela que era opinión de sus miembros, de acuerdo con la actitud de algunas delegaciones Americanas, que debería solicitarse de la Asamblea de la Organización, tan pronto como ella se instalase, la elaboración de una declaración formal de los derechos humanos.

\section{Proyectos ANTERIORMENTE ELABORADOS POR ASOCIAGIONES PRIVADAS}

1. El Instituto de Derecho Internacional, en su sesión de Octubre 12, 1929, celebrada en Briarcliff Manor, New York, adoptó una "Declaración de los Derechos Internacionales del Hombre". El preámbulo de la declaración recuerda "que la conciencia jurídica del mundo civilizado exige el reconocimiento para el individuo de derechos protegidos contra toda violación de parte del Estado"; proclama "el derecho igual de cada individuo a la vida, libertad y prosperidad" y la más completa y absoluta protección del derecho, sin discriminación, al libre ejercicio de la religión, al libre empleo del idioma de su predilección, al derecho de los nacionales a ser admitidos en las instituciones educacionales y al ejercicio de profesiones y de actividades económicas, así como al de conservar la nacionalidad.

A pesar del espíritu progresista de la Declaración adoptada por el Instituto de Derecho Internacional, ella no consiguió alcanzar resultados prácticos. Las naciones no estaban aún preparadas, en 1929, para una decisión colectiva sobre el asunto. Fué necesaria la experiencia de la serie de actos de agresión de los gobiernos totalitarios para hacer comprender a los gobiernos democráticos que la adopción de una declaración de los derechos del hombre no constituía simplemente un ideal de conducta humanitaria, sino una condición necesaria para la paz internacional.

2. En 1942 el Instituto de Derecho Americano (American Law Institute) nombró un comité de abogados y expertos en ciencias políticas, representantes de las principales culturas del mundo, para elaborar una declaración de los derechos considerados esenciales a la efectiva libertad del individuo. El pro- [18] yecto preparado por el Comité consiste de una aserie de diez y ocho artículos que tratan sucesivamente sobre libertad de religión, libertad de opinión, libertad de palabra, libertad de reunión, libertad para formar asociaciones, garantías contra intervenciones perjudiciales de terceros, justicia imparcial, garantía contra la detención arbitraria, leyes retroactivas, derecho de propiedad, educación, trabajo, condiciones de trabajo, alimentación y vivienda, seguro social, participación en el gobierno, igualdad ante la ley y limitaciones sobre el ejercicio de los derechos. El preámbulo de dicha declaración afirma que "de la libertad del individuo dependen el bienestar del pueblo, la seguridad del Estado y la paz del mundo", y que es la obligación del Estado promover las condiciones en las cuales el individuo pueda alcanzar la mayor libertad posible. De esta manera la lista de 
libertades fundamentales incluye, no solamente los derechos tradicionales del hombre contra la intervención del Estado, sino también los derechos más recientemente reconocidos que han surgido de las nuevas condiciones de la vida económica, y la necesidad de una acción positiva de parte del Estado para capacitar el individuo a ser libre en una sociedad altamente industrializada y de economía interdependiente.

3. Después de muchos años, la Comisión de Estudio para la Organización de la Paz, que se estableció inmediatamente después de estallar la guerra en Europa, presentó su informe sobre la "Protección Internacional de los Derechos del Hombre", que constituyó la III Parte del Cuarto Relatorio de la Comisión. En este informe la Comisión trata, primeramente, del significado de los derechos humanos en la organización internacional, de la proyectada Conferencia de las Naciones Unidas sobre los Derechos Humanos, de las medidas existentes para salvaguardar los derechos humanos, y de los métodos indispensables para hacer efectivas las normas internacionales. El informe apoya la creación, por parte de las Naciones Unidas, de una comisión Especial de Derechos Humanos, investida de poderes para investigar y opinar, y cuya función sería la de desarrollar normas de derechos humanos y medidas para su salvaguardia efectiva. La Comisión sería una entidad de expertos, casi autónoma, con su secretariado permanente y habilitada a presentar recomendaciones a la organización general internacional, pero nó subordinada a ésta. El informe reconoce, al mismo tiempo, que la protección de los derechos humanos debe hacerse con el debido respeto a las costumbres de cada país y el mismo respeto y utilización de sus sistemas legales. La Comisión de Derechos humanos ${ }^{10 E}$ sería el "puente" entre los órganos y las normas internacionales, de un lado, y el sistema legal de cada país, del otro. El informe expresa la confianza de que la "organización legal de cada país puede ser un medio efectivo para cumplir los deberes internacionales de la nación y para proteger los derechos concedidos a cualquier individuo, de acuerdo con el derecho internacional".

4. La Conferencia General de la Organización Internacional de Trabajo, en su vigésima sexta $\left(26^{\circ}\right)$ sesión celebrada en Filadelfia, en 10 de Mayo de 1944, adoptó una declaración de fines y propósitos bajo el nombre de "Carta de Filadelfia". La Conferencia reafirmó los principios fundamentales sobre los cuales se basa la Organización. Estableció que el trabajo no es una mercancía; que la libertad de expresión y de asociación son esenciales para el progreso contínuo ${ }^{11 \mathrm{E}}$; que la pobreza constituye, en cualquier parte, un peligro para la prosperidad general; que la lucha contra la miseria reclama acción del Estado y cooperación internacional. De acuerdo con el principio de su Estatuto, de que una paz duradera solamente puede ser establecida si ella se basa en la justicia social, la Conferencia afirmó "Todos los seres humanos, cualquiera que sea su raza, creencia religiosa o sexo, tienen derecho de procurar [19] su bienestar material y su desenvolvimiento espiritual, dentro de condiciones de libertad y dignidad, seguridad económica e igualdad de posibilidades". La obtención de estos objetivos debe ser el propósito primordial de la política nacional e internacional, y todas las medidas específicas, particularmente aquellas de carácter económico y financiero, debe ser juzgadas a la luz de este objetivo fundamental.

\section{ALCANCE DE UNA DECLARACIÓN INTERNACIONAL DE DERECHOS}

1. A juzgar por los varios documentos, tanto públicos como privados, a que se ha hecho referencia, es evidente que en la proyectada "Declaración de los Derechos y Deberes Inter-

\footnotetext{
$10 \mathrm{E}$ Sic. Nota del editor A. P. D.

$11 \mathrm{E}$ Sic. Nota del editor A. P. D.
} 
nacionales del Hombre", deben incluirse, no solamente los derechos de libertad tradicionales reconocidos por las constituciones de la gran mayoría de los Estados, sino también los nuevos derechos económicos y sociales, de carácter positivo, que han venido a ser reconocidos en los últimos años, como una necesaria consecuencia de la concepción del Estado democrático en su significación de entidad cooperativa que persigue el bienestar general de todos sus miembros.

2. Los derechos de libertad tradicionales, del hombre, deben ser reexaminados de modo a tomar en consideración cambios producidos en la actualidad, y permitir que se formulen estos derechos fundamentales en términos más específicos de lo que hasta ahora se ha venido haciendo. Las grandes proclamaciones históricas de los derechos humanos, como la Carta Magna, la Declaración de la Independencia de los Estados Unidos, la Declaración Francesa de los Derechos del Hombre y del Ciudadano, que forman parte del patrimonio del mundo civilizado, no han perdido nada de su valor teórico; ellas marcan puntos de partida en el desenvolvimiento del gobierno democrático. Los principios que establecieron fueron incorporados a las primeras Constituciones de los Estados Latino-Americanos. No obstante, los derechos que proclamaron fueron expuestos en términos amplios, aplicables a las condiciones de la época. Las garantías de los derechos humanos, consignadas en Constituciones posteriores de los Estados Americanos, reflejan, del mismo modo, las circunstancias que las hacen necesarias, y los ideales predominantes en cada época. El Comité Jurídico ha procurado interpretar esas disposiciones de modo a armonizarlas, en lo posible, respetando su esencia y tratando de adaptarlas a las necesidades actuales para darles así una renovada vitalidad.

En vista de la reiterada negación de estos derechos políticos por parte de los gobiernos totalitarios, en los últimos años, no está demás ${ }^{12 \mathrm{E}}$ reafirmar la base teórica en la cual descansan. El Estado no es una finalidad en sí; es solamente un medio para alcanzar un fin. No es, en sí propio, una fuente de derechos, sino un órgano por cuyo intermedio pueden hacerse efectivos los derechos inherentes a la personalidad humana. El hombre es, sin duda, por su naturaleza, un ser social; el Estado le proporciona la oportunidad para el desenvolvimiento de sus intereses morales y materiales; pero no por eso inviste al Estado de una personalidad mística, que justifique el crecimiento de su poder y prestigio a expensas de los derechos que son fundamentales a la conservación de la dignidad y valor del hombre. Como se expresa en la Declaración de Principios Sociales de América, adoptada por la Conferencia sobre los Problemas de la Paz y de la Guerra, en la Ciudad de México, "el hombre debe ser el centro de interés de todos los esfuerzos de los pueblos y de los gobiernos". Por lo tanto, no solamente los gobiernos están obligados a respetar los derechos fundamentales del hombre, sino que el Estado no tiene autoridad para sobreponerse a ellos. El hombre, individualmente, es el titular del derecho, y puede hacer [20] valer sus derechos esenciales, tanto contra el Estado como contra los agentes del gobierno, en particular.

3. La teoría sobre la cual descansa el conjunto de nuevos derechos económicos y sociales es el principio amplio de la justicia distributiva. Una o más generaciones atrás los Estados tenían una comprensión limitada de las obligaciones de la comunidad para promover el bienestar individual de sus ciudadanos. Los derechos del individuo consistían, en realidad, en derechos contra la intervención del Estado, pero nó derechos a contar con la ayuda activa del Estado. En los últimos años ha llegado a comprenderse que el individuo no puede, por sus propios esfuerzos, alcanzar siempre el nivel de vida adecuado para el desenvolvimiento de su personalidad humana. Las complicaciones de la vida económica de los Estados modernos han demostrado que la antigua doctrina del "laissez faire" ya no prevalece. Al mismo tiempo,

12E Sic. Nota del editor A. P. D. 
el concepto del Estado democrático como entidad de carácter cooperativo, cuyo objetivo es el bienestar general de todos sus miembros, ha llegado a ser mejor comprendido. Se ha comprobado, de un modo más general, la relación entre el desenvolvimiento espiritual y el nivel de bienestar material. La Carta de las Naciones Unidas expresa la determinación de promover el progreso social y el mejoramiento de las condiciones de vida, dentro de un concepto más amplio de la libertad. De este modo puede considerarse que los derechos fundamentales del individuo crecen con el desarrollo de la civilización, tomando nuevas formas, de acuerdo con los nuevos ideales de justicia social.

\title{
VI. ANÁLISIS DETALLADO DE DERECHOS Y DEBERES
}

En la clasificación de los derechos fundamentales seguida por las Constituciones de los Estados y por los proyectos de asociaciones particulares o individuos, no existe uniformidad. Aun cuando sería conveniente mencionar los derechos en el orden de su importancia, no es posible hacerlo, en forma rígida, porque resultaría por demás difícil llegar a un acuerdo sobre la importancia relativa de determinados derechos; y, al mismo tiempo, porque el ejercicio de un derecho, por regla general, se asocia en la práctica al ejercicio de otro. Es posible, sin embargo, establecer una diferencia entre el antiguo cuerpo de derechos políticos, creado contra la intervención del Estado en la libertad del individuo, y el más reciente, de derechos económicos y sociales, que reclama una acción afirmativa de parte del Estado. Además, el antiguo conjunto de derechos políticos permite una diferenciación entre los derechos comunes del individuo para el goce de ciertas libertades, y los derechos especiales de las personas acusadas por violación de la ley. El derecho fundamental de igualdad ante la ley se presenta al final de la serie, porque es un derecho que califica a todos los demás derechos.

\section{ARTÍCULO I \\ DERECHO A LA VIDA}

\begin{abstract}
Toda persona tiene el derecho a la vida. Este derecho lo tiene el que está por nacer y lo tienen también los incurables, los débiles mentales y los dementes. Los incapaces de sostenerse por su propio esfuerzo tienen derecho a manutención y amparo; y a este derecho corresponde el deber del Estado de velar por la efectividad de ese amparo.

[21] Unicamente a base de una condena por crímenes graves, a los cuales se aplique la pena capital, puede el Estado abrogar el derecho a la vida.
\end{abstract}

El primero de los derechos fundamentales del hombre, en orden lógico y de importancia es, sin duda, el derecho a la propia vida.

La Declaración de Independencia de los Estados Unidos, al proclamar determinados derechos inalienables del hombre, afirma que se incluyen entre ellos "la vida, la libertad y la conquista de la felicidad".

El derecho a la vida podría, sin duda, considerarse como una presunción necesaria de la existencia de todos los otros derechos. Sin el derecho a la vida, los derechos a la libertad, a la propiedad, a la igualdad, no tendrían ninguna significación. Pero en vista de recientes violaciones de este derecho en algunas de sus concretas aplicaciones, se impone reafirmarlo separadamente y con significación propia. 
La Declaración garantiza el derecho a la vida a los seres humanos que están por nacer, en concordancia con la ley civil de la mayoría de los países. Ella proclama el derecho a la vida de los individuos que por defectos físicos o mentales no pueden ejercer otros derechos fundamentales y deben, para la protección de la comunidad, ser recluídos. La Declaración establece que el Estado debe amparar a esos individuos, e implícitamente condena el procedimiento llamado destrucción "humanitaria" de la vida. El hombre no debe ser utilizado, sin su expreso consentimiento, para experimentos científicos que pongan su vida en posible peligro.

La Declaración reconoce que una persona puede perder el derecho a la vida como consecuencia de actos criminales del más grave carácter. Cada Estado es libre, por lo tanto, para imponer la pena de muerte a las personas responsables por esos crímenes. Algunos Estados profesan el principio de que la imposición de la pena de muerte representa un elemento de degradación moral de parte del propio Estado. Sobre este punto el Comité Jurídico no emite opinión, limitándose a declarar que el derecho a la vida no exime al individuo del castigo establecido para los más graves crímenes.

\section{ARTÍCULO II DERECHO DE LIBERTAD INDIVIDUAL}

Toda persona tiene el derecho a su libertad individual.

El derecho de libertad individual incluye el derecho de libre tránsito de una parte del territorio del Estado a otra, y el derecho de salir de ese territorio. Comprende también la libertad de fijar residencia en cualquier parte del territorio, si bien sujeta a las restricciones que puedan ser impuestas por las leyes generales, en consideración al orden público y a la seguridad del Estado.

El derecho de libertad individual incluye la inviolabilidad del domicilio del individuo y de su correspondencia personal.

El Estado puede restringir este derecho solamente en cuanto sea necesario para proteger la salud pública, la seguridad, la moral y bienestar generales, de conformidad con las subsiguientes estipulaciones de esta Declaración.

[22] El derecho del Estado de exigir los servicios del individuo en época de emergencia o para hacer frente a las necesidades de la defensa nacional, no podrá ser considerado como una limitación al derecho fundamental de libertad individual, sino simplemente como una restricción temporaria durante la existencia de la necesidad nacional.

Ninguna persona puede ser detenida o mantenida en prisión por la mera inobservancia de obligaciones contractuales.

El derecho a la libertad individual, tomado en el más amplio sentido del Artículo II, podría, al igual que el derecho a la vida, ser considerado como comprendido en otros derechos fundamentales proclamados en los artículos subsiguientes. En vista, sin embargo, de tradiciones históricas y de la preeminencia dada a la "libertad" en las constituciones de los Estados Americanos, se considera conveniente afirmar el derecho en una forma general, dejando para disposiciones subsiguientes la definición de los aspectos especiales del derecho y las restricciones a que necesariamente debe estar sujeto.

Íntimamente asociado con el derecho a la libertad personal está el derecho a libre tránsito de un lugar a otro del Estado, y la libertad del individuo para establecer su residencia en cualquier parte del territorio y para salir del territorio nacional. La Declaración proyectada reconoce que pueden imponerse restricciones a la libertad de tránsito en el interés del orden 
y seguridad públicos; pero deben ser impuestos por leyes generales, aplicables a todas las personas, sin distinción. Se reconoce, también, que en épocas de emergencia, cuando, de acuerdo con el artículo XIV, el Estado tiene el derecho de exigir los servicios de sus ciudadanos, puedan decretarse restricciones a la libertad de tránsito que han de ser de carácter temporario, y terminar con la causa que los motivó.

La Declaración establece que el derecho a la libertad individual comprende la inviolabilidad del domicilio. De acuerdo con la tradición legal de los Estados Americanos, el domicilio de una persona no puede ser allanado sin una orden judicial, debidamente emitida por las autoridades competentes, y con declaración del objeto para el cual se solicita el allanamiento. No solamente la persona que ocupa el domicilio no puede ser arrestada sin un mandato judicial, sino que el allanamiento del domicilio no puede hacerse sino para el fin concreto expresado en el mandato, y ninguno de los bienes u objeto ${ }^{13 \mathrm{E}}$ de pertenencia del individuo pueden ser aprehendidos, salvo que lo sean de acuerdo con el mandato. El Estado tiene, sin embargo, el derecho de señalar en leyes generales, las excepciones para los casos de emergencia pública, en los cuales la seguridad general prevalece sobre el derecho del individuo.

Íntimamente asociada con la libertad personal del individuo está la inviolabilidad de su correspondencia. Las autoridades públicas, encargadas del servicio de correos, deben respetar absolutamente la correspondencia confiada para su traspaso de una persona a otra. Se prohibe la censura de correspondencia, salvo durante la emergencia de guerra; y las transgresiones de los reglamentos del servicio postal, en lo que respecta a la correspondencia cerrada, deberán ser sancionadas a base de otras pruebas que no sean las obtenidas por la violación del secreto de la correspondencia al pasar del remitente al destinatario.

\section{ARTÍCULO III DERECHO DE LIBERTAD DE PALABRA Y DE EXPRESIÓN}

Toda persona tiene el derecho de libertad de palabra y de expresión.

[23] Este derecho incluye la libertad de emitir y sostener opiniones y de darles expresión, en privado y en público, y de publicarlas en forma escrita o impresa.

El derecho de libertad de palabra y de expresión se extiende al uso de cualquier medio de comunicación disponible: libertad de usar los servicios de correos, telégrafos, radio y teléfonos; libertad de usar las artes gráficas, el teatro, el cinematógrafo y otros medios para la propagación de ideas.

El derecho de libertad de palabra y de expresión comprende la libertad de acceso a las fuentes de información, tanto nacionales como extranjeras.

El derecho de libertad de palabra y de expresión incluye el especial y altamente privilegiado derecho de libertad de prensa.

Las únicas limitaciones que el Estado puede imponer a esta libertad son aquéllas prescritas por leyes generales, para la protección de la paz pública contra libelos difamatorios y calumniosos de las personas; contra lenguaje o publicaciones obscenas, y lenguaje o publicaciones que inciten directamente a la violencia.

La censura de la prensa está prohibida, ya sea por medios directos o indirectos, y todas las limitaciones impuestas en interés del orden público serán aplicadas únicamente después de la publicación del escrito considerado de carácter ofensivo, definido por la ley. La censura del cinematógrafo puede anticiparse a la exhibición pública, teniendo en cuenta la forma especial de

\footnotetext{
13E Sic. Nota del editor A. P. D.
} 
publicidad y la necesidad de proteger al público contra materias consideradas ofensivas para las normas de conducta generalmente admitidas. El Estado no puede reservarse el monopolio de la radiodifusión con el propósito de negar al individuo la oportunidad de la libre expresión de su opinión a través de ese vehículo de publicidad.

El derecho de libertad de palabra y de expresión es amplio, susceptible de ser subdividido en varias categorías de libertades, las cuales, para mayor claridad, son presentadas aquí en conjunto, como partes de un todo. Se incluye entre ellas la libertad de opinión, libertad de propaganda, libertad de prensa, libertad de comunicación, y libertad de acceso a las fuentes de información. Cada una de estas libertades separadas está tan íntimamente asociada con las otras que se justifica su inclusión bajo un título general.

La libertad de opinión, tomada en el sentido restricto de tener opiniones, está, sin duda, fuera de cualquiera acción del Estado. Pero la libertad de opinión sería de muy poco valor si la persona no tuviera acceso a las fuentes de información en las cuales se basan las opiniones. En este respecto, la libertad de opinión y la libertad de información son partes de una misma libertad. La importancia de la libertad de información está claramente señalada en la Resolución XXVII de la Conferencia sobre Problemas de la Guerra y de la Paz, en la cual las repúblicas Americanas reconocieron la obligación de garantizar a sus habitantes "el acceso libre e imparcial a las fuentes de información"**

[24] La libertad de palabra es uno de los derechos tradicionales garantizados en las Constituciones de todos los países democráticos. Esta no se limita a la libertad de expresión oral, sino que comprende también la libertad de propagar opiniones en forma escrita o impresa. Al igual que la libertad de opinión, esa libertad comprende la de acceso a las fuentes de información, tanto nacionales como extranjeras, y la libertad de utilizar cualesquiera de los medios de transmisión disponibles.

[25] El término "libertad de expresión" comprende el uso de todos los medios de difusión de ideas y opiniones tales como el teatro y el cinematógrafo, y la divulgación por medio del radio, de ideas o acontecimientos.

\footnotetext{
* [24] El texto de la Resolución XXVII es el siguiente:
}

\section{LIBERTAD DE INFORMACION}

La Conferencia Interamericana sobre Problemas de la Guerra y de la Paz, Considerando:

Que es un firme anhelo, reiteradamente sostenido por las Repúblicas Americanas, asegurar una paz que defienda y proteja, en todas las regiones de la tierra, los derechos fundamentales del hombre y que permita a los pueblos vivir libres de los males de la tiranía, la opresión y la esclavitud;

Que el progreso de la humanidad depende de la supremacía de la verdad entre los hombres;

Que la verdad es enemiga de la tiranía, la cual no puede subsistir donde prevalece ésta y, por tal razón, los que intentan implementar tiranías se ven compelidos a suprimir la verdad o a levantar obstáculos contra ella;

Que la libertad de comunicación del pensamiento, tanto de palabra como por escrito, representa la condición esencial para desarrollar una opinión pública mundial, activa y vigilante, frente a cualquier intento de agresión;

Que uno de los métodos más perniciosos a la Humanidad ha sido el empleado por los gobiernos totalitarios consistente en aislar a sus propios pueblos de la influencia de la información extranjera, impidiéndoles el acceso a la verdad internacional, como también obstaculizando en el exterior un exacto conocimiento de la situación interna; 
La Declaración señala expresamente que la libertad de palabra y de expresión comprende la libertad de acceso a las fuentes de información, tanto nacionales como extranjeras. Este aspecto del problema es de la más alta importancia. Sin duda, ninguna otra restricción a la libertad humana ha sido empleada con mayor éxito para crear el fanatismo nacional que ha sido responsable, en gran parte, de la reciente guerra, como la clausura de los medios de información dentro de los países de regímenes fascistas y entre ellos y otros países. Como el texto de la Resolución citada lo establece bien claramente, la clausura de los medios de información hizo posible que los Gobiernos de esos países envenenasen la mente de sus poblaciones y las preparasen psicológicamente para aceptar los actos de agresión que aquellos Gobiernos habían preparado. Es claro que, en el futuro, la esperanza de una cooperación amistosa entre los pueblos dependerá, en gran parte, del intercambio de informaciones que hagan desaparecer los malentendidos y promuevan los intereses comunes. Muchos publicistas lo consideran una de las principales condiciones para la manutención de una paz permanente.

Las Constituciones y las leyes de numerosos Estados consignan la "libertad de la prensa" como un derecho separado y distinto, rodeado de garantías especiales y sujeta a condiciones también especiales. En importancia práctica la prensa pública, por su carácter permanente y sus relaciones políticas, económicas y sociales, continúa siendo el medio más importante para la expresión de la opinión pública y para la educación del pueblo en los asuntos de interés general. Desgracidamente, ${ }^{14 \mathrm{E}}$ su responsabilidad no ha sido establecida debidamente en la misma forma en que han sido defendidos sus derechos. El servicio de la prensa pública se ha vuelto vital, al punto que en la mayoría de los países ha adquirido un carácter altamente privilegiado, dándosele el status de una institución, más que el de un simple medio para la expresión de opiniones individuales.

Pero ni la libertad de palabra ni ninguna de las libertades conexas han sido jamás consideradas como libertades absolutas e ilimitadas. Estas libertades se han calificado de "inherentes e inalienables" solamente en la forma relativa y calificada en que han sido establecidas y reconocidas. Como en el caso de otros derechos, el derecho de libertad de palabra y de expresión debe ser ejercido dentro del debido respeto por los derechos de los otros y para el bien general de la comunidad y la conservación del orden y seguridad públicos.

Que una de las experiencias fundamentales derivadas de la actual guerra mundial es que no puede haber libertad, ni paz, ni seguridad, si no se garantiza a los hombres el libre acceso a la verdad, a través de los diversos medios de información pública.

Recomienda:

$1^{\circ}$ Que las Repúblicas Americanas reconozcan la obligación esencial que tienen de garantizar a sus pueblos el acceso libre e imparcial a las fuentes de información.

$2^{\circ}$ Que teniendo presente esta garantía, una vez terminada la guerra, eliminen cuanto antes las medidas de censura y de restricción de los servicios de prensa, cinematógrafo y radiodifusión, que han sido necesarias en tiempo de guerra para combatir las tácticas políticas subversivas y el espionaje de las potencia del Eje.

$3^{\circ}$ Que los Gobiernos de las Repúblicas americanas adopten medidas, por separado y en colaboración unos con otros, para fomentar el libre intercambio de información entre sus pueblos.

$4^{\circ}$ Que las Repúblicas Americanas, al aceptar el principio del libre acceso de todos a las fuentes de información, hagan todo lo posible por lograr que, al garantizarse un orden jurídico en el mundo, se establezca el principio de la libre transmisión y recepción de informaciones, de palabra o por escrito, publicadas en el libro o en la prensa, difundidas por la radio o divulgadas por cualquier otro medio, bajo la debida responsabilidad y sin necesidad de previa censura, al igual que ocurre con la correspondencia epistolar, telegráfica o de cualquier otra clase de los particulares en tiempos de paz.

$14 \mathrm{E}$ Sic. Nota del editor A. P. D. 
La determinación de las limitaciones a que está sujeta la libertad de palabra y de expresión es un asunto que concierne a la ley de cada Estado en particular; pero a condición de que no se sacrifique fundamentalmente el derecho en sí. Está universalmente reconocido que la libertad de palabra no se debe utilizar como justificación para la difamación o la injuria. Aquí entra en función el principio de reciprocidad de derechos y deberes; y el individuo, al mantener su propio derecho a la libertad de palabra, debe respetar el mismo derecho de los otros al goce de su reputación y tranquilidad personales.

En igual forma, la libertad de palabra no debe convertirse en justificación para el empleo de lenguaje o publicaciones encaminados directamente a [26] provocar la violencia. La incitación a la violencia es contraria al principio de todo régimen democrático. Ella se justifica solamente cuando el Estado viola los derechos fundamentales en forma tal que no exista posibilidad de obtener reparación por los medios jurídicos.

La libertad de palabra tampoco debe ser empleada como un medio para la difusión de propaganda subversiva, tal como fué practicada en el extranjero por los países del Eje, en tanto ellos clausuraban arbitrariamente los medios de información en sus propios países. La Resolución VII de la Conferencia sobre Problemas de la Guerra y de la Paz reconoce que la propaganda de doctrinas totalitarias en este continente crearía un peligro para el ideal democrático americano, y prevé medidas para la eliminación de los centros de influencia subversiva.

El Comité Jurídico reconoce que no siempre es posible trazar una línea rigurosa que señale las limitaciones de la libertad de palabra con relación a la conservación del orden público. Cada Estado deberá trazar esta separación por si ${ }^{15 \mathrm{E}}$ mismo, siempre que las restricciones impuestas en interés del orden público no desmedren fundamentalmente el derecho de libre expresión.

El proyecto de Declaración prohibe en forma absoluta la censura previa de la prensa. Esto no exime a la prensa de la responsabilidad por la publicación de ataques injuriosos a particulares o funcionaros públicos, ni protege a la prensa contra las consecuencias de publicar informaciones falsas. Se establece, sin embargo, que el carácter ofensivo de determinadas publicaciones de prensa sea objeto de calificación judicial de acuerdo con las leyes.

El proyecto de Declaración reconoce que el cinematógrafo debe ser reglamentado por leyes especiales, en el sentido de proteger al público contra exibiciones ${ }^{16 \mathrm{E}}$ contrarias a las normas aceptadas de moralidad pública. La razón para que se ejerza un contralor más restrictivo en el caso del cinematógrafo, y nó en el de la prensa, se debe al hecho de que el cinematógrafo impresiona más viva y gráficamente la imaginación de los espectadores y, por lo tanto, es capaz de provocar reacciones de mayor alcance. En consecuencia, el Estado puede, si así lo juzga conveniente, exigir que los "films" sean sometidos a prévia ${ }^{17 \mathrm{E}}$ censura antes de su exibición ${ }^{18 E}$ pública.

En los últimos años el empleo de la radiodifusión se ha convertido en uno de los medios más importantes para la expresión de ideas y para la propaganda de todo género. Algunos Estados han colocado los medios de radiodifusión bajo su control directo. En el caso de gobiernos totalitarios, la radiodifusión ha sido empleada en muchas ocasiones como vehículo de falsa propaganda, directamente perjudicial para la conservación de las relaciones pacíficas entre los

\footnotetext{
15E Sic. Nota del editor A. P. D.

$16 \mathrm{E}$ Sic. Nota del editor A. P. D.

17 Sic. Nota del editor A. P. D.

$18 \mathrm{E}$ Sic. Nota del editor A. P. D.
} 
Estados. En consecuencia de esos abusos, el Comité Jurídico considera que es aconsejable incluir la prohibición del monopolio gubernamental de la radiodifusión, porque éste es un medio de negar a los individuos o a las asociaciones el uso de un instrumento para la libre expresión de opiniones.

\section{ARTÍCULO IV \\ DERECHO DE LIBERTAD RELIGIOSA}

Toda persona tiene el derecho de libertad de creencia y de culto religiosos.

[27] Este derecho comprende la libertad de culto tanto en público como en privado; la libertad de culto por grupos o por individuos; la libertad de sostener iglesias y otros lugares de culto público y de reunirse en ellos sin restricciones; la libertad de los padres de educar a los hijos en su creencia religiosa y la libertad de propaganda religiosa en forma escrita o hablada.

Las únicas restricciones que el Estado puede imponer a la libertad de culto son aquéllas exigidas por los requisitos de salud pública, seguridad y sana moral; pero dichas restricciones deben conformarse con las leyes generales y serán fijadas sin discriminaciones.

Existe una diferencia entre las actividades estrictamente religiosas y otras actividades de carácter económico y financiero, asociadas al sostenimiento del culto, pero que no forman parte esencial del mismo. Estas actividades económicas o financieras pueden ser reglamentadas por el Estado, de conformidad con las leyes generales que rigen tales actividades.

En la misma forma que la libertad de palabra y de prensa, la libertad de creencia y cultos es uno de los derechos tradicionales garantizados en las Constituciones de los Estados democráticos. Las creencias religiosas, desde los tiempos primitivos, han ejercido una gran influencia sobre el hombre y la intensidad de esa convicción ha hecho que frecuentemente un sector religioso procure proteger sus creencias oprimiendo y persiguiendo las de otros de diferente credo. Algunas de las páginas más obscuras de la historia son aquéllas que describen las guerras religiosas, tales como la Guerra de los Treinta Años, que terminó con la Paz de Wesphalia. Con la colonización del Nuevo Mundo y el desarrollo de Estados independientes, el principio de tolerancia religiosa llegó a ser generalmente reconocido, y poco a poco pasó de una teoría abstracta a una norma práctica de conducta, respetada y amparada por la ley.

La Declaración incluye la libertad de creencias religiosas y la manifestación externa de las creencias en actos de culto. Aun cuando no exista duda de que la libertad de creencias, como la libertad de opinión en otros asuntos, está fuera del alcance de la intervención directa del Estado, se considera aconsejable afirmar este derecho pues en reiteradas ocasiones se ha procurado eliminarlo por medios indirectos, como la fiscalización de las fuentes de información. Estas medidas indirectas tienen su condenación en otros artículos de la Declaración; pero, se considera esencial proclamar la libertad de creencias, o "libertad de conciencia", en categoría de derecho con expresión propia.

La Declaración presenta los derechos conexos que necesariamente deben acompañar a la libertad de creencias y cultos, si ha de dársela ${ }^{19 \mathrm{E}}$ una aplicación práctica. El derecho del culto público y privado debe ser respetado; así mismo el ejercicio por grupos organizados o individuos aislados. A los grupos organizados se les debe asegurar el derecho de sostener templos, o sea lugares permanentes de culto público, y garantizarles el derecho de reunión en dichos lugares, sin necesidad de obtener previamente el consentimiento del Estado para

\footnotetext{
19E Sic. Nota del editor A. P. D.
} 
cada reunión. Las leyes sobre propiedad no deben ser de tal carácter que interfieran en la administración que los grupos religiosos ejercen sobre sus locales destinados al culto.

[28] La libertad de creencias y de cultos claramente incluye la libertad para propagar la fé de cada grupo. Los padres deben gozar de la libertad de educar a los hijos en sus propias creencias religiosas; los grupos organizados deben tener el derecho de enseñar tanto públicamente como en privado; debe existir libertad para la distribución de impresos en forma de propaganda religiosa, así como para emplear los otros medios de difusión, a los cuales se ha hecho referencia al tratar de la libertad de palabra y de expresión. La Resolución XLI de la Conferencia sobre Problemas de la Paz y de la Guerra reafirma "el principio reconocido por todos los Estados Americanos de igualdad de derechos y oportunidades para todos los hombres, sin consideración de raza o religión".

Pero, para que esta libertad sea respetada y defendida por el Estado, debe someterse a las leyes establecidas para la protección de la salud pública, seguridad, moral y bienestar general, en cada país. Los ritos religiosos que representen un peligro para la salud pública pueden, por lo tanto, ser reglamentados de modo a evitar ese riesgo. No se podrán justificar las prácticas contrarias a la moral con la alegación de que constituyen manifestaciones de credos religiosos.

Corresponde a cada Estado, en particular, el establecimiento de las restricciones necesarias a la libertad de cultos; pero ellas deben obedecer a leyes de carácter general, aplicadas sin discriminación, y no deberán afectar substancialmente el derecho en sí mismo.

Uno de los principales problemas relacionados con la libertad de cultos, hoy en día, es la diferencia que se debe establecer entre las actividades estrictamente religiosas y las otras actividades de carácter económico o financiero, relacionadas con el mantenimiento del culto, pero sin formar parte esencial del mismo. La división entre estas dos clases de actividades solamente puede ser señalada cuando se presenten casos concretos, que cada Estado resolverá. Sin embargo, se juzga conveniente reconocer en esta Declaración el hecho de que esa distinción existe, y que su determinación en cada caso particular debe hacerse de modo que se armonicen el principio de la libertad religiosa con el derecho del Estado de reglamentar la vida normal, económica y financiera del país.

Si por una parte las organizaciones religiosas tienen el derecho de sustentar principios morales, por otra tienen la obligación de abstenerse de intervenir en las luchas de los partidos políticos.

\section{ARTÍCULO V \\ DERECHO DE LIBERTAD DE REUNIÓN}

Toda persona tiene el derecho de reunirse pacíficamente, con otras, para tratar asuntos de interés común.

El Estado está obligado a permitir el uso de los sitios públicos para esas reuniones; pero tiene el derecho de ser informado de las reuniones que deban efectuarse en lugares públicos, a designar localidades y a imponer condiciones para el uso de tales sitios, en interés de la seguridad y orden públicos. Condiciones parecidas pueden ser impuestas a las [29] asambleas celebradas en recintos cerrados, públicos o particulares. Pero las condiciones impuestas por el Estado para la realización de reuniones públicas no deben ser tales que sacrifiquen fundamentalmente dicho derecho. Ninguna condición será necesaria para la reunión de pequeños grupos de personas en sitios públicos o privados. El derecho de reunión incluye el derecho de realizar desfiles públicos, sujetos a las mismas restricciones a que están sujetas las asambleas. 
El derecho de reunión figura entre los derechos garantizados por las Constituciones de los Estados democráticos. Es un derecho sin el cual los hombres no podrían actuar colectivamente para la protección de sus otros derechos, o para el fomento de sus intereses comunes.

De tiempo en tiempo gobiernos despóticos han procurado negar el derecho de reunión, para evitar que la colectividad ciudadana ejerza fiscalización sobre su política, y por esta razón el derecho de asociación ha sido considerado, generalmente, como vinculado a las reuniones de carácter político. Su alcance es tan amplio como lo requieren los intereses que los ciudadanos desean promover por medio de la acción pública.

El derecho de reunión depende para su ejercicio del derecho de usar las plazas y otros lugares públicos, así como edificios públicos y particulares que se encuentren en condiciones adecuadas para reuniones de esta naturaleza. Correlativamente el Estado tiene el derecho de reglamentar el uso de tales lugares, de modo que se protejan debidamente los intereses del público, para asegurar que el derecho de reunión no sea aprovechado en practicar actos de violencia. Por esta razón se reconoce que el Estado tiene el derecho de ser informado previamente de las reuniones que van a celebrarse en lugares públicos, designar los locales apropiados para esas reuniones, e imponer limitaciones con el fin de mantener la ley y el orden. La Declaración especifica que las condiciones impuestas para la celebración de reuniones públicas no deben ser de tal naturaleza que lleguen a anular el derecho de reunión. La necesidad de un permiso prévio $^{20 \mathrm{E}}$ para celebrar reuniones no se aplicará a grupos reducidos que no son susceptibles de ofrecer ningún peligro apreciable.

El derecho de reunión no implica el derecho de expresar públicamente opiniones que inciten a la violencia, y que constituyan una amenaza para la seguridad del Estado. Los derechos de libertad de palabra y de reunión no pueden ser ejercidos para la propagación de sistemas de gobierno basados en principios que representan una negación de los derechos fundamentales del hombre.

\title{
ARTÍCULO VI DERECHO DE LIBERTAD DE ASOGIAGIÓN
}

\begin{abstract}
Toda persona tiene el derecho de asociarse con otras personas para proteger y promover intereses legítimos.

El Estado tiene el derecho de adoptar medidas que reglamenten las actividades de las asociaciones, siempre que sean aplicadas sin distinción contra cualquier grupo particular, y siempre que no perjudiquen fundamentalmente el derecho de asociación.
\end{abstract}

[30] La libertad de reunión está estrechamente relacionada con el derecho de asociación; pero en vista de que presenta problemas especiales que le son propios, y que las Constituciones de muchos Estados Americanos la proclaman separadamente, el Comité Jurídico considera conveniente declararla como un derecho distinto. Es verdad que no siempre es posible trazar claramente la diferencia entre derecho de asociación y derecho de reunión, pero existen diferencias fundamentales entre el carácter de las restricciones que el Estado puede imponer respectivamente al ejercicio de estos dos derechos, justificándose de esta manera el hecho de que sean contemplados en artículos separados.

El derecho de asociación se ha presentado bajo diversas formas en las diferentes épocas, de acuerdo con las condiciones del tiempo y las necesidades de clase, para fomentar o prote-

\footnotetext{
$20 \mathrm{E}$ Sic. Nota del editor A. P. D.
} 
jer sus intereses propios. En la actualidad se organizan asociaciones para innumerables fines, que varían desde los pequeños grupos sin personalidad jurídica, hasta las grandes potentes organizaciones que ejercen poderosa influencia en la vida política, económica y social del Estado. En muchos Estados los partidos políticos, aun cuando no son parte del Gobierno en sí, constituyen la fuerza dominante en la determinación de la política interna. Las Asociaciones ${ }^{21 \mathrm{E}}$ de industriales, cámaras de comercio, y sociedades mercantiles y de agricultores han venido a ejercer influencias de trascendental alcance en la vida económica del país, dentro de los respectivos campos en que desenvuelven sus actividades. En algunos Estados las organizaciones cooperativas funcionan como si fuesen municipalidades independientes. Existe también una gran variedad de organizaciones con objetivos sociales. La gran mayoría de las personas procura en estas organizaciones la protección y el desenvolvimiento de sus intereses particulares, a diferencia de sus intereses como miembros de la comunidad general.

En consecuencia, mientras hace un siglo se prestaba mayor atención al derecho de formar asociaciones, ahora esa atención se dirige, de preferencia, al derecho del Estado de reglamentar las grandes asociaciones, que llegan a rivalizar con el propio Estado, por la grandeza de su poder y la fidelidad de sus miembros. Es evidente que el bienestar social deberá siempre sobreponerse a las exigencias de un sector del pueblo, o de una clase económica o social. El Estado debe tener así el derecho de intervenir para proteger el interés público contra el interés de un grupo, pero sin dejar de respetar por eso los derechos fundamentales del hombre.

De ahí que el proyecto de Declaración reconozca el derecho del Estado de adoptar disposiciones que reglamenten la actividad de las asociaciones. Esa reglamentación deberá aplicarse por igual a todas las asociaciones dentro de la misma clase, y no debe ser tan rigurosa que sacrifique fundamentalmente el mencionado derecho. En este punto, el problema principal consiste en establecer la responsabilidad de los dirigentes de la asociación por los actos de ella, y el grado de responsabilidad que la asociación debe asumir por los actos de sus miembros, de acuerdo con los estatutos de la organización.

El proyecto de Declaración no llega al extremo de afirmar que el derecho fundamental de asociación comprenda al mismo tiempo el derecho de formar asociaciones basadas en el principio de las asociaciones corporativas como diferentes de las de responsabilidad personal. Pero es práctica general de todos los Estados permitir la formación de compañías privadas de responsabilidad limitada; y está admitido que el Estado puede someter esas sociedades a disposiciones especiales con el objeto de establecer la responsabilidad de sus directores, para la protección del público en sus relaciones con ellas. [31]

\section{ARTÍCULO VII DEREGHO DE PETICIÓN}

Toda persona tiene el derecho, ejercido por acción individual o colectiva, de presentar peticiones al gobierno para la reparación de agravios o sobre cualquier otro asunto de interés público o particular.

La publicación de dichas peticiones no puede tomarse como base para castigar de ningún modo, directa o indirectamente, a la persona o personas que formulen la petición.

$21 \mathrm{E}$ Sic. Nota del editor A. P. D. 
El derecho de petición, bien para la reparación de agravios o en razón de cualquier otro interés público o privado, está tan claramente definido como los derechos de reunión y de asociación. En la Declaración de Derechos de la Constitución de los Estados Unidos y en otras constituciones, el derecho de reunión y el derecho de petición aparecen como partes de un solo derecho. En las Constituciones de ciertos Estados Americanos se enuncian separadamente. El Comité Jurídico considera conveniente, para mayor claridad, presentarlos en dos artículos distintos.

El derecho de petición puede ser ejercido tanto por individuos como por colectividades. Su fin directo es llamar la atención pública o de las autoridades hacia situaciones no solucionadas por la acción normal del gobierno nacional o de los gobiernos locales. En consecuencia, es esencial que el derecho de petición se vincule al derecho de publicar las peticiones, de manera que éstas puedan llegar al conocimiento del público en general. El proyecto de Declaración establece, por lo tanto, que la publicación de una petición no será considerada base para proceder en cualquier forma, directa o indirectamente, contra la persona o personas que la presentan.

\section{ARTÍCULO VIII DERECHO DE PROPIEDAD}

Toda persona goza del derecho de propiedad.

El Estado tiene el deber de cooperar con el individuo para que éste consiga un mínimo de propiedad privada correspondiente a las necesidades esenciales de una vida decorosa, y que contribuya a mantener la dignidad de la persona humana y la santidad de su hogar.

El Estado puede determinar por ley las limitaciones susceptibles de ser impuestas a la propiedad, para el mantenimiento de la justicia social y para promover el interés de la comunidad.

El derecho de propiedad privada comprende el derecho de la libre disposición de la propiedad, sujeta sin embargo a las limitaciones impuestas por el Estado en beneficio de la permanencia del patrimonio familiar

La propiedad privada está subordinada al derecho del Estado de expropiarla de conformidad con las normas públicas mediante justa indemnización.

El derecho de propiedad, declarado en un sentido general, encuentra expresión directa o indirecta en las Constituciones de casi todos los países. [32] Este es un derecho tan profundamente arraigado en la naturaleza del hombre que las disposiciones constitucionales más antiguas reconocen su existencia y se limitan a prohibir cualquier acción de parte del Estado que pueda privar al individuo de la vida, de la libertad y de la propiedad, sin el debido procedimiento legal. El Comité Jurídico considera preferible declarar este derecho en forma positiva, prohibiendo, por lo tanto, la intervención del Estado en el ejercicio normal de ese derecho.

Los Estados Americanos, herederos del Derecho Romano y Anglo-Sajón, consideraron, desde su formación, el derecho de propiedad privada como algo sagrado, y han orientado su legislación en el sentido de proteger la propiedad, real y personal, con relación a la posesión y uso, herencia o transferencia, contratos, impuestos, y otras relaciones comerciales y públicas.

El problema de las limitaciones del derecho de propiedad es relativamente moderno. Siempre se reconoció al Estado el derecho del dominio eminente, de acuerdo con el cual puede expropiar la propiedad particular por causa de utilidad pública, mediante justa compensación. Pero en estos casos, el derecho mismo de propiedad privada no se discute. Última- 
mente, sin embargo, se ha llegado a reconocer que la propiedad tiene una "función social". Han progresado las teorías de la justicia distributiva, acentuándose la necesidad de asegurar a toda persona un mínimum de propiedad privada conforme a las exigencias de un nivel de vida aceptable. La acumulación de grandes fortunas trajo a muchos Estados la convicción de que era imposible la existencia de la democracia y de la libertad frente a una gran desigualdad entre ricos y pobres. Para atenuar esa disparidad se ha recurrido al gravamen de las rentas y herencias. Muchos Estados se inclinan a convertir en propiedad del Estado los servicios de utilidad pública que atienden a las necesidades del pueblo. Estas reformas van produciendo modificaciones de importancia en el derecho de propiedad, pero sin negar el derecho en sí mismo.

Por otra parte, la política de propiedad colectiva se ha desenvuelto en algunos países, al punto de aparecer como una negación del principio fundamental del derecho de propiedad privada. El futuro decidirá si la aplicación práctica de esta política deba modificarse a su debido tiempo, de modo a reconocer el derecho de propiedad sobre pequeñas parcelas de tierra. Hasta ahora ninguno de los Estados Americanos ha acogido las teorías en las cuales se basa esa política; ni tampoco ha demostrado la intención de negar ese derecho, en el sentido restrictivo conforme al cual el proyecto de Declaración lo proclama como un derecho fundamental.

En vista de las opiniones divergentes sobre el carácter y alcance de las limitaciones que pueden o deberían aplicarse al derecho de propiedad, el Comité Jurídico ha considerado conveniente presentar un padrón mínimo de propiedad privada que no solamente debe ser reconocido por el Estado, en el caso de personas que ya lo poseen, sino que debe considerarse como un objetivo social en el caso de personas que aun no lo han alcanzado.

De acuerdo con la definición del anteproyecto, ese padrón mínimo de propiedad privada debe basarse en las necesidades esenciales de una vida decorosa. Toda la Declaración de Derechos y Deberes se inspira en el concepto de que el ser humano posee una dignidad y valor inherentes, a los cuales se les debe proporcionar la más completa oportunidad para su pleno desenvolvimiento. La propiedad es indispensable para la prosperidad de los atributos físicos y morales del hombre. En los casos especiales en que el individuo no pueda alcanzar [33] por sus propios esfuerzos lo necesario a una existencia conveniente, el proyecto de Declaración coloca en el Estado el deber de cooperar con el individuo para que éste logre ese objetivo. Al obrar así el Estado utiliza sus propios recursos; y como esos recursos provienen del pueblo, en general, puede decirse que las medidas que el Estado tome con ese fin, son de justa distribución, y así la propiedad cumple su función social.

El Comité Jurídico no procura fijar, ni siquiera aproximadamente, la extensión máxima de propiedad privada. Hoy se reconoce generalmente que la interpretación amplia que se daba a los derechos de propiedad con relación a las empresas industriales, representa una concepción enteramente diversa de aquélla que se asocia con las necesidades de una existencia decorosa y el desenvolvimiento de la personalidad del individuo. El problema de establecer el límite de la propiedad personal y real que el individuo pueda poseer, para evitar los abusos, es una cuestión interna que corresponde resolver a los Estados en particular. Las condiciones económicas y sociales varían de Estado a Estado, y no puede establecerse ninguna regla general sobre la materia. La "Justicia Social", en los términos en que se usa en la actualidad la expresión, admite las más diversas interpretaciones, de acuerdo con la intensidad o extensión en que el bienestar social pueda ser promovido, alentando la iniciativa privada en algunos casos y controlándola en otros. 
El proyecto de Declaración establece que el derecho de propiedad privada comprende el derecho de disponer libremente de ella. Podrían constituir una excepción las limitaciones impuestas por el Estado sobre la propiedad respecto de la cual el propio Estado ha sido parte contribuyente para el fondo de un más elevado nivel de vida, o las limitaciones impuestas a la transferencia del patrimonio familiar.

\section{ARTÍCULO IX \\ DERECHO DE NACIONALIDAD}

Toda persona tiene derecho a una nacionalidad.

Ningún ${ }^{22 E}$ Estado puede negar su nacionalidad a las personas nacidas en su territorio, de padres legalmente presentes en el país.

Ninguna persona puede ser privada de su nacionalidad de nacimiento, salvo que por su propia y libre voluntad adquiera otra.

Toda persona tiene el derecho de renunciar a su nacionalidad de nacimiento, o a la que haya adquirido, en el momento de adquirir una nueva nacionalidad en otro Estado.

El problema de los apátridas es relativamente moderno. Antes de la primera ${ }^{23 E}$ Guerra Mundial pocos Estados consideraban dentro de la órbita de su política interna negar su nacionalidad a personas nacidas en su territorio, o nacidas de padres de la nacionalidad del Estado. También eran pocos los Estados que negaban la naturalización a las personas domiciliadas por largo tiempo en sus territorios, y que se encontraban en condiciones de cumplir con los requisitos exigidos para la nacionalización, excepto en los casos en que las divergencias raciales llegaban al punto de hacer demasiado difícil la asimilación.

Pero, en los últimos años, algunos Estados comenzaron a privar de su [34] nacionalidad a personas pertenecientes a minorías raciales, no obstante su nacimiento en el territorio del Estado. Otros Estados privaron de su nacionalidad a personas que, habiendo nacido en su territorio, pasaron después a residir en el extranjero, y en la misma forma a personas consideradas culpables de delitos políticos u otros crímenes. Son frecuentes los casos de personas naturalizadas a quienes se priva de la nacionalidad, sin que les sea posible readquirir la nacionalidad anterior.

Consecuencia de estos actos es que el número de apátridas va en aumento; y en muchos casos tales personas, siendo extranjeras en el país de refugio, no reciben toda la protección de la ley. Los padecimientos a que se ven sometidas son incompatibles con la dignidad del ser humano. En numerosas ocasiones han sido también víctimas de graves injusticias de parte de las autoridades administrativas y judiciales del Estado de refugio.

El proyecto de Declaración se concreta a declarar que un Estado no debe negar su nacionalidad a personas nacidas en su territorio. Esto limita, sin duda, el derecho a una nacionalidad a proporciones en cierto modo estrechas, y no ofrece protección a personas residentes en otros países que no son los de su nacimiento. En la práctica, sin embargo, tales personas, si son menores, pueden tener la protección de la nacionalidad de sus padres, y si son adultas, podrán adquirir la nacionalidad mediante el procedimiento legal de naturalización. El Comité Jurídico no juzga apropiado el momento actual para formular una regla general respecto al conflicto entre el jus soli y jus sanguinis; ni juzga conveniente imponer a los Estados la obligación absoluta

\footnotetext{
$22 \mathrm{E}$ Sic. Nota del editor A. P. D.

23E Con minúscula en el original. Nota del editor A. P. D.
} 
de conceder la naturalización a todas las personas residentes en su territorio, sin tomar en consideración las circunstancias bajo las cuales entraron al país.

Por otro lado, se observará que el anteproyecto de Declaración, en sus líneas generales, ha sido formulado en favor de "personas", sin especificar si se trata de nacionales o extranjeros; de modo que con el transcurso del tiempo, cuando los principios de la Declaración se hayan aceptado como normas para las relaciones interamericanas, ${ }^{24 \mathrm{E}}$ los extranjeros recibirán igual protección que los nacionales, y desaparecerán en su mayor parte, los inconvenientes y, en ciertas ocasiones, las injusticias inherentes a la falta de nacionalidad. En las actuales condiciones, sin embargo, el Comité Jurídico considera conveniente afirmar el derecho a la nacionalidad, como un derecho separado y distinto de los otros.

El Comité Jurídico recomienda, al mismo tiempo, que los Estados Americanos adopten medidas especiales para resolver los casos de los refugiados o inmigrantes que en consecuencia de modificaciones territoriales o alteraciones políticas, en otros continentes, se han visto imposibilitados de regresar, o lo han rehusado, al país de su nacionalidad, no deseando naturalizarse en el Estado en que se encuentran. Se espera que la Asamblea General de las Naciones Unidas adopte medidas rápidas para la protección de esas personas. Después de la primera guerra mundial, ${ }^{25 \mathrm{E}}$ la Liga de las Naciones tomó las disposiciones por las cuales se crearon los "Pasaportes Nansen", para atender a los refugiados que se encontraban temporalmente sin nacionalidad, o que se hallaban imposibilitados de recibir la protección del Gobierno del Estado del cual eran naturales. Podría adoptarse un sistema parecido de protección internacional para la situación actual.

El derecho de la persona a renunciar la nacionalidad de nacimiento está claramente expreso en la ley de la gran mayoría de los Estados Americanos. Sin ese derecho, la personalidad del individuo quedaría subordinada a la política del Estado del cual es nacional, por el hecho accidental de haber nacido en su territorio. Aun cuando se reconoce que el Estado puede hacer del pago de deudas, sean públicas o privadas, una condición para permitir la salida del país, éste no puede [35] crear condiciones que sacrifiquen el derecho de renunciar a la nacionalidad. El Estado existe para el hombre, no el hombre para el Estado; y constituye una violación del derecho fundamental de libertad personal, desconocer al hombre el derecho de convertirse en ciudadano de otro Estado que está dispuesto a aceptarlo como nacional.

\section{ARTÍCULO X DERECHO DE LIBERTAD DE RELACIONES FAMILIARES}

Toda persona tiene el derecho de estar libre de intervención en sus relaciones familiares.

Es deber del Estado respetar y proteger los derechos recíprocos de marido y mujer, en sus relaciones mutuas.

Los padres tienen el derecho de patria potestad sobre sus hijos durante su minoridad, y la obligación de mantenerlos y ampararlos.

Es deber del Estado ayudar a los padres en su esfuerzo para mantener normas adecuadas al bienestar de la niñez en el núcleo de la familia y de promover, en lo posible, la propiedad de hogares como un medio de fortalecer las relaciones familiares.

El Estado puede restringir la autoridad de los padres sobre sus hijos únicamente en cuanto los padres sean incapaces de cumplir sus deberes para con ellos o fracasen en su cumplimiento. Cuando sea necesario, el Estado debe proveer a la protección y amparo de tales hijos.

24E Las frase "relaciones interamericanas" se encuentra unida en el original. Nota del editor A. P. D.

25E Con minúsculas en el original. Nota del editor A. P. D. 
El respeto a la familia como una unidad moral y social está universalmente reconocido por los Estados Americanos de acuerdo con la tradición que hace diez y nueve siglos heredó la cristiandad. La unidad de la vida de familia no es una creación del Estado; es una situación surgente de la propia naturaleza del hombre. El concepto de la unidad de las relaciones de familia se halla tan profundamente arraigado en la tradición jurídica de los Estados Americanos, que no ha habido necesidad de formular la afirmación de este derecho fundamental del hombre en las declaraciones de derechos de las diferentes constituciones.

Con todo, en la época contemporánea aparecieron nuevas teorías de los derechos, predominantes en los Estados totalitarios, enderezadas, indirectamente, y algunas veces directamente, contra la unidad de la familia. La policía secreta infiltrada en los hogares, no ha vacilado en separar a sus miembros. Los hijos han sido aparatados violentamente de sus padres y educados en doctrinas hostiles a las de ellos, enseñándoseles que el deber para con el Estado es el más alto de todos los deberes, por encima del amor y lealtad debidos a la familia, y superior a cualquiera otra convicción de conciencia. La concepción mística de la entidad "Estado" se convirtió en objeto de devoción, casi de culto, y las violaciones de las normas tradicionales de moralidad y de justicia se han querido justificar como medios para promover el interés del Estado. Desde que estos principios repugnan a los pueblos americanos, se considera necesaria una salvaguardia contra ellos en vista de la proporción de simpatizantes que han conseguido en ciertos grupos, merced a la propaganda extranjera. En consecuencia, el proyecto de Declaración insiste en proclamar los derechos recíprocos del esposo y de la esposa y el derecho elemental de los padres de ejercer autoridad y vigilancia sobre sus hijos durante la minoridad, acompañado de la obligación primaria de mantenerlos y ampararlos.

El Estado, por su parte, tiene derechos y deberes en relación a la integridad del núcleo familiar. Su derecho se limita a la intervención entre padres e hijos en los casos excepcionales en que los padres estén imposibilitados de cumplir sus deberes para con sus hijos, o los desatiendan, a pesar de la asistencia del Estado. Los deberes del Estado son de mayor alcance aún; y uno de los aspectos [36] más expresivos de la cooperación interamericana en el campo de las relaciones sociales, es que se ha recalcado la necesidad de fortalecer los vínculos de la familia y de ayudar a los padres en las normas de bienestar de los hijos. La resolución LV de la Conferencia sobre Problemas de la Paz y de la Guerra, titulada "Carta de la Mujer y del Niño", asevera en su preámbulo "que la familia es la institución social primaria para la formación de la mente y el carácter de los niños", y aconseja la rápida aprobación de disposiciones y recomendaciones a favor de las mujeres, de los niños y de la familia. La Resolución LVI, sobre "Cuestiones Sociales", se refiere a la familia como "la fuerza más potente en el desarrollo de la mente y del carácter de la juventud" y recomienda medidas para la conservación de la familia y su bienestar. La "Declaración de Principios Sociales de América", de la misma Conferencia, dice: "la familia, como célula social, se proclama institución fundamental" y el documento recomienda "que el Estado dicte las medidas necesarias para asegurar su estabilidad moral, su mejoramiento económico y su bienestar social". En uno de los Estados Americanos se ha hecho recientemente la proposición de establecer el "sufragio familiar", señalándose la mayor responsabilidad que tienen los padres de familia.

Inspirado en estos ideales, el presente anteproyecto de Declaración consigna el deber del Estado de auxiliar a los padres en el bienestar de los hijos dentro del núcleo familiar, y al mismo tiempo el deber de promover, en lo posible, la propiedad de la casa habitación. El Artículo VIII del proyecto de Declaración expresa la necesidad de fomentar la propiedad privada, como un medio para mantener la dignidad humana y la unidad del hogar. El Comité 
Jurídico considera oportuno reafirmar en este artículo la estrecha relación que existe entre la propiedad de la casa habitación y el fortalecimiento de los vínculos familiares.

\section{ARTÍCULO XI \\ DEREGHO DE PROTEGGIÓN CONTRA LA PRISIÓN ARBITRARIA}

Toda persona acusada de delito tiene el derecho de no ser arrestada sino por mandato debidamente expedido de acuerdo con la ley, a menos que la persona sea sorprendida in fraganti. Tendrá el derecho a un juicio rápido, y a un tratamiento adecuado durante el tiempo que permanezca detenida.

En las Constituciones y leyes fundamentales de todos los Estados Americanos se encuentran disposiciones para la protección de las personas acusadas de crimen. Desgraciadamente no ha desaparecido la necesidad de mantener dichas disposiciones. Con frecuencia los gobiernos dictatoriales recurren a la detención arbitraria, sin causa alguna justificada, en caso de supuestos delitos políticos. Desde que el derecho de libertad personal, consignado en el Artículo II del proyecto de Declaración, depende del respeto a las leyes del Estado que prohíben ciertos actos reputados delictuosos, es de capital importancia que la persona no sea privada de su libertad por la supuesta comisión de un delito cuya existencia no se funda en hechos.

En consecuencia, el proyecto de Declaración dispone que ninguna persona puede ser detenida, sino en virtud de una orden emanada de autoridad competente. De acuerdo con la tradición, la orden de arresto debe designar por su nombre a la persona, calificar el delito del cual es acusada y especificar el [37] lugar de la detención donde debe ser recluida durante el juicio. Exceptúanse de esta disposición los casos de actual violencia o cuando el autor del delito es sorprendido in fraganti. En tales casos la protección contra detención arbitraria radicará en la presencia de los testigos del acto. En las condiciones actuales no es necesario exigir que el funcionario que practica la detención sea siempre portador de la orden, pues de lo contrario sería mayor la dificultad para prender a los delincuentes. Será suficiente la fijación de copias de la orden de prisión en lugares públicos.

La jurisprudencia de los Estados Americanos establece claramente el derecho de los acusados a exigir que se les juzgue sin demora. Históricamente, talvez sea ésta la protesta más necesaria del hombre contra la conducta arbitraria de los gobiernos. El derecho fundamental de libertad personal sería de poco valor si cualquiera persona pudiese ser detenida o presa indefinidamente, aguardando la instauración del juicio. De ahí la importancia atribuída al mandato de habeas corpus, mediante el cual un amigo del acusado puede obtener del Tribunal que corresponda, una orden que fije la fecha para la comparecencia ante las autoridades judiciales. La Constitución del Perú, Artículo 56, ofrece un buen ejemplo de esta disposición, al exigir que "cualquier persona detenida deberá ser presentada dentro de veinte y cuatro horas, o en el intervalo de tiempo necesario por la distancia, ante el tribunal, que deberá ordenar su libertad o emitir el mandato de prisión, dentro del tiempo marcado por la ley". Disposiciones semejantes se encuentran en las constituciones y leyes de garantía de los otros Estados Americanos.

Tan necesaria como la disposición relativa a que el acusado sea oído sin demora, es la exigencia de que se le trate sin vejaciones durante el tiempo de su detención. Es profundamente repulsivo a todo sentimiento humano emplear la tortura como medio para obtener confesión de culpabilidad del propio acusado o de otras personas. Ninguna declaración de derechos fun- 
damentales sería completa sin la prohibición del empleo de la tortura mental o física, durante las investigaciones para decidir si la persona deba ser procesada, o durante el proceso.

\title{
ARTÍCULO XII DERECHO A PROCESO REGULAR
}

\begin{abstract}
Toda persona acusada de un delito tendrá derecho a que su causa sea ventilada en audiencia imparcial y pública, a ser careada con testigos, y a ser juzgada por tribunales establecidos de acuerdo con la ley vigente en el momento en que fué cometido el acto. No podrá imponerse multa alguna sino de acuerdo con las especificaciones de las leyes generales, ni imponerse castigos corporales crueles y extraordinarios.
\end{abstract}

Con el propósito de señalarlos de modo especial, el Comité Jurídico ha preferido enunciar los derechos de las personas acusadas de delito, en dos artículos separados, distinguiendo el derecho contra detención arbitraria y el derecho a ser juzgado regularmente. Ambos se hallan consignados en las Constituciones de todos los Estados Americanos. A pesar de que el procedimiento penal debe ser establecido por cada Estado en particular, es conveniente enumerar algunos requisitos esenciales para la substanciación de un juicio regular. Ningún proceso podrá ser considerado como regular si alguien es condenado después [38] de ser oído en forma secreta, solamente. La publicidad de la prueba es esencial para la protección del acusado contra una condenación arbitraria. Para la substanciación de un juicio regular es necesario que éste sea ventilado ante un tribunal con jurisdicción sobre el delito del cual se acusa a la persona.

El efecto retroactivo de las leyes penales se halla expresamente prohibido por las Constituciones de la mayoría de los Estados Americanos, e implícitamente por todas. La Constitución de los Estados Unidos prohíbe que el Congreso dicte leyes ex post facto, es decir, aquellas leyes que castiguen delitos no castigables en la fecha en que fueron cometidos, o imponen otro castigo, además del prescrito anteriormente por ley, o modifican el procedimiento de pruebas en detrimento del acusado. La Constitución del Perú de 1933, explícitamente determina que: "Nadie podrá ser condenado por un acto u omisión que, en la fecha en que fué cometido, no estuviese previsto en forma expresa e incontrovertible como un delito sujeto a castigo".

La prohibición de usar crueldad en los castigos comprende los métodos de tortura que prolonguen los sufrimientos físicos del condenado y violen los sentimientos de humanidad.

\section{ARTÍCULO XIII DERECHO DE SUFRAGIO}

Toda persona, nacional del Estado, tiene el derecho de participar en las elecciones para la formación de los poderes legislativos y ejecutivo del gobierno, de acuerdo con las disposiciones de la Constitución nacional. El ejercicio de este derecho puede, sin embargo, ser condicionado al deber de la persona de probar que es competente para comprender los principios en que se funda la Constitución. La Constitución del Estado proveerá para la formación de un gobierno del pueblo, por el pueblo y para el pueblo.

Este derecho presupone el derecho de organizar partidos políticos.

A ninguna persona le será negado el derecho a desempeñar una función pública, o a ser designada para cualquiera de los servicios públicos del Estado del cual es nacional, por motivo de raza, religión o sexo, o cualquiera otra distinción arbitraria; y la administración de los servicios públicos del Estado se llevará también sin distinciones arbitrarias, en lo concerniente a nombramientos, períodos y condiciones de servicio. 
Declarado como un principio general, es claro que el derecho de participar en la elección del Gobierno, e indirectamente así, en la orientación de la política del poder público, es esencial para el goce de la verdadera libertad. La Declaración de Independencia de los Estados Unidos afirma el gran principio democrático de que el Gobierno "deriva su poder del consentimiento de los gobernados". Los Gobiernos son los agentes por intermedio de los cuales los pueblos formulan y ejecutan su voluntad colectiva. Un Gobierno que no emane de la voluntad del pueblo no es un agente de éste, sino su amo. La libertad del individuo debe estar sujeta, sin duda a restricciones impuestas por ley, para proteger la libertad de los otros y asegurar el bienestar general; pero su libertad fundamental no será sino una abstracción, si el individuo [39] mismo no participa en el establecimiento de esas restricciones.

La aplicación práctica del principio del gobierno por consentimiento de los gobernados crea, no obstante, numerosas dificultades. El Gobierno constituído por voluntad de los gobernados implica que las personas que participan de la elección de los miembros del Gobierno comprenden los objetivos generales de la Constitución y los medios que ésta consagra para que la voluntad del pueblo se manifieste. Aun cuando sea verdad que todo individuo tiene derechos humanos que proteger, y que la necesidad de protegerlos sea proporcionalmente mayor que sus necesidades morales y materiales, es evidente que si el individuo no es suficientemente competente para comprender la esencia del Gobierno, corre el peligro de perjudicar con su voto sus propios intereses.

El problema siempre presente a la atención de todo Estado democrático consiste en determinar la línea que separa el derecho abstracto del sufragio, como un instrumento para la elección de los miembros del Gobierno, de la capacidad real de algunas personas para usar su derecho de voto en beneficio de sus propios intereses y de los de la comunidad en general. El proyecto de Declaración deja que cada Estado determine las restricciones que deberán establecerse con relación al ejercicio del derecho de sufragio. Estas restricciones deberán aplicarse, de acuerdo con los términos del Artículo XVIII, a todas las personas, sin discriminación; ellas deben establecerse por medio de leyes generales, y deben permitir que una persona que haya perdido ese derecho, pueda más tarde recuperarlo, desaparecidas las causas por las cuales lo perdió.

En numerosas ocasiones los Estados Americanos han afirmado la necesidad de un tratamiento igual para las mujeres, en lo que respecta a la capacidad de sufragio. La Octava Conferencia Internacional de Estados Americanos, celebrada en Lima en 1938, declaró que entre otros, la mujer tenía el derecho al tratamiento político a base de la igualdad con el hombre, y urgió a los Gobiernos que aun ${ }^{26 \mathrm{E}}$ no lo hubiesen hecho, a que adoptasen la legislación necesaria para poner en práctica dicho principio. La Resolución XXVIII de la Conferencia sobre Problemas de la Guerra y de la Paz, titulada "Derechos de la Mujer en América", recomienda que los Gobiernos de las Repúblicas Americanas dentro de las condiciones peculiares de los respectivos países, modifiquen sus legislaciones con el objeto de hacer efectiva la Declaración de Lima, de modo que se elimine cualquier distinción subsistente por razones de sexo.

Teniendo en vista la posición adoptada con relación al status de igualdad de las mujeres en la vida política del Estado, el proyecto de Declaración emplea la palabra "persona" para indicar los individuos con derecho a participar en la elección del Gobierno. Al mismo tiempo que el proyecto de Declaración repudia taxativamente toda distinción por motivos de raza, religión o sexo, repudia también toda distinción basada en estos mismos motivos con relación al derecho de elegibilidad para funciones o cargos públicos, o en cuanto a los requisitos exigidos.

$26 \mathrm{E}$ Sic. Nota del editor A. P. D. 
El Comité Jurídico entiende que el principio declarado en el Artículo XIII, de que la administración civil del Estado, al ser, con relación a nombramientos y condiciones del servicio, libre de favoritismos y discriminaciones, implica que el Gobierno no podrá usar los medios de que dispone para presionar u obstruir la libre expresión de la voluntad popular.

El proyecto de Declaración no entra en consideraciones respecto del problema relativo al gobierno de pueblos retrasados que por falta de tradiciones [40] legales, orden y justicia, y por falta de experiencia del gobierno propio, no se consideran estar en condiciones de alcanzar el "status" de Estados democráticos. Los Estados Americanos no tienen colonias y, por lo tanto, el problema no los afecta. Este es un asunto que toca a la Asamblea General de las Naciones Unidas decidir.

Es importante señalar aquí que el derecho de sufragio implica una obligación de parte del ciudadano, no solamente para sufragar cuando la ocasión lo exige, sino sufragar con la convicción de que está cumpliendo un deber cívico al contribuir directa o indirectamente a la orientación de la política general del Gobierno y a la consecución de los medios de mejorar las condiciones de vida del pueblo en general. El Estado no es un mero conjunto de individuos; es la expresión histórica de los varios grupos sociales dentro de los cuales el hombre ha encontrado la oportunidad para el desenvolvimiento de sus mejores facultades. Comprende una herencia cultural de la cual el individuo se aprovecha profundamente para satisfacer sus necesidades morales y materiales. El hombre no puede disfrutar de los beneficios de la civilización, proporcionados por una vida social organizada, a menos que, dentro del límite de sus fuerzas, también él coopere lo más posible al desenvolvimiento de los grandes objetivos del Estado y a los de la ley, del orden, de la justicia y del bienestar general.

\section{ARTÍCULO XIV \\ DERECHO AL TRABAJO}

Toda persona tiene el derecho a trabajar, como medio de mantenerse a sí misma y de contribuir al sostenimiento de su familia.

Este derecho comprende el de seguir libremente una vocación en cuanto lo permitan las oportunidades de trabajo existentes. Tiene también el derecho de cambiar de empleo y de mudarse del lugar de un empleo para otro. Asociado al derecho de trabajar se encuentra el de formar uniones obreras y profesionales.

Toda persona tiene el deber de trabajar para contribuir al bienestar general del Estado.

El Estado tiene el deber de ayudar al individuo en el ejercicio de su derecho de trabajar cuando sus propios esfuerzos no son suficientes para la obtención de un empleo; debe hacer todo esfuerzo para promover la estabilidad de los empleos y para asegurar condiciones apropiadas de trabajo, debiendo fijar normas mínimas de justa compensación.

El Estado tiene el derecho, en caso de emergencia, de exigir los servicios del individuo, cuando dichos servicios sean requeridos para hacer frente a una necesidad pública urgente.

El derecho al trabajo se clasifica, como queda dicho, en el nuevo grupo de derechos sociales y económicos. Esto no significa, sin embargo, que sea por eso menos fundamental, sino que ha tenido que esperar las circunstancias creadas en los tiempos modernos para poder ser formulado en términos [41] precisos. Como un derecho fundamental, el derecho al trabajo es tan antiguo como el mandato bíblico que ordena al hombre ganar el pan con su propio esfuerzo. Durante el último cuarto del siglo XVIII, cuando se produjo la declaración formal de los derechos políticos del hombre, surgieron voces que indicaron la relación estrecha entre 
los derechos de libertad y las condiciones económicas y sociales. Pero los proyectos presentados tenían como objetivo principal el deber del Estado de acudir en auxilio del pobre y del anciano, y nó el derecho del hombre capaz, que estando en condiciones de ganarse la vida por medio del trabajo de su competencia, no podía hacerlo por no requerírsele. En el año 1848 los autores de la nueva Constitución Francesa discutieron ampliamente la inclusión del derecho al trabajo entre los derechos que debía garantizarse a los ciudadanos; pero llegaron a la conclusión de que no era apropiado considerar ese derecho como tal, porque una garantía implicaba una acción de la ley, cosa que no era posible en el caso del derecho al trabajo.

Pero el advenimiento de los períodos de desocupación en vasta escala, en los tiempos actuales, ha llevado a afirmar el derecho fundamental del hombre al trabajo, como base de un deber de parte del Estado para reglamentar la industria privada, para evitar, en lo posible, los repetidos ciclos de expresión económica con la consiguiente masa de desocupados; afirmándose, paralelamente, el deber del Estado de proporcionar oportunidades de trabajo que permita a las personas ganar la subsistencia por su propio esfuerzo. No se compadece con la dignidad de la persona humana que el hombre sea sustentado contínuamente ${ }^{27 \mathrm{E}}$ por la caridad pública o el auxilio del Estado; y es al mismo tiempo desmoralizador para el hombre permanecer ocioso.

A principios de 1943, el Presidente Roosevelt habló de la aceptación, evidente por sí misma, de una "segunda declaración de derechos", y puso en el primer lugar de la enumeración, "el derecho a un trabajo útil y remunerativo en las industrias, en los talleres, en los campos o en las minas de la nación". En la Carta de Filadelfia, adoptada por la Conferencia General de la Organización Internacional del Trabajo, el 17 de Mayo de 1944, se estableció el principio de que "todos los seres humanos, cualquiera que sea su raza, creencia, o sexo, tiene el derecho de procurar su bienestar material y su mejoramiento espiritual en condiciones de libertad y dignidad, de seguridad económica e iguales posibilidades", y la Conferencia procedió a elaborar un programa detallado para alcanzar dicho "objetivo fundamental"."

27 Sic. Nota del editor A. P. D.

* La Sección III de la Carta de Filadelfia declara lo siguiente:

La Conferencia reconoce la obligación solemne de la Organización Internacional del Trabajo de desenvolver entre las naciones del mundo programas que contemplen:

(a) La ocupación permanente y la elevación de los niveles de vida;

(b) el empleo de trabajadores en los oficios en los cuales puedan ellos sentir mayor satisfacción de poder dar plena demostración de su habilidad y de capacidad de realización, colaborando así para el bienestar común. [Sin punto y coma en el original, nota del editor A. P. D.]

(c) como medio de alcanzar este propósito y con las debidas garantías para [42] todos los interesados, crear facilidades para la preparación y mudanzas de oficios, incluyendo el cambio de empleo y de lugar de trabajo;

(d) normas con relación a jornales y sueldos, horarios y otras condiciones de trabajo, establecidas de modo a asegurar a todos una justa participación en los resultados del mejoramiento alcanzado, y un jornal mínimo a todos los que trabajan y que necesitan de esa protección. [Sin punto y coma en el original, nota del editor A. P. D.]

(e) el reconocimiento positivo del derecho de hacer contratos colectivos, la cooperación de la dirección y del trabajo para contínuo mejoramiento de la producción, y la colaboración de los patrones y obreros en la elaboración y aplicación de las medidas sociales y económicas;

(f) ampliar las medidas de seguro social para el establecimiento de un auxilio básico para todos aquellos que tengan necesidad de esa protección, además de la asistencia médica;

(g) protección adecuada para la vida y salud de los trabajadores de todas las profesiones;

(h) disposiciones para el bienestar de la infancia y protección y asistencia a la maternidad; 
[42] La aplicación práctica del derecho de trabajo presenta, indudablemente, muchas dificultades. De ahí que tanto el derecho del individuo como el deber correspondiente del Estado, solamente puedan enunciarse en términos generales.

El deber del Estado de ayudar al individuo en el ejercicio de su derecho no deberá entrar en conflicto con el derecho de libertad individual. El principio de la libre elección de profesión, y el de libertad de cambiar de empleo, deben ser respetados, pero sin colocar al Estado en dificultades para enfrentar el problema de la desocupación en masa. Por sobre todo, el deber del Estado de promover la estabilidad del trabajo, de asegurar las condiciones apropiadas y de fijar normas sobre justo salario mínimo, no debería conducir a las condiciones extremas que por exceso de reglamentación de la vida económica harían que el Estado democrático se convierta totalitario, sacrificando la libertad personal al derecho al trabajo.

Es obvio que cada Estado deberá determinar por sí mismo las medidas factibles y la manera de mantener el equilibrio entre el derecho de libertad personal y el derecho al trabajo. En la "Carta Económica de las Américas", adoptada por la Conferencia sobre Problemas de la Guerra y de la Paz, los Estados Americanos manifestaron su aspiración a un programa económico positivo que permita a los respectivos pueblos alcanzar mejores condiciones de vida, y afirmar, al mismo tiempo, la necesidad de conservar y fortalecer "la libertad de acción en el terreno económico, que sustenta a las instituciones de libertad política [43] y personal”. Se dice que las dos columnas sobre las cuales se puede edificar un programa económico positivo que satisfaga los deseos de los pueblos Americanos son "la elevación del nivel de vida y la libertad económica que promoverán la producción y el trabajo".

El proyecto de Declaración se limita a asentar ciertos principios generales, reconociendo que el objetivo sólo puede alcanzarse por etapas y por vias ${ }^{28 E}$ diversas de acuerdo con las condiciones de cada país.

El Proyecto de Declaración afirma no sólo el deber del individuo de contribuir con su propio trabajo al desenvolvimiento general de los recursos del Estado, sino también el de estar pronto para responder al llamamiento de la Nación en épocas de emergencia, cuando surja un peligro para la nación. Los derechos y deberes son recíprocos entre el individuo y el Estado, así como entre los individuos.

\section{ARTÍCULO XV \\ DERECHO DE PARTICIPAR EN LOS BENEFICIOS DE LA CIENCIA}

Toda persona tiene el derecho de participar en los beneficios resultantes de descubrimientos e invenciones de la ciencia, bajo condiciones que permitan una compensación razonable a la industria y a la capacidad de los autores del descubrimiento o invención.

El Estado tiene el deber de fomentar el desarrollo de las artes y ciencias: pero debe tomar medidas para que las leyes de protección de la propiedad literaria y artística, patentes de invención y marcas de fábrica y comercio no sean usadas para el establecimiento de monopolios que puedan impedir que todas las personas participen de los beneficios de la ciencia. Es el deber del

(i) garantía de alimentación adecuada, vivienda y facilidades para para [La preposición "para" se encuentra repetida en el original, nota del editor A. P. D.] las diversiones y la cultura;

(j) garantía de igualdad en la educación y oportunidad para seguir la vocación.

$28 \mathrm{E}$ Sic. Nota del editor A. P. D. 
Estado proteger al ciudadano contra el empleo de descubrimientos científicos que puedan crear la intranquilidad o atemorizar al pueblo.

El Artículo XV de la Declaración parte del principio que el Estado democrático es una entidad de carácter cooperativo, en que las oportunidades para descubrimientos e invenciones son el resultado del trabajo progresivo de muchas generaciones, cada una heredera del acervo de la civilización anterior y, como tal, tiene el derecho a participar colectivamente de los beneficios que sus hombres de genio son capaces de obtener de las facilidades puestas por la sociedad a su disposición. Al mismo tiempo el Artículo reconoce la necesidad de compensar el trabajo y la habilidad de descubridor o inventor, estimulando de esta manera los estudios o investigaciones, que pueden conducir a nuevos adelantos en el campo de la ciencia.

En este caso, como en el del derecho al trabajo, debe buscarse el equilibrio entre el estímulo a la iniciativa individual, por la concesión de patentes y derechos de autor, y la protección del público contra el abuso de los privilegios concedidos. El deber del Estado de proteger al individuo contra monopolios en la explotación de las riquezas naturales del Estado se halla reconocido en la legislación de todos los Estados Americanos. Es también deber del Estado reglamentar el uso de marcas de fábrica y patentes para evitar los monopolios de producción o distribución de los productos legalmente protegidos en esa forma, contra la competencia ilegal.

[44] Los últimos párrafos del Artículo, referentes a los descubrimientos que pueden provocar temor o inquietud en los pueblos, se dirigen principalmente contra el perfeccionamiento de los medios para el empleo de la energía atómica con fines de destrucción. En este caso la garantía del Estado a sus nacionales dependerá de la cooperación de otros Estados, en el mismo sentido. En vista de este nuevo progreso de la ciencia, puede decirse que el primero y más importante derecho del hombre es en la actualidad, nó únicamente el derecho a la vida, a su libertad individual y a otros derechos conexos, sino su derecho a preservar la civilización de que forma parte, y sin la cual la vida sería intolerable, para los mismos que pudiesen sobrevivir a la destrucción. Adquiere un mayor significado la garantía contra el miedo que la Carta del Atlántico consigna entre los resultados de la paz, porque los medios bélicos recién descubiertos son capaces de llevar la devastación de la guerra a sus lógicos extremos.

\section{ARTÍCULO XVI DERECHO DE SEGURO SOGIAL}

Toda persona tiene derecho al seguro social.

El Estado tiene el deber de ayudar a las personas a alcanzar el seguro social. Con este fin el Estado debe promover las medidas de salud y seguridad públicas y debe establecer sistemas de seguro social y agencias de cooperación, por medio de las cuales a todas las personas se les pueda asegurar un nivel de vida adecuado, y la protección contra las contingencias del desempleo, de accidentes, incapacidad, enfermedad y vejez.

Toda persona tiene el deber de cooperar con el Estado, de acuerdo con sus medios, en la manutención y administración de medidas tomadas para promover su propia seguridad social.

La afirmación del derecho de toda persona al seguro social se basa en la conservación de la dignidad humana, frente a todas las contingencias que puedan surgir, de las cuales no es responsable el individuo, durante el transcurso de su vida. Desde el comienzo de la era Cris- 
tiana se siguió reconociendo que los miembros más pudientes de la comunidad estaban en la obligación de contribuir al amparo de los necesitados. Sin menoscabo de esta obligación moral, se acepta ahora que el Estado tiene el deber de organizar sus recursos y emplear servicios públicos para asegurar la protección que hasta ahora ha sido otorgada de una manera incompleta. El individuo, como miembro del Estado, tiene el derecho al seguro social, no como una concesión graciosa, sino como parte que es de la entidad cooperativa de la Nación.

Los Estados Americanos, individual y colectivamente, han reconocido la necesidad de implantar la previsión y el seguro social. Algunas de las constituciones de los Estados Americanos son notables ejemplos de disposiciones detalladas en lo referente al seguro social, en todos sus aspectos. Las Conferencias Interamericanas han adoptado numerosas resoluciones en favor de la cooperación para el desenvolvimiento de las diversas formas de seguro social, y se han creado numerosos órganos para llevar a la práctica las disposiciones. La V Conferencia Internacional Americana, reunida en Santiago de Chile en 1923, adoptó una serie de resoluciones con relación a la administración de la salud pública y recomendó que los problemas sociales fuesen considerados en los programas de las futuras conferencias. Las conferencias de la Habana en 1928, de Montevideo [45] en 1933, de Buenos Aires en 1936 y de Lima en 1938, ampliaron progresivamente los planes para el mejoramiento de la salud pública, seguridad, bienestar moral y general de la comunidad Interamericana. A los actos de dichas Conferencias deben agregarse los de las conferencias técnicas periódicas sobre salud pública, y sobre protección de las mujeres, de los niños y de las clases trabajadoras.

En su discurso de 7 de Enero de 1941, el Presidente Roosevelt se refirió a la necesidad de estar exento de penuria, concepto que, traducido en términos de aplicación universal, significa un "entendimiento de carácter económico que asegure durante la paz en cada país, una vida sana a los habitantes, en todos los sectores del mundo". La Conferencia Interamericana de Seguridad Social, reunida en Santiago de Chile, en Setiembre de 1924, aprobó una serie de resoluciones que definen minuciosamente los diversos aspectos de la seguridad social y proponen medidas concretas para desarrollar un "programa continental" de cooperación a fin de alcanzar las finalidades del sistema. La "Declaración de México" estatuye que "la colaboración económica es esencial a la prosperidad común de las Naciones Americanas. La miseria de cualquiera de sus pueblos, ya como pobreza, desnutrición o insalubridad, afecta a cada uno de ellos y por tanto, a todos en su conjunto". La "Declaración de los Principios Sociales de América", aprobada en la misma Conferencia, particulariza la cooperación internacional en la solución de los problemas sociales como uno de los objetivos esenciales de la futura organización internacional, y acentúa la necesidad de "programas integrales de seguridad social", como un medio de proteger el trabajador contra la pérdida de salarios, causada por motivos ajenos a su voluntad.

Estas declaraciones y resoluciones Inter-Americanas han sido ahora complementadas por las disposiciones de la Carta de las Naciones Unidas. El Artículo 55 que trata de la Cooperación Internacional Económica y Social, establece que la Organización deberá promover:

niveles de vida más elevados, trabajo permanente para todos, y condiciones de progreso y desarrollo económico y social;

la solución de problemas internacionales de carácter económico, social y sanitario, y de otros problemas conexos; y la cooperación internacional en el orden cultural y educativo; y

el respeto universal a los derechos humanos y a las libertades fundamentales de todos, sin hacer distinción por motivos de raza, sexo, idioma o religión, y la efectividad de tales derechos y libertades. 
Se observará que el Artículo XVI del proyecto de Declaración presentado por el Comité Jurídico trata del derecho al seguro social en un sentido general, aplicable nó simplemente a las llamadas "clases trabajadoras", sino a todos los miembros de la comunidad. Aun cuando las disposiciones del artículo encuentran su aplicación principalmente entre los trabajadores manuales, la finalidad es extender el amparo a todos aquéllos que lo necesiten, sin distinciones por motivos de sus antecedentes económicos y sociales.

[46] El deber del individuo de cooperar con el Estado, dentro de sus posibilidades, en la preservación y administración de las medidas para fomentar el seguro social, está implícito en el principio de su participación en una comunidad cooperativa. Se considera conveniente, sin embargo, proclamar este deber en forma especial, para sentar de manera bien clara que el Estado no ha de ser considerado como una institución de caridad, a la cual el individuo puede recurrir sin contribuir con su aporte proporcional a la creación de los recursos necesarios.

\section{ARTÍCULO XVII DERECHO A LA EDUGACIÓN}

Toda persona tiene el derecho a la educación.

El derecho de los niños a la educación es primordial.

El Estado tiene el deber de ayudar al individuo en el ejercicio de este derecho a la educación, en conformidad con sus recursos. Las oportunidades de educación deben ser franqueadas a todos en iguales condiciones, de acuerdo con las capacidades naturales y el deseo de aprovechar las facilidades proporcionadas.

El Estado tiene el derecho de fijar normas generales a las cuales las instituciones educacionales deben ajustarse, siempre que estas normas se hallen de acuerdo con otros principios fundamentales y sean las mismas para las escuelas públicas o particulares.

El derecho a la educación comprende el derecho de enseñar, sujeto a las restricciones inherentes al ejercicio de aquel derecho.

El derecho a la educación, como los otros derechos económicos y sociales, se basa en el derecho del individuo a participar de los beneficios de la vida civilizada, en la medida en que el Estado, del cual es miembro, pueda ofrecérselos. No se necesita de ningún argumento para demostrar que el analfabeto no puede participar plenamente de la vida política, económica y social del Estado, y que no puede aprovecharse de las muchas posibilidades de desarrollo material y cultural que se le presentan, siendo también menos capaz de contribuir eficientemente al bienestar general. La educación es indispensable para el completo desenvolvimiento de la personalidad humana; y la concepción del Estado democrático, como una entidad cooperativa, justifica correlativamente la afirmación del derecho del individuo a la educación y el deber del Estado de auxiliar al individuo en su esfuerzo por alcanzarla.

Tomando en debida consideración la diversidad de los recursos, es evidente que los Estados Americanos no se encuentran todos en la misma situación de capacidad para dar a cada individuo las facilidades de obtener una educación conveniente. De ahí que el proyecto de Declaración formule tanto el derecho del individuo como el deber del Estado, en términos amplios, dejando que cada Estado lo cumpla progresivamente de acuerdo con los recursos de que disponga. Pero cualesquiera que sean estos recursos, deben ser puestos al alcance de todos, en igualdad de condiciones. La igualdad de posibilidades, como se acentuará al ocuparse del derecho general de igualdad, es una cuestión fundamental en la administración 
de los sistemas educacionales. Es evidente que los resultados prácticos de las medidas que tome el Estado dependerán de la aptitud individual de las personas, así como de su deseo de aprovecharse de las facilidades que el Estado se halle en condiciones de ofrecerles.

[47] El proyecto de Declaración establece que el Estado tiene no solamente el deber de ayudar al individuo en el ejercicio de su derecho a la educación, sino también el de fijar las normas generales a ser seguidas por las instituciones educacionales. Este derecho del Estado no llega al extremo de revestirlo del monopolio de las actividades educacionales, ni justifica el establecimiento de normas que en la práctica tengan por efecto negar el derecho de sostener instituciones educacionales privadas. El Estado tiene, sin embargo, el derecho de fiscalizar si la educación privada es en esencia del mismo nivel científico que la recibida en las instituciones oficiales. Aun cuando los padres tienen el derecho de educar a sus hijos, ese derecho debe ser ejercicio de conformidad con el derecho del Estado para vigilar la calidad de esa educación.

\title{
ARTÍCULO XVIII DERECHO DE IGUALDAD ANTE LA LEY
}

\begin{abstract}
Todas las personas son iguales ante la ley en lo que concierne al goce de sus derechos fundamentales. No habrá clases privilegiadas de ninguna índole.

Es deber del Estado respetar los derechos fundamentales de todas las personas dentro de su jurisdicción y de protegerlas en el goce de ellos contra la intervención de terceros.

En todos los procedimientos relacionados con los derechos fundamentales, el Estado debe actuar de acuerdo con las normas legales, y debe asegurar a cada persona la igual protección de la ley.

Las restricciones impuestas a los derechos fundamentales deben ser únicamente aquéllas que sean necesarios ${ }^{29 \mathrm{E}}$ para la conservación del orden público; y deben ser de carácter general y aplicables a todas las personas, dentro de una misma categoría.
\end{abstract}

El derecho de igualdad ante la ley se halla implícito en la propia existencia de los derechos fundamentales. Aun más, puede decirse que constituye la base teórica sobre la cual descansan todos los otros derechos fundamentales. La Declaración de Independencia de los Estados Unidos de 1776, que ha servido de modelo a otras declaraciones de derechos, establece: "Para nosotros son verdades incontestables que todos los hombres nacen iguales; que a todos les ha concedido el Creador algunos derechos inalienables, que entre éstos se encuentran la vida, la libertad y el derecho a conquistar la felicidad”. La Declaración de los Derechos del Hombre y del Ciudadano, dictada por la Revolución Francesa de 1789, afirma en su artículo primero, que: "Los hombres nacen y se conservan libres e iguales en derecho". La igualdad ante la ley es el primer derecho proclamado en las constituciones de Argentina, Brasil, Chile, Cuba y otros Estados Americanos.

Como un principio jurídico, de aplicación práctica, la igualdad ante la ley se refiere tanto a la esencia de los derechos como a la protección que se les debe dar por los órganos ejecutivos del Estado. Toda persona tiene igual derecho a exigir el respeto por la dignidad de su personalidad; todo individuo tiene el mismo derecho a la vida, a la libertad, y a todos los que se deriven de ellos, en las mismas condiciones en que son reconocidos a otros. Mientras

${ }_{29 E}$ Sic. Este error no aparece en la primera sección, donde se copia el anteproyecto completo. Nota del editor A. P. D. 
el individuo se halle capacitado para el ejercicio de esos derechos, podrá hacerlo sin ninguna restricción legal que no sea igualmente impuesta por ley a todas las otras personas. No existen clases privilegiadas a las cuales se apliquen leyes especiales.

[48] Igualdad ante la ley implica también igualdad de posibilidades; comprende la ausencia de cualquiera traba legal arbitraria, que impida el desenvolvimiento de cualquier talento que el hombre posea, de cualquier aptitud que tenga en las diversas esferas de actividad humana. La Declaración de México, adoptada en la Conferencia sobre Problemas de la Guerra y de la Paz, afirma que "Entre los derechos del hombre, figura, en primer término, la igualdad de oportunidad para disfrutar de todos los bienes espirituales y materiales que ofrece nuestra civilización, mediante el ejercicio lícito de su actividad, su industria y su ingenio". La Resolución (XLI) sobre "Discriminación Racial" adoptada en la misma Conferencia, reafirma "el principio reconocido por todos los Estados Americanos, de igualdad de derechos y oportunidades para todos los hombres, sin consideración de raza o religión. La igualdad ante la ley no excluye las desigualdades mentales y físicas de las personas; pero asegura que la ley no agregará restricciones arbitrarias a las impuestas por la naturaleza. El proyecto presentado por la delegación Cubana a la Conferencia sobre Problemas de la Guerra y de la Paz condena las discriminaciones basadas en el sexo, raza, religión, color, idioma o por cualquier otro motivo, y propone el establecimiento de la garantía de completa igualdad de oportunidades en el ejercicio de las diferentes actividades económicas, profesionales e industriales. La supresión de derechos políticos y sociales a los individuos condenados por crimen no constituye, sin duda, una negación de la igualdad ante la ley, si se considera que esas personas, en violación de la ley, se han creado a sí mismas la situación de desigualdad.

Igualdad ante la ley significa, no solamente igualdad en relación a la esencia de los derechos humanos, sino en relación a la protección que ha de concederse contra su violación por parte de otros individuos. El proyecto de Declaración sostiene que es deber del Estado respetar los derechos fundamentales de todas las personas y, al mismo tiempo, asegurar a todas el goce de sus derechos sin interferencia de terceros. El proyecto presentado por la delegación Cubana a la Conferencia sobre Problemas de la Guerra y de la Paz, se refiere al principio de la Enmienda Decimocuarta $\left(14^{\circ}\right)$ de la Constitución de los Estados Unidos, que establece que "ningún Estado podrá privar a ninguna persona de la vida, la libertad o los bienes de fortuna, sin el debido proceso legal, ni negar a nadie en su jurisdicción la igual protección de las leyes", y que ha sido adoptado por las constituciones de la mayoría de las Repúblicas progresistas.

Pero el principio de igualdad ante la ley no debe ser interpretado tan rígidamente que llegue a destruir la finalidad del propio derecho, como es la de mantener la dignidad de la personalidad humana bajo las diferentes condiciones económicas y sociales. Podrán establecerse aparentes diferencias cuando la desigualdad de capacidades de las personas haga necesario imponer más responsabilidades a quienes puedan asumirals ${ }^{30 \mathrm{E}}$ mejor, y crear esas diferencias cuando sea menester para evitar que la igualdad se convierta en injusticia. La exención de impuestos sobre pequeñas propiedades, se practica para corregir una desigualdad formal con el fin de buscar una igualdad más amplia. La creación de impuestos progresivos puede servir para distribuir la carga de los impuestos de modo que recaiga proporcionalmente sobre las personas de desigual capacidad contributiva. El proyecto de Declaración establece únicamente la regla general de que las restricciones a los derechos fundamentales

30E Sic. Nota del editor A. P. D. 
no sean otras que las estrictamente necesarias para la preservación del orden público, y que sean de carácter general y aplicables a todas las personas dentro de una misma clase.

¿Hasta qué punto el principio de igualdad ante la ley se aplica a extranjeros residentes temporal o permanentemente en el Estado? El proyecto de Declara- [49] ción, con una sola excepción, emplea la palabra "persona" para designar quienes son los sujetos de los derechos establecidos por la Declaración. El derecho de sufragio se refiere a "toda persona natural del Estado" y no a "toda persona". Los derechos llamados políticos son generalmente vedados a los extranjeros sin que eso represente una injusta discriminación, ya que esos derechos influyen en la política del Estado, de la cual participan únicamente quienes por su nacionalidad deben fidelidad a la Nación. Difícilmente podrían los extranjeros reclamar como un derecho fundamental una participación tan íntima en la vida del Estado, desde que sus relaciones con éste son más o menos inestables.

Fuera de esta excepción, el proyecto no distingue entre nacionales y extranjeros en lo que dice relación con los derechos fundamentales. En cuanto a otros derechos, si se quiere menos fundamentales, el Estado es libre de adoptar la legislación especial que reglamente la participación de extranjeros en la vida económica y social del Estado. Es claro que la reglamentación no debe ser de tal rigidez que al colocar a los extranjeros en una situación de desventaja frente a los nacionales, eso equivalga a una denegación de sus derechos fundamentales. Por lo tanto, el Estado puede, por razones de seguridad nacional, rehusar a los extranjeros el derecho de trabajo en determinadas profesiones o en ciertas y determinadas localidades, ofreciéndoseles otras oportunidades de trabajo. En igual forma puede prohibir a los extranjeros la propiedad sobre minas, depósitos petrolíferos, fuerza hidráulica; pero no podría prohibir la posesión del patrimonio familiar, a que se refiere el Artículo VIII como un derecho fundamental.

Es admitido que no se puede señalar una diferencia absoluta entre derechos fundamentales y derechos menos fundamentales. Debe darse al Estado cierta amplitud para determinar qué derechos civiles de los nacionales pueden ser restringidos en su aplicación a extranjeros. Al reclamante corresponde, como en otros casos, probar que determinadas restricciones son arbitrarias e injustas. La Convención de la Habana sobre Condiciones de los Extranjeros establece la regla de carácter general, de que los "Estados deben reconocer a los extranjeros domiciliados o transeúntes en su territorio, todas las garantías individuales que reconocen a favor de sus propios nacionales y el goce de los derechos civiles esenciales sin perjuicio, en lo que concierne a los extranjeros, de las prescripciones legales relativas a la extensión y modalidades del ejercicio de dichos derechos y garantías". El Código de Bustamante, anexo a la Convención de Derecho Internacional Privado, suscrito en la misma Conferencia de la Habana, asienta disposiciones para el goce por parte de los extranjeros de los mismos derechos civiles de los nacionales, sujetos, naturalmente, a que es derecho de cada Estado, "por motivos de orden público," rehusar o subordinar a condiciones especiales el ejercicio de ciertos derechos civiles a los nacionales de los demás Estados. Los extranjeros pertenecientes a cualquiera de los Estados contratantes tienen derecho, de acuerdo con el Código, a gozar de "garantías individuales idénticas" a las de los nacionales, salvo las limitaciones establecidas por las leyes y la constitución de cada Estado. El proyecto de Declaración aclara ahora estas reglas, admitiendo la igual protección de la ley a nacionales y extranjeros, en lo que se refiere a los derechos establecidos en la Declaración, como dundamentales. ${ }^{31 \mathrm{E}}$

\footnotetext{
31E Sic. Nota del editor A. P. D.
} 


\section{ARTÍCULO XIX DEREGHOS Y DEBERES GORRELATIVOS}

Los derechos y los deberes son correlativos; y el deber de respetar los derechos de los otros será32E en todo tiempo, una restricción [50] al ejercicio arbitrario de los derechos.

El principio amplio de que todos los derechos y deberes son correlativos es, como el principio de igualdad ante la ley, una condición esencial para el ejercicio de los derechos humanos. El derecho de uno implica el deber correlativo de parte de otros de respetarlo; así como a él le corresponde el deber recíproco de respetar el derecho de los otros. La función primordial del Estado es armonizar los derechos de los unos con los de los otros, y prescribir penalidades para la violación de esos derechos. El proyecto de Declaración simplemente repite una condición necesaria de la ley y del orden, sin la cual resultaría vana toda reclamación concerniente a la violación de algún derecho.

Los deberes del individuo con relación a los de los otros, y con relación a la comunidad como conjunto, son por lo tanto, consecuencia lógica de los derechos que el individuo posee. Si de tiempo en tiempo es necesario reafirmar los derechos humanos fundamentales, como parece serlo en la actualidad, ello deberá hacerse teniendo en consideración los deberes correlativos. Como miembro de un Estado democrático, el hombre debe estar preparado para cooperar en la protección de los derechos de sus semejantes, con una firmeza no inferior a la que emplearía para defender los propios. Su derecho a la vida no es mayor que el de los otros. Su libertad debe ser una libertad que permita a los otros ser igualmente libres.

\section{ARTÍCULO XX \\ INGORPORAGIÓN DE LA DEGLARAGIÓN EN LAS LEYES NACIONALES}

Las disposiciones de esta Declaración formarán parte de la ley de cada Estado, para ser respetadas y puestas en vigor por las autoridades administrativas y judiciales de la misma manera que todas las demás leyes del Estado.

Las disposiciones de esta Declaración no pueden ser revocadas o modificadas, salvo que sea de conformidad con un acuerdo Interamericano o un acuerdo de las Naciones Unidas que vincule a los Estados Americanos.

\section{ARTÍCULO XXI \\ PROCEDIMIENTO EN CASOS GONCERNIENTES A EXTRANJEROS}

En los casos en que individuos de nacionalidad extranjera aleguen violación de los precedentes derechos fundamentales por el Estado en el cual residen, la reclamación será decidida ${ }^{33 \mathrm{E}}$ en primer término, por los tribunales de dicho Estado. En caso que el Estado del cual es nacional el reclamante alegue denegación de justicia por el otro Estado, y de no llegarse a un acuerdo por

32E Aquí aparece sin coma, lo que difiere de la sección en que se copia el anteproyecto completo. Nota del editor A. P. D.

33E Aquí aparece sin coma, lo que difiere de la sección en que se copia el anteproyecto completo. Nota del editor A. P. D. 
la vía diplomática, el caso será sometido a una Corte Internacional, cuyo estatuto será incluído como parte integrante del instrumento por el cual sea adoptada la presente Declaración.

Estos dos artículos del anteproyecto tratan, respectivamente, de la manera de aplicar las disposiciones de la Declaración: uno es de carácter general, aplicable indistintamente a nacionales y extranjeros; y el otro se [51] refiere a los casos especiales de presunta violación de las disposiciones de la Declaración, en cuanto aplicables sólo a los extranjeros. Más adelante, en otra sección de este Informe, se encontrarán los comentarios explicativos de ambos Artículos.

\section{IDEALES POLITICOS Y POSIBILIDADES PRACTICAS $34 \mathrm{E}$}

1. Todas las grandes declaraciones de derechos humanos, desde la Declaración de Independencia de los Estados Unidos, hasta la Carta del Atlántico, incluso las declaraciones de derechos incorporadas a las Constituciones de todas las otras Repúblicas Americanas, son en mayor o menor grado, de carácter idealista; vale decir que ellas establecen una finalidad que el Estado debe considerar como su más alto objetivo, y cuya realización debe buscar por los medios con que cuenta.

Podría pensarse que no deberían presentarse obstáculos substanciales para la efectividad de los derechos de libertad del individuo, porque éstos en su mayor expresión descansan en la no-intervención por parte del Gobierno en las actividades normales de los individuos. Es cierto que el Estado debe intervenir para proteger los derechos de un individuo con relación a otro, y para asegurar el cumplimiento de los deberes correlativos; pero esto no requiere de parte del Estado esfuerzo alguno que no esté a su alcance.

Por otro lado, los nuevos derechos económicos y sociales del hombre reclaman la cooperación activa de los recursos materiales del Estado, en favor de quienes no están en condiciones de ejercer sus derechos por el mero esfuerzo propio. En este caso, la cooperación del Estado dependerá, sin duda, no solamente del grado de sus recursos materiales, sino de su aptitud para organizarlos y distribuir eficazmente el auxilio entre sus habitantes, de acuerdo con las respectivas necesidades. No se debe esperar, por lo tanto, que el objetivo proclamado por la declaración de derechos y deberes pueda alcanzarse con la simple adopción de una muy avanzada legislación social. Será necesario algún tiempo, en unos casos mayor que en otros, antes que el ideal de justicia social pueda lograrse por completo. Cada Estado debe de sustentar este ideal, y tomar las medidas que prácticamente estén dentro de su capacidad.

2. Es de esperar que en relación a los derechos económicos y sociales del hombre y a los deberes correlativos del Estado, la cooperación internacional se manifieste respecto de aquellos Estados que no se hallan todavía en situación de elevar las condiciones sociales de sus habitantes al nivel deseado. La Carta de las Naciones Unidas prevé esa cooperación. El estímulo al respeto y efectividad de los derechos humanos y libertades fundamentales es considerado como asunto de interés común para la Organización, y como un objetivo que debe ser procurado por la acción conjunta. En una amplitud todavía indeterminada, la cooperación internacional debe esforzarse por vencer las disparidades sociales entre los Estados, en la misma forma en que cada Estado trata de eliminar las disparidades entre sus ciudadanos. La realización de este ideal tendrá que ser progresiva, por etapas, y la conquista del objetivo final estará condicionada a las posibilidades prácticas dentro de las circunstancias.

34E La numeración de este título debiera ser VII, pero este título y el que sigue cuentan con un desfase respecto de la numeración anterior. Nota del editor A. P. D. 


\section{UNA NORMA INTERNAGIONAL PARA LA PROTEGGIÓN DE LOS DERECHOS FUNDAMENTALES}

1. Aunque la interpretación literal del encargo confiado al Comité [52] Jurídico por la Resolución XL de la Conferencia de la Ciudad de México, pueda dar idea de que la función del Comité está limitada a la elaboración del anteproyecto de Declaración de los Derechos y Deberes Internacionales del Hombre, sin referencia al papel que esta Declaración podrá presentar dentro del sistema Interamericano, el Comité Jurídico estima que los aspectos administrativos del problema de protección de los derechos humanos, entran en la esfera de su competencia, y de ahí que haya considerado los medios y modos por los cuales la Declaración pueda ser aplicada en la práctica.

Como quedó señalado más arriba, la Resolución IX de la Conferencia de México ordenó la preparación de un proyecto de pacto constitutivo para mejorar y fortalecer el sistema Panamericano. La Resolución estipula que, en primer término, debe proclamarse, por parte de las Repúblicas Americanas, el reconocimiento del derecho internacional como regla efectiva de su conducta, juntamente con el compromiso de observar las normas enunciadas en la Declaración de Derechos y Deberes de los Estados, y en la Declaración de los Derechos y Deberes Internacionales del Hombre. El Comité Jurídico recibió instrucciones de elaborar esta última. Las dos Declaraciones aparecerán como un anexo al Pacto, de modo que, sin enmendarlo, las Declaraciones puedan ser revisadas de tiempo en tiempo, de acuerdo con las necesidades.

Por esta razón el Comité Jurídico llega a la conclusión de que es propio incluir en su informe la cuestión relativa a la administración de la norma internacional de los derechos y deberes del hombre. Este aspecto del problema es, por cierto, el más difícil de todos.

Las Repúblicas Americanas, en la citada Resolución, mostraron su propósito de que los principios de la proyectada Declaración constituyan "una regla efectiva de su conducta" $35 \mathrm{E}$ ¿Se infiere de esto alguna otra cosa, sino que los principios serán incorporados a la legislación nacional de cada Estado, y que serán aplicados en igual forma que las leyes dictadas por los poderes nacionales de cada país? En la Resolución se dice que las dos Declaraciones servirán "para precisar los principios fundamentales del Derecho Internacional". La Resolución XL, que trata especialmente de la proyectada Declaración de Derechos Esenciales del Hombre, proclama "la adhesión de las Repúblicas Americanas a los principios consagrados en el derecho internacional para la salvaguardia de los derechos esenciales del hombre" y se pronuncia en favor de un sistema de protección internacional de dichos derechos. ¿Qué significado se debe atribuir a las palabras "protección internacional"? ¿Se infiere de esta frase que una violación de los principios adoptados en la Declaración podrá constituir un asunto que afecte a la comunidad Interamericana?

2. En su desarrollo durante los últimos trescientos años, las reglas del derecho internacional han sido aplicadas al ${ }^{36 E}$ través de la acción del Estado. La comunidad internacional no se ha organizado todavía hasta el punto de crear órganos ejecutivos para la aplicación de sus decisiones. La Carta de las Naciones Unidas señala el principio esencial de derecho de que la fuerza no deberá emplearse para la solución de conflictos internacionales, y establece un órgano central para la aplicación de ese principio. Pero la aplicación de las otras reglas del derecho internacional continúan a cargo de los Estados en particular, y a cada uno de ellos

35E Sin puntuación en el original. Nota del editor A. P. D.

36E Sic. Nota del editor A. P. D. 
corresponde la obligación de poner en ejecución dichas reglas, con la adopción de la legislación nacional que sea necesaria para realizar ese propósito.

Aun cuando las reglas del derecho internacional constituyan una obligación directa de todos los Estados, la relación de estas disposiciones con las leyes na- [53] cionales es una cuestión que debe ser resuelta por cada Nación de acuerdo con su propia constitución. En algunos Estados los convenios internacionales automáticamente se incorporan a la ley de la Nación, de manera que los tribunales nacionales tienen que aplicarlos en la misma forma que aplican las leyes emanadas del parlamento nacional. En otros Estados puede ser necesario un acto de la legislatura nacional para poner en vigencia una regla de derecho internacional. En uno u otro caso, sin embargo, la regla de derecho internacional, una vez declarada en vigencia, constituirá una obligación primordial, y ningún Estado podrá invocar disposiciones de su Constitución o leyes nacionales como excusa para justificar su incumplimiento. Debe llamarse la atención sobre la Resolución XIII de la Conferencia sobre Problemas de la Guerra y de la Paz, en la cual se indica la necesidad de que todos los Estados se esfuercen en incorporar al cuerpo del derecho positivo interno, los principios esenciales del derecho internacional.

3. Es evidente que la aplicación de las disposiciones de la Declaración de los Derechos y Deberes Internacionales del Hombre, deben formar parte esencial de la legislación y administración nacionales de cada Estado en particular. En las circunstancias actuales es entendido que las obligaciones creadas por esta Declaración deben ser cumplidas por los órganos de cada Estado de acuerdo con su propia Constitución. Para garantizar una aplicación efectiva de la Declaración, de acuerdo con las disposiciones de la legislación nacional, el Comité Jurídico sugiere que se agregue a la convención contemplada en la Resolución XL de la Conferencia de la Ciudad de México, un artículo concebido más o menos en los siguientes términos:

Las disposiciones de esta Declaración formaran parte de la legislación de cada Estado, en particular, para ser respetadas y aplicadas por las autoridades administrativas y judiciales, en la misma forma que las otras leyes del país.

Las disposiciones de esta Declaración no podrán ser derogadas o modificadas, sino de acuerdo con las estipulaciones de un convenio Interamericano, o de las Naciones Unidas, obligatorio para los Estados Americanos.

4. Aun cuando la responsabilidad principal por el cumplimiento de las obligaciones de la Declaración de Derechos y Deberes Internacionales del Hombre recaiga sobre cada Estado en particular, en relación con sus habitantes, el Comité Jurídico es de opinión que la forma convencional que se piensa dar a la Declaración, de acuerdo con los términos de la Resolución XL, justifica la creación de un órgano Interamericano, con funciones de carácter consultivo, respecto a la protección de los derechos fundamentales, dentro de cada Estado. El Comité se permite sugerir que este órgano sea denominado Comisión Consultiva Interamericana de los Derechos del Hombre, concebida como un órgano subsidiario del Consejo Económico y Social Interamericano, creado por la Conferencia sobre Problemas de la Guerra y de la Paz, y encargada de estimular el cumplimiento de las recomendaciones correspondientes de las Conferencias Internacionales de los Estados Americanos. La Comisión podría componerse de un pequeño número de miembros, nombrados por los Estados que hayan sido designados para ese fin por el Consejo Directivo de la Unión Panamericana a indicación del Consejo Económico y Social. 
[54] Las atribuciones de esta Comisión Consultiva de los Derechos del Hombre serían las de fomentar el respeto a los derechos humanos y las libertades fundamentales de acuerdo con las disposiciones de la Declaración respectiva que adopten los Estados Americanos. Serviría como un órgano central para el estudio de las cuestiones prácticas relacionadas con la protección de los derechos humanos; y tendría competencia para proponer recomendaciones, basadas en los informes recibidos del Consejo Económico y Social, o en sus propias investigaciones. Las recomendaciones de la Comisión deberían ser sometidas, nó a un determinado Gobierno, sino a todos los Gobiernos Americanos, en conjunto, por intermedio del Consejo Económico y Social. Solamente con el consentimiento del Consejo podría la Comisión dirigirse a cualquier Gobierno, en relación a casos concretos.

Una atribución especial de la Comisión Consultiva sería la de mantener contacto con la Comisión de los Derechos Humanos del Consejo Económico y Social de las Naciones Unidas. Los Estados Americanos son, al mismo tiempo, miembros del sistema regional Interamericano, y miembros de la Organización de las Naciones Unidas, de manera que será necesario coordinar el trabajo de las respectivas Comisiones de los Derechos Humanos, para evitar conflictos, tanto en lo que se relacione con los principios, como respecto de las medidas tomadas para la promoción de los derechos. Es posible que la Declaración de Derechos que adopten los Estados Americanos sea más amplia que la que los otros miembros de las Naciones Unidas estén en condiciones de acoger; pero esa posibilidad no deberá impedir que se suscriba independientemente una Declaración Interamericana. Esta Declaración previa Interamericana podrá servir de antecedente para la declaración universal facilitando de esa manera un mayor estímulo al respeto de "los derechos humanos y libertades fundamentales", de acuerdo con las disposiciones de la Carta.

5. El Comité Jurídico no estimó deseable entrar en la cuestión de las medidas que cada Estado tome para asegurar el cumplimiento de las obligaciones contenidas en la Declaración. Como más arriba se observó, el instrumento en que vaya incorporada la Declaración formará parte de la legislación de cada Estado, y sus disposiciones serán aplicadas por las autoridades administrativas y judiciales del Estado. Para los casos en que estén envueltos los nacionales, la decisión de la más alta Corte del Estado a la cual se apele conforme a la Constitución, sería normalmente final. La posibilidad de graves y persistentes violaciones de la Declaración, por parte de un Estado determinado, no debe, sin embargo, descartarse, y es obvio que si tales violaciones de los derechos fundamentales fuesen de carácter sistemático, indicando una política deliberada de parte de las autoridades administrativas o cuerpos legislativos, que haga ineficaz la acción de los tribunales e imposible la resistencia del pueblo, dichas violaciones no podrían ser desestimadas por los otros miembros de la comunidad, sin desmedro del sistema Interamericano. Una situación tan extrema, si infortunadamente se presentase, estaría fuera de la competencia aquí señalada a la Comisión de Derechos Humanos. Los Estados Americanos han aceptado el principio de la consulta, en presencia de amenazas a la paz; y correspondería a ellos determinar si las violaciones de la Declaración tendrían un carácter tal como para alterar sus buenas relaciones y llegaran a constituir, en el hecho, una amenaza para la paz, justificando, por lo tanto, el recurso a los procedimientos aceptados para tales situaciones.

6. El Comité Jurídico ha dispensado la más atenta consideración a la difícil cuestión de la inclusión de los extranjeros en el amplio término de "personas". Es evidente que el propósito primordial de la proyectada Declaración de los Derechos y Deberes Internacionales del Hombre es proteger los derechos de las personas dentro de la jurisdicción del Estado del cual son nacionales. La gran [55] mayoría de la población de un país está formada por ciudadanos 
de ese Estado; y la característica más significativa de la Declaración es que por primera vez se busca ampliar la protección del derecho internacional a los ciudadanos del Estado. Como se ha explicado al comienzo de este Informe, este objetivo se basa, en parte, en la necesidad de proteger a la comunidad internacional contra los efectos perjudiciales del gobierno totalitario que oprima física y moralmente a los propios ciudadanos; y se basa, también, en el sentimiento de idealismo humanitario implícito en el reconocimiento de la necesidad de una comunidad internacional mejor organizada.

Pero el propio hecho de que la Declaración contemple la protección del hombre como hombre, hace imposible limitar la Declaración a los ciudadanos o nacionales de los diferentes Estados. Con excepción de determinados derechos propiamente políticos, los extranjeros residentes en el Estado deben gozar de todos los "derechos humanos y libertades fundamentales", cuyos respeto y estímulo son uno de los propósitos de la Carta de las Naciones Unidas. Excluir a los "extranjeros", como una clase separada, con derechos distintos a los reconocidos a los naturales del Estado, sería negar el carácter "humano" de los derechos establecidos para los nacionales, y el carácter "fundamental" y "esencial" ${ }^{77 \mathrm{E}}$ de las libertades proclamadas a favor de los propios nacionales.

La inclusión de los extranjeros en el término "personas" plantea la cuestión del efecto que puede producir la Declaración sobre la protección diplomática debida a ciudadanos residentes en el extranjero. Durante muchos años dicha protección ha sido una fuente de controversias y de conflictos dentro de la comunidad Interamericana. Si la Declaración ha de definir más específicamente los derechos de los extranjeros, y ampliarlos quizá a nuevo campo, es indispensable encarar el problema de su protección diplomática, y buscarle una solución constructiva. El Comité Jurídico reconoce la obligación que se ha impuesto, y opina que el anteproyecto de Declaración debiera ser seguido de un detallado estudio del problema de la protección diplomática bajo todos sus aspectos. En el momento actual se limita a formular un único artículo, concebido en líneas generales, con el propósito de segregar los casos que afecten a los extranjeros y proponer un método especial de protección.

En el preámbulo de la Resolución XL de la Conferencia sobre Problemas de la Guerra y de la Paz, en la cual se encargó al Comité Jurídico la preparación del presente anteproyecto, se especifica que "la protección internacional de los derechos esenciales del hombre eliminaría el uso indebido de la protección diplomática de los ciudadanos en el exterior, cuyo ejercicio ha determinado en más de una vez la violación del principio de no intervención y también el de igualdad entre nacionales y extranjeros, en cuanto a los derechos esenciales del hombre". El empleo de la expresión "eliminar el uso indebido" parece indicar, nó la completa eliminación del amparo diplomático, sino el abuso que de él se ha hecho en el pasado, como queda dicho en el citado párrafo. Nada se expresa, sin embargo, con respecto a los procedimientos y medios por los cuales la Declaración de los Derechos y Deberes Internacionales del Hombre sustituiría a las normas actuales del derecho internacional, en lo relativo a la protección de los extranjeros. El texto original del proyecto de resolución presentado a la Conferencia por la Delegación Mexicana, pone sin embargo, alguna luz sobre el asunto. En ese proyecto de resolución se solicita del Consejo Directivo de la Unión Panamericana que estudie, para su inclusión en la reorganización del sistema Interamericano, la creación de un "órgano especialmente encargado de fiscalizar la reglamentación y la aplicación práctica de los principios proclamados en la Declaración”. En la exposición de motivos que acompaña

37E En el original, no hay un espacio entre la preposición "y" y las comillas que anteceden a la palabra "esencial". Nota del editor A. P. D. 
al proyecto se hace referencia, igualmente, a la "organización de un organismo internacional" con el mismo objetivo. En vista de que el [56] Proyecto Mexicano parece haber influído poderosamente en la adopción de la Resolución XL, el Comité Jurídico ha hecho un estudio especial de las proposiciones que contiene.

El Comité Jurídico opina que los abusos de la protección diplomática a ciudadanos residentes en el extranjero se ha debido, principalmente, al carácter unilateral del procedimiento empleado para conceder esa protección; y que el remedio más práctico consiste en la substitución de ese procedimiento por el sometimiento de los casos a un tribunal internacional, de acuerdo con los principios del derecho. Se propone, por lo tanto, que en los casos en que extranjeros aleguen violación de los derechos asegurados por la Declaración, una vez que ésta sea adoptada, la denuncia debe ser juzgada en la misma forma que actualmente, es decir, en primer lugar, por los tribunales del propio Estado. De acuerdo con las disposiciones del Artículo XX, cada Estado podrá decidir si los fallos de los tribunales locales son apelables ante el más alto tribunal del país, o ante un tribunal especial creado para esos casos.

Se confía que en la mayoría de los casos la decisión de los tribunales del país dará solución definitiva a las reclamaciones. Pero, en casos excepcionales, cuando el Estado del cual el extranjero es nacional, tenga fundamentos para creer que hubo denegación de justicia, y si las negociaciones directas entre los Estados resultaren infructuosas, el caso sería sometido a un organismo internacional, conforme se prevé en el Proyecto Mexicano. El estatuto de ese organismo internacional, designado en el proyecto de Declaración como un Tribunal Internacional, sería elaborado separadamente y formaría parte integrante del convenio definitivo que los Estados Americanos decidan adoptar para dar forma legal a la proyectada Declaración.

El Comité Jurídico reconoce que el propósito enunciado en el preámbulo de la Resolución XL, de eliminar "el uso indebido de la protección diplomática a ciudadanos en el exterior", requiere un estudio más profundo de lo que constituye la denegación de justicia, cosa que no ha sido posible realizar dentro de los límites del problema, como ha sido considerado por el Comité. Por esta razón, el Comité recomendaría que la competencia del Tribunal Internacional propuesto en el Artículo XXI sea limitada - por ahora - a los casos que afecten derechos fundamentales, y no se extienda a casos relacionados con reclamaciones que versen sobre contratos para obras públicas o servicios personales, o reclamaciones relativas a empréstitos públicos. Tampoco deberán incluirse dentro de la competencia del tribunal proyectado, los casos relacionados con indemnizaciones resultantes de revueltas internas, guerras internacionales o transferencia de territorios. Para la solución de estos casos se deberá esperar la adopción de normas de derecho internacional mas ${ }^{38 \mathrm{E}}$ precisas que las generalmente admitidas en la actualidad respecto a la protección diplomática.

El Comité Jurídico se propone estudiar a su debido tiempo este problema que tan íntimamente afecta la tranquilidad entre las Naciones Americanas. Pero en lo que se refiere a los objetivos del presente anteproyecto de Declaración de los Derechos y Deberes Internacionales del Hombre, opina que la solución propuesta en el Artículo XXI, es realmente constructiva y que ayudará poderosamente a alcanzar la finalidad proclamada en el preámbulo de la Resolución.

[57] $\mathrm{Al}$ someter el presente Anteproyecto de Declaración, el Comité Jurídico ha procurado, tanto conciliar los puntos de vista divergentes como formular una declaración en lo posible específica y detallada, dentro de las circunstancias. Si una Declaración de los Dere-

$38 \mathrm{E}$ Sic. Nota del editor A. P. D. 
chos y Deberes Internacionales del Hombre ha de realizar sus propósitos, no debe limitarse a meras generalizaciones y abstracciones. Por otra parte, debe restringirse a derechos fundamentales y esenciales que pueden considerarse como el actual mínimum de protección. La Resolución IX de la Conferencia de México, sobre Reorganización, Consolidación y Fortalecimiento del Sistema Interamericano, establece que las dos Declaraciones, la de los derechos y deberes de los Estados y la de los derechos y deberes del hombre, figurarán como un anexo al Pacto constitutivo del Sistema Panamericano, en forma que las dos Declaraciones "puedan ser revisadas de tiempo en tiempo con el objeto de que correspondan a las necesidades y aspiraciones de la convivencia internacional".

El Comité Jurídico espera las observaciones que los Gobiernos Americanos juzguen pertinente formular al texto del Anteproyecto, a fin de proceder entonces a elaborar el proyecto final contemplado en la Resolución XL. ${ }^{39 E}$

Río de Janeiro,

31 de diciembre de 1945 .

(F) Francisco Campos (F) F. Nieto del Río

(F) Charles G. Fenwick

(F) A. Gómez Robledo 
Este libro forma parte del acervo de la Biblioteca Jurídica Virtual del Instituto de Investigaciones Jurídicas de la UNAM www.juridicas.unam.mx

\section{NOVENA \\ CONFERENCIA INTERNACIONAL \\ AMERICANA}

Bogotá, Colombia

marzo 30-mayo 2 de 1948

ACTAS Y DOGUMENTOS

VOLUMEN I

Antecedentes-Secretaria General

Reunión Preliminar-Sesiones Plenarias

MINISTERIO DE RELACIONES EXTERIORES

DE COLOMBIA

Bogotá, 1953

DR @ 2017.

Instituto de Investigaciones Jurídicas - Universidad Nacional Autónoma de México. 
Este libro forma parte del acervo de la Biblioteca Jurídica Virtual del Instituto de Investigaciones Jurídicas de la UNAM www.juridicas.unam.mx

Se advierte que las ligeras discrepancias entre los documentos publicados durante la Novena Conferencia Internacional Americana y el contenido de la presente compilación, resultan de que se ha procurado hacer las enmiendas necesarias en cuanto a la clasificación, títulos y disposición de los documentos, eliminando también los errores textuales más evidentes. Las normas ortográficas aplicadas fueron, en general, las de las oficinas editoriales encargadas de la publicación del manuscrito.

En cambio, por las lagunas y demás defectos de la documentación de la Conferencia, así como por la premura con que se ha tenido que redactar los Volúmenes I-V, pueden haber quedado algunas imperfecciones, de las que se hará relación en el Volumen VII, en el cual se darán detalladas explicaciones, tanto sobre el sistema de redacción empleado como sobre otros asuntos que puedan interesar al lector. -NOTA DE LA REDACGIÓN 


\section{ANTEGEDENTES DE LA GONFERENGIA}

[6]

$$
\text { INVITACIONES Y ACEPTACIONES }
$$

Mensaje del Canciller de Colombia a los Ministros de Relaciones Exteriores de las Repúblicas Americanas ${ }^{2}$

Excelentísimo señor:

La Resolución CVIII de la Octava Conferencia Internacional Americana, reunida en Lima en 1938, escogió a Bogotá, capital de Colombia, como sede de la Novena Conferencia Internacional Americana, y de conformidad con la decisión adoptada por el Consejo Directivo de la Unión Panamericana, en la sesión del día 7 de mayo último, la inauguración de dicha Conferencia deberá efectuarse el sábado 17 de enero de 1948.

En nombre del Gobierno de Colombia tengo la honra de invitar, por el elevado conducto de Vuestra Excelencia, al Gobierno de la República de... a hacerse representar en la Novena Conferencia Internacional Americana, mediante la designación de delegados que serán recibidos en Colombia con la más viva simpatía y cuya cooperación para el feliz éxito de tan importante certamen habrá de ser especialmente valiosa.

El Programa de la Novena Conferencia Internacional Americana será enviado directamente al Gobierno de Vuestra Excelencia, por el Consejo Directivo de la Unión Panamericana.

Mi Gobierno apreciará debidamente que Vuestra Excelencia se digne comunicarle, tan pronto como sea posible, el número y los nombres de las personas que hayan de integrar la Delegación de la República.

Aprovecho esta oportunidad para ofrecer a Vuestra Excelencia el testimonio de mi más alta y distinguida consideración.

DOMINGO EsGUERRA, Ministro de Relaciones Exteriores de Colombia

Mensaje del Canciller de Colombia al Director General de la Unión Panamericana

Excelentísimo señor:

La Resolución CVIII de la Octava Conferencia Internacional Americana, reunida en Lima en 1938, escogió a Bogotá, capital de Colombia, como sede de la [7] Novena Conferencia Internacional Americana, y de conformidad con la decisión adoptada por el Consejo Directivo de la Unión Panamericana, en la sesión del día 5 de diciembre último, la inauguración de dicha Conferencia deberá efectuarse el martes 30 de marzo del presente año.

\footnotetext{
2 Igual oficio fué remitido en la misma fecha y con el mismo número a los Ministros de Relaciones Exteriores de los países americanos. Asimismo, con número OI. 661 de 8 de marzo de 1948, se envió al Gobierno de Nicaragua.
} 
En nombre del Gobierno de Colombia tengo el honor de invitar a Vuestra Excelencia a venir a Bogotá para asistir a las sesiones de la Novena Conferencia Internacional Americana, invitación que hago extensiva a los funcionarios de la Unión Panamericana, de quienes Vuestra Excelencia tenga a bien hacerse acompañar.

Para el Gobierno de Colombia es particularmente grata y honrosa la coincidencia de que sea un ilustre y benemérito Colombiano quien, con el elevado carácter de Director General de la Unión Panamericana, venga a participar, por derecho propio, en las deliberaciones de la Conferencia Internacional Americana que tiene precisamente por sede la capital de su patria.

Ruego a Vuestra Excelencia comunicarme, tan pronto como sea posible, el número y los nombres de las personas que hayan de acompañar a Vuestra Excelencia.

Aprovecho esta oportunidad para renovar a Vuestra Excelencia los sentimientos de mi más alta y distinguida consideración.

DOMingo EsGuerRA, Ministro de Relaciones Exteriores

Al Excelentísimo señor doctor don Alberto Lleras Camargo, Director General de la Unión Panamericana, Washington, D. C.

\author{
Mensaje del Canciller de Colombia \\ al Secretario General de las Naciones Unidas
}

REPÚBLICA DE COLOMBIA

OI. 299

MINISTERIO DE RELACIONES EXTERIORES

Bogotá, febrero 5 de 1948

Excelentísimo señor:

La Resolución CVIII de la Octava Conferencia Internacional Americana, reunida en Lima en 1938, escogió a Bogotá, capital de Colombia, como sede de la Novena Conferencia Internacional Americana, y de conformidad con la decisión adoptada por el Consejo Directivo de la Unión Panamericana, en la sesión del día 5 de diciembre último, la inauguración de dicha Conferencia deberá efectuarse el martes 30 de marzo del presente año.

En nombre del Gobierno de Colombia tengo el honor de invitar a Vuestra Excelencia a venir a Bogotá para asistir a las sesiones de la Novena Conferencia Internacional Americana, invitación que hago extensiva a los funcionarios de la Secretaría General de las Naciones Unidas, de quienes Vuestra Excelencia tenga a bien hacerse acompañar

[8] Para el Gobierno de Colombia será especialmente honrosa la presencia en Bogotá, con motivo de la mencionada asamblea internacional americana, del muy digno Secretario General de las Naciones Unidas, organización a la cual Colombia se halla estrechamente vinculada en pro de la paz, la seguridad y la justicia internacionales.

Ruego a Vuestra Excelencia comunicarme, tan pronto como sea posible, el número y los nombres de las personas que hayan de acompañar a Vuestra Excelencia.

Aprovecho esta oportunidad para renovar a Vuestra Excelencia los sentimientos de mi más alta y distinguida consideración.

DOMingo EsGuerRA,

Ministro de Relaciones Exteriores

Al Excelentísimo señor Trygve Lie, Secretario General de las Naciones Unidas, Lake Success, New York 


\title{
REUNION PRELIMINAR
}

\author{
ACTA DE LA PRIMERA PARTE \\ DE LA REUNION PRELIMINAR ${ }^{1}$
}

(Versión taquigráfica) $^{2}$

FECHA: martes, 30 de marzo de 1948

HORA: 11:00-13:30

RECiNTO: Salón "Caro”, Capitolio Nacional

PRESIDENTE: señor Laureano Gómez, Ministro de Relaciones Exteriores de Colombia

SECRETARIos: señores Camilo de Brigard Silva, Secretario General de la Conferencia José Joaquín Gori; Alfonso Bonilla Aragón; y Carlos Borda Mendoza

Presentes: señores Juan Atilio Bramuglia (Argentina); Javier Paz Campero (Bolivia); João Neves da Fontoura (Brasil); Carlos Lozano y Lozano (Colombia); Alejandro Aguilar Machado (Costa Rica); Guillermo Belt (Cuba); Juvenal Hernández (Chile); Antonio Parra Velasco (Ecuador); Héctor David Castro (El Salvador); George C. Marshall (Estados Unidos de América); Enrique Muñoz Meany (Guatemala); Joseph D. Charles (Haití); Marco Antonio Batres (Honduras); Jaime Torres Bodet (México); Luis Manuel Debayle (Nicaragua); Mario de Diego (Panamá); César A. Vasconsellos (Paraguay); Armando Revoredo Iglesias (Perú); Arturo Despradel (República Dominicana); Dardo Regules (Uruguay); Rómulo Betancourt (Venezuela); Alberto Lleras Camargo (Unión Panamericana); y Byron Price (Naciones Unidas)

El señor PRESIDENTE provisional (señor Laureano GÓMEZ): Excelentísimos señores delegados: las primeras palabras al comenzar la Reunión Preliminar de la Novena Conferencia Internacional Americana, deben ser para transmitiros, con la mayor cordialidad, los votos del pueblo y del Gobierno Colombianos por la prosperidad personal de Vuestras Excelencias y por el éxito de las labores que han sido encomendadas a vuestra inteligencia, a vuestra grande práctica y a la tradición de esfuerzo por el magno ideal que aquí nos tiene reunidos.

El Excelentísimo señor Presidente de la República quiere que en esta ocasión se conozcan sus sinceros votos por el resultado favorable de esta magna asamblea, que debe dar, no solamente el ejemplo de solidaridad ya adquirido, sino avanzar acaso un poco más en el terreno de asegurar la paz y la justicia, la libertad y el orden entre las naciones de nuestro Continente.

Con estas palabras declaro inaugurada la Reunión Preliminar de la Novena Conferencia Internacional Americana.

El señor Secretario General: De acuerdo con el orden del día fijado para [82] la Reunión Preliminar, se debe proceder a tomar un acuerdo sobre la elección del Presidente de la Conferencia.

El señor TORRES BODET (MÉXICO): Pido la palabra.

El señor PRESIDENTE provisional: Tiene la palabra el señor Canciller de México.

1 Referencia. - Reglamento de la Conferencia, Artículo 5: "Antes de la Primera Sesión Plenaria se verificará una reunión de carácter preliminar con la presencia de los Presidentes de las delegaciones con el fin de considerar el siguiente orden del día: (a) Acuerdo sobre elección del Presidente de la Conferencia; (b) Designación de la Comisión de Credenciales; (c) Creación de comisiones; (d) Establecimiento, mediante sorteo, de la presidencia de las delegaciones; $(e)$ Nuevos temas; $(f)$ Asuntos varios".

2 La correspondiente acta resumida fué publicada durante la Conferencia con la clasificación CB49/CIN-15. 
El señor TORRES BODET (MÉXICO): Señores jefes de delegación: la Delegación de México desea rendir un cordial y sincero homenaje a la República de Colombia por la forma como su Gobierno ha sabido organizar, en esta hermosa e histórica ciudad de Bogotá, la celebración de la Novena Conferencia Internacional Americana.

Representa a Colombia entre nosotros un hombre cuya figura se ha destacado con perfiles claros y firmes como una de las personalidades contemporáneas más caracterizadas dentro de la vida política americana. Me refiero al eminente Canciller Colombiano, de cuyos méritos no creo necesario hacer mención específica aquí, puesto que todos los conocemos y los apreciamos debidamente.

En tal virtud, y creyendo interpretar un deseo general, tengo la honra de proponeros la elección del Excelentísimo señor doctor Laureano Gómez para que presida los trabajos de nuestra Conferencia. (Aplausos) ${ }^{1 \mathrm{E}}$ [Después de varias expresiones de apoyo, esta moción es aceptada. Nota del editor A. P. D.]

1E Dentro de esta misma reunión preliminar, en página 105, el delegado de República Dominicana dejó la siguiente constancia:

"El señor DESPRADEL (REPÚBLICA DOMINICANA): Antes de pasar a la consideración del próximo capítulo del orden del día, la Delegación de la República Dominicana, completamente de acuerdo con las tesis de los distinguidos Cancilleres de la Argentina y México, tiene interés en dejar constancia que está enviando hoy a la Secretaría, un proyecto de resolución que cabría dentro del capítulo de asuntos jurídicos y políticos, encaminado a recomendar a los gobiernos de América que aun [sic, nota del editor A. P. D.] no lo hayan hecho, se adhieran al Estatuto de la Corte Internacional de Justicia.

"El señor PRESIDENTE: El señor Secretario tomará nota de esa constancia."

Nota del editor A. P. D. 


\section{SESIONES PLENARIAS 1}

\section{ACTA DE LA SESIÓN PLENARIA}

DE INAUGURACIÓN ${ }^{1}$

(Versión taquigráfica-documento publicado

con la clasificación CB-52/SP-5)

FECHA: martes, 30 de marzo de 1948

Hora: 16:30-17:30

Recinto: Salón Central, Capitolio Nacional

PRESIDENTE: señor Laureano Gómez, Ministro de Relaciones Exteriores de Colombia

SECRETARIO: señor Camilo de Brigard Silva, Secretario General de la Conferencia

PRESENTES: señores Marco Antonio Batres (Honduras); Enrique Muñoz Meany (Guatemala); Juvenal Hernández (Chile); Dardo Regules (Uruguay); Guillermo Belt (Cuba); George C. Marshall (Estados Unidos de América); Arturo Despradel (República Dominicana); Javier Paz Campero (Bolivia); Armando Revoredo Iglesias (Perú); Luis Manuel Debayle (Nicaragua); Jaime Torres Bodet (México), Mario de Diego (Panamá); Hector David Castro (El Salvador); César A. Vasconsellos (Paraguay); Alejandro Aguilar Machado (Costa Rica); Antonio Parra Velasco (Ecuador); João Neves da Fontoura (Brasil); Joseph D. Charles (Haití); Rómulo Betancourt (Venezuela); Juan Atilio Bramuglia (Argentina); Carlos Lozano y Lozano (Colombia); Alberto Lleras Camargo (Unión Panamericana); y Byron Price (Naciones Unidas)

El señor PRESIDENTE provisional, acordado para ser elegido Presidente permanente de la Conferencia en la Reunión Preliminar, doctor Laureano GómEz, Ministro de Relaciones Exteriores de Colombia, declara abierta la sesión.

$[\ldots]$

[Discurso de Brasil sobre la DADDH y el individuo como sujeto del Derecho Internacional Público]

El señor Presidente de la Conferencia concedió en seguida la palabra al Excelentísimo señor Jỗo Neves dA Fontoura, Presidente de la Delegación del Brasil, en cuyo país tuvo lugar la Conferencia Interamericana para el Mantenimiento de la Paz y la Seguridad del Continente, última de las reuniones americanas.

El Excelentísimo señor Presidente de la Delegación del Brasil pronuncia e siguiente discurso (Documento publicado con la clasificación CB-33/SP-2):

IE La mayoría de las menciones que se hacen en este volumen a la DADDH son simples menciones discursivas o que hacen referencia a los contenidos importantes de la Novena Conferencia, por lo que se transcriben sólo aquellas referencias relevantes. Nota del editor A. P. D.

Referencia.- Reglamento de la Conferencia, Artículo 26: La Sesión Inaugural se celebrará, en el lugar y en la fecha que fije el Gobierno Colombiano ...." (Sin inicio de comillas en el original. Nota del editor A. P. D.). 
Uno de los temas más deslumbrantes de la agenda es el que se refiere a la declaración de los derechos y deberes internacionales del hombre: hasta hoy, la materia no ultrapasó la órbita de medidas de protección para ciertos grupos.

Corresponderá a América, la gloria de considerar al individuo, además de sujeto del derecho interno, también como sujeto del derecho internacional público.

Cuando me refiero al individuo como sujeto del derecho internacional público, estoy [130] pensando en el papel que le cabe, y que brevemente le será reconocido, de partícipe de las garantías de orden jurídico internacional, en la misma medida con que disfruta de esta prerrogativa en el ámbito del derecho público interno. Así, estoy pensando en la formación inevitable de un derecho constitucional internacional, en que haya, al lado de una técnica internacional de la paz, una técnica internacional de la libertad de la persona humana.

Guando por la creación de una corte internacional de franquicias individuales, fuere completada la declaración de derechos, tanto los ciudadanos como las naciones, estarán virtualmente más protegidas contra la violencia, porque ese fundamento de la vida democrática podrá tener la virtud de influir como parapeto contra las tentaciones del cesarismo, puesto que tutelará desde el derecho de objeción, el de información y el de crítica.

\section{ACTA DE LA QUINTA SESION PLENARIA \\ (Versión taquigráfica-documento publicado con la clasificación CB-186/SP-28)}

FECHA: miércoles, 7 de abril de 1948

HORA: 17:35-19:15

RECINTO: Salón Central, Capitolio Nacional

PRESIDENTE: señor Laureano Gómez, Ministro de Relaciones Exteriores de Colombia

SECRETARIos: señores Camilo de Brigard Silva, Secretario General de la Conferencia; José Joaquín Gori; y Guillermo Arévalo Amador

Presentes: señores Marco Antonio Batres (Honduras); Jorge Garcia Granados (Guatemala); Juvenal Hernández (Chile); Dardo Regules (Uruguay); Ernesto Dihigo (Cuba); George C. Marshall (Estados Unidos de América); Arturo Despradel (República Dominicana); Javier Paz Campero (Bolivia); Armando Revoredo Iglesias (Perú); Luis Manuel Debayle (Nicaragua); Jaime Torres Bodet (México); Hector David Castro (El Salvador); Ramón E. Martino (Paraguay); Mariano Anderson (Costa Rica); Homero Viteri Lafronte (Ecuador); João Neves da Fontoura (Brasil); Joseph D. Charles (Haití); Rómulo Betancourt (Venezuela); Juan Atilio Bramuglia (Argentina); Carlos Lozano y Lozano (Colombia); Alberto Lleras Camargo (Unión Panamericana); y Manuel Albornoz (Naciones Unidas)

El señor PRESIDENTE: Queda abierta la Quinta Sesión Plenaria. 
El señor Secretario General: Señor Presidente, el primer punto del orden del día de la sesión de hoy es la consideración del Acta correspondiente a la Cuarta Sesión Plenaria, que ha sido repartida entre los señores delegados; y si ninguno de ellos desea lo contrario, puede prescindirse de su lectura y ponerse en discusión.

El señor PRESIDENTE: Está en discusión el Acta correspondiente a la sesión anterior. Continúa la discusión. Va a cerrarse. Queda cerrada. Los señores delegados que la aprueben, sírvanse manifestarlo levantando la mano derecha.

El señor Secretario General: Informo al señor Presidente que el Acta ha sido aprobada.

[Discurso de Uruguay sobre protección de los derechos humanos y un sistema judicial internacional]

El señor PResidente: Tiene la palabra Su Excelencia el señor Dardo Regules, Presidente de la Delegación de la Republica del Uruguay.

El señor REGULES (URUGUAY) improvisa el siguiente discurso:

Señor Presidente, señores delegados: el Uruguay saluda al Gobierno y al pueblo de Colombia y, por intermedio de la Delegación, declara que se siente cómodo en el seno de vuestra hospitalidad generosa y en el clima de vuestras magnificas instituciones libres.

El Uruguay saluda, además, a los delegados de la Conferencia, y a los pueblos de América, cuya presencia invisible, pero real, en esta sala, es razón de ser de nuestras deliberaciones, y la medida de nuestras responsabilidades de conciencia.

El Uruguay no tiene en este momento nada ni nuevo ni docto para esta asamblea, sobre todo después de las magníficas y conceptuosas exposiciones doctrinarias y políticas que hemos estado oyendo estos días, y que honran las deliberaciones de la Conferencia.

Va, por lo tanto, a expresar con la sobriedad mayor, cinco verdades, simples y sencillas, en el lenguaje más accesible y metódico posible.

El Uruguay, sin desentenderse de ninguna de las cuestiones que están aflorando en la Conferencia, en las distintas comisiones, pone el acento en cinco directivas esenciales:

Primero: el Uruguay desea colaborar en la fundación de una comunidad regional de derecho, de conformidad con el proyecto que tiene a estudio esta Conferencia, con leves reservas, para organizar hasta la mayor extensión posible las competencias regionales que autoriza el pacto de las Naciones Unidas.

Segundo: el Uruguay desea colaborar en la extensión de las medidas pacíficas hasta crear una jurisdicción judicial y arbitral, incondicionada y automática, para que sirva de base a nuestras relaciones pacíficas.

Tercero: el Uruguay desea colaborar para obtener la jerarquización de los derechos humanos, de tal manera que se logre no solo el reconocimiento sino la protección internacional de esos mismos derechos, porque considera que, para que América pueda vivir en paz en el mundo, es preciso que empiece por asegurar que el hombre en América pueda vivir en paz.

Cuarto: el Uruguay desea colaborar en una cooperación económica, que sea efectiva cooperación, entendiendo que la cooperación económica no tiene ninguna solución jurídica sino el ejercicio, hasta donde se pueda, de la experiencia de la buena vecindad. 
Quinto: por fin, el Uruguay desea colaborar en obtener una unidad de América, leal, clara, responsable y consciente, para que América pueda ser, en esta hora aciaga de la postguerra, un órgano auténtico de paz y, si por desgracia la paz se quiebra, un órgano autentico de defensa de la civilización amenazada, que vale tanto como lo que vale cada una de nuestras vidas.

En tercer término, deseamos colaborar en el estatuto de los derechos humanos, de conformidad con la proclamación que ya se hizo en Río y con respecto a la cual no podemos de ninguna manera dar un paso atrás.

Entre el reconocimiento y la protección de los derechos humanos, ponemos el acento en la protección de los derechos humanos. Es en la protección internacional de los derechos humanos, donde está la lección que América debe dar al mundo; en este "tema deslumbrante", como lo decía el ilustre intérprete del pensamiento del Brasil en esta Conferencia.

\section{[202]}

Digamos de inmediato: proteger no es intervenir. Los derechos humanos son naturales, anteriores a la comunidad internacional, y la comunidad internacional lo único que hace es reconocerlos; pero los derechos existen en la conciencia individual y en la naturaleza humana.

La protección internacional es materia de un estatuto y de un pacto. Y cuando en nombre de ese estatuto se actúe para proteger los derechos, no hay intervención, sino ejecución de un pacto libremente acordado, que, en ese caso, no es sino poner el derecho en acto y cumplir el mandato de la comunidad.

Para que el sistema americano sea realmente vital en esta materia, tenemos que ajustar los derechos que proclamamos a la política que realizamos. La contradicción entre los dos términos, crea un gran escepticismo entre los pueblos de América. Levantamos al hombre en América hasta convertirlo en protagonista de la paz. Confiamos a su brío la seguridad. Le aseguramos una carta de garantías sociales. Y le ponemos después, en las manos, un manojo de derechos imprescriptible. Y, ¿después de todo esto? Después de todo esto, ¿̇lo dejamos abandonado en el fondo de las prisiones, sin proceso, o en los caminos del exilio sin recursos? Esto no puede ser, porque no podemos sostener la impunidad de los quebrantamientos constitucionales contra las personas humanas como ley de América, si nosotros queremos que el Continente realice, sobre la base de la persona humana, su vocación rectora y protagonista en la civilización.

Para demostrar cuál es todo nuestro pensamiento a este respecto, para desprevenir a los que resisten, como una intervención, la protección de los derechos, como lo quieren defender los déspotas grandes y los chicos, y para que se vea el pensamiento exacto con que afirmamos la protección de esos derechos, voy a leer las cuatro normas que hemos presentado a la comisión respectiva.

La competencia internacional está subordinada, desde luego, a dos ajustes: el ajuste de la competencia internacional con las competencias constitucionales internas; y, segundo, el 
ajuste del estatuto sobre la prueba que respete las soberanías establecidas. Organizaríamos la competencia a través de estas cuatro normas.

Primero: el fuero internacional queda reconocido sólo para los dos siguientes casos: $a$ ) violación de las libertades sin proceso o con retardo evidente de justicia; $b$ ) violación de las libertades que sean susceptibles de comprometer la paz.

Segundo: el sujeto titular de la acción - que puede ser individual o colectivo- debe promover la demanda ante la Corte Internacional de Justicia, que actuará, en primera etapa, como Tribunal de Calificación, en previo y especial pronunciamiento sobre la pertinencia de la competencia internacional reclamada. (Modificando el Artículo 34, inc. 1, del Estatuto de la Corte)

Tercero: creación de una Sala Especial Americana en la Corte Internacional de Justicia, para substanciar y fallar las demandas surgidas entre las personas y los Estados, siendo el fallo puramente declaratorio en cuanto a si hubo o no hubo agravio al derecho.

Cuarto: la sentencia condenatoria dará derecho, en los casos de demandas individuales, a la correspondiente indemnización pecuniaria, a fijar por la Corte Internacional de Justicia.

Este es el pensamiento de protección de los derechos humanos con el cual crearíamos, de aceptarse, un instituto de paz auténtico y daríamos a los pueblos la sensación de que el hombre americano puede vivir en paz en su Continente. Y cuando no pueda vivir en paz, por el quebrantamiento, sin proceso, de sus institutos constitucionales, sabrá que un tribunal internacional vigila su libertad, y que en América no se puede, impunemente, sofocar las libertades individuales, sin que esa fuerza expansiva de la libertad sofocada quebrante las aplastantes coacciones internas y llegue hasta la protección internacional organizada por el derecho.

\section{$[\ldots]$}

\section{ACTA DE LA SEPTIMA SESION PLENARIA \\ Versión taquigráfica - documento publicado con la clasificación CB-452/SP-36)}

FECHA: viernes, 30 de abril de 1948

HORA: 11:15-13:30

RECINTO: Salón Central, Capitolio Nacional

PResidente: señor Eduardo Zuleta Angel, Ministro de Relaciones Exteriores de Colombia

SECRETARIOS: señores Camilo de Brigard Silva, Secretario General de la Conferencia; Jaime López Mosquera; Ernesto Jara Castro; y Enrique Soto

PRESENTES: señores Marco Antonio Batres (Honduras); Enrique Munoz Meany (Guatemala); Juvenal Hernández (Chile); Dardo Regules (Uruguay); Oscar Gans (Cuba); Norman Armour (Estados Unidos de América); Arturo Despradel (República Dominicana); Javier Paz Campero (Bolivia); Armando Revoredo Iglesias (Perú); Luis Manuel Debayle (Nicaragua); Jaime Torres Bodet (México); Mario de Diego (Panamá); Hector David Castro (El Salvador); Cesar A. Vasconsellos (Paraguay); Emilio Valverde (Costa Rica); Antonio Parra Velasco (Ecuador); Gabriel de Rezende Passos (Brasil); Joseph D. Charles (Haití); Luis Lander (Venezuela); Enrique Corominas (Argentina); Carlos Lozano y Lozano (Colombia); Alberto Lleras Camargo (Unión Panamericana); y Alfonso Garcia Robles (Naciones Unidas) 
[Votación sobre la propuesta cubana de reconocer un derecho de resistencia]

El señor PRESIDENTE: [...] y así pasamos a los puntos siguientes del orden del día, pues me parecen muy pertinentes las observaciones del señor Canciller de México y no quisiera, ni pedir conceptos sobre documentos que no tienen en sus manos todas las delegaciones, ni suscitar una discusión sobre el particular. Me permito pues, pasar al informe de la Comisión Sexta, que espero ya haya sido distribuído [235] y que contiene los siguientes documentos: las resoluciones aprobadas por la Comisión Sexta, o sean, la Declaración de los Derechos y Deberes del Hombre y las demás declaraciones aprobadas por dicha Comisión. Tiene la palabra el señor Delegado de Cuba.

El señor GANS (CUBA): Señor Presidente y señores delegados: América odia la tiranía y la opresión, y por eso ha acordado esta Conferencia un pronunciamiento feliz contra el activismo internacional que, socavando la democracia y los derechos del hombre, trata de imponer las concepciones totalitarias por gestiones foráneas o extracontinentales. La Delegación de Cuba somete a esta Honorable asamblea plenaria una enmienda adicional a la Declaración de los derechos del hombre, en el sentido de que a continuación del Artículo XVIII de esta Declaración Americana de los Derechos y Deberes Esenciales del Hombre, se agregue el siguiente concepto: "Se reconoce el derecho de resistencia ante actos ostensibles de opresión o tiranía", porque esta adición juega armónicamente con el pronunciamiento contra el activismo internacional de carácter totalitario, y haciendo un concepto más amplio, impide que por gestión americana y sin activismo foráneo pudieran también organizarse formas de vida y sistemas dentro de América que liquidaran los propios pronunciamientos de esta Conferencia respecto de los derechos del hombre. Así, terminando, la Delegación de Cuba entiende que de acordarse esta adición a los derechos del hombre, se completa la iniciativa aprobada hace algunos días a fin de que quede América garantizada contra todo riesgo de opresión o tiranía, ya tenga por agencia grupos internacionales foráneos o propios elementos nativos del Continente Americana.

El señor PRESIDENTE: Señores delegados: como la Delegación de Cuba acaba de presentar una moción de enmienda a la Declaración Americana de los Derechos y Deberes Esenciales del Hombre que aparece en el legajo que contiene las resoluciones de la Comisión Sexta, es de mi deber poner en consideración, por separado, ese primer documento que figura en el legajo mencionado, titulado "Declaración Americana de los Derechos y Deberes Esenciales del Hombre", y poner en consideración de la Conferencia, en primer término, de acuerdo con el Reglamento de la Conferencia, la enmienda presentada por el señor Delegado de Cuba que fué largamente discutida anoche en una sesión especial de la Comisión de Iniciativas. Ruego a los señores delegados que estén por la afirmativa con respecto a la moción que acaba de leer el señor Delegado de Cuba...

El señor GANS (GUBA): Pido votación nominal.

El señor PRESIDENTE: Se hará votación nominal.

El señor REVOREdo IGLESIAS (PERÚ): Señor Presidente, ¿el texto?

El señor PRESIDENTE: El texto se sirvió leerlo ahora el señor Delegado de Cuba, pero la Secretaría repetirá su lectura con mucho gusto. 
El señor SECRetario General: La proposición del señor Delegado de Cuba consiste en agregar al Articulo XVIII de la Declaración Americana de los Derechos y Deberes Esenciales del Hombre, el siguiente párrafo: "Se reconoce el derecho de resistencia ante actos ostensibles de opresión o tiranía."

El señor PRESIDENTE: Tiene la palabra el señor Delegado del Perú.

El señor REVOREDO IGLESIAS (PERÚ): En consideración de lo acordado ayer en la sesión de la Comisión, que se fije en sesión plenaria...

El señor PRESIDENTE: El artículo que ha sido propuesto por la Delegación de Cuba, al que se refiere el señor Delegado del Perú, fué - no recuerdo si exactamente - el mismo texto considerado por la Comisión de Iniciativas. De todos modos cada delegación tiene derecho, aun habiendo sido negada en una comisión cualquier moción, de presentarla a la plenaria. Ruego a los señores delegados que estén por la afirmativa con respecto a la moción cubana, que contesten en voz alta cuando el señor Secretario lea el nombre respectivo.

El señor Secretario General: Argentina, no; Bolivia, no; Brasil, no; Colombia, no; Costa Rica, sí; Cuba, sí; Chile, no; Ecuador, sí; El Salvador se abstiene; Estados Unidos, no; Guatemala, sí; Haití, no; Honduras, sí; México, sí; Nicaragua, no; Panamá, sí; Paraguay, no; Perú, no; Republica Dominicana, sí; Uruguay, sí; Venezuela, sí.

Me permito informarle que ha habido 10 votos afirmativos, 10 negativos y una abstención.

[Votación sobre aprobación de la DADDH y del germen de la Corte Interamericana]

El señor PRESIDENTE: Me parece que el empate significa que la Conferencia no desea aprobar la proposición. En estas condiciones me permito someter a votación el texto que aparece en el documento a que vengo refiriéndome, titulado, "Declaración Americana de los Derechos y Deberes Esenciales del Hombre". Ruego a los señores delegados manifestar si tienen algún reparo u observación que hacer con respecto a él. Si no lo tienen, lo declaro aprobado. Queda aprobado.

En este mismo documento de la Comisión Sexta, aparece el proyecto sobre creación de una Corte Interamericana para proteger los derechos del hombre. Si no hay reparos ni observaciones con respecto a este proyecto, voy a declararlo aprobado. Queda aprobado. 
Este libro forma parte del acervo de la Biblioteca Jurídica Virtual del Instituto de Investigaciones Jurídicas de la UNAM www.juridicas.unam.mx

\section{NOVENA \\ CONFERENGIA INTERNAGIONAL \\ AMERICANA}

Bogotá, Colombia

marzo 30-mayo 2 de 1948

ACTAS Y DOGUMENTOS

VOLUMEN V

COMISION QUINTA-COMISION SEXTA

MINISTERIO DE RELACIONES EXTERIORES

DE COLOMBIA

Bogotá, 1953

DR @ 2017.

Instituto de Investigaciones Jurídicas - Universidad Nacional Autónoma de México. 
Este libro forma parte del acervo de la Biblioteca Jurídica Virtual del Instituto de Investigaciones Jurídicas de la UNAM www.juridicas.unam.mx

\section{SUMARIO GENERAL}

VOLUMEN I:

VOLUMEN II:

VOLUMEN III:

VOLUMEN IV:

VOLUMEN V:

VOLUMEN VI:

VOLUMEN VII:

\author{
Antecedentes \\ Secretaría General \\ Reunión Preliminar \\ Sesiones Plenarias
}

COMISIONES REgLAMENTARIAS

Comisión de Credenciales

Comisión de Iniciativas

Comisión de Coordinación

Comisión de Estilo

Comisiones de Trabajo

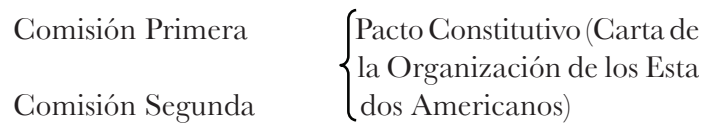

Comisión Tercera

$\left\{\begin{array}{l}\text { Solución pacífica de las } \\ \text { controversias y seguridad } \\ \text { colectiva }\end{array}\right.$

Comisión Guarta Asuntos económicos

$\begin{array}{ll}\text { Comisión Quinta } & \text { Asuntos sociales } \\ \text { Comisión Sexta } & \text { Asuntos jurídico-políticos }\end{array}$ 
Este libro forma parte del acervo de la Biblioteca Jurídica Virtual del Instituto de Investigaciones Jurídicas de la UNAM www.juridicas.unam.mx

http://biblio.juridicas.unam.mx/bjv

\section{PROGRAMA DE LA COMISION SEXTA ${ }^{1}$}

Asuntos Jurídico-políticos

\section{SUbCOMISIÓN A}

Derechos y deberes internacionales del hombre

\section{SubCOMISIÓN B}

Reconocimiento de gobiernos de facto

Defensa y preservación de la democracia en América

\section{SubCOMISIÓn C}

Colonias europeas en América

1 De acuerdo con lo resuelto en la Primera Sesión de la Comisión. Véase el Acta respectiva (versión taquigráfica), transcrita en la p. 517 y siguientes. La Agenda de la Comisión Sexta se publicó durante la Conferencia con la clasificación CB-64/C.VI-1. 


\section{DOCUMENTOS CORRESPONDIENTES A LA COMISIÓN SEXTA}

$[\ldots]$

[449]

Documento publicado con la clasificación CB-7

\section{COMITE JURIDICO INTERAMERICANO}

\section{PROYECTO DE DECLARACION DE LOS DERECHOS Y DEBERES INTERNAGIONALES DEL HOMBRE}

\section{ARTículo I.-Derecho a la Vida}

Toda persona tiene derecho a la vida, inclusive los que están por nacer así como también los incurables, dementes y débiles mentales.

La pena capital sólo puede aplicarse en los casos en que una ley preexistente la haya establecido para crímenes de excepcional gravedad.

\section{ARTículo II.-Derecho de Libertad Personal}

Todo individuo tiene derecho a su libertad personal, la cual comprende la libertad de tránsito dentro del territorio del Estado, y de salir y regresar al mismo; la de fijar residencia en cualquier parte de dicho territorio, sujeta a las restricciones que pueden ser impuestas por las leyes generales, por motivos de orden público y de seguridad del Estado; y la inviolabilidad del domicilio y de la correspondencia. El Estado puede restringir este último derecho solamente en cuanto sea necesario para proteger la salud, la seguridad y la moralidad públicas, de conformidad con las subsiguientes estipulaciones de esta Declaración.

El derecho del Estado a exigir los servicios del individuo en casos de calamidad pública, no podrá ser considerado como una limitación al derecho fundamental de libertad personal.

Ninguna persona puede ser detenida o mantenida en prisión por la mera inobservancia de obligaciones contractuales.

\section{ARTículo III.-Derecho de Libertad de Palabra y de Expresión en General}

Toda persona tiene el derecho a la libertad de palabra y expresión. 
La libertad de expresar y sostener opiniones se extiende a la de usar los servicios de correos, radio y teléfonos, así como la de valerse de las artes gráficas, el teatro, el cinematógrafo y otros medios adecuados de comunicación y divulgación.

[450] En el derecho de libertad de palabra y expresión, se comprende la libertad de acceso a las fuentes de información, tanto nacionales como extranjeras.

El derecho de palabra y expresión incluye el derecho especial y de suma importancia de la libertad de prensa.

Es prohibida, ya sea por medios directos o indirectos, la censura previa de la prensa. A ésta solamente podrán aplicarse medidas de carácter civil o penal en el caso de publicaciones inmorales, difamatorias o que inciten a la violencia, y mediante proceso judicial adecuado.

La censura del cinematógrafo puede anticiparse a la exhibición pública.

El Estado no puede reservarse el monopolio de la radiodifusión.

\section{ARTículo IV.-Derecho de Libertad Religiosa}

Toda persona tiene el derecho de libertad de creencia y de culto religiosos.

Este derecho comprende la libertad de culto tanto en público como en privado; la libertad de culto por grupos o por individuos; la libertad de sostener iglesias y otros lugares de culto público y de reunirse en ellos sin restricciones; la libertad de los padres de educar a los hijos en su creencia religiosa; y la libertad de propaganda religiosa en forma escrita o hablada.

Las únicas restricciones que el Estado puede imponer a la libertad de culto son aquéllas exigidas por los requisitos de salud pública, seguridad y sana moral; pero dichas restricciones deben conformarse con las leyes generales y serán fijadas sin discriminaciones.

\section{ARTículo V.-Derecho de Libertad de Reunión}

Toda persona tiene el derecho de reunirse con otras pacíficamente, para tratar asuntos de interés común.

El Estado está obligado a permitir el uso de sitios públicos para esas reuniones; pero tiene el derecho a ser informado de las reuniones que deban efectuarse en lugares públicos, a designar localidades y a imponer condiciones para el uso tales sitios, en interés de la seguridad y orden públicos. Condiciones parecidas pueden ser impuestas a las asambleas celebradas en recintos públicos o particulares. Pero las condiciones impuestas por el Estado para la realización de reuniones públicas no deben ser tales que sacrifiquen fundamentalmente dicho derecho. Ninguna condición será necesaria para la reunión de pequeños grupos de personas en sitios públicos o privados. El derecho de reunión comprende el derecho de realizar desfiles públicos, sujetos a las mismas restricciones que las asambleas.

\section{ARTículo VI.-Derecho de Libertad de Asociación}

Toda persona tiene el derecho de asociarse con otras para proteger y promover intereses legítimos.

El Estado puede reglamentar las actividades de las asociaciones, siempre que no haya discriminación contra cualquier grupo en particular y no perjudique fundamentalmente el derecho de asociación. 


\section{ARTículo VII.-Derecho de Petición}

Toda persona tiene el derecho de presentar peticiones al gobierno, para la reparación de agravios o sobre cualquier otro asunto de interés público o particular. Este derecho puede ser ejercido individual o colectivamente.

La publicación de dichas peticiones no puede servir de motivo para castigar de ningún modo, directa o indirectamente, a la persona o personas que formulen la petición, salvo por las calumnias o injurias que lo publicado contenga.

\section{ARTículo VIII.-Derecho de Propiedad}

Toda persona tiene derecho a la propiedad.

El Estado tiene el deber de cooperar con el individuo para que éste obtenga un mínimo de propiedad privada correspondiente a las necesidades esenciales de una vida decorosa y que contribuya a mantener la dignidad de la persona y del hogar.

El Estado puede determinar por ley las limitaciones que deba sufrir la propiedad por motivos de interés público o social.

La propiedad privada puede ser expropiada por motivos de utilidad pública, mediante justa indemnización.

\section{ARTículo IX.-Derecho de Nacionalidad}

Toda persona tiene derecho a una nacionalidad.

El Estado no puede negar su nacionalidad a las personas que a ella tengan derecho, de acuerdo con el criterio general por él adoptado para determinar la nacionalidad.

\section{ARTículo X.-Derecho de Libertad de Relaciones Familiares}

Toda persona tiene el derecho de estar libre de intervención en sus relaciones familiares.

Es deber del Estado respetar y proteger los derechos recíprocos de marido y mujer.

Los padres tienen el derecho de patria potestad sobre sus hijos durante su menor edad, y la obligación de mantenerlos y ampararlos.

Es deber del Estado ayudar a los padres en su esfuerzo para proveer al bienestar de la niñez en el núcleo de la familia y de promover, en lo posible, la institución de la casa propia como un medio de fortalecer las relaciones familiares.

El Estado puede restringir la autoridad de los padres sobre sus hijos únicamente en cuanto los padres sean incapaces de cumplir sus deberes para con ellos o fracasen en su cumplimiento. Cuando sea necesario, el Estado debe proveer a la protección y amparo de tales hijos.

\section{ARTículo XI.-Derecho de Protección contra la Prisión Arbitraria}

Toda persona acusada de un delito tiene el derecho de no ser arrestada sino por mandato debidamente expedido de acuerdo con la ley, a menos que la persona [452] sea sorprendida in fraganti. Tendrá también el derecho a un juicio rápido y a un tratamiento humano durante la detención. 


\section{ARTículo XII.-Derecho a Proceso Regular}

Toda persona acusada de un delito tendrá derecho a ser oída en forma legal, imparcial y pública, así como a ser careada con testigos y juzgada de acuerdo con la ley vigente en el momento en que fué cometido el delito y por tribunales organizados anteriormente.

No pueden imponerse penas crueles o inusitadas.

\section{ARTículo XIII.-Derecho de Sufragio}

Toda persona, nacional del Estado, tiene el derecho de participar en la elección de los poderes legislativo y ejecutivo, de acuerdo con las disposiciones de la constitución nacional. El ejercicio de este derecho puede, sin embargo, ser condicionado por el requisito de no ser analfabeto. La constitución proveerá a la formación de un gobierno representativo al servicio del bien común.

Este derecho presupone el de organizar partidos políticos.

A nadie le será negado el derecho a desempeñar una función pública, o a ser designado para cualquiera de los servicios públicos del Estado del cual es nacional, por motivo de partido, raza, religión o sexo, o cualquiera otra distinción arbitraria.

\section{ARTÍcUlO XIV.-Derecho al Trabajo}

Toda persona tiene el derecho a trabajar, como medio de mantenerse a sí misma y de contribuir al sostenimiento de su familia.

Este derecho comprende el de seguir libremente su vocación, en cuanto lo permitan las oportunidades de trabajo existentes. Tiene también el derecho de cambiar de empleo y de mudarse de un lugar a otro.

Los incapaces de sostenerse por su propio esfuerzo, tienen derecho a manutención y amparo; y a este derecho corresponde el deber del Estado de velar por la efectividad de ese amparo.

Toda persona tiene el deber de trabajar para contribuir al bienestar general del Estado.

El Estado está en el deber de ayudar al individuo en el ejercicio de su derecho de trabajar, cuando sus propios esfuerzos no sean suficientes a la obtención de un empleo; debe hacer todo esfuerzo para promover la estabilidad de los empleos y asegurar condiciones apropiadas, debiendo fijar normas mínimas de justa compensación.

\section{ARTículo XV.-Derecho a Participar en los Beneficios de la Ciencia}

Toda persona tiene el derecho a participar en los beneficios resultantes de descubrimientos e invenciones de la ciencia, bajo condiciones que permitan una compensación razonable a la industria y a la capacidad de los autores del descubrimiento o invención.

[453] El Estado tiene el deber de fomentar el desarrollo de las artes y ciencias; pero debe tomar medidas para que las leyes de protección de la propiedad literaria y artística, patentes de invención y marcas de fábrica y comercio, no sean usadas para el establecimiento de monopolios. Es deber del Estado proteger al ciudadano contra el empleo de descubrimientos científicos que puedan crear intranquilidad o temor. 


\section{ARTículo XVI.-Derecho a la Seguridad Social}

Toda persona tiene derecho a la seguridad social.

Es deber del Estado ayudar a la obtención de esa seguridad, y con este fin debe tomar medidas de salud y seguridad públicas y establecer sistemas de seguro social y agencias de cooperación, por medio de las cuales a todas las personas se les pueda asegurar un nivel de vida adecuado, y la protección contra las contingencias del desempleo, accidentes, incapacidad, enfermedad y vejez.

Toda persona tiene el deber de cooperar con el Estado, de acuerdo con sus medios, en la manutención y administración de medidas tomadas para promover la seguridad social.

\section{ARTículo XVII.-Derecho a la Educación}

Toda persona tiene el derecho a la educación.

El derecho de los niños a la educación es primordial.

Es deber del Estado ayudar al individuo en el ejercicio de este derecho a la educación, en conformidad con sus recursos. Las oportunidades de educación deben ser franqueadas a todos en iguales condiciones, de acuerdo con las capacidades naturales y el deseo de aprovechar las facilidades proporcionadas.

El Estado tiene el derecho de fijar las normas a las cuales deben ajustarse las instituciones educacionales, siempre que sean las mismas para las escuelas públicas y las particulares.

El derecho a la educación comprende el de enseñar, sujeto a las restricciones inherentes a su ejercicio.

\section{ARTíCULO XVIII.-Derecho de Igualdad ante la Ley}

Todas las personas son iguales ante la Ley. No habrá clases privilegiadas de ninguna índole.

Es deber del Estado respetar los derechos de cuantos estén bajo su jurisdicción, brindándoles igual protección en el goce de ellos, ya se trate de normas substanciales o simplemente procedimentales.

Las restricciones a los derechos fundamentales deben ser únicamente las necesarias a la conservación del orden público; y, por su carácter, éstas deben ser generales y aplicables a todas las personas dentro de una misma categoría.

\section{ARTíCUlo XIX.-Derechos y Deberes Correlativos}

Los derechos y los deberes son correlativos; y el deber de respetar los derechos de los otros determina, en todo tiempo, el alcance de los derechos propios.

Río de Faneiro, 8 de diciembre de 1947

(Fdo) Francisco Campos, José Joaquín Caicedo Castilla, E. Arroyo Lameda Y CHARLES G. FENWICK 


\section{Informe Anexo al Proyecto Definitivo de Declaración de los Derechos y Deberes Internacionales del Hombre ${ }^{1 \mathrm{E}}$}

\section{ANTECEDENTES}

1. Es una idea moderna la de incluir en instrumentos internacionales los derechos esenciales del hombre. Si - como es de esperarse - la Declaración contenida en este proyecto es aprobada por la Conferencia de Bogotá, sería en América en donde por primera vez se realizaría una iniciativa de esa naturaleza; porque en la vida internacional se han adoptado medidas de protección para ciertos grupos de hombres, mas ha faltado un sistema general, entre otras cosas, porque esta materia siempre se ha calificado como de jurisdicción interna, como de las que pertenecen al llamado dominio reservado del Estado.

2. Después de la Primera Guerra Mundial, aparecen tendencias para amparar a las minorías étnicas o religiosas. Su vocero generoso es el Presidente Wilson, quien, al discutirse el Tratado de Versalles y la fundación de la Liga [Sociedad] de las Naciones, propuso se exigiera a los nuevos Estados, como condición previa al reconocimiento de su independencia, el compromiso de otorgar a las minorías étnicas o nacionales sometidas a su autoridad el mismo tratamiento y la misma seguridad, tanto en derecho como en el hecho, que se concediese a la mayoría étnica o nacional de su población.

De ahí que en los diversos tratados que sellaron la paz se incluyesen cláusulas sobre protección a las minorías, cláusulas contra las cuales reclamaron en ocasiones varios Estados, alegando que no era justo aplicarlas solamente a ellos y no al conjunto de los que integran la comunidad internacional. Pero, en todo caso, eran disposiciones que se referían, no al factor humano en sí mismo, sino a grupos que por residir en determinados territorios originaban problemas políticos relacionados con la situación internacional.

Posteriormente, se presentaron también acuerdos internacionales sobre refugiados políticos emigrados en masa-como los Rusos blancos y los Armenios - los republicanos españoles y los Judíos. Igualmente, en el Pacto de la Sociedad de las Naciones y en la Carta de las Naciones Unidas hay estipulaciones sobre los derechos de los habitantes de los territorios sujetos a mandato o a fideicomiso. Pero son igualmente estipulaciones que guardan estrecha conexión con problemas internacionales.

3. En la Carta de las Naciones Unidas se va más allá y se hace referencia a los derechos fundamentales del hombre, mas sin que hasta ahora se haya ensayado definir esos derechos y consagrarlos en un tratado, aun cuando hay una Comisión que labora en ese particular. Así, en los considerandos de la Carta, se dice que los [455] pueblos de las Naciones Unidas reafirman "la fe en los derechos fundamentales del hombre, en la dignidad y el valor de la persona humana, en la igualdad de derechos de hombres y mujeres"; en el Artículo 1 sobre "Propósitos y Principios", se inserta entre aquéllos la realización de la cooperación internacional "en el desarrollo y estímulo del respeto a los derechos humanos y a las libertades fundamentales"; en el Artículo 5 [55, ordinal c], se manda a la organización promover "el respeto universal a los derechos humanos y a las libertades fundamentales de todos, sin hacer distinción por motivos de raza, sexo, idioma o religión, y la efectividad de tales derechos y libertades."

4. Antes de la Carta de las Naciones Unidas, el Instituto [Americano] de Derecho Internacional, en su sesión de Nueva York de 1929, se había ocupado de los derechos del

IE Este documento cuenta con varios paréntesis cuadrados. Todos ellos son del original, salvo los números de página. Nota del editor A. P. D. 
hombre, redactando una Declaración que mereció entusiasta aprobación. "En mi opinión", dijo el ilustre internacionalista Brown Scott, "la Declaración Internacional de Derechos del Hombre que acaba de votarse es la comprobación solemne del nuevo espíritu de un mundo nuevo". Esa Declaración de Nueva York es la siguiente:

1. Es deber de todo Estado reconocer a todo individuo igual derecho a la vida, a la libertad y a la propiedad y conceder a todos, en su territorio, plena y entera protección a ese derecho, sin distinción de nacionalidad, sexo, raza, lengua o religión.

2. Es deber de todo Estado reconocer a todo individuo igual derecho al libre ejercicio, tanto público como privado, de toda fe, religión o creencia, cuya práctica no sea incompatible con el orden público o con las buenas costumbres.

3. Ningún motivo resultante, directa ni indirectamente, de la diferencia de sexo, raza, lengua, nacionalidad o religión, autoriza a los Estados para rehusar a ninguno de sus nacionales los derechos privados y los derechos públicos, especialmente la admisión a los establecimientos públicos de enseñanza, y al ejercicio de las diferentes actividades económicas, profesiones e industrias.

4. La igualdad prevista no deberá ser nominal sino efectiva. Ella excluye toda discriminación directa o indirecta.

5. Ningún Estado tendrá el derecho de retirar su nacionalidad, salvo por motivos de carácter general consignados en su legislación, a aquellos que por razones de sexo, raza, lengua o religión, no podría privar de las garantías previstas en los artículos anteriores.

5. En 1942, el Instituto de Derecho Americano [Instituto Americano de Derecho Internacional ?] elaboró una Declaración de los derechos esenciales a la libertad efectiva del individuo. Consiste en 18 artículos que versan sucesivamente sobre libertad de religión, libertad de opinión, libertad de palabra, libertad de reunión, libertad para formar asociaciones, garantías contra intervenciones perjudiciales de terceros, justicia imparcial, garantía contra la detención arbitraria, leyes retroactivas, derecho de propiedad, educación, trabajo, condiciones de trabajo, alimentación y vivienda, seguro social, participación en el gobierno, igualdad ante la ley y limitaciones sobre el ejercicio de los derechos.

6. En cuanto al panamericanismo, fué la Conferencia de México, de 1945, la que impulsó vigorosamente la protección de los derechos del hombre. Proyectos trascendentales en ese particular fueron presentados por las Delegaciones de Cuba, México y el Uruguay; y finalmente la Conferencia aprobó [en la Resolución XL] los siguientes puntos:

[456] $1^{\circ}$. Proclamar la adhesión de las Repúblicas Americanas a los principios consagrados en el Derecho Internacional para la salvaguardia de los derechos esenciales del hombre y pronunciarse en favor de un sistema de protección internacional de los mismos.

$2^{\circ}$. Encomendar al Comité Jurídico Interamericano la redacción de un anteproyecto de Declaración de los Derechos y Deberes Internacionales del Hombre...

7. También la Conferencia de Petrópolis se preocupó de esta cuestión; y en el preámbulo del Tratado Interamericano de Asistencia Recíproca, firmado en Río de Janeiro en septiembre de 1947, se dice lo siguiente:

Que la comunidad regional americana afirma como verdad manifiesta que la organización jurídica es una condición necesaria para la seguridad y la paz y que la paz se funda en la justicia y en el orden moral y, por tanto, en el reconocimiento y la protección internacionales de los derechos y libertades de la persona humana, en el bienestar indispensable de los pueblos y en la efectividad de la democracia, para la realización internacional de la justicia y de la seguridad ... 


\section{EXPLICACIÓN DE LAS REFORMAS INTRODUCIDAS en el Proyecto Definitivo}

8. De acuerdo con la Resolución XL de la Conferencia sobre Problemas de la Guerra y de la Paz, de México, el Comité Jurídico, en diciembre de 1946,2Е elaboró un anteproyecto de Declaración de Derechos y Deberes Internacionales del Hombre, que pasó al estudio de los Gobiernos Americanos.

Habiendo varios gobiernos formulado sus observaciones, el Comité procedió a estudiarlas y a redactar, en vista de ellas, el proyecto definitivo que debe ser considerado por la Novena Conferencia Internacional Americana, que se reunirá en Bogotá en el curso del próximo año. Dicho proyecto definitivo modifica substancialmente los Artículos I, II, III, IV, VII, VIII, IX, XIII, XIV, XVI, XVIII y XIX, suprime los Artículos XX y XXI y altera la redacción general del anteproyecto.

A continuación se exponen las razones que tuvo el Comité Jurídico Interamericano para efectuar las varias modificaciones en los artículos susodichos. Respecto a la explicación doctrinaria de cada uno de los artículos del anteproyecto, en el informe anexo al mismo, presentado el año pasado por el Comité, páginas 19 a 77, se encuentra un análisis detallado.

\section{ARTículo I.-Derecho a la Vida}

9. El cambio, en primer lugar, consistió en suprimir del Artículo I del anteproyecto el inciso que dice, "Los incapaces de sostenerse por su propio esfuerzo, tienen derecho a manutención y amparo; y a este derecho corresponde el deber del Estado de velar por la efectividad de ese amparo", para insertarlo en el Artículo XIV del proyecto ("Derecho al Trabajo"), con el cual se vincula estrechamente.

10. Se reforma también la última parte de este Artículo I, para destacar que el Comité no toma partido en favor de la pena de muerte, sino que, admitiendo el hecho de que hay en el Continente diversidad de legislaciones al respecto, reconoce la facultad de cada Estado de regular esta cuestión.

Sin embargo, el Comité tiene que anotar que varias constituciones de América, [457] fundadas en generosas concepciones humanitarias, prohiben ${ }^{3 \mathrm{E}}$ al legislador imponer la mencionada pena.

Eso ocurre en las siguientes constituciones:

La de Colombia, que en su Artículo 29 dice: "El legislador no podrá imponer la pena capital en ningún caso";

La de Panamá, de 1946, que en su Artículo 30, dice: "No hay pena de muerte, de expropiación ni de confiscación de bienes";

2E Posiblemente esta fecha se debe a un error (debiera decir 1945). Afirmamos esto porque el APDADDH fue firmado con fecha diciembre de 1945 (a pesar de que la portada del libro es de fecha abril de 1946). Véase AD, pp. 1, 11 y 57. Además, en AD 57 se lee que el anteproyecto fue sometido a los gobiernos americanos. Por otro lado, la Resolución XL, aprobada en marzo de 1945, le da un plazo de seis meses al Comité Jurídico Interamericano para que redacte el APDADDH. CA, p. 52. Además, el plazo entregado al Comité Jurídico para la redacción de un anteproyecto de pacto constitutivo (que también estaría relacionado con la DADDH), era el 31 de diciembre de 1945 (CA, p. 23), misma fecha que aparece en el APDADDH. Nota del editor A. P. D.

3E Sic. Nota del editor A. P. D. 
La del Uruguay, que en su Artículo 25 determina que, "A nadie se aplicará la pena de muerte";

La del Brasil, de 1946, que en su Artículo 141, numeral 31, ordena: "No habrá pena de muerte, de confiscación ni de carácter perpetuo. Quedan a salvo, en cuanto a la pena de muerte, las disposiciones de la legislación militar en tiempo de guerra con país extranjero"; y

La de Venezuela, de 1947, cuyo Artículo 29 es del siguiente tenor: "La nación garantiza a todos sus habitantes la inviolabilidad de la vida. Ninguna ley podrá establecer la pena de muerte, ni autoridad alguna podrá aplicarla."

\section{ARTículo II.-Derecho de Libertad Personal}

11. El calificativo de "personal" pareció más adecuado a esta libertad que el de "individual", usado preferentemente cuando se contraponen la libertad del individuo y la de la sociedad.

Para efectuar la modificación substancial del penúltimo parágrafo, se tuvo principalmente en cuenta que la mayoría de los Estados Americanos excluye a los extranjeros de la obligación de servir en épocas de defensa nacional. La expresión "en casos de calamidad pública" fué considerada más cónsona con las prácticas internacionales y las leyes más generalizadas en nuestros países.

\section{ARTículo III.-Derecho de Libertad de Palabra y de Expresión en General}

12. Este artículo ha sido reformado en varios puntos: en primer lugar, para extenderlo en general a los diversos medios de comunicación y divulgación, extensión necesaria, debido a los grandes progresos obtenidos por la ciencia en lo referente a dichos medios, y a los que seguramente obtendrá en lo porvenir; en segundo término, en lo relacionado con la libertad de prensa, porque las disposiciones del anteproyecto, inspiradas en el deseo nobilísimo de asegurar aquélla en la forma más amplia, no ofrecían la precisión jurídica indispensable; en tercer lugar, para eliminar las explicaciones sobre la autorización de la censura del cinematógrafo, porque ellas no deben figurar en el texto mismo; y, finalmente, para establecer la prohibición del monopolio de la radiodifusión, sin sujetar dicha prohibición a condiciones que pudieran desvirtuarla.

13. Las reglas sobre la libertad de prensa quedan consignadas con toda claridad en el nuevo artículo del proyecto definitivo: se reconoce como comprendida en la libertad de palabra y de expresión y, además, se la considera como un derecho especial y de suma importancia. Se determina que no puede haber censura previa, y [458] que la responsabilidad civil o penal respectiva no podrá deducirse sino con posterioridad a la publicación, y únicamente cuando se trate de escritos difamatorios, inmorales o que inciten a la violencia. Por último, se establece que en materia de prensa ninguna medida de carácter civil o penal puede imponerse sino mediante procedimiento judicial adecuado. Esta es una garantía preciosa para el periodista, porque lo defiende de la arbitrariedad de autoridades de policía o simplemente administrativas, y coloca el ejercicio de su derecho bajo la protección de las autoridades judiciales.

$\mathrm{Al}$ señalar la importancia y significación de la libertad de prensa, el Comité Jurídico recuerda que sin ella muchas otras libertades, como la del sufragio, la de reunión, etcétera, no podrán seriamente ejercerse. De tal suerte que ella es una de las características esenciales 
de la existencia de un régimen genuinamente democrático y, en consecuencia, todo lo que la afecte, sea directa o indirectamente, vulnera el propio sistema democrático.

14. Se ha conservado en el proyecto la disposición sobre libre acceso a las fuentes de información, tanto nacionales como extranjeras, porque la libertad de opinión sería de muy poco valor si la persona no tuviera acceso a las fuentes de información en las cuales se basan las opiniones. En este respecto, la libertad de opinión y la de información son partes de una misma libertad. La importancia de la libertad de información está claramente señalada en la Resolución XXVII de la Conferencia sobre Problemas de la Guerra y de la Paz, en la cual las Repúblicas Americanas reconocieron la obligación de garantizar a sus habitantes el acceso libre e imparcial a las fuentes de información.

15. La prohibición del monopolio de la radiodifusión se explica por la importancia que ha adquirido ese medio de propaganda y divulgación. Conceder a un gobierno el privilegio de ese formidable instrumento de acción espiritual podría dar lugar a que se realizara una propaganda parcial, una presentación inverídica de las noticias y, en general, a que se mantuviera al pueblo engañado sobre la verdad de los sucesos y sobre las diversas y contradictorias manifestaciones del pensamiento. Sería abrir el camino al despotismo.

En cuanto a la censura del cinematógrafo, tal como se viene haciendo, no la encontramos inconveniente, ya que tiene por causa la defensa de la moral.

Por último, es obvio que el proyecto no podría desconocer ciertos preceptos de las leyes internas, que en lo referente a la libertad de expresión y tratándose de extranjeros establecen algunas limitaciones, como la de que éstos no pueden ser directores de periódicos políticos y otras semejantes.

\section{ARTículo IV.-Derecho de Libertad Religiosa}

16. Se convino en suprimir el último párrafo por encerrar una aclaración que no se estimó necesaria. Sin duda alguna, el Estado puede reglamentar las actividades económicas y financieras conexas con el sostenimiento del culto.

\section{ARTículo VII.-Derecho de Petición}

17. Se añadió, al final de este artículo, "salvo por las calumnias o injurias que lo publicado contenga", lo cual se justifica plenamente.

\section{ARTículo VIII.-Derecho de Propiedad}

18. Se resumieron en uno solo los párrafos tercero y cuarto, a fin de expresar en términos jurídicos el derecho del Estado a limitar el derecho de propiedad por motivos de interés público o social.

\section{ARTíCUlo IX.-Derecho de Nacionalidad}

19. Considerando las observaciones de algunos gobiernos y los criterios en conflicto que en materia de nacionalidad $\operatorname{privan}^{4 \mathrm{E}}$ en los Estados Americanos, el Comité decidió

4E La palabra "privan", en lugar de "priman", aparece en el original. Nota del editor A. P. D. 
reducir este artículo a los términos más generales. En efecto, hay Estados que sujetan a determinadas condiciones la adquisición de la nacionalidad por el jus soli o el jus sanguinis, así como los hay que admiten la pérdida de la nacionalidad de origen por cambio de domicilio o por otras causas, como servir al enemigo, etcétera. La fórmula adoptada en el proyecto de que, "El Estado no puede negar su nacionalidad a las personas que a ella tengan derecho, de acuerdo con el criterio general por él adoptado para determinar la nacionalidad", fué sugerida por el Gobierno del Brasil. Ofrece la ventaja de poder amoldarse a los diversos criterios nacionales.

\section{ARTíCULO XIII.-Derecho al Sufragio}

20. En este artículo, sobre derecho al sufragio, se ha eliminado la exigencia de que para poder participar en las elecciones, se requiere que la persona pruebe ser competente para comprender los principios en que se funda la constitución.

Era tal exigencia de casi imposible aplicación en la práctica, carecía de antecedentes en la legislación positiva y, de mantenerse, hubiera dado a los gobiernos el poder de convertir en nugatorio el derecho del sufragio.

Se ha dicho en el nuevo artículo que puede haber restricciones al sufragio en cuanto a los analfabetos, porque hay algunas leyes de América que las consagran, y una declaración internacional, como la presente, debe ajustarse a la realidad. Empero, tenemos también que decir que varios de nuestros países prohijan el sistema, sin duda alguna más justo, del sufragio universal.

Al hablar el artículo de que toda persona, con la nacionalidad del respectivo Estado, tiene derecho al sufragio, claramente incluye a las mujeres; y aun cuando es cierto que varios Estados Americanos no admiten todavía la participación de la mujer en las elecciones, es asimismo evidente que esa exclusión debería desaparecer y, por consiguiente, conviene señalar a los miembros de la comunidad americana la necesidad de unificar sus orientaciones en este punto.

Siendo el del sufragio un derecho primordial en la organización democrática, cuya base se halla precisamente en la facultad del pueblo de escoger libremente sus representantes y dirigentes, subrayamos que el artículo es trascendental, mas de nada valdrá si no es cumplido lealmente, si en la realidad no se crea un mecanismo que registre con fidelidad la voluntad popular, si los gobiernos y los estadistas de América no se empeñan en mejorar las costumbres políticas y en que sus reiteradas protestas y declaraciones en favor de la democracia estén acompañadas por un esfuerzo tesonero con el fin de que en el terreno de los hechos el sistema democrático sea aplicado y respetado, así como constantemente perfeccionado.

\section{ARTÍcUlo XIV.-Derecho al Trabajo}

Como se dijo al principio de esta exposición, fué trasladado a este artículo, por guardar con él más estrecha conexión, el inciso referente a los "incapaces de sostenerse por su propio esfuerzo". El párrafo último de este Artículo XIV fué suprimido por innecesario, ya que en el Artículo II se establece el derecho del Estado a exigir los servicios del individuo "en casos de calamidad pública". 


\section{ARTículo XVI.-Derecho a la Seguridad Social}

Así en el título como en el texto del artículo, se cambió la expresión "seguro social” por la de "seguridad social", dando así a las disposiciones que contiene, su verdadero y amplio alcance. El seguro social pasa a ser tan sólo uno de los medios de la seguridad social, la cual requiere el concurso de varias otras medidas y providencias.

\section{ARTÍcUlO XVIII.-Derecho de Igualdad ante la Ley}

Los párrafos segundo y tercero se resumieron en uno solo, a fin de evitar posibles redundancias. Se aclaró que la igualdad ante la ley comprende las normas substantivas tanto como las adjetivas.

\section{ARTíCUlo XIX.-Derechos y Deberes Correlativos}

La idea fundamental del artículo queda, sin duda alguna, mejor y más lógicamente expresada en la forma adoptada por el proyecto, la cual fué sugerida por el Gobierno de Venezuela.

\section{ARTículO XX.-Incorporación de la Declaración en las Leyes Nacionales}

Acordó el Comité suprimir este artículo, porque su primera parte contiene una disposición que el organismo considera obvia, ya que de ser incorporada esta Declaración en un tratado, pasa ipso facto a ser ley de cada Estado, sin necesidad de que así lo prescriba la propia Declaración. Su segunda parte fué también considerada innecesaria, por ser principio universal del derecho que las obligaciones contraídas por acuerdo de las partes no pueden ser abrogadas sino por otro acuerdo.

\section{ARTículo XXI.-Procedimiento en Casos concernientes a Extranjeros}

También acordó el Comité suprimir este artículo. Los gobiernos que hicieron observaciones, desaprueban la idea de una corte internacional que conozca de las reclamaciones de extranjeros, pues ello equivaldría a crear indebidos privilegios a favor de estos últimos. Los tribunales y cortes nacionales serían los llamados a conocer de las reclamaciones de esta índole.

\section{OBSERVACIONES GENERALES}

Ante todo, el Comité observa que la Declaración de derechos debe apenas considerarse como un mínimum. Por consiguiente, las legislaciones de los Estados [461] Americanos pueden reconocer otros derechos, o suprimir algunas de las restricciones consignadas en el proyecto, o atribuir a los derechos que contiene una extensión mayor.

En este sentido, la Declaración no constituye una limitación al derecho interno, ni un obstáculo para el progreso futuro de las instituciones o para el mantenimiento de aquellas que hoy van más allá que la Declaración.

No obstante que el informe con que se acompañó el primitivo anteproyecto se refiere en uno de sus parágrafos a la aplicación de sanciones en el caso de flagrante violación de los derechos del hombre, es lo cierto que el proyecto no consigna ninguna medida de esa natura- 
leza y que la cuestión no fué objeto de consideración en el seno del Comité, en esta segunda fase de elaboración del proyecto.

El Comité ha conservado la expresión "Derechos y Deberes Internacionales del Hombre", por haber sido empleada por la Conferencia de Chapultepec, mas encuentra que sería mejor decir simplemente "Derechos y Deberes del Hombre".

En la extensa exposición de motivos con que el Comité acompañó su anteproyecto del año pasado, se analizan todos y cada uno de los artículos de aquél y se exponen los antecedentes que en el derecho internacional existen sobre declaraciones relativas a los derechos esenciales. Llamamos, por lo tanto, la atención al citado documento, como ilustrativo para un estudio completo de la materia. Dos disposiciones de este proyecto, las referentes a seguridad social y a derecho del trabajo, contienen normas análogas a las que se consignan en la Carta de Garantías Sociales, pero aquí se contemplan dichos asuntos desde un punto de vista más general que en aquélla.

Se ha hecho al primer anteproyecto del Comité la crítica de no reducirse a la simple enunciación de principios generales. Procurando considerar esa objeción, en lo que tiene de atendible, hemos tratado en este proyecto definitivo de hacer más sintética la redacción del articulado, prescindiendo de detalles y teniendo en cuenta solamente los principios fundamentales. Pero hemos estimado, también, que la simple enunciación de normas generalísimas, que teóricamente se aceptan por unanimidad sin que en la práctica sean realmente efectivas, no respondería a la generosa aspiración de las asambleas panamericanas de garantizar en este Hemisferio los derechos y libertades de la persona humana, que son hoy la verdadera expresión de un sistema representativo.

Río de Faneiro, 8 de diciembre de 1947

(Fdo) Francisco Campos, José Joaquín Caicedo Gastilla, E. Arroyo lameda y CHARLES G. FENWICK

Documento publicado con la clasificación CB-101/C.VI-Sub A-l

\section{MEXICO}

\section{PROPUESTA PARA QUE DURANTE LAS DISGUSIONES SOBRE DERECHOS Y DEBERES INTERNACIONALES DEL HOMBRE SE TENGA A LA VISTA EL PROYEGTO DE LAS NAGIONES UNIDAS SOBRE ESTA MATERIA}

Unos cuantos días después de que quedó terminado el Proyecto de Declaración de los Derechos y Deberes Internacionales del Hombre, ${ }^{1}$ formulado por el Comité Jurídico Interamericano para esta Novena Conferencia Internacional Americana, la Comisión de los Derechos y Deberes del Hombre de las Naciones Unidas concluyó un proyecto, cuya importancia mundial induce a la Delegación Mexicana a pedir que se le tenga a la vista en los textos oficiales, versiones en inglés y francés, durante el estudio y disensión del proyecto del Comité Jurídico, toda vez que este último no pudo conocer aquel otro documento :

\section{Bogotá, 2 de abril de 1948}

Documento publicado durante la Conferencia con la clasificaci6n CB-7, transcrito en la pág. 449 y siguientes. 
Documento publicado con la clasificación CB-112/C.VI-Sub A-3

\section{URUGUAY}

\section{PROPUESTA SOBRE LA ORGANIZACION DE LA GOMPETENGIA INTERNACIONAL PARA LA GARANTIA DE LOS DERECHOS DE LA PERSONA HUMANA}

[El Delegado del Uruguay, señor Dardo Regules, presentó la siguiente fórmula:]

1. El fuero internacional queda reconocido sólo para los siguientes casos:

a) Violación de las libertades sin proceso o con retardo evidente de justicia; y

b) Violación que sea susceptible de comprometer la paz.

2. El sujeto titular de la acción debe promover la demanda, ante la Corte Internacional de Justicia, que actuará en primera etapa como tribunal de calificación, en previo y especial pronunciamiento sobre la pertinencia de la competencia internacional reclamada.

3. Creación de una Sala Especial Americana en la Corte Internacional de Justicia, para substanciar y fallar las demandas surgidas entre las personas y los Estados - siendo el fallo puramente declaratorio - en cuanto a si hubo o no hubo agravio del derecho.

4. La sentencia condenatoria dará derecho, en los casos de demandas individuales, a la correspondiente indemnización pecuniaria, a fijar por la Corte Internacional de Justicia.

Documento publicado con la clasificación CB-125/C.VI-6

BRASIL

\section{PROYECTO DE RESOLUCION SOBRE LA CREACION DE UNA CORTE INTERAMERICANA DESTINADA A GARANTIZAR LOS DERECHOS DEL HOMBRE}

La Novena Conferencia Internacional Americana, CONSIDERANDO:

Que los derechos del hombre, internacionalmente reconocidos, deben tener garantía adecuada;

Que esa garantía debe estar sancionada por un órgano jurídico, puesto que no hay derecho propiamente garantizado sin la protección de un tribunal; y

Que, cuando se trata de derechos internacionalmente reconocidos, la protección jurídica, para ser eficaz, debe emanar de un órgano internacional, RECOMIENDA:

A la Comisión Jurídica Interamericana [Al Comité Jurídico Interamericano], que elabore un proyecto de Estatuto para la creación y el funcionamiento de una Corte Interamerica- 
na destinada a garantizar los derechos del hombre. Ese proyecto, después de ser sometido al examen y a las observaciones de los Gobiernos de todos los Estados Americanos, deberá ser discutido y aprobado por una Conferencia Interamericana de Jurisconsultos o, a falta de ésta, por la Décima Conferencia Internacional Americana [Décima Conferencia Interamericana].

\section{ExPosición DE Motivos}

La Novena Conferencia Internacional Americana va a aprobar una Declaración de los Derechos y Deberes Internacionales del Hombre. No basta, sin embargo, proclamarlos: es necesario, además, que esos derechos sean respetados.

En lo que concierne a los deberes, cada Estado, en la esfera de su jurisdicción, dispone de elementos para hacerlos cumplir.

En lo tocante, sin embargo, a los derechos, la cuestión es más difícil. No obstante, cumple dar a los individuos a quienes les sean reconocidos, la posibilidad de que los sancione cualquier jurisdicción que sea adecuada.

Sin duda, en cada Estado existen ya tribunales organizados de acuerdo con el respectivo sistema jurídico, los cuales tienen la facultad, por lo menos teórica, de dirigirse a los individuos a quienes no se les reconozcan o se les violen sus derechos o libertades. Sabemos, con todo, que muchas veces esos recursos de orden interno son insuficientes, no sólo porque con frecuencia no han sido previstas todas las hipótesis, sino porque además, en ciertos casos, el individuo es víctima de arbitrariedades insuperables por parte de las propias autoridades gubernamentales. Algunas veces, los propios tribunales, estrechamente subordinados a un poder ejecutivo opresor, cometen injusticias evidentes; o bien, el individuo se ve privado de acceso a los tribunales locales. En tales casos, si se trata realmente de derechos fundamentales, se impone la posibilidad de recurrir a una jurisdicción internacional.

[465] Esa posibilidad será menos imperiosa en el caso de un extranjero, porque éste debe encontrar la protección de su propio Estado, que lo representará hasta que eventualmente recurra a una jurisdicción internacional.

Si se trata, sin embargo, de un apátrida o de un nacional del propio Estado, no hay duda de que sus derechos esenciales, reconocidos internacionalmente, necesitan de semejante garantía.

No obstante, conviene observar que no será fácil admitir el principio de la facultad de acceso directo de los individuos a un proceso de jurisdicción internacional.

En efecto, de acuerdo con la doctrina tradicional, sólo los Estados poseen la facultad de comparecer ante una corte internacional, aunque se trate de la defensa de los derechos de sus ciudadanos. A los simples particulares no les está todavía generalmente reconocido el derecho de acceso directo a una jurisdicción de esa naturaleza.

El dogma de la soberanía absoluta de los Estados se opone a esto y, todavía con mayor fuerza, a la idea de que un individuo pueda recurrir ante un tribunal internacional contra su propio Estado.

A pesar de que ese dogma está ya muy anticuado, habrá seguramente fuerte oposición a una evolución en ese sentido.

En la Comisión de Juristas que elaboró el primer Estatuto de la Corte Permanente [de Justicia] Internacional, y en la cual el Brasil tuvo la honra de ser representado por su actual Ministro de Estado, doctor Raul Fernandes, la idea del reconocimiento del derecho de acceso directo de los individuos a la Corte fué sustentada por uno de los Miembros de la Comisión, mas no encontró acogida favorable en la mayoría y fué considerada inadmisible o prematura. 
Entretanto, los tribunales mixtos, creados aproximadamente en la misma época por los tratados de paz, permitieron tal acceso contra un Estado extranjero sin intervención alguna del Estado nacional del demandante.

Pero la evolución se paralizó, y cuando se elaboró en San Francisco el Estatuto de la actual Corte Internacional de Justicia, no se admitió el recurso directo de los individuos a su jurisdicción

Hoy, la situación ha cambiado. Se trata de establecer una Carta internacional de los derechos del hombre, y no se puede negar que esa Carta sólo podrá tener eficacia real si se asegura a los titulares de tales derechos, el libre acceso a un tribunal internacional.

Documento publicado con la clasificación CB-139/C.VI-8

BRASIL

\section{PROPUESTA DE ENMIENDAS AL PROYEGTO \\ DE DECLARACION DE LOS DERECHOS Y DEBERES INTERNACIONALES DEL HOMBRE}

[La Delegación del Brasil propone que se hagan las enmiendas siguientes al Proyecto de Declaración de los Derechos y Deberes Internacionales del Hombre: ${ }^{1}$

\section{ARTÍCULO II}

Después de las palabras "y de seguridad del Estado", añádase, "y las que determina el Derecho Internacional".

\section{ARTículo III.-Derecho de Libertad de Palabra y de Expresión del Pensamiento}

Toda persona tiene derecho a la libertad de opinión y de expresión del pensamiento.

Es libre el acceso a las fuentes de información, nacionales y extranjeras.

El Estado podrá, sin embargo, imponer a esta libertad las limitaciones previstas en las leyes generales relativas a la protección de la paz y del orden público o la seguridad del Estado.

Se prohibe la censura previa de la imprenta. La censura del cinematógrafo podrá ser previa.

Toda persona que se sirva de cualquiera de las formas de expresión del pensamiento, tiene para con la sociedad el deber de dar las informaciones y las noticias con lealtad e imparcialidad.

\section{ARTÍCULO IV.-Derecho de Libertad Religiosa y de Culto ${ }^{5 \mathrm{E}}$}

\section{ARTÍ́CULO V}

Después de las palabras "de interés común", añádase "o para manifestar sus creencias u opiniones."

Documento publicado durante la Conferencia con la clasificación CB-7, transcrito en la pág. 449 y siguientes.

5E Artículo sin comentarios en el original. Nota del editor A. P. D. 


\section{ARTículo VI.-Derecho de Libertad de Asociación}

Toda persona tiene el derecho de asociarse con otras para proteger y promover intereses legítimos, observando las limitaciones establecidas por las leyes generales.

\section{ARTÍcUlO IX}

Añádanse al final las siguientes palabras: "salvo cuando la pérdida de nacionalidad constituya una sanción por actos irreconciliables con la existencia de la nacionalidad."

\section{ARTíCULO XI.-Derecho de Seguridad Individual}

Nadie podrá ser arrestado más que en flagrante delito, o en virtud de una orden firmada por la autoridad competente en los casos que prescribe la Ley.

Todo detenido tendrá derecho a un juicio rápido y a un tratamiento humano durante la detención.

Documento publicado con la clasificación CB-163/C.VI-9

\section{BOLIVIA}

\section{PROPUESTA DE ENMIENDAS AL PROYECTO DE DEGLARACION DE LOS DE- RECHOS Y DEBERES INTERNACIONALES DEL HOMBRE}

[La Delegación de Bolivia propone que se hagan las enmiendas siguientes al Proyecto de Declaración de los Derechos y Deberes Internacionales del Hombre:] ${ }^{1}$

l. El párrafo relativo al respeto de los derechos y libertades fundamentales de la persona humana, se redactaría así:

"Incumbe a cada Estado, dentro de su jurisdicción, hacer respetar los derechos y libertades fundamentales de la persona humana, pudiendo ella emplear en garantía de estos derechos y libertades otros procedimientos jurídicos internacionales, de acuerdo a los pactos que se subscriban al efecto."

2. [Agregar un artículo que diga:]

ARTículO... Toda persona tiene el derecho de asilo, en las condiciones estipuladas por convenios internacionales.

Documento publicado durante la Conferencia con la clasificación CB-7, transcrito en la pag. 449 y siguientes. 
Documento publicado con la clasificación CB-194/C.VI-10

\section{PANAMA}

\section{PROYEGTO DE DEGLARACION DE LOS DERECHOS Y LIBERTADES FUNDAMENTALES DEL HOMBRE ${ }^{2}$}

De la libertad del individuo dependen el bienestar del pueblo, la seguridad del Estado y la paz del mundo. No se puede gozar de libertad completa en sociedad; [470] las libertades de cada uno están limitadas por las libertades de los otros, y el mantenimiento de la libertad exige que el individuo cumpla con sus deberes como miembro de la sociedad.

La función del Estado es promover las condiciones bajo las cuales puede ser más libre el individuo.

Para expresar las libertades a que tiene derecho todo ser humano, y para asegurar que todos vivan bajo gobiernos del pueblo, por el pueblo y para el pueblo, se hace la presente declaración.

\section{1.- Libertad Religiosa}

La libertad de conciencia y de culto es derecho de toda persona.

El Estado tiene el deber de proteger esta libertad.

\section{2.- - Libertad de Pensamiento}

La libertad de formarse y de sostener opiniones y de recibir opiniones e información, es derecho de toda persona.

El Estado tiene el deber de proteger esta libertad.

\section{3.- Libertad de Expresión}

La libertad de expresión es derecho de toda persona.

El Estado tiene el deber de abstenerse de limitar arbitrariamente esta libertad, y de impedir que se niegue acceso a los medios de comunicación.

\section{4.- - Libertad de Reunión}

La libertad de reunirse pacíficamente con otros es derecho de toda persona.

El Estado tiene el deber de proteger esta libertad.

\section{5.- Libertad de Asociación}

La libertad de formar con otros asociaciones de carácter político, económico, religioso, social, cultural o de cualquier otro carácter, para fines que no sean incompatibles con esta declaración, es derecho de toda persona.

El Estado tiene el deber de proteger esta libertad.

2 Este documento substituye al texto de la "Declaración de los Derechos y Libertades Fundamentales del Hombre" incluída en el documento CB-25/SG-7 como anexo al Proyecto de Pacto para la Organización de una Asociación de las Naciones Americanas. Véase el Volumen III, pág. 49 y siguientes. 


\section{6.-Seguridad contra Molestias Injustas}

Toda persona tiene el derecho de vivir libre de toda molestia injustificada a su persona, su hogar, su reputación, su vida privada, sus actividades y sus bienes. El Estado tiene el deber de proteger este derecho.

\section{7.-_Proceso fusto}

Toda persona tiene derecho a que sus responsabilidades criminales y civiles, así como también sus derechos, sean determinados sin demora indebida y mediante [471] proceso justo y público, por un tribunal competente ante el cual haya tenido plena oportunidad de ser oída.

El Estado tiene el deber de mantener tribunales y procedimientos adecuados para hacer efectivo este derecho.

\section{8. - Libertad Individual}

Toda persona detenida tiene derecho a que se determine judicialmente y sin demora la legalidad de su detención.

\section{9.- Irretroactividad de las Leyes}

Nadie puede ser sentenciado criminalmente salvo que sea por infracción de una ley vigente al tiempo de ejecutarse el acto definido como delito; ni puede ser sometido a una pena mayor que la aplicable al tiempo de la comisión del delito.

\section{0. - Derecho de Propiedad}

Toda persona tiene el derecho de poseer bienes conforme a la ley general.

El Estado no podrá privar a nadie de sus bienes, salvo que sea para fines de utilidad pública y mediante justa indemnización.

\section{1.-Educación}

Toda persona tiene derecho a la educación.

El Estado tiene el deber de exigir que todo niño dentro de su jurisdicción reciba enseñanza primaria; el de mantener o velar por el mantenimiento de instituciones para la educación que sean a la vez adecuadas y gratuitas; y el de promover el desarrollo de instituciones para la educación superior que sean adecuadas y que puedan aprovechar todos los habitantes.

$$
\text { 12.- Trabajo }
$$

Toda persona tiene derecho al trabajo.

El Estado tiene el deber de tomar las medidas necesarias para asegurar que todos los habitantes tengan oportunidad de trabajo útil.

$$
\text { 13.-Condiciones de Trabajo }
$$

Toda persona tiene el derecho de trabajar en condiciones equitativas. 
El Estado tiene el deber de tomar las medidas que sean necesarias para asegurar que los salarios, horas y otras condiciones de trabajo sean equitativos.

$$
\text { 14.-Alimentación y Vivienda }
$$

Toda persona tiene derecho de alimentos y viviendas adecuados.

El Estado tiene el deber de tomar las medidas que sean necesarias para asegurar que todos los habitantes tengan oportunidad de satisfacer estas necesidades esenciales.

\section{5.- - Seguridad Social}

Toda persona tiene derecho a la seguridad social.

El Estado tiene el deber de mantener o asegurar el mantenimiento de medidas adecuadas para la conservación de la salud, para la prevención de enfermedades y accidentes, para el suministro de asistencia médica y para el pago de indemnizaciones por la pérdida de la capacidad de ganar la vida.

\section{6.-Participación en el Gobierno}

Toda persona tiene el derecho de tomar parte en el gobierno de su Estado.

El Estado tiene el deber de obrar conforme a la voluntad del pueblo, manifestada en elecciones democráticas.

\section{7.-_Igualdad ante la Ley}

Toda persona tiene el derecho de ser protegida contra diferencias arbitrarias en los mandatos y en la aplicación de la Ley por motivo de raza, religión, sexo o cualquier otro.

\section{8.- Limitaciones en el Ejercicio de los Derechos}

Toda persona está limitada en el ejercicio de sus derechos, por los derechos de los demás y por los justos requerimientos del Estado democrático.

Documento publicado con la clasificación CB-310/CIN-41

\section{INFORME DEL RELATOR DEL GRUPO DE TRABAJO SOBRE DERECHOS DEL HOMBRE}

\section{INTRODUCCIÓN}

1. Establecimiento del Grupo de Trabajo. En su Tercera Sesión, celebrada en el Gimnasio Moderno de la ciudad de Bogotá, el día 17 de abril de 1948, la Comisión Sexta (JurídicoPolítica) de la Novena Conferencia Internacional Americana, resolvió crear un Grupo de 
Trabajo sobre derechos del hombre, integrado por las delegaciones de los siguientes países: Argentina, Bolivia, Brasil, Colombia, Cuba, Estados Unidos de América, México, Perú, Uruguay y Venezuela.

2. Mandato del Grupo de Trabajo. El mandato del Grupo de Trabajo, tal como lo determinó la Comisión Sexta, fué el de preparar, en el más breve plazo posible, un texto para la Declaración de los Derechos y Deberes del Hombre, que pudiera servir de base única a los debates de la Comisión Sexta en cuyo orden del día figura el mencionado tema.

[475] 3. Documentación del Grupo de Trabajo. Para el cumplimiento de su mandato, la Comisión Sexta indicó al Grupo de Trabajo que debía tener en cuenta los siguientes documentos:

a) El "Proyecto de Declaración de los Derechos y Deberes Internacionales del Hombre", ${ }^{1}$ formulado por el Comité Jurídico Interamericano de Río de Janeiro, el 8 de diciembre de 1947;

b) El Proyecto de Declaración Internacional sobre Derechos Humanos, formulado por la Comisión de Derechos del Hombre, de las Naciones Unidas, en el curso de su Segunda Sesión, celebrada en Ginebra del 2 al 17 de diciembre de 1947; y

c) Las enmiendas y consideraciones al Proyecto de Declaración del Comité Jurídico de Río de Janeiro, presentadas a la consideración de la Novena Conferencia Internacional Americana por las delegaciones de los siguientes países: Argentina, Bolivia, Brasil, Colombia, Cuba, Estados Unidos de América, Haití, México, Panamá, Perú, Uruguay y Venezuela.

4. Sesiones del Grupo de Trabajo. El Grupo de Trabajo celebró seis sesiones en la residencia de la Delegación Argentina, iniciando sus labores el día 17 de abril a las 4 p.m. y terminándolas el día 20 de abril a las 7:15 p.m.

5. Funcionarios del Grupo de Trabajo. En el curso de su primera sesión, el Grupo de Trabajo designó a los señores Luis Fernán Cisneros (Perú) y Guy Pérez Cisneros (Cuba), como Presidente y Relator, respectivamente. Asesoró al Grupo, en calidad de secretario, el señor Gerardo Melguizo.

6. Miembros del Grupo de Trabajo. Todas las delegaciones de los países que integraban el Grupo de Trabajo, enviaron un representante, con excepción de la del Uruguay, que se excusó por tener otras y múltiples reuniones de la Conferencia que atender.

Fueron miembros del Grupo de Trabajo las siguientes personas [además de las ya mencionadas que constituyeron la Mesa Directiva]: Enrique V. Corominas (Argentina); Alberto Salinas López (Bolivia); Camillo de Oliveira (Brasil); Luis López de Mesa (Colombia); Edward A. Jamison (Estados Unidos de América); Germán Fernández del Castillo (México) y Melchor Monteverde (Venezuela).

\section{LABOR DEL GRUPO DE TRABAJO}

1. Consideraciones generales. En el curso de sus sesiones, no obstante la variedad y la gravedad de los problemas que encierra la redacción de una Declaración de Derechos y Deberes del Hombre, y a pesar, también, de las numerosas enmiendas presentadas por las distintas delegaciones, que fueron todas estudiadas cuidadosamente, el Grupo de Trabajo alcanzó siempre, con cordial entendimiento y sorprendente rapidez, acuerdos unánimes.

Documento publicado durante la Conferencia con la clasificación CB-7, transcrito en la pág. 449 y siguientes. 
Respecto a la buena marcha de sus trabajos, el Grupo de Trabajo desea dejar constancia de su agradecimiento al Embajador Luis Fernán Cisneros (Perú), que presidió sus sesiones con ponderada bondad y claro espíritu jurídico, y a los doc- [476] tores Luis López de Mesa (Colombia) y Germán Fernández del Castillo (México), que aportaron una contribución del más alto valor, caracterizada por su espíritu progresista y su vastísima erudición.

2. Deberes de los Estados. En el proyecto del Comité Jurídico de Río, cada artículo encierra una segunda parte que se refiere, de modo detallado y casi exhaustivo, a los deberes que tiene el Estado para garantizar la efectividad de los derechos del hombre definidos en la primera parte.

El Grupo de Trabajo optó por no incluir, en el texto que preparó, dichos deberes, considerando por una parte que lo apartarían de su mandato y por otra que le restaría fuerza de expresión y claridad a la Declaración.

3. Limites de los derechos. Por razones similares, el Grupo de Trabajo prefirió suprimir todos los pasajes del proyecto de Río, en los cuales, con gran lujo de detalle, se precisaban todos los casos en que el Estado - por razón, precisamente, de tener que defender los derechos del hombre - se vería obligado a fijarles límites razonables.

El Grupo de Trabajo concentró en un solo artículo, inspirado en la segunda sección del proyecto de la Comisión de las Naciones Unidas, la explicación de la justa necesidad de tales limitaciones. El nuevo artículo dice como sigue:

\section{Alcance de los Derechos del Hombre}

"Los derechos del hombre están limitados por los derechos de los demás, por la seguridad de todos y por las justas exigencias del bienestar general y del desenvolvimiento democrático."

4. Título. Modificó el Grupo de Trabajo el título propuesto por el Comité de Río, "Declaración de los Derechos y Deberes Internacionales del Hombre", con la supresión del adjetivo "Internacionales", substituído por el de "Esenciales", y con la adición del adjetivo "Americana". El adjetivo "Esenciales", además de haber sido consagrado por la Resolución XL de la Conferencia de Chapultepec, tiene la ventaja de no limitar los derechos y la de indicar la jerarquía de los que encierran la Declaración. Por otra parte, el calificativo de "Americana" no le resta a la Declaración proyectada ningún valor universal; con ese adjetivo, el Grupo de Trabajo se ha limitado a consignar con justicia el hecho de que han sido los pueblos americanos los primeros que, en el campo internacional, han llegado a un acuerdo unánime sobre el reconocimiento de los derechos esenciales del hombre, y sobre la necesidad de considerar y estimular su protección internacional.

Se lee ahora el título: "Declaración Americana de los Derechos y Deberes Esenciales del Hombre".

5. Los considerandos. El Proyecto de Declaración que, junto con el presente informe, se eleva a la consideración de la Comisión Sexta, comienza con varios considerandos, en los cuales el Grupo de Trabajo ha tratado de precisar las razones que ha tenido la Novena Conferencia para adoptar una Declaración de derechos y deberes del hombre. Se recuerda en dichos considerandos que los pueblos americanos han dignificado la persona humana; que sus constituciones reconocen que las [477] instituciones políticas tienen como fin principal la protección de la dignidad del hombre, que dicha protección debe ser guía principalísima del derecho en evolución, nacional e internacional; y que la consagración americana de los derechos del hombre es un factor importantísimo para el establecimiento del sistema inicial de 
la protección internacional. Con estos considerandos, se precisa el progreso realizado desde la Conferencia de Chapultepec (Resolución XL), que reconoció:

Que para que esa protección [internacional de los derechos esenciales del hombre] sea llevada a la práctica se requiere precisar tales derechos - así como los deberes correctivos - en una Declaración adoptada en forma de Convención por los Estados...

6. Preámbulo. Le pareció oportuno al Grupo de Trabajo hacer preceder el texto de [la Declaración de] derechos y deberes por un breve preámbulo, en el cual estuvieran sintetizadas las creencias de orden moral que legitiman el reconocimiento y la protección de los derechos de la persona humana y de sus consecuencias en el seno de la sociedad y del Estado. A ese efecto, utilizó, ligeramente modificado, el Artículo 1 del proyecto [de Declaración] de las Naciones Unidas, que dice en nuestro texto:

"Todos los hombres nacen libres e iguales en dignidad y derechos, y como están dotados por naturaleza de razón y conciencia, deben conducirse como hermanos los unos con los otros."

7. Deberes del Hombre. En el proyecto de Río, que declara con mucho acierto que, "Los derechos y los deberes son correlativos", unos y otros van íntimamente asociados en el articulado. Sin negar en absoluto las razones muy atendibles de ese método, el Grupo de Trabajo ha estimado que su texto ganaría en claridad y alcanzaría más fácilmente el entendimiento popular, si quedaban claramente separados los derechos de los deberes. Así lo ha hecho, subdividiendo su proyecto en dos partes. En la segunda parte, relativa a los deberes, las principales fuentes han sido el tantas veces mencionado proyecto de Río y la Convención sobre Condiciones de los Extranjeros, firmada en La Habana, en 1928, en el curso de la Sexta Conferencia Internacional Americana.

8. Articulado. La mayor parte de los nuevos títulos de artículo en el proyecto adjunto no son más que el resultado de la disociación de conceptos, ya expresados en el texto del Comité Jurídico de Río; el Grupo de Trabajo creyó oportuna esta disociación, en beneficio de la claridad.

Debe agregarse que algunos artículos nuevos han sido inspirados, ya sea por el proyecto de las Naciones Unidas o bien por las consideraciones y enmiendas presentadas por las distintas delegaciones.

En sus grandes líneas, el orden seguido para la enunciación de derechos y deberes ha sido el siguiente: a) naturales; b) sociales; c) políticos; y d) jurídicos.

9. Derecho de resistencia contra la violación de los derechos. En vista de las consideraciones de algunos miembros del Grupo de Trabajo, contrarios a incluir en el [478] texto [de la Declaración] de los derechos del hombre, una proposición cubana redactada como sigue,

\section{ARTículo... Derecho de Resistencia}

Todo hombre tiene derecho a la resistencia contra la violación de los derechos que, por esta Declaración, se le reconocen,

el doctor Guy Pérez Cisneros (Cuba) reservó el derecho de su delegación a presentar dicha proposición en la sesión plenaria de la Comisión Sexta. 
10. Posición de los miembros del Grupo de Trabajo. Los miembros del Grupo de Trabajo han tenido empeño especial en cumplir, en el más corto plazo, con el mandato de la Comisión Sexta. Como miembros de un grupo de trabajo, se han sentido libres en sus deliberaciones para hacer proposiciones, sugestiones y comentarios. Desean dejar constancia que, bien que unánimes en la redacción del documento adjunto, reservan la posición de sus respectivas delegaciones en el seno de la Comisión Sexta.

Desean asimismo reconocer expresamente la cordial hospitalidad que les ofreció para sus labores la Delegación Argentina, y la eficaz ayuda técnica prestada por los funcionarios de esta última, señores León Fidel y Casimiro Díaz.

Presento mi testimonio de agradecimiento a los miembros del Grupo de Trabajo que me han honrado inmerecidamente con el cargo de Relator de sus labores.

$$
\begin{aligned}
& \text { (Fdo) Guy Pérez Cisneros (Cuba) } \\
& \text { Relator del Grupo de Trabajo }
\end{aligned}
$$

\section{Proyecto DE TeXto}

Como resultado de sus labores, el Grupo de Trabajo sobre derechos del hombre tiene el honor de elevar a la consideración de la Comisión Sexta de la Novena Conferencia Internacional Americana el siguiente proyecto de texto para la

\section{DEGLARAGION AMERICANA DE LOS DERCHOS Y DEBERES ESNCIALES DEL HOMBRE ${ }^{1}$}

\section{La Novena Conferencia Internacional Americana, CONSIDERANDO:}

Que los pueblos americanos han dignificado la persona humana y que sus constituciones nacionales reconocen que las instituciones jurídicas y políticas, rectoras de la vida en sociedad, tienen como fin principal la protección de los derechos esenciales del hombre y la creación de circunstancias que le permitan progresar espiritual y materialmente y alcanzar la felicidad;

Que, en repetidas ocasiones, los Estados Americanos han reconocido que los derechos esenciales del hombre no nacen del hecho de ser nacional de determinado Estado sino que tienen como fundamento los atributos de la persona humana;

[479] Que la protección de los derechos del hombre debe ser guía principalísima del derecho en evolución, tanto nacional como internacional; y

Que la consagración americana de los derechos esenciales del hombre unida a las garantías ofrecidas por el régimen interno de los Estados, establece el sistema inicial de protección que los Estados Americanos consideran adecuado a las actuales circunstancias sociales y jurídicas, no sin reconocer que deberán fortalecerlo cada vez más en el campo internacional, a medida que esas circunstancias vayan siendo más propicias,

ACUERDA:

Adoptar la siguiente

1 Véase el documento publicado durante la Conferencia con la clasificación CB-401/C.VI-30, transcrito en la pág. 494 y siguientes, y la Resolución XXX del Acta Final de la Conferencia, transcrita en el Volumen VI. 
Este libro forma parte del acervo de la Biblioteca Jurídica Virtual del Instituto de Investigaciones Jurídicas de la UNAM

\section{Declaración AMERICANA DE los DeRECHOS Y Deberes \\ ESENCIALES DEL HOMBRE}

\section{PREÁMBULO}

Todos los hombres nacen libres e iguales en dignidad y derechos, y como están dotados por naturaleza de razón y conciencia, deben conducirse como hermanos los unos con los otros.

\section{CAPITULO PRIMERO-DERECHOS}

\section{ARTículo I.-Derecho a la Vida, a la Libertad, a la Seguridad y a la Integridad de la Persona}

Todo ser humano tiene derecho a la vida, a la libertad y a la seguridad y a la integridad de su persona.

\section{ARTículo II.-Derecho de Igualdad ante la Ley}

Todas las personas son iguales ante la Ley y tienen los derechos y deberes consagrados en esta Declaración, sin distinción de raza, sexo, idioma, religión ni otra alguna.

\section{ARTíCULO III.-Derecho a la Libertad Religiosa y de Culto}

Toda persona tiene el derecho de profesar libremente una creencia religiosa y de manifestarla y practicarla públicamente y en privado.

ARTículo IV.-Derecho de Libertad de Investigación, Opinión, Expresión y Difusión

Toda persona tiene derecho a la libertad de investigación, de opinión y de expresión y difusión del pensamiento por cualquier medio.

\section{ARTículo V.-Derecho de Protección a la Honra, la Reputación Personal y la Vida Privada y Familiar}

Toda persona tiene derecho a la protección de la Ley contra los ataques abusivos a su honra, a su reputación y a su vida privada y familiar.

[480]

\section{ARTículo VI.-Derecho a la Familia y a su Protección}

Toda persona tiene derecho a constituir familia, elemento fundamental de la sociedad, y a recibir protección para ella.

\section{ARTículo VII.-Derecho de Protección a la Maternidad y a la Infancia}

Toda mujer en estado de gravidez o en época de lactancia y todo niño, tienen derecho a protección, cuidados y ayuda especiales. 


\section{ARTículo VIII.-Derechos de Residencia y Tránsito}

Toda persona tiene el derecho de fijar su residencia en el territorio del Estado de que es nacional, de transitar por él libremente y de no abandonarlo sino por su voluntad.

\section{ARTículo IX.-Derecho de Inviolabilidad de Domicilio}

Toda persona tiene derecho a la inviolabilidad de su domicilio.

\section{ARTículo X.-Derecho de la Correspondencia}

Toda persona tiene derecho a la inviolabilidad y circulación de su correspondencia.

\section{ARTículo XI.-Derecho a la Saludy al Bienestar}

Toda persona tiene derecho a que su salud sea preservada por medidas sanitarias y sociales, relativas a la alimentación, el vestido, la vivienda y los cuidados médicos, correspondientes al nivel más alto que permitan los recursos del Estado y de la comunidad.

\section{ARTícUlo XII.-Derecho a la Educación}

Toda persona tiene derecho a la educación, la cual debe estar inspirada en los principios de libertad, moralidad y solidaridad humanas.

Asimismo, tiene el derecho de que, mediante esa educación, se le prepare para su digna subsistencia, para el mejoramiento del nivel de su vida y para ser útil a la sociedad. El derecho de educación comprende el de igualdad de oportunidades en todos los casos, de acuerdo con las dotes naturales, los méritos y el deseo de aprovechar los recursos que puedan proporcionar la comunidad y el Estado.

Toda persona tiene derecho a recibir gratuitamente la educación primaria.

\section{ARTículo XIII.-Derecho a los Beneficios de la Cultura}

Toda persona tiene el derecho de tomar parte en la vida cultural de la comunidad, de gozar de las artes y de participar de los beneficios que resultan de los descubrimientos científicos.

[481] Asimismo, tiene derecho a ser protegida, en sus intereses morales y materiales, por los inventos, obras literarias, científicas o artísticas de que sea autor.

\section{ARTículo XIV.-Derecho al Trabajo y a una fusta Retribución}

Toda persona tiene el derecho al trabajo en condiciones dignas y el de seguir libremente su vocación, en cuanto lo permitan las oportunidades de empleo existentes.

Toda persona que trabaja, tiene el derecho de recibir una retribución que, en relación con su capacidad de destreza, le asegure un nivel de vida conveniente para sí misma y para su familia.

\section{ARTículo XV.-Derecho al Descanso y a su Aprovechamiento}

Toda persona tiene derecho a descanso, a honesta recreación y a la oportunidad de aprovechar útilmente el tiempo libre, en beneficio de su mejoramiento espiritual, cultural y físico. 


\section{ARTículo XVI.-Derecho a la Seguridad Social}

Toda persona tiene derecho a la seguridad social que la proteja contra las consecuencias de la desocupación, la incapacidad, la vejez y otras causas de pérdida de los medios de subsistencia, por razones ajenas a su voluntad.

\section{ARTículo XVII.-Derecho de Reconocimiento de la Personalidad Jurídica y de los Derechos Civiles}

Toda persona tiene derecho a que se le reconozca en cualquier parte como sujeto de derechos y obligaciones, y a gozar de los derechos civiles fundamentales.

\section{ARTículo XVIII.-Derecho de Fusticia}

Toda persona puede ocurrir a los tribunales para hacer que se respete su derecho. Asimismo, debe disponer de un procedimiento sencillo y breve por el cual la justicia la ampare contra actos de la autoridad que violen, en su perjuicio, alguno de los derechos fundamentales consagrados constitucionalmente.

\section{ARTÍCULO XIX.-Derecho de Nacionalidad}

Toda persona tiene derecho a la nacionalidad que legalmente le corresponde y el de cambiarla, si así lo desea, por la de cualquier otro país que esté dispuesto a otorgársela.

\section{ARTículo XX.-Derecho de Sufragio $y$ de Participación en el Gobierno}

Toda persona, legalmente capacitada, tiene el derecho de tomar parte efectiva en el gobierno de su país, directamente o por medio de sus representantes, y de participar en las elecciones populares, que serán de voto secreto, genuinas, periódicas y libres.

\section{ARTículO XXI.-Derecho de Reunión}

Toda persona tiene el derecho de reunirse pacíficamente con otras, en manifestación pública o en asamblea transitoria [, para tratar de sus intereses comunes de cualquier índole]. ${ }^{1}$

\section{ARTículo XXII.-Derecho de Asociación}

Toda persona tiene el derecho de asociarse con otras para promover, ejercer y proteger sus intereses legítimos, de orden político, económico, religioso, social, cultural, profesional, sindical o de cualquiera otro.

\section{ARTículO XXIII.-Derecho de Propiedad}

Toda persona tiene derecho a la propiedad privada correspondiente a las necesidades esenciales de una vida decorosa que contribuya a mantener la dignidad de la persona y del hogar.

$1 \quad$ Agregado en la Sexta Sesión de la Comisión Sexta. Véase la pág. 591. 


\section{ARTículo XXIV. - Derecho de Petición}

Toda persona tiene derecho de presentar peticiones respetuosas a cualquier autoridad competente, ya sea por motivo de interés general, ya de interés particular, y el de obtener pronta resolución.

\section{ARTíCULO XXV.-Derecho de Protección contra la Detención Arbitraria}

Nadie puede ser privado de su libertad, sino en los casos y según las formas establecidas por leyes preexistentes.

Nadie puede ser detenido por incumplimiento de obligaciones de carácter netamente civil.

Todo .individuo que haya sido privado de su libertad tiene derecho a que el juez verifique sin demora la legalidad de la medida y a ser juzgado sin dilación injustificada, o, en contrario, a ser puesto en libertad. Tiene derecho, también, a un tratamiento humano durante la detención.

\section{ARTículo XXVI.-Derecho a Proceso Regular}

Se presume que todo acusado es inocente, hasta que se pruebe su culpabilidad.

Toda persona acusada de delito tiene derecho a ser oída en forma imparcial y pública, a ser juzgada por tribunales anteriormente establecidos de acuerdo con leyes preexistentes y a que no se le impongan penas crueles, infamantes o inusitadas.

\section{ARTículo XXVII.-Derecho de Asilo}

Toda persona tiene el derecho de buscar y recibir asilo en territorio extranjero, en caso de persecución que no sea motivada por delitos de derecho común y de acuerdo con los convenios internacionales.

[483]

\section{ARTículo XXVIII.-Alcance de los Derechos del Hombre}

Los derechos del hombre están limitados por los derechos de los demás, por la seguridad de todos y por las justas exigencias del bienestar general y del desenvolvimiento democrático.

\section{CAPITULO SEGUNDO-DEBERES}

\section{ARTÍcUlo XXIX.-Deberes ante la Sociedad}

El individuo tiene el deber de conducirse con relación a los demás de manera que todos puedan formar y desenvolver íntegramente su personalidad.

\section{ARTículo XXX.-Deberes para con los Hijos y los Padres}

Toda persona tiene el deber de asistir, alimentar, educar y amparar a sus hijos menores de edad, y los hijos tienen el de asistir, alimentar y amparar a sus padres cuando éstos lo necesiten y el de honrarlos siempre. 
Este libro forma parte del acervo de la Biblioteca Jurídica Virtual del Instituto de Investigaciones Jurídicas de la UNAM

\section{ARTÍCULO XXXI.-Deberes de Instrucción}

Toda persona tiene el deber de adquirir, a lo menos, la instrucción primaria.

$$
\text { ARTículO XXXII.-Deber de Sufragio }
$$

Toda persona, legalmente capacitada, tiene el deber de votar en las elecciones populares del país de que sea nacional.

\section{ARTículo XXXIII.-Deber de Obediencia a la Ley}

Toda persona tiene el deber de obedecer a la Ley y demás mandamientos legítimos de las autoridades del país en que se encuentre.

\section{ARTÍCULO XXXIV.-Deber de Servir}

Toda persona tiene el deber de prestar servicio de armas y de desempeñar los cargos de elección popular en el Estado de que sea nacional.

Tiene asimismo el deber de prestar los servicios civiles que fueren necesarios en caso de calamidad pública.

\section{ARTÍculo XXXV.-Deberes de Asistencia y Seguridad Social}

Toda persona está obligada a cooperar con el Estado y con la comunidad en la asistencia y seguridad sociales, de acuerdo con sus posibilidades y con las circunstancias.

\section{ARTíCULO XXXVI.-Deber de Pagar Impuestos}

Toda persona tiene el deber de pagar los impuestos establecidos por las leyes para el sostenimiento de los gastos públicos del país de su residencia.

[484]

\section{ARTículo XXXVII.-Deber de Trabajo}

Toda persona tiene el deber de trabajar, dentro de su capacidad y posibilidades, a fin de obtener los recursos para su subsistencia o en beneficio de la comunidad.

\section{ARTículo XXXVIII.-Deber de Abstenerse de Actividades Politicas en País Extranjero}

Toda persona tiene el deber de abstenerse de tomar parte en las actividades políticas privativas de los ciudadanos del Estado en que sea extranjera. 


\section{PROYECTO DE RESOLUCION SOBRE LOS DEBERES INTERNACIONALES DEL HOMBRE}

La Novena Conferencia Internacional Americana,

CONSIDERANDO:

Que la Conferencia Interamericana sobre Problemas de la Guerra y de la Paz, reunida en México en 1945, estableció que para que la protección de los derechos esenciales del hombre "sea llevada a la práctica se requiere precisar tales derechos-así como los deberes correlativos"; y

Que una declaración de los derechos internacionales del hombre sin la correlativa declaración de los deberes de la misma índole quedaría incompleta, pues si [485] los primeros alcanzan un reconocimiento internacional, es lógico que también lo alcancen los segundos, por tener también una importancia humana que trasciende de la esfera nacional, RESUELVE:

Encomendar al Comité Jurídico Interamericano de Río de Janeiro la preparación de una enunciación sistemática de los deberes internacionales del hombre, que, después de consultada con los respectivos Gobiernos Americanos a través de la Unión Panamericana, será remitida al estudio y resolución de la Décima Conferencia Interamericana.

Bogotá, 17 de abril de 1948

(Fdo) Luis Fernán Cisneros

Documento publicado con la clasificación CB-328/C.VI-19

\section{HAITI}

\section{PROPUESTA DE ENMIENDA AL ARTICULO I DEL PROYECTO DE DEGLARAGION DE LOS DEREGHOS Y DEBERES INTERNACIONALES DEL HOMBRE, SOBRE LA PENA DE MUERTE}

La Delegación de Haití propone la siguiente redacción para la última parte del Artículo I del Proyecto de Declaración de los Derechos y Deberes Internacionales del Hombre:1

"La pena de muerte sólo podrá aplicarse en el caso de que haya sido previamente establecida por la Ley y, en materia política, no se establecerá sino para castigar el delito de alta traición y el de atentado contra la vida de un jefe de Estado."

1 Documento publicado durante la Conferencia con la. clasificación CB-7, transcrito en la pág. 449 y siguientes. 


\section{PROYECTO DE RESOLUCION SOBRE LA GREACION DE UNA CORTE INTERAMERICANA DESTINADA A GARANTIZAR LOS DERECHOS DEL HOMBRE²}

\section{[La Novena Conferencia Internacional Americana,]}

CONSIDERANDO:

Que los derechos del hombre internacionalmente reconocidos deben tener una adecuada garantía;

[486] Que esa garantía debe tener la sanción de un órgano judicial, porque no existe derecho garantizado alguno sin la protección de un tribunal; y

Que, cuando se trata de derechos internacionalmente reconocidos, la protección judicial, para ser eficaz, debe emanar de un órgano internacional, RECOMIENDA:

A la Comisión Jurídica Interamericana [Comité Jurídico Interamericano] que elabore, a la brevedad posible, un proyecto de Estatuto para la creación y el funcionamiento de una corte interamericana destinada a garantizar los derechos del hombre, estudiando dicho proyecto en una reunión especial, a la que se invitará un delegado de cada país de América.

La Comisión así integrada, estudiará los proyectos presentados por las Delegaciones del Uruguay, Brasil [y] Colombia, y cualquier otro proyecto que presente cualquiera de las otras delegaciones de la Conferencia.

El proyecto que así se redacte, deberá ser discutido y aprobado por la Décima Conferencia Interamericana.

Documento publicado con la clasificación CB-400/C.VI-29

\section{PROYEGTO DE RESOLUCION SOBRE GREACION DE UNA GORTE INTERAMERICANA DESTINADA A GARANTIZAR LOS DEREGHOS DEL HOMBRE ${ }^{1}$}

\section{La Novena Conferencia Internacional Americana,} CONSIDERANDO

Que los derechos del hombre, internacionalmente reconocidos, deben tener garantía adecuada;

2 Véanse [sic. Nota del editor A. P. D.] el documento publicado durante la Conferencia con la clasificación CB-400/C.VI-29, transcrito en la pág. 494, y la Resolución XXXI del Acta Final de la Conferencia, transcrita en el Volumen VI.

1 Texto aprobado por la Comisión Sexta. Véanse el documento publicado durante la Conferencia con la clasificación CB-337/C.V1-20, transcrito en la pág. 485, y la Resolución XXXI del Acta Final de la Conferencia, transcrita en el Volumen VI. 
Que esa garantía debe estar sancionada por un órgano jurídico, puesto que no hay derecho propiamente garantizado sin la protección de un tribunal; y

Que, cuando se trata de derechos internacionalmente reconocidos, la protección jurídica, para ser eficaz, debe emanar de un órgano internacional,

\section{RECOMIENDA:}

Que la Comisión Jurídica Interamericana elabore un proyecto de estatuto para la creación y el funcionamiento de una Corte Interamericana destinada a garantizar los derechos del hombre. Ese proyecto, después de ser sometido al examen y a las observaciones de los Gobiernos de todos los Estados Americanos, deberá ser remitido a la Décima Conferencia Internacional Americana [Décima Conferencia Interamericana], para que ésta lo estudie, si considera que ha llegado el momento para una decisión sobre la materia.

Bogotá, 24 de abril de 1948

Documento publicado con la clasificación CB-401/C.VI-30

\section{DECLARACION AMERICANA DE LOS DERECHOS Y DEBERES ESENGIALES DEL HOMBRE ${ }^{2}$}

La Novena Conferencia Internacional Americana,

CONSIDERANDO:

Que los pueblos americanos han dignificado la persona humana y que sus [495] constituciones nacionales reconocen que las instituciones jurídicas y políticas, rectoras de la vida en sociedad, tienen como fin principal la protección de los derechos esenciales del hombre y la creación de circunstancias que le permitan progresar espiritual y materialmente y alcanzar la felicidad;

Que, en repetidas ocasiones, los Estados Americanos han reconocido que los derechos esenciales del hombre no nacen del hecho de ser nacional de determinado Estado, sino que tienen como fundamento los atributos de la persona humana;

Que la protección internacional de los derechos del hombre debe ser guía principalísima del derecho americano en evolución; y

Que la consagración americana de los derechos esenciales del hombre unida a las garantías ofrecidas por el régimen interno de los Estados, establece el sistema inicial de protección que los Estados Americanos consideran adecuado a las actuales circunstancias sociales y jurídicas, no sin reconocer que deberán fortalecerlo cada vez más en el campo internacional, a medida que esas circunstancias vayan siendo más propicias,

ACUERDA:

Adoptar la siguiente

\section{Declaración Americana de los Derechos y Deberes Esenciales del Hombre}

\section{PREÁMBULO}

Todos los hombres nacen libres e iguales en dignidad y derechos, y como están dotados por naturaleza de razón y conciencia, deben conducirse fraternalmente los unos con los otros.

2 Véanse los documentos publicados durante la Conferencia con la clasificación CB-310/CIN-41 y CB-420/C.VI-34, transcritos respectivamente en la pág. 474 y siguientes, y en la pág. 504 y siguientes, y la Resolución XXX del Acta Final de la. Conferencia, transcrita en el Volumen VI. 


\section{CAPITULO PRIMERO-DERECHOS}

\section{ARTículo I.-Derecho a la Vida, a la Libertad, a la Seguridad e Integridad de la Persona}

Todo ser humano tiene derecho a la vida, a la libertad y a la seguridad e integridad de su persona.

\section{ARTículo II.-Derecho de Igualdad ante la Ley}

Todas las personas son iguales ante la Ley y tienen los derechos y deberes consagrados en esta Declaración, sin distinción de raza, sexo, idioma, religión ni otra alguna.

\section{ARTículo III.-Derecho a la Libertad Religiosa y de Culto}

Toda persona tiene el derecho de profesar libremente una creencia religiosa y de manifestarla y practicarla públicamente y en privado.

ARTículo IV.-Derecho de Libertad de Investigación, Opinión, Expresión y Difusión

Toda persona tiene derecho a la libertad de investigación, de opinión y de expresión y difusión del pensamiento por cualquier medio.

\section{ARTículo V.-Derecho de Protección a la Honra, la Reputación Personal y la Vida Privada y Familiar}

Toda persona tiene derecho a la protección de la Ley contra los ataques abusivos a su honra, a su reputación y a su vida privada y familiar.

\section{ARTículo VI.-Derecho a la Familia y a su Protección}

Toda persona tiene derecho a constituir familia, elemento fundamental de la sociedad, y a recibir protección para ella.

\section{ARTículo VII.-Derechos de Protección a la Maternidad y a la Infancia}

Toda mujer en estado de gravidez o en época de lactancia y todo niño, tienen derecho a protección, cuidados y ayuda especiales.

\section{ARTículo VIII.-Derechos de Residencia y Tránsito}

Toda persona tiene el derecho de fijar su residencia en el territorio del Estado de que es nacional, de transitar por él libremente y de no abandonarlo sino por su voluntad.

\section{ARTículo IX.-Derecho de Inviolabilidad del Domicilio}

Toda persona tiene derecho a la inviolabilidad de su domicilio. 


\section{ARTículo X.-Derecho a la Inviolabilidad y Circulación de la Correspondencia}

Toda persona tiene derecho a la inviolabilidad y circulación de su correspondencia.

\section{ARTíCUlo XI.-Derecho a la Preservación de la Saludy al Bienestar}

Toda persona tiene derecho a que su salud sea preservada por medidas sanitarias y sociales, relativas a la alimentación, el vestido, la vivienda y los cuidados médicos, correspondientes al nivel que permitan los recursos públicos y los de la comunidad.

\section{ARTícUlo XII.-Derecho a la Educación}

Toda persona tiene derecho a la educación, la cual debe estar inspirada en los principios de libertad, moralidad y solidaridad humana.

Asimismo, tiene el derecho de que, mediante esa educación, se le prepare para su digna subsistencia, para el mejoramiento del nivel de su vida y para ser útil a la sociedad.

El derecho de educación comprende el de igualdad de oportunidades en todos los casos, de acuerdo con las dotes naturales, los méritos y el deseo de aprovechar los recursos que puedan proporcionar la comunidad y el Estado.

Toda persona tiene derecho a recibir gratuitamente, a lo menos, la educación primaria.

\section{ARTículo XIII.-Derecho a los Beneficios de la Cultura}

Toda persona tiene el derecho de tomar parte en la vida cultural de la comunidad, de gozar de las artes y de participar de los beneficios que resulten de los progresos intelectuales y especialmente de los descubrimientos científicos.

Asimismo, tiene derecho a ser protegida, en sus intereses morales, por los inventos, obras literarias, científicas o artísticas de que sea autor.

\section{ARTíCULO XIV.-Derecho al Trabajo y a una fusta Retribución}

Toda persona tiene el derecho al trabajo en condiciones dignas y el de seguir libremente su vocación, en cuanto lo permitan las oportunidades de empleo existentes.

Toda persona que trabaja, tiene el derecho de recibir una retribución que, en relación con su capacidad de destreza, le asegure un nivel de vida conveniente para sí misma y para su familia.

\section{ARTículo XV.-Derecho al Descanso y a su Aprovechamiento}

Toda persona tiene derecho a descanso, a honesta recreación y a la oportunidad de aprovechar útilmente el tiempo libre, en beneficio de su mejoramiento espiritual, cultural y físico.

\section{ARTículo XVI.-Derecho a la Seguridad Social}

Toda persona tiene derecho a la seguridad social, que proteja contra las con secuencias de la desocupación, de la vejez y la incapacidad que, proveniente de cualquier otra causa ajena a su voluntad, la imposibilite físicamente o mentalmente, para obtener los medios de subsistencia. 


\section{ARTículo XVII.-Derecho de Reconocimiento de la Personalidad Furídica y de los Derechos Civiles}

Toda persona tiene derecho a que se le reconozca en cualquier parte como sujeto de derechos y obligaciones, y a gozar de los derechos civiles fundamentales.

\section{ARTícUlo XVIII.-Derechos de Fusticia ${ }^{1}$}

Toda persona puede ocurrir a los tribunales para hacer que se respete su derecho. Asimismo, debe disponer de un procedimiento sencillo y breve por el cual la justicia lo ampare contra actos de la autoridad que violen, en su perjuicio, alguno de los derechos fundamentales consagrados constitucionalmente.

\section{ARTícUlo XIX.-Derecho de Nacionalidad}

Toda persona tiene derecho a la nacionalidad que legalmente le corresponde y el de cambiarla, si así lo desea, por la de cualquier otro país que esté dispuesto a otorgársela.

\section{ARTículo XX.-Derecho de Sufragio y de Participación en el Gobierno}

Toda persona, legalmente capacitada, tiene el derecho de tomar parte efectiva en el gobierno de su país, directamente o por medio de su representante, y de participar en las elecciones populares, que serán de voto secreto, genuinas, periódicas y libres.

\section{ARTículO XXI.-Derecho de Reunión}

Toda persona tiene el derecho de reunirse pacíficamente con otras, en manifestación pública o en asamblea transitoria, en relación con sus intereses comunes de cualquier índole.

\section{ARTÍ́culo XXII.-Derecho de Asociación}

Toda persona tiene el derecho de asociarse con otras para promover, ejercer y proteger sus intereses legítimos, de orden político, económico, religioso, social, cultural, profesional, sindical o de cualquier otro.

\section{ARTículO XXIII.-Derecho de Propiedad}

Toda persona tiene el derecho a la propiedad privada correspondiente a las necesidades esenciales de una vida decorosa que contribuya a mantener la dignidad de la persona y del hogar.

1 La Comisión Sexta resolvió incluir como un inciso a este artículo, la consagración del derecho de oponer resistencia; pero, como no se logró acuerdo sobre su texto, decidió pasar el asunto a la Comisión de Iniciativas. Esta reforma presupone el cambio del título, así: "Derecho de Justicia y de Resistencia".NOTA DEL DOCUMENTO [Sin punto después de la palabra "documento" en el original. Nota del editor A. P. D.]

Véanse el documento publicado durante la Conferencia con la clasificación CB-413/C.VI-31, transcrito en la pág. 501, y el Acta (versión taquigráfica) de la Décimasexta Sesión de la Comisión de Iniciativas, transcrita en el Volumen II, pág. 415 y siguientes. 


\section{ARTículo XXIV.-Derecho de Petición}

Toda persona tiene derecho de presentar peticiones respetuosas a cualquiera autoridad competente, ya sea por motivo de interés general, ya de interés particular, y el de obtener pronta resolución.

\section{ARTíCULO XXV.-Derecho de Protección contra la Detención Arbitraria}

Nadie puede ser privado de su libertad, sino en los casos y según las formas establecidas por leyes preexistentes.

Nadie puede ser detenido por incumplimiento de obligaciones de carácter netamente civil.

Todo individuo que haya sido privado de su libertad, tiene derecho a que el juez verifique sin demora la legalidad de la medida y a ser juzgado sin dilación injustificada, o, en contrario, a ser puesto en libertad. Tiene derecho, también, a un tratamiento humano durante la detención.

\section{ARTícUlo XXVI.-Derecho a Proceso Regular}

Se presume que todo acusado es inocente, hasta que se pruebe su culpabilidad.

Toda persona acusada de delito tiene derecho a ser oída en forma imparcial y pública, a ser juzgada por tribunales anteriormente establecidos de acuerdo con leyes preexistentes y a que no se le impongan penas crueles, infamantes o inusitadas.

\section{ARTículo XXVII.-Derecho de Asilo}

Toda persona tiene el derecho de buscar y recibir asilo en territorio extranjero, en caso de persecución que no sea motivada por delitos de derecho común y de acuerdo con la legislación de cada país y con los convenios internacionales.

\section{ARTículo XXVIII.-Alcance de los Derechos del Hombre}

Los derechos del hombre están limitados por los derechos de los demás, por la seguridad de todos y por las justas exigencias del bienestar general y del desenvolvimiento democrático.

\section{CAPITULO SEGUNDO-DEBERES}

\section{INTRODUCCIÓN}

El cumplimiento del deber por cada cual es exigencia del derecho de todos. Derechos y deberes se integran correlativamente en toda actividad social y política del hombre. Si los derechos exaltan la libertad individual, los deberes expresan la dignidad de esa libertad.

\section{PREÁmbUlo}

Los deberes de orden jurídico que constituyen la presente Declaración presuponen otros, de orden moral, que los apoyan conceptualmente y en mucho los fundamentan: 
1. DEBER ANTE EL ESPIRITU. Por cuanto el espíritu es la finalidad suprema de la existencia humana y su máxima categoría, es deber del hombre servir a éste con todas sus potencias y recursos.

2. DEBER DE CULTURA. Y por cuanto la cultura es la máxima expresión social e histórica de ese espíritu, es deber supremo del hombre mantenerla, ejercerla y prosperarla por todos los medios que estén a su alcance.

3. DEBER DE MORALIDAD Y BUENAS MANERAS. Y puesto que la moral y buenas maneras constituyen la floración más noble de esa cultura, es deber de todo hombre acatarlas siempre.

\section{ARTícUlo XXIX.-Deberes ante la Sociedad}

El individuo tiene el deber de convivir con relación a los demás de manera que todos y cada uno puedan formar y desenvolver íntegramente su personalidad.

\section{ARTículo XXX. - Deberes para con los Hijos y los Padres}

Toda persona tiene el deber de asistir, alimentar, educar y amparar a sus hijos menores de edad, y los hijos tienen el de asistir, alimentar y amparar a sus padres cuando éstos lo necesiten y el de honrarlos siempre.

\section{ARTíCULO XXXI.-Deberes de Instrucción}

Toda persona tiene el deber de adquirir, a lo menos, la instrucción primaria.

\section{ARTículo XXXII.-Deber de Sufragio}

Toda persona tiene el deber de votar en las elecciones populares del país de que sea nacional, cuando esté legalmente capacitada para ello.

\section{ARTículo XXXIII.-Deber de Obediencia a la Ley}

Toda persona tiene el deber de obedecer a la Ley y demás mandamientos legítimos de las autoridades del país en que se encuentre.

\section{ARTÍculO XXXIV.-Deber de Servir a la Comunidad y a la Nación}

Toda persona hábil tiene el deber de prestar los servicios civiles y militares que la patria requiera para su defensa y conservación y, en caso de calamidad pública, los civiles que estén a su alcance.

Asimismo tiene el deber de desempeñar los cargos de elección popular que le correspondan en el Estado de que sea nacional.

\section{ARTículo XXXV.-Deberes de Asistencia y Seguridad Sociales}

Toda persona está obligada a cooperar con el Estado y con la comunidad en la asistencia y seguridad sociales, de acuerdo con sus posibilidades y con las circunstancias. 


\section{ARTícUlO XXXVI.-Deber de Pagar Impuestos}

Toda persona tiene el deber de pagar los impuestos establecidos por la Ley para el sostenimiento de los servicios públicos del país de su residencia.

\section{ARTículo XXXVII.-Deber de Trabajo}

Toda persona tiene el deber de trabajar, dentro de su capacidad y posibilidades, a fin de obtener los recursos para su subsistencia o en beneficio de la comunidad.

\section{ARTículo XXXVIII.-Deber de Abstenerse de Actividades Politicas en País Extranjero}

Toda persona tiene el deber de abstenerse de tomar parte en las actividades políticas que de conformidad con la Ley sean privativas de los ciudadanos del Estado en que sea extranjera.

Documento publicado con la clasificación CB-413/C.VI-31

\section{INFORME DEL RELATOR DEL GRUPO DE TRABAJO SOBRE DERECHO DE RESISTENCIA}

Señor Presidente:

Por honroso encargo de los distinguidos miembros del Grupo de Trabajo designado para convenir en un texto sobre el "Derecho de Resistencia", tengo el honor de informar a la Comisión Sexta lo siguiente:

1. Al terminar la sesión de la mañana, nos reunimos en este mismo salón, los señores: Héctor A. Grauert (Uruguay); Guy Pérez Cisneros (Cuba); Diego Manuel Chamorro (Nicaragua); Arturo Despradel (República Dominicana,); Humberto García Ortiz (Ecuador); y José Luis Mendoza (Guatemala).

2. Los presentes estuvimos de acuerdo en que el derecho de resistencia está íntimamente relacionado con el derecho de justicia, y podría funcionar únicamente después de agotar ese recurso, en los casos en que se registrara una manifiesta denegación de justicia o evidente retardo de la misma. Se expresó también que este derecho tenía por objeto principal la protección de los derechos humanos contra arbitrariedades de los propios tribunales encargados de su protección.

3. Los señores miembros del Grupo de Trabajo concordaron ${ }_{1}$ en la conveniencia de no redactar un artículo separado y aprobaron, por unanimidad, adicionar el Artículo XVIII de la Declaración [Americana de los Derechos y Deberes Esenciales del Hombre'], en los siguientes términos:

\section{ARTíCULO XVIII.-Derecho de fusticia y de Resistencia}

"Toda persona puede ocurrir a los tribunales para hacer que se respete su derecho. Asimismo, debe disponer de un procedimiento sencillo y breve por el cual la justicia lo ampare 
contra actos de la autoridad que violen, en su perjuicio, alguno de los derechos fundamentales consagrados constitucionalmente."

"Se reconoce el derecho de resistencia adecuada, en los casos de denegación de justicia o retardo evidente de la misma."

Bogotá, 24 de abril de 1948

(Fdo)José Luis Mendoza (Guatemala) Relator del Grupo de Trabajo

[503]

Documento publicado con la clasificación CB-419/C.VI-33

\section{INFORME DEL SECRETARIO DE LA COMISION SEXTA SOBRE LOS DOCUMENTOS APROBADOS POR ELLA}

Señor Presidente de la Comisión de Coordinación:

Bogotá, 27 de abril de 1948

Tengo el honor de remitir a usted los siguientes documentos definitivos correspondientes a la Comisión Sexta:

1. [Proyecto de] Declaración Americana de los Derechos y Deberes Esenciales del Hombre, documento CB-420/C.VI-341

2. [Proyecto de] Declaración sobre Colonias Europeas en América, documento CB338/C.VI-Sub C-5²

3. [Proyecto de] Declaración sobre Defensa y Presentación de la Democracia en América, documento CB-418/C.VI-323

4. [Proyecto de] Resolución sobre Creación de una Corte Interamericana Destinada a Garantizar los Derechos del Hombre, documento CB-400/C.VI-294

5. [Proyecto de] Declaración sobre Ejercicio del Derecho de Legación, documento CB$387 /$ C.VI- $27^{5}$

6. [Proyecto de] Resolución sobre Reconocimiento de Gobiernos de facto, documento CB-386/C.VI-266

7. [Proyecto de] Resolución sobre Demarcación de Fronteras y Reposición de Hitos, documento CB-39/CIN-87

Los instrumentos números 2, 3, 5 y 6, que pertenecían a la Agenda de la Comisión Sexta, fueron considerados y aprobados por la Comisión de Iniciativas y acogidos luego por esta Comisión. Los números 1, 4 y 7 fueron estudiados y aprobados directamente por la Comisión Sexta.

\footnotetext{
Transcrito en la pág. 504 y siguientes.

Transcrito en las págs. 486-87.

3 Transcrito en las págs. 502-503.

4 Transcrito en la pág. 494.

5 Transcrito en la pág. 493.

6 Transcrito en la pág. 493.

7 Transcrito en la pág. 462.
} 
Me valgo de la oportunidad para expresar al señor Presidente mis sentimientos de la más distinguida consideración.

(Fdo) Gabriel ARAngo Restrepo Secretario de la Comisión Sexta

[504]

Documento publicado con la clasificación CB-420/C.VI-34

\section{DEGLARACION AMERICANA DE LOS DERECHOS Y DEBERES ESENCIALES DEL HOMBRE ${ }^{1}$}

La Novena Conferencia Internacional Americana,

CONSIDERANDO:

Que los pueblos americanos han dignificado la persona humana y que sus constituciones nacionales reconocen que las instituciones jurídicas y políticas, rectoras de la vida en sociedad, tienen como fin principal la protección de los derechos esenciales del hombre y la creación de circunstancias que le permitan progresar espiritual y materialmente y alcanzar la felicidad;

Que, en repetidas ocasiones, los Estados Americanos han reconocido que los derechos esenciales del hombre no nacen del hecho de ser nacional de determinado Estado sino que tienen como fundamento los atributos de la persona humana;

Que la protección internacional de los derechos del hombre debe ser guía principalísima del derecho americano en evolución; y

Que la consagración americana de los derechos esenciales del hombre unida a las garantías ofrecidas por el régimen interno de los Estados, establece el sistema inicial de protección que los Estados Americanos consideran adecuado a las actuales circunstancias sociales y jurídicas, no sin reconocer que deberán fortalecerlo cada vez más en el campo internacional, a medida que esas circunstancias vayan siendo más propicias,

ACUERDA:

Adoptar la siguiente

\section{DECLARACión AMERICANA de los DERECHOS \\ y DEBERES ESENCIALES DEL HOMBRE}

\section{PREÁMBULO}

Todos los hombres nacen libres e iguales en dignidad y derechos, y como están dotados por naturaleza de razón y conciencia, deben conducirse fraternalmente los unos con los otros.

El cumplimiento del deber por cada cual, es exigencia del derecho de todos. Derechos y deberes se integran correlativamente en toda actividad social y política del hombre. Si los derechos exaltan la libertad individual, los deberes expresan la dignidad de esa libertad.

Este documento, presentado como anexo al informe del Relator de la Comisión Sexta y publicado durante la Conferencia con la clasificación CB-445/C.VI-36, esta transcrito en la pág. 510 y siguientes. El texto fué aprobado por la [505] Comisión Sexta. Véanse los documentos publicados durante la Conferencia con la clasificación CB-310/CIN-41 y CB-401/C.VI-30, transcritos respectivamente en la pág. 474 y siguientes y en la pág. 494 y siguientes, y la Resolución XXX del Acta Final de la Conferencia, transcrita en el Volumen VI. 


\section{CAPITULO PRIMERO-DERECHOS}

Artículo I.-Derecho a la Vida, a la Libertad, a la Seguridad e Integridad de la Persona

Todo ser humano tiene derecho a la vida, a la libertad y a la seguridad e integridad de su persona.

\section{ARTícUlo II.-Derecho de Igualdad ante la Ley}

Todas las personas son iguales ante la Ley y tienen los derechos y deberes consagrados en esta Declaración, sin distinción de raza, sexo, idioma, religión ni otra alguna.

\section{ARTíCULO III.-Derecho a la Libertad Religiosa y de Culto}

Toda persona tiene el derecho de profesar libremente una creencia religiosa, y de manifestarla y practicarla públicamente y en privado.

\section{ARTículo IV.-Derecho de Libertad de Investigación, Opinión, Expresión y Difusión}

Toda persona tiene derecho a la libertad de investigación, de opinión y de expresión y difusión del pensamiento por cualquier medio.

ARTículo V.-Derecho a la Protección a la Hora, la Reputación Personal y la Vida Privada y Familiar

Toda persona tiene derecho a la protección de la Ley contra los ataques abusivos a su honra, a su reputación y a su vida privada y familiar.

\section{ARTículo VI.-Derecho a la Familia y a su Protección}

Toda persona tiene derecho a constituir familia, elemento fundamental de la sociedad, y a recibir protección para ella.

\section{ARTíCUlO VII-Derecho de Protección a la Maternidad y a la Infancia}

Toda mujer en estado de gravidez o en época de lactancia y todo niño, tienen derecho a protección, cuidados y ayuda especiales.

\section{ARTículo VIII.-Derechos de Residencia y Tránsito}

Toda persona tiene el derecho de fijar su residencia en el territorio del Estado de que es nacional, de transitar por él libremente y de no abandonarlo sino por su voluntad.

\section{ARTículo IX.-Derecho de Inviolabilidad del Domicilio}

Toda persona tiene derecho a la inviolabilidad de su domicilio.

\section{ARTículo X.-Derecho a la Inviolabilidad y Circulación de la Correspondencia}

Toda persona tiene derecho a la inviolabilidad y circulación de su correspondencia. 


\section{ARTícUlO XI-Derecho a la Preservación de la Saludy al Bienestar}

Toda persona tiene derecho a que su salud sea preservada por medidas sanitarias y sociales, relativas a la alimentación, el vestido, la vivienda y los cuidados [506] médicos, correspondientes al nivel que permitan los recursos públicos y los de la comunidad.

\section{ARTícUlO XII.-Derecho a la Educación}

Toda persona tiene derecho a la educación, la cual debe estar inspirada en los principios de libertad, moralidad y solidaridad humana.

Asimismo, tiene el derecho de que, mediante esa educación, se le prepare para su digna subsistencia, para el mejoramiento del nivel de su vida y para ser útil a la sociedad

El derecho de educación comprende el de igualdad de oportunidades en todos los casos, de acuerdo con las dotes naturales, los méritos y el deseo de aprovechar los recursos que puedan proporcionar la comunidad y el Estado.

Toda persona tiene derecho a recibir gratuitamente, a lo menos, la educación primaria.

\section{ARTíCulo XIII.-Derecho a los Beneficios de la Cultura}

Toda persona tiene el derecho de tomar parte en la vida cultural de la comunidad, de gozar de las artes y de participar de los beneficios que resulten de los progresos intelectuales y especialmente de los descubrimientos científicos. Asimismo, tiene derecho a ser protegida, en sus intereses morales y materiales, por los inventos, obras literarias, científicas o artísticas de que sea autor.

\section{ARTículo XIV.-Derecho al Trabajo y a una Fusta Retribución}

Toda persona tiene el derecho al trabajo en condiciones dignas y el de seguir libremente su vocación, en cuanto lo permitan las oportunidades de empleo existentes.

Toda persona que trabaja, tiene el derecho de recibir una retribución que, en relación con su capacidad de destreza, le asegure un nivel de vida conveniente para sí mismo y para su familia.

\section{ARTículo XV.-Derecho al Descanso y a su Aprovechamiento}

Toda persona tiene derecho a descanso, a honesta recreación y a la oportunidad de aprovechar útilmente el tiempo libre, en beneficio de su mejoramiento espiritual, cultural y físico.

\section{ARTículo XVI.-Derecho a la Seguridad Social}

Toda persona tiene derecho a la seguridad social que la proteja contra las consecuencias de la desocupación, de la vejez y [de] la incapacidad que, proveniente de cualquier otra causa ajena a su voluntad, la imposibilite, física o mentalmente, para obtener los medios de subsistencia.

\section{ArTículo XVII.-Derecho de Reconocimiento de la Personalidad Jurídica y de los Derechos Civiles}

Toda persona tiene derecho a que se le reconozca en cualquier parte como sujeto de derechos y obligaciones, y a gozar de los derechos civiles fundamentales.

[507] 


\section{ARTícUlo XVIII.-Derecho de fusticia ${ }^{1}$}

Toda persona puede ocurrir a los tribunales para hacer que se respete su derecho. Asimismo, debe disponer de un procedimiento sencillo y breve por el cual la justicia lo ampare contra actos de la autoridad que violen, en su perjuicio, alguno de los derechos fundamentales consagrados constitucionalmente.

\section{ARTícUlo XIX. - Derecho de Nacionalidad}

Toda persona tiene derecho a la nacionalidad que legalmente le corresponda, y el de cambiarla, si así lo desea, por la de cualquier otro país que esté dispuesto a otorgársela.

\section{ARTíCUlo XX.-Derecho de Sufragio y de Participación en el Gobierno}

Toda persona, legalmente capacitada, tiene el derecho de tomar parte efectiva en el gobierno de su país, directamente o por medio de sus representantes, y de participar en las elecciones populares, que serán de voto secreto, genuinas, periódicas y libres.

\section{ARTÍ́cUlo XXI.-Derecho de Reunión}

Toda persona tiene el derecho de reunirse pacíficamente con otras, en manifestación pública o en asamblea transitoria, en relación con sus intereses comunes de cualquier índole.

\section{ARTÍculo XXII. - Derecho de Asociación}

Toda persona tiene el derecho de asociarse con otras para promover, ejercer y proteger sus intereses legítimos, de orden político, económico, religioso, social, cultural, profesional, sindical o de cualquier otro.

\section{ARTículO XXIII.-Derecho de Propiedad}

Toda persona tiene derecho a la propiedad privada correspondiente a las necesidades esenciales de una vida decorosa que contribuya a mantener la dignidad de la persona y del hogar.

\section{ARTículo XXIV.-Derecho de Petición}

Toda persona tiene derecho de presentar peticiones respetuosas a cualquiera autoridad competente, ya sea por motivos de interés general, ya de interés particular, y el de obtener pronta resolución.

\section{ARTículo XXV. - Derecho de Protección contra la Detención Arbitraria}

Nadie puede ser privado de su libertad, sino en los casos y según las formas establecidos por leyes preexistentes.

[508] Nadie puede ser detenido por incumplimiento de obligaciones de carácter netamente civil.

1 Véase la nota 1 en la pág. 497. 
Todo individuo que haya sido privado de su libertad tiene derecho a que el juez verifique sin demora la legalidad de la medida y a ser juzgado sin dilación injustificada o, en contrario, a ser puesto en libertad. Tiene derecho, también, a un tratamiento humano durante la detención.

\section{ARTículo XXVI.-Derecho a Proceso Regular}

Se presume que todo acusado es inocente, hasta que se pruebe su culpabilidad. Toda persona acusada de delito tiene derecho a ser oída en forma imparcial y pública, a ser juzgada por tribunales anteriormente establecidos de acuerdo con leyes preexistentes y a que no se le impongan penas crueles, infamantes o inusitadas.

\section{ARTículo XXVII.-Derecho de Asilo}

Toda persona tiene el derecho de buscar y recibir asilo en territorio extranjero, en caso de persecución que no sea motivada por delitos de derecho común y de acuerdo con la legislación de cada país y con los convenios internacionales.

\section{ARTículo XXVIII.-Alcance de los Derechos del Hombre}

Los derechos del hombre están limitados por los derechos de los demás, por la seguridad de todos y por las justas exigencias del bienestar general y del desenvolvimiento democrático.

\section{CAPITULO SEGUNDO-DEBERES}

\section{ARTícUlo XXIX.-Deberes ante la Sociedad}

El individuo tiene el deber de convivir con relación a los demás de manera que todos y cada uno puedan formar y desenvolver integralmente su personalidad.

\section{ARTículo XXX. - Deberes para con los Hijos y los Padres}

Toda persona tiene el deber de asistir, alimentar, educar y amparar a sus hijos menores de edad, y los hijos tienen el de asistir, alimentar y amparar a sus padres cuando éstos lo necesiten y el de honrarlos siempre.

\section{ARTícUlO XXXI.-Deberes de Instrucción}

Toda persona tiene el deber de adquirir a lo menos la instrucción primaria.

$$
\text { ARTículo XXXII.-Deber de Sufragio }
$$

Toda persona tiene el deber de votar en las elecciones populares de cada país de que sea nacional, cuando esté legalmente capacitada para ello.

[509]

\section{ARTÍculo XXXIII.-Deber de Obediencia a la Ley}

Toda persona tiene el deber de obedecer a la Ley y demás mandamientos legítimos de las autoridades del país en que se encuentre. 


\section{ARTíCULO XXXIV.-Deber de Servir a la Comunidad y a la Nación}

Toda persona hábil tiene el deber de prestar los servicios civiles y militares que la patria requiera para su defensa y conservación y, en caso de calamidad pública, los civiles que estén a su alcance.

Asimismo tiene el deber de desempeñar los cargos de elección popular que le correspondan en el Estado de que sea nacional.

\section{ARTículo XXXV.-Deberes de Asistencia y Seguridad Sociales}

Toda persona está obligada a cooperar con el Estado y con la comunidad en la asistencia y seguridad sociales, de acuerdo con sus posibilidades y con las circunstancias.

\section{ARTículo XXXVI.-Deber de Pagar Impuestos}

Toda persona tiene el deber de pagar los impuestos establecidos por la Ley para el sostenimiento de los servicios públicos del país de su residencia.

\section{ARTículo XXXVII.-Deber de Trabajo}

Toda persona tiene el deber de trabajar, dentro de su capacidad y posibilidades, a fin de obtener los recursos para su subsistencia o en beneficio de la comunidad.

\section{ARTículo XXXVIII.-Deber de Abstenerse de Actividades Políticas en País Extranjero}

Toda persona tiene el deber de abstenerse de tomar parte en las actividades políticas que de conformidad con la Ley sean privativas de los ciudadanos del Estado en que sea extranjera.

\section{ADICIÓN}

Los deberes de orden jurídico que constituyen la presente Declaración presuponen otros, de orden moral, que los apoyan conceptualmente y en mucho los fundamentan:

1. DEBER ANTE EL ESPIRITU. Por cuanto el espíritu es la finalidad suprema de la existencia humana y su máxima categoría, es deber del hombre servir a éste con todas sus potencias y recursos.

2. DEBER DE CULTURA. Y por cuanto la cultura es la máxima expresión social e histórica de ese espíritu, es deber supremo del hombre mantenerla, ejercerla y prosperarla por todos los medios que estén a su alcance.

[510] 3. DEBER DE MORALIDAD Y BUENAS MANERAS. Y puesto que la moral y buenas maneras constituyen la floración más noble de esa cultura, es deber de todo hombre acatarlas siempre.

Documento publicado con la clasificación CB-445/C.VI-36

\section{INFORME DEL RELATOR DE LA COMISION SEXTA}

A invitación formal del Gobierno de Colombia, firmada por su Ministro de Relaciones Exteriores, doctor Domingo Esguerra, el 26 de junio de 1947, en cumplimiento de la Resolución CVIII de la precedente Conferencia de Lima de 1938, la Novena Conferencia 
Internacional Americana se reunió en esta ciudad de Bogotá y fué inaugurada oficialmente el 30 de marzo de 1948, en su sede inicial del Capitolio Nacional.

Como hubiese alguna discrepancia de criterios acerca del número de comisiones en que la Conferencia debía de distribuir sus trabajos, en la Reunión Preliminar se sometió a una Subcomisión especial el resolver este asunto, compuesta por los delegados: José A. Mora (Uruguay); Pascual La Rosa (Argentina); Antonio Camillo de Oliveira (Brasil); Antonio Rocha (Colombia); Walter J. Donnelly (Estados Unidos de América); Roberto Córdova (México); y William Manger, Representante de la Unión Panamericana. Aprobó el $1^{\circ}$ de abril el que hubiese seis Comisiones, según lo acordado en dicha Reunión Preliminar.

De ahí surgió, pues, la Comisión Sexta de la Novena Conferencia Internacional Americana en que me ocuparé adelante, con el encargo de estudiar los cuatro puntos siguientes del programa general: "Deberes y Derechos del Hombre", "Reconocimiento de Gobiernos de facto", "Defensa y Preservación de la Democracia" y "Colonias Europeas en América".

En ella estuvieron representadas las distintas delegaciones en el siguiente orden alfabético: ${ }^{1}$ Argentina, Enrique V. Corominas; Bolivia, Alberto Salinas López; Brasil, Antonio Camillo de Oliveira; Colombia, Luis López de Mesa; Costa Rica, Mariano Anderson; Cuba, Guy Pérez Cisneros; Chile, Enrique Bernstein; Ecuador, Pío Jaramillo Alvarado; El Salvador, Héctor Escobar Serrano; Estados Unidos de América, Paul C. Daniels; Guatemala, Jorge García Granados; Haití, Joseph L. Déjean; Honduras, Virgilio R. Gálvez; México, Germán Fernández del Castillo; Nicaragua, Diego Manuel Chamorro; Panamá, Eduardo A. Chiari; Paraguay, César R. Acosta; Perú, Luis Fernán Cisneros; República Dominicana, Carlos Sánchez y Sánchez; Uruguay, Héctor A. Grauert; y Venezuela, Simón Gómez Malaret. También estuvieron representadas la Unión Panamericana, por Charles G. Fenwick, y las Naciones Unidas, por Alfonso García Robles.

Instalada la Comisión Sexta el $1^{\circ}$ de abril en el Salón Guillermo Valencia, del Capitolio Nacional, eligió para Presidente suyo al señor Carlos Sánchez y Sánchez, [511] de la República Dominicana, y Relator, en sesión del día siguiente, al señor Luis López de Mesa, de Colombia. Actuaron en la secretaría los señores Gabriel Arango Restrepo, Manuel Holguín Dávila, Jaime Jaramillo y Gerardo Melguizo.

A intento de realizar mejor estas labores, la susodicha Comisión Sexta dispuso que hubiese en su seno tres subcomisiones de trabajo, a saber:

Subcomisión A, "Derechos y Deberes Internacionales del Hombre": constituída por Delegados de Honduras, Guatemala, Chile, Uruguay, Cuba, Estados Unidos de América, República Dominicana, El Salvador, Paraguay, Costa Rica, Ecuador, Brasil, Haití, Venezuela, Argentina y Colombia.

Subcomisión B, "Reconocimiento de Gobiernos de facto" y "Defensa y Preservación de la Democracia en América": constituída por Delegados de Honduras, Guatemala, Chile, Uruguay, Cuba, Estados Unidos de América, República Dominicana, Bolivia, Perú, Nicaragua, México, Panamá, El Salvador, Paraguay, Costa Rica, Ecuador, Brasil, Venezuela, Argentina y Colombia.

Subcomisión C, "Colonias Europeas en América": constituída por Delegados de Honduras, Guatemala, Chile, Uruguay, Cuba, Estados Unidos de América, República Dominicana, Bolivia, Nicaragua, México, Paraguay, Brasil, Venezuela, Argentina y Colombia.

1 Véase la Nómina completa de la Comisión Sexta, transcrita en la pág. 438. 
Esas Subcomisiones fueron instaladas el día 5 de abril e incontinenti procedieron a la elección de sus respectivos dignatarios, para poder iniciar trabajos normales, como efectivamente lo hicieron.

En todas ellas se dispuso que hubiese primero una disertación general acerca de los temas que les incumbían, a fin de establecer un a modo de tanteo de opiniones, lo que resultó muy útil, pues dió ocasión a emitir conceptos substanciales, precisar actitudes y organizar juicios para la dilucidación de los puntos más arduos. Así, por ejemplo, después de escuchar las exposiciones verbales correspondientes, de Argentina, muy documentada, de Chile, Guatemala y Venezuela, sobre el grave asunto de los territorios americanos ocupados por naciones extracontinentales, se confirmó la convicción, desde antes muy difundida, de que era ineludible separar en dos el estudio de esta materia, según se tratase de regímenes coloniales indisputados aun, o de litigios de soberanía en proceso de consideración ya vigente.

En ese sentido, no era difícil apreciar, desde el primer momento, que existían en el ambiente de la mayoría, si no de la totalidad de las delegaciones, dos normas de conducta inmutables: la de que cesara algún día, lo más cercano posible, toda dominación extracontinental en América; y la de que toda negociación a este respecto se condujese por los cauces procesales de la paz, de la legalidad y la justicia, conforme a los postulados del derecho internacional americano. Asimismo, se advertía en las palabras y general actitud de los representantes de América en esta asamblea augusta, la irrevocable aspiración a que, en todo caso, las gentes de los prenombrados territorios, disputados o no, fuesen favorecidas con el mayor bienestar y la mejor educación asequibles dentro de la respectiva capacidad de sus metrópolis y de las condiciones de su propio ambiente, y preparadas, en la medida de lo factible, propiciatoriamente contemplado, para su independencia o máxima posible autonomía a lo menos.

[512] Por lo que concierne a la Subcomisión A ("Derechos y Deberes Internacionales del Hombre"), muy presto surgieron las dos cuestiones capitanas de este asunto: la de formularlo como convenio de obligación pactada, o como simple declaración abstracta de principios; y la de darle o no garantía internacional de efectivo acatamiento. Desde el comienzo de las deliberaciones, pudo advertirse muy diáfanamente que existían tres grupos casi irreductibles: el de quienes, como Brasil y Uruguay, adelantaban la máxima aspiración a que fuese pacto con obligación nacional y garantía internacional americana; el de quienes, a la manera de Colombia, buscaban para esa garantía de seguridad lo más suave posible, para no alarmar la conciencia asustadiza de las soberanías nacionales, yendo, como en la propuesta colombiana, hasta sugerir que sólo hubiese "investigación informativa" en el caso de presunto incumplimiento de las normas que iban a acordarse; y, por último, el de los que, hallando - como todos unánimemente - razonable y útil el que se tuvieran en cuenta aquellos sagrados principios que son medula ${ }^{6 \mathrm{E}}$ y como esencia de lo americano en sí (o de la "americanidad", como hoy se dice), no se atreven a implantarlos ahora, por conceptuar que algunos países de América no están aun social y políticamente acondicionados para asumir dichas responsabilidades, y así, prefieren posponer el compromiso obligatorio para otra oportunidad futura, que todos, en fin, quisieran que adviniese pronto.

Cuanto a la Subcomisión B y por lo que hace al espinoso tema del reconocimiento de los gobiernos de facto, hubo también desde el principio varios puntos de vista y copiosas opiniones. Quiénes (México, verbi gratia) mantuvieron la tesis de la no intervención absoluta; quiénes la preconizaban como eminentísimo recurso para depurar la democracia en América y contener posibles revoluciones o golpes de Estado que la hiciesen deleznable a las veces

6E Sic. Nota del editor A. P. D. 
y seguramente débil; otros, en fin, buscaban términos medios de conciliación, como el de conservar las relaciones diplomáticas bajo la especie de mero vínculo jurídico de Estado a Estado, y no de asentimiento político a sus gobiernos (cual lo establece la proposición de los Estados Unidos de América), o añadiendo a esta actitud algún recurso de previa consulta diplomática para autorizar el reconocimiento político (como lo sugiere el respectivo proyecto colombiano), o, en fin, recomendando su estudio definitivo a una de las instituciones ya existentes de la Organización de los Estados Americanos.

En estos trámites marchaba la Conferencia, cuando le ocurrió la necesidad de mudarse a nueva sede y trastornar un tanto sus funciones. ¡Gracias sean dadas a la perfecta y oportunísima hospitalidad del Gimnasio Moderno y a la serenidad y admirable nobleza de todas las delegaciones que en este duro trance asistieron y confortaron a Colombia: ni una ni otra generosa actitud olvidaremos!

En su nueva morada, la Conferencia tuvo que concentrar sus funciones; y así ocurrió que la Comisión de Iniciativas dióse a entender en la mayor parte de los temas fundamentales de su cometido, por lo que la de Asuntos Jurídico-políticos, a que corresponde este relato, quedó reducida al estudio de los "Derechos y Deberes Esenciales del Hombre".

En consecuencia de esta nueva situación, la Comisión Sexta a que voy refiriéndome, encomendó la redacción de este asunto a un Grupo de Trabajo, compuesto [513] de los siguientes delegados: Enrique V. Corominas (Argentina); Alberto Salinas López (Bolivia); Antonio Camillo de Oliveira (Brasil); Luis López de Mesa (Colombia); Guy Pérez Cisneros (Cuba); Edward A. Jamison (Estados Unidos de América); Germán Fernández del Castillo (México); Luis Fernán Cisneros (Perú); Dardo Regules (Uruguay) y Melchor Monteverde (Venezuela). El Grupo de Trabajo reunióse por primera vez en la residencia de la Delegación Argentina, el 17 de abril a las 4 p.m., y eligió para Presidente suyo al señor Luis Fernán Cisneros y para Relator al señor Guy Pérez Cisneros. Actuó como Secretario el señor Gerardo Melguizo. Terminó sus labores el Grupo de Trabajo el 20 de abril a las 7:15 p.m., después de una labor no menos admirable por la intensidad del esfuerzo que por la armonía de la colaboración mental.

En efecto, en ese corto plazo los delegados de ese Grupo de Trabajo tuvieron que abocar el conocimiento de varios y, a las veces, voluminosos documentos, como son: el proyecto del Comité Jurídico de Río de Janeiro; ${ }^{1}$ el proyecto de las Naciones Unidas; las disposiciones de la Conferencia de Chapultepec; las de la Convención de La Habana de 1928 sobre las condiciones de los extranjeros; las pertinentes a otros asuntos, de la Sociedad de las Naciones de Ginebra; las múltiples adiciones, supresiones y enmiendas presentadas al anteproyecto de Río por las delegaciones que constituyen esta Novena Conferencia de Bogotá; y las que, en fin, fueron aportando los mismos miembros del Grupo de Trabajo en el curso de sus deliberaciones.

Como punto de partida, se acordó rápidamente que derechos y deberes debían ordenarse en capítulos aparte, para su mejor entendimiento y consulta. Asimismo, se dispuso redactarlos en su mera esencia, sin enumeraciones ejemplares o taxativas, que llevan consigo el riesgo de la difusión inútil y de la confusión peligrosa de sus límites.

Fué, pues, una tarea de interpretación, de compulsa y adecuación de textos, que en ocasiones impuso la necesidad de redactarlos del todo nuevamente. Principiando por el título, el Grupo de Trabajo modificó el primitivo de "Declaración de los Derechos y Deberes Inter-

Documento publicado durante la Conferencia con la clasificación CB-7, transcrito en pág. 449 y siguientes. 
nacionales del Hombre", al parecer poco adecuado y aun confuso, por el de "Declaración Americana de los Derechos Esenciales del Hombre", más aproximado a la intención que mueve esta materia y a su propio contenido conceptual.

Quiso igualmente el Grupo de Trabajo que tanto la redacción de los derechos como la de los deberes estuviesen precedidas de algún preámbulo sustentador y en parte aclaratorio; y, por lo que concierne a los primeros, adoptó el correspondiente de las Naciones Unidas, variándolo apenas, como sigue:

"Todos los hombres nacen libres e iguales en dignidad y derechos, y como están dotados por naturaleza de razón y conciencia, deben conducirse fraternalmente los unos con los otros."

En cuanto fué factible, el Grupo de Trabajo ordenó la serie de los artículos conforme a su contenido natural, social, político y jurídico, respectivamente, y [514] conservó hasta el máximo de la posibilidad la redacción que se les dió en los documentos originales.

Consideró con simpático entendimiento las tesis nuevas que presentaron algunas delegaciones: como la de Cuba sobre el derecho ciudadano a resistir los abusos e injusticias de la autoridad, su arbitrariedad y su desidia dolosas; la de Uruguay acerca de la constitución de un tribunal de garantía para los derechos del hombre americano en general; y la de Brasil respecto de someter este grave negocio a la jurisdicción del Comité Jurídico Interamericano de Río de Janeiro. La magnitud de dichos problemas movió a los miembros del Grupo de Trabajo a referirlos al estudio más autorizado de la Comisión Sexta en pleno, como luego se hizo, muy atinadamente.

Respecto de las posibles medidas de sustentación internacional americana de los comentados derechos y deberes, la Delegación Colombiana, con el propósito de soslayar las dificultades más notorias, sometió a la consideración del Grupo de Trabajo susodicho, un texto de resolución que reza así:

Cuando quiera que, a juicio del Consejo de la Organización de los Estados Americanos, hubiere motivo serio para pensar que en alguno de ellos se estuvieren quebrantando gravemente las normas de los derechos y de los deberes esenciales del hombre que la presente Declaración estatuye, dicho Consejo procederá a hacer la investigación informativa correspondiente, y el Estado a que ella se refiere no impedirá que en él se verifique tal investigación, meramente informativa.

Era una a modo de "sanción" moral, muy tenue en su expresión, pero grávida de fuerza, que el Grupo de Trabajo declinó también.

Asimismo, fué interesante el estudio acerca del derecho de asilo, y muy cuidadosa la consideración de los otros temas de la Declaración, como lo expuso fiel y hábilmente el señor Pérez Cisneros, Relator de ese Grupo de Trabajo. ${ }^{1}$

$\mathrm{Al}$ reanudar la Comisión Sexta sus sesiones ordinarias, deliberó ampliamente sobre el proyecto elaborado por el Grupo de Trabajo a que acabo de referirme, y puede decirse que replanteó las discusiones habidas en él acerca de cada uno de los artículos de la Declaración. Fueron particularmente intensas las que se relacionaron con los derechos de educación; seguridad social; beneficios de la cultura en general y de la ciencia; de la personalidad jurídica y derechos civiles; del sufragio y participación en el gobierno; de reunión y de asociación; de

1 Véase el documento publicado durante la Conferencia con la clasificación CB-310/CIN-41, transcrito en la pág. 474 y siguientes. 
propiedad; y la adecuada garantía para el cumplimiento de todos estos deberes y derechos, que se aprobó como sigue, según la fórmula del Brasil:²

"Que la Comisión Jurídica Interamericana [el Comité Jurídico Interamericano] elabore un proyecto de Estatuto para la creación y el funcionamiento de una Corte Interamericana destinada a garantizar los derechos del hombre. Ese proyecto, después de ser sometido al examen y a las observaciones de los Gobiernos de todos los Estados Americanos, deberá ser remitido a la Décima Conferencia Internacional [515] Americana [Décima Conferencia Interamericana] para que ésta lo estudie, si considera que ha llegado el momento para una decisión sobre la materia."

Por lo que se refiere al [proyecto sobre el] derecho de resistencia presentado por la Delegación de Cuba, la Comisión aprobó por breve mayoría el que fuese incluído en este documento, mas luego halló dificultades para acortar el texto respectivo y resolvió finalmente dejar su elaboración a la asamblea plenaria, como tengo el honor de comunicarlo a ella en este instante.

$\mathrm{Al}$ terminar la discusión y aprobación de los artículos pertinentes a los deberes esenciales del hombre, el Delegado de Colombia presentó tres más, aditivos, de índole moral, que fueron efusivamente aceptados, con la indicación de que figurasen aparte de los que entrañan obligación jurídica. Y comoquiera que surgiese alguna dificultad para incluirlos en la introducción o en el preámbulo, la Comisión delegó en el proponente mismo la tarea de colocarlos en el texto, según ese ordenamiento conceptual. Siendo ello ya muy arduo, el dicho autor hubo de optar por añadirlos simplemente, a manera de un complemento ideológico de la Declaración. Sin embargo, la Comisión de Coordinación determinó a la postre que fuesen reajustados a la estructura del preámbulo, en cláusula conjunta, y así quedaron definitivamente. ${ }^{1}$

El texto original de ellos es como sigue:

"Los deberes de orden jurídico que constituyen la presente Declaración presuponen otros, de orden moral, que los apoyan conceptualmente y en mucho los fundamentan:

"1. DEBER ANTE EL ESPIRITU. Por cuanto el espíritu es la finalidad suprema de la existencia humana y su máxima categoría, es deber del hombre servir a éste con todas sus potencias y recursos.

“2. DEBER DE CULTURA. Y por cuanto la cultura es la máxima expresión social e histórica de ese espíritu, es deber supremo del hombre mantenerla, ejercerla y prosperarla por todos los medios que estén a su alcance.

“3. DEBER DE MORALIDAD Y BUENAS MANERAS. Y puesto que la moral y buenas maneras constituyen la floración más noble de esa cultura, es deber de todo hombre acatarlas siempre."

No acaeció duda semejante con la cláusula adicional del señor Delegado del Perú, de índole vinculativa y exegética de los derechos y deberes esenciales del hombre; porque desde un principio se advirtió que casaba estupendamente con la correspondiente del preámbulo, donde, en consecuencia, quedó desde luego articulada.

En su última sesión, la Comisión Sexta manifestó unánime y efusivamente un voto de aplauso para su eximio Presidente, señor Sánchez y Sánchez, de la República Dominicana y para los infatigables y peritos funcionarios colombianos de su Secretaría. Aclamó asimis-

2 Véanse los documentos publicados durante la Conferencia con la. clasificación CB-125/C.VI-6 y CB-400/C.VI-29, transcritos, respectivamente, en las págs. 464 y 494.

1 Véase el Acta (versión taquigráfica) de la Tercera Sesión de la Comisión de Coordinación, transcrita en el Volumen II, pág. 485 y siguientes. 
mo la colaboración sobre-excelente de algunos delegados, que - como el señor Fernández del Castillo de México, el señor Pérez Cisneros de [516] Cuba, el señor Cisneros del Perú, el señor Corominas de la Argentina y el señor de Oliveira del Brasil-aportaron mucha luz conceptual a las deliberaciones, y sorprendente laboriosidad. El Relator, por su parte, se permite añadir que todos los delegados miembros de esta Comisión se mostraron dignos del más alto encomio moral y habilísimos en sus respectivas intervenciones.

En la última hora, broche de cierre, el Delegado del Perú, señor Luis Fernán Cisneros, presentó gentilísima proposición de saludo y fraternal sentimiento a Colombia; y la Comisión, de pie toda, la aclamó noblemente.

Añado a lo expuesto, temeroso ya de ser demasiado prolijo, el texto de la Declaración Americana de los Derechos y Deberes Esenciales del Hombre, tal como la aprobó la Comisión Sexta; ${ }^{1}$ y ambos documentos someto a la ilustrada consideración de la sesión plenaria a que asistimos, pues los otros asuntos inicialmente encomendados a aquélla - como son: el reconocimiento de los gobiernos de facto; la defensa y preservación de la democracia en América; y el caso de las colonias y territorios de metrópoli extracontinental - fueron ya resueltos por una y otra.

Bogotá, Abril 30 de 1948

(Fdo) Luis López De Mesa (Colombia) Relator de la Comisión Sexta

Documento publicado durante la Conferencia con la clasificación CB- 420/C.VI-34, transcrito en la pág. 504 y siguientes. 


\section{SESIONES DE LA COMISION SEXTA}

\section{ACTA DE LA SESION DE INSTALACION DE LA GOMISION SEXTA}

(Versión taquigráfica) ${ }^{1}$

FECHA: jueves, $1^{\circ}$ de abril de 1948

HORA: 15:15-16:00

REciNTO: Salón "Valencia", Capitolio Nacional

PREsIDENTE: señor Carlos Sánchez y Sánchez (República Dominicana)

ViCEPRESIDENTE: señor Marco Antonio Batres (Honduras)

RELATOR: señor Emilio Pando (Cuba)

SECRETARIO: señor Gabriel Arango Restrepo

Presentes: señores José Luis Mendoza A. (Guatemala); Enrique Bernstein (Chile); Héctor A. Grauert (Uruguay); Paul C. Daniels (Estados Unidos de América); Alberto Salinas López (Bolivia); Luis Fernán Cisneros (Perú); Guillermo Sevilla Sacasa (Nicaragua); Roberto Córdova (México); Eduardo A. Chiari (Panamá); Héctor Escobar Serrano (El Salvador); César R. Acosta (Paraguay); Mariano Anderson (Costa Rica); Pío Jaramillo Alvarado (Ecuador); Antonio Camillo de Oliveira (Brasil); Joseph L. Déjean (Haití); Simón Gómez Malaret (Venezuela); Enrique V. Corominas (Argentina); y Augusto Ramírez Moreno (Colombia)

(El señor Camilo de Brigard Silva, Secretario General De la Conferencia, abre la sesión.)

\section{[INSTALación de la COMisión SEXTA]}

El señor SECRETARIo GeNERAL: Excelentísimos señores: en mi calidad de Secretario General de la Novena Conferencia Internacional Americana, me es muy grato proceder a la instalación de la Comisión Sexta de la Conferencia.

Me parece inútil insistir ante ustedes sobre los trascendentes temas que serán materia de discusión en esta Comisión, posiblemente los más delicados, arduos y difíciles de cuantos figuren en la agenda de la Conferencia.

Sin embargo, estoy seguro de que, dadas las luces y capacidades de los delegados que representan a las naciones de América en el seno de esta Comisión, con gran habilidad, sabiduría y tino se logrará llegar a conclusiones que puedan servir de norma en el futuro para señalar un nuevo camino a las naciones americanas.

1 La correspondiente acta resumida fué publicada durante la Conferencia con la clasificación CB78/C.VI-2. 


\section{[ELECGión DEL PRESIDENTE DE LA COMISIÓN]}

Como dentro del orden del día se halla en primer término la elección de Presidente de la Comisión, me permito someter a los señores delegados este punto.

Tiene la palabra el señor Delegado de Bolivia.

El señor SALINAS LóPez (BOLIVIA): Señor Presidente: por la circunstancia de haber sido el señor delegado Carlos Sánchez y Sánchez el primer diplomático acreditado ante el Gobierno de mi patria, me permito en esta oportunidad el honor de [518] proponer, a nombre de Bolivia, la Presidencia para la Comisión Sexta de dicho señor delegado, quien representa aquí a la República Dominicana. La personalidad del candidato que propongo es harto conocida: eminente catedrático, tratadista de derecho público e internacional, jurista de grandes perspectivas, hará seguramente honor al cargo para el cual me permito proponerlo, a nombre de la Delegación de Bolivia.

El señor SEGRETARIo General: Tiene la palabra el señor Delegado de Colombia.

El señor RAmírez Moreno (COLOMBIA): La Delegación de Colombia secunda con entusiasmo la candidatura del doctor Sánchez y Sánchez para la Presidencia de la Comisión Sexta. El doctor Sánchez y Sánchez es uno de los internacionalistas más distinguidos de América, y su libro El Derecho Internacional Americano es una obra de consulta en todas las universidades. Su autor merece la consagración que hoy le vamos a hacer, al elegirlo para la Presidencia de esta Comisión.

El señor Secretario General: Tiene la palabra el señor Delegado de la República de Argentina.

El señor Corominas (ARGEnTina): Señor Presidente: la representación de la Argentina expresa también su adhesión a tal candidatura, en homenaje a las razones fundamentales que ha expresado el señor Delegado de Colombia así como a la tradición internacionalista del delegado que ocuparía la Presidencia en representación de su país, doctor Sánchez y Sánchez, y en mira a la cordialidad y sentimiento de solidaridad con que se dirijan los trabajos dentro de la Conferencia.

El señor SEGRetario General: Tiene la palabra el señor Delegado del Paraguay

El señor Acosta (PARAguaY): La Delegación del Paraguay adhiere con simpatía a la moción del distinguido representante de Bolivia.

El señor SeVIlla Sacasa (Nicaragua): Pido la palabra, señor Presidente.

El señor SECRETARIO GENERAL: Tiene la palabra el señor Delegado de Nicaragua.

El señor Sevilla Sacasa (Nicaragua): Para expresar, señor Presidente, el entusiasmo con que Nicaragua acoge la candidatura del distinguido Delegado Dominicano, doctor Sánchez y Sánchez, en homenaje tanto a sus títulos reconocidos como a su ilustre patria.

El señor Secretario General: Tiene la palabra el señor Delegado del Perú.

El señor Cisneros (PERÚ): Con complacencia, la Delegación del Perú adhiere también a la candidatura del doctor Sánchez y Sánchez, no sólo como homenaje a la nación dominicana, cuyos méritos tanta gravitación tienen para Hispano América, sino también como reconocimiento a las virtudes del candidato.

El señor SEGRETARIO General: Tiene la palabra el señor Delegado de Venezuela.

El señor Gómez MaLaret (Venezuela): Señor Presidente, señores delegados: la Delegación de Venezuela vería con agrado que esta Comisión la presidiera el señor Delegado de la República de Guatemala, por ser ésta una de las Repúblicas Americanas que más se han caracterizado en los últimos tiempos en la defensa de los derechos del hombre, de la democracia en nuestro Continente y de su propia [519] soberanía. Creemos nosotros que estará muy bien frente a esta Presidencia la delegación de esa República hermana. 
El señor Secretario General: Tiene la palabra el señor Delegado de Panamá.

El señor Chiari (PANAmá): Como Delegado de Panamá, quiero hacer constar que me sumo a la propuesta del señor Delegado de Bolivia, a fin de que ocupe la Presidencia la delegación propuesta por él.

El señor SECRETARIO General: Como parece que no hay unanimidad de criterio en relación con la elección de Presidente de la Comisión, deseo preguntar a los señores delegados si quieren que se someta la elección a votación nominal o escrita.

Tiene la palabra el señor Delegado de Chile.

El señor BERnSTEIN (CHILE): En las reuniones de todas las otras Comisiones, ha habido acuerdo unánime para la designación de Presidente. Aquí se presentan dos candidaturas: la de la República Dominicana y la de Guatemala.

Nuestro Gobierno mantiene cordiales relaciones con la República Dominicana y con Guatemala. Yo creo que podríamos levantar la sesión y buscar una fórmula cordial para llegar a votación unánime en esta materia.

El señor Secretario General: Tiene la palabra el señor Delegado de la República de Argentina.

El señor COROMINAS (ARGENTINA): Señor Presidente: si bien es cierto que esta elección se encuentra frente a dos candidaturas, no es menos cierto que el propósito que impulsa a la Novena Conferencia, es distribuir en la mejor medida y con el mejor acierto los honores que representan las Presidencias, Vicepresidencias y Relatorías dentro de las Comisiones de esta Honorable asamblea. Guatemala, país hermano al que todos rendimos gran tributo de admiración y respeto, ha sido ya consagrada en la Mesa Directiva de una Comisión de dicha asamblea. En consecuencia, con el fin de que no haya superposición de cargos, yo me inclinaría a rogar al Honorable representante de Guatemala que retirara su candidatura o hiciera una indicación al Delegado proponente de Venezuela para que esa candidatura fuera retirada, en obsequio a algunos otros países que no han merecido todavía consideración en los títulos honoríficos dentro de la asamblea.

No se trata, señor Presidente, de abrir un debate, en un procedimiento claro. La unanimidad encontrada en otras Comisiones durante su instalación, en las horas de la mañana y de la tarde, nos lleva en este caso a procurar, si no la unanimidad, por lo menos el acuerdo general en una sola sesión, sin necesidad de hacer un breve paréntesis.

Por ello es, que me permito solicitar del cuerpo de que formo parte, la mejor voluntad para sortear dificultades y elegir así la Mesa que habrá de conducir estos debates tan trascendentales y vitales para la asamblea.

El señor SEcretario General: Tiene la palabra el señor Delegado del Brasil.

El señor DE OLIVEIRA (BRASIL): Debo hacer una insinuación semejante a la hecha por la Delegación Argentina.

El señor Secretario General: Tiene la palabra el señor Delegado de Guatemala.

El señor Mendoza (Guatemala): Para la Delegación de Guatemala, hubiera [520] sido un alto honor la Presidencia de esta Comisión. A nuestro modo de pensar, ésta es una de las más importantes de la Conferencia; y a nosotros nos interesa directamente, porque tenemos dos o tres ponencias que constan en la Agenda de la Comisión.

Pero, como bien ha dicho el señor Corominas, parece que a Guatemala se le ha otorgado otro cargo de importancia. En tal virtud, yo propondría como un candidato de transacción al señor Delegado de Cuba, cuya delegación no tiene ningún puesto en la distribución que se ha hecho.

El señor SECRETARIo General: Está pendiente la proposición del señor Delegado de Chile. 
El señor GRAUERT (URUGUAY): Pido la palabra, señor Presidente.

El señor SEGRETARIO GENERAL: Tiene la palabra el señor Delegado del Uruguay.

El señor GRAUERT (URUGUAY): Yo he sido, como todos, un poco sorprendido en esta reunión, con respecto a la proposición sobre la persona del representante del país que vaya a presidir la Comisión. En mi carácter de Delegado del Uruguay, solicito un corto intermedio de 10 minutos, para consultar al jefe de mi delegación sobre el voto que hemos de emitir en esta oportunidad.

El señor SEcretario General: Tiene la palabra el señor Delegado de Venezuela.

El señor GÓmEZ MALARET (VENEZUELA): Voy a apoyar la petición del Uruguay.

El señor SEcretario General: Someto a consideración la proposición de los señores Delegados de Chile y del Uruguay, sobre que se suspenda la sesión durante 10 minutos, para resolver la elección de Presidente. Los señores delegados que estén por la afirmativa se servirán levantar la mano.

Está aprobada. Entonces, se suspende la sesión por 10 minutos.

(Receso)

El señor SECRETARIO GENERAL: Se reanuda la sesión.

Tiene la palabra el señor Delegado de Chile.

El señor BERNSTEIN (CHILE): Hemos estudiado detenidamente la distribución de los cargos de Presidente, Vicepresidente, Relator, etcétera, en las demás Comisiones y, por mi parte, he llegado a la conclusión de que no habiendo sido la República Dominicana elegida en ninguna otra Comisión, es muy lógico y natural que ella ocupe la Presidencia de esta Comisión.

El señor Secretario General: Tiene la palabra el señor Delegado de Costa Rica.

El señor Anderson (COSTA Rica): La Delegación de Costa Rica coincide en las ideas de la Delegación de Chile, y da su apoyo a la elección de la República Dominicana para la Presidencia de esta Comisión.

El señor Corominas (ARGENTINA): Hay indicación de que se vote, señor Presidente.

El señor SEGRETARIO General: Tiene la palabra el señor Delegado del Uruguay.

[521] El señor Grauert (URUGUAY): No voy a votar en favor de la República Dominicana, a pesar de que reconozco en el doctor Sánchez y Sánchez un grande internacionalista americano, un profesor cuyas obras en esta materia han transcendido a todas las universidades del Continente; pues debo aclarar que nuestra delegación había acordado votar en favor de la República de Cuba y, no estando en el recinto el señor Presidente de la Delegación del Uruguay, yo no puedo, personalmente, cambiar la determinación ya acordada.

El señor SECRETARIO GENERAL: Pregunto a los señores delegados si desean que se someta a votación nominal esta elección. Los que estén por la afirmativa, sírvanse levantar la mano.

El señor SEGRETARIo General: Señor Presidente, ha sido aprobada la moción de que se haga una votación nominal.

El señor SECRETARIO: Se va a someter a votación nominal la candidatura de la República Dominicana para la Presidencia de la Comisión Sexta. El señor Secretario se servirá llamar a cada uno de los países, por orden alfabético.

El señor SECRETARIO: Argentina.

El señor Corominas (ARgentina): Voto por la República Dominicana.

El señor SEGRETARIO: BOLIVIA.

El señor SALINAS LÓPEZ (BOLIVIA): Voto por la República Dominicana.

El señor SECRETARIO: Brasil.

El señor DE OLIVEIRA (BRASIL): Voto por la República Dominicana. 
El señor SECRETARIO: Colombia.

El señor RAmírez Moreno (COLOMBIA): Voto por la República Dominicana.

El señor SECRETARIO: Costa Rica.

El señor ANDERson (COSTA RICA): Voto por la República Dominicana.

El señor SECRETARIO: Cuba.

El señor PANDO (CUBA): Voto por la República Dominicana.

El señor SECRETARIO: Chile.

El señor BERNSTEIN (CHILE): Voto por la República Dominicana.

El señor SECRETARIO: Ecuador.

El señor Jaramillo Alvarado (ECUADOR): Voto por la República Dominicana.

El señor SECRETARIO: El Salvador.

El señor Escobar SERRANO (El SALVADOR): Voto por la República Dominicana.

El señor SECRETARIO: Estados Unidos.

El señor DANiels (Estados Unidos DE AMÉRICA): Voto por la República Dominicana.

El señor SECRETARIO: Guatemala.

El señor Mendoza (Guatemala): Voto por Cuba.

El señor SECRETARIO: Haití, ausente. Honduras.

El señor BATRES (HONDURAS): Voto por la República Dominicana.

El señor SECRETARIO: México.

El señor CóRDOVA (MÉXICO): Voto por la República Dominicana.

El señor SEGRETARIO: Nicaragua.

[522] El señor Sevilla Sacasa (Nicaragua): Voto por la República Dominicana.

El señor SECRETARIO: Panamá.

El señor CHIARI (PANAMÁ): Voto por la República Dominicana.

El señor SEGRETARIO: Paraguay.

El señor AcOsta (PARAgUaY): Voto por la República Dominicana.

El señor SECRETARIO: Perú.

El señor Cisneros (PERÚ): Voto por la República Dominicana.

El señor SECRETARIO: República Dominicana-se abstiene. Uruguay.

El señor GRAUERT (URUGUAY): Por Cuba, fundando mi voto en las razones anteriormente expuestas.

El señor SECRETARIO: Venezuela.

El señor Gómez Malaret (Venezuela): Por Cuba, fundando mi voto en la resignación que ha hecho Guatemala de su candidatura.

El señor SECRETARIO: El resultado de la votación es el siguiente: 16 votos por la República Dominicana; tres votos por Cuba; una abstención; y una ausencia.

El señor SEGRETARIO GENERAL: En consecuencia, declaro elegido como Presidente de esta Comisión al ilustre representante de la República Dominicana, y ruego al doctor Sánchez y Sánchez que tenga la bondad de ocupar la Presidencia.

\section{(Aplausos)}

El señor PRESIDENTE: Es para mí un abrumador honor el de presidir esta Comisión tan ilustre, la que tendrá tal vez los problemas más delicados y compuesta por los más destacados juristas de cada país. Recibo el honor a nombre de mi Gobierno, a nombre de la República Dominicana, el país más viejo de América y el que, con Colombia y México, viene luchando desde más largo tiempo por dotar a las naciones americanas de un instituto orgánico. 
Espero tener la suficiente flexibilidad y, al propio tiempo, el suficiente tino, ayudado por ustedes, para no defraudar la confianza que en mí acaban de depositar.

Me obliga más a ello la circunstancia especial en que se ha desarrollado esta votación. Todos ustedes, cada uno de ustedes, es más digno que yo de ocupar este puesto. Cualquiera de ustedes presidiría mejor que yo. Permítanme, pues, sentirme Presidente entre Presidentes. No quiero yo presidir, sin que ustedes presidan conmigo. Vamos a empujar una barca difícil de conducir. Espero que todos remarán conmigo.

Muchas gracias.

\section{(Aplausos)}

\section{[ELEGCión DEL Vicepresidente de La COMISIÓN SEXTA]}

Conforme al orden del día, vamos a proceder a completar la Mesa Directiva con la elección del Vicepresidente de esta Comisión.

Tiene la palabra el señor Delegado de los Estados Unidos.

El señor DANiels (Estados Unidos DE AMÉRICA): Por parte de la Delegación de los Estados Unidos, quiero proponer para el alto puesto de Vicepresidente de esta Comisión Sexta al distinguido representante de Honduras, Excelentísimo señor Marco Antonio Batres. Lo propongo, no solamente tomando en cuenta la distribución de los puestos, no solamente por los lazos de amistad que me unen con este [523] país donde residí el año pasado, sino muy especialmente por los méritos personales del señor Batres.

El señor PRESIDENTE: Ustedes lo han oído: vamos a proceder a la elección de Vicepresidente, y el señor Delegado de Estados Unidos propone al señor Delegado de Honduras, doctor Marco Antonio Batres.

Tiene la palabra el señor Delegado de Nicaragua.

El señor SEvilla SaCaSa (Nicaragua): Como homenaje al doctor Batres, Nicaragua acoge con entusiasmo y con absoluta convicción la candidatura del digno representante de Honduras.

El señor PRESIDENTE: Tiene la palabra el señor Delegado de Chile.

El señor BERnSTEIN (CHILE): Chile acoge gustoso la proposición del señor Delegado de Estados Unidos, como un homenaje tanto a Honduras como a su distinguido representante en nuestra Comisión.

El señor PRESIDENTE: Tiene la palabra el señor Delegado de la Argentina.

El señor COROMINAS (ARGENTINA): Dos palabras, señor Presidente, para apoyar de manera decidida la candidatura propuesta por el señor Delegado de Estados Unidos. Con Honduras nos vinculan en América todas las tradiciones internacionales y, en consecuencia, muy honrados estamos en ver a Honduras integrando la Mesa Directiva de esta Comisión.

El señor PRESIDEnTE: Tiene la palabra el señor Delegado de Colombia.

El señor RAMíREz MoReno (COLOMBIA): La Delegación de Colombia adhiere con mucho placer y entusiasmo a la candidatura lanzada por el señor Delegado de los Estados Unidos, y respetuosamente adiciona esa propuesta sugiriendo que se apruebe por aclamación.

El señor PRESIDENTE: Tiene la palabra el señor Delegado de El Salvador.

El señor Escobar Serrano (El SAlvador): La Delegación de El Salvador adhiere con el mayor entusiasmo a la propuesta hecha en favor de Honduras. Además, conocemos y apreciamos altamente las cualidades ilustres de su representante.

El señor PRESIDENTE: Tiene la palabra el señor Delegado de la República Dominicana. 
El señor Despradel (República Dominicana): La Delegación de la República Dominicana acoge con sincera simpatía la proposición hecha por el Honorable Delegado de Estados Unidos, así como también la fórmula de Colombia, como un justo homenaje a la figura del doctor Batres y a su ilustre patria. El doctor Batres representa a un país que está unido a nosotros por lazos de antigua confraternidad.

El señor PRESIDENTE: En vista de que no se ha presentado otra candidatura y que hay una proposición para que la elección sea por aclamación, propongo que se haga por aclamación la elección a la Vicepresidencia, del ilustre representante de Honduras.

\section{(Aplausos)}

Suplico que pase a la Mesa el señor representante de Honduras.

El señor BATRES (HONDURAS): Considero como un alto honor para mi patria el que se me haya designado, tal vez inmerecidamente, para ocupar el puesto de Vicepresidente de esta importante Comisión. Creo que ello se debe únicamente a la [524] práctica de ese principio universalmente reconocido, de la igualdad jurídica de los Estados y de que lo mismo puede ocupar un alto puesto una nación grande como una nación pequeña. Así es que, al aceptarlo, rindo mis más expresivos agradecimientos, tanto al señor representante de los Estados Unidos que tuvo la bondad de proponerme, como a todos los demás delegados que apoyaron entusiastamente esa proposición.

Ofrezco poner mis escasas capacidades al servicio de la Comisión, y trabajar tesoneramente para obtener el buen éxito que deseamos en estas labores.

Muy agradecido.

\section{[ELEGCión DEL RELATOR DE LA COMISIÓN SEXTA]}

El señor PRESIDENTE: Continuando con la integración de la Mesa, vamos a proceder a la designación del señor Relator.

Tiene la palabra el señor Delegado de la Argentina.

El señor Corominas (ARgentina): Señor Presidente: la representación argentina va a proponer, para integrar la Mesa Directiva de esta Comisión en el cargo de Relator, a la Delegación de Cuba.

Si bien es cierto que en algún momento se ha razonado afirmando que los representantes de Cuba ante esta Conferencia actúan en un grupo reducido, no es menos cierto que el talento y la capacidad de los hombres que integran la representación de Cuba bien podrán superar ese inconveniente de número y prestar el mayor concurso a estas deliberaciones. No nos resignaríamos, señor Presidente, a que Cuba no estuviese representada en la Directiva de esta Comisión. Acaso pudiera pasarse por alto su designación para tales cargos directivos en alguna de las otras Comisiones; pero yo reclamo de los señores delegados me acompañen a convencer a la representación de Cuba de que acepte el cargo de Relator en esta Comisión, prestando así una colaboración extraordinaria a la labor magnífica que ella deberá cumplir.

Nada más, señor Presidente.

El señor PRESIDENTE: Tiene la palabra el señor Delegado de Honduras.

El señor Batres (Honduras): Para pedir que la designación del Delegado de Cuba sea hecha por aclamación, adhiriendo con mucho entusiasmo, en nombre de Honduras, a todo lo que han expresado anteriormente mis distinguidos colegas. 
El señor PREsidente: Tiene la palabra el señor Delegado de Colombia.

El señor RAMírez MOREno (COLOMBIA): Para mí es una gran sorpresa el saber que tal vez Cuba rehuse prestar su asistencia a las labores de la Comisión, en cargo de tanta responsabilidad y trabajo como es el de Relator. Aunque no tengo el privilegio de estar personalmente conectado con mi noble amigo el Embajador de Cuba, conozco las abundantes y preeminentes calidades que tiene para desempeñar este cargo de tanta importancia.

Desde luego, para Colombia es muy grato, tratándose de un país con el cual desde hace tiempo conserva cordiales relaciones, ofrecer el voto por el distinguido representante de Cuba.

El señor PRESIDENTE: Tiene la palabra el señor Delegado de Cuba.

El señor PANDO (CUBA): Señor Presidente, señores delegados: pueden tener ustedes la completa seguridad de que la emoción me embarga, nubla mi pensa- [525] miento, y que no puedo coordinar bien mis palabras después de manifestaciones tan generosas que, partiendo de la representación argentina, han sido sostenidas por otros delegados que piden que sea Cuba quien asuma esta Relatoría.

Mas crean ustedes que la situación en este momento es terriblemente difícil para la Delegación de Cuba, pues solamente tiene cinco miembros, en espera de la llegada de otros, y uno de los cinco ha sido llamado a La Habana. El honor abruma en ese sentido a nuestra delegación, y quisiera saber expresarme en todas esas bellas palabras que he oído aquí, para decirles, en nombre de mi país y en nombre de la Delegación de Cuba, cuanto desde el corazón surge en estos momentos. Pero reclamo la benevolencia de todos los señores delegados aquí presentes, para que en lugar de designar a Cuba para la Relatoría, se designe a un país grande en todo, como lo es el Ecuador. Aunque agradezco enormemente la designación de que se hace objeto a mi país, me atrevo a declinar el honor ante una situación que nos tiene encadenados de manos y pies por el corto y escaso personal de nuestra delegación.

Nuevamente, mis gracias de corazón; pero suplico a todos que señalen para Relator de esta Comisión, y por voto unánime, al representante del Ecuador. Muchas gracias, señor Presidente y señores delegados.

El señor PRESIDENTE: Ustedes han oído las palabras del representante de Cuba.

Yo lo invito a él a reflexionar sobre lo que ha dicho y a no privarnos de su preciosa colaboración, sobre todo como un homenaje a aquellos que le han otorgado su voto. Desde luego, la colaboración del dignísimo representante del Ecuador, para nosotros sería igualmente honrosa; pero, dadas las circunstancias en que ha aparecido su candidatura, quería oír primero la opinión de los que han solicitado el derecho de hablar, y luego la de los que han propuesto votar por Cuba, para saber si ratifican su voto o si aceptan las excusas de nuestro distinguido colega.

Tiene la palabra el señor Delegado de los Estados Unidos.

El señor Daniels (Estados Unidos De AMÉRICA): Parece que es un poco tardía, señor Presidente, mi intervención. Yo había pedido antes la palabra para proponer el nombramiento de Cuba; pero ahora la situación ha cambiado, en vista de la renuncia del señor Delegado de Cuba.

El señor PRESIDENTE: Tiene la palabra el señor Delegado del Uruguay.

El señor GRAUERT (URUGUAY): Había solicitado la palabra para adherir a la proposición hecha por el distinguido representante de la Argentina, compartiendo absolutamente todos los conceptos que fundamentaron dicha proposición. Además, corresponde al anhelo de la Delegación Uruguaya, que había escogido el nombre de Cuba para presidir esta Comisión, que un delegado de ese país integre la Mesa, en calidad de Relator. 
Voy a insistir, señor Presidente y señores delegados, ante el argumento hecho por el señor Delegado de Cuba de la pequeñez numérica de la delegación de su país en estos momentos; porque nosotros conocemos, y hemos visto en diversas oportunidades, de cuánto esfuerzo son capaces los Delegados de Cuba y cuánto coraje tienen para realizar sus trabajos; por lo cual creo que no debe acobardarlos este recargo de tarea que queremos adjudicarles.

Con mucho gusto hubiera votado por el Ecuador, si se hubiera propuesto en [526] primer término; pero, cuando se ha propuesto a Cuba, insisto - ratificando las palabras pronunciadas por el Presidente de esta Comisión - en solicitar al señor Delegado de Cuba que retire la renuncia que nos acaba de hacer.

El señor PRESIDENTE: Tiene la palabra el señor Delegado de la República Dominicana.

El señor DESPRADEL (República Dominicana): Señor Presidente, señores delegados: la representación de la República Dominicana ha escuchado la exposición que acaba de hacer el Honorable y distinguido representante de la hermana República de Cuba; pero, no obstante las razones que él ha expuesto, la Delegación de la República Dominicana muy complacida adhiere a las razones que con tanto brillo expuso el señor representante del Uruguay, y ruega al señor Delegado de Cuba se sirva aceptar esa labor extraordinaria que, en atención a las aptitudes y a la capacidad de dicho delegado y como homenaje a la hermana República de Cuba, le han conferido aquí los señores delegados que me han precedido en el uso de la palabra.

El delegado que os habla tiene el placer y el privilegio de conocer íntimamente al distinguido Delegado de Cuba. Está perfectamente seguro de que su capacidad, sus dotes y su inteligencia suplirán cualquier circunstancia adversa que pueda concurrir en este caso, y de que podrá aportar el brillante concurso que todos los delegados piden le preste a esta Comisión.

El señor PRESIDENTE: Tiene la palabra el señor Delegado del Ecuador.

El señor JARAMILlO ALVARADO (ECUADOR): Me toca dar las más profundas gracias al señor Delegado de la República de Cuba por haber postulado al Ecuador para la Relatoría; pero, por la gratitud que el Ecuador tiene para con la Delegación de Cuba, mi voto será por ella, pues creo que está dotada de magníficas manos para la dirección de la Relatoría.

Hago presente, por ese motivo, la simpatía y agradecimiento del Ecuador para con la representación de Cuba.

El señor PRESIDENTE: Tiene la palabra el señor Delegado de México.

El señor CóRDova (MÉXICO): Ante la declaración que acaba de hacer el señor Delegado del Ecuador y ante el clamor que se ha oído en esta Comisión en favor de que el señor Delegado de Cuba no renuncie, de que se abstenga de insistir en rehusar, yo creo que no cabe otra cosa sino pedirle al señor Delegado de Cuba que, haciendo honor al gran sentido de responsabilidad de su país y dando una demostración de su empeño en colaborar en el esfuerzo interamericano, acepte, como le pedimos con sincero entusiasmo, esa responsabilidad que todos le conferimos, seguros del éxito en su labor.

El señor PRESIDENTE: Tiene la palabra el señor Delegado del Perú.

El señor Cisneros (PERÚ): Creo que precisamente las razones alegadas por el señor Delegado de Cuba para la declinación, han demostrado tanta sensibilidad suya en el cumplimiento del deber, que es de pensar que, si insistimos, ha de tomarlo como caso honroso de fuerza mayor.

El señor PRESIDENTE: Me parece que el debate está cerrado. No veo cómo el señor Delegado de Cuba pueda defenderse.

[527] El señor PANDO (CUBA): Pido la palabra, señor Presidente, para decir exclusivamente que me rindo. 


\section{(Aplausos)}

El señor PRESIDENTE: Señor delegado: lo invito a pasar a honrarnos en la Mesa Directiva.

El señor PANDO (CUBA): Señor Presidente, señores delegados: únicamente para agradecer una vez más el honor tan grande que le confieren ustedes a nuestro país y a la delegación que represento. Se me ocurre, después de todas las cosas que hice para declinar tan honroso cometido, que no nos queda más remedio que trabajar, tratando de multiplicarnos hasta lo infinito para poder cumplir este honroso cargo que me han encomendado.

Muchas gracias a todos.

El señor PRESIDENTE: Pasamos al punto $3^{\circ}$ del orden del día: "Designación o creación de subcomisiones". Vamos a darle lectura al Artículo $16^{\circ}$, modificado, del Reglamento.

El señor CóRDOva (MÉXICO): La sesión plenaria está citada para las 4. Si entramos a discutir otro punto del orden del día, mucho me temo que no vayamos a poder asistir a esa sesión plenaria.

Yo les ruego que dejemos los otros puntos para la próxima sesión.

El señor PRESIDENTE: Si no hay objeción, se levanta la sesión.

\section{ACTA DE LA PRIMERA SESION DE LA COMISION SEXTA \\ (Versión taquigráfica) ${ }^{1}$}

FECHA: viernes, 2 de abril de 1948

HORA: 11:15-12:35

Recinto: Salón Central, Capitolio Nacional

PRESIDENTE: señor Carlos Sánchez y Sánchez (República Dominicana)

Vicepresidente: señor Marco Antonio Batres (Honduras)

RELATOR: señor Luis López de Meza (Colombia)

SEGRETARIO: señor Gabriel Arango Restrepo

Presentes: señores Virgilio R. Gálvez (Honduras); Jorge García Granados (Guatemala); Enrique Bernstein (Chile); Héctor A. Grauert (Uruguay); Emilio Pando (Cuba); Paul C. Daniels (Estados Unidos de América); Arturo Despradel (República Dominicana); Luis Fernán Cisneros (Perú); Diego Manuel Chamorro (Nicaragua); Gabriel Ramos Millán (México); Eduardo A. Chiari (Panamá); Héctor Escobar Serrano (El Salvador); Mariano Anderson (Costa Rica); Pío Jaramillo Alvarado (Ecuador); Antonio Camillo de Oliveira (Brasil); Joseph L. Déjean (Haití); Simón Gómez Malaret (Venezuela); Enrique V. Corominas (Argentina); Charles G. Fenwick (Unión Panamericana); y Alfonso García Robles (Naciones Unida $\mathrm{s})^{7 \mathrm{E}}$

[528] El señor PRESIDENTE: Se declara abierta la sesión. Vamos a pasar a la consideración del Acta de la anterior. ¿No hay ninguna observación al Acta?

Entonces, queda aprobada.

1 La correspondiente acta resumida fué publicada durante la Conferencia con la clasificación CB98/C.VI-3.

7E Sin punto en el original. Nota del editor A. P. D. 


\section{[RENUNCIA DEL RELATOR Y NUEVA ELEGCIÓN]}

Hemos recibido una comunicación que nos causa bastante pena, del señor Presidente de la Delegación de Cuba, en la cual se somete la renuncia del Relator que elegimos ayer. El señor Secretario se servirá darle lectura.

El señor SECRETARIO (Leyendo):

Señor Presidente [de la Comisión Sexta]:

La Delegación de Cuba se ve precisada, muy a su pesar, a declinar el honor que unánimemente le otorgaron los miembros de esa Comisión, al elegir a uno de sus delegados para la Relatoría de la misma.

Nos obliga a tomar esta decisión irrevocable, la circunstancia de no contar nuestra delegación con bastantes delegados para dedicarse uno exclusivamente a una tarea que, por su importancia, exige una consagración absoluta.

La Delegación de Cuba desea, una vez más, dejar constancia de su gratitud a los delegados ante esa Comisión por el señalado honor que le otorgaron.

De usted con la más alta consideración,

\section{(Fdo) Guillermo BELT \\ Presidente [de la Delegación de Cuba]}

El señor PRESIDENTE: Tiene la palabra el señor Delegado de la República Argentina.

El señor COROMINAS (ARGENTINA): Señor Presidente: las razones que tiene la representación de Cuba para hacer renuncia del cargo honorífico con que esta Comisión había querido premiar la tradición y los esfuerzos cubanos al servicio del panamericanismo, son demasiado fuertes para que esta Comisión insista.

Ayer, durante nuestras deliberaciones, pudimos comprobar la voluntad de la misma, en demostrarle a Cuba el testimonio de nuestra solidaridad. Sin que haya una variante en el espíritu que nos llevó a proponer el nombre de Cuba para la Relatoría, la Comisión se ve obligada, a mi juicio, a aceptar la determinación cubana.

Me tocó, en representación de mi país, realizar la propuesta inicial, postulando el nombre de Cuba para la Relatoría.

Frente a la renuncia, me permito aconsejar a la Comisión su aceptación y me permito asimismo rogarle quiera contemplar la posibilidad de votar, para la Relatoría, por la representación de Colombia, en la seguridad de que, por residir sus miembros en esta histórica ciudad de Bogotá, por estar integrada por un gran número de excelentísimos caballeros y americanistas que conocen y comprenden la importancia de los asuntos que se van a tratar en esta Comisión, habrá de aportar una unidad humana, capaz como todas y dispuesta a trabajar armónicamente con nosotros. En consecuencia, señor Presidente, dolorosamente debo inclinarme por la aceptación de la renuncia de Cuba y proponer a la Delegación Colombiana.

Mientras yo estaba formulando esta exposición, escuchaba el consejo que se le suministraba al señor representante de Colombia, en el sentido de que Colombia ya tenía posiciones en la Presidencia de la Conferencia y en algunas Comisiones, y [529] que existían todavía algunos Estados que no habían merecido la mención honorífica de estar ocupando puestos en las Mesas Directivas de las Comisiones. La verdad es que los países que no están actualmente representados en esas Mesas, no lo están porque sus grupos de representantes son reducidos para las necesidades de la Conferencia misma. En este caso, la abundante representación colombiana podrá permitirnos usar de algunos de sus miembros para esta tarea dificilísima.

Yo ruego entonces, señor Presidente, quiera usted poner a consideración la aceptación de la renuncia de Cuba, con la enorme pena que nos provoca, y el voto consagratorio y por aclamación para la representación colombiana para el cargo de Relator. 
El señor PRESIDENTE: Tiene la palabra el señor Delegado del Uruguay.

El señor GRAUERT (URUGUAY): Para expresar, señor Presidente, que a pesar de los conceptos vertidos en la sesión de ayer, acepto la renuncia presentada por el señor Delegado de Cuba, por los mismos motivos expresados por el señor Delegado de la República Argentina; y adhiero fervorosamente a la proposición de que sea un Delegado de la República de Colombia quien actúe como Relator de esta Comisión.

El señor PRESIDENTE: Tiene la palabra el señor Delegado de Colombia.

El señor LÓPEZ DE MESA (COLOMBIA): Señor Presidente: pido el favor de ser escuchado acerca de este honor con que nos van a regalar en esta Comisión, por muy gentil invitación del señor Delegado de Argentina. Colombia desearía, como huésped privilegiado en esta ocasión, que todo lo que sea favorable a la manifestación de las múltiples capacidades y estupendo espíritu de las delegaciones americanas, se manifieste en todas estas Comisiones. Uno de los motivos para distribuir en seis comisiones esta Conferencia, fué el que hubiese oportunidad, para cada una de las delegaciones, de obtener esa capacidad de expresión. Yo vería con inmenso placer que pasara de nosotros ese honor, que es muy grande (porque aprecio la Relatoría como puesto fundamental en las Comisiones), para ser concedido a otra delegación, que dejo al escogimiento de los señores delegados.

Pero tengo que advertir esto: si hubiere, por algún motivo de organización de esta Comisión, necesidad de que Colombia preste ese servicio, como un mandato de la Comisión lo aceptaría Colombia.

El señor PRESIDENTE: Tiene la palabra el señor Delegado de Cuba.

El señor PANDO (CUBA): Señor Presidente: para reiterar nuestro agradecimiento por las manifestaciones aquí vertidas, especialmente por el Honorable representante de la República Argentina, y para secundar la moción presentada por él, en apoyo de la Delegación de Colombia en el cargo de la Relatoría de esta Comisión.

El señor PRESIDENTE: Tiene la palabra el señor Delegado de Guatemala.

El señor GARCía GRANADOS (GUATEMALA): La Delegación de Guatemala siente muchísimo la imposibilidad de la Delegación de Cuba de servir en esta Comisión. Sin embargo, cree que estará brillantemente substituída por la Delegación de Colombia, y se adhiere con todo fervor a la propuesta hecha por el señor Delegado de la Argentina, esperando - conforme a las palabras del señor representante de Colombia - que haga un sacrificio y sirva en esta Comisión.

[530] El señor Presidente: Tiene la palabra el señor representante de Venezuela.

El señor Gómez MaLaret (VENEzuela): La Delegación de Venezuela apoya en todas sus partes la exposición hecha por el señor Delegado de la Argentina, y propone que se someta a aclamación la candidatura para la Relatoría de esta Comisión.

El señor PRESIDENTE: Tiene la palabra el señor Delegado de Nicaragua.

El señor ChAmorro (NicARAGUA): La Delegación de Nicaragua lamenta mucho que la Delegación de Cuba no haya podido aportar su valioso concurso en esta Comisión tan importante, debido a la carencia de personal, y al mismo tiempo considera brillante el pensamiento expuesto por el señor Delegado de la Argentina, para que ocupe el cargo un Delegado de Colombia, que tiene una numerosa delegación y que, además, está compuesta por elementos de una extraordinaria capacidad para esta clase de trabajos.

Creo que estaría muy bien representado el trabajo por la Delegación de Colombia, y me adhiero a la moción del señor representante de Venezuela para que sea electa por aclamación la Delegación Colombiana, como un mandato, como ella misma lo reclama para dar su aceptación. 
El señor PRESIDENTE: Tiene la palabra el señor Delegado del Perú.

El señor Cisneros (Perú): La Delegación del Perú se inclina, lamentándolas, ante las razones de fuerza mayor que ha alegado la Delegación de Cuba; y, al mismo tiempo, se suma al vivísimo interés que manifiesta la Comisión para que sea substituída esta designación por la de Colombia.

El señor PRESIDENTE: Tiene la palabra el señor Delegado de la República Dominicana.

El señor Despradel (República Dominicana): La Delegación de la República Dominicana se asocia de la manera más sincera al pesar de esta Comisión, con motivo de la declinación que hace Cuba de la elección de que fué objeto ayer para desempeñar la Relatoría de esta Comisión; pero, a la vez, interpreta fielmente las poderosas razones que mueven a la Delegación de Cuba a adoptar esta actitud. Por ese motivo, la Delegación Dominicana adhiere, con todo su entusiasmo, a la proposición formulada por el señor representante de la República Argentina y secundada tan entusiastamente por otros representantes de delegaciones, a fin de que la Relatoría de esta Comisión recaiga en la Delegación de Colombia, tan brillantemente representada en esta Comisión y tan competentemente integrada en la Conferencia.

El señor PRESIDENTE: Si no hay ningún delegado que desee hacer uso de la palabra, por los votos motivados de cada uno queda aceptada la renuncia presentada por el señor Relator, Delegado de Cuba. La Presidencia se asocia a las manifestaciones formuladas por los delegados, lamentando el abandono, por razones de fuerza mayor, en que nos deja el Delegado Cubano.

Igualmente, toma en consideración las manifestaciones hechas por los señores delegados en relación con la candidatura para la Relatoría del señor Delegado de Colombia. La substitución, desde luego, nos compensará, en la misma medida, la ausencia en nuestros trabajos del señor Delegado de Cuba.

[531] Puesto que se formula esa elección de Colombia por aclamación, si no hay absolutamente ninguna discrepancia, como veo que no la hay, y con el permiso de ustedes, vamos a proclamar elegido al señor representante de Colombia para ayudarnos en nuestros trabajos. (Aplausos)

La Presidencia agradecería al señor Delegado de Colombia la gentileza de venir a acompañarnos en este estrado.

El señor LÓPEZ DE MESA (COLOMBIA): Con permiso del señor Presidente, expreso a los señores delegados de esta Comisión mi efusiva gratitud por el honor con que hemos sido obsequiados en esta ocasión. Voy a tomar este asiento interinamente, mientras nuestra delegación designa al miembro correspondiente en este caso.

Desearía, desde luego - y creo que puedo emplear la voz de la conjunta delegaciónque nuestros servicios fueran gratos a los miembros de esta Comisión y a la Conferencia en general.

\section{(Aplausos)}

\section{[CREACIÓN DE SUBCOMISIONES]}

El señor PRESIDENTE: Prosiguiendo con el orden del día, vamos a pasar a la creación de las subcomisiones.

De acuerdo con las disposiciones del Artículo $16^{\circ}$ (modificado) del Reglamento, las comisiones tienen la facultad de establecer las subcomisiones que estimen convenientes y de 
determinar el número de miembros que deban integrarlas. Esto significa que nuestro trabajo habrá de desdoblarse en dos etapas: la determinación del número de las subcomisiones; y la determinación del número de miembros que deberán integrar cada subcomisión. Se abre el debate sobre esta cuestión.

Tiene la palabra el señor Delegado de la República Argentina.

El señor COROMINAS (ARGENTINA): La importancia de los asuntos jurídico-políticos que son de competencia de esta Comisión, nos lleva a la necesidad de distribuir el trabajo de la mejor manera.

El delegado que habla, ha mantenido algunas consultas con los señores delegados que integran esta Comisión y, después de haber intercambiado opiniones, hemos llegado a la siguiente conclusión: creemos que deben constituirse tres subcomisiones.

La primera de ellas deberá conocer de los deberes y derechos internacionales del hombre. Hemos querido que una sola subcomisión estudie este problema, por la naturaleza misma del asunto.

La segunda subcomisión estudiará el reconocirniento de los gobiernos de facto, y la defensa y preservación de la democracia en América. La conexión de estos dos problemas y la importancia de los mismos, están determinando la formación de tal subcomisión. Casi podría decirse que fundamentan su constitución los dos asuntos enunciados.

La tercera subcomisión trataría del problema de las colonias europeas en América. Hemos querido también, como en el caso de la primera subcomisión, darle al problema de las colonias europeas en América toda la trascendencia, toda la importancia, que tiene este asunto; y por ello queremos que sea una sola comisión, específicamente, la que estudie tan claro tema.

[532] Enunciadas así las tres subcomisiones que propongo a la consideración de la Comisión, después de haber intercambiado opiniones con los Honorables colegas, me permito hacer también una adición.

Estos temas son de palpitante actualidad, y no creo que haya delegación que se resigne a no integrar la rueda de su discusión. En consecuencia, pese a que existe casi siempre la norma de constituir las subcomisiones con un número de representantes inferior al que constituye la Comisión propiamente dicha, me permito sugerir también a la Honorable Presidencia, quiera contemplar la posibilidad de que en las subcomisiones participen todos los Estados que así lo deseen, en virtud de la importancia y trascendencia de los temas por tratar en las mismas.

Con estas palabras, señor Presidente, dejo planteada mi moción, en el sentido de la constitución de las subcomisiones y de su integración, en cuanto al número se refiere. Nada más, señor Presidente.

El señor PRESIDENTE: Sigue abierto el debate sobre la cuestión planteada en la agenda, es decir, sobre la creación de las subcomisiones y sobre el número de países que deberán integrarlas.

El señor Delegado de la Republica Dominicana tiene la palabra.

El señor Despradel (República Dominicana): La Delegación de la República Dominicana considera que lo expuesto por el señor Delegado de la Argentina, es lo que más se ajusta y lo que resulta más conveniente para la eficaz labor de esta Comisión. La división que se hace en la propuesta del señor Delegado de la Argentina, a juicio también de la Delegación de la República Dominicana es la que más convendría adoptar, de acuerdo con la naturaleza de las distintas materias que integran el capítulo que corresponde a esta Comisión. 
Tal como lo expresó brillantemente el señor Delegado de la Argentina, el primer tema, relativo a la Declaración de los Derechos y Deberes Internacionales del Hombre, por su importancia y por su trascendencia, requiere la atención y la consideración de una subcomisión especialmente dedicada a ese tema. Los temas siguientes, o sean los relativos al reconocimiento de los gobiernos de facto, y a la preservación de las democracias en el Continente, por su afinidad, podrían ser estudiados y considerados por otra subcomisión. Luego, el tema relativo a colonias europeas en América, que ya presenta una naturaleza algo distinta de los otros, requeriría también el estudio por parte de otra subcomisión.

De modo que la Delegación de la Republica Dominicana considera muy atinada la proposición formulada por la Delegación Argentina. En cuanto a los países que deban integrar esas subcomisiones, considera lo mismo: que, dada la importancia de las materias, las subcomisiones deberán estar integradas por todos los países representados en esta Comisión. Por lo tanto, la Delegación de la República Dominicana adhiere con todo su entusiasmo a la propuesta formulada por la Delegación de la República Argentina.

El señor PRESIDENTE: Tiene la palabra el señor Delegado de Honduras.

El señor GÁLvez (Honduras): La Delegación de Honduras estima apropiadísima la adición de las subcomisiones propuestas por el señor Delegado de la Argentina. La apoya cálidamente, pero estima que hay aquí un asunto de orden, [533] que debíamos someter primero a debate: la creación de las subcomisiones, y luego, el número de países que las han de integrar.

El señor PRESIDENTE: Voy a hacer una observación. Desde luego, eso era precisamente lo que pensaba hacer la Presidencia, por la forma en que el Artículo $16^{\circ}$ está concebido. Por eso había hablado de que se trataba de dos etapas, lo que no se opone a que cada cual, al hablar sobre un tópico, dé su pensamiento completo, como lo hizo el señor Delegado de la Argentina. Lo tomaremos en cuenta y seguiremos ese trámite.

Sigue abierto el debate para cualquier observación que se quiera hacer sobre lo que se está considerando.

Tiene la palabra el señor Delegado de Venezuela.

El señor Gómez MaLaret (Venezuela): Venezuela, señor Presidente, no tiene ninguna objeción que hacer a la brillante exposición que ha hecho el señor Delegado de la República Argentina sobre estos tan interesantes temas de la Comisión Sexta.

Estima, pues, que la subdivisión en tres subcomisiones, dada la conexión que existe entre el segundo y el tercer temas, favorecería enormemente la discusión y la apreciación de ellos. Al mismo tiempo, está perfectamente de acuerdo con que el problema palpitante del coloniaje extracontinental en América, sea tratado separadamente, como corresponde a su importancia; y apoya también el corolario de esa proposición, en el sentido de que todos los países aquí representados tomen parte en las discusiones de las subcomisiones.

El señor PRESIDENTE: Sigue abierto el debate sobre la designación de las subcomisiones que habrán de trabajar en esta Comisión. Si ningún delegado tiene una nueva aportación que hacer en el debate, vamos a someter el asunto a votación, llamando la atención de la Comisión respecto de la forma en que quedarán integradas esas subcomisiones.

Como todos ustedes saben, en la Agenda había cuatro temas: el relativo a los derechos y deberes internacionales del hombre; el relativo al reconocimiento de gobiernos de facto; el relativo a defensa y preservación de la democracia en América frente a la eventual instalación de regímenes antidemocráticos en el Continente; y el que se refiere a las colonias europeas en América. La proposición de la Delegación Argentina, apoyada por la Delegación de la República Dominicana en primer término y por otras de las delegaciones luego, me parece que trata de unir en una sola subcomisión los temas segundo y tercero de la Agenda. 
Vamos, pues, a proceder a la votación de esta integración de las subcomisiones, es decir: una para derechos y deberes internacionales del hombre; otra que comprenda los temas segundo y tercero; y una sola para el cuarto. Los que estén de acuerdo pueden permanecer sentados.

Los que no estén de acuerdo pueden manifestarlo en otra forma.

El señor SECRETARIO: Ha sido aprobada por unanimidad.

El señor PRESIDENTE: Vamos ahora a proceder a la determinación del número de miembros que deban integrar estas tres subcomisiones. El Presidente desea oír la opinión de los señores delegados, a pesar de que ya se han adelantado algunas, como la del señor Delegado de la República Argentina, que es precisa.

[534] En el Artículo $16^{\circ}$ (modificado) del Reglamento, se establece que, teniendo en cuenta el sentido de los debates y las peticiones recibidas, el Presidente de cada comisión designará los países que deban formar parte de las subcomisiones. Fué siempre mi pensamiento a este respecto que, dada la importancia y la envergadura de los temas que van a ser considerados en esta Comisión, el Presidente abriría una inscripción en el sentido de que todos los países que tuvieran interés en figurar en una subcomisión pudieran hacerlo libremente, por una simple manifestación de voluntad y una inscripción en la Secretaría. Entonces, yo procedería a integrar las subcomisiones, de acuerdo con la voluntad expresa de cada delegación.

Desde luego, nadie más que cada delegación por sí misma, es capaz de apreciar la conveniencia que tiene de figurar en una subcomisión y el número de delegados que tiene; y acoplará esa circunstancia con la de que muchas subcomisiones van a estar trabajando al mismo tiempo. Esa es una cuestión, como lo digo, de las delegaciones.

La manera de pensar de la Presidencia a este respecto, es completamente amplia. Todos los países que lo deseen, podrán inscribirse en aquellas de las subcomisiones en que crean que tengan interés en actuar. Planteada así la cuestión, vamos entonces, salvo su mejor opinión, a conceder un receso para que los señores delegados hagan a la Secretaría la manifestación de las subcomisiones en que desean figurar.

El señor Despradel (República Dominicana): La Delegación de la República Dominicana se permite considerar que no sería necesario el procedimiento del receso. Ya el señor Delegado de la República Argentina y - apoyando su proposición - la Republica Dominicana, el señor Delegado de Venezuela y el señor Delegado de Honduras, han manifestado que se adhieren a la sugestión de que todas las delegaciones formen parte de las subcomisiones. De manera que lo más procedente me parece someter a la consideración esa proposición. De ser aprobada por la Comisión, quedarían las tres subcomisiones integradas automáticamente por los representantes de todas las delegaciones.

El señor PRESIDENTE: Me parece, si mal no recuerdo - y le pido auxilio en esto a la Delegación de Argentina - que su proposición fué que formaran parte de las subcomisiones todas aquellas delegaciones miembros de la Comisión que desearan formar parte de ellas, sin que se les impusiese a todas como obligación; porque habría un momento en que sería absolutamente incompatible con los trabajos que todos participasen, porque no habría quórum. Es evidente que algunos delegados tendrían que estar en otras comisiones. Cada delegación, pues, apreciará si tiene interés; y la que no tiene interés, no se inscribe, obrando sobre todo en razón del número de sus representantes. Me parece que ésa fué la proposición de la Delegación de Argentina.

Tiene la palabra el señor Delegado de la Argentina.

El señor COROMINAS (ARGENTINA): Sin querer ir en auxilio del señor Presidente, que interpreta tan fielmente el pensamiento, deseo expresar lo siguiente: primero, respecto al Reglamento, la Presidencia está facultada para la integración de las subcomisiones; y segundo, 
en el deseo de que los temas vitales que deberá [535] tratar esta Comisión a través de las subcomisiones, cuenten con el auxilio indispensable del pensamiento de todas las delegaciones, yo sugerí oportunamente a la Presidencia, que abriera las posibilidades para que todas las delegaciones que así lo desearan, participaran libremente de esos debates, es decir, que no hubiese una obligatoriedad para participar en esas subcomisiones, sino un libre acceso a las mismas de las delegaciones aquí representadas. Esa era la síntesis del pensamiento, señor Presidente.

El señor PRESIDENTE: Desde luego, yo había pensado en eso, porque mi idea era darles la mayor amplitud a las delegaciones para que figuraran en todas las subcomisiones; pero después me tropecé con el argumento expuesto, y pensé entonces que, si se inscribían todas, podrían convertirse las subcomisiones prácticamente en la Comisión misma. Puede haber alguna delegación que no tenga interés. La que tenga interés, pues, que se inscriba; y después vendrá el debate en la Comisión.

De modo que, si no hay ninguna observación que hacer, podríamos pasar a un corto intermedio de 10 minutos, o un cuarto de hora, para que las delegaciones hagan su manifestación en la Secretaría. También podría ser que la hiciéramos ahora, de viva voz, sin necesidad de suspender la sesión. Como a ustedes les parezca más cómodo.

El señor Cisneros (Perú): Mejor sería el intermedio de 15 minutos, porque la mayor parte de las delegaciones tendría que consultar con su Presidente y con los demás delegados.

El señor GRAUERT (URUGUAY): Yo creo, señor Presidente, que el temperamento más ajustado de acuerdo con las propias palabras de la Presidencia, sería el de que, aceptada por usted la proposición del señor Delegado de la República Argentina, cada una de las delegaciones comunicara a la Secretaría en el día de hoy, cuáles serían sus delegados que participarían en las distintas subcomisiones en que desearan y pudieran actuar.

El señor PRESIDENTE: Yo aprecio las palabras del señor Delegado del Uruguay; pero le pregunto si no le parece que eso nos detendría un poco el trabajo, porque yo no podría proceder a la designación de las subcomisiones hasta que se hiciera esa indicación. Se detendría, entonces, el orden del día, y no podríamos pasar a los demás puntos, salvo que la Comisión resolviera otra cosa.

El señor GARcía GRANAdos (GUATEMALA): Quiero apoyar la proposición de la Mesa Directiva; yo creo que el señor Presidente está absolutamente en la razón.

En primer lugar, está conforme al Reglamento, puesto que éste indica que la Presidencia sea la que designa los miembros de las comisiones. En este caso, como una gentileza del señor Presidente, él solicita que sean los propios interesados quienes se inscriban. Por otra parte, parece que lo que se necesita, es inscribir los nombres de los países y no de los delegados personalmente.

En segundo lugar, con esto ganamos tiempo. Los países que estén interesados en formar parte de alguna de las subcomisiones, lo harán saber dentro de un momento a la Mesa; y, en el curso del día, o en las próximas sesiones, indicarán los nombres de sus representantes.

[536] El señor COROMINAS (ARGENTINA): En la interpretación exacta, y concordante con la proposición del señor Delegado de Guatemala, deseo aportar una expresión acorde con la ya mencionada. En el propósito de facilitar la tarea, sería conveniente que cada una de las delegaciones aquí representadas expresara a la Presidencia, de viva voz, su determinación de actuar en algunas de las subcomisiones. Por lo pronto, en el caso de la representación argentina, debo decir que rogamos a la Presidencia que la incluya en las tres subcomisiones.

El señor PRESIDENTE: Para facilitar el trabajo de la Secretaría, la Presidencia agradecería también a los señores delegados que, al hacer su inscripción, determinaran el delegado que va a formar parte de la respectiva subcomisión, en representación de su país. Es una 
cuestión de ordenación del trabajo de la Secretaría, y eso sí se puede hacer en el curso del día; porque habiendo manifestado cada país que tiene interés en tal subcomisión, el nombre ya es una cuestión secundaria.

De modo que les ruego precisar esto: ¿lo hacemos de viva voz, o no? De todas maneras, vamos a tener los 10 ó 15 minutos de receso en ese sentido; porque, haciéndolo de viva voz, vamos a tener que tomar nota. Podríamos hacerlo más fácilmente, si cada uno se acerca a la Secretaria y manifiesta su interés en formar parte de las subcomisiones.

Si no hay oposición, podemos tener un receso por 10 minutos.

$($ Receso $)$

El señor PRESIDENTE: Reanudamos el trabajo.

De acuerdo con las peticiones recibidas y según el método que adoptamos, la Presidencia va a proceder a designar los países que van a integrar las tres Subcomisiones en que ha quedado dividida esta Comisión, para la facilidad de nuestro trabajo. El Secretario dará lectura a la lista de países Miembros de esas Subcomisiones, y la Presidencia suplica que se hagan observaciones sobre cualquiera error material que pudiera haberse deslizado. Luego de hecho esto y después que se levante la sesión, ruego que las distintas delegaciones depositen en la Secretaría los nombres de los representantes que van a integrar esas Subcomisiones. En el curso del día pueden hacerlo.

El señor SECRETARIO: Subcomisión A (las Subcomisiones se distinguirán por letras, y no por números, para que no haya confusión con los números de las Comisiones; la letra "A" corresponde, desde luego, a la primera): la integran Argentina, Bolivia, Brasil, Colombia, Costa Rica, Cuba, Chile, Ecuador, El Salvador, Estados Unidos de América, Guatemala, Haití, Honduras, México, Nicaragua, Panamá, Paraguay, Perú, República Dominicana, Uruguay y Venezuela. ¿Es correcto?

Subcomisión B (la segunda): Argentina, Bolivia, Brasil, Colombia, Costa Rica, Cuba, Chile, Ecuador, El Salvador, Estados Unidos de América, Guatemala, Honduras, México, Nicaragua, Panamá, Paraguay, Perú, República Dominicana, Uruguay y Venezuela.

Subcomisión C: Argentina, Bolivia, Brasil, Colombia, Chile, Estados Unidos de América, Guatemala, Honduras, México, Nicaragua, Paraguay, República Dominicana, Uruguay y Venezuela.

[537] El señor PRESIDENTE: Si no hay ninguna observación que hacer, ninguna omisión, ésas son las Subcomisiones que procederemos a instalar el lunes, en el salón y a la hora que oportunamente se les indicará.

Vamos a conocer entonces de los asuntos varios que puedan presentarse. El señor Delegado de la Argentina tiene la palabra.

El señor COROMinas (ARgentina): Señor Presidente: si bien es cierto que la Presidencia nos acaba de anunciar que el día lunes se constituirán las Subcomisiones, me permito rogarle poner en consideración, al concluir el punto $4^{\circ}$ del orden del día, "Asuntos Varios", la posibilidad de dejar constituidas en esta sesión las Subcomisiones respectivas, en la seguridad de que los miembros aquí presentes (que ya hemos realizado algún acuerdo previo) podríamos dar los nombres de los Estados que tendrán a su cargo las Presidencias y las Relatorías de las tres Subcomisiones. En ese caso, el día lunes las Subcomisiones, más bien que constituirse, ya entrarían en funcionamiento.

Si esta sugestión en homenaje a la rapidez y a la comodidad de las deliberaciones tuviese éxito, yo, señor Presidente, me sentiría muy satisfecho de haber interpretado el pensamiento de los señores miembros de la Comisión. 
El señor PRESIDENTE: ¿Ningún otro delegado desea hacer alguna sugestión?

A mí me parece muy bien lo que han sugerido los señores delegados que han tomado la palabra y, en particular, lo que ha propuesto el señor Delegado de la República Argentina; pero me parece que va a ser un poco difícil hacerlo hoy mismo por la mañana. ¿Qué les parecería a ustedes, entonces, dejarlo para las 5 de la tarde? Entonces, el lunes procederíamos a la instalación. Es que el Secretario se queja. Parece que hay dificultades materiales.

Tiene la palabra el señor Delegado del Perú.

El señor Cisneros (PERÚ): Yo creo, señor Presidente, que sería tan poco lo que avanzáramos, dejando instalada ahora las Subcomisiones, o a primera hora del lunes, que no vale la pena impedir que los delegados que estamos aquí nos pongamos de acuerdo con nuestras propias delegaciones y con nuestro Presidente de delegación, para traer una opinión un poco más concertada.

El señor COROMINAS (ARGENTINA): Yo retiro la moción. No hay ningún inconveniente. Mi propósito era ganar tiempo, nada más, señor Presidente.

El señor PRESIDENTE: Bueno, entonces vamos a considerar los "Asuntos varios".

Tiene la palabra el señor Delegado de México.

El señor CóRdova (MÉXICO): Solamente quiero preguntar, en relación con la observación que nos hizo la Presidencia de que entregáramos la lista de delegados y asesores que van a cubrir por cada delegación las Subcomisiones, si no sería suficiente con la lista que ya tiene registrada cada delegación, de los miembros de esta Comisión.

El señor PRESIDENTE: Haciéndose la declaración de que esos son los que forman parte de las Subcomisiones, no hay ningún inconveniente.

Tiene la palabra el señor Delegado del Perú.

El señor CiSNEROS (PERÚ): Yo, por mi parte, hago una declaración a ese efecto.

[538] El señor PRESIDENTE: Tiene la palabra el señor Delegado de México.

El señor CóRdOVA (MéXICO): La misma declaración hace México.

El señor PRESIDENTE: Tiene la palabra el señor delegado de El Salvador.

El señor ESCOBAR SERRANO (EL SALVADOR): Idéntica declaración hace El Salvador.

El señor PRESIDENTE: Me parece que hemos agotado el orden del día. Si no hay nada que proponer, la Presidencia se prepara a declarar cerrada la sesión.

Se levanta la sesión.

\section{ACTA RESUMIDA DE LA SEGUNDA SESION DE LA COMISION SEXTA}

FECHA: viernes, 16 de abril de 1948

HORA: 15:30-17:45

REGINTO: Gimnasio Moderno

PResidente: señor Carlos Sánchez y Sánchez (República Dominicana)

VICEPRESIDENTE: señor Marco Antonio Batres (Honduras)

RELATOR: señor Luis López de Mesa (Colombia)

Documento publicado durante la Conferencia con la clasificación CB-290/C.VI-12 y reproducido con la clasificación CB-354/C.VI-21.

Por dificultades insalvables, no hubo servicios taquigráficos para esta sesión. 
SECRETARIO: señor Gabriel Arango Restrepo

PResentes: señores José Luis Mendoza (Guatemala); Enrique Bernstein (Chile); Héctor A. Grauert (Uruguay); Guy Pérez Cisneros (Cuba); Paul C. Daniels (Estados Unidos de América); Arturo Despradel (República Dominicana); Alberto Salinas López (Bolivia); Luis Fernán Cisneros (Perú); Roberto Córdova (México); Eduardo A. Chiari (Panamá); Héctor Escobar Serrano (El Salvador); César A. Vasconsellos (Paraguay); Humberto García Ortiz (Ecuador); Antonio Camillo de Oliveira (Brasil); Joseph L. Déjean (Haití); José Rafael Pocaterra (Venezuela); Enrique V. Corominas (Argentina); Augusto Ramírez Moreno (Colombia); y Charles G. Fenwick (Unión Panamericana)

\section{[SOBRE LOS TRABAJOS DE LAS SUBCOMISIONES]}

El señor PRESIDENTE abrió la sesión. Advirtió que no existía orden del día porque la convocación había sido hecha por el señor Presidente de la Conferencia.

Solicitó a los señores Presidentes de las Subcomisiones que informaran sobre el estado en que habían quedado los trabajos, en cada una de ellas; y sugirió que luego se resolviera si continuarían estudiando las Subcomisiones los temas encomendados a éstas, o si los consideraría directamente la Comisión.

El señor BERNSTEIN (CHILE) hizo un relato sucinto de las deliberaciones realizadas en la Subcomisión A, las cuales constaban en las minutas ya distribuídas.

El señor REGULES (URUGUAY) sugirió que los delegados que aun no habían participado en el debate general se abstuvieran de hacerlo, para acelerar los trabajos; y que se nombrara luego un grupo de trabajo de pocos miembros que prepara el proyecto de resolución sobre derechos y deberes del hombre, como lo había hecho la Comisión de Iniciativas.

[539] El señor MENDOZA (GUATEMALA) observó que el tema de los derechos y deberes del hombre no se había desprendido de la Agenda de la Comisión de Iniciativas. Propuso, en consecuencia, que se entrara a estudiar el segundo tema, "Reconocimiento de los Gobiernos de facto".

El señor PRESIDENTE expresó su deseo de escuchar, antes, la exposición del señor Córdova (México), Presidente de la Subcomisión C.

El señor CóRdova (MÉXICO) hizo un recuento de los trabajos de tal Subcomisión, que constaban igualmente en las minutas de sus sesiones, y expresó su convicción de que el debate estaba a punto de cristalizar en fórmulas concretas, las cuales se hallarían una vez que pudieran ser consideradas las nuevas enmiendas anunciadas.

El señor DESPRADEL (REPÚBLICA DOMINICANA) pidió que la Comisión absorbiera los trabajos de las Subcomisiones; y que se precisara, en primer término, si la Declaración de los Derechos y Deberes del Hombre debía figurar como un anexo al Pacto Constitutivo o en el articulado, teniendo en cuenta que esta decisión variaría la forma misma del texto.

El señor PRESIDENTE aclaró que, en su concepto, la finalidad de la convocación de la Comisión era adelantar los trabajos a la de Iniciativas, en lo cual estuvieron de acuerdo los Delegados de la República Dominicana y de Chile.

El señor COROMinas (ARgentina) manifestó que en la Subcomisión A varias delegaciones habían expresado su criterio de que la Declaración de Derechos y Deberes del Hombre fuese anexa al Pacto. Agregó que las Subcomisiones B y C tenían casi terminados sus trabajos, con excepción del tema sobre "Defensa y Preservación de la Democracia", que aun no había sido abordado. Concretamente propuso que se estudiaran las materias por la 
Comisión, en el siguiente orden, ya establecido por la Comisión de Iniciativas: 1², "Declaración de Derechos y Deberes del Hombre"; 2, "Reconocimiento de los Gobiernos de facto"; $3^{\circ}$, "Colonias Europeas en América"; y 4, "Defensa y Preservación de la Democracia en América". Concluyó opinando que sólo en caso de discrepancias mayores debían volver los temas a las Subcomisiones.

\section{[LA COMISIÓN ABSORBE EL TRABAJO DE LAS SUBCOMISIONES]}

El señor PÉrez Cisneros (CUBA) propuso, primero, que se suprimieran las Subcomisiones y que la Comisión absorbiera sus trabajos; y, segundo, que se comenzaran los trabajos de la Comisión por la Agenda de la Subcomisión B, que era la que había llegado a mayor madurez en sus estudios.

El señor RAMíREz MORENO (COLOMBIA) declaró, a nombre de su Gobierno, que éste no tenía ningún afán en que la Conferencia llegara a un desenlace apresurado, y que invitaba a los delegados a que tomaran el tiempo necesario en sus deliberaciones. Respecto al punto en debate, dijo que su delegación no adoptaba ninguna posición en él.

El señor DE OLIVEIRA (BRASIL) se mostró de acuerdo con las tesis sostenidas por los señores Delegados de Argentina y Cuba, aclarando al primero y al señor Delegado de México que el debate general en la Subcomisión C había sido postergado para el lunes, 12 de abril, en atención a que su delegación esperaba instrucciones de su Gobierno para presentar una fórmula nueva.

[540] Sometida a votación la propuesta de Cuba, apoyada por Argentina, sobre absorción del trabajo de las Subcomisiones por la Comisión, fué aprobada con la abstención del señor Delegado de Colombia.

El señor PRESIDENTE sometió a consideración el punto siguiente: si en las deliberaciones se seguiría el orden de temas adoptado por la Comisión de Iniciativas o el orden de la Agenda de la Comisión.

El señor Mendoza (GUATEMALA) explicó las causas que produjeron el retiro del señor García Granados, Presidente de la Subcomisión B, y preguntó a la Presidencia si deseaba que el propio señor Mendoza resumiera los trabajos de dicha Subcomisión.

El señor PRESIDENTE conceptuó que la cuestión principal era resolver sobre el orden de los trabajos y que, una vez convenido esto y en el momento oportuno, se debía escuchar la exposición del señor Delegado de Guatemala.

El señor Despradel (República Dominicana) se manifestó partidario de que se adoptara el orden establecido por la Comisión de Iniciativas en atención a que, aunque el tema sobre "Reconocimiento de los Gobiernos de facto" estaba agotado, el de "Defensa y Preservación de la Democracia en América" no había sido tratado aun.

El señor COROMINAS (ARGENTINA) pidió que se votara la propuesta de su delegación antes que ninguna otra, en lo cual fué secundado por el señor CóRDOVA (MÉXICO) y el señor DESPRADEL (REPÚblica DOMINICANA).

El señor PÉREZ Cisneros (CUBA) insistió en sus puntos de vista, manifestando que el orden establecido por la Comisión de Iniciativas no era un dogma y que, suprimidas las Subcomisiones, sería posible estudiar los temas. Explicó su insistencia aduciendo que el debate general estaba agotado, que ya se había podido advertir que existía una mayoría de votos en torno a una solución y que, además, disponiendo de textos concretos, se podía aprovechar mejor el resto de la sesión. 
Después, retiró su proposición, oído el aviso dado por el señor Pocaterra (VenEZUELA), de que su delegación tenía pendiente una exposición sobre la materia, y el anuncio similar que hizo el señor GRAUERT (URUGUAY).

Previa una repetición hecha por el señor Delegado de ARGENTINA del orden que había propuesto, apoyado por los señores Delegados de MéXICo y HONDURAS, el señor PRESIDENTE sometió a votación la propuesta de Guatemala, sobre consideración simultánea de los temas "Reconocimiento de los Gobiernos de facto" y "Defensa y Preservación de la Democracia en América", que consideró íntimamente conexos. La proposición fué negada por mayoría de votos.

Abierta por el señor PRESIDENTE la votación sobre el orden de temas propuesto por la Delegación Argentina, fué aprobado por mayoría de votos.

\section{[SOBRE SI LA COMISIÓN DISGUTIRÍA EL ARTICULADO DEL PDADDH]}

El señor DÉJEAN (HAITí) pidió que, como base previa a las consideraciones de fondo, se estudiara si la Declaración sobre Derechos y Deberes del Hombre debía ser votada en globo, como un todo orgánico, o artículo por artículo. Al respecto, advirtió que, como la Comisión de Iniciativas estaba estudiando todas las materias que pudieran ser susceptibles de promover controversias, a ella podían referirse las cuestiones que se presentaran al discutirse temas tan importantes.

[541] El señor Pérez Cisneros (CUBA) sugirió que se discutiera el articulado de la Declaración sobre Derechos y Deberes del Hombre.

El señor Despradel (República Dominicana) manifestó que, como la Comisión de Iniciativas había devuelto a la Comisión Sexta los temas de la Agenda que le correspondían, ésta podía, por tener suficiente jurisdicción, resolver sobre ellos.

El señor Corominas (ARGEntina) dijo que el Continente Americano había sido el primero en derrotar al privilegio, y que la Carta Orgánica de la Argentina contenía dos principios fundamentales, inspiradores de toda su legislación, que su Gobierno aspiraba a incorporar en todos los convenios internacionales: el de la universalidad, y el de la fraternidad.

Aclaró que la Argentina, campeona de la Declaración internacional de los derechos individuales, había sostenido en el año pasado, en las deliberaciones de la Organización de las Naciones Unidas, que todos los estudios regionales sobre este tema debían ser referidos a dicha organización; pero, por sugestión de varios delegados de países latinoamericanos, había desistido de ello. La Argentina no veía inconveniente, en consecuencia, en que el asunto fuera debatido en la Comisión Sexta de la Novena Conferencia.

El hombre, para la realización de sus fines vitales, no sólo requiere que se le garanticen ciertas condiciones básicas de orden jurídico y político, sino que exige un medio económico de abundancia. Esta era la razón para que una declaración de la índole contemplada, no podía considerarse completa si no incluyese, además de los derechos civiles y políticos, los derechos de la justicia social.

La Argentina había consignado, en un Proyecto de Carta especial, ${ }^{1}$ los derechos y deberes del trabajador, a saber: primero, derecho de trabajar; segundo, derecho a una retribución justa; tercero, derecho a la capacitación; cuarto, derecho a condiciones dignas de trabajo; quinto, derecho a la preservación de la salud; sexto, derecho al bienestar; séptimo, derecho a

Documento publicado durante la Conferencia con la clasificación CB-206/C.V-Sub A-2, transcrito en la pág. 65 y siguientes. 
la seguridad social; octavo, derecho a la protección de su familia; noveno, derecho al mejoramiento económico; y décimo, derecho a la defensa de los intereses profesionales.

Anunció el señor Corominas que oportunamente la Delegación Argentina presentaría un proyecto en el sentido de que se incorporaran los derechos enumerados a la Carta que se estaba elaborando, siempre que no hubiera incongruencia o repetición en relación con los artículos propuestos por el Comité Jurídico, ${ }^{2}$ caso en el cual se preferiría el texto mejor.

Finalmente dijo que, a juicio de la Argentina, esas declaraciones tenían una obligatoriedad moral, pero no se les debía dar el valor de tratados con fuerza jurídica.

El señor Cisneros (PERÚ) afirmó que, en su concepto, la materia de que se ocupaba esta Comisión estaba llamada a ennoblecer los afanes del panamericanismo. Historió el proceso de estos estudios hasta su fase actual.

Dijo que el Perú había avanzado bastante en la protección de la persona humana, pero que no estimaba suficiente el progreso logrado y trataba de superarlo con programas surgidos del avance de la sociología y del apremio de la justicia.

[542] Ahora, más que nunca, era preciso exaltar al hombre para que afirmara la conciencia de su significación, ante el embate de las ideologías totalitarias que trataban de rebajarla.

En concepto de la Delegación del Perú, la realidad estaba madura para una declaración de los derechos y deberes del hombre.

Propuso que la Subcomisión pasara a discutir el Proyecto de Declaración presentado por el Comité Jurídico de Río de Janeiro; y que pidiera a la Conferencia que encomendara al mismo Comité la enunciación sistemática de los respectivos deberes del hombre, no incluídos en el mencionado proyecto, y remitiera a la próxima Conferencia Interamericana la consideración de las proyecciones presuntas de esta declaración, en relación con la posibilidad de garantizar esos derechos más allá de las legislaciones internas de cada país.

El señor PRESIDENTE citó para una nueva reunión, en el mismo local, el día 17 de abril a las 10 de la mañana. Hecha la convocación, levantó la sesión.

\section{ACTA DE LA TERCERA SESION DE LA COMISION SEXTA \\ (Versión taquigráfica) ${ }^{1}$}

FECHA: sábado, 17 de abril de 1948

HORA: 10:30-13:15

RECINTO: Gimnasio Moderno

PRESIDENTE: señor Carlos Sánchez y Sánchez (República Dominicana)

VICEPRESIDENTE: señor Marco Antonio Batres (Honduras)

RELATOR: señor Luis López de Mesa (Colombia)

SECRETARIO: señor Gabriel Arango Restrepo

PResentes: señores Virgilio R. Gálvez (Honduras); José Luis Mendoza (Guatemala); Enrique Bernstein (Chile); Dardo Regules (Uruguay); Guy Pérez Cisneros (Cuba); Paul C. Daniels (Estados Unidos de América); Joaquín Balaguer (República Dominicana); Alberto

2 Documento publicado durante la Conferencia con la clasificación CB-7, transcrito en la pág. 449 y siguientes.

1 La correspondiente acta resumida fué publicada durante la Conferencia con la clasificación CB$287 /$ C.VI-13. 
Salinas López (Bolivia); Luis Fernán Cisneros (Perú); Diego Manuel Chamorro (Nicaragua); Germán Fernández del Castillo (México); Eduardo A. Chiari (Panamá); Héctor Escobar Serrano (El Salvador); Carlos Augusto Saldívar (Paraguay); Mariano Anderson (Costa Rica); Humberto García Ortiz (Ecuador); Antonio Camillo de Oliveira (Brasil); Joseph L. Déjean (Haití); Melchor Monteverde (Venezuela); Enrique V. Corominas (Argentina); y Charles G. Fenwick (Unión Panamericana)

\section{[RECAPITULACIÓN DE LA SESIÓN ANTERIOR]}

El señor PRESIDENTE: Se abre la sesión.

El Acta de la sesión anterior, en la que se discutió el trabajo de la Subcomisión que trató lo relativo a los derechos y deberes internacionales del hombre, está casi terminada y va a ser distribuída.

Mientras tanto, como estamos ahora en un proceso irregular, tenemos que ir ajustándonos a las cosas, de modo que esos pequeños defectos no detengan nuestro [543] trabajo. Pasaremos, pues, a concluir inmediatamente el debate general. Creo que solamente faltan unos pocos delegados por intervenir, de modo que aquellos que estén pendientes de dejarnos oír su opinión global y sintética, pueden hacerlo brevemente, sobre el punto que está sometido a discusión.

Tiene la palabra el señor Delegado de los Estados Unidos.

El señor DANIELS (ESTADos Unidos DE AMÉRICA): Quiero manifestar que, en la semana pasada, la Delegación de los Estados Unidos presentó unas consideraciones generales ante la Comisión. No sé si todos los miembros recuerdan todas esas consideraciones, pero no estoy dispuesto a presentarlas nuevamente, a menos que haya interés especial por parte de alguno de los señores delegados en escucharlas.

El señor PRESIDENTE: Tiene la palabra el señor Delegado de México.

El señor FERnández del Castillo (MéXico): Para una moción de orden, señor Presidente. Como lo ha expresado Su Excelencia hace un momento con toda precisión, la mayor parte de las delegaciones tomó ya la palabra para expresar sus puntos de vista, antes de la interrupción de las sesiones; pero puede ocurrir la misma duda que se presenta al señor Delegado de los Estados Unidos, o sea, que no se recuerde qué fué lo que cada delegación expuso.

Por ese motivo, me permito sugerir a la Presidencia que, como una medida de trámite no sujeta a discusión, el señor Presidente de la Subcomisión A, quien dirigió esos debates y debe tener las versiones de lo expuesto por todas las delegaciones, haga una fijación del debate tal como se encontraba. Este procedimiento nos serviría a todas las delegaciones presentes.

El señor PRESIDENTE: Me permito observar al señor Delegado de México que me parece que esto fué lo primero que se hizo ayer. Lo que sucede, es que el actual representante de México no estaba allí; pero estaba el doctor Córdova. Creo que el relato del señor Córdova se hizo a fin de orientar el debate y el criterio de las distintas delegaciones.

Desde luego, si algún delegado tiene duda sobre cualquier punto, puede hacer la interrogación pertinente; de modo que se concede la palabra para terminar el debate general.

\section{[REFERENCIA AL GUESTIONARIO PRESENTADO POR URUGUAY]}

Tiene la palabra el señor Delegado de Cuba.

El señor Pérez Cisneros (CUBA): Señor Presidente: de acuerdo con las actas de las sesiones a que no he asistido y con lo que he podido oír en las sesiones que he presenciado, es 
la Delegación de Cuba la única que en este asunto de los derechos y deberes internacionales del hombre no ha participado en el debate general.

El señor Regules (URUguaY): También la del Uruguay, que simplemente presentó un cuestionario $^{1}$ que no ha sido contestado.

\section{[CUBA PRESENTA GUATRO DOCUMENTOS]}

El señor Pérez Cisneros (CUBA): Sin embargo, la Delegación de Cuba renuncia a ese derecho y no tomará parte en el debate general, porque entiende que su opinión es bastante conocida sobre este asunto de los derechos del hombre. Pero anuncia que hoy presentará a la Secretaría cuatro documentos y espera que sean distribuídos oportunamente. En ellos consta su posición respecto a la Declaración [544] de Derechos y Deberes Internacionales del Hombre. Para mayor claridad, voy a hacer un breve resumen de ellos.

El primer documento es el Proyecto de Declaración de Derechos del Hombre, que Cuba presentó (siendo la primera nación que lo hizo) a las Naciones Unidas, en su Asamblea General de Londres, en 1946.

Hay aquí algunos aspectos de los derechos del hombre que son importantes, tales como el derecho a la resistencia contra toda forma de opresión. Ese derecho no está en el Proyecto de Declaración del Comité Jurídico. ${ }^{1}$ Creo que es un olvido, y debemos lamentarlo, porque precisamente nuestras naciones se deben al uso y a la defensa que hemos hecho de ese derecho.

También Cuba presenta las contestaciones al cuestionario muy preciso y muy conflictivo de la Delegación del Uruguay. En tesis general, la Delegación de Cuba cree que los derechos del individuo no nacen del hecho de ser nacional de determinado Estado, sino que tienen por base la ley natural, de modo que su efectividad no debe estar garantizada únicamente por el derecho interno, sino también por el derecho internacional.

Asimismo, como aporte a los trabajos de esta Comisión y como referencia al cuestionario presentado por la Delegación del Uruguay, la Delegación de Cuba se permite invitar a esta Comisión a leer, a estudiar y a tener en cuenta las conclusiones que sobre la defensa internacional de los derechos del hombre se adoptaron en la Academia Internacional de Derecho Comparado, en La Habana, en 1947. Aquí traigo esas conclusiones, que pueden ser instructivas y ayudarnos en algo.

Finalmente, la Delegación de Cuba presenta unas cuantas enmiendas y adiciones al Proyecto de Declaración de los Derechos y Deberes Internacionales del Hombre. Estas enmiendas las voy a comentar en dos palabras, a fin de que se vea cuáles son los aportes que Cuba desea ver incluídos en la Declaración definitiva.

\section{[Propuestas Gubanas DE MODificaciones AL PDADDH]}

En vez de la primera palabra, "internacionales", debería decirse acaso "universales"; pero basta que se diga, con este mismo sentido, "los derechos del hombre".

Hay algunos puntos incluídos que no son derechos, sino declaraciones; los derechos tienen que ser sacados de unas premisas. En esto tenemos que agradecer a la Delegación

\footnotetext{
1 Véanse la Minuta de la Primera Sesión de la Subcomisión A de la Comisión Sexta, pág. 612, y también el discurso pronunciado por el señor Delegado del Uruguay en la Quinta Sesión Plenaria (Volumen I, pág. 202).

1 Documento publicado durante la Conferencia con la clasificación CB-7, transcrito en la pág. 449 y siguientes.
} 
de México la traducción del proyecto de Ginebra sobre derechos del hombre. Hace falta apuntar algunas premisas ideológicas, teóricas y filosóficas de donde se sacarán los demás derechos. Cuba aceptaría el encabezamiento del proyecto de Ginebra.

Cuba desea se incluya el punto del derecho de resistencia a la opresión.

Otra cosa que desearía mi país, es la interpretación de la palabra "hombre", "persona" o "individuo" en el sentido de que estas palabras se refieren indistintamente, en todos los casos, a hombres y mujeres. La Carta de las Naciones Unidas en este aspecto es muy clara. En su preámbulo dice:

Nosotros los pueblos de las Naciones Unidas resueltos... a reafirmar la fe en los derechos fundamentales del hombre, en la dignidad y el valor de la persona humana, en la igualdad de derechos de hombres y mujeres y de las naciones grandes y pequeñas...hemos decidido aunar nuestros esfuerzos para realizar estos designios...

[545] Debe quedar bien clara esta igualdad absoluta de los derechos de hombres y mujeres, ya que todos los parlamentos han ratificado la Carta de las Naciones Unidas y, en consecuencia, ninguno podrá oponerse a ella.

La Delegación de Cuba, entre otras proposiciones, defenderá el derecho de la libre investigación, que no aparece en el Tratado de Río; el derecho de asilo, que ya apuntó - creo- el señor Delegado del Brasil; y el derecho de participación en el gobierno.

Estas son las consideraciones que Cuba desea aportar y que he expuesto de la manera más breve posible.

\section{[URUGUAY COMENTA LA NEGESIDAD DE UNA PROTECGIÓN INTERNACIONAL DE DERECHOS]}

El señor PRESIDENTE: Tiene la palabra el señor Delegado del Uruguay.

El señor Regules (URUGUAY): Aceptando la invitación del señor Presidente, de hacer un fundamento global y sintético, voy a expresar de la manera más rápida posible cuál es la respuesta del Uruguay a los cuestionarios que han sido acogidos por la Comisión.

El Uruguay contesta, en síntesis, a las cinco preguntas propuestas, lo siguiente. ${ }^{8 \mathrm{E}}$

Primero, que en el orden regional tenemos la capacidad para organizar el reconocimiento y la protección de los derechos individuales sin subordinarlos, salvo en la continuidad natural con el orden universal. Tenemos la plena libertad de acción en el orden regional, mientras no tropecemos con un pacto universal.

El Uruguay sostiene: $a$ ) el reconocimiento internacional de los derechos del hombre; $b$ ) la inclusión de ese reconocimiento en el pacto de las naciones americanas; y $c$ ) la institución, en el mismo pacto, de un poder jurisdiccional que garantice internacionalmente los derechos reconocidos por el pacto.

Ahora bien, en esta respuesta, debo decir dos palabras sobre dos aspectos esenciales del reconocimiento de los derechos internacionales del hombre y de la protección de los mismos. $\mathrm{Al}$ reconocimiento casi no hago comentarios, porque el Uruguay acepta que se incluyan los derechos políticos individuales, sociales y económicos; acepta también que se incluyan las tres clases de derechos desde una realidad política, social y económica propia que ya tiene medio siglo de existencia; y se permite ofrecer a la Mesa su propio capítulo sobre los derechos individuales y sociales, para que se incorpore al pacto.

${ }_{8 \mathrm{E}}$ Punto aparte en el original. Nota del editor A. P. D. 
Los derechos políticos tienen más de un siglo de elaboración y, hoy, una consolidación segura; y los sociales tienen ya casi medio siglo de trabajo real. Los derechos políticos los hemos ido implantando en todos los países americanos, en medio de grandes conflictos internos. Los derechos sociales y económicos los hemos ido otorgando en el Uruguay desde principios del siglo, por la obra de un gobernante, el señor Batlle y Ordóñez, quien vió en esta materia, con profunda visión de estadista, cuál era el rumbo del porvenir. Estos estatutos son una realidad viva en el Uruguay, porque las libertades individuales están garantizadas por un estado de conciencia individual que hace imposible desafiarlas o suprimirlas. Tal conjunto de realidades vitales y claras hace que en esta materia podamos abrir las puertas a cualquiera investigación internacional, seguros de que no hay un solo hombre que diga: "Falta la libertad de pensamiento; falta la libertad de expresión; falta la libertad de prensa o de comunicación." Por el contrario, todos gozan de las liber- [546] tades fundamentales del hombre, y viven en el seno de garantías sociales que les permiten una vida honorable.

[OBSERVACIÓN URUGUAYA SOBRE UN SISTEMA JUDICIAL INTERNACIONAL DE PROTECCIÓN DE DERECHOS]

El Uruguay pone acento en que el reconocimiento de esos derechos reporte la necesaria protección internacional de los mismos. Dejar esos derechos confiados al orden jurisdiccional interno (lo demuestra la experiencia) es dejar desamparados los derechos individuales. Cartas de reconocimiento a esos derechos individuales se firman en todo el mundo, inclusive por gobiernos que no reconocen el fuero personal. Si esos derechos reconocidos no tienen la protección jurisdiccional, se desprestigia el derecho. ¡Cuántos hombres de América se sienten sofocados por una dictadura en su país, sin tener el medio de invocar sus derechos individuales! Queremos la protección internacional de los derechos del hombre como expresión real. Ponemos bien el acento en la protección de los derechos individuales; en que se debe dar definitivamente este paso, si queremos realmente hacer de América un continente donde el derecho no se desafíe en vano y no quede desprestigiado por falta de garantías.

Quiero llevar a la convicción de ustedes esta consideración. Cuando planteamos el problema aquí, deben considerar los señores delegados que no hemos planteado nada nuevo para el estudio de las delegaciones de América, porque nosotros ya estamos en un régimen de protección internacional de los derechos humanos. En realidad, reunidas aquí las naciones americanas, no podemos discutir de ninguna manera que, como punto previo, haya un reconocimiento internacional de los derechos del hombre; que haya una protección internacional a los derechos humanos; que haya una competencia internacional en esos derechos.

La Delegación del Uruguay propone, no que nosotros resolvamos crear una competencia que ya está creada y aceptada, sino que haya, en lugar de una competencia política, una competencia judicial en la protección de esos derechos.

Es preciso recordar un poco, para descubrir la verdadera posición de nuestros países. Todos los países de América pertenecen a las Naciones Unidas y están representados en un órgano que se llama el "Consejo Económico y Social de las Naciones Unidas". De acuerdo con el Artículo 55 de su Carta, las Naciones Unidas tienen por objeto, promover,

...el respeto universal a los derechos humanos y a las libertades fundamentales de todos, sin hacer distinción... 
Según el Artículo 62,

El Consejo Económico y Social podrá hacer recomendaciones con el objeto de promover el respeto a los derechos humanos y a las libertades fundamentales de todos, y la efectividad de tales derechos y libertades.

En segundo término, dice la Carta, en el Artículo 68, que:

El Consejo Económico y Social establecerá comisiones de orden económico y social y para la promoción de los derechos humanos, así como las demás comisiones necesarias...

Estamos, por tanto, dentro de un régimen que ha creado una competencia internacional de protección a los derechos humanos y a la efectividad de los mismos. Hay, además, un Consejo internacional que tiene la facultad de crear comisiones [547] para la protección de los derechos humanos y para hacer declaraciones sobre su violación o inefectividad.

Repito, estamos en un régimen de competencias internacionales. Si un grupo desposeído de sus derechos en el Uruguay, por ejemplo, acudiera hoy al Consejo Económico y Social de las Naciones Unidas, ese Consejo podría nombrar una comisión investigadora, la que haría una averiguación especial en el Uruguay sobre si se ha faltado a esos derechos sociales, pudiendo hacer después una declaración de que en el Uruguay se han violado esos derechos individuales y deben restituirse.

La Carta no da específicamente esos recursos; pero es evidente que una moción desacatadora del Consejo Económico y Social de las Naciones Unidas podría provocar un reclamo internacional. La protección internacional es el régimen actual al cual nos hemos acogido todos; y, aunque hasta este momento ningún grupo o país ha hecho uso de esos artículos, eso no quiere decir que no se pueda hacerlo cuando la ocasión se presente. Los grupos desposeídos de los distintos sitios de la tierra, todavía no han puesto en movimiento este magnífico instrumento internacional; pero, el día en que ese instrumento se ponga en marcha y se use, veremos cómo funciona la competencia internacional para proteger los derechos del hombre.

Ahora bien, si esto es así, ¿qué viene a proponer la Delegación del Uruguay, cuando pone acento en este asunto? Propone lo siguiente: como nosotros entendemos que la vida internacional se rige por el derecho, que sea la justicia quien pronuncie en este sentido la palabra final. América debe dar ejemplo al mundo, completando la competencia política aceptada por las naciones americanas; o sea, transformándola en una competencia jurídica que nos dé a todos la seguridad de que estas cuestiones, cuando se promuevan, van a ser resueltas por medio del derecho.

En este terreno, por tanto, tenemos que comprender que la persona humana tiene garantías de cuatro órdenes: las del fuero nacional; y, en la esfera internacional, las de orden político, jurisdiccional y penal. Las garantías del fuero nacional ya están consagradas dentro de todas las constituciones. Las de orden internacional política, ya las tenemos, creadas por las Naciones Unidas. Nosotros queremos crear las jurisdiccionales, que todavía no han sido instituídas. No entramos en la vía de las garantías penales, porque creemos que éste es un asunto demasiado nuevo y esperamos que el porvenir reglamente las competencias que sean posibles en un terreno que, de por sí, comprendemos es peligroso.

Pero estamos obligados a dar este paso en América. Tenemos que resolvernos a crear la tercera garantía indispensable: la jurisdiccional internacional. América debe dar el paso 
inevitable, y el hombre de América se sentirá entonces protegido en sus derechos por tres órdenes de garantías: por una constitución nacional; por las Naciones Unidas; y por los jueces que América es capaz de poner al lado de cada hombre, para que sea más fuerte su derecho.

Nosotros, queriendo pasar de las palabras a los hechos, hemos propuesto una fórmula concreta, ${ }^{1}$ porque en tal materia es necesario hablar concretamente. Hemos elaborado la fórmula más moderada posible, para que se vea que queremos trabajar [548] con un gran sentido de responsabilidad. No nos interesa en esta materia tener pequeñas pugnas, ni formar discusión con los pueblos hermanos. Comprendemos con espíritu de fraternidad las situaciones difíciles que atraviesa el mundo. No queremos convertir esto en una bandera de enjuiciamiento de nadie, y lo hacemos sólo para ayudar a todos los hombres de América. Pero nos parece que ésta es una vía que no podemos perder en este momento; debemos demostrar al mundo que América no es un territorio donde se pueda sofocar, quedando impura, una organización internacional.

Nosotros hemos propuesto una fórmula moderada, y yo quiero hacerle un último comentario. Fíjense ustedes que hemos querido, primero, prevenir a los países frente a la doctrina del intervencionismo, porque somos anti-intervencionistas totales. Queremos defender la soberanía totalmente. No podemos trampear este concepto, que está en la conciencia íntima de América. Pero hoy, soberanía y comunidad no son factores que se excluyan, sino que más bien se complementan. Hemos querido, en primer término, determinar bien el territorio que va a comprender la competencia internacional, y para ello hemos dado dos normas.

La primera consiste en crear la competencia internacional para evitar la violación de libertades sin proceso, o con retardo evidente de justicia. La violación de las libertades sin proceso es realmente un abuso del poder. El término "con retardo evidente de justicia" que usamos aquí, no ofrece dificultades, por ser de uso frecuente en el derecho internacional. No es posible que un dictador, demorando indefinidamente la aplicación de las leyes del país, cree un régimen de violación a la libertad, sin proceso o sin garantías procesales, cuando la violación de esas libertades pueda comprometer la paz.

La segunda norma, a la que hemos de sujetar nuestro procedimiento, es ésta:

El sujeto titular de la acción debe promover la demanda, ante la Corte Internacional de Justicia, que actuará en primera etapa como Tribunal de Calificación, previo especial pronunciamiento sobre la pertinencia de la competencia internacional reclamada.

Es decir, la alta Corte de Justicia decide, en primer término, si es uno de los casos previstos en el convenio o no. Si la Corte de Justicia Internacional considera que el caso planteado afecta el fuero internacional, entonces, se acude a un tribunal especial americano, que será el que tendrá que resolver sobre la demanda. Pero hemos puesto una limitación muy seria: este tribunal no puede hacer nada más que la declaración de que ha habido un abuso del derecho. No puede intervenir dentro de la soberanía nacional para restituir ese derecho agraviado, sino que sólo puede hacer la declaración.

Entendemos que hay dos puntos a resolver: primero, ajustar este procedimiento con las competencias internacionales; y segundo, ajustar en el pleito los medios procedimentales, para que no se viole la soberanía del país respectivo. Esta es una vía por la cual el Uruguay considera que se puede llegar a constituir la competencia judicial internacional de garan-

Véase el documento publicado durante la Conferencia con la clasificación CB-112/C.VI-Sub A-3, transcrito en la pág. 463. 
tías de las libertades individuales, con una seguridad que nos permitirá guardar siempre un equilibrio; porque los pleitos se resolverán por una sentencia que dará a cada uno lo que le corresponda.

[549] Yo no sé si estoy fuera de lo "global y sintético", señor Presidente, pero aseguro que termino pronto y que éste es un problema de interés vital.

Creemos que en América existe la supresión de las libertades individuales, bien por conmociones internas o por la perpetuación indefinida de los gobernantes en el poder, al frente de los Estados. Estas son las causas de las fricciones que desgraciadamente tenemos los países de América. Esta situación de las libertades individuales es un explosivo demasiado grande, es una bomba atómica demasiado fuerte, para que sean suficientemente poderosas las convenciones de las dictaduras. Por ello se ve, muchas veces, el caso de que los hombres que buscan la protección de las libertades individuales, tienen que salir fuera de su nación a buscarla en los países libres; y entonces los países libres nos vemos en una situación dificilísima para conciliar nuestras libertades con las que de hecho no existen en otros Estados. Este es el problema con el cual estamos tropezando todos los días.

El respeto a las libertades individuales es base de la paz. Así lo ha dicho elocuentemente el señor Delegado de los Estados Unidos. La paz depende del respeto al hombre. Mientras el hombre no sea respetado en sus libertades individuales, económicas y sociales, ella no puede existir ni en el mundo ni en América.

Las explosiones en todas partes son fruto de ese choque, o de que las clases privilegiadas se perpetúen en el poder, o de la aparición de salvadores mesiánicos que no tenemos por qué aceptar en ninguna parte del mundo, o - en todo caso - de razones que vuelven sobre las libertades individuales.

Hay grandes masas humanas que no creen en estos congresos; ni en la posibilidad de que podamos darles, u obtener para ellas, ningún beneficio. El hombre, como hombre, tiene que saber que nos reunimos en su interés, y que no puede haber en América un solo país que no vea en cada hombre del Continente una unidad y una realidad sagrada. Para ese hombre - así pueda ser el último que esté viviendo en el fondo de la selva - construiremos enteros todos los institutos salvadores de América y de la civilización.

Era lo que quería decir, señor Presidente.

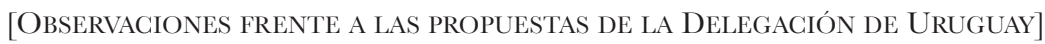

El señor PRESIDENTE: Quería hacer una pequeña petición a la sala: que todos aquí nos comprometiéramos, en un pacto de caballeros, a guardar las réplicas - en este debate general que todavía no se ha concluído - para cuando se presente la discusión del proyecto definitivo, ocasión en la cual todos los señores delegados tendrán la facultad de hacer las réplicas pertinentes. De modo que a cualquiera que vaya a hacer una intervención, le agradezco que sea lo más breve posible, a fin de que no suceda que la Comisión de Iniciativas agote los temas que viene tratando y se apodere de los que se han encargado a esta Comisión; porque, en vez de ser nosotros colaboradores de ellos, pasará que estamos perdiendo el tiempo.

En ese entendimiento, voy a conceder la palabra al señor Delegado de México, por dos minutos.

El señor FERnÁNDEZ DEL CASTILlO (MÉXICO): La exposición brillante que acaba de hacer el doctor Regules me induce a resumir, de manera breve y concreta, cuáles son los argumentos esgrimidos por las diversas delegaciones en contra de lo expuesto por el señor Delegado del Uruguay. 
En los trabajos de la Subcomisión A, la proposición del Uruguay fué patro- [550] cinada por la Delegación de Guatemala, y en contra habíamos hablado los Delegados de los Estados Unidos, Argentina, Brasil, Bolivia, República Dominicana, Chile, Ecuador, Panamá y México. Los argumentos de las distintas delegaciones que no opinamos con el Uruguay, son los siguientes:

1. La convención contemplada implicaría sanciones para hacerla cumplir, impuestas por uno o varios órganos.

2. Esos órganos juzgarían sobre el régimen interno de los Estados, lo que constituye una verdadera intervención.

3. El criterio de esos órganos correspondería a la mentalidad de las personas que los integran, y no a la del Estado de que se trate, frente a sus propias necesidades.

4. Todo hombre vería en el régimen internacional una esperanza, en los casos en que las decisiones del Estado le fueran desfavorables, multiplicándose así indefinidamente las reclamaciones internacionales, lo cual complicaría desorbitadamente el mecanismo internacional.

5. El problema principal en lo tocante a los derechos del hombre radica en la regulación, por medio de la Ley, de la conducta del individuo con el Estado, cuyas bases principales tendrían que incluirse en la convención para que ésta tuviera una aplicación práctica, lo que traería las siguientes consecuencias, que la hacen inaceptable: interna;

a) Fijaría una norma uniforme y rígida, a todos los Estados, sobre su organización

b) Esa norma daría lugar a que todos los Estados tuvieran que modificar sus constituciones o sus legislaciones internas; $y$

c) Objetivamente, todas las constituciones de América consagran los derechos del hombre, por lo que, para los fines de la Conferencia, es suficiente hacer una declaración general de esos derechos y recomendar a los Estados la adopción de un procedimiento sencillo y breve, por el cual, en el régimen interno de cada Estado, la justicia ampare a toda persona contra los actos de la autoridad que violen alguno de los derechos fundamentales.

Un argumento nuevo aducido por el doctor Regules se deriva del texto de la Carta de las Naciones Unidas, aprobada por todos los países de América. A ese respecto, hago constar que la interpretación del doctor Regules no corresponde al criterio de las Naciones Unidas, las cuales recomiendan que se garanticen los derechos del hombre, pero no dicen si eso ha de hacerse dentro del régimen interno o dentro del régimen internacional. Tanto es así, que la Comisión de estudios económicos y sociales se abstuvo de pronunciarse al respecto, y se limitó - en los documentos que ha hecho circular entre los Gobiernos — a decidir el sentido de la institución, y nada más.

Muchas gracias, señor Presidente.

El señor PRESIDENTE: Tiene la palabra el señor Delegado de Bolivia.

El señor SALINAS LÓPEZ (BOLIVIA): Voy a ser breve, señor Presidente, porque el jefe de mi delegación tuvo la oportunidad de expresar su criterio al respecto.

[551] Desde luego, en principio, Bolivia cree que la Declaración de los Derechos y Deberes Internacionales del Hombre no estaría completa si no nos preocupásemos por establecer alguna fórmula que permita que estos derechos y deberes sean efectivos dentro de la 
convivencia del individuo, internacionalmente considerado. En ese sentido, la Delegación de Bolivia proyectó un artículo, ${ }^{1}$ redactado en los siguientes términos:

Incumbe a cada Estado, dentro de su jurisdicción, hacer respetar los derechos y libertades fundamentales de la persona humana, pudiendo ella emplear en garantía de estos derechos y libertades otros procedimientos jurídicos internacionales, de acuerdo a los pactos que se subscriban al efecto.

La Delegación de Bolivia entiende que la Novena Conferencia debe preocuparse de este aspecto, para que realmente pueda ser operante la Declaración de los derechos y deberes internacionales.

Finalmente, sugiere, señor Presidente y señores delegados, la inclusión de un artículo al que ya se ha referido el Delegado de Cuba; o sea, el que proclama el derecho de asilo, proyectando el siguiente artículo:

Toda persona tiene el derecho de asilo, en las condiciones estipuladas por convenios internacionales. ${ }^{2}$

Nada más, señor Presidente.

El señor PRESIDENTE: Tiene la palabra el señor Delegado de Honduras.

El señor GÁlvEZ (HONDURAS): Quería hacer una pregunta al señor Regules, quien en este momento no está aquí. Quería saber cómo podría un individuo que considere lesionados sus derechos, recurrir a la Corte Internacional de Justicia; ya que el Estatuto de la Corte en el Capítulo II (que se refiere a las competencias), dice taxativamente que, "Sólo los Estados podrán ser partes en casos ante la Corte."

El señor PRESIDENTE: Tiene la palabra el señor Delegado de Haití.

El señor DÉJEAN (HAití): Señores delegados, señor Presidente: la opinión de la Delegación de Haití en relación con el asunto en debate, ha sido ya expuesta. Ayer mismo lo fué, con mucha elocuencia, por el jefe de nuestra delegación. No tengo, pues, nada que agregar.

Sin embargo, yo recalco el que Haití es partidaria del establecimiento de una jurisdicción especial relativa a la violación de los derechos del hombre; y que, por consiguiente, apoya con entusiasmo la proposición presentada por el señor Delegado del Uruguay.

Desde el origen de la historia contemporánea - a partir de la constitución de los Estados Unidos de América y desde la Revolución Francesa, en 1789 - se han venido proclamando los derechos del hombre. No obstante, hasta los días en que esta Novena Conferencia se está desarrollando, no venimos a preocuparnos por decidir la cuestión de si es, o no, necesario que tales derechos tengan una efectiva salvaguardia; y, entretanto, los hombres se han matado unos a otros y sus derechos, en realidad, han quedado indefensos.

[552] El problema para nosotros es saber si, por fin, abandonando la hipocresía y apartándonos de la forma platónica de declarar los derechos del hombre, vamos a consagrarlos definitivamente; y si vamos, al propio tiempo, a crear el organismo que sancione toda violación de esos derechos.

Tal es la cuestión que tenemos ante nosotros. Esta Conferencia no habrá llegado a un fin práctico, si eludimos tan grave problema, que en épocas demasiado recientes ha incendiado al mundo y que acaba de causar tantas catástrofes y sufrimientos, desgraciadamente no

Véase el documento publicado durante la Conferencia con la clasificación CB-163/C.VI-9, transcrito en la pág. 468.

2 Ibidem. 
eliminados todavía. Preciso es que sepamos, en la hora que vivimos y para honor de América, que este Continente proclama muy alto que el hombre, cualquiera que sea su raza, tiene derecho al respeto de sus semejantes y derecho, sobre todo, al respeto del Estado.

Debemos preocuparnos de modo general por la realización de cuanto beneficie la personalidad del hombre, y de cuanto las naciones reconocen hoy en favor de sus ciudadanos. Debemos orientar el ejercicio de los derechos del hombre por una ruta efectiva.

Por estas razones, la Delegación de Haití, con entusiasmo, así se quede sola en el empeño, apoya la proposición presentada por el señor Delegado del Uruguay.

El señor REgules (URUguaY): Unas cortas palabras, señor Presidente. Quiero explicar al señor Delegado de Honduras, cómo pueden tener acceso a la Corte los individuos. Naturalmente, en el proyecto que yo presenté a la Comisión, está incluída la reforma al Artículo 34 del Estatuto de la Corte, sin lo cual solamente los Estados podrían ser partes ante la Corte.

El señor PRESIDENTE: Tiene la palabra el señor Delegado de Cuba.

El señor PÉRez Cisneros (GUBA): Señor Presidente: quería proponer una cuestión de orden.

Como usted advirtió, hace un instante, el debate general está terminado. Entonces, creo que lo oportuno sería plantear contestaciones definitivas, que representen el sentido de la mayoría de esta Comisión, a las preguntas bien claras y bien precisas que ha presentado la Delegación del Uruguay. Por tanto, señor Presidente, si la Comisión lo aprueba y si usted cree que este método es conveniente, yo propondré discutir muy rápidamente, con turnos de unos minutos más, cada cuestión, dando a la Delegación Uruguaya una respuesta concreta y definitiva.

Sería natural proceder así, puesto que la Comisión de Iniciativas, que tenía inscritos todos los temas de esta Comisión en su Agenda, nos ha convocado. Como usted decía ayer, con mucho acierto, tenemos jurisdicción plena y tenemos también el deber de adelantar los trabajos. Por consiguiente, señor Presidente, presento esta proposición de procedimiento para nuestros trabajos.

\section{[DISGUSIÓN SOBRE LA NATURALEZA JURÍDICA DEL PDADDH]}

El señor PRESIDENTE: Yo le agradezco mucho al señor Delegado de Cuba, como una demostración de cooperación para el mejor desarrollo de los trabajos, la propuesta que ha hecho.

Por ahora, declaro cerrados los debates generales, para pasar al conocimiento de algo que es fundamental y sobre lo cual algunos delegados ya se pronunciaron ayer. Comprende la primera pregunta formulada por el señor Delegado del Uruguay, o sea, si se elabora un tratado o una simple declaración; y si ese instrumento se [553] incorpora o no en el Pacto Constitutivo, o, lo que es lo mismo, si va dentro del Pacto o como un anexo a él. Esta es una cuestión fundamental.

Me parece que podría invertirse el orden; porque de si el instrumento va o no dentro del Pacto, depende mucho la forma que se le dé. No es lo mismo una declaración que una articulación jurídica para ser cumplida dentro de un instrumento contractual.

Tiene la palabra el señor Delegado de Cuba.

El señor Pérez Cisneros (CUBA): Creo, señor Presidente, que ya estamos tratando la pregunta número uno del cuestionario presentado por la Delegación del Uruguay. Como no he tenido oportunidad ahora de hablar sobre este punto, voy a hacerlo, en dos minutos.

La Delegación de Cuba ve que la Delegación del Uruguay ofrece una de dos soluciones: bien la Declaración, o bien el Tratado. Mi delegación cree que se deben hacer las dos cosas; 
la Declaración pura y simple, completamente aislada, pero también un tratado, o un instrumento ratificable, que contenga los principios de esta Declaración. En efecto, algunas naciones aquí han puesto reparos, pues no podrían aquellos Estados ratificarlo. Sin embargo, si se hace un instrumento ratificable, independiente del Pacto Constitutivo, aquellas naciones que tienen un espíritu progresista para defender internacionalmente los derechos del hombre, lo ratificarán, y esto es lo que se debe hacer ver: el espíritu de desarrollo, de progreso continuo, y el fijar los rumbos por los cuales este desarrollo debe encauzarse.

Si se plantea la solución de manera demasiado definitiva, tememos que no ayudaremos al desarrollo de esta idea que queremos ver triunfar. Por eso, la Delegación de Cuba vería complacida el que ustedes quisieran aprobar la solución doble que ella tiene el honor de presentar a la Comisión Sexta.

El señor Mendoza (Guatemala): Señor Presidente, señores delegados: con el objeto de evitar una posible confusión, yo quería que al usar la palabra "declaración" no se incurriera en el equívoco de decir "una declaración anexa al Pacto". Voy a explicar por qué: la Delegación de Guatemala precisamente se manifestó en favor de una declaración que fuera anexa al Pacto, pero a la parte ${ }^{9 \mathrm{E}}$ integrante de él, ratificable y obligatoria, de manera que yo entiendo así ese término. Si no es ése el pensamiento, yo agradecería que no dijeran "declaración anexa al Pacto"; porque entiendo que así se trata de una parte integrante de él, obligatoria, como lo sugirió la Delegación de Guatemala.

El señor PRESIDENTE: Tiene la palabra el señor Delegado de Chile.

El señor BERNSTEIN (CHILE): Hay tres soluciones a la primera pregunta formulada por el señor Delegado del Uruguay. Una es: si la discusión de los derechos del hombre forma parte integrante del Pacto; otra, si es una declaración anexa al pacto, como lo dice el señor Delegado de Guatemala; y la tercera, si es una simple declaración no ratificable y separada del Pacto, que no necesitaría ratificación. Hay tres puntos que son distintos.

El señor Pérez Cisneros (CUBA): Hay un cuarto punto, que es hacer un instrumento ratificable.

El señor PRESIDENTE: Tiene la palabra el señor Delegado de El Salvador.

[554] El señor Escobar SERRANo (El SALVADOR): Yo creo que debemos, ante todo, dilucidar el primer punto: si la declaración de derechos forma parte integrante o no del Pacto Constitutivo, y si va intrínsecamente en forma de articulado o no. Una vez dilucidado este punto podríamos presentar las otras posibles soluciones que han enunciado las Delegaciones de Guatemala y Chile.

El señor PRESIDENTE: Por eso la Presidencia observa que se ha invertido un poco el orden de la proposición del doctor Regules: es decir, determinar primero si el instrumento se incorpora o no al Pacto. De modo que los que estén de acuerdo con que el instrumento se incorpore al Pacto pueden manifestarlo levantando la mano.

El señor GÁLVEZ (HONDURAS): Señor Presidente: mi delegación querría hacer una declaración sobre este particular.

Según manifestamos en el debate general, somos partidarios de un anexo al Pacto: en forma de declaración, pero como anexo al Pacto; como parte integrante de él, pero siempre que se explique en el Pacto, en el articulado, cuál es el alcance de esa declaración, de manera que se sepa concretamente hasta dónde llega, cuál es su efectividad y cuál su contenido. Deseamos un artículo que diga expresamente cuál es el alcance de esa declaración anexa al Pacto.

9E El original usa la expresión "a la parte", pero probablemente la afirmación del Delegado fue "haga parte". Nota del editor A. P. D. 


\section{[SE RechaZa QUe El Instrumento SEa Parte Del Pacto Constitutivo]}

El señor PRESIDENTE: Primero vamos a votar si el instrumento se incorpora o no al Pacto. Incorporado o no incorporado, entonces habrá lugar de decir qué alcance tiene ese punto. De modo que vamos a someterlo a votación. Los que estén por que se incorpore en el Pacto, que levanten la mano.

Seis votos. No se incorpora al Pacto.

El señor Regules (URUguaY): Puede haber abstenciones. Hay que verificar los votos negativos.

El señor PRESIDENTE: ¿Los que estén en contra de que se incorpore al Pacto?

Nueve votos. ¿Los que se abstienen?

Cinco votos. Por la no incorporación hay mayoría, de modo que queda decidido que no se incorpore al Pacto.

El señor Pérez Cisneros (CUBA): Señor Presidente: Cuba reserva un voto favorable cuando se ponga a votación la cuestión de si esos derechos forman parte integrante del Pacto Constitutivo.

El señor Mendoza (Guatemala): Señor Presidente: quiero esclarecer una duda: nosotros votamos por que se incorpore la Declaración al Pacto, pero como un anexo. Es parte integrante del instrumento, pero como un anexo.

\section{[SE REGHAZA LA ELABORACIÓN UN TRATADO]}

El señor PRESIDENTE: Entonces se va a votar si se elabora un tratado o una simple declaración.

El señor Pérez Cisneros (GUBA): O ambas cosas, señor Presidente. La Delegación de Cuba propone ambas cosas: que de todas maneras haya declaración; pero también un tratado, que ratifique ${ }^{10 E}$ aquellos que quieran hacerlo.

El señor PRESIDENTE: Pero a mí me parece que si se vota por que no haya un tratado, entonces puede considerarse si ha de ser una simple declaración. Pero si se vota por que haya un tratado, ya es tratado y no una declaración. De modo que vamos a someter la siguiente propuesta a votación; si se elabora un tratado que [555] contenga los derechos y deberes internacionales de la persona humana. Los que estén por la afirmativa, sírvanse levantar la mano.

Ocho. ¿Los que estén por la negativa?

Once. ¿Los que se abstengan?

El señor PÉREZ CiSNEROS (CUBA): Yo creo que sería interesante una votación nominal, señor Presidente. La Delegación de Cuba la pide.

El señor BERnsteIn (CHILE): Señor Presidente: la votación se ha efectuado. Lo que se hace es una comprobación, porque no es posible que la votación nominal altere el resultado de la votación anterior.

El señor PRESIDENTE: Es para comprobar.

El señor DÉJEAN (HAITí): Soy partidario de la votación nominal, como lo solicitó el señor Delegado de Cuba, para que conste la posición expresa de cada delegación.

El señor SECretario: Argentina, no; Bolivia, sí; Brasil, no; Colombia, sí; Costa Rica, no; Cuba, sí; Chile, no; Ecuador, no; El Salvador, sí; Estados Unidos, no; Guatemala, sí; Haití, sí; Honduras, sí; México, no; Nicaragua, ausente; Panamá, no; Paraguay, no; Perú, no; República Dominicana, no; Uruguay, sí; Venezuela, no.

\footnotetext{
$10 \mathrm{E}$ Sic. Nota del editor A. P. D.
} 
El resultado de la votación fué el siguiente: ocho votos afirmativos; 12 negativos; y una ausencia. No hay abstenciones.

El señor FERnÁNDEZ DEL CASTILlo (MÉXICO): Señor Presidente: para una cuestión de orden.

Me avisa ahora mismo el señor Canciller de México que en estos instantes se va a discutir en la Comisión de Iniciativas lo relativo a los derechos y deberes internacionales del hombre. Me permito sugerir a la Comisión, se sirva indicar al señor Relator de ella que se traslade a la Comisión de Iniciativas, para que pueda informar el estado en que se encuentran los trabajos.

El señor PéREZ GiSNeros (CUBA): Señor Presidente, también creo que sería importante terminar la votación, para que el Relator pueda dar un informe que sea bastante completo.

El señor PREsidente: Apoyo entusiastamente la moción del señor Delegado de México, pero creo que para facilitar el trabajo de la Comisión de Iniciativas será mejor que el señor Relator lleve el dato completo de la votación, para ilustrar el criterio de los jefes de delegación. Ya votamos por que no sea un tratado; ahora vamos a votar por que sea una declaración simplemente.

El señor Mendoza (Guatemala): La Delegación de Guatemala preferiría que fuese un tratado que se incluyese dentro del Pacto; pero, entre nada y una simple declaración, vota por la simple declaración.

El señor Regules (URUguaY): Aduzco las mismas razones que el señor Delegado de Guatemala. Entre nada y una simple declaración, pues, que sea una simple declaración.

\section{[SE DEGIDE ELABORAR UNA SIMPLE DECLARACIÓN]}

El señor PRESIDENTE: Los que estén por que sea una simple declaración, se servirán manifestarlo de viva voz.

El señor Secretario: Argentina, sí; Brasil, sí; Bolivia no; Colombia, sí; Costa Rica, sí; Cuba, sí; Chile, sí; Ecuador, sí; El Salvador, sí; Estados Unidos, sí; Guate- [556] mala, sí; Haití, no; Honduras, sí; México, sí; Nicaragua, ausente; Panamá, sí; Paraguay, sí; Perú, sí; República Dominicana, sí; Uruguay, sí; Venezuela, sí.

El resultado de la votación fué el siguiente: 18 afirmativos, dos votos negativos y una ausencia.

El señor PRESIDENTE: Quiero advertir a la sala que como la votación ha sido nominal, nominalmente constará en actas; de modo que la posición de cada delegación que ha votado y la forma como lo ha hecho, no ofrecerán lugar a dudas.

El señor REgUles (URUGUAY): Muy bien, muy bien.

El señor Pérez Cisneros (CUBA): Para una cuestión de orden, señor Presidente. ¿Vamos o no a continuar el trabajo? Si vamos a continuarlo, entonces propongo al señor Presidente de la Subcomisión A como Relator interino de la Comisión.

El señor PRESIDENTE: En realidad, creo que el señor Relator va a estar inmediatamente de regreso. Aunque me sería muy grato continuar la sesión asesorado por el señor Delegado de Chile, me parece que lo que conviene es un receso de cinco minutos.

El señor Monteverde (VEnezuela): Desearía concretamente que el Pacto haga una referencia a esa Declaración, de modo que se le dé un vínculo más concreto con el Pacto mismo.

El señor PRESIDENTE: Se declara la sesión en receso durante 10 minutos. 


\section{[SOBRE SI EL PDADDH DEBE INCLUIR DERECHOS SOCIALES]}

El señor PRESIDENTE: Se reanuda la sesión. Primero vamos a oír lo que tiene que decirnos el señor Relator, respecto de su visita a la Comisión de Iniciativas.

El señor RELATOR: Muy pocas palabras, porque la Comisión de Iniciativas ha sido muy gentil. Se ha sentado la plena autonomía de la Comisión Sexta en el tratamiento de este punto. Simplemente se ha ordenado que refiramos la solución final a la plenaria, según el Reglamento.

El señor PRESIDENTE: Según eso, parece que vamos a poder trabajar tranquilos, sin recibir avisos que sean prácticamente asaltos.

En vista de lo cual, quiero llamar la atención de la Comisión respecto al segundo punto del cuestionario formulado por la Delegación del Uruguay: si el Estatuto ha de contener solamente los derechos individuales, o si deben incluirse también los derechos sociales. Me parece que sobre ese punto existe específicamente una proposición de la Delegación Argentina, que ha sido depositada en la Secretaría. ${ }^{11 \mathrm{E}}$

\section{[SOBRE LA GREACIÓN DE UNA COMPETENCIA JUDICIAL INTERNACIONAL]}

El tercer punto dice: si la protección de tales derechos se constriñe a la competencia interna de los respectivos regímenes constitucionales de cada país, o si se crea una competencia internacional de tipo jurisdiccional; crear una competencia internacional de tipo jurisdiccional equivaldría a darle juridicidad a lo que se ha adoptado ya, que va a ser una simple declaración.

Tratándose de una simple declaración, no hay lugar a seguir discutiendo esos puntos; yo invito a la Comisión a que exprese su opinión al respecto, dirigiéndome primero al señor Delegado del Uruguay.

[557] El señor REgules (URUGUAY): Habiéndose anotado al principio que se trata de una simple declaración, no va a tener fuerza ni juridicidad.

El señor PRESIDENTE: ¿Desea decir algo el señor Delegado del Brasil?

El señor DE OLIVEIRA (BRASIL): Señor Presidente: la Delegación del Brasil entiende que el hecho de que haya sido formulada como una simple declaración no impide la posibilidad de que se constituya en el futuro una institución internacional para la garantía de los derechos del hombre. Esta delegación la sugiere, para que sea base de la revisión del acuerdo sobre la idea de los derechos del hombre. Es posible que en cinco años más, hasta la reunión de la Décima Conferencia Interamericana, se hagan progresos substanciales sobre este punto.

La Delegación del Brasil ha presentado un Proyecto de Resolución, ${ }^{1}$ para que sea remitido al Comité Jurídico Interamericano el estudio del Estatuto de un tribunal interamericano para la defensa de los derechos del hombre. Anexa al texto de la proyectada resolución, hay una explicación detallada del punto de vista de la Delegación del Brasil.

Yo creo que el hecho de haberse decidido la votación a favor de una simple declaración, no impide que se remita al Comité Jurídico, con competencia mejor, el encargo de estudiar un anteproyecto de Estatuto de ese tribunal interamericano. Por consiguiente, me permito pedir a la Presidencia que se tenga en cuenta este proyecto de resolución que presenta la Delegación del Brasil.

11 E Véase NCV, p. 541.

1 Véase el documento publicado durante la Conferencia con la clasificación CB-125/C.VI-6, transcrito en la pág. 464 . 
El señor PRESIDENTE: Nuestro objeto es ganar tiempo, porque en la mesa tenemos entre otros proyectos, adiciones, modificaciones, etcétera - el voluminoso proyecto original del Comité Jurídico Interamericano (documento CB-7).

Para hacer más práctico el trabajo, la Presidencia había pensado, salvo mejor parecer de la Comisión, crear un grupo de trabajo constituído por los países que han presentado enmiendas fundamentales al texto de dicho proyecto original. Cuando el grupo de trabajo nos presenta $^{12 \mathrm{E}}$ su propio texto, para que sea discutido por la Comisión en pleno, habrá tiempo de exponer todos los puntos de vista.

Esto es lo que propongo, salvo que a ustedes les parezca mejor entrar ahora a considerar las otras preguntas que ha formulado el doctor Regules.

Tiene la palabra el señor Delegado de los Estados Unidos.

El señor DANIELS (ESTADOS UNIDOS DE AMÉRICA): Mi delegación desea expresar que está en un todo de acuerdo con el punto de vista de la Delegación del Brasil, y que con mucho gusto participaría en el grupo de trabajo propuesto por el señor Presidente.

El señor PRESIDENTE: Tiene la palabra el señor Delegado del Uruguay.

El señor REgules (URUGUAY): Yo creo que, habiendo sido votada negativamente la primera cuestión planteada por la Delegación del Uruguay, resulta en estos momentos innecesario votar la tercera y cuarta preguntas.

A pesar de este convencimiento, apoyo calurosamente la proposición hecha por el señor Delegado del Brasil para que, de acuerdo con estos antecedentes, se con-[558] templen las posibilidades futuras de que se establezca un tribunal de competencia jurisdiccional; y también sus propuestas para que esta simple Declaración de los derechos del hombre se transforme en un tratado con fuerza y juridicidad obligatorias para los Estados, y que esas posibilidades sean objeto del estudio del Comité Jurídico de Río.

Creo, pues, que podemos apoyar la proposición de la Delegación del Brasil, sin que ello implique dejar de reconocer que en estos momentos ya es innecesaria la votación de la tercera y cuarta preguntas.

El señor PRESIDENTE: Ya eso sería una proposición totalmente diferente, que no tiene nada que ver intrínsecamente con las preguntas formuladas por el señor Regules. Sería una cuestión que podría resolverse o no resolverse, según el buen criterio de la Comisión; pero me parece que no sería una cuestión intrínsecamente relacionada con la que estábamos considerando.

Tiene la palabra el señor Delegado de Cuba.

El señor PÉREz Cisneros (CUBA): Creo, señor Presidente, que es inútil votar la tercera y cuarta preguntas. Sin embargo, como la Delegación de Cuba no ha presentado su opinión al respecto, desearía que esto constara en actas.

Respecto de la tercera pregunta, mi delegación es partidaria de una jurisdicción internacional mediante la creación de un órgano jurídico encargado de la protección de los derechos del hombre, cuya jurisdicción abarque, por ahora, solamente ciertos derechos fundamentales.

Respecto del cuarto punto del cuestionario propuesto por el doctor Regules, sin que éste sea un criterio definitivo, la Delegación Cubana se inclina por el tipo jurisdiccional; pero no disimula que habrá de estudiar con mucho cuidado cúales ${ }^{13 \mathrm{E}}$ son las facultades del órgano jurídico que se llegará a constituir, para que no resulten inefectivas sus decisiones.

El señor PRESIDENTE: Yo desearía, para orientar los debates, llamar la atención de la Comisión a la siguiente cuestión: ¿cómo podría funcionar una jurisdicción internacional,

\footnotetext{
12E Sic. Nota del editor A. P. D.

13E Sic. Nota del editor A. P. D.
} 
si no hay un convenio sobre la materia que se le va a someter? Si los Estados no están de acuerdo sobre los distintos derechos individuales del hombre que deben ser concedidos jurídicamente, entonces, sobre qué versaría la competencia de ese órgano internacional? ${ }^{14 \mathrm{E}}$ No puede haber juridicidad si no hay una norma escrita obligatoria.

Es ésta una observación que hago para orientar mejor los debates.

Tiene la palabra el señor Delegado de Guatemala.

El señor Mendoza (GUATEMALA): Señor Presidente, señores delegados: estoy absolutamente de acuerdo con los puntos de vista que la Presidencia ha expresado.

Si se descarta la posibilidad de un compromiso contractual en la defensa de los derechos del hombre, ya está fuera de tema tratar la parte sancionante.

Me parece muy constructiva la proposición del señor Delegado del Brasil, que apoyo enteramente; pero quisiera sugerir lo siguiente: en el texto de la Declaración, después de la parte declarativa, conviene poner una parte resolutiva que encomiende al Comité Jurídico Interamericano el estudio de los diferentes proyectos... ${ }^{15 \mathrm{E}}$

El señor PRESIDENTE: El señor Delegado de Chile tiene la palabra.

[559] El señor BeRnsteIn (CHILE): Señor Presidente: yo creo que hay aquí dos cosas distintas: una va a ser la Declaración de los Derechos y Deberes Esenciales del Hombre, que todos los países aquí reunidos están dispuestos a firmar y que es lo que discutimos; y en seguida vendría una proposición — entiendo que aparte de la propuesta por la Delegación del Brasil— encomendándole al Comité Jurídico Interamericano que estudie la posibilidad de formar un tribunal que tenga jurisdicción para la aplicación de esos derechos. Me parece que por el momento debemos limitarnos a la Declaración; y, en seguida, votar la proposición de la Delegación del Brasil, que estoy seguro va a contar con el apoyo de todos nosotros, porque todos tenemos la intención y la seguridad de que ese tribunal va a funcionar a la perfección. Pero yo separaría las dos materias.

El señor PRESIDENTE: Al efecto, la Presidencia agradecería al señor Delegado del Brasil, para más precisión del trabajo, que redactara por escrito su proposición.

El señor DE OLIVEIRA (BRASIL): Está impresa y ha sido distribuída.

El señor PRESIDENTE: Entonces tiene la palabra el señor Delegado del Brasil.

El señor DE OLIVEIRA (BRASIL): Lo creo innecesario, señor Presidente. Ya el señor Delegado de Chile ha expresado con mucha claridad lo que yo quería decir.

El señor BERnSTEIN (CHILE): Muchas gracias.

El señor PRESIDENTE: Tiene la palabra el señor Relator.

\section{[SOBRE LA CREACIÓN DE UN TRIBUNAL MORAL]}

El señor ReLATOR: Para decir al señor Presidente y a los señores delegados que, por parte de Colombia, habíamos sido muy adictos a la constitución de un tratado sobre los derechos del hombre. Pero, habiendo resuelto ya la Comisión, con plena jurisdicción para ello, que fuese una simple declaración, debemos atenernos al significado de esta Declaración y pensar que, como declaración, algo significa.

Como declaración, significa compromiso moral. Es indudable, para honor de todos nosotros los Americanos, que aquí estamos hablando, pensando y anhelando, que el convenio, por aparte o incluído en la Carta Constitutiva, nada añada a lo ya existente en América. Puesto que todas las Constituciones Americanas defienden los derechos del hombre, esto

\footnotetext{
14E Sin signo de interrogación inicial en el original. Nota del editor A. P. D.
}

15E Sic. Nota del editor A. P. D. 
será una ratificación, y no una innovación. Pero hay alguna reticencia explicable respecto de que entre en el fuero de la soberanía, no ya el implantamiento de esos derechos existentes, sino la investigación de su quebrantamiento.

Atengámonos al significado de la Declaración, que obliga moralmente, y establezcamos un tribunal moral, con resoluciones morales que representen la pena o- como ahora solemos decir, no muy justamente - la sanción. En ese sentido, busquemos la constitución de una entidadque puede ser este Comité Jurídico en que han pensado algunos con mucho acierto, o que bien puede ser el mismo Consejo Directivo de la Unión Panamericana - la cual, cuando quiera que en un Estado se perturben los derechos del hombre, haga una investigación informativa, nada más. La investigación informativa es el respaldo de los derechos del hombre, porque constituye un apoyo moral. Si de la información sale que se han quebrantado los derechos del hombre, no se va a castigar a nadie; se castiga ipso facto al que los ha quebrantado. En ese sentido no habrá intervención alguna de ningún Estado, ni grupo de Estados, ni entidad nueva en la soberanía de otro Estado; sino que simple- [560] mente, ante una declaración moral de que hay derecho del hombre, habrá otra declaración moral de que no se cumplieron los derechos del hombre.

El señor COROMINAS (ARgentina): Pido la palabra, señor Presidente.

El señor PRESIDENTE: Tiene la palabra.

El señor Corominas (ARgentina): Señor Presidente: la posición de la Delegación Argentina va a ser en cierta medida solidaria con el pensamiento expresado por los señores Delegados del Brasil y de Chile.

Pero yo deseo, para concretarlo, afirmar primero que las declaraciones en todos los casos tienen una obligatoriedad jurídica. Las declaraciones, por regla general, siempre reflejan un ideal jurídico, político o social innegable; pero los ideales no se consagran en los pueblos a través de simples declaraciones. No basta una declaración, ni un tratado, para que un pueblo por arte de magia alcance la madurez natural que el individuo en otros Estados tiene. La maduración política de los pueblos es la resultante de un proceso lento y natural, acomodado a los principios constitucionales de cada país. En consecuencia, muchas veces el apuro por dotar a los pueblos de una organización fundamental, se ve quebrado por las posibilidades propias de cada Estado.

Esto no significa que yo quiera perturbar el valor de las proposiciones presentadas por los señores Delegados del Brasil y de Chile. Yo, también, voy a adherir a estas declaraciones que ahora, aquí, habremos de sancionar, mirándolas como elementos indispensables y necesarios para que el Comité Jurídico Interamericano pueda elaborar definitivamente la gran declaración continental en esta materia.

Yo soy un hombre que confía en el valor moral de las declaraciones, más que en su valor jurídico; acaso porque para mí las reglas morales están por encima de las reglas jurídicas, en virtud de disciplinas emocionales y- ¿por qué no decirlo? - de disciplinas cristianas.

En estas circunstancias, señor Presidente, la Delegación Argentina dará su voto a la proposición del señor Delegado del Brasil, para que todo esto sea remitido al Comité Jurídico, en la inteligencia de que no se desvirtuará la declaración hecha aquí, de que no se alterará con esa proposición, y de que sí se instrumente la posibilidad de que en el futuro alcancemos nosotros la gran declaración que buscamos.

[DESIGNAGión DE Un GRUPO DE TRABAJO PARA LA ELABORACIÓN DE UN PROYEGTO DEFINITIVO]

El señor PRESIDENTE: Entonces, para acelerar los trabajos e ir ordenándolos al mismo tiempo, me parece - salvo el mejor criterio de la Comisión - que, habiendo algunos proyec- 
tos que son adicionales y otros que enmiendan el proyecto original del Comité Jurídico, lo que procede es que designemos un grupo de trabajo que haga un acoplamiento y nos traiga un proyecto definitivo, tomando en cuenta el texto original sobre el cual estamos trabajando, así como las modificaciones, adiciones, etcétera, que han sido formuladas por los distintos países. Si no hay al respecto alguna objeción, la Presidencia se va a permitir designar a todos aquellos países que han formulado modificaciones substanciales sobre la cuestión, para que formen parte de ese grupo de trabajo.

Me parece que el señor Delegado de Haití desea decir algo.

El señor DÉJEAN (HAITí): Señor Presidente, señores delegados: al principio de [561] esta semana, toda la Conferencia estaba animada del espíritu de rapidez; y desde el momento mismo en que la Comisión de Iniciativas se reservó para sí la mayor parte de los temas difíciles de esta Conferencia, con ese mismo espíritu nuestra Comisión, reunida ayer, decidió suprimir las Subcomisiones y reservarse, igualmente, los diferentes temas que debe tratar, para discutirlos directamente. Yo me pregunto qué ha pasado; y por qué, hoy, nosotros parecemos dispuestos a volver sobre lo que ya está decidido. Es decir, ¿por qué volvemos de una manera indirecta a las Subcomisiones, creando un grupo de trabajo?

La Delegación de Haití desea declarar que ella está contra toda creación de subcomité o grupo de trabajo. Propone, más bien (como ya lo ha hecho a esta Comisión), tratar directamente los diferentes temas.

Parece - y digo esto sin ánimo de mortificar a nadie - que el trabajo nos repugna un poco y que, desde el comienzo de esta Conferencia, nosotros lo que buscamos, al fin y al cabo, es descargar nuestra propia responsabilidad sobre los hombros de los demás.

Según la opinión de la Delegación de Haití, esta Comisión debe continuar sesionando en pleno y debe tratar de estudiar directamente las diferentes cuestiones que le han sido asignadas, sin descargarse sobre un grupo de trabajo que invertiría ciertamente varios días, antes de traernos un proyecto definitivo. Esa es la opinión de la Delegación de Haití.

El señor PREsidente: La Presidencia, desde luego, quería facilitar el trabajo de la Comisión, adoptando exactamente el mismo procedimiento que ha adoptado la Comisión de Iniciativas y que allá ha dado muy buen resultado. Por otra parte, si la Comisión resuelve lo contrario, la Presidencia no tiene ningún inconveniente en que estudiemos aquí, punto por punto, el Proyecto de Declaración del Comité Jurídico; pero les prevengo que tal vez nos va a ser un poco difícil coordinar todas las proposiciones que hay al respecto, y que sería mucho más fácil - imitando el procedimiento establecido en la Comisión de Iniciativas - que se nombrara un grupo de coordinación, que en realidad no sería una subcomisión como la que teníamos constituída, sino que solamente se encargaría de coordinar los distintos puntos de vista, para traer algo ya hecho, sobre lo cual pudiéramos caminar más fácilmente.

El señor DÉJEAN (HAITí): Una moción de orden, señor Presidente.

Es evidente que yo no estoy, en principio, contra un grupo de trabajo; no estoy contra esa forma de labores en principio. Simplemente deseo proponer a esta Comisión que ella forme un grupo de trabajo solamente cuando se encuentre en presencia de ciertas dificultades, en casos muy litigiosos, pero que no se nos exija la creación de este grupo de trabajo para estudiar los diferentes proyectos o las diferentes enmiendas. Eso tomaría mucho tiempo, y durante el lapso de tiempo, ¿qué trabajo haríamos nosotros?

A mi juicio, conviene que nosotros comencemos a estudiar, a coordinar los otros textos con el proyecto inicial presentado por el Comité Jurídico Interamericano. Es evidente que hay muchos puntos de contacto entre ese proyecto y los proyectos propuestos por las dele- 
gaciones. En todas las ocasiones en que nos encontráramos [562] con un punto un poco delicado, un poco difícil para discutir, en ese momento podríamos crear un grupo de trabajo especial, encargado de estudiar la cuestión y de informar sobre ella. Pero no debemos crear tal grupo de trabajo ahora mismo.

El señor PRESIDENTE: La Comisión ha oído la exposición y la oposición del señor Delegado de Haití. De modo que se va a someter a votación lo siguiente: los que estén de acuerdo con que se cree un grupo de trabajo coordinador...

El señor DÉJEAN (HaITí): Un momento, señor Presidente: entiendo que el señor Delegado de Cuba ha pedido la palabra sobre el mismo asunto.

El señor Pérez Gisneros (CUBA): He pedido la palabra, señor Presidente.

Yo creo que el equívoco que se ha presentado se debe, quizás, a las dificultades de nuestra instalación material; y que tal vez, en el fondo, el señor Delegado de Haití y la Presidencia están de acuerdo. Lo que dice la Presidencia, cuando propone un grupo de trabajo, es que nos encontramos precisamente delante de una dificultad de orden material, que también señala el señor Delegado de Haití, y que no puede ser resuelta sino por un grupo pequeño.

La dificultad de orden material es ésta: estamos en presencia de un documento de base; tenemos delante, el documento de las Naciones Unidas que nos ha suministrado la Delegación de México; tenemos delante, 20 proposiciones que emanan de Miembros diferentes, dispersas en diversos textos. Hay que poner orden en ellas de una manera constructiva, para facilitar los trabajos de la Comisión. La Comisión no puede aventurarse en un verdadero bosque de proposiciones y de enmiendas. Hay necesidad de tener un documento único, que nos sirva de base, sobre el cual serán coordinadas las diversas enmiendas.

Es por eso por lo que yo creo, señor Delegado de Haití, que después de haber oído la explicación que me he permitido dar, le será a usted quizás, más fácil comprender la situación. Yo estoy completamente de acuerdo con usted en que la Conferencia debe sesionar, debe trabajar y debe contemplar ella misma los problemas. Pero se trata de una dificultad particular, que no puede ser resuelta sino por un grupo de trabajo. Es por eso por lo que, al mismo tiempo, apoyo también la proposición de la Presidencia.

El señor DÉJEAN (HaITí): Pido la palabra, señor Presidente.

Agradezco muy sinceramente al señor Delegado de la República de Cuba las explicaciones que ha tenido a bien suministrarme, y me declaro satisfecho. Sin embargo, yo debo agregar lo siguiente: me pareció que, al principio de los trabajos de esta Comisión, se decidió que el proyecto presentado por el Comité Jurídico Interamericano había de servir de base a nuestras tareas. Por eso, la Delegación de Haití desea que se estudie el proyecto y que, si se presentan ciertas dificultades y ciertas enmiendas, se encargue a un grupo de trabajo el armonizarlas y coordinarlas. Es eso lo que yo propongo.

Sostengo que la creación inicial de un grupo de trabajo es una pérdida de tiempo. Sería mejor, en mi opinión, que se comenzara por estudiar el proyecto más a fondo y, cada vez que una dificultad se presentase, encargáramos a un grupo de trabajo de resolver los puntos pertinentes.

[563] Eso se ha hecho siempre en la Comisión de Iniciativas. La Comisión de Iniciativas no ha comenzado por un grupo de trabajo.

El señor PRESIDENTE: Sería conveniente, puesto que no estoy seguro de que todos entienden lo que ha dicho el señor Delegado de Haití, si el servicio de interpretación repitiera a los delegados su exposición.

(El intérprete hace la traducción de lo dicho por el señor Delegado de HAITÍ). 
El señor PRESIDENTE: Muy bien.

Yo deseo observar lo siguiente: a juicio de la Presidencia, la necesidad de crear un grupo de trabajo desde el principio, era precisamente porque ya sobre el proyecto original del Comité Jurídico existían proyectos o modificaciones de Bolivia, Brasil, Uruguay, México, Perú, Argentina, Cuba y los Estados Unidos; de modo que parecía justificada la creación de tal grupo. Pero, si la Comisión decide lo contrario, yo no ofreceré ninguna objeción.

Tiene la palabra el señor Delegado del Brasil.

El señor DE OliveIRA (BRASIL): Muchas gracias, señor Presidente, pero no deseo decir nada.

El señor PRESIDENTE: Tiene la palabra el señor Delegado de Chile.

El señor BERnSTEIN (CHILE): Creo que la Presidencia está en lo cierto, al proponer la creación de ese grupo de trabajo, para que coordine el proyecto del Comité Jurídico Interamericano con las modificaciones presentadas. No veo cómo una Comisión de 21 miembros va a poder abocar la redacción de una declaración de derechos humanos, que es un trabajo muy pesado y en el que, mientras más reducido sea el grupo de trabajo, mejor podrá trabajar. Por lo demás, la Comisión en pleno va a tener la oportunidad de discutir en seguida, ya sobre una base coordinada, el informe de ese grupo de trabajo; y si dejamos de lado este asunto de los derechos del hombre y lo pasamos a un grupo de trabajo, podremos entrar a los temas antes encomendados a la Subcomisión B, que nos están esperando.

Con el fin de facilitar y acelerar el trabajo de la Comisión, me atrevo a pedir al señor Delegado de Haití, que no insista en su proposición.

El señor PRESIDENTE: Yo creo que ya está suficientemente debatida esta cuestión. Han pedido la palabra muchísimos delegados y cada uno va a expresar sus opiniones en una forma más o menos parecida; de manera que lo más lógico es decidir por votación. La votación es la opinión por excelencia. El que no esté de acuerdo, pues vote en contra; y el que lo esté, vote a favor.

El señor Monteverde (Venezuela): Pido la palabra para una cuestión previa. La Delegación de Venezuela presentó un pliego de observaciones al primer proyecto del Comité Jurídico, y desearía que fuera tenido en cuenta por ese grupo de trabajo.

El señor PRESIDENTE: Entonces, está suficientemente discutida la cuestión de si procede o no la formación de un grupo de trabajo o pequeño comité de coordinación que, tomando por base el proyecto definitivo, coordine las diversas enmiendas, modificaciones y adiciones formuladas al proyecto original. Los que estén por la afirmativa pueden manifestarlo en la forma acostumbrada, levantando la mano.

El señor SECRETARIO: Ha sido aprobado por 16 votos afirmativos, señor Presidente.

[564] El señor PREsidente: Ha sido aprobado el nombramiento de dicho grupo de trabajo.

Tiene la palabra el señor Delegado de la Argentina.

El señor COROMINAS (ARGENTINA): Deseo proponer que discuta ese grupo únicamente lo relacionado con los derechos del hombre, para acelerar el trabajo; y que se prescinda de todo obstáculo que demore la decisión final que nos ha de presentar.

El señor DÉJEAN (HAITÍ): Señor Presidente: yo ruego que se fije un tiempo limitado a los trabajos de ese grupo.

El señor PREsidente: Voy a nombrar los países Miembros, y ellos entre sí podrán indicar o convenir el plazo más breve para rendir su informe. Quedan designados: Argentina, Bolivia, Brasil, Uruguay, México, Perú, Cuba, Estados Unidos y Venezuela. Me parece que deberíamos agregar también a Colombia. 
Desearía oír la opinión de los integrantes del Grupo en cuanto a la brevedad con que podrán terminar el proyecto. Suplicaría que fuera cuanto antes. Este es un caso de trabajar los domingos, de manera que sería excelente que fuera el lunes o martes, para no retardar el trabajo de la Comisión.

El señor BERnSTEIN (CHILE): Dénos ${ }^{16 E}$ plazo hasta el miércoles; y mientras tanto, sigamos con los otros temas.

El señor PRESIDENTE: Tiene la palabra el señor Relator.

El señor RELATOR: Quería informar a los presentes compañeros del Grupo de Trabajo que nosotros no podemos definir este término, sin establecer previamente si estamos autorizados o no para modificar la redacción. Advierto a ustedes que la Delegación Colombiana trabajó con cinco miembros en un Grupo de Trabajo, durante un mes, sin que hubiera una palabra de discrepancia entre esos cinco miembros. Es de tal naturaleza exquisita la redacción de un tema de esta magnitud, que nosotros nos veíamos agobiados, y muchas veces teníamos que suspender la sesión en busca de un adjetivo que expresara el pensamiento.

De manera que si es simplemente para articular las enmiendas dentro del texto primitivo, habrá muy poca dificultad, y en unos tres días podrá hacerse el trabajo; pero, si nos autorizan para hacer una redacción que corresponda a la dignidad conceptual del Pacto Constitutivo, esto demandaría un tiempo largo y pediría, con mucha prudencia, al menos una semana.

El señor PRESIDEnTE: Yo creo que la labor del Grupo de Trabajo va a ser de coordinación, respetando hasta donde sea posible el texto del proyecto del Comité Jurídico Interamericano. Cuando acá estudiemos el proyecto del Grupo, coordinado con el proyecto del Comité Jurídico, entonces podremos ir agregando las modificaciones de fondo y de forma, según lo determine el propio Grupo de Trabajo. Así entendido, ese trabajo me parece que podría terminar un poco antes.

Tiene la palabra el señor Delegado de la Argentina.

El señor COROMINAS (ARGENTINA): Tengo un profundo respeto por las manifestaciones hechas por el doctor López de Mesa, ilustre Delegado de Colombia y Relator de esta Comisión. Entiendo que ésta es una materia trascendental. Pero, en homenaje a la verdad, debo decir que se trata de un documento que es viejo [565] amigo de todas las Cancillerías y que ha sido considerado, palabra por palabra, por todos los Gobiernos aquí representados. En consecuencia, no ha de haber muchas dificultades en buscar la cuerda tensa para que salte el adjetivo.

Aquí se trata, señor Presidente, de encontrar una solución exacta, común, fácil, accesible al hombre de la calle, a quien le vamos a instrumentar la vida con esta declaración de derechos. No es necesario trabajar con el diccionario enciclopédico bajo el brazo. No es un problema de comas, sino de sentido común, de buena razón y de juicio sereno. Creo que podremos entregar, en el brevísimo plazo de horas, las características de este articulado que se nos ha encomendado por la Presidencia. Cada artículo lleva un comentario y ese comentario no puede ser reformado. La Delegación Argentina ofrece para esta tarde, a la hora que la Comisión indique, su residencia, a fin de trabajar con algún margen de comodidad. Yo creo que en cuestión de horas podremos tener solucionado este asunto.

El señor PRESIDENTE: Tiene la palabra el señor Delegado de Cuba.

El señor Pérez Cisneros (CUBA): La Delegación de Cuba apoya en un todo al señor Delegado de la Argentina. Cree que se trata solamente de una cuestión de horas y, como sugestión realista, tiene el honor de presentar la siguiente proposición: que el martes por la

16E Sic. (debiera decir "Demos", ya que Chile no formaba parte de la Comisión a la que se le otorgó el plazo) Nota del editor A. P. D. 
mañana se convoque a la Comisión y entregaremos lo que hemos hecho; si hemos terminado, estaremos muy contentos; y si no, ya la Comisión tendrá una materia muy concreta para trabajar y adelantar así el trabajo.

El señor PRESIDENTE: Tiene la palabra el señor Delegado de Chile.

El señor BERnSTEIN (CHILE): No comparto el optimismo de mis colegas de Argentina y Cuba.

El señor COROMINAS (ARGENTINA): ¡Es la juventud, señor delegado, es la juventud!

El señor BERNSTEIN (CHILE): Me parece que si el martes tienen un informe completo, que lo traigan; y si no, fijaremos una nueva fecha. De todos modos, debemos pedirles un informe completo. No debemos estudiar esto por partes.

El señor PRESIDENTE: En firme el martes a las 10 nos reuniremos, ya sea aquí o en el Capitolio, para conocer el trabajo que haya hecho el Grupo.

Tiene la palabra el señor Delegado de Cuba.

El señor Pérez Cisneros (CUBA): Yo desearía que para la reunión de esta tarde, la Secretaría nos pudiera facilitar todos los documentos necesarios, pues carecemos de ellos. Que se nos repartan copias, a fin de poder trabajar con mayor facilidad y rapidez.

El señor PRESIDENTE: Tiene la palabra el señor Delegado de Venezuela.

El señor Monteverde (Venezuela): Deseo pedir que se incluya en el Acta de esta sesión una aclaración que yo hice unos minutos antes del receso, en el sentido de que en el Pacto Constitutivo se incluyera una referencia expresa a la Declaración de los Derechos y Deberes del Hombre. Quiero que quede constancia en el Acta de esta sesión.

El señor PRESIDENTE: Sírvase tomar nota, señor Secretario.

Tiene la palabra el señor Delegado de Haití.

El señor DÉJEAN (HAITí): La Delegación de Haití confiaba en que estos traba- [566] jos serían tratados por la Comisión; pero, en vista de la imposibilidad en que se encuentra ahora para presentar ante ella varias enmiendas, desea saber a quién se pueden presentar.

El señor PREsidente: Deben ser entregadas a la Secretaría de la Comisión, señor delegado.

Tiene la palabra el señor Delegado de Chile.

El señor BERnsteIn (CHILE): Creo que bien podría formar parte del Grupo de Trabajo el señor Delegado de Haití.

El señor DÉJEAN (HAiTí): Muchas gracias, señor Delegado de Chile, pero el reducido número de los miembros de mi delegación hace que me vea imposibilitado para aceptar tan gentil oferta. Muchas gracias.

\section{[OBSERVACIONES DEL RELATOR]}

El señor PRESIDENTE: Tiene la palabra el señor Relator de la Comisión.

El señor RELATOR: Señor Presidente, señores delegados: estoy gratamente impresionado por la interpretación tan realista que ha hecho el ilustre Delegado de la Argentina acerca de la misión que le fué encomendada al Grupo de Trabajo. Quería simplemente anotar el por qué me expresé así, y hasta dónde alcanza mi observación a ser válida conceptualmente.

Este proyecto ha sido redactado por una mente latina. El problema es el de armonizar la mente sajona con la mente latina, y esto no es de diccionario enciclopédico. La mente sajona tiene un proceso suyo peculiar, de un alcance histórico extraordinario. La mente sajona es analítica. La mente latina es sintética. Entonces, siendo éste un proyecto perfecto dentro de la juridicidad de la mente latina, puede ser inadecuado para la juridicidad de la mente sajona. El 
problema, pues, llega a ser un poquito más que una simple cuestión gramatical de adjetivos, y entraña la psicología de los continentes. De otra manera, tenemos que decir: este proyecto, ¿tiene una expansión de tipo reglamentario que corresponde perfectamente a esa mentalidad sajona analítica que termina siempre en forma casuística taxativamente sajona? ¿Determina todas las cosas que va a emprender? El latino las abarca todas en un arco iris conceptual. De esa manera, si nosotros, por ejemplo, tomamos como punto de partida que este proyecto ha de ser un epítome de esencias conceptuales y no una reglamentación de constituciones, es necesario que la mente latina coordine ese punto de vista sintético con el punto de vista analítico de la mente sajona; porque nosotros aquí no podemos hacer un resumen de diversas constituciones nacionales, sino un extracto del punto de vista latino de los derechos y deberes del hombre.

Hay otro punto más grave todavía, que yo quiero precisar a ustedes. De milenio en milenio - no de siglo en siglo, de milenio en milenio - el hombre tiene que remodelar el concepto del hombre. El concepto del hombre que aparece- hace dos milenios - con Cristo, no es el concepto del hombre que hoy tenemos, porque las necesidades han sido superiores; nos han abrumado. Tenemos a la vista nuevos mundos que contemplar. El hecho de que esos principios esenciales de los deberes y derechos del hombre tengan el asenso de la humanidad, no satisface a América, porque América tiene que añadir un punto de vista continental nuevo; América tiene un mensaje que dar a la humanidad que no es la repetición del mensaje reci- [567] bido tradicionalmente, sino que consiste en acuñar aquel articulado a un nuevo Estatuto de vida.

De manera que yo conceptúo que debemos ser muy cuidadosos en la redacción. Esto no es solamente una materia superficial, porque palabra y concepto están íntimamente ligados dentro de la cultura humana, de manera indisoluble. La palabra es algo más que el retrato del concepto. La palabra tiene en sí un germen de suyo conceptual. Yo creo que si algo vale hoy en América, es el Código de Andrés Bello, por esa hermosura de redacción y por la precisión conceptual. Si nosotros, ahora, reunidos en representación de América, hacemos algo caótico y vago, habremos faltado a la oportunidad de que América se presente culturalmente como una aportación universal.

Nosotros no codificamos simplemente hechos más o menos dispersos en todas nuestras constituciones, sino que armonizamos un espíritu; y ese espíritu, desde hace tres mil años, es el verbo.

El señor PRESIDENTE: La Presidencia desea que la Comisión tenga en cuenta los bellos conceptos expresados por el señor Delegado de Colombia.

Se levanta la sesión. ${ }^{17 \mathrm{E}}$

\section{ACTA DE LA GUARTA SESION DE LA COMISION SEXTA}

(Versión taquigráfica) ${ }^{1}$

FeCHA: miércoles, 21 de abril de 1948

HORA: 15:30-16:45

REcinTO: Gimnasio Moderno

PRESIDENTE: señor Carlos Sánchez y Sánchez (República Dominicana)

17E El informe del Grupo de Trabajo creado en esta sesión puede observarse en NCV, pp. 474-484.

1 La correspondiente acta resumida fué publicada durante la Conferencia con la clasificación CB$317 /$ C.VI-16. 
VICEPRESIDENTE: señor Marco Antonio Batres (Honduras)

RELATOR: señor Luis López de Mesa (Colombia)

SECRETARIO: señor Gabriel Arango Restrepo

PRESENTES: señores Vicente Sáenz (Guatemala); Ricardo Latcham (Chile); Carlos Manini Ríos (Uruguay); Guy Pérez Cisneros (Cuba);Jack B. Tate (Estados Unidos de América); Joaquín Balaguer (República Dominicana); Alberto Salinas López (Bolivia); Luis Fernán Cisneros (Perú); Diego Manuel Chamorro (Nicaragua); Germán Fernández del Castillo (México); Eduardo A. Chiari (Panamá); Héctor Escobar Serrano (El Salvador); Humberto García Ortiz (Ecuador); Antonio Camillo de Oliveira (Brasil); Melchor Monteverde (Venezuela); Enrique V. Corominas (Argentina); Jorge Soto del Corral (Colombia); y Charles G. Fenwick (Unión Panamericana)

\section{[PROYEGTO DE REGOMENDACIÓN DE GREAR UNA CORTE INTERAMERICANA]}

El señor PRESIDENTE: Se declara abierta la sesión.

Tiene la palabra el señor Delegado de Colombia.

[568] El señor LÓPEZ DE MESA (COLOMBIA): Señor Presidente, yo creo que nuestro primer punto de esta tarde podría ser la consideración del proyecto brasileño; ${ }^{1}$ así tendremos tiempo de estudiar el documento sin perder ni un momento.

El señor PRESIDENTE: Me parece muy juiciosa la sugerencia suya. Vamos a entrar en el conocimiento de la propuesta de la Delegación del Brasil, que ha sido distribuída previamente; pero creo que tenemos primero dos Actas que aprobar, las de la segunda y tercera sesiones, que ya están distribuídas. Si no hay ninguna observación a las Actas, las declararemos aprobadas, y podremos pasar al conocimiento de la proposición del Brasil.

Tiene la palabra el señor Delegado de Colombia.

El señor LÓPEZ DE MESA (COLOMBIA): Me reservo el derecho de hacer una pequeña enmienda a las declaraciones contenidas en una de las Actas. Yo hice renuncia a pronunciar un discurso, pero presenté algunas ideas y no aparece en el Acta nada de eso.

El señor PRESIDENTE: La Secretaría tomará atenta nota de este punto. Si no hay ninguna otra observación, se declaran aprobadas las Actas con las modificaciones debidas.

Tiene la palabra el señor Delegado del Uruguay.

El señor MANiNi Ríos (URUGUAY): La Delegación del Brasil ha presentado a la consideración de la Comisión, la fórmula que aparece en el documento número CB-125, y que aquí ya todos conocemos.

Yo propongo que esta fórmula, si lo acepta el señor Delegado del Brasil, quede así:

\section{La Novena Conferencia Internacional Americana}

\section{RECOMIENDA:}

A la Comisión Jurídica Interamericana [Al Comité Jurídico Interamericano] que elabore, a la mayor brevedad posible, un proyecto de Estatuto sobre la creación y funcionamiento de una Corte Interamericana destinada a garantizar los derechos del hombre, estudiando dicho proyecto en una reunión especial, a la que se invitaría un delegado de cada país de América.

La comisión así integrada estudiaría los proyectos presentados por las Delegaciones del Uruguay, Brasil y Colombia, y cualquier otro proyecto que presente cualquiera de las otras delegaciones de la Conferencia. El proyecto que así se redacte, deberá ser discutido y aprobado por la Décima Conferencia Internacional Americana [Décima Conferencia Interamericana].

1 Documento publicado durante la Conferencia con la clasificación CB-125/C.VI-6, transcrito en la pág. 464 . 
Las modificaciones consisten en que, en lugar de estudiar el asunto solamente el Comité Jurídico, lo haga - cuando se decida a estudiarlo - invitando a que vaya un jurista de cada país; de manera que tenga un poco más de control este proyecto y se manden a esa Conferencia las tres iniciativas que han surgido a este respecto: la del Uruguay, ${ }^{2}$ la del Brasil y la sugestión de Colombia hecha a través del eminente doctor Luis López de Mesa, así como cualquier otro proyecto que los señores delegados quieran presentar. La fórmula se podría modificar a tal efecto, si el señor Delegado del Brasil quiere aceptar estas enmiendas.

[569] El señor DE OlIVEIRA (BRASIL): Señor Presidente: la Delegación del Brasil acepta con mucho gusto la proposición hecha por el señor Delegado del Uruguay, relacionada con que a ese proyecto de resolución se agreguen tres elementos nuevos.

Uno de ellos se refiere a la invitación de un delegado de cada país. El objeto de la proposición del Brasil es que el asunto sea estudiado por un comité de técnicos como el Comité Jurídico; pero, si la Comisión encuentra que debe aumentarse ese Comité por un número de tres técnicos más, la Delegación del Brasil no ve inconveniente.

En cuanto a la segunda idea nueva- la de que el Comité Jurídico estudie el asunto a la mayor brevedad posible - me permito observar que el Comité tiene cinco años, por lo menos, para esos estudios. Pero, de todos modos, aceptamos las enmiendas del Uruguay con mucho gusto, y proponemos que se agreguen al proyecto.

Además, quisiera hacer notar que nuestro Proyecto de Resolución viene acompañado de una exposición de motivos, y que todo esto debe ser remitido al Comité Jurídico de Río.

El señor Cisneros (PERÚ): Señor Presidente: yo había considerado que este problema era de alguna trascendencia, teniendo en cuenta las opiniones que se habían emitido respecto de la necesidad de considerar una jurisdicción internacional para la eficacia y conservación de los derechos y deberes del hombre.

Me parece que no podría resolverse este asunto así, apenas con una lectura del proyecto. Sugiero que debe remitirse a otro pequeño grupo de trabajo, o al mismo (según el criterio de la Comisión), y que conviene dar unas cuantas horas para que conozcan dicho proyecto nuestras respectivas delegaciones. Mi proposición, pues, consiste en que se nombre un grupo de trabajo para estudiar el asunto.

El señor Pérez Cisneros (CUBA): Señor Presidente: deseo recordar a los miembros de esta Comisión, que el proyecto presentado por la Delegación Brasileña ha sido uno de los primeros documentos distribuídos por la Secretaría General. Conocemos ese documento desde hace casi 15 días. También deseo recordar que el señor Delegado del Brasil tuvo la bondad, en la última sesión de la Comisión, de explicar detalladamente el alcance de su proposición y las consecuencias que podría tener.

Pero yo creo que en todas las discusiones que hemos tenido en esta Comisión sobre los derechos internacionales del hombre, nos hemos olvidado de un texto muy importante, que ha sido aprobado por todos los representantes aquí presentes. Me refiero a la Resolución XL de Chapultepec. En la Conferencia de Chapultepec, en un generoso impulso quizá debido al momento de guerra, y al peligro en que se veían los derechos internacionales del hombre y el respeto que todas las naciones deben tener por ellos, se aprobó una resolución cuyo texto dice, entre otras cosas lo siguiente:

2 Documento publicado durante la Conferencia con la clasificación CB-1 12/C.VI-Sub A-3, transcrito en la pág. 463. 
Que para que esa protección [internacional de los derechos esenciales del hombre] sea llevada a la práctica se requiere precisar tales derechos - así como los deberes correlativos - en una Declaración adoptada en forma de Convención...

Este principio fué reconocido ya en Chapultepec. Aquí (siento decirlo), hemos dado un paso hacia atrás. Reconozco que la primera parte de las ideas expresadas [570] en Chapultepec ha sido aprobada; es decir, ha sido elaborada, puesto que hemos expresado tales derechos. Pero los hemos expresado en una declaración que no corresponde a la definición de Chapultepec, pues allí se dice que la declaración ha de tener forma de convención.

El señor Delegado del Brasil nos viene a dar una sugestión muy feliz, que creo que realmente debe aprobar la opinión unánime de las delegaciones presentes, ya que se ve muy difícil que las delegaciones cambien de opinión, de tiempo de guerra a tiempo de paz. La Delegación del Brasil nos da una solución muy razonable para que no nos quedemos estancados en el desarrollo de nuestros derechos. Creo, también, que la proposición del señor Delegado del Uruguay tiene gran valor, porque igualmente nos impide dar un paso hacia atrás, después de lo aprobado en Chapultepec.

En efecto, la Delegación de Cuba da su más caluroso apoyo a ambas proposiciones.

\section{[OTRAS OBSERVACIONES SOBRE UNA CORTE INTERAMERICANA]}

El señor PRESIDENTE: Tiene la palabra el señor Delegado del Perú.

El señor CISNEROS (PERÚ): Yo estaría absolutamente de acuerdo con el proyecto del señor Delegado del Brasil, como lo adelanté en mi declaración que formulé en sesión anterior, si no hubiera surgido una nueva iniciativa que en realidad lo transforma, que es la de agregar, al Comité Jurídico, jurisconsultos de todos los países. Eso tampoco merece de mi parte un rechazo. Simplemente me parece digno de contemplación y estudio, por lo menos de 24 horas, y de consulta con nuestras respectivas delegaciones.

En resumen, lo que pido es que este asunto pase al estudio de un grupo de trabajo y se someta, además, a consulta de nuestras delegaciones.

El señor FERNÁNDEZ DEL CASTILlo (MÉXICO): El señor Relator del Grupo de Trabajo ha informado con claridad cuál es la posición en que dicho Grupo de Trabajo se consideró, alrededor del problema relativo a la garantía de los derechos humanos, tomando como base las resoluciones previas adoptadas en esta Comisión. Sin embargo, conviene tener presente algunos elementos que nos permitió afirmar el señor Delegado del Brasil, cuando se sometieron a debate las diversas propuestas hechas por la Delegación del Uruguay.

Más que la conveniencia de hacerse una convención, un tratado sobre los derechos y deberes del hombre, lo que se discutía era la importancia y las consecuencias que tendría la creación de un tribunal internacional. Esa fué la base, propiamente, de la discusión y la circunstancia que orientó el voto de la mayoría de las delegaciones representadas en el Grupo de Trabajo. Los 11 miembros de este Grupo (formado por 11 delegaciones) glosaron la proposición por diversos puntos de vista, y fué con todo acierto subscrita por el señor Relator, en el informe que tiene para dar cuenta a la Comisión. Las delegaciones consideran que es un ideal, poder llegar a una garantía internacional de los derechos del hombre por la creación de un tribunal; pero la situación jurídica y social de América en el tiempo que corre, de ninguna manera acredita la creación de este tribunal.

La proposición del Brasil está plenamente compenetrada de esa idea; pero su proposición fué hecha con fecha 6 de abril, anteriormente a la resolución tomada por [571] la Co- 
misión y, por lo mismo, está formulada dentro del lenguaje propio del desconocimiento de qué resoluciones habrían de tomarse. La Delegación del Brasil propone la creación de una Corte Interamericana; y la Delegación del Brasil, desde el momento en que tomó la palabra, manifestó que no creía oportuna la creación de la Corte.

Por tal motivo, creo conveniente esperar y sugiero que se debiera hacer el estudio respectivo. La Comisión resolvió que esa Corte no debía crearse por el momento, pero la redacción de tal proposición implica aparentemente la aprobación de la creación de esa Corte. Yo me permito suplicar al señor Delegado del Brasil que le haga las correcciones de redacción correspondientes a cuál es la decisión en el seno de la Comisión; y de ese modo creo que no habrá oposición a su moción, sino que la acogeremos todos.

El señor PRESIDENTE: Tomo la palabra para hacer una aclaración a la Comisión: la proposición del Brasil (que ustedes conocen, porque fué distribuída oportunamente) tiene una enmienda que acaba de ser presentada y que no ha sido distribuída todavía. La Delegación de México, además, hizo una nueva observación, con la cual parece que no está de acuerdo la Delegación del Brasil. Habíamos comenzado a discutir esta cuestión previamente, porque estábamos esperando la repartición del documento en que se contiene el proyecto general de los derechos y deberes internacionales del hombre. Yo creo, pues, salvo mejor parecer de la Comisión, que como ha habido varias enmiendas a la proposición del Brasil, debemos considerar el proyecto del Brasil con las enmiendas y someter a debate las observaciones que haya de hacer también el señor Delegado de México.

[SE PROPONE DECLARAR QUE INCUMBE AL ESTADO HACER RESPETAR LOS DERECHOS EN SU JURISDICGIÓN]

El señor SOTO DEL GORRAL (COLOMBIA): Pido la palabra para solicitar una aclaración de los proponentes y, especialmente, del señor Delegado del Brasil.

Considero que debe haber sido incorporado un artículo en el preámbulo, que estipule que incumbe a cada Estado, dentro de su jurisdicción, hacer respetar los derechos fundamentales de la persona humana; porque indudablemente dentro de la protección establecida en el Pacto Constitutivo viene la garantía de esos derechos. Naturalmente, el Estado que no los protege dentro de su jurisdicción, viola el Pacto Constitutivo. Quisiera que se me explicara este punto.

El señor Presidente: Desde luego, entiendo que como vamos a considerar esta materia mañana, no debemos perder tiempo esta tarde en la discusión de la misma.

El señor DE OLIVEIRA (BRASIL): Señor Presidente: en la declaración que tuve ocasión de hacer el día 6 de este mes, reconocía que, efectivamente, la protección de los derechos del hombre debería quedar dentro de la jurisdicción de cada Estado, tal como se dice en la Carta. Consecuentemente con el desarrollo de las ideas sobre los derechos del hombre, llegará el día en que se designará especialmente la parte internacional de esos derechos, que confirmamos internacionalmente. Para esa eventualidad futura, propuse que se sometiera el asunto al Comité Jurídico Interamericano, para que estudiara un proyecto de Estatuto que una próxima conferencia aprobara o no aprobara, punto sobre el cual creo que todos los delegados están de acuerdo. Reconocemos que en este momento América no está preparada [572] para estudiar de un día para otro una Carta interamericana sobre los derechos del hombre, aunque estamos caminando para ese día.

En esta previsión, habíamos propuesto una forma de resolución que tomase en cuenta el factor tiempo. En tal sentido iniciamos nuestro proyecto. Esta proposición, una vez apro- 
bada, iría a Río de Janeiro y al conocimiento del Comité Jurídico, que tendría cinco años para conocerla y estudiarla. En cinco años, la Conferencia Interamericana decidirá si se debe aprobar, o no, el proyecto de Estatuto así redactado. Yo propongo que se decida desde ahora remitir el asunto al Comité Jurídico, a fin de que estudie ese proyecto de Estatuto, o futura Carta interamericana para la garantía de los derechos del hombre.

El señor FERnÁNDEZ DEL CASTILlo (MéXICO): La decisión de la Comisión de Iniciativas en relación con los trabajos de la Comisión Sexta, fué la de dejar a las decisiones de ésta lo que concierne a los derechos humanos; de tal manera que todo depende de las decisiones que sigamos tomando aquí. Todo está sujeto a lo que nosotros decidamos.

\section{[ORGANIZACIÓN DE LA DISCUSIÓN DEL PDADDH PREPARADO POR EL GRUPO DE TRABAJO]}

El señor PRESIDENTE: Si están todos de acuerdo en que la proposición del Brasil se deje para mañana, vamos a pasar al conocimiento del trabajo preparado por el Grupo de Trabajo sobre los derechos del hombre, de acuerdo con el informe del señor Relator del Grupo. ${ }^{1}$

No sé si todos tienen conocimiento del informe y si valdría la pena leerlo íntegramente. Tal vez lo más conveniente sería dejar que cada cual lo estudiara suficientemente en su casa; y luego, en una próxima reunión, podríamos tomar conocimiento a fondo de este informe. Entiendo que se acaba de distribuir, de modo que si lo desean, procederemos en esta forma. De lo contrario, se procederá a leerlo. Quisiera oír la opinión de los delegados expresamente sobre este punto.

(Indicado el deseo de algunos delegados de que se dé lectura al informe, el señor PÉREZ CISNEROS, Delegado de CUBA $y$ RELATOR DEL GRUPO DE TRABAJO, empieza a leer el documento CB-310.)

El señor PRESIDENTE: Antes de seguir adelante, la Presidencia desea saber si la Comisión quiere conocer globalmente todo el articulado, para poder ir anotando las observaciones que se deban hacer cuando se someta el proyecto a discusión; o si los señores delegados prefieren que el señor Secretario lea el articulado en su integridad.

Tiene la palabra el señor Relator del Grupo de Trabajo, Delegado de Cuba.

El señor Pérez Cisneros (CUBA): Yo creo que sería preferible darle una lectura general al texto y abrir luego un debate muy limitado, para formular las observaciones que ocurran. El proyecto de texto ha sido acogido en su totalidad por el Grupo de Trabajo, y éste se siente con toda sinceridad satisfecho de su labor; pero no puede menos de reconocer que existen todavía algunos detalles por corregir. Opino que debe continuar la lectura del proyecto.

(El señor SECRETARIO da lectura al articulado.)

\section{[CONSIDERACIONES GENERALES SOBRE EL PDADDH]}

El señor PRESIDENTE: Todos ustedes han oído la lectura del interesantísimo trabajo presentado por el Grupo de Trabajo al cual se le difirió ese encargo por esta [573] Comisión. La Presidencia, interpretando el sentir de la Comisión, quiere dar las gracias a los miembros del Grupo por tan valioso documento y por tan provechoso esfuerzo. Como ha sido distribuído hace un momento, y tal vez algunos delegados reclamarían el derecho muy justo de estudiarlo más a fondo, para en una próxima sesión hacer sus observaciones, yo creo, salvo

1 Documento publicado durante la Conferencia con la clasificación CB-310/CIN-41, transcrito en la pág. 474 y siguientes. 
el mejor parecer de la Comisión, que podríamos esta tarde hacer unas consideraciones generales sobre el texto y mañana traer las modificaciones que cada uno de los delegados crea oportuno hacer. En esa forma, las disposiciones que no fueran objeto de modificación, implícitamente quedarían aprobadas.

Deseo oír sobre esta sugestión el parecer de los distintos delegados presentes. Se concede la palabra para observaciones de carácter general sobre el proyecto, a todos aquellos que quieran formularlas.

Tiene la palabra el señor Delegado del Uruguay.

\section{[OBSERVACIÓN URUGUAYA SOBRE EL FORTALEGIMIENTO INTERNACIONAL DE LAS GARAN- TÍAS HUMANAS]}

El señor MANINI Ríos (URUguAY): Señor Presidente: yo me voy a permitir hacerle breves observaciones a este documento que ha llegado en este instante a nuestras manos y que no hemos tenido oportunidad de analizar. La lectura que se le ha dado, le ha sugerido a la Delegación del Uruguay algunas observaciones.

En el segundo considerando se señala:

Que, en repetidas ocasiones, los Estados Americanos han reconocido que los derechos esenciales del hombre no nacen del hecho de ser nacional de determinado Estado sino que tienen como fundamento los atributos de la persona humana...

En esta doctrina estamos perfectamente identificados; encontramos que, pese a las salvedades, no se ajusta, a nuestro juicio, exactamente con la doctrina que en el cuarto considerando se establece. Si los derechos de la persona humana son el sujeto esencial cuya tradición tiene el carácter nacional de la referida persona humana, las garantías establecidas para la persona humana en los Estados no son, a juicio de la Delegación del Uruguay, suficientes, adecuadas, en las actuales circunstancias, como señala ese considerando. Nosotros preferiríamos que se acentuara más la última parte del mismo, en la cual se reconoce que deberán fortalecerse en el campo internacional dichas garantías. Hacemos esta sugestión porque tal vez, cambiando el orden de las palabras, podría quedar mejor expresado el concepto; que si bien comprendemos que esta materia, en este momento internacional, no puede ser sujeto de la persona humana, deseamos que se afirme la voluntad futura de ir a ese reconocimiento y a la aprobación que es la consecuencia del reconocimiento.

\section{[OBSERVACIÓN URUGUAYA SOBRE LA GRATUIDAD DE LA EDUCACIÓN]}

La segunda observación es la que se refiere al derecho de educación; o sea, a la última parte del Artículo XII, donde se habla del derecho de recibir gratuitamente educación. Esta gratuidad la limita dicho párrafo a la educación primaria. Si bien comprendemos que en algunas naciones existen problemas sobre la educación, sobre la gratuidad de la enseñanza superior, nuestro país, que tiene establecida la educación gratuita superior, estima que ése debe ser el desiderátum de los pueblos y que sería un error que se limitara la gratuidad a la enseñanza primaria. Conviene decir, como lógica correspondencia a los tres párrafos anteriores:

Toda persona tiene derecho a recibir gratuitamente la educación que el Estado pueda ofrecerle. 
[574] El derecho no debe limitarse a la educación primaria, pues si el Estado puede dar gratuitamente la enseñanza secundaria o superior, no conviene dejar de reconocer el derecho a la misma. Este es el complemento lógico de lo que se establece en el párrafo anterior, que se refiere a "igualdad de oportunidades".

\section{[OBSERVACIÓN URUGUAYA SOBRE LA FRASE “PRESTAR SERVICIO DE ARMAS”]}

El señor PRESIDENTE: ¿Terminó, señor delegado?

El señor MANINI Ríos (URUGUAY): Voy a señalar dos observaciones más.

En el Artículo XXXIV, se establece lo siguiente:

Toda persona tiene el deber de prestar servicio de armas y de desempeñar los cargos de elección popular en el Estado de que sea nacional.

Tiene asimismo el deber de prestar los servicios civiles que fueren necesarios en caso de calamidad pública.

Yo deseo dejar aclarado aquí este deber de prestar servicio de armas. No puede referirse a servicio militar, ni a instrucción militar obligatoria. Me interesa puntualizar este punto, porque creo que no puede establecerse el servicio militar obligatorio. Me imagino que se trata del servicio de sangre que todos debemos a nuestra patria en caso de guerra internacional; pero desearía que fuera aclarado este punto por el Grupo de Trabajo, porque podría parecer que se refiere al servicio militar obligatorio.

\section{[SOBRE EL DEBER DE ABSTENERSE DE ACTIVIDADES POLÍTICAS EN EL EXTRANJERO]}

La cuarta observación se refiere al deber de abstenerse de actividades políticas en país extranjero; es decir, al Artículo XXXVIII. Esto tiene una finalidad y un propósito muy noble: el de evitar intromisión extranjera en cuestiones internas de nuestros países, sobre todo en estos momentos en que están en el espíritu de todos, esas intromisiones extranjeras. Pero no puedo olvidar que en nuestra América, la intervención de ciudadanos nobles extranjeros se realizó primero para la independencia de nuestros pueblos. Yo no puedo olvidar que San Martín y Bolívar recorrieron fronteras para libertarnos; no puedo olvidar que otros extranjeros, como Garibaldi, tuvieron una acción preponderantemente en el establecimiento de las libertades públicas; no puedo olvidar que grandes ciudadanos de la República Argentina han sido factores esenciales en nuestro medio político, para el adelanto en mi país. Cuando se trata, sobre todo, de ciudadanos eminentes, no se puede impedir que tomen parte en actividades de otros países, pues al fin y al cabo aspiran a una ciudadanía. En América, hay ciertas actividades que me parecen demasiado restrictivas. Si en el pasado se hubiera declarado este principio, nuestros países se hubieran visto privados de las gestas heroicas de Bolívar y San Martín.

Es cuanto tengo que manifestar, señor Presidente.

El señor PRESIDENTE: El señor delegado, ¿está por la supresión del artículo, o por una modificación o redacción nueva?

El señor MANINI Ríos (URUGUAY): Yo creo que si se tomara en cuenta la sugestión que he hecho, podría dársele una redacción nueva; pero, como acabo de decir, no quiero manifestar puntos concretos sin haber leído detenidamente el proyecto. 
El señor PRESIDENTE: Entonces propongo al señor delegado que las sugestiones que tenga que hacer, las formule por escrito, para que así puedan ser estudiadas [575] por todos los delegados y podremos entrar en debate sobre las modificaciones a cada uno de los artículos. La Secretaría sacará copia de las modificaciones y las repartirá.

Tiene la palabra el señor Delegado de Cuba.

El señor Pérez Cisneros (CUBA): Nada más que para decir esto: creo expresar el sentir del Grupo de Trabajo al manifestar que lamenta haberse privado de la colaboración del señor Delegado del Uruguay, que era miembro de dicho Grupo y que tenía tan interesantes sugerencias que hacer.

El señor PRESIDENTE: Sigue concedida la palabra para las observaciones de carácter general sobre el proyecto que acaba de ser leído.

Tiene la palabra el señor Delegado de la Argentina.

El señor COROMINAS (ARGENTINA): Yo propongo que entremos en un receso, hasta mañana a las 10 de la mañana, a propósito de leer este documento integralmente y comentarlo con nuestras delegaciones, con el fin de darle debate mañana en la primera hora y ponerlo en consideración por artículos. Desde luego, por felices que puedan ser las sugestiones, no se podrían traer, sin leer con atención un documento de esta naturaleza.

Respondiendo a los conceptos enunciados por nuestro querido amigo el señor Delegado del Uruguay, le digo que nosotros podríamos en el debate general indicar cuáles son los alcances de cada uno de los artículos. Por ahora, podría referirme al problema político que señala en el último artículo el señor Delegado del Uruguay. La Comisión estará mañana en condiciones de ofrecer una respuesta a las demás observaciones, pero deseo expresar ahora mismo que no nos hemos referido a la prohibición de tránsito glorioso, en forma de gesta heroica; a aquel tránsito que se hizo cuando la nacionalidad continental no estaba todavía elaborada y no se había hecho el diagrama que ahora tenemos. Se refiere a la no cooperación de elementos foráneos en los cuadros políticos de cada República. Lo que queremos, es que cada ciudadano extranjero comience por acogerse a las leyes y tradiciones de cada país. ¿Cuáles son éstas? Nacionalidad, religión, idioma, etcétera. No es posible aceptar la turbación política dentro del Continente, que un ciudadano de otra nacionalidad fuera a perturbar las actividades de un pueblo. En lo que respecta a Argentina, nosotros nos sentimos muy satisfechos de lo que dijo el señor Delegado del Uruguay del General San Martín; pero el artículo se refiere a lo que convino el Continente de América sobre toda perturbación de elementos disociantes de otros países.

Yo pido, pues, con el permiso de los señores delegados y con el permiso de la Presidencia, levantar la sesión y entrar en un receso hasta mañana a las 10 de la mañana, para entrar entonces, no a una discusión general amplia, sino a una discusión general de tono menor, con el propósito de llevar a cabo rápidamente el análisis de cada uno de los elementos. Para la sesión de la mañana, creo que nosotros estaríamos ya en condiciones de estudiar un poco en definitiva este asunto, poniéndolo a votación.

Por otra parte, me permito también sugerirles a los señores delegados que van a entrar al estudio de esta materia, que lo hagan con el espíritu libre de reservas y prejuicios, sin la creencia de que este documento constituya el texto definitivo. Si (como nosotros proponemos) se da aprobación a la propuesta del Brasil con la [576] modificación del Uruguay, el Comité Jurídico que así labore, o la asamblea de juristas que así se convoque, acaso va a tomar este documento como base y ordenar entonces la definitiva Carta Fundamental de los derechos del hombre en América. 
No se trata de restarle la posibilidad de crítica a los delegados. Lo que yo solamente pido es que este documento sea observado con la generosidad de espíritu con que fué hecho; sin ninguna reserva espiritual y puestos los ojos en el hombre masa del Continente, que es el lazo surgido de todos nosotros para un documento de esta naturaleza. Si esta Conferencia pasara sin bases a estudiar tal documento, prácticamente la Conferencia tendría un cargo de conciencia. Por eso es por lo que hay que hacer algún sacrificio para poner todo el cuidado posible al texto; de ahí que hayamos dedicado trabajo de 72 horas a un documento de esta naturaleza.

[OBSERVACIÓN ESTADOUNIDENSE SOBRE EL DESEQUILIBRIO ENTRE DERECHOS Y DEBERES]

El señor PRESIDEnte: Tiene la palabra el señor Delegado de los Estados Unidos.

El señor TATE (Estados Unidos DE AMÉRICA): Estoy perfectamente de acuerdo con la sugestión de la Argentina de que se pase a discusión general, para que podamos tener tiempo hasta mañana de examinar los documentos. Esto se aplica especialmente a mi caso, puesto que es un tanto incierta la traducción que tengo.

Hay una observación general que me parece que podré formular, con respecto a lo que he visto del documento. Es la referente a la importancia y a la dignidad de tal documento en la parte que se refiere a los derechos del hombre, si se compara con la parte que se refiere a los deberes del hombre.

Después de todo, los derechos del hombre, la libertad del individuo, los derechos del individuo, han sido estudiados durante siglos enteros. Es una cosa fundamental para la civilización occidental que el individuo sea respetado como individuo y como persona, y que se respeten sus méritos individuales y su libertad individual. En otras palabras, cuando nos ocupamos de los derechos del hombre, tratamos el asunto de hasta qué punto y de qué modo los Estados en general deben no intervenir en la vida y en los derechos del hombre. Todos los Estados respetan los derechos del individuo para el completo desarrollo de su personalidad.

En cambio, cuando nos adentramos en la parte relativa a los deberes del hombre, nos ocupamos especialmente de la relación entre los deberes propios del hombre con respecto a su propio Estado. Me parece que si consideramos este documento en su totalidad, veremos que la segunda parte no tiene la dignidad que tiene la primera.

No hago sino bosquejar esta sugestión para una ulterior consideración. Pero ello refuerza la opinión de mi delegación de que se podría insistir acerca de este punto con relación al Comité Jurídico Interamericano, para que se estudie ulteriormente el modo de coordinar los trabajos que se están realizando aquí con los trabajos que se están realizando en las Naciones Unidas y que ya ustedes conocen.

El señor PRESIDENTE: Si ningún delegado tiene ninguna observación que hacer, se levanta la sesión.

El señor Pérez Cisneros (CUBA): Sugiero que se convoque la próxima sesión, no para la mañana, sino para la tarde de mañana.

El señor PRESIDENTE: Entonces se convoca para mañana a la misma hora de hoy, es decir, a las 3 de la tarde.

Se levanta la sesión. 


\section{ACTA RESUMIDA DE LA QUINTA SESION DE LA COMISION SEXTA ${ }^{1}$}

FECHA: jueves, 22 de abril de 1948

HORA: 15:10-19:00

RECinTO: Cámara de Representantes, Capitolio Nacional

Presidente: señor Carlos Sánchez y Sánchez (República Dominicana)

VICEPRESIDENTE: señor Marco Antonio Batres (Honduras)

RELATOR: señor Luis López de Mesa (Colombia)

SECRETARIO: señor Gabriel Arango Restrepo

PREsentes: señores Virgilio R. Gálvez (Honduras); Ricardo Latcham (Chile); Héctor A. Grauert (Uruguay); Emilio Pando y Guy Pérez Cisneros (Cuba); Jack B. Tate (Estados Unidos de América); Joaquín Balaguer (República Dominicana); Alberto Salinas López (Bolivia); Luis Fernán Cisneros (Perú); Diego Manuel Chamorro (Nicaragua); Germán Fernández del Castillo (México); Eduardo A. Chiari (Panamá); Héctor Escobar Serrano (El Salvador); Humberto García Ortiz (Ecuador); Antonio Camillo de Oliveira (Brasil); Melchor Monteverde (Venezuela); Leonidas Vásquez (Argentina); Jorge Soto del Corral (Colombia); Charles G. Fenwick (Unión Panamericana); y Alfonso de Rosenzweig-Díaz Azmitia (Naciones Unidas)

\section{[APERTURA DEL DEBATE SOBRE EL ARTIGULADO DEL PDADDH]}

El señor PRESIDENTE abrió la sesión.

Sometió a consideración el Acta de la anterior, que fué distribuída oportunamente. Se aprobó sin observación.

Acto seguido se abrió la discusión sobre el articulado del Proyecto de Declaración sobre derechos y deberes del hombre, ${ }^{2}$ elaborado por el Grupo de Trabajo designado al efecto en la sesión del 17 de abril, el cual fué distribuído a las delegaciones.

\section{[SOBRE LOS CONSIDERANDOS]}

Abierta la discusión sobre los considerandos del Proyecto de Declaración Americana de los Derechos y Deberes Esenciales del Hombre, el señor GRAUERT (URUGUAY) manifestó que el representante de su país, señor Manini Ríos, había propuesto en la sesión anterior algunas enmiendas; entre ellas, una relacionada con el cuarto considerando de la Declaración y consistente en cambiar la redacción original por el texto siguiente: ${ }^{3}$

Que la consagración americana de los derechos esenciales del hombre, requiere como natural complemento la protección internacional de los mismos, lo que deberá establecerse en el futuro más próximo posible...

1 Documento publicado durante la Conferencia con la clasificación CB-362/C.VI-22.

Por dificultades insalvables, no hubo servicios taquigráficos para esta sesión.

2 Contenido en el documento publicado durante la Conferencia con la clasificación CB-310/CIN41, transcrito en la pág. 474 y siguientes.

3 Sometido por escrito a la Secretaría, pero no propuesto textualmente durante la Cuarta Sesión de la Comisión. 
Los señores Fernández del Castillo (MéXico) y Cisneros (PERÚ) se opusieron a la anterior enmienda y defendieron el texto original del proyecto.

[578] El señor SOTO DEL CORRAL (COLOMBIA) presentó la siguiente moción substitutiva del tercer considerando:

Que la protección internacional de los derechos del hombre debe ser guía principalísima del derecho americano en evolución...

Sustentado por el proponente, el señor FERnÁndez del Castillo (MéXICO) insistió en que se mantuviera el texto primitivo de los considerandos. Sometidas a votación ambas enmiendas, la de Colombia fué aprobada y la del Uruguay negada.

[SOBRE EL PREÁMbULO]

Abierta la discusión sobre el preámbulo, el señor FENWICK (UNIÓN PANAMERICANA) manifestó que debería reemplazarse la expresión "como hermanos" por "fraternalmente". Así se aprobó.

[APROBACIÓN SIN OBSERVACIONES DE LOS DERECHOS A LA VIDA, LIBERTAD, SEGURIDAD E INTEGRIDAD, A LA IGUALDAD ANTE LA LEY Y A LA LIBERTAD RELIGIOSA Y DE GULTO (ARTS. I-III)]

Sometido a votación el Artículo I, sobre "Derecho a la Vida, a la Libertad, a la Seguridad y a la Integridad de la Persona", se enmendó tanto el título como el artículo mismo, en este sentido:

Derecho a la Vida, a la Libertad, a la Seguridad e Integridad de la Persona

Todo ser humano tiene derecho a la vida, a la libertad y a la seguridad e integridad de su persona.

Así fué aprobado.

Discutido el Artículo II, "Derecho de Igualdad ante la Ley", fué aprobado sin observación alguna.

El Artículo III, “Derecho a la Libertad Religiosa y de Culto”, fué aprobado igualmente en su texto original.

[APROBAGIÓN DEL DEREGHO DE LIBERTAD DE INVESTIGAGIÓN, OPINIÓN, EXPRESIÓN Y DIFUSIÓN (ART. IV)]

Con respecto al Artículo IV, "Derecho de Libertad de Investigación, Opinión, Expresión y Difusión", el señor CHAMORRO (NICARAGUA) solicitó la supresión de la frase "por cualquier medio." Luego de breve discusión, se aprobó el texto original del proyecto, por 10 votos afirmativos contra seis negativos.

[APROBACIÓN DEL DERECHO DE PROTEGCIÓN A LA HONRA, LA REPUTACIÓN PERSONAL Y LA VIDA PRIVADA Y FAMILIAR (ART. V)]

En cuanto al Artículo V, "Derecho de Protección a la Honra, la Reputación Personal y la Vida Privada y Familiar”, el señor GARCía ORTIZ (ECUADOR) sugirió la supresión del 
término "abusivos", contenido en el texto del artículo. El señor FENWICK (UNIÓN PANAMERICANA) fué de parecer que se reemplazara el expresado vocablo por "injustificados". El señor CHAMORRO (NICARAGUA) apoyó el texto original. El señor SALINAS LÓPEZ (BOLIVIA) adhirió a la enmienda propuesta por el señor Delegado del Ecuador, quien, por vía de transacción, aceptó el cambio de "abusivos" por "injustificados". El señor SOTO DEL CORRAL (COLOMBIA) encontró fundada la observación hecha por el señor Delegado del Ecuador sobre eliminación de la palabra "abusivos", pues no debía hacerse distinción alguna en el texto del artículo, a su juicio. Por fin, el artículo original fué aprobado, por seis votos contra dos, con nueve abstenciones.

[APROBACIÓN SIN OBSERVACIONES DE LOS DERECHOS A LA FAMILIA Y SU PROTECGIÓN, A LA PROTECCIÓN DE LA MATERNIDAD Y LA INFANCIA, Y AL DERECHO DE RESIDENCIA Y TRÁNSITO (ARTS. VI-VIII)]

El Artículo VI, "Derecho a la Familia y a su Protección", fué aprobado sin observación alguna.

Al Artículo VII, "Derecho de Protección a la Maternidad y a la Infancia", igualmente se le impartió aprobación, sin discusión.

También se aprobó el texto original del Artículo VIII, "Derechos de Residencia y Tránsito".

\section{[APROBACIÓN DEL DERECHO DE INVIOLABILIDAD DEL DOMICILIO (ART. IX)]}

[579] Respecto del Artículo IX, "Derecho de Inviolabilidad de Domicilio", a petición del señor ChIARI (PANAMÁ), el título se modificó así: "Derecho de Inviolabilidad del Domicilio".

[APROBACIÓN DEL DERECHO A LA INVIOLABILIDAD Y CIRCULACIÓN DE LA CORRESPONDENCIA (ART. X)]

En cuanto al Artículo X, "Derecho de la Correspondencia”, el señor FENwiCK (UNIÓN PANAMERICANA) preguntó si la norma de este artículo no estaba ya consignada en el Artículo IV del proyecto. El señor CHAMORRO (NiCARAGUA) observó que una cosa es el derecho a la difusión del pensamiento, y otra es el de la libre circulación de la correspondencia, sin censuras ni violaciones, y garantizándose su secreto. El señor CiSNEROS (PERÚ) manifestó que los dos conceptos anteriores se complementaban, y se mostró por ello partidario de conservar el texto primitivo del artículo.

Refiriéndose al mismo artículo, el señor VÁSQUEZ (ARGENTINA) pidió el cambio de "circulación" por "entrega" o por "circulación y entrega". El señor CHAMORRO (NICARAGUA) observó que cuando no existe entrega no se puede hablar de circulación, ya que ésta presupone aquélla.

A propuesta del señor EScobar SERRANO (EL SALVADOR), se aprobó la modificación del título así: "Derecho a la Inviolabilidad y Circulación de la Correspondencia".

\section{[APROBACIÓN DEL DERECHO A LA PRESERVACIÓN DE LA SALUD Y AL BIENESTAR (ART. XI)]}

Al discutirse el Artículo XI, "Derecho a la Salud y al Bienestar", el señor Cisneros (PERÚ) propuso la enmienda del texto del artículo, en el sentido de que se incluyera la frase "preservada por todos los medios". 
El señor CHAMORRo (Nicaragua) solicitó que el título se modificara así: "Derecho a la Preservación de la Salud y al Bienestar". En esta forma fué aprobado.

\section{[APROBACIÓN DEL DERECHO A LA EDUCACIÓN (ART. XII)]}

Con respecto al Artículo XII, "Derecho a la Educación”, el señor GRAUERT (URUGUAY) expresó su deseo de no restringir la educación gratuita a la primaria, y propuso el siguiente texto para la parte final del artículo:

Toda persona tiene derecho a recibir educación gratuita.

El señor FERnÁNDez Del Castillo (MéXICO) defendió la redacción del proyecto, alegando que no es esencial para el hombre adquirir todos los grados de enseñanza, sino solamente los necesarios para bastarse a sí mismo en el medio social en que actúe; estos conocimientos son los que los pedagogos han denominado "enseñanza elemental". El señor Cisneros (PERÚ) sugirió agregar al texto, en su parte final, la expresión "a lo menos", en relación con la educación primaria.

El señor GRAUERT (URUGUAY), después de algunas informaciones generales sobre la situación de su país (que imparte enseñanza gratuita en todos los grados), terminó por adherir a la sugerencia del señor Delegado del Perú. El señor CHAMORRO (NICARAGUA) igualmente manifestó su acuerdo con las tesis de los señores Delegados de México y Perú, estimando que sólo se trataba de consignar los derechos esenciales o mínimos. El señor TATE (EsTADOs UNIDOS DE AMÉRICA) sustentó los puntos de vista del señor Delegado de Nicaragua.

Además, el señor TATE manifestó su deseo de reconsiderar el Artículo XI, ya aprobado; pero la PRESIDENCIA, por razones de orden, optó por continuar el debate sobre el artículo en discusión e invitó al señor Delegado de los Estados Unidos para que en su debida oportunidad solicitara tal reconsideración.

[580] Al continuar en el uso de la palabra, el señor Delegado de los EsTADOs UNIDOS advirtió que no debía hacerse la referencia al sentido filosófico de la educación que consagraba el texto del artículo debatido, sino tratar simplemente sobre la educación misma. Por ello, sugirió la abolición de la parte final del párrafo primero, y de todo el párrafo segundo.

El señor DE OLIVEIRA (BRASIL) se mostró partidario de suprimir el plural en la palabra "humanas", que sólo se refería a solidaridad; de agregar la libertad de cátedra en el párrafo tercero; y de prescindir de las supresiones propuestas por el señor Delegado de los Estados Unidos, ya que, en su concepto, la referencia al sentido filosófico de la educación contribuía a mantener la dignidad y elevado nivel de la primera parte de la Declaración, relativa a los derechos, que había sido encomiada por dicho delegado.

El señor CHAMORRo (NiCARAGUA) advirtió que en el texto se había omitido el derecho de impartir educación y sólo se aludía al de recibirla. El señor PRESIDENTE leyó a este propósito el texto respectivo del proyecto del Comité Jurídico Interamericano. ${ }^{1}$

El señor SALINAS LÓPEZ (BOLIVIA) solicitó que se concretara la discusión a la propuesta del señor Delegado de los Estados Unidos, sobre supresión de una parte del artículo.

El señor GRAUERT (URUGUAY) se manifestó conforme con lo expuesto por el señor Delegado de Bolivia.

Documento publicado durante la Conferencia con la clasificación CB-7, transcrito en la pág. 449 y siguientes. 
En cuanto a las enmiendas de los señores Delegados del Brasil y de Nicaragua, sobre libertad de cátedra y de enseñanza, respectivamente, el señor GRAUERT conceptuó que quedaban comprendidas en el Artículo IV, ya aprobado.

El señor FERNÁNDEZ DEL CASTILLO (MéXICO) expresó su acuerdo con las opiniones de los señores Delegados de Bolivia y Uruguay y con la adición propuesta por el señor Delegado del Perú.

En lo tocante a las proposiciones de los señores Delegados del Brasil y de Nicaragua, el señor Delegado de MéXICO informó que aun cuando el proyecto del Comité Jurídico incluía el derecho de enseñar, ponía como limitaciones "las inherentes a su ejercicio", con lo que invalidaba completamente el derecho.

Respecto a la libertad de cátedra, conceptuó que no estaba incluído ese concepto en el proyecto del Comité Jurídico ni en el de las Naciones Unidas, exclusión que se explicaba por varias razones. En primer término, la libertad de la persona para enseñar sólo es una forma de la libertad de expresión consagrada en el Artículo IV, y la libertad para dedicarse a la enseñanza es una de las modalidades de la de trabajo, consignada igualmente en el Artículo IV. La libertad de cátedra, en el sentido de que el profesor al servicio del Estado enseñe conforme a su propio criterio, no es un derecho esencial sino una conveniencia pedagógica, de carácter técnico y jurídico, cuya regulación corresponde al Estado, al realizar sus fines de procurar el bienestar general. La libertad de cátedra no puede confundirse con la de fundar escuelas, que tampoco corresponde a un derecho esencial del hombre, sino que entra en la esfera administrativa, en cuanto se refiere a la facultad que tiene el Estado de [581] cerciorarse de la seriedad del establecimiento y de la aptitud del profesorado, con el fin de evitar fraudes al público y peligros a la sociedad, cuidar de las condiciones higiénicas y asegurar que los estudios efectivamente capaciten al alumno para continuar los que corresponden a grados superiores o para ejercer una profesión. Por último, el Estado es responsable de la preparación de buenos ciudadanos para el futuro, y tiene que atender a esa responsabilidad, fijando los lineamientos generales de la educación. Terminó el señor FERnÁnDEZ DEL CASTILLO, opinando que dentro de ese orden de ideas la libertad del catedrático estaba amparada por la libertad de expresión.

El señor Monteverde (VEnezuela) se refirió al deseo del señor Delegado de Nicaragua sobre el derecho de enseñar, y conceptuó que éste quedaba suficientemente protegido con lo consagrado en el aparte tercero del artículo en discusión.

El señor PRESIDENTE consideró que se contaba con suficiente información al respecto e hizo un recuento de las proposiciones formuladas.

El señor SoTO DEL CORRAL (COLOMBIA) opinó que, efectivamente, en el Artículo IV estaba garantizado el derecho a enseñar, pero que no sobraba repetir ciertos principios consignados en las distintas constituciones; agregó que, si bien es cierto que dicho Artículo IV consagraba la libertad de expresión, con intención de proteger las difusiones por la radio, la prensa, etcétera, siempre convendría incluir en el Artículo XII el derecho a enseñar. Por lo que respectaba a la observación del señor Delegado de México, advirtió que el reconocimiento de tal derecho no impedía que el Estado reglamentara la educación. Presentó la siguiente enmienda:

El derecho de educación comprende el de dar enseñanza con libertad de cátedra y el de igualdad de oportunidades en todos los casos, de acuerdo...

El señor MONTEVERde (VENEZuela) insistió en la exclusión del derecho de suministrar enseñanza y sugirió, como transacción, que se hablara simplemente de la libertad "de enseñar". 
El señor PRESIDENTE consideró suficientemente discutido el tema y puso en votación las proposiciones del señor Delegado de los Estados Unidos sobre supresión de la parte final del primer párrafo y de la totalidad del segundo. Ambas fueron negadas.

Sometida a votación la proposición del señor Delegado de Colombia, resultó negada por nueve votos en contra, cinco en favor y dos abstenciones. Dicha proposición incluía la fórmula propuesta por los señores Delegados del Brasil y Nicaragua.

Puesta en votación la proposición del señor Delegado de Venezuela, también resultó negada, por nueve votos en contra y siete en favor.

El señor CiSNEROS (PERÚ) hizo constar su voto negativo a todas las modificaciones anteriores, por estimar que el derecho de aprender es fundamental pero el de impartir enseñanza no. El señor CHAMORRO (NiCARAGUA) dejó constancia de que había votado afirmativamente la inclusión del derecho de enseñar, fundado en su convicción de que éste es igualmente fundamental.

En vista de que fueron negadas casi todas las enmiendas propuestas, el señor [582] PRESIDENTE consideró aprobados todos los párrafos del artículo, con la adición, en el último, de la expresión "a lo menos" antes de "la educación primaria".

\section{[APROBACión DEL DERECHO A LOS BENEFICIOS DE LA GULTURA (ART. XIII)]}

Respecto del Artículo XIII, "Derecho a los Beneficios de la Cultura", el señor TATE (EsTAdos Unidos DE AMÉRICA) propuso la supresión de la segunda parte del artículo, estimando que no contenía derechos esenciales.

El señor FernáNDEZ DEL Castillo (MéXICO) no compartió la opinión expresada, pues consideró que los derechos intelectuales, sí son esenciales para el hombre, toda vez que las obras de los inventores y de los autores son la expresión directa de su genio, atributo principal y característico de la persona humana, al grado de que a ésta se le sigue conociendo, estudiando y discutiendo, aun después de la muerte, a través de sus obras; que los derechos de que se trataba siempre habían sido considerados como esenciales a la persona, aun cuando en las enunciaciones de las constituciones tradicionalistas no se les hubiera incluído, por mera omisión política. Tan es así, que con relación a ellos se emplean términos como el de "paternidad" y "propiedad" de la obra, por analogía con la creación natural del hombre y con la propiedad. Agregó que no se trataba de proteger a una clase determinada, sino a todos los hombres creadores, intelectuales, pues ellos contribuían fundamentalmente al mejoramiento social, por medio de las artes y de las ciencias. Terminó diciendo que no podía dejarse de considerar como esencial para el hombre la protección otorgada a las creaciones de su espíritu, siendo así que tal protección es nada menos que el impulsor de la cultura.

El señor GARcía ORTIZ (EGUADOR) apoyó la tesis del señor Delegado de México.

El señor CHAMORRO (NiCARAGUA) explicó que se trataba de dar a los trabajadores intelectuales las mismas garantías que a los trabajadores materiales. Propuso agregar, donde se hablaba de los beneficios en el artículo discutido, la frase "y de las obras de la inteligencia".

En votación la propuesta del señor Delegado de los Estados Unidos sobre supresión del segundo párrafo del artículo, fué negada, ya que sólo contó con el voto afirmativo del proponente. En tal virtud, se consideró aprobado dicho segundo párrafo.

El señor LATCHAM (CHILE) manifestó que convendría darle otra forma a la modificación del señor Delegado de Nicaragua. Al efecto presentó la siguiente redacción:

Toda persona tiene derecho de tomar parte activa en la vida cultural de la comunidad, de gozar de los beneficios de las artes y de la plenitud del progreso intelectual y científico de la sociedad. 
El señor FENWICK (UNIÓN PANAMERICANA) solicitó la lectura de la primera parte del Artículo XV del proyecto del Comité Jurídico Interamericano, por considerarlo más adecuado que el Artículo XIII en discusión.

El señor FERNÁNDEZ (MÉXICO) objetó lo anterior. Estimó que el primer párrafo del Artículo XIII en discusión contemplaba el derecho de todo hombre a los beneficios de la cultura, y que el segundo párrafo protegía a toda persona en cuanto fuera creadora de alguna obra.

El señor PÉrez Cisneros (CUBA) propuso esta adición:

[583] ...y de participar de los beneficios que resulten de los progresos intelectuales y especialmente de los descubrimientos científicos.

$\mathrm{Al}$ respecto, recibió información de la Presidencia y del señor Delegado de México, entre otros, acerca de que ya el punto materia de la enmienda propuesta por Cuba había sido ampliamente debatido.

El señor LÓPEZ DE MESA (COLOMBIA) apoyó la redacción primitiva del texto, y la enmienda de Cuba en cuanto agregaba la frase "y especialmente". Esta fórmula fué aprobada.

El señor PÉREZ GiSNeros (CUBA) declaró que su delegación estaba dispuesta a defender, en cualquier momento y con todo entusiasmo, el contenido del segundo párrafo del Artículo XIII. Sin embargo creía lo siguiente: primero, que se trataba de un derecho de "propiedad" intelectual y que, por consiguiente, ese texto no podía figurar bajo el título de "Derecho a los Beneficios de la Cultura"; y segundo, que por tratarse tan sólo de derecho de autor y de inventor, no podía decirse que éste fuera un derecho esencial del hombre. Agregó que sentía escrúpulo de incluir tal cláusula en su forma actual en la Declaración, siendo éste un documento cuya elaboración debía hacerse cuidadosamente, sin particularizar ni subrayar en ella los derechos de determinada clase de individuos, por legítimos que fuesen tales derechos.

El señor PRESIDENTE, aludiendo a la ausencia transitoria del señor Delegado de Cuba, explicó que, después de largas consideraciones, se había negado la supresión del párrafo segundo del artículo en discusión. Consideró que podría más bien cambiarse el título respectivo, para que comprendiera el segundo párrafo.

El señor GRAUERT (URUGUAY) dijo que había escuchado al señor Delegado de los Estados Unidos, quien en principio lo impresionó con su disertación, lo mismo que las opiniones del señor Delegado de Nicaragua y de algunos otros, pero que ahora estaba de acuerdo en que el segundo párrafo del Artículo XIII no estaba en el sitio que le correspondía y debía quedar como segunda parte del Artículo XIII [XIV]. ${ }^{18 E}$ El señor SOTO DEL CORRAL (COLOMBIA) apoyó lo anterior. El señor FERNÁNDEZ DEL CASTILLO (MÉXICO) se mostró partidario de que el párrafo quedara en el lugar donde estaba en el texto original del proyecto. Dijo que en caso contrario sería más indicado redactar un artículo nuevo, por razones de técnica.

El señor CHAMORRO (NICARAGUA) sugirió que se modificara el título, para englobar los dos casos, en este sentido: "Derecho a los Beneficios de la Cultura y a la Protección a los Derechos del Autor".

El señor Fenwick (Unión PANAmericana) explicó las razones que se tuvieron en cuenta en el Comité Jurídico Interamericano, al estudiar esta materia, y expuso los motivos para adoptar el texto aprobado por dicho Comité.

Sometida a votación la proposición del señor Delegado de Chile, fué negada por nueve votos contra cuatro; hubo cuatro abstenciones. El señor PÉREZ CiSNEROS (CUBA) se reservó el derecho de plantear de nuevo el caso ante la Comisión de Iniciativas.

${ }_{18 \mathrm{E}}$ Sic. Nota del editor A. P. D. 
[APROBACIÓN SIN OBSERVACIONES DEL DERECHO AL TRABAJO Y A UNA JUSTA RETRIBUCIÓN Y AL DESCANSO Y SU APROVECHAMIENTO (ARTS. XIV-XV)]

El Artículo XIV, "Derecho al Trabajo y a una Justa Retribución”, sin modificación alguna fué aprobado.

[584] El Artículo XV, "Derecho al Descanso y a Su Aprovechamiento" igualmente fué aprobado en su texto original.

El señor PRESIDENTE convocó la próxima sesión para el 23 de abril, a las 4 de la tarde.

Se levantó la sesión.

\section{ACTA RESUMIDA DE LA SEXTA SESION DE LA COMISION SEXTA ${ }^{1}$}

FECHA: viernes, 23 de abril de 1948

HORA: 16:30-18:50

Recinto: Cámara de Representantes, Capitolio Nacional

PResidente: señor Carlos Sánchez y Sánchez (República Dominicana)

VICEPRESIDENTE: señor Marco Antonio Batres (Honduras)

RELATOR: señor Luis López de Mesa (Colombia)

SECRETARIO: señor Gerardo Melguizo

PRESENTES: señores Virgilio R. Gálvez (Honduras); José Luis Mendoza (Guatemala); Sergio A. Labarca y Ricardo Latcham (Chile); Esteban Bacigalupi (Uruguay); Guy Pérez Cisneros (Cuba); John Halderman (Estados Unidos de América); Joaquín Balaguer (República Dominicana); Alberto Salinas López (Bolivia); Luis Fernán Cisneros (Perú); Diego Manuel Chamorro (Nicaragua); Germán Fernández del Castillo (México); Eduardo A. Chiari (Panamá); Héctor Escobar Serrano (El Salvador); Humberto García Ortiz (Ecuador); Antonio Camillo de Oliveira (Brasil); Leonidas Vásquez (Argentina); Jorge Soto del Corral y Luis Guillermo Echeverri (Colombia); y Charles G. Fenwick (Unión Panamericana)

[CUBA SE RESERVA EL DEREGHO DE PRESENTAR UN ARTÍGUlO SOBRE EL DEREGHO DE RESISTENCIA]

El señor PRESIDENTE abrió la sesión.

Pidió a los señores delegados toda la intensidad posible en el trabajo, a fin de satisfacer los deseos de la Comisión de Coordinación. Como el Acta de la sesión anterior no había sido distribuida, sugirió a la Comisión que continuara la discusión del informe del Grupo de Trabajo. ${ }^{2}$

1 Documento publicado durante la Conferencia con la clasificación CB-377/C.VI-25.

Por dificultades insalvables, no hubo servicios taquigráficos para esta sesión.

2 Documento publicado durante la Conferencia con la clasificación CB-310/CIN-41, transcrito en la pág. 474 y siguientes. 
El señor PÉrez Cisneros (CUBA) dijo que su delegación se reservaba el derecho de presentar oportunamente un nuevo artículo, sobre "Derecho de Resistencia", ${ }^{3}$ que en su concepto debía considerarse antes que la proposición brasileña. ${ }^{4}$

\section{[APROBAGIÓN DEL DEREGHO A LA SEGURIDAD SOCIAL (ART. XVI)]}

El señor PRESIDENTE hizo leer por el Secretario el Artículo XVI del informe del Grupo de Trabajo, sobre "Derecho a la Seguridad Social".

El señor HaLderman (Estados Unidos de AmÉRICA) manifestó que, en su [585] opinión, en la parte del texto que decía, "Toda persona tiene derecho a la seguridad social y a la protección del Estado", debía eliminarse la frase "del Estado"; pues no era solamente el Estado quien pudiera otorgar y proteger ese derecho. Agregó que en su país la seguridad social se prestaba por el Estado, la industria, etcétera. El señor PRESIDENTE manifestó al señor Delegado de los Estados Unidos que en el texto español no estaba incluida la frase referente al Estado, y que se suprimiría, al redactar definitivamente el texto inglés.

El señor Gálvez (HONDURAS) dijo que las palabras "medios de subsistencia" tenían una significación demasiado amplia. Por ejemplo, un rentista tendría como medios de subsistencia sus rentas. Propuso, en consecuencia, que el artículo quedara redactado así:

Toda persona tiene derecho a la seguridad social que la proteja contra las consecuencias de la desocupación, de la vejez, o de cualquiera otra causa que la incapacite física o mentalmente para obtener los medios de subsistencia.

El señor Mendoza (Guatemala) apoyó la proposición del señor Delegado de Honduras que, en su opinión, era muy atinada y conveniente.

El señor FERNÁNDEZ DEL CASTILLO (MÉXICO) manifestó que no consideraba muy feliz la modificación, puesto que la vejez no era sino una de las causas de la incapacidad y, por consiguiente, bastaba con proteger al hombre contra la incapacidad en general.

El señor PÉREZ CISNEROS (CUBA) expresó que le parecía clara y necesaria la modificación propuesta por el señor Delegado de Honduras y que, por lo tanto, se complacía en apoyarla.

El señor DE OLIVEIRA (BRASIL) observó que no era posible proteger contra las causas de incapacidad, sino solamente contra la incapacidad proveniente de ciertas causas.

El señor MENDOZA (GUATEMALA) sugirió la siguiente fórmula:

Toda persona tiene derecho a la seguridad social que la proteja contra las consecuencias de la desocupación, de la vejez y de otras causas que la incapaciten física o mentalmente para obtener los medios de subsistencia.

El señor CISNEROS (PERÚ) propuso la siguiente modificación:

...y de la incapacidad que, proveniente de otras causas ajenas a su voluntad, la imposibilite física o mentalmente para obtener los medios de subsistencia.

3 Discutido en varias sesiones de la Comisión Sexta y también, más detalladamente, en la Décimasexta Sesión de la Comisión de Iniciativas, Volumen II, pág. 422 y siguientes. Véase también el punto 9 del documento publicado durante la Conferencia con la clasificación CB-310/CIN-41, transcrito en la pág. 474 y siguientes.

4 Documento publicado durante la Conferencia con la clasificación CB-125/C.VI-6, transcrito en las págs. $464-65$. 
El señor HALDERMan (Estados Unidos DE AMÉRICA) dijo que deseaba observar que la primera fórmula quizás no incluía a las personas que dependían de otras para su vida y cuyo derecho a los medios de subsistencia resultaba de otras causas; pero creyó que la modificación que acababa de proponer el señor Delegado del Perú, comprendía estas posibilidades.

El señor CHAMORRO (NiCARAGUA) manifestó que sería más indicado que la Comisión se transformara en Comisión de Estilo, pues la discusión estaba versando casi exclusivamente sobre problemas de redacción. Agregó que no veía más discrepancia de fondo que la aludida por los Estados Unidos al insinuar que se supri- [586] miera la posibilidad de reclamar al Estado el derecho a la seguridad; y que, en este caso, la controversia debería centralizarse en proposiciones como ésta.

El señor PRESIDENTE, en vista de que el señor Delegado de los Estados Unidos se mostraba satisfecho con la modificación introducida por la Delegación del Perú, y de que las proposiciones de Honduras y Guatemala podían unificarse fácilmente, puso en votación el artículo primitivo, con las modificaciones de Perú, Guatemala y Honduras.

El artículo fué aprobado en la siguiente forma:

Toda persona tiene derecho a la seguridad social que la proteja contra las consecuencias de la desocupación, de la vejez, y [de] la incapacidad que, proveniente de cualquier otra causa ajena a su voluntad, la imposibilite, física o mentalmente, para obtener los medios de subsistencia.

[APROBACIÓN DEL DERECHO DE RECONOCIMIENTO DE LA PERSONALIDAD JURÍDICA Y DE LOS DERECHOS CIVILES (ART. XVII)]

A continuación, el señor Secretario dió lectura al Artículo XVII sobre "Derecho de Reconocimiento de la Personalidad Jurídica y de los Derechos Civiles".

El señor HALDERMAN (ESTADOS UNIDOS DE AMÉRICA) sugirió que este artículo fuera suprimido, pues en su concepto el Artículo II, que proclamaba la igualdad de todos los hombres ante la Ley, implicaba la consagración del derecho que tenía toda persona a que se le reconociera como sujeto de derecho.

El señor FERnÁNDEZ DEL CaSTILlo (MÉXICO) observó que el Grupo de Trabajo redactor del proyecto había considerado necesarios los dos artículos, en su esencia completamente diferentes. El Artículo II se refería a la igualdad de todos los hombres ante la Ley, y el Artículo XVII contemplaba el derecho de reconocimiento de la capacidad jurídica de las personas, suprimiendo así toda posibilidad de la esclavitud y de la llamada capitis diminutio del derecho romano (es decir, la incapacidad de las personas para disfrutar de los derechos y ser sujetos de obligaciones). Dijo que, en su opinión, éste era uno de los artículos que daban mayor altura al proyecto; y que, en consecuencia, su delegación se oponía a que fuera suprimido.

El señor GARCíA ORTIZ (ECUADOR) manifestó que consideraba el Artículo XVII como uno de los más importantes del proyecto, puesto que establecía que cualquier hombre, en cualquier parte, tenía el derecho de ser considerado como persona jurídica. Añadió que sentía no compartir el punto de vista del señor Delegado de los Estados Unidos, pero que pedía, en nombre de su delegación, que el artículo fuera conservado.

El señor PRESIDENTE hizo leer por la Secretaría los Artículos II y XVII del proyecto, con el fin de orientar la discusión.

El señor Halderman (Estados Unidos de América) dijo que, debido a dificultades de interpretación, no había podido seguir el curso del debate. 
El señor PRESIDENTE explicó al señor Delegado de los Estados Unidos la oposición de algunos delegados a la supresión del Artículo XVII, cuyo sentido no era el del Artículo II, ya que éste hacía sólo una enunciación general, mientras que el XVII especificaba la consagración de un derecho fundamental para el hombre. Por tanto, los oradores que habían intervenido, pedían la conservación de los dos artículos.

El señor MENDOZa (GUATEMALA) preguntó si el artículo implicaba alguna [587] limitación para los Estados en su facultad de reglamentar la capacidad de las personas en lo referente a edad, condiciones mentales, etcétera.

El señor PÉrez Cisneros (CUBA), respondiendo a la pregunta del señor Delegado de Guatemala, señaló que el Artículo XXVIII del proyecto resolvía todas las dudas semejantes a la planteada por Guatemala, cuando decía:

Los derechos del hombre están limitados por los derechos de los demás, por la seguridad de todos y por las justas exigencias del bienestar general y del desenvolvimiento democrático.

El señor Mendoza (GUATEMALA) consideró satisfactorias las explicaciones del señor Delegado de Cuba.

El señor PRESIDENTE sometió a votación el Artículo XVII, que fué aprobado.

[APROBAGIÓN DEL DERECHO DE JUSTICIA (ART. XVIII)]

El señor SECRETARIO leyó el Artículo XVIII, sobre "Derecho de Justicia".

El señor GARCía ORTIZ (ECUADOR) observó que las palabras "sencillo y breve" podrían ser reemplazadas por una expresión de mayor precisión jurídica, "procedimiento sumario".

El señor HALDERMAN (ESTADOS UNIDOS DE AMÉRICA) observó, respecto al término "sumario" de la moción del señor Delegado del Ecuador, que en su país las expresiones "breve y sumario" y "rápido" no tenían el mismo significado; que "breve y sumario" se denominaba, en su legislación, al procedimiento atañedero al habeas corpus.

Propuso, además, que se modificara la primera parte del artículo así:

Todas las personas pueden ocurrir ante los tribunales para hacer que se respeten sus derechos legalmente obtenidos...

Dijo que sugería esta modificación porque los derechos humanos no siempre tenían carácter legal y, si no se estableciese una diferencia entre ambas categorías, el artículo carecería de armonía.

El señor PRESIDENTE dió la siguiente explicación destinada a orientar el debate.

'La palabra 'sumario' tiene un significado diferente en las diversas legislaciones. En la legislación francesa, significa lo contrario de 'procedimiento ordinario'. En este caso, si pusiésemos 'procedimiento sumario', parecería que dejábamos por fuera el derecho que tiene el ciudadano de pedir un procedimiento ordinario, que es más lento, pero mucho más jurídico y seguro. En todo caso, creo que la Comisión de Estilo sabrá buscar las palabras necesarias en los distintos idiomas para que se logre el espíritu del artículo."

El señor PÉREZ CiSNEROS (CUBA) dijo que, en su concepto, el artículo del proyecto era perfectamente claro y que su delegación lo votaría tal como allí aparecía.

El señor FERNÁNDEZ DEL CASTILLO (MÉXICO) manifestó que, en su opinión, el artículo era claro y completo, ya que en la primera parte establecía la existencia de los deberes y, 
en la segunda, la garantía procesal de los mismos. Además (dijo), protegía todos los derechos, tanto los derechos humanos en general como los derechos civiles.

El señor MENDOZA (GUATEMALA) sugirió que se modificara el título del artículo [588] y que, en lugar de "Derecho de Justicia", se dijera "Derecho de Amparo", tal como se llamaba a este derecho en muchas constituciones del mundo.

El señor PÉREZ Cisneros (CUBA) se refirió a las opiniones del señor Delegado de Guatemala, y dijo que el derecho de amparo era reconocido por algunas legislaciones, pero no por todas; y que, por tal razón, era más práctico llamar "Derecho de Justicia" al que se venía discutiendo.

El señor BACIGALUPI (URUGUAY) pidió que se aprobara el artículo del proyecto; y el señor MENDOZA (GUATEMALA) retiró la enmienda que había propuesto.

El señor HALDERMAN (ESTADOS Unidos DE AMÉRICA) repitió que, en su opinión, había una diferencia entre "derechos del hombre" y "derechos reconocidos por las leyes": por ejemplo, había países que no reconocían el derecho al voto, que es uno de los derechos del hombre. Por lo tanto, era necesario distinguir entre los derechos humanos generales y los derechos especiales reconocidos por la ley.

Contestando a estas observaciones del señor Delegado de los Estados Unidos, el señor PRESIDENTE aclaró que cuando en la lengua castellana se hablaba de "derechos", se refería siempre a todos los derechos de la persona; que si en la lengua inglesa ocurría otra cosa, la Comisión de Estilo se encargaría de subsanar la dificultad.

Puesto en votación el artículo, fué aprobado.

\section{[APROBACIÓN DEL DERECHO DE NACIONALIDAD (ART. XIX)]}

La Secretaría dió lectura al Artículo XIX, que se refería al "Derecho de Nacionalidad".

El señor MENDOZa (GUATEMALA) observó que este artículo podría entrar en conflicto con la ley interna de algunos países; como era el caso de Guatemala, donde la nacionalidad no podía adquirirse por simple gusto o capricho, por un nacional residente en el territorio guatemalteco que en un momento dado deseara cambiar de nacionalidad.

El señor FERnándeZ DEL CaSTILLO (MéXICO) dijo que no veía contradicción posible entre el artículo y algunas legislaciones nacionales que establecían condiciones especiales para adquirir y cambiar de nacionalidad. Agregó que, por otra parte, cualquier dificultad quedaría solucionada con la aplicación del Artículo XXVIII del proyecto.

El señor CHAMORRO (NICARAGUA) manifestó que el caso planteado por el señor Delegado de Guatemala era de gran interés, pues según la doctrina internacional nadie podía ser extranjero en su propio territorio. Añadió que, en su opinión, cualquier dificultad en este sentido sería claramente resuelta por la doctrina jurídica internacional, y que no veía oposición entre el artículo que se discutía y el caso particular presentado por Guatemala.

Puesto en votación el artículo, fué aprobado.

\section{[APROBACIÓN DEL DERECHO DE SUFRAGIO Y PARTICIPACIÓN EN EL GOBIERNO (ART. XX)]}

Leído por el Secretario el Artículo XX, sobre "Derecho de Sufragio y de Participación en el Gobierno", el señor PRESIDENTE lo sometió a discusión.

El señor ESCObar SERRANO (EL SALVADOR) opinó que debía suprimirse del artículo la parte que decía "voto secreto", ya que, como estaba, podía entrar en conflicto con legislaciones nacionales (como la de su país) en donde no existía el voto secreto. 
[589] El señor Chamorro (Nicaragua) manifestó que, en su concepto, debía volver a decirse en este articulo, "Toda persona, sin distinción de raza, religión o sexo" pues había países, como el suyo, que establecían discriminación en contra de la mujer, a pesar de lo estatuido en la Carta Universal de los Derechos del Hombre promulgada por las Naciones Unidas.

El señor BACIGALUPI (URUGUAY) se opuso a la supresión propuesta por el señor Delegado de El Salvador, fundándose en la consideración de que el secreto era fundamental en el voto. En cuanto a la propuesta de Nicaragua, manifestó que la estimaba innecesaria, y que los deseos expresados por el señor Chamorro quedarían satisfechos, agregando al final del proyecto un artículo en el cual se estipulase que todos los artículos se interpretarían de acuerdo con el espíritu general que informaba la Declaración.

El señor PRESIDENTE observó que el artículo propuesto por el señor Delegado del Uruguay era superfluo, ya que existía un principio universal de hermenéutica jurídica según el cual, en toda codificación o cuerpo de disposiciones jurídicas, unos artículos debían interpretarse en armonía con los otros y de acuerdo con el espíritu general.

El señor Fernández Del Castillo (MéXiCO) pidió que el señor Delegado de Cuba, Relator del Grupo de Trabajo, expusiera cuál había sido el criterio de éste sobre el particular.

El Relator del Grupo de Trabajo, señor Pérez Cisneros (CUBA), se manifestó de acuerdo con lo expresado por el señor Presidente sobre el hecho de que la interpretación del artículo en discusión debía hacerse en función del contenido de todos los demás. En cuanto a la propuesta del señor Delegado de El Salvador, dijo que su delegación consideraba esencial que el voto fuera secreto y que no daría su asentimiento a ninguna modificación sobre la materia.

El señor GÁLVEZ (HONDURAS) se refirió a lo dicho por el señor Delegado de Nicaragua respecto a la oposición entre el proyecto y una ley nacional que excluyese del voto a la mujer.

El señor CHAMORRO (NICARAGUA) aclaró que, al hablar de "discriminación”, se refería a personas de cualquier sexo y que, por lo demás, no insistía sobre tal punto y consideraba satisfactorias las razones expuestas por el señor Presidente.

El señor PRESIDENTE sugirió que se votara el artículo tal como estaba en el proyecto y que, para resolver las dudas y problemas planteados por las Delegaciones de El Salvador, Nicaragua, Uruguay y Cuba, se pusiera al final el artículo sobre interpretación general del proyecto, ya mencionado. Con este fin, solicitó a los delegados respectivos que tuvieran listo su texto en el momento oportuno.

El señor FERNÁNDEZ DEL CASTILlO (MÉXICO) aclaró al señor Delegado de Cuba que el proyecto de Declaración de derechos de las Naciones Unidas no contenía la cláusula referente a interpretación de unos artículos por otros. Agregó que, en su opinión, un artículo de tal naturaleza no era congruente con la Declaración, y estaría mejor en un convenio o tratado.

El señor PRESIDENTE intervino en la discusión para observar que, como se trataba de una Declaración de carácter moral, el conflicto sería de conciencia. Se [590] manifestó de acuerdo con el señor Delegado de El Salvador en el sentido de que se suprimiera del Artículo XX lo referente a "voto secreto", pues en esa forma podría llegarse más rápidamente a un acuerdo.

El señor GARCÍA ORTIZ (ECUADOR) propuso que se agregara al artículo, en calidad de inciso, el derecho de organizar partidos políticos, tal como constaba en el proyecto del Comité Jurídico Interamericano. ${ }^{1}$ La democracia (dijo) era esencialmente un régimen de partidos

Documento publicado durante la Conferencia con la clasificación CB-7, transcrito en la pág. 449 y siguientes. 
y, por eso, en una disposición que garantizara el derecho al voto y a la participación en el gobierno, debía ampararse también el de organizar partidos políticos.

El señor Fernández del Castillo (MéXICO) manifestó que el Artículo XXII del proyecto consagraba tal derecho.

El señor PRESIDENTE hizo leer por la Secretaría el mencionado artículo, hecho lo cual, el señor GARCía ORTIZ (ECUADOR) observó que en este momento de crisis de las instituciones políticas tradicionales era urgente hacer una consagración especial del derecho de formar partidos políticos; que era cierto que el Artículo XXII se refería, aunque de manera muy general, al derecho de asociación dentro del cual cabía el derecho de organizar partidos, pero que sería mejor, para darle mayor fuerza a este último derecho, incluirlo en el artículo que concedía el derecho a participación en el gobierno. Agregó que la democracia era un régimen que presuponía por lo menos dos partidos y que en ello radicaba su principal diferencia en relación con el totalitarismo. Por las razones anteriores, insistió en que el inciso propuesto por él hiciera parte del artículo en discusión.

El señor PÉrez Cisneros (CUBA) observó que el derecho a formar partidos había sido considerado por la Comisión Primera. Agregó que estaba de acuerdo con el señor Delegado de México en estimar que el derecho de asociación incluía también el de formar partidos políticos.

El señor PRESIDENTE sometió a votación la propuesta de El Salvador sobre supresión de las palabras "voto secreto". Fué negada por seis votos a favor, y 12 en contra.

En seguida, el señor PRESIDENTE puso en votación la adición propuesta por el señor Delegado del Ecuador, e igualmente fué negada.

El Artículo XX del proyecto, en consecuencia, fué aprobado sin modificaciones.

\section{[APROBACIÓN DEL DEREGHO DE REUNIÓN (ART. XXI)]}

A continuación, la Secretaría dió lectura al Artículo XXI, sobre el "Derecho de Reunión".

El señor Halderman (ESTADOS UNIDOS DE AMÉRICA) sugirió la posibilidad de suprimir los adjetivos "pública” y "transitoria” de la cláusula que decía, "en manifestación pública o en asamblea transitoria"; ya que dichos adjetivos, en lugar de aclarar, hacían confusa la significación del artículo, al menos en su traducción inglesa.

El señor Pérez GiSneros (GUBA) dijo que el Grupo de Trabajo había estudiado la conveniencia de separar los derechos de reunión y asociación, coincidiendo en que era necesario hacerlo, ya que la reunión tenía el carácter de transitoria y la asociación era permanente. El derecho de reunirse pacíficamente puede referirse a la [591] reunión en un solo lugar, o en una forma móvil. En el texto español (afirmó), las palabras "reunión” y "asociación" no ofrecían ninguna duda en cuanto a su significado.

El señor PRESIDENTE se manifestó de acuerdo con el señor Delegado de Cuba y observó que, según su interpretación de las palabras del señor Delegado de los Estados Unidos, lo que éste quería decir, era que el concepto de "asamblea" llevaba involucrado el concepto de transitoriedad y que en ese sentido el adjetivo sobraba.

El señor BACIGALUPI (URUGUAY) manifestó que la expresión "transitoria", en el sentido en que la había empleado el señor Delegado de Cuba, se refería a "tránsito"; pero que era necesario aclarar la duda planteada por el señor Delegado de los Estados Unidos sobre si las asambleas podían ser permanentes o transitorias.

El señor CHAMORRO (NiCARAGUA) dijo que en su opinión el adjetivo "transitoria" era superfluo, puesto que era de la esencia de las reuniones el ser transitorias, como lo era de las asociaciones el ser permanentes. 
El señor GÁLVEz (HONDURAS) propuso que a las palabras "derecho de reunirse" del artículo original, que constituían una expresión muy general, se agregara la expresión, "para tratar de sus intereses legítimos comunes de cualquier índole.”

El señor PÉREZ Cisneros (CUBA) manifestó que era muy poco feliz la interpretación que se había dado al término "transitoria" del proyecto. Aclaró que no había estado en el ánimo del Grupo de Trabajo establecer un sinónimo de movilidad, sino referirse a agrupaciones transitorias en cuanto al tiempo, para diferenciar el derecho de asociación del derecho de reunión. Así, por ejemplo, en las Naciones Unidas había Asamblea General, y en una compañía de tipo financiero había asamblea general o asamblea especial. Con esto, sólo se quería precisar que se trataba de una asamblea de tipo especial. Debido a circunstancias particulares de la vida de un país o comunidad, "asamblea transitoria" correspondería solamente al derecho de reunión y no al de asociación, que sería tratado después.

El señor FERnÁNDEZ DEL CASTILLO (MÉXICO) observó que el adjetivo "transitoria” podía suprimirse, sin que el texto perdiera claridad ni precisión.

El señor PRESIDENTE, para aclarar el debate, recordó a los señores delegados que estaban en discusión dos propuestas: primera, la del señor Delegado de los Estados Unidos para que se suprimiese el adjetivo "transitoria"; y segunda, la del señor Delegado de Honduras para que se añadiese "para tratar de sus intereses legítimos comunes de cualquier índole."

El señor CHAMORRO (NicARAGUA) dijo que, en su opinión, la enmienda propuesta por el señor Delegado de Honduras podía hacer nugatorio el derecho de reunión, puesto que un gobierno dado podía perfectamente considerar que los propósitos que animaban a un grupo de personas a reunirse, no eran legítimos.

El señor GÁLVEZ (HONDURAS) manifestó que, para abreviar y facilitar la discusión, no insistía en la adición propuesta por su delegación.

El señor ECHEVERRI (COLOMBIA) dijo lo siguiente:

"Quiero hacer notar que en algunas constituciones, como por ejemplo en la colombiana, están prohibidas las reuniones públicas de carácter permanente y que, al suprimir la palabra 'transitoria', el artículo quedaría en pugna con los principios [592] constitucionales de ciertos países. La palabra 'transitoria' es clara, y no limita el derecho de reunión."

En consecuencia, era de opinión que dichas palabras no debían suprimirse del texto.

El señor HaLderman (Estados Unidos DE AMÉRICA) expresó que, en su concepto, el Artículo XXVIII tomaba en consideración todas las oposiciones posibles entre el Proyecto de Declaración y las leyes nacionales. Agregó:

"Desearía que se comprendiese que el espíritu de mi proposición es el de que el derecho de asociación quede garantizado sin limitación."

El señor BALAGUeR (REPÚblica Dominicana) preguntó si el texto del Artículo XXI excluía el derecho de toda persona a reunirse con otras en manifestación secreta para fines legítimos.

El Relator del Grupo de Trabajo, señor Pérez Cisneros (CUBA), dijo que no se consideraba autorizado para responder a la pregunta del señor Delegado de la República Dominicana.

El señor PRESIDENTE aclaró el significado de la palabra "manifestación", en el sentido de que ésta no podía ser sino pública. Se refirió al caso de las logias masónicas, que verificaban reuniones secretas con móviles que no estaban en pugna con la ley ni los intereses sociales, pero que en ningún caso tenían el carácter de manifestaciones.

El señor PRESIDENTE, considerando que había suficiente ilustración sobre el tema debatido, puso en votación la enmienda de los Estados Unidos para que se suprimiesen del texto los adjetivos "pública" y "transitoria". 
A favor de la supresión hubo seis votos; en contra 12 votos. El artículo original del proyecto quedó aprobado.

\section{[APROBAGIÓN SIN OBSERVAGIONES DEL DEREGHO DE ASOGIAGIÓN (ART. XXII)]}

La Secretaría dió lectura al Artículo XXII, que se refería al "Derecho de Asociación". Este artículo fué aprobado sin discusión, por unanimidad.

\section{[APROBACIÓN DEL DERECHO DE PROPIEDAD (ART. XXIII)]}

El señor PRESIDENTE abrió la discusión sobre el Artículo XXIII, referente al "Derecho de Propiedad".

El señor HALDERMAN (ESTADOS Unidos DE AMÉRICA) propuso que se dijera, "Toda persona tiene derecho a adquirir la propiedad..."; pues en otra forma habría lugar a confusiones, como en el caso de las personas que no podían trabajar y que, sin embargo, se verían autorizadas para reclamar el derecho de propiedad.

El señor FERnÁNDEZ DEL CASTILLO (MÉXICO) apoyó la enmienda del señor Delegado de los Estados Unidos.

El señor CHAMORRO (NICARAGUA) dijo que, en su opinión, la modificación propuesta por el señor Delegado de los Estados Unidos restringiría el derecho de propiedad. Le parecía que tal como estaba redactado el artículo original del proyecto, la propiedad quedaba garantizada en forma más explícita.

El señor SALINAS LÓPEZ (BOLIVIA) manifestó que, en su concepto, el problema tenía dos aspectos: primero, el derecho de amparar lo adquirido; y, segundo, el derecho de propiedad en sí mismo, con sus atributos de goce, conservación, etcétera. Anunció que no consideraba conveniente la enmienda propuesta por el señor Delegado de los Estados Unidos.

El señor ECHEVERRI (COLOMBIA) estuvo de acuerdo con la tesis expuesta por [593] el señor Delegado de Bolivia, y manifestó que el texto del artículo contemplaba todos los casos referentes a la protección de la propiedad.

El señor DE OlIVEIRA (BRASIL) se mostró de acuerdo con los señores Delegados de Colombia y de Bolivia. Manifestó que si se garantizaba el derecho de adquirir la propiedad, automáticamente se garantizaba el derecho de conservarla. Dijo que, en su opinión, el texto era de un alcance más restringido, y anunció su apoyo a la propuesta de los Estados Unidos.

El señor PRESIDENTE observó que si se ponía "adquirir", habría que agregar también el concepto de "disponer de" la propiedad.

El señor FERNÁNDEZ DEL CASTILLO (MÉXICO) apoyó la sugestión del señor Presidente en el sentido de que se incluyeran los dos términos, "adquirir" y "disponer de" la propiedad. Agregó que sería conveniente que todas estas expresiones estuvieran precedidas por la frase "a ser protegida".

El señor BaLaguer (República Dominicana) observó que en el proyecto del Comité Jurídico de Río de Janeiro se establecía el derecho "a un mínimo de propiedad”, y sugirió que en el artículo en discusión se dijera, "a la propiedad privada suficiente para llevar una vida decorosa..."; o, también, "Toda persona tiene derecho, por lo menos, a un mínimo de propiedad..."

El señor Cisneros (PERÚ) manifestó que había meditado el sentido de la reforma propuesta por el señor Delegado de los Estados Unidos y que estaba de acuerdo en que se agregara la expresión "adquirir"; pues en otra forma podría entenderse que había personas que tenían derecho a la propiedad sin adquirirla. 
El señor Chamorro (NiCARagua) conceptuó que la Comisión estaba perdiendo el sentido del documento que se discutía.

"Lo que estamos buscando aquí", agregó, "es declarar que la propiedad debe ser defendida, para colocarnos en contraposición a ideologías o sistemas políticos que niegan el amparo a la propiedad privada."

El señor PRESIDENTE sometió a votación la enmienda propuesta por el señor Delegado de los Estados Unidos. Fué negada por cinco votos contra 13. En consecuencia, se consideró aprobado el texto original del proyecto.

El señor PRESIDENTE citó para el día siguiente, a las 9:50, y levantó la sesión.

\section{ACTA RESUMIDA DE LA SEPTIMA SESION DE LA GOMISION SEXTA ${ }^{1}$}

FECHA: sábado, 24 de abril de 1948

HORA: 10:20-12:10

RECINTO: Cámara de Representantes, Capitolio Nacional

PRESIDENTE: señor Carlos Sánchez y Sánchez (República Dominicana)

VICEPRESIDENTE: señor Marco Antonio Batres (Honduras)

RELATOR: señor Luis López de Mesa (Colombia)

SECRETARIO: señor Gabriel Arango Restrepo

[594] PRESENTES: señores Virgilio R. Gálvez (Honduras); José Luis Mendoza (Guatemala); Ricardo Latcham (Chile); Héctor A. Grauert (Uruguay); Guy Pérez Cisneros (Cuba); Paul C. Daniels (Estados Unidos de América); Arturo Despradel (República Dominicana); Alberto Salinas López (Bolivia); Luis Fernán Cisneros (Perú); Diego Manuel Chamorro (Nicaragua); Germán Fernández del Castillo (México); Eduardo A. Chiari (Panamá); Héctor Escobar Serrano (El Salvador); Humberto García Ortiz (Ecuador); Antonio Camillo de Oliveira (Brasil); Leonidas Vásquez (Argentina); y Silvio Villegas (Colombia)

\section{[RECHAZO DE PROPUESTA HAITIANA DE RECONSIDERAR ARTÍCULOS YA APROBADOS]}

El señor PRESIDENTE abrió la sesión.

El señor PÉrez Gisneros (CUBA) presentó a la Secretaría un pliego con enmiendas propuestas por la Delegación de Haití al proyecto del Comité Jurídico Interamericano sobre derechos y deberes del hombre. ${ }^{1}$ Dicho pliego, en vista de que se relacionaba con artículos ya aprobados definitivamente a base del informe del Grupo de Trabajo ${ }^{2}$ sobre la misma materia, no fué puesto en consideración de la Comisión.

1 Documento publicado durante la Conferencia con la clasificación CB-376/C.VI-24. Por dificultades insalvables, no hubo servicios taquigráficos para esta sesión.

1 Documento publicado durante la Conferencia con la clasificación CB-7, transcrito en la pág. 449 y siguientes.

2 Documento publicado durante la Conferencia con la clasificación CB-310/CIN-41, transcrito en la pág. 474 y siguientes. 
[APROBACIÓN SIN MODIFICACIONES DE LOS DERECHOS DE PETICIÓN Y DE PROTECGIÓN CONTRA LA DETENCIÓN (ARTS. XXIV-XXV)]

Siguiendo el orden del día, el señor PRESIDENTE sometió a consideración el Artículo XXIV del Proyecto de Declaración Americana de los Derechos y Deberes Esenciales del Hombre, contenido en el susodicho informe. El Artículo XXIV decía:

\section{Derecho de Petición}

Toda persona tiene derecho de presentar peticiones respetuosas a cualquier autoridad competente, ya sea por motivo de interés general, ya de interés particular, y el de obtener pronta resolución.

Sometido a votación el anterior artículo, fué aprobado sin observaciones.

El señor PRESIDENTE puso en consideración el Artículo XXV, que decía:

\section{Derecho de Protección contra la Detención}

Nadie puede ser privado de su libertad, sino en los casos y según las formas establecidas por leyes preexistentes.

Nadie puede ser detenido por incumplimiento de obligaciones de carácter netamente civil.

Todo individuo que haya sido privado de su libertad tiene derecho a que el juez verifique sin demora la legalidad de la medida y a ser juzgado sin dilación injustificada, o, en contrario, a ser puesto en libertad. Tiene derecho, también, a un tratamiento humano durante la detención.

Sometido a votación, el Artículo XXV fué aprobado sin observaciones.

\section{[APROBACIÓN DEL DERECHO A PROGESO REGULAR (ART. XXVI)]}

El señor PRESIDENTE puso en consideración el Artículo XXVI, el cual fué aprobado con la modificación propuesta por el Brasil, consistente en invertir el orden de sus dos partes. Quedó, pues, así:

\section{Derecho a Proceso Regular}

Toda persona acusada de delito tiene derecho a ser oída en forma imparcial y pública, a ser juzgada por tribunales anteriormente establecidos de acuerdo con leyes preexistentes y a que no se le impongan penas crueles, infamantes o inusitadas.

Se presume que todo acusado es inocente, hasta que se pruebe su culpabilidad.

\section{[APROBAGIÓN DEL DERECHO DE ASILO (ART. XXVII)]}

[595] El señor PRESIDENTE sometió a consideración el Artículo XXVII, redactado así:

\section{Derecho de Asilo}

Toda persona tiene el derecho de buscar y recibir asilo en territorio extranjero, en caso de persecución que no sea motivada por delitos de derecho común y de acuerdo con los convenios internacionales.

El señor DANiEls (Estados Unidos De AMÉRICA) preguntó si se estimaba que este derecho estaba sujeto a la legislación interna de cada país; y si se refería al asilo diplomático 
o tenía un sentido mucho más amplio, que pudiera abarcar, por ejemplo, a los refugiados europeos, caso en el cual habría que tener en cuenta las normas de inmigración de cada país.

El señor SALINAS LÓPEZ (BOLIVIA) aclaró que en el Grupo de Trabajo, para atender a las sugerencias hechas por la Delegación de los Estados Unidos, se agregó al final del artículo la frase, "de acuerdo con los convenios internacionales".

El señor FERnándeZ DEL Castillo (MéXiCO) observó que la duda del señor Delegado de los Estados Unidos quedaba aclarada, además, en el artículo siguiente. Lo secundó en esta opinión el señor SALINAS LóPEZ (BOLIVIA).

El señor Despradel (República Dominicana), con el apoyo de los señores CHAmorro (Nicaragua), Cisneros (Perú) y Salinas López (Bolivia), manifestó que, no obstante la observación del señor Delegado de México, consideraba conveniente que en el artículo apareciera la reserva que pudiesen hacer los Estados para no recibir refugiados indeseables; por lo cual proponía que la parte final del artículo se adicionara así:

...de acuerdo con la legislación de cada país y con los convenios internacionales.

El señor MENDOZa (GUATEMALA) objetó la adición propuesta porque, en su concepto, el artículo no sólo se refería al refugio en territorio extranjero sino también al asilo en las legaciones, caso en el cual no podía aplicarse la legislación nacional.

A esto contestó el señor Despradel (REPÚblica Dominicana) que el artículo contemplaba exclusivamente el caso de refugio en territorio extranjero, y que el caso de asilo en legaciones se seguiría rigiendo exclusivamente por las estipulaciones de los tratados internacionales.

El señor PRESIDENTE sometió a votación el Artículo XXVII, con la adición propuesta por el señor Delegado de la República Dominicana, y así fué aprobado. En consecuencia, su texto quedó así:

\section{Derecho de Asilo}

Toda persona tiene el derecho de buscar y recibir asilo en territorio extranjero, en caso de persecución que no sea motivada por delitos de derecho común y de acuerdo con la legislación de cada país y con los convenios internacionales.

\section{[DISCUSIÓN Y APROBACIÓN DE LA PROPUESTA DE AGREGAR EL “DERECHO DE RESISTENCIA”]}

El señor Pérez Gisneros (CUBA) pidió que, antes de entrar a considerar los artículos correspondientes a los deberes del hombre, se agregara el artículo sobre "Derecho de Resistencia" a que se refería el punto 9 del informe del Grupo de Trabajo. Dijo que creía que todas las delegaciones aceptarían este artículo, relativo a un derecho consagrado ya por muchas legislaciones (inclusive las de Cuba y Francia), del cual se había tratado en Ginebra y que iba a ser considerado por las [596] Naciones Unidas. Insistió sobre el hecho histórico de que el derecho a la resistencia contra la violación de los derechos esenciales de la persona humana, legitimado por todos los libertadores americanos, había dado nacimiento a todas las naciones representadas en la Novena Conferencia.

El señor DeSPRADEL (REPÚblica DOMINICANA) apoyó la proposición cubana, en el entendimiento de que este derecho se refería exclusivamente a los casos de denegación de justicia, o de retardo notorio en la administración de la misma, y que su ejercicio debía efectuarse siempre por las vías legales ordinarias. 
Intervinieron en seguida varios delegados para exponer sus puntos de vista en favor o en contra de la inclusión de este artículo. Algunos de los que apoyaron dicha inclusión, pidieron que se modificara el texto del artículo. En sentido favorable a la proposición de Cuba, hablaron los señores: MENDOZA (GUATEMALA), Grauert (URUGUAY), CHAMORRO (NicARAGUA) y GARCía ORTIZ (ECUADOR); para oponerse a ella hicieron uso de la palabra los señores Daniels (Estados de América), Fernández del Castillo (MÉXico), De OliVeira (Brasil), Gisneros (Perú), VÁsquez (Argentina) y SAlinas López (Bolivia).

A petición del señor Delegado de México, el señor PRESIDENTE sometió a votación el punto concreto de sí la Comisión deseaba que se incluyera el derecho de resistencia, dejando para la sesión vespertina, en el caso de que dicho punto fuera aprobado, la redacción definitiva del texto.

En votación nominal, solicitada por el señor Delegado de Cuba, fué aprobada la inclusión del nombrado derecho por nueve votos afirmativos (los de Colombia, Cuba, Ecuador, El Salvador, Guatemala, Honduras, Nicaragua, República Dominicana y Uruguay), contra ocho negativos (los de Argentina, Bolivia, Brasil, Chile, Estados Unidos, México, Panamá y Perú).

Para que se acordara, de conformidad con las distintas opiniones emitidas, un texto que pudiera considerar la Comisión en la sesión de la tarde, el señor PRESIDENTE designó a los señores Pérez Cisneros (Cuba), García Ortiz (Ecuador), Mendoza (Guatemala), Chamorro (Nicaragua), Despradel (República Dominicana) y Grauert (Uruguay).

[APROBACIÓN DEL ARTÍ́CULO SOBRE EL ALCANCE DE LOS DEREGHOS DEL HOMBRE (ART. XXIX, EX XXVIII)]

El señor PRESIDENTE puso en consideración el Artículo XXVIII del proyecto, con la nueva numeración (XXIX).

El señor CHAMORRO (NICARAGUA) sugirió una modificación; pero, debido a una aclaración hecha por el señor FERNÁNDEZ DEL CASTILLO (MÉXICO) la retiró.

El Artículo XXIX fué aprobado, en la siguiente forma:

\section{Alcance de los Derechos del Hombre}

Los derechos del hombre están limitados por los derechos de los demás, por la seguridad de todos y por las justas exigencias del bienestar general y del desenvolvimiento democrático.

\section{[APROBACIÓN DEL PROYEGTO DE RESOLUCIÓN SOBRE UNA CORTE INTERAMERICANA]}

El señor DE OLIVEIRA (BRASIL) pidió que, antes de entrar en el estudio del capítulo de los deberes, se sometiese a votación el Proyecto de Resolución sobre la Creación de una Corte Interamericana Destinada a Garantizar los Derechos del Hombre, presentada por su delegación. ${ }^{1}$

[597] El señor PRESIDENTE observó que en relación con este proyecto había una enmienda propuesta por la Delegación del Uruguay. ${ }^{1}$

1 Documento publicado durante la Conferencia con la clasificación CB-125/C.VI-6, transcrito en la pág. 464 .

1 Véase el punto 3 del documento publicado durante la Conferencia con la clasificación CB112/C.VI-Sub A-3, transcrito en la pág. 463. 
Después de algunas explicaciones dadas por el señor DE OLIVEIRA (BRASIL), el señor GRAUERT (URUGUAY) señaló la diferencia entre los dos proyectos y terminó manifestando que retiraba el de su delegación y adhería al del Brasil.

Los señores Mendoza (GuATemala), Daniels (Estados Unidos de América) y DesPRADEL (REPÚBLICA DOMINICANA) solicitaron algunas aclaraciones sobre el alcance del proyecto que se discutía, aclaraciones que les fueron hechas por el señor PRESIDENTE y por el señor DE OLIVEIRA (BRASIL). El señor DESPRADEL (REPUBLICA DOMINICANA) propuso, además, una modificación que, sometida a votación por el señor PRESIDENTE, fué negada por la Comisión.

El señor PRESIDENTE pidió entonces que se votara el proyecto de resolución de la Delegación del Brasil, con la modificación propuesta por el señor de Oliveira.

La Comisión aprobó así dicha resolución, cuyo texto, en consecuencia, es el siguiente:

La Novena Conferencia Internacional Americana,

CONSIDERANDO:

Que los derechos del hombre, internacionalmente reconocidos, deben tener garantía adecuada;

Que esa garantía debe estar sancionada por un órgano jurídico, puesto que no hay derecho propiamente garantizado sin la protección de un tribunal; y

Que, cuando se trata de derechos internacionalmente reconocidos, la protección jurídica, para ser eficaz, debe emanar de un órgano internacional,

RECOMIENDA:

A la Comisión Jurídica Interamericana [Al Comité Jurídico Interamericano], que elabore un proyecto de Estatuto para la creación y el funcionamiento de una Corte Interamericana destinada a garantizar los derechos del hombre. Este proyecto, después de ser sometido al examen y a las observaciones de los Gobiernos de todos los Estados Americanos, deberá ser remitido a la Décima Conferencia Internacional Americana [Décima Conferencia Interamericana] para que ésta lo estudie, si considera que ha llegado el momento para una decisión sobre la materia.

[PROPUESTA DOMINICANA DE SEÑALAR QUE EL LISTADO DE DEREGHOS NO ES TAXATIVO]

El señor DesPradel (RePública DOMINICANa) propuso que se incluyera un último artículo, que dijera que la enumeración de los derechos hecha en el Capítulo Primero no era limitativa, a lo cual se opuso el señor FERnÁndez del Castillo (MéXico).

Sometida a votación la inclusión del nuevo artículo propuesto por el señor Delegado de la República Dominicana, fué negada por nueve votos contra ocho.

[APROBAGIÓN DE LA PROPUESTA ESTADOUNIDENSE DE RECONSIDERAR UN ARTÍCULO YA APROBADO]

El señor DANiels (Estados Unidos DE AMÉRICA) manifestó que, en relación con el Artículo XI, "Derecho a la Salud y al Bienestar", su delegación tendría que hacer una salvedad, a menos que la Comisión accediera a reconsiderar la aprobación impartida a tal artículo y a estudiar un texto substitutivo que propondría dicha delegación.

El señor PRESIDENTE sometió a votación la solicitud de reconsideración del Artículo XI hecha por el señor Delegado de los Estados Unidos, la cual fué aprobada.

El señor PRESIDENTE pidió al señor Daniels que presentara por escrito el texto [598] que proponía para el citado Artículo XI, con el fin de someterlo al estudio de la Comisión en la sesión próxima.

Acto seguido, levantó la sesión. 


\section{ACTA RESUMIDA DE LA OCTAVA SESION DE LA COMISION SEXTA ${ }^{1}$}

FECHA: sábado, 24 de abril de 1948

HORA: 15:30-19:20

REcinto: Cámara de Representantes, Capitolio Nacional

PRESIDENTE: señor Carlos Sánchez y Sánchez (República Dominicana)

VICEPRESIDENTE: señor Marco Antonio Batres (Honduras)

RELATOR: señor Luis López de Mesa (Colombia)

SECRETARIO: señor Gabriel Arango Restrepo

Presentes: señores Virgilio R. Gálvez (Honduras); José Luis Mendoza (Guatemala); Sergio A. Labarca (Chile); Héctor A. Grauert (Uruguay); Guy Pérez Cisneros (Cuba); Paul C. Daniels (Estados Unidos de América); Arturo Despradel (República Dominicana); Alberto Salinas López (Bolivia); Luis Fernán Cisneros (Perú); Diego Manuel Chamorro (Nicaragua); Germán Fernández del Castillo (México); Eduardo A. Chiari (Panamá); Héctor Escobar Serrano (El Salvador); Humberto García Ortiz (Ecuador); Antonio Camillo de Oliveira (Brasil); Enrique V. Corominas (Argentina); y Carlos Holguín Holguín (Colombia)

[MODIFICACIÓN DEL DERECHO A LA PRESERVACIÓN DE LA SALUD Y AL BIENESTAR (ART. XI)]

El señor PRESIDENTE abrió la sesión y, acto seguido, sometió a discusión el nuevo texto propuesto por la Delegación de los Estados Unidos para el Artículo XI del Proyecto de Declaración Americana de los Derechos y Deberes Esenciales del Hombre. ${ }^{2}$ El texto propuesto decía así:

Toda persona tiene derecho a la preservación de su salud, de conformidad con el nivel higiénico y de asistencia médica existente en su comunidad.

El señor Mendoza (Guatemala) manifestó que, al discutirse el Artículo XVI, sobre "Derecho a la Seguridad Social", no había hecho objeción alguna, porque los miembros del Grupo de Trabajo le habían explicado que la protección a los huérfanos y a las viudas quedaba comprendida en el Artículo XI. Si se limitaba el texto del mismo de la manera propuesta, no podía caber allí dicha protección y, por ello, se vería obligado a no prestarle su apoyo.

El señor CisNeros (PERÚ) dijo que, en su concepto, en el texto primitivo estaban contenidos los mismos principios que inspiraban la enmienda de los Estados Unidos.

El señor PRESIDENTE manifestó que quizás el motivo que había movido al [599] señor Delegado de los Estados Unidos era el problema de la legislación federal en su país. El señor DANIELS (ESTADOS UNIDOS DE AMÉRICA) respondió que, en parte, era ése el motivo; pero, además, encontraba un poco exagerado el texto primitivo al hablar de "nivel más alto”. Agregó que, por otro concepto, no estimaba conveniente que se especificara a quién correspondía prestar esa protección: si al Estado, al municipio, a la sociedad, a la medicina privada, etcétera.

El señor FERnÁNDEZ DEL CASTILLO (MÉXICO) aclaró que la expresión jurídica "Estado" comprendía la totalidad del gobierno, sin discriminar entre administración nacional,

1 Documento publicado durante la Conferencia con la clasificación CB-397/C.VI-28.

Por dificultades insalvables, no hubo servicios taquigráficos para esta sesión.

2 Véase el documento publicado durante la Conferencia con la clasificación CB-310/CIN-41 transcrito en la pág. 474 y siguientes. 
estatal, municipal, etcétera. Se manifestó partidario de la supresión de las palabras "más alto", en el texto original.

El señor GRAUERT (URUGUAY) apoyó esta última sugestión del señor Delegado de México. Propuso, además, que se cambiara la frase "recursos del Estado" por "recursos públicos", con el fin de salvar las dificultades expuestas por el señor Delegado de los Estados Unidos y de facilitar la aprobación del texto primitivo, que era más amplio que el que acababa de proponerse.

El señor DANIELS (ESTADOS UNIDOS DE AMÉRICA) solicitó que se dejara constancia en actas de que este artículo en ningún caso implicaba perjuicio alguno para la medicina privada.

El señor PRESIDENTE sometió a votación el texto primitivo, con las modificaciones propuestas por los señores Delegados de Uruguay y México, aceptadas por el de los Estados Unidos, y así fué aprobado. En consecuencia, el Artículo XI quedó así:

\section{Derecho a la Preservación de la Salud y al Bienestar}

Toda persona tiene derecho a que su salud sea preservada por medidas sanitarias y sociales, relativas a la alimentación, al vestido, la vivienda y los cuidados médicos, correspondientes al nivel que permitan los recursos públicos y los de la comunidad.

[RECHAZO DE LA PROPUESTA DE REDACGIÓN DEL DERECHO DE RESISTENCIA Y APLAZAMIENTO DE SU DISCUSIÓN]

El señor Mendoza (Guatemala), Relator del Grupo de Trabajo que estudió lo relativo al derecho de resistencia, leyó la fórmula adoptada para el Artículo XVIII por dicho Grupo, cuyo texto era:

\section{Derecho de Fusticia y de Resistencia}

Toda persona puede ocurrir a los tribunales para hacer que se respeten sus derechos. Asimismo, debe disponer de un procedimiento sencillo y breve por el cual la justicia lo ampare contra actos de la autoridad que violen, en su perjuicio, alguno de los derechos fundamentales consagrados constitucionalmente.

Se reconoce el derecho de resistencia adecuada, en los casos de denegación de justicia o retardo evidente de la misma.

El señor Relator del Grupo explicó que los miembros del mismo habían estado de acuerdo en que el derecho de resistencia estaba íntimamente relacionado con el de justicia, y por ello habían resuelto colocar aquél a continuación de éste, como un párrafo adicional. El derecho de resistencia, según la opinión del Grupo de Trabajo, sólo podría ser efectivo después de agotar los procedimientos de la justicia, en los casos en que hubiera una manifiesta denegación o evidente retardo de ella; [600] pues este derecho tenía por objeto principal la protección de los derechos humanos contra arbitrariedades de los propios tribunales encargados de su protección.

Sometido a consideración ese texto por el señor PRESIDENTE, el señor Cisneros (PERÚ) dijo que insistía en su voto contrario, emitido en la sesión anterior, no obstante el espíritu cívico y patriótico que inspiraba la adición. A su juicio, con este artículo se establecía una especie de autojurisdicción individual, sin norma alguna que la controlara, llamada a provocar una serie de desinteligencias en los elementos populares. Al adoptarlo, se haría todo lo contrario a lo que constituía la misión de la Conferencia: defender a la democracia. 
El señor FERnÁndeZ DEL CastiLlo (MéXICO) advirtió que la expresión "derecho de resistencia" no era conocida, ni estaba bien precisado su alcance. Propuso que antes de la palabra "resistencia" se colocara algún verbo como "oponer", u otro semejante; que se suprimiera por inútil la palabra "adecuada"; y que se aclarara que la expresión "denegación de justicia" se refería a los casos de manifiesta y notoria injusticia. Advirtió, igualmente, que seguía siendo partidario de la no inclusión de este llamado "derecho", pues no era otra cosa que el derecho de no dar nunca por realizados los fines de la justicia, que consistían en determinar los litigios; pero, ya que se iba a hacer una declaración en ese sentido, la Comisión debía tratar de que fuera precisa y clara.

El señor DESPRADEL (REPÚBLICA DOMINICANA) explicó que la expresión “denegación de justician se refería al caso en que el tribunal se negara a conocer del asunto litigioso, según lo expresado en el Grupo de Trabajo.

El señor DANIELS (ESTADOS UNIDOS DE AMÉRICA) manifestó que encontraba alguna discrepancia entre el artículo que se discutía y el Artículo XXXIII, sobre el deber de obediencia a la Ley. Pero se le aclaró que los dos artículos simplemente se completaban; que este derecho era correlativo a ese deber.

El señor PRESIDENTE expuso que el derecho internacional contemplaba dos casos en que había fundamento para reclamación diplomática: el de denegación de justicia y el de injusticia notoria; en cambio, el derecho privado no tenía en cuenta, por lo general, sino el caso de denegación de justicia, pues para el de injusticia notoria establecía recursos como el de apelación y casación. El artículo de que se estaba hablando era aplicable únicamente en la hipótesis de la denegación de justicia.

El señor MENDOZA (GUATEMALA) juzgó atinadas las observaciones hechas por el señor Delegado de México, y preguntó a éste si quedaría satisfecho con la adopción de las mismas en la fórmula definitiva. Agregó que también podía dejarse una constancia en actas, en el sentido de que, al incluir el referido artículo, lo que se había tenido en mente era poner término al fusilamiento de reos políticos y a la práctica de mantenerlos en prisión sin haberles abierto proceso.

El señor Corominas (ARGENTINA) manifestó que se oponía a este principio, no por considerarlo como una innovación revolucionaria, sino porque era contrario a normas fundamentales de la Constitución de su país, en la cual se afianzaba la justicia, garantizando a todos el respeto a sus derechos por medio de los tribunales. Habría aceptado la inclusión de la fórmula si hubiese tenido una finalidad docente o [601] meramente enunciativa; pero evidentemente consagraba un ejercicio defensivo de carácter revolucionario, es decir, la traición contra la nación, que consistía en tomar las armas contra ella. Adoptarla sería establecer un factor de disociación permanente; equivaldría a regresar al período primitivo de aplicación de la justicia por mano propia. Terminó afirmando que no creía conveniente colocar en manos de un niño arma tan peligrosa, si se le permitía el símil; y, además, no había que olvidar que las delegaciones habían venido a Bogotá, no a consagrar el derecho a la revolución social, sino a tratar de obtener la paz social y la armonía política.

El señor PRESIDENTE dijo que estimaba expresados los dos puntos de vista opuestos sobre la cuestión en debate y, por consiguiente, se podía someterla a votación, siendo entendido que el texto sobre el cual se iba a decidir era el adoptado por el Grupo de Trabajo, con las reformas sugeridas por el señor Delegado de México. La votación se realizó, pues, sobre el siguiente texto, como segunda parte del Artículo XVIII, ya aprobado: 
Se reconoce el derecho de oponer resistencia en los casos de denegación de justicia o retardo evidente de la misma.

El señor Fernández del Castillo (MéXico) propuso que, en lugar de la palabra "evidente", se pusiera la palabra "intencionado", y con esa modificación se sometió el texto a votación. Realizada ésta nominalmente, por solicitud del señor Delegado de CuBA, dió el siguiente resultado: votaron afirmativamente los señores Delegados de Cuba, Ecuador, El Salvador, Guatemala, Honduras, Nicaragua, República Dominicana y el Uruguay; votaron negativamente los señores Delegados de Argentina, Bolivia, Brasil, Chile, Estados Unidos, México, Panamá y Perú; y el señor Delegado de Colombia se abstuvo.

El señor Delegado de ARGENTINA advirtió que votaría negativamente mientras no se le explicara el significado del término "resistencia". Tanto éste como el señor Delegado de la REPÚBLICA DOMINICANA anunciaron que fundamentarían posteriormente sus votos.

En vista del empate surgido, el señor PRESIDENTE, por sugestión del señor Delegado de la ARGENTINA y con el asentimiento de la Comisión, resolvió dejar la decisión del asunto para las sesiones plenarias.

\section{[APERTURA DE LA DISCUSIÓN SOBRE LOS DEBERES DEL HOMBRE]}

El señor PRESIDENTE abrió la discusión sobre la segunda parte del proyecto, relativa a los deberes del hombre.

El Relator de la Comisión Sexta, señor López de Mesa (COlOmbia) manifestó que el Grupo de Trabajo había elaborado un anteproyecto con 28 derechos y sólo 10 deberes (por lo cual se le debía gratitud), y que evidentemente esta segunda parte, como lo había expresado ya el señor Delegado de los Estados Unidos, no tenía la importancia y dignidad de la primera. En vista de ello, se permitía proponer la inclusión de tres artículos nuevos, al comienzo del capítulo de los deberes, los cuales no eran otra cosa que el enaltecimiento de la posición idealista de América ante el espíritu y la cultura, en esta hora de concupiscencia y de materialismo.

\section{[APROBAGIÓN DE TRES NUEVOS DEBERES Y DE UN PREÁMBULO ADICIONAL]}

[602] Los tres artículos nuevos decían así:

DEBER ANTE EL ESPIRITU. Por cuanto el espíritu es la finalidad suprema de la existencia humana y su máxima categoría, es deber del hombre servir a éste con todas sus potencias y recursos.

DEBER DE CULTURA. Y por cuanto la cultura es la máxima expresión social e histórica de ese espíritu, es deber supremo del hombre mantenerla, ejercerla y prosperada por todos los medios que estén a su alcance.

DEBER DE MORALIDAD Y BUENAS MANERAS. Y puesto que la moral y buenas maneras constituyen la floración más noble de esa cultura, es deber de todo hombre acatarlas siempre.

El señor PÉRez Cisneros (CUBA) elogió los artículos propuestos y sugirió, interpretando el sentimiento de la Comisión, que se aprobaran en conjunto y de manera unánime.

Sometidos a consideración por el señor PRESIDENTE, fueron aprobados por unanimidad. 
El señor Cisneros (Perú) propuso la adición, en esta parte del proyecto y antes de comenzar el articulado, de un preámbulo concebido así:

\section{PREÁMBULO}

El cumplimiento del deber por cada cual es exigencia del derecho de todos. Derechos y deberes se integran correlativamente en toda actividad social y política del hombre. Si los derechos exaltan la libertad individual, los deberes expresan la dignidad de esa libertad.

Sometido a votación, fué aprobado por unanimidad.

\section{[AProbación DE LOS DEBERES ANTE LA SOCIEDAD (ART. XXIX)]}

El señor PRESIDENTE sometió en seguida a consideración el Artículo XXIX, que dice así:

\section{Deberes ante la Sociedad}

El individuo tiene el deber de conducirse con relación a los demás de manera que todos puedan formar y desenvolver íntegramente su personalidad.

El señor Pérez Cisneros (CUBA) propuso que se substituyera el término "conducirse" por "convivir", concepto que se aplica únicamente al hombre.

El señor Cisneros (PERÚ) sugirió que después de la palabra "todos", se agregara la frase "y cada uno".

Sometido a votación, con las enmiendas propuestas, fué aprobado en la siguiente forma:

\section{Deberes ante la Sociedad}

$\mathrm{El}$ individuo tiene el deber de convivir con relación a los demás de manera que todos y cada uno puedan formar y desenvolver íntegramente su personalidad.

\section{[APROBACIÓN DE LOS DEBERES PARA CON LOS HIJOS Y LOS PADRES (ART. XXX)]}

Fué puesto en consideración por el señor PRESIDENTE el Artículo XXX, que decía:

$$
\text { Deberes para con los Hijos y los Padres }
$$

Toda persona tiene el deber de asistir, alimentar, educar y amparar a sus hijos menores de edad, y los hijos tienen el de asistir, alimentar y amparar a sus padres cuando éstos lo necesiten y el de honrarlos siempre.

[603] El señor CHIARI (PANAMÁ) propuso que, para evitar repetición, se suprimiera la frase "los hijos tienen"; a lo cual observó el señor PéREz CISNEROs (CUBA) que, si bien era cierto que se evitaba la repetición, no lo era menos que el texto perdía su belleza original. El señor LÓPEZ DE MESA (COLOMBIA) recordó que uno de los principales motivos de triunfo de la literatura hebrea era justamente el paralelismo consistente en que cada verso se repite de alguna manera en el siguiente, reforzándolo extraordinariamente. Agregó que la delicuescencia en la bondad filial imponía ese énfasis en el artículo. El señor CHIARI (PANAMÁ) retiró su enmienda. 
El señor CHAMORRO (NICARAGUA) solicitó que se dejara constancia en actas de que los padres podían educar a sus hijos por sí o por delegación, ya que así lo exigía la vida moderna.

Sometido a votación, el artículo fué aprobado, tal como se transcribió atrás.

\section{[APROBAGIÓN SIN OBSERVAGIONES DE LOS DEBERES DE INSTRUGGión (ART. XXXI)]}

Acto seguido, el señor PRESIDENTE abrió la discusión sobre el Artículo XXXI, que decía:

\section{Deberes de Instrucción}

Toda persona tiene el deber de adquirir, a lo menos, la instrucción primaria.

Fué aprobado así.

\section{[APROBACIÓN DEL DEBER DE SUFRAGIO (ART. XXXII)]}

El señor PRESIDENTE puso en discusión el Artículo XXXII, cuyo texto era:

\section{Deber de Sufragio}

Toda persona, legalmente capacitada, tiene el deber de votar en las elecciones populares del país de que sea nacional.

El señor DE OLIVEIRA (BRASIL) dijo que cuando se discutió ese artículo en el Grupo de Trabajo, los señores Delegados del Perú y del Brasil solicitaron que se introdujera la frase "legalmente capacitada", en vista de que en sus países los analfabetas no tenían derecho al voto; pero que, además, en el Brasil los soldados en servicio activo, aunque estaban capacitados para todos los otros actos de la vida civil, no gozaban del derecho de sufragio. Por tal razón, sería conveniente agregar, después de "capacitada", la expresión "para ello". El señor PRESIDENTE opinó que era innecesaria la adición. El señor FERNÁNDEZ DEL CASTILLO (MÉXICO) aclaró que el Grupo de Trabajo había entendido que el deber se circunscribía a las personas que tuvieran capacidad política para el sufragio.

El señor CHAMORRO (NicARAGUA) advirtió que, como muchos Estados no habían establecido el voto obligatorio, quizás sería conveniente incluir este deber como esencial.

El señor Fernández DEL Castillo (MéXICO) dijo que, en su opinión, coincidían las dificultades expresadas por los señores Delegados del Brasil y Nicaragua. Propuso, para salvarlas, el siguiente texto:

\section{Deber de Sufragio}

Toda persona tiene el deber de votar en las elecciones populares del país de que sea nacional, cuando esté legalmente capacitada para ello.

Así fué aprobado.

[APROBAGIÓN SIN OBSERVACIONES DEL DEBER DE ObEDIENCIA A LA LEY (ART. XXXIII)]

[604] El señor PRESIDENTE sometió a consideración el Artículo XXXIII, cuyo texto decía: 
Toda persona tiene el deber de obedecer a la Ley y demás mandamientos legítimos de las autoridades del país en que se encuentre.

Fué aprobado así.

\section{[APROBACIÓN DEL DEBER DE SERVIR A LA GOMUNIDAD Y A LA NACIÓN (ART. XXXIV)]}

A continuación, el señor PRESIDENTE abrió el debate sobre el Artículo XXXIV, concebido así:

\section{Deber de Servir}

Toda persona tiene el deber de prestar servicio de armas y de desempeñar los cargos de elección popular en el Estado de que sea nacional.

Tiene asimismo el deber de prestar los servicios civiles que fueren necesarios en caso de calamidad pública.

El señor GRAUERT (URUGUAY) manifestó que, como en su país no existía el servicio militar obligatorio, sólo podría dar su aprobación al artículo en el caso de que se entendiera que el deber consignado era el de prestar su concurso a la nación en el evento de una guerra. Propuso la siguiente modificación a la primera parte:

Toda persona tiene el deber de prestar su concurso para la defensa de la nación según sus leyes...

El señor FERnÁNDEZ DEL Castillo (MéXICO) informó que el Grupo de Trabajo había estimado inconveniente limitar el deber, haciendo alusión a las leyes. Propuso que se suprimiera esta última condición.

El señor CiSNEROS (PERÚ) propuso el siguiente texto:

Toda persona tiene el deber de desempeñar los cargos de elección popular en el Estado de que sea nacional.

Tiene asimismo el deber de prestar los servicios civiles que fueren necesarios en caso de calamidad pública y los civiles y militares que la patria en peligro requiera.

El señor GRAUERT (URUGUAY) adhirió a la fórmula anterior.

El señor PÉREZ Cisneros (CUBA) observó que en la enumeración de estos deberes no se había tenido en cuenta su jerarquía.

Después de breves intervenciones de varios delegados sobre este punto, se resolvió encomendarle al señor LÓPEZ DE MESA, Relator de la Comisión, la redacción definitiva del artículo sobre la base del texto propuesto por el señor Delegado del Perú, el cual había sido aprobado. Se le autorizó asimismo para modificar el título, como lo sugirió uno de los delegados.

El señor LÓPEZ DE MESA (COLOMBIA), en cumplimiento del encargo, presentó posteriormente a la Secretaría el siguiente texto, que es el definitivo:

\section{Deber de Servir a la Comunidady a la Nación}

Toda persona hábil tiene el deber de prestar los servicios civiles y militares que la patria requiera para su defensa y conservación y, en caso de calamidad pública, los civiles que estén a su alcance. 
[605] Asimismo tiene el deber de desempeñar los cargos de elección popular que le correspondan en el Estado de que sea nacional.

\section{[APROBaCión DE LOS DEBERES DE ASISTENCIA Y SEGURIDAD SOCIALES (ART. XXXV)]}

A continuación, el señor PRESIDENTE abrió el debate sobre el Artículo XXXV, el cual fué aprobado con una leve modificación en su título, consistente en poner la palabra "Social" en plural. Quedó así, definitivamente:

\section{Deberes de Asistencia y Seguridad Sociales}

Toda persona está obligada a cooperar con el Estado y con la comunidad en la asistencia y seguridad sociales, de acuerdo con sus posibilidades y con las circunstancias.

\section{[APROBAGIÓN DEL DEBER DE PAGAR IMPUESTOS (ART. XXXVI)]}

El señor PRESIDENTE sometió a consideración el Artículo XXXVI, que decía así:

\section{Deber de Pagar Impuestos}

Toda persona tiene el deber de pagar los impuestos establecidos por las leyes para el sostenimiento de los gastos públicos del país de su residencia.

El señor DE OLIVEIRA (BRASIL) dijo que, al redactarse el artículo en el Grupo de Trabajo, se había tenido en mente evitar la doble tributación, pero que, por lo visto, se había caído en el exceso contrario. Era indiscutible que una persona debía contribuir a los gastos públicos en el país de su residencia, pero también era cierto que en muchos casos esa misma persona debía pagar impuesto de renta en el país de origen. Para comprender ambos casos, proponía la siguiente redacción:

Toda persona tiene el deber de pagar los tributos legítimos...

El señor GRAUERT (URUGUAY)19E observó al señor Delegado del Brasil que "impuestos establecidos por las leyes" e "impuestos legítimos" era la misma cosa.

El señor SALINAS LÓPEZ (BOLIVIA) propuso la supresión del objeto de los impuestos, contenida a partir de la palabra "leyes", en lo cual fué apoyado por el señor PÉREZ CiSNEROS (CUBA).

El señor GRAUERT (URUGUAY) propuso la eliminación de la frase "del país de su residencia”. Explicó que en el Uruguay pagaban impuestos los ciudadanos extranjeros que poseían allí bienes raíces, aunque tuvieran la residencia en el exterior. Terminó aprobando la supresión propuesta por el señor Delegado de Bolivia. El señor FERNÁNDEZ DEL CASTILLO (MÉXICO) explicó que la intención del Grupo de Trabajo, al elaborar el artículo, había sido la de establecer el deber para los extranjeros residentes en un país, de pagar allí impuestos. Recordó que se trataba de establecer, no los deberes nacionales del hombre, sino los deberes esenciales del hombre. El señor GRAUERT (URUGUAY) se manifestó satisfecho con la interpretación anterior y retiró su observación.

19E Sin margen en el original. Nota del editor A. P. D. 
El señor CHAMORRO (NICARAGUA) propuso que al final del artículo se agregara la frase "y de donde radiquen sus bienes".

El señor GÁLVEZ (HONDURAS) propuso el cambio de la palabra "gastos" por "servicios".

El señor Holguín (COLOMBIA) observó que, al elaborar este texto, se debía tener en cuenta que hay escuelas morales que no obligan en conciencia a pagar impuestos.

[606] Después de algunas explicaciones suministradas por los redactores del artículo, el señor PRESIDENTE resolvió someterlo a votación en su texto original, con el único cambio de la palabra "gastos" por "servicios". Así fué aprobado, de modo que quedó así:

\section{Deber de Pagar Impuestos}

Toda persona tiene el deber de pagar los impuestos establecidos por las leyes para el sostenimiento de los servicios públicos del país de su residencia.

\section{[APROBACIÓN DEL DEBER DE TRABAJO (ART. XXXVII)]}

El señor PRESIDENTE sometió a consideración el Artículo XXXVII, que decía:

\section{Deber de Trabajo}

Toda persona tiene el deber de trabajar, dentro de su capacidad y posibilidades, a fin de obtener los recursos para su subsistencia o en beneficio de la comunidad.

El señor CHAMORRO (NiCARAGUA) observó que el artículo eliminaba, aparentemente, el derecho de huelga. El señor FERnÁndeZ DEL Castillo (MÉXICO) explicó que la intención del Grupo de Trabajo había sido evitar la ociosidad, simplemente. Que la huelga era una interrupción transitoria apenas y que, además, este tema de la huelga correspondía a la Comisión Quinta.

El señor DANIELS (ESTADOS UnIDOS DE AMÉRICA) preguntó si este deber impediría, por ejemplo, a una persona que no necesitara trabajar para subsistencia, dedicarse a la música para propio deleite.

El señor CHAMORRO (NICARAGUA) solicitó que se dejara constancia en actas de que este artículo no impedía el derecho de huelga, según la interpretación que se había expresado.

Sometido a votación por el señor PRESIDENTE, fué aprobado el Artículo XXXVII

[APROBACIÓN DEL DEBER DE ABSTENERSE DE ACTIVIDADES POLÍTICAS EN PAÍS EXTRANJERO (ART. XXXVIII)]

En seguida el señor PRESIDEnTE abrió el debate sobre el Artículo XXXVIII, cuyo texto decía:

\section{Deber de Abstenerse de Actividades Politicas en País Extranjero}

Toda persona tiene el deber de abstenerse de tomar parte en las actividades políticas privativas de los ciudadanos del Estado en que sea extranjera.

El señor GRAUERT (URUGUAY) pidió que se eliminara el artículo, por ser contrario a la tradicional formación de nuestros pueblos, constituídos por españoles, italianos, etcétera. Agre- 
gó que entendía que muchas de nuestras constituciones permitían esa actividad, con ciertas condiciones. Recordó las acciones gloriosas de Bolívar y San Martín. El señor SALINAS LÓPEZ (BOLIVIA) aclaró que lo que el Grupo de Trabajo había tratado de impedir con dicho artículo, era que elementos extranjeros aun no nacionalizados intervinieran en la política interna de un país. El señor LABARCA (CHILE) adhirió a las opiniones expuestas por el señor Delegado del Uruguay. Los señores Delegados de GUATEMALA y de la REPÚBLICA DOMINICANA se manifestaron partidarios de la adopción del artículo, así como el señor Delegado de MéXICO.

[607] El señor PRESIDENTE dijo que, en su concepto, todos estaban de acuerdo, puesto que en el artículo se establecía el deber de abstención en las actividades políticas "privativas" de los ciudadanos del Estado respectivo y cada Estado podía señalar, en su legislación interna, cuáles eran esas actividades privativas de los nacionales.

El señor FERNÁNDEZ DEL CASTILlO (MÉXICO) advirtió que esta norma no constituía una innovación, puesto que ya obligaba desde hacía 20 años a todos los países de América que habían ratificado la Convención sobre Condiciones de los Extranjeros adoptada en la Sexta Conferencia Internacional Americana. Aclaró que de allí se había tomado esta norma.

El señor LABARCA (CHILE) manifestó que en su país los extranjeros podían, por ejemplo, votar en las elecciones municipales que envolvían solamente intereses económicos, pero no grandes intereses políticos. Sugirió que valdría la pena buscar una fórmula que conciliara todos los puntos de vista expresados.

El señor VÁSQUEZ (ARGENTINA) propuso la siguiente fórmula que, a su juicio, evitaba el carácter negativo que tenía el artículo:

Toda persona tiene el deber de tomar ciudadanía, o ser contribuyente, para poder practicar actividades políticas en el Estado en que sea extranjera.

El señor CISNEROS (PERÚ) propuso este otro texto:

Toda persona tiene el deber de abstenerse de tomar parte en las actividades políticas que de conformidad con la Ley sean privativas de los ciudadanos del Estado en que sea extranjera.

Fué sometida a consideración por el señor PRESIDENTE la fórmula definitiva propuesta por la Delegación Argentina, cuyo texto era:

Toda persona tiene el deber de tomar ciudadanía para poder participar en las actividades políticas en el Estado en que sea extrajera.

Esta fórmula fué negada.

Puesta en votación la fórmula peruana transcrita atrás, fué aprobada. Quedó en consecuencia así el artículo:

\section{Deber de Abstenerse de Actividades Políticas en País Extranjero}

Toda persona tiene el deber de abstenerse de tomar parte en las actividades políticas que de conformidad con la Ley sean privativas de los ciudadanos del Estado en que sea extranjera.

\section{[TRASLAdO DE LOS TRES ARTíCUlOS NUEVOS AL PREÁMBUlO DEL PDADDH]}

El señor FERnández del Castillo (MÉXICO), después de elogiar la intervención del señor López de Mesa, de Colombia, y el texto de los tres artículos propuestos por él, mani- 
festó que, desde un punto de vista estrictamente jurídico, se atrevía a sugerir que no se les colocara dentro del articulado de la Declaración, pues ésta contenía principios de carácter netamente jurídico susceptibles de sanción por su violación, y con mayor razón en el caso de que se estableciera una jurisdicción internacional encargada de su protección. En consecuencia, se permitía proponer que pasaran al preámbulo los tres artículos mencionados. El señor LÓPEZ DE MESA (COLOMBIA) agradeció los conceptos elogiosos del señor Delegado de México y dijo [608] que no tenía inconveniente alguno en que la Comisión decidiera sobre el lugar en donde debían colocarse esos tres artículos. Sometida la cuestión a votación por el señor PRESIDENTE, se resolvió que se incluyeran en el preámbulo, respetando su esencia y su redacción, y se autorizó al señor López de Mesa para hacer la necesaria adaptación.

$\left[\ldots{ }^{20 \mathrm{E}}\right]$

Luego, el señor PRESIDENTE levantó la sesión.

[609]

\section{ACTA RESUMIDA DE LA NOVENA SESION DE LA COMISION SEXTA ${ }^{1}$}

FECHA: lunes, 26 de abril de 1948

HORA: 10:30-12:30

RECINTO: Cámara de Representantes, Capitolio Nacional

PResidente: señor Carlos Sánchez y Sánchez (República Dominicana)

VICEPRESIDENTE: señor Marco Antonio Batres (Honduras)

RELATOR: señor Luis López de Mesa (Colombia)

SECRETARIO: señor Gabriel Arango Restrepo

PResentes: señores Virgilio R. Gálvez (Honduras); José Luis Mendoza (Guatemala); Sergio A. Labarca y Ricardo Latcham (Chile); Héctor A. Grauert (Uruguay); Guy Pérez Cisneros (Cuba); Paul C. Daniels (Estados Unidos de América); Arturo Despradel (República Dominicana); Alberto Salinas López (Bolivia); Luis Fernán Cisneros (Perú); Diego Manuel Chamorro (Nicaragua); Germán Fernández del Castillo (México); Humberto García Ortiz (Ecuador); Antonio Camillo de Oliveira (Brasil); Enrique V. Corominas y Leonidas Vásquez (Argentina); Carlos Arango Vélez (Colombia); y Alfonso García Robles (Naciones Unidas)

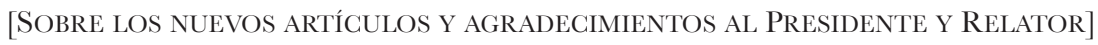

El señor PRESIDENTE abrió la sesión y sometió a consideración las Actas de la Quinta, Sexta y Séptima Sesiones, las cuales fueron aprobadas.

En seguida, el señor PRESIDENTE hizo dar lectura por la Secretaría al Acta de la Octava Sesión, que aun no había sido distribuída. Fué igualmente aprobada.

El Relator de la Comisión, señor LÓPEZ DE MESA (COLOMBIA), informó a la Comisión que, después de un detenido estudio del problema de la inserción en el texto del proyecto de

20E A continuación, en la misma página 608, la Comisión aprueba la resolución "Demarcación de Fronteras y Reposición de Hitos", y se refrendan diversos instrumentos aprobados por la Comisión de Iniciativas.

1 Documento publicado durante la Conferencia con la clasificación CB-431/C.VI-35.

Por dificultades insalvables, no hubo servicios taquigráficos para esta sesión. 
los tres artículos nuevos por él propuestos, referentes a deberes, y del nuevo artículo presentado por el señor Delegado del Perú, había resuelto colocar este último como una introducción al capítulo de deberes, y aquéllos como preámbulo del mismo capítulo.

El señor FERNÁNDEZ DEL CASTILLO (MÉXICO) observó que, por una parte, quizás no era estético que en un documento de esta clase hubiera un preámbulo para los derechos y otro para los deberes; y que, por otra, debía tenerse en cuenta que los nuevos deberes propuestos por el señor Delegado de Colombia tenían más bien el carácter de postulados morales, por lo cual no parecía conveniente que se insertaran en el cuerpo de un articulado de carácter jurídico.

Después de una activa discusión, en la cual tomaron parte los señores CiSNEROS (PERÚ), Chamorro (Nicaragua), Mendoza (Guatemala), Salinas López (Bolivia), el señor PRESIDENTE y el señor RELATOR, se resolvió autorizar al señor López de Mesa para que, teniendo en cuenta las observaciones hechas, procediera a realizar su colocación definitiva en el texto de la Declaración.

El señor CHAMORRO (NICARAGUA) propuso un voto de aplauso para los señores Presidente y Relator de la Comisión, como reconocimiento de su acertada actuación. [610] Apoyaron la moción del señor Delegado de Nicaragua los señores Delegados de ARGENTINA, HONDURAS, ECUADOR Y PERÚ, adicionándola el del ECUADOR en el sentido de hacerla extensiva a la Secretaría, y el del Perú solicitando que se hiciera especial mención de la labor realizada por los señores Guy Pérez Cisneros, de Cuba, y Germán Fernández del Castillo, de México. Con las anteriores adiciones, la moción de aplauso fué aprobada por unanimidad.

El señor PRESIDENTE expresó su agradecimiento a los señores delegados e hizo fervientes votos por que el espíritu de colaboración, comprensión y amistad que había reinado durante las labores de la Comisión, perdurara a través de las futuras relaciones personales entre todos sus miembros.

El señor Cisneros (PERÚ) presentó la siguiente proposición:

"La Delegación del Perú invita a la Comisión a formular, en circunstancias en que da por terminadas sus labores, un voto fervoroso por la República de Colombia; un voto que diga nuestros vivos anhelos por su felicidad, a la que tiene, por razones honrosísimas de ayer y de hoy, un derecho tan excepcional, y que a la vez exprese la honda simpatía, la conmovida adhesión con que nos hemos confundido en el dolor y la preocupación del Gobierno y el pueblo colombianos en los días dramáticos en que estuvieron a prueba, hasta salir triunfantes, el patriotismo y las claras y arraigadas virtudes democráticas de sus hijos. Estamos con Colombia y en nuestro contacto con su espíritu llevamos renovada y reforzada la fe en su destino. De pie, con un aplauso, digamos este sentimiento."

La proposición fué aprobada por unanimidad.

El señor LÓPEZ DE MESA (COLOMBIA) en emocionadas palabras expresó su agradecimiento a todos los señores delegados por tan generosa proposición.

El señor PRESIDENTE levantó la sesión. 


\section{SESIONES DE LAS SUBCOMISIONES DE LA COMISIÓN SEXTA}

\section{MINUTA DE LA SESIÓN DE INSTALACIÓN DE LA SUBCOMISIÓN A ${ }^{1}$}

FECHA: lunes, 5 de abril de 1948

HORA: 9:50-10:15

RECINTO: Salón "Valencia", Capitolio Nacional

PRESIDENTE: señor Enrique Bernstein (Chile)

RELATOR: señor Luis López de Mesa (Colombia)

SECRETARIO: señor Gabriel Arango Restrepo

PResentes: señores Marco Antonio Batres (Honduras); José Luis Mendoza (Guatemala); Dardo Regules (Uruguay); Paul C. Daniels (Estados Unidos de América); Arturo Despradel (República Dominicana); Alberto Salinas López (Bolivia); Manuel Félix Maúrtua (Perú); Diego Manuel Chamorro (Nicaragua); Germán Fernández del Castillo (México); Humberto García Ortiz (Ecuador); Ernesto de Araújo (Brasil); Joseph L. Déjean (Haití); Simón Gómez Malaret (Venezuela); y Enrique V. Corominas (Argentina)

\section{[Elecaión del PResidente de la Subcomisión]}

El señor PRESIDENTE DE LA COMISIÓN SEXTA abrió la sesión.

Acto continuo se procedió a elegir el Presidente de la Subcomisión.

El señor CoRominas (ARgEntina) propuso al señor Delegado de Haití para la Presidencia y al señor Delegado del Uruguay para la Relatoría.

El señor DÉJEAN (HAITÍ) no aceptó, por carecer su delegación de personal suficiente.

El señor DESPRADEL (REPÚBLICA DOMINICANA), en vista de las razones expuestas por el señor Déjean, propuso la candidatura del señor Delegado de Chile.

El señor BeRnsteIn (CHILE) insinuó que, dado el caso de integrar la Subcomisión los mismos miembros que componían la Comisión, sería preferible que los señores Presidente y Relator de ésta lo fuesen también de la Subcomisión A.

El señor PRESIDENTE DE LA COMISIÓN SEXTA manifestó que podrían presentarse dificultades para el funcionamiento simultáneo de una y otra, y por tal razón declinó el ofrecimiento y rogó al señor Delegado de Chile que aceptara su postulación.

El señor MENDOZA (GUATEMALA) encontró acertada la razón expuesta por el señor Presidente de la Comisión. Insistió en que la Delegación Chilena aceptara el nombramiento,al propio tiempo que adhirió a la postulación del señor Delegado del Uruguay para Relator.

1 Documento publicado durante la Conferencia con la clasificación CB-120/C.VI-Sub A-2.

Por no exigirlo el Reglamento de la Conferencia, no hubo servicios taquigráficos para esta sesión. 
El señor BERNSTEIN (CHILE) reiteró su no aceptación, por cuanto su país se hallaba representado en las tres Subcomisiones y vería con agrado que otro país aceptase el cargo.

[612] El señor PRESIDENTE DE LA COMISIÓn SEXTA invitó a las delegaciones a hacer un sacrificio en el sentido de aceptar la Presidencia, para poder entrar de lleno al estudio de fondo de los temas de la Subcomisión.

El señor BERnstein (CHILE) expresó que, como ya estaba acordado que estos cargos directivos se daban a los países representados y no a determinada persona, Chile podría aceptar la Presidencia y haría posteriormente la elección de su representante.

El señor COROMINAS (ARGENTINA) adhirió a lo expuesto y pidió la aclamación del señor Delegado de Chile.

El señor PRESIDENTE DE LA COMISIÓN SEXTA declaró electo por aclamación al señor Delegado de Chile, quien asumió la Presidencia y expresó sus agradecimientos.

El señor PRESIDENTE DE LA Subcomisión procedió a la elección de Relator, abriendo la discusión.

\section{[ELECGión DEL RELATOR DE LA SUbCOMISIÓN]}

El señor REGULES (URUGUAY) agradeció su postulación, pero la declinó por estar ya en desempeño de otra Relatoría. Sugirió al señor Delegado de Colombia como Relator.

El señor LÓPEZ DE MESA (COLOMBIA) dijo que Colombia estaba dispuesta a aceptar los cargos de servicio que se le señalaran y, en esa virtud, la PRESIDENCIA consideró resuelto el asunto y declaró electo como Relator al señor Delegado de Colombia.

El señor PRESIDENTE inquirió si la Subcomisión conceptuaba que debía abrirse un debate general sobre el tema que le había sido asignado (derechos y deberes del hombre), cosa que él estimaba conveniente.

El señor DE ARAÚJO (BRASIL) apoyó la tesis del señor Presidente, y en igual sentido se pronunció el señor FERNÁNDEZ DEL CASTILLO (MÉXICO).

El señor DÉJEAN (HAITí) expresó su acuerdo con lo propuesto por el señor Presidente y pidió que se tomara como base el proyecto del Comité Jurídico Interamericano. ${ }^{1}$

El señor PRESIDENTE estimó acordada la realización del debate general y anunció que oportunamente se convendría con el señor Secretario de la Subcomisión el día y hora de la próxima reunión. Luego, levantó la sesión.

\section{MINUTA DE LA PRIMERA SESIÓN DE LA SUBCOMISIÓN A²}

FECHA: martes, 6 de abril de 1948

HORA: 10:15-11:15

RECINTO: Salón "Valencia", Capitolio Nacional

PRESIDENTE: señor Enrique Bernstein (Chile)

RELATOR: señor Luis López de Mesa (Colombia)

[613] SECRETARIO: señor Gabriel Arango Restrepo

1 Documento publicado durante la Conferencia con la clasificación CB-7, transcrito en las págs. 449 y siguientes.

2 Documento publicado durante la Conferencia con la clasificación CB-147/C.VI-Sub A-4.

Por no exigirlo el Reglamento de la Conferencia, no hubo servicios taquigráficos para esta sesión. 
PResentes: señores Virgilio R. Gálvez (Honduras); José Luis Mendoza (Guatemala); Dardo Regules (Uruguay); Ricardo Sarabasa (Cuba); Paul C. Daniels (Estados Unidos de América); Arturo Despradel (República Dominicana); Javier Paz Campero (Bolivia); Luis Fernán Cisneros (Perú); Diego Manuel Chamorro (Nicaragua); Germán Fernández del Castillo (México); Eduardo A. Chiari (Panamá); Héctor Escobar Serrano (El Salvador); Humberto García Ortiz (Ecuador); Antonio Camillo de Oliveira (Brasil); Joseph L. Déjean (Haití); Simón Gómez Malaret (Venezuela); Enrique V. Corominas (Argentina); Charles G. Fenwick (Unión Panamericana); y Alfonso García Robles (Naciones Unidas)

El señor PRESIDENTE abrió la sesión.

\section{[Propuesta URUGUaya DE DisGUTIR Un GUESTIONARIO]}

El señor REgUlES (URUGUAY) propuso que, sin perjuicio de que se adelantara el debate general, las diversas delegaciones comunicaran al señor Relator de la Subcomisión, en el curso del mismo día, su opinión sobre algunos puntos esenciales respecto a los cuales podría haber divergencias, tales como: primero, si debía elaborarse un tratado o una simple declaración sobre los derechos y deberes del hombre, y si el instrumento elaborado debía incorporarse al Pacto Constitutivo, o no; segundo, si en dicho instrumento se trataría solamente de derechos individuales, o de derechos sociales también; tercero, si la protección de tales derechos había de confiarse a la competencia interna de los respectivos regímenes constitucionales de cada país, o si había de crearse una competencia internacional de tipo jurisdiccional; y, cuarto, si esa competencia internacional debía ser de carácter político, como la establecida por las Naciones Unidas a través del Consejo Económico y Social, o si sería de tipo jurisdiccional.

Declaró que la Delegación del Uruguay emitía desde ahora su opinión de que los derechos y deberes del hombre debían estar garantizados por un tratado y por una jurisdicción internacional; pues, a su juicio, el reconocimiento y protección de los mencionados derechos no podía confiarse a los sistemas constitucionales internos.

Sobre la organización de esta competencia, la Delegación del Uruguay presentaba una proposición $^{1}$ que sería distribuida ese mismo día.

\section{[BREVE DISCUSIÓN SOBRE LA PROPUESTA DE URUGUAY]}

El señor COROMINAS (ARGENTINA) manifestó que apoyaba el procedimiento sugerido por el Uruguay, con la salvedad de que no debía implicar limitación a la libre expresión del pensamiento político de las delegaciones sobre otros temas. Agregó que su país no era partidario de la elaboración de un tratado, sino de una declaración anexa al Pacto Constitutivo; y que ella debería tomar en cuenta no solamente los derechos políticos, sino también los sociales.

El señor FERnÁndez del Gastillo (MÉXICO) propuso que se discutiera primero el proyecto del Comité Jurídico, ${ }^{2}$ teniendo a la vista el formulado por la Comisión sobre los derechos del hombre, del Consejo Económico y Social de las Naciones Unidas; y que se in-

1 Documento publicado durante la Conferencia con la clasificación CB-1 12/C.VI-Sub A-3, transcrito en la pág. 463.

2 Documento publicado durante la Conferencia con la clasificación CB-7, transcrito en la pág. 449 y siguientes. 
cluyera una declaración de deberes del hombre, la cual se había omitido del proyecto del Comité Jurídico. Agregó que, además de la Declaración propiamente dicha, debía elaborarse un proyecto que contuviera las normas generales [614] con arreglo a las cuales los Estados regularían esos derechos en su régimen interno, pues esta materia debía reservarse al derecho interno de las naciones; y que, una vez elaborado este estudio, se entrara a examinar otros asuntos, como los planteados por la Delegación del Uruguay.

El señor CHAMORRO (NICARAGUA) adhirió a las tesis sostenidas por el señor Delegado de México. Observó que la Comisión Primera estaba estudiando si los derechos del hombre se incorporarían o no dentro del Pacto Constitutivo, y si habría que establecer su protección internacional o si se podía dejar su protección a cada Estado. Al modo de ver del señor Chamorro, existía cierto conflicto de competencia entre las dos Comisiones que debía ser resuelto anticipadamente.

El señor DANiEls (Estados Unidos DE AMÉRICA) apoyó la sugestión hecha por el señor Delegado del Uruguay. Luego, anunció que leería un documento con opiniones generales sobre el tema encomendado a la Subcomisión A.

El señor DE OLIVEIRA (BRASIL) declaró que adhería en principio a la proposición del Uruguay; y que podía contestar a las preguntas formuladas por el señor Regules, así: la definición de si había de elaborarse una convención o una declaración correspondía a la Comisión Primera; a la Comisión Sexta correspondía definir los derechos del hombre y hasta qué punto los garantizarían los Estados. El proyecto del Comité Jurídico debía tomarse como base muy útil, al realizar este estudio.

El señor DesPradel (REPública DOMINICANA) expuso su adhesión a la sugerencia hecha por el señor Delegado del Uruguay, sin perjuicio de que se realizara el debate general. Asimismo, se manifestó de acuerdo con la observación hecha por el señor Delegado del Brasil.

El señor PRESIDENTE sometió a votación la proposición del Uruguay, que fué aprobada.

El señor Corominas (ARGEnTina) declaró que, en su concepto, la Subcomisión A tenía competencia para tratar el asunto que se le había sometido y que, si se presentaban repeticiones o incongruencias, correspondía a la Comisión de Coordinación evitarlas.

El señor CHAMORRO (NICARAGUA) aclaró que su ánimo había sido únicamente advertir lo que estaba ocurriendo, pero que no tenía interés alguno en que fuera la Comisión Primera o la Sexta la que estudiara el punto. Dijo que, en su opinión, correspondía a la Sexta.

\section{[SE ABRE EL DEBATE GENERAL]}

El señor PRESIDENTE abrió el debate general.

El señor DANIELS (ESTADOs UNIDOS DE AMÉRICA) dió lectura a unos conceptos generales sobre el tema encomendado a la Subcomisión, cuyo texto entregó a la Secretaría.

El señor FERnÁNDEZ DEL CASTILlo (MéXICO) solicitó que se tuvieran en cuenta, en el debate general, las tres proposiciones ${ }^{1}$ que presentaba, las cuales habían sido leídas y se distribuirían oportunamente.

El señor PRESIDENTE levantó la sesión.

1 Fue clasificado durante la Conferencia solamente el documento CB-101/C.VI-Sub A-1, transcrito en la pág. 462. 


\title{
ACTA DE LA SEGUNDA SESIÓN DE LA SUBCOMISIÓN A
}

\author{
(Versión taquigráfica) $^{1}$
}

FECHA: jueves, 8 de abril de 1948

HORA: 10:20-11:55

RECinTO: Cámara de Representantes, Capitolio Nacional

PRESIDENTES: señores Enrique Bernstein (Chile) y Virgilio R. Gálvez (Honduras)

RELATOR: señor Luis López de Mesa (Colombia)

SECRETARIO: señor Gerardo Melguizo

PREsentes: señores José Luis Mendoza (Guatemala); Rodrigo González (Chile); Guy Pérez Cisneros (Cuba); Paul C. Daniels (Estados Unidos de América); Arturo Despradel (República Dominicana); Javier Paz Campero (Bolivia); Luis Fernán Cisneros (Perú); Diego Manuel Chamorro (Nicaragua); Germán Fernández del Castillo (México); Eduardo A. Chiari (Panamá); Héctor Escobar Serrano (El Salvador); Humberto García Ortiz (Ecuador); Antonio Camillo de Oliveira (Brasil); Joseph D. Charles (Haití); Luis Lander (Venezuela); Enrique V. Corominas (Argentina); y Alfonso García Robles (Naciones Unidas)

\section{[RESPUESTA DE GUATEMALA AL GUESTIONARIO URUGUAYO]}

El señor PRESIDENTE: Se abre la sesión.

Continúa el debate que quedó pendiente en la sesión anterior. Tiene la palabra el señor Delegado de Guatemala.

El señor Mendoza (Guatemala): Señor Presidente: la Delegación de Guatemala desea dar a conocer su opinión en relación con los puntos que formuló por vía de información el Honorable Delegado del Uruguay.

Dada la enorme importancia que la protección de los derechos del hombre tiene para la mayor eficacia de los pueblos de América, considera la Delegación de Guatemala que la Carta contentiva de tales derechos no debe limitarse a una simple declaración. Nosotros creemos que debe quedar como parte integrante de un tratado o convenio que sea obligatorio para todos los Estados. Sugeriríamos, sin embargo, que esta Carta estuviera contenida en un protocolo, adicional al acto Constitutivo y a la vez parte integrante de él. El objeto de formularla así es para que la Carta de los derechos del hombre pueda ser revisada, de tiempo en tiempo, con facilidad, sin que para ello sea necesario revisar el Pacto Constitutivo.

Esa Carta debe, como es lógico, incluir los derechos individuales y sociales del hombre. En la mayor parte de las constituciones de los países de América, o en todas ellas, se enuncian y se protegen debidamente los derechos individuales y sociales del hombre. De hecho, la competencia de los derechos humanos está en el orden interno de los Estados. Es ésta una expresión no sólo de los países de América sino de todos los países del mundo.

La Delegación de Guatemala desea que, una vez elaborada la Carta, la competencia a juzgar la protección de los derechos del hombre, quede encomendada a un [616] organismo internacional. Ahora, en cuanto a esa competencia, la Delegación de Guatemala no cree que

1 Preparada por razón de la importancia de los temas tratados.

La correspondiente Minuta fue publicada durante la Conferencia con la clasificación CB220/C.VI-Sub A-6. 
deba ser de carácter político; nosotros nos inclinamos por la competencia de orden jurídico. Es de desearse - y así lo expresa con sinceridad la Delegación de Guatemala - que estos derechos humanos en América sean protegidos con la competencia de la Corte Internacional de Justicia, que ha sido muchas veces tema de discusión en las diferentes conferencias interamericanas. Tengo entendido que en la Conferencia de Lima, celebrada en 1938, se dejó uno de los proyectos en discusión, sobre la Corte Interamericana de Justicia, a la Novena Conferencia Internacional Americana. ${ }^{21 \mathrm{E}}$ Esto es cierto; pero he visto con bastante extrañeza que en el Programa de la Novena Conferencia nada se ha dicho sobre la Corte Interamericana de Justicia. Nosotros, sí tenemos una absoluta confianza en la Corte Interamericana de Justicia. Creemos que América tiene problemas de carácter jurídico, y de orden bastante amplio, que ameritan la creación de una corte de justicia entre nosotros.

La protección de los derechos humanos en una Corte Interamericana de Justicia no será una invención en el orden internacional americano. Sabemos perfectamente, y conocemos por experiencia, las ventajas que los países centroamericanos tuvimos con la Corte Centroamericana de Justicia. Tanto en la protección de las parcelas centroamericanas como en cualquier otro caso, cualquier individuo o cualquier cuerpo podía acusar a cualquier Gobierno Centroamericano de violación de los derechos humanos. Con esta experiencia, la Delegación de Guatemala considera que la creación de la Corte Interamericana de Justicia debe ser un anhelo de los países americanos; y cree que en esta Conferencia, o en la próxima, pueda llegar a ser realidad esta aspiración de justicia.

El Sistema Interamericano, tal como se formula en el Pacto Constitutivo, coincide en muchos puntos con la organización mundial. La organización mundial tiene una Corte Internacional de Justicia. ¿Por qué la nuestra, no va a tener también su Corte? Hay muchos problemas en América de carácter puramente interno que no sería conveniente llevar a los tribunales mundiales.

La Delegación de Guatemala, en todas las ocasiones, ha apoyado la idea de la creación de la Corte Interamericana de Justicia. Creemos especialmente que, para el caso de protección de los derechos internacionales del hombre, para que esos derechos queden protegidos internacionalmente, la mejor competencia sería la de la Corte Interamericana de Justicia. Sobre este punto, tratándose de que la creación de esa Corte no saliera de la Conferencia de Bogotá, no tendríamos ninguna sugestión concreta sobre a qué organismo se le deberá dar la protección de los derechos del hombre en América.

La Delegación de Guatemala quiere someter a la consideración de los señores delegados, que se cree una Comisión Interna de Divulgación de los Derechos del Hombre. Esto tiene por objeto que, bajo el control internacional, todos los hombres de América sepan perfectamente cuáles son sus derechos, y que sus derechos básicos no sólo son una cosa escrita en constituciones que muchas veces se desconocen. Hay interés continental en que estos derechos se hagan efectivos, y que sean plenamente protegidos. Esa Comisión podría encargarse, además, por todos los [617] medios modernos de comunicación, de supervigilar el efectivo cumplimiento de los derechos humanos en todos los países de América.

El señor PRESIDENTE: Ofrezco la palabra a cualquier otro delegado que quiera tomar parte en el debate.

\section{[RESPUESTA DE Bolivia AL GUESTIONARIO URUGUAYO]}

Tiene la palabra el señor Delegado de Bolivia.

21E El texto de esa declaración se encuentra recogido en la sección principal de este libro, en una nota al pie en el apartado sobre el germen de la Corte Interamericana. Nota del editor A. P. D. 


\section{(El señor PAZ CAMPERO, Delegado de BOLIVIA, pronuncia el siguiente discurso $)^{1}$}

La Delegación de Bolivia considera muy interesante la proposición del señor Delegado de Guatemala en sentido de dar un carácter contractual, y no meramente declarativo, al reconocimiento internacional de los derechos y libertades del hombre.

Encuentra, sin embargo, que el procedimiento no sería de inmediato aplicable, por falta de tiempo. Será mejor dar un primer paso con la simple declaración, que ya por sí tiene un gran significado. El hombre no es, como ha sido hasta ahora, un simple elemento constitutivo del Estado, sino persona de derecho internacional. Tiene una situación propia dentro de la comunidad jurídica.

Pero no basta hacer la declaración de los derechos y libertades del hombre. Sería quedar en medio camino. Las constituciones de todos los Estados de América reconocen esos derechos y libertades. Conviene ir más allá, estableciendo también instituciones protectoras de carácter internacional El Pacto Constitutivo del Sistema Interamericano dispone que cada Estado, dentro de su jurisdicción, se halla obligado a resguardar los derechos y libertades del hombre. Eso es insuficiente. Necesitamos que esa protección se extienda en el orden internacional, respecto de los gobiernos que conculcan esos derechos y libertades.

En manera alguna sería admisible una protección política internacional que daría lugar a la intervención, siempre odiosa y contraproducente, por nobles que sean los propósitos que la determinen. Esa protección tiene que ser de carácter judicial y diplomática, limitada a ciertos derechos y libertades.

La proposición uruguaya de reconocer jurisdicción a la Corte de Justicia Internacional, tropieza con el inconveniente de que necesitamos previamente modificar el Estatuto de la Corte, y no sabemos si ello será posible. De adoptarla, en caso de rechazarse la reforma del Estatuto por las Naciones Unidas, nos dejaría en una situación equívoca.

Guatemala nos habla de crear la Corte Interamericana de Justicia; Bolivia sostuvo ya desde 1936, en la Conferencia de Consolidación de la Paz, la creación de dicho organismo. Pero tampoco podemos aplazar hasta que se cree la Corte, la protección de los derechos del hombre.

Por lo menos, consignemos el principio general de protección internacional y señalemos el recurso, dejando el procedimiento y la limitación que propone el Uruguay, para cuando se subscriba un convenio al respecto.

Existe en América una institución cuyos beneficios se ha llegado a apreciar en numerosos casos, y gracias a la cual varios personajes americanos han salvado la vida: es el asilo diplomático. Llega el momento de dar al asilo un nuevo sentido jurídico: que no sea más, una consecuencia de la ficción de extraterritorialidad, ni un acto humanitario o de favor. Reconozcámoslo como un derecho del hombre a ser protegido en determinadas circunstancias y en conformidad con los pactos que reglamentan su ejercicio.

Es por estos antecedentes que la Delegación de Bolivia se permite someter a consideración de los señores delegados, los siguientes artículos adicionales:

Primero, el párrafo relativo a los derechos y libertades fundamentales de la persona humana, se redactaría así:

"Incumbe a cada Estado, dentro de su jurisdicción, hacer respetar los derechos y libertades fundamentales de la persona humana, pudiendo ella emplear en garantía de estos derechos y libertades otros procedimientos jurídicos internacionales, de acuerdo con los pactos que se subscriban al efecto".

1 Documento publicado durante la Conferencia con la clasificación CB-228/C.VI-Sub A-5. 
[618] Segundo, se agregaría el siguiente artículo:

"Toda persona tiene el derecho de asilo, en las condiciones estipuladas por convenios internacionales."

El señor PRESIDENTE: Ofrezco la palabra a cualquier otro delegado que quiera hacer uso de ella en este debate.

\section{[RESPUESTA DEL BRASIL AL GUESTIONARIO URUGUAYO]}

Tiene la palabra el señor Delegado del Brasil.

El señor DE OLIVEIRA (BRASIL): Señor Presidente, señores delegados: el Brasil desea manifestar su más decidido apoyo a la idea de formular en esta Conferencia una Carta de los derechos y deberes del hombre. Aprovecho también esta oportunidad, para manifestar el aprecio que la Delegación del Brasil tiene por el proyecto elaborado por el Comité Jurídico Interamericano de Río de Janeiro ${ }^{1}$ sobre este asunto. Estamos nosotros seguros de que esta Subcomisión encontrará en ese documento una pauta muy útil para el desempeño de la tarea que se nos ha encargado.

Se suscita así, en esta Subcomisión, la cuestión de saber si debemos elaborar el texto de un convenio, o de una declaración, sobre derechos y deberes del hombre; o si tal texto deberá ser incorporado al Pacto Constitutivo del Sistema Interamericano.

En la última sesión de esta Subcomisión, yo manifesté que la Comisión Primera discutiría también el mismo punto de derechos y deberes del hombre, tocando a dicha Comisión elaborar un texto. Hoy, mejor informado sobre los debates de la Comisión Primera, corrijo lo que dije y me inclino a admitir la competencia de la Comisión Sexta para deliberar sobre aquello plenamente.

La Delegación del Brasil no tiene duda alguna en definirse a favor de una declaración que sería anexa al Pacto Constitutivo como instrumento jurídico, susceptible de revisión de acuerdo con la evolución de las ideas en esta materia. Lo que nos parece indispensable, en cumplimiento del mandato que hemos recibido, es que logremos ponernos de acuerdo sobre un texto de declaración, en que se defiendan los derechos y deberes del hombre, en forma aceptable para todos los Estados Americanos.

Estos Estados acaban de fijar en Río de Janeiro las normas que regulan la pauta de sus trabajos. Como bien lo expresó el doctor Alberto Lleras Camargo en la Conferencia de Petrópolis, estos trabajos no serán un punto de llegada, sino un punto de partida, para un ajuste relativo, para la solución pacífica de controversias internacionales para, el instrumento que esta Conferencia está llamada a estudiar y, eventualmente, a aprobar.

En estos momentos, la Novena Conferencia Internacional Americana, de Bogotá, tiene para mejor reafirmar las reglas de derecho en las relaciones interamericanas, que regular el Estatuto necesario para la protección del hombre americano contra los abusos del poder. Comprendo que es tarea muy difícil hallar una definición que sea aceptada por todos los países de América, comprensiva de los derechos del hombre susceptibles de protección internacional.

La Delegación del Brasil se permite opinar, por su parte, que lo más indicado será, quizá, que las fórmulas de tales declaraciones lleven siempre en ellas el margen [619] de garantías que las democracias americanas han conquistado a favor del individuo. En la Consti

1 Documento publicado durante la Conferencia con la clasificación CB-7, transcrito en la pág. 449 siguientes. 
tución del Brasil, por ejemplo, el ciudadano encuentra sus derechos y libertades consagrados en términos muy liberales, no sólo en lo que se refiere a principios políticos, sino también en lo referente a principios económicos, culturales, etcétera.

Ahora tenemos que dedicarnos a llevar la protección de tales derechos a cada uno de los Estados Americanos, dentro de los límites de su jurisdicción. El propio Proyecto de Pacto Constitutivo del Sistema Interamericano, ${ }^{2}$ sobre el cual todos los Estados Americanos han sido llamados a opinar, indica el límite, cuando dice:

Incumbe a cada Estado, dentro de su jurisdicción, hacer respetar los derechos y libertades fundamentales de la persona humana.

El Tratado Interamericano de Asistencia Recíproca declara que:

...la paz se funda en la justicia y en el orden moral y, por tanto, en el reconocimiento y la protección internacionales de los derechos y libertades de la persona humana...

Así, pues, vamos a formular una Carta de los derechos del hombre; y es obvio que la protección de tales derechos no podrá quedar siempre a la buena fe de cada Estado; ésos son los preceptos que habremos de establecer aquí. Una vez reconocidos, como materia de observación común por los países americanos, tales derechos pueden ser efectivos por medio del pronunciamiento de una justicia internacional adecuada. La idea de esa justicia internacional es un nuevo espíritu que surge hoy en América, pues en el pasado, todo se basaba en el dogma de la soberanía de los Estados. Ahora, los Estados Americanos se hallan reunidos aquí con el propósito de sentar (siguiendo la marcha ascendente del panamericanismo) nuevas normas de convivencia pacífica.

En estas evoluciones que esperamos continúen en el futuro en beneficio de las normas de convivencia americana, la Delegación del Brasil desea que se le deje al Comité Jurídico Interamericano la tarea de estudiar las bases del orden internacional, ante el cual se puedan llevar los casos de violación de los derechos del hombre. Esta iniciativa podrá parecer prematura a muchos delegados. El proyecto de Río, que hemos tenido el honor de tomar en cuenta para llegar a los fines deseados, es el pensamiento de un cuerpo de juristas, el Comité Jurídico Interamericano.

La propuesta que formulamos, es someter a los países de América un interrogatorio sobre la materia, para que el asunto sea tenido en cuenta - si no se alcanza en ésta- en la próxima Conferencia Interamericana.

En cuanto al proyecto del Comité Jurídico, el Brasil se ha permitido presentar enmiendas que tendrá ocasión de formular en el curso del debate.

El señor PRESIDENTE: Ofrezco la palabra al señor Delegado de Haití.

\section{[RESPUESTA DE HAITí AL CUESTIONARIO URUGUAYO]}

El señor CHARles (HAITí): Señor Presidente, todos estamos de acuerdo sobre la oportunidad que existe de contemplar la Declaración de los Derechos y Deberes Internacionales del Hombre. Las circunstancias cambian en el mundo, día por día. [620] Parece en estos

2 Documento publicado durante la Conferencia con la clasificación CB-10. La parte pertinente está transcrita en el Volumen III, pág. 9. 
momentos indispensable el definir cuáles son los límites de los derechos del hombre, y cuáles son tales derechos.

Pero, ¿cuál será el alcance de esa declaración? Sobre este punto el acuerdo ya no es unánime; la Delegación de Haití desea presentar su opinión al respecto. Nos parece indispensable que nos detengamos en una declaración pura y simple. Esa declaración debe quedar integrada en el Pacto Constitutivo que contemplamos, con el propósito de que adquiera mayor fuerza; con el propósito de que se demuestre al mundo que las Repúblicas Americanas están decididas a respetar los principios que libremente puedan proclamar. Naturalmente, esta gestión exige cierto valor, entraña cierto sacrificio; pero las circunstancias actuales del mundo nos hacen comprender con toda claridad que esa nueva actitud es la norma que debemos convenir en tomar.

En el fondo, los derechos internacionales del hombre ya los conocemos, y han sido concretados en textos. Puesto que tales derechos, tales deberes, nacieron ya, no es suficiente expresarlos; pues no hubiéramos dado un gran paso con hacerlo. Hay que darles forma de declaración, aunque eso tampoco sería suficiente.

Cuando libremente hayamos determinado que no importa de qué hombre se trate y no importa qué Estados hayan sido víctimas de violación, esas personas podrán quejarse ante un tribunal internacional, con el propósito de obtener una sanción justa. Entonces podremos decir que el derecho internacional americano ha dado un paso adelante, que ha adquirido un aspecto nuevo y que ha propuesto algo grande, algo digno de todo el mundo.

\section{[RESPUESTA DE VENEZUELA AL GUESTIONARIO URUGUAYO]}

El señor LANDER (VENEZUELA): Señor Presidente: me voy a permitir hacer algunas observaciones, en nombre de la representación venezolana, con respecto a la materia de que se trata. En la oportunidad en que las diferentes delegaciones presentan sus puntos de vista generales acerca de la muy importante materia encomendada al estudio de esta Subcomisión, la representación de Venezuela se complace en formular algunas consideraciones de carácter general que, en su opinión, pueden contribuir a una mejor orientación de esta Subcomisión y facilitar la discusión del tema.

Atribuimos trascendental importancia a la consagración de los derechos y deberes fundamentales del hombre, como base esencial de un pacto destinado a consagrar la conquista de la democracia, obtenida en muchas ocasiones como consecuencia de grandes sacrificios de los pueblos americanos, que más de una vez han derramado su sangre para alcanzar el goce pleno de esta garantía. Si tiene suma importancia la consagración de los derechos y deberes de los Estados, como sujeto de las relaciones internacionales, no menor importancia ha de tener la presentación de derechos y deberes de la persona humana, ya que ésta debe constituir en todo momento la máxima preocupación de los gobiernos en defensa de la dignidad humana, muy especialmente en estos tiempos en que graves amenazas se ciernen sobre los individuos y sobre su integridad espiritual y material.

$\mathrm{Al}$ abordar los diferentes puntos de la materia que aquí vamos a tratar, la Delegación Venezolana quiere dejar constancia de su pensamiento, y orientará su [621] acción, en el espíritu de su Carta Fundamental, razón primordial que guía a la nación venezolana. La libertad espiritual, política y económica del hombre, asentada en la dignidad humana, la justicia social y la equitativa participación de todo el pueblo en la riqueza nacional, se sustentan en la democracia como único e irreconciliable sistema de orientar su conducta exterior y su colaboración pacífica, en el designio de auspiciar ese mismo sistema para los gobiernos de todo el mundo. 
$\mathrm{Al}$ hacer esta alusión a nuestra Constitución, hemos tenido en cuenta la estrecha relación del proyecto que se va a discutir, con las leyes fundamentales de otros países. Piensa, además, la Delegación de Venezuela que la Declaración de los derechos y deberes del hombre debe hacerse con criterio universalista, a fin de que en un próximo futuro puedan estar esos derechos al alcance mundial y a fin de concretar el límite común de derechos individuales aceptables por los Estados.

Oportuno es recordar la Carta de las Naciones Unidas, a este respecto: los esfuerzos que representa para lograr la consagración de esas normas esenciales y la cordial radicación de la democracia. Al efecto de estudiar los medios necesarios para coordinar nuestros esfuerzos con los de la citada organización mundial, la representación de Venezuela redactó oportunamente un pliego de observaciones al anteproyecto original del Comité Jurídico Interamericano (el de diciembre de 1946), ${ }^{22 E}$ las cuales han sido incorporadas al texto que vamos a discutir.

Refiriéndonos al texto mismo, observamos lo siguiente: en su oportunidad, Venezuela objetó el título del anteproyecto, por cuanto no se trataba de estudiar los derechos y deberes internacionales del hombre, sino de especificar los derechos y deberes esenciales del hombre, de acuerdo con la Resolución XL de Chapultepec. Pero el título de la Declaración queda redactado así: "Declaración de los Derechos y Deberes Internacionales del Hombre". Es obvio que, al hablar de derechos y deberes del hombre, aludimos a derechos y deberes de los Estados; pero creemos que, en un documento de esta índole, debe tomarse como sujeto al individuo mismo, evitando entrar en los derechos y deberes de los Estados formados por los individuos. En el texto que vamos a discutir, ocurre precisamente que la materia consiste en los derechos internacionales de cada país, más bien que en los del individuo.

Venezuela se permitirá decir a las delegaciones, que desea hacer especial hincapié en la conveniencia de fijar esencialmente normas de igualdad en los postulados que consagra la Declaración, a fin de evitar sentar una discriminación con respecto a sexo, raza o credo: normas que garantizan las funciones políticas y sociales de la mujer.

Uno de los objetivos principales de nuestras intervenciones en esta Subcomisión es que las cláusulas del documento que se va a discutir sean redactadas con la mayor amplitud posible y que se sostengan aquellas excepciones a estas reglas generales que se consideren indispensables, o sean, las que exigen al Estado el sostenimiento de la moral pública o que tienden al mantenimiento de la paz. La declaración de Venezuela, como una promulgación de los derechos y deberes del hombre, habrá dado un paso hacia el perfeccionamiento democrático; y confiamos en que la tradicional vocación de los pueblos de América ha sentado una base que tiene por objeto [622] garantizar el ejercicio de estos derechos humanos sin menoscabo para la soberanía, de modo que constituirán la base efectiva de las constituciones de las Repúblicas Americanas.

Justamente como aquí se ha planteado ya lo relativo a esta fórmula, yo quisiera insistir en ese punto; porque creo que en este mismo momento están reunidas aquí las naciones de América para reorganizar y afianzar el Sistema Interamericano, sobre bases más positivas.

22E Posiblemente esta fecha se debe a un error (debiera decir 1945). Decimos esto porque el APDADDH fue firmado con fecha diciembre de 1945 (sin perjuicio de que el libro que lo contiene es de fecha abril de 1946). Véase AD, pp. 1, 11 y 57. También, porque en AD 57 se lee que el anteproyecto fue sometido a los gobiernos americanos. Por otro lado, la Resolución XL, aprobada en marzo de 1945, le da un plazo de seis meses al Comité Jurídico Interamericano para que redacte el APDADDH. CA, p. 52. Además, el plazo entregado al Comité Jurídico para la redacción de un anteproyecto de pacto constitutivo (que también estaría relacionado con la DADDH), era el 31 de diciembre de 1945 (CA, p. 23), misma fecha que aparece en el APDADDH. Nota del editor A. P. D. 
De manera, pues, que debemos darle mayor vigor y mayor efectividad a todo cuanto aquí resolvamos. Dicha fórmula debemos discutirla aquí. Según nuestra opinión, es necesaria tal fórmula, porque de lo contrario no se lograría nada; todo quedaría en simple enunciado, y una serie de principios vitales en un momento dado podrían ser violados por los Gobiernos. Yo creo que los hombres de América están pidiendo la fórmula efectiva que garantice sus derechos. Sin ella, nuestras reuniones serían, en verdad, más o menos inútiles.

Por ejemplo, se han mencionado repetidamente las amenazas totalitarias que actualmente inquietan al mundo, y se piden medidas muy enérgicas para combatir esas amenazas. La Delegación de Venezuela sustenta el criterio de que, además de las medidas de carácter económico y de justicia social que se deben adoptar para protección de los ciudadanos de América y que en cierto modo son una defensa contra el totalitarismo que explota o que especula sobre las condiciones de nuestros pueblos, también deben tomarse medidas efectivas para defender los derechos políticos de los hombres de América.

Una de las formas de defendernos de esas amenazas totalitarias, es garantizando la libertad, sobre una base plena de las garantías de todos los hombres de América. De esta manera, podríamos nosotros, mediante esa fórmula que se podría adoptar aquí, garantizar a los pueblos de América - y asegurarles nuestras garantías - para contrarrestar esa amenaza totalitaria que se menciona y que (como todos sabemos) se basa en falsas promesas.

Por eso, la Delegación de Venezuela sostiene el criterio de que se adopte aquí una fórmula capaz de hacer efectivos los principios y garantías que va a consagrar el documento.

\section{[RESPUESTA DE REPÚblica DOMINICANA AL CUESTIONARIO URUGUAYO]}

El señor PREsidente: Tiene la palabra el señor Delegado de la República Dominicana.

El señor DeSPRADEL (REPública Dominicana): Señor Presidente, señores delegados: no es mi propósito hacer un discurso de carácter doctrinario acerca de los derechos y deberes internacionales del hombre. Esta es una materia que, por el elevado y generoso espíritu en que se inspira, ha merecido, merece y merecerá siempre, la más absoluta simpatía de todos los pueblos de este Continente. Todas las constituciones de las naciones americanas - estoy seguro de que sin excepción alguna- consagran con sentido de legislación continental los más liberales principios acerca de esta generosa materia; de modo que la simpatía con que han acogido siempre los pueblos de América esta materia, me redime en estos momentos de hacer, como dije, un discurso de carácter doctrinario sobre la misma.

Quiero, sí, en breves palabras, concretar el criterio de mi Gobierno sobre dicha materia. El Gobierno Dominicano contempla, con el mayor entusiasmo y simpatía, [623] todo lo que se oriente y todo lo que tienda a consagrar y a vigorizar los conceptos esenciales que ya se encuentran sentados en el Continente acerca de los derechos y deberes internacionales del hombre.

Ahora bien, sobre este asunto se plantean en la Conferencia dos aspectos esenciales: se tratará, o se resolverá, acerca de esta materia en el sentido de pronunciarse por el simple reconocimiento; o se resolverá en el sentido de pronunciarse por la protección internacional efectiva de esos derechos y deberes.

El Gobierno Dominicano considera que, dada la trascendencia y dada la importancia de la materia, debemos trabajar con sentido liberal y con sentido amplio, pero a la vez con prudencia. Cree el Gobierno Dominicano, relacionando esta materia con los derechos y deberes de los Estados - como es natural, pues guarda íntima relación con ellos - que deberíamos dar un paso de avance en lo relativo a los derechos y deberes de los Estados; esto es, que 
deberíamos incorporar, con sentido normativo del derecho positivo, en el Pacto orgánico, todo lo relativo a los derechos y deberes de los Estados.

El Gobierno Dominicano sustenta la tesis de que debemos trabajar en forma de gradación: incorporar primero, en el Pacto, con sentido normativo del derecho positivo, lo relativo a derechos y deberes de los Estados; y limitarnos en esta ocasión a una declaración de los derechos internacionales del hombre, la cual naturalmente podría vigorizarse, ampliarse y redactarse con el más amplio sentido de liberalismo y con el mayor espíritu de nobleza y de elevación, que la materia requiere.

La Delegación de la República Dominicana está completamente de acuerdo con ese anhelo común, tan justo y tan simple. Por eso le ha prestado especial atención, sintiendo movido su interés de manera extraordinaria, a la brillante exposición que formuló, hace un momento, el distinguido señor representante del Brasil. Considera la Delegación de la República Dominicana que, si es verdad que debemos limitarnos por ahora a una simple declaración sobre esta materia, no debemos tampoco permanecer inactivos sobre las perspectivas futuras y sobre lo que podamos hacer en las próximas conferencias, en el sentido de concretar este importantísimo concepto.

De modo que, concretando así la opinión de la Delegación Dominicana, debo expresar que se pronuncia por que en esta ocasión se haga una declaración sobre derechos y deberes internacionales del hombre. Esta Conferencia podría resolver una fórmula perfecta. La que ha sugerido el Honorable representante del Brasil, permite el estudio de esa materia con miras a llegar a un resultado completamente satisfactorio; ha recibido la aprobación personal de muchos delegados; y la Delegación Dominicana la comparte en un principio, pero con el sentido de prudencia que ya hemos expresado.

Así es que la República Dominicana aprobará la Declaración, y apoyará todo esfuerzo que se haga en el sentido de hacer un estudio, una consideración consciente y reposada, sobre esta materia, para resolver acerca de la misma cuando ya la conciencia colectiva de América tenga la madurez necesaria para realizar ese propósito con sentido positivo y concreto.

\section{[RESPUESTA DE MÉXICO AL GUESTIONARIO URUGUAYO]}

El señor PRESIDENTE: Tiene la palabra el señor Delegado de México.

El señor Fernández del Castillo (MéXiCO): La Delegación de México opina [624] que los derechos fundamentales del hombre deben ser reconocidos con la mayor amplitud, y deben ser respetados por todos los países de América.

Considera también que deben ser protegidos esos derechos en el régimen interno de cada país y en el régimen internacional.

El derecho del hombre, en su enunciación propia, consagrado por la totalidad de las constituciones americanas, es por sí solo suficiente para dar a la dignidad individual el respeto debido; pero al hombre no lo podemos considerar aislado en sus derechos, sino que debemos compaginar la posición que guarda dentro de la sociedad.

La amplitud de los derechos del hombre con relación a la sociedad es el problema fundamental que ha preocupado, desde principios del siglo pasado y especialmente después de la Segunda Guerra Mundial, a los filósofos, a los juristas, a los internacionalistas. Es materia todavía de la preocupación del pensamiento humano. Esto me hace guardar la esperanza de que la Conferencia se guiará por un criterio preciso.

Es motivo de inquietud que todavía el mundo - y América, en particular - no está en la posibilidad de adoptar una fórmula definitiva en relación con este importante asunto. 
Todos los países tienen sus propias necesidades específicas, que constituyen un motivo de preocupación especial en cuanto a sus relaciones con los demás países del Continente y las necesidades comunes.

Este problema se hace aún más agudo en el caso de los países del Continente Americano que tienen la forma federal de gobierno; porque en tales casos las necesidades nacionales, en lo que se refiere a la organización de la vida individual del hombre, no pueden vincularse a ella, sino que esa organización corresponde a los regímenes propios de los elementos constitutivos de la federación.

La principal finalidad es procurar mantener el equilibrio económico, pero procurando también el bienestar general. Confieso que ha de serme especialmente grato contribuir al estudio detenido sobre esta materia, para procurar el bienestar general en relación con el respeto al ser humano.

Los países de América y, en particular, los países de Latino América, nos encontramos todavía en un período de evolución. Tenemos problemas sociales graves con relación a la persona humana, a la cual - dicho sea de paso - respetamos dentro del derecho de nuestras propias constituciones. En Norte América, también, existen leyes que permiten la protección a la persona humana, como la de habeas corpus. Las Constituciones del Brasil y de la República Dominicana parecen realmente sabias. En cambio, la Delegación Mexicana es un poco más escéptica en cuanto a la posibilidad de encomendar la solución de estos problemas a una próxima conferencia.

Debo recordar que México ha sido el país más internacionalista de todos. En la reunión de Chapultepec, fué México el país que propuso la Declaración de Derechos y Deberes del Hombre, y la elaboración de un tratado que viniera a resolver estos problemas. Una vez llevada a efecto tal proposición, los países extranjeros tendrán a la vista una Carta, un documento, en el que se anuncia cuáles son los derechos del hombre.

[625] Por otra parte, los derechos del hombre tienen que compaginarse con las necesidades de la sociedad. Es natural que no puedan considerarse las necesidades ajenas sin juzgarlas a través de las necesidades propias, porque bien puede ocurrir que cada uno de nuestros países tenga necesidades distintas del país que se trate de juzgar. Nos encontraríamos con una frontera internacional de personas no suficientemente identificadas en sus necesidades para poder dar cumplimiento a una declaración que tuviera el carácter de obligación legal internacional y que tal vez se viese en conflicto con los sistemas constitucionales de los varios Estados.

El proyecto formulado por el Comité Jurídico, que merece el respeto de todos, pero al cual tenemos que hacer observaciones, no es conveniente; porque el instrumento adoptado tendría que ser de tal magnitud que pudiera satisfacer a las constituciones de todos los países, o bien, todos los países se verían en el caso de modificar sus constituciones internas.

En la constitución de cada uno de nuestros países, existe la norma de que los derechos del hombre son respetados; pero, sobre todo, hay que establecer una declaración internacional que, aunque no tenga obligatoriedad a través de órganos propulsores, tendrá el respeto correspondiente por haber sido formulado por el órgano más importante del Sistema Interamericano. Este será un documento doctrinal respetado por todos los países, y no habrá ninguno que se atreva a opinar en contra de tal declaración contractual; o bien, si hubiere un país que resolviere oponerse a esa declaración contractual, entonces, en los conflictos internacionales que se presentaren, ella tendrá el valor de un instrumento doctrinal.

La Delegación de México manifiesta, con el mayor entusiasmo, su adhesión a la Declaración de los Derechos y Deberes Internacionales del Hombre; y apoya los propósitos 
tendientes al perfeccionamiento de la protección de esos derechos con un ideal elevado. Además, cree que podría llegarse en el futuro a una solución de la posición individual en todos los países de América.

Por último, la Delegación Mexicana se adhiere a las opiniones manifestadas por los distintos delegados, de que la Declaración de los Derechos y Deberes del Hombre debe ser una mera declaración, anexa al Pacto Constitutivo.

\section{[Respuesta de Chile al Guestionario uruguayo]}

El señor PRESIDENTE: Ruego al señor Delegado de Honduras pase a la Mesa para asumir la Presidencia mientras yo formule algunas observaciones en nombre de la Delegación de Chile.

(El señor GÁlvez, Delegado de Honduras, asume la Presidencia, y el señor BERnsteIn sigue hablando, como Delegado de CHILE.)

La Delegación de Chile ha escuchado complacida la opinión expuesta por el Honorable Delegado de México.

El Gobierno de Chile tiene una tradición muy hermosa y muy respetable de libertad, y no acepta lecciones de ningún otro país. El Gobierno de Chile corresponderá al momento en que vivimos, en que el totalitarismo rojo es mucho más peligroso que el fascismo o el nazismo. Espera de la Conferencia de Bogotá que haga una declaración en favor de los principios que tienen al hombre como centro y supremo árbitro de la felicidad.

No es esto un problema que interese solamente ahora a mi Gobierno. En la [626] Conferencia de Consolidación de la Paz, celebrada en Buenos Aires hace 11 años, la Delegación Chilena propuso el reconocimiento de los derechos de todos los individuos a la vida, a la libertad y al libre ejercicio de todo culto; y se comprometió a otorgar a todos los habitantes de su territorio eficaz protección de sus derechos, sin distinción de sexo, de raza ni de religión. Más tarde, en la Conferencia de San Francisco, el antiguo Delegado de Chile y actual Presidente de la República, Gabriel González Videla, sostuvo con energía se encargase la organización mundial de garantizar a los individuos sus derechos, sin distingos de nacionalidad, raza, sexo, ni religión, inclusive el derecho del libre ejercicio - tanto público como privado - de su profesión, religión, ciencia o arte, que no fuere incompatible con la moral pública. Tampoco tuvo éxito aquella tentativa. Por último, en la reciente Conferencia de Quitandhina y en asocio del señor Delegado del Uruguay, señor Regules, nuestro delegado, propuso la inclusión de la norma de que la paz se funda necesariamente en los derechos de libertad de la persona humana.

Mi Gobierno considera, en efecto, que la Declaración de los derechos fundamentales del hombre es una condición esencial para la cooperación amistosa entre las naciones y para la paz del mundo. Considera que allí donde se desconocen los derechos individuales, se hallan la reacción y la opresión; que allí se encuentran los gérmenes de la guerra. Sostiene que, para la paz del mundo, es necesario que no se sometan los individuos al poder omnímodo del Estado.

La Delegación de Chile estima indispensable que en esta Conferencia se adopte una declaración por la cual se conceda al hombre el derecho de tener su bienestar material, dentro de condiciones de dignidad, de libertad, de igualdad. Al efecto, considera de importancia el proyecto sometido por el Comité Jurídico de Río de Janeiro. Sin embargo, mi delegación encuentra inconvenientes serios en este proyecto, pues contiene normas demasiado detalladas. 
El Consejo Económico y Social de las Naciones Unidas ha creado una Comisión destinada al estudio de los derechos humanos. Existe, por tanto, una organización internacional de carácter general que está considerando la misma materia que aquí tratamos. El derecho del hombre es el mismo, en cualquier país del mundo en que se encuentre. Debemos dar a todos los miembros de la sociedad un derecho igual, con un generoso impulso universal. La opresión a un ciudadano en Checoeslovaquia o en Yugoeslavia debe considerarse como si sucediera en este Continente nuestro. La delegación que represento demuestra su anhelo en el sentido de esperar el resultado de los trabajos de las Naciones Unidas en pro de los principios fundamentales de los derechos del individuo, de carácter político, económico y social.

No quiero entrar en detalles en esta ocasión en la enumeración de los propósitos expuestos en 1939, de que se ampliaran los derechos y deberes del individuo, para contar con la ayuda eficaz del mismo en la elevación del nivel de vida, adecuada para el desenvolvimiento de su personalidad.

Respecto a la Declaración que hemos de formular aquí de los derechos del hombre, debe ser incorporada al Pacto Constitutivo del Sistema Interamericano.

(Tomando de nuevo la Presidencia, el señor Presidente concede la palabra al señor Delegado del Ecuador.)

\section{[RESPUESTA DE ECUADOR AL GUESTIONARIO URUGUAYO]}

[627] El señor García ORTIZ (EGUAdOR): Señor Presidente: a nombre de la Delegación del Ecuador, solicito se me permita expresar brevemente algunas ideas a este respecto.

La Delegación del Ecuador se halla perfectamente enterada, como lo están todos los delegados de los demás países, de la importancia que reviste esta Declaración interamericana de los derechos y deberes del hombre, y se complace en que este Continente sea el primero que formule una declaración de tal índole.

La Delegación del Ecuador estima que los deberes y derechos de los Estados, sí pueden constar como parte integrante del Pacto Constitutivo.

Dejo así expuestos los puntos de vista de mi delegación, que felizmente coinciden con los de muchos de los delegados, señor Presidente.

\section{[Respuesta de Panamá al Guestionario uruguayo]}

El señor PRESIDENTE: Tiene la palabra el señor Delegado de Panamá.

El señor Chiari (PANAMÁ): La Delegación de Panamá tiene presente lo establecido en la Resolución XL de Chapultepec, según la cual la declaración que adopten en firme los Estados debe ser consagrada en forma de convención.

Además, considera la Delegación de Panamá que, para obtener resultados efectivos de la Declaración dentro de un término breve, conviene constituir un comité de derechos y deberes. El proyecto de Panamá sobre este punto será distribuido en la próxima sesión.

Convendría no cerrar el debate hasta la próxima sesión, en que ya se podrá entrar al estudio detallado del asunto. Entonces, cuando tengamos información completa, también deberán ser ampliamente discutidas las proposiciones que han sido presentadas.

Ruego que la Secretaría se digne distribuir copias del proyecto elaborado por el Consejo Económico y Social de las Naciones Unidas que, según información que he recibido, han sido traídas en inglés. Podrían hacerse copias en español, también, y quizá en francés. Además, espero que los señores delegados que han leído proyectos o documentos relacionados 
con el debate, se sirvan hacer entregar a la Secretaria dichos documentos, a efecto de que la Secretaría los copie y los haga distribuir entre todos los delegados aquí presentes, a fin de facilitar las tareas de las delegaciones.

El señor PRESIDENTE: Tiene la palabra el señor Delegado de Bolivia.

El señor Paz Campero (BOLIVIA): Creo que podría hacer un resumen de lo que he dicho, y pasarlo a la Secretaría.

El señor PRESIDENTE: Tiene la palabra el señor Delegado de Cuba.

El señor PÉrez Cisneros (CUBA): A pesar de las varias solicitudes que han sido elevadas hoy a la Secretaría, quisiera añadir una más. En realidad, considero que sería muy conveniente que la Secretaría nos presentara, no uno o dos, sino todos los documentos de esta Subcomisión, para que los estudiáramos. Sería útil conocer todos los documentos que se refieren a nuestros trabajos.

El señor PRESIDENTE: Me permito informarles que ya han sido distribuidos a las varias delegaciones los documentos entre los cuales figura el proyecto presentado por la Delegación de México, y los puntos de vista de los señores Delegados del Uruguay y del Brasil.

[628] El señor FERnáNDEZ DEL CASTILlO (MÉXICO): Yo tuve oportunidad de entregar al señor Relator los puntos de vista de las diversas delegaciones sobre el asunto en discusión. Sería muy importante para las delegaciones saber cuál fué el resultado.

El señor PRESIDENTE: Se han recibido 11 ó 12. Esperamos recibir las que faltan para completar los 21 países.

El señor DeSPRADEL (REPÚBliCa DOMINICANA): Están contestadas explícitamente las preguntas planteadas por la Delegación del Uruguay.

El señor Mendoza (Guatemala): Por un retraso lamentable, no fué posible a la Delegación de Guatemala presentar ayer sus puntos de vista sobre este asunto; pero prometo serán entregadas esta mañana a la Secretaría.

El señor PRESIDENTE: Se levanta la sesión. ${ }^{1}$

1 No volvió a reunirse la Subcomisión A. Véase el resumen general de los trabajos de la Comisión Sexta y de sus Subcomisiones, contenido en el documento publicado durante la Conferencia con la clasificación CB-445/C.VI-36, pág. 510 y siguientes. 
Este libro forma parte del acervo de la Biblioteca Jurídica Virtual del Instituto de Investigaciones Jurídicas de la UNAM www.juridicas.unam.mx

\author{
NOVENA \\ GONFERENGIA INTERNACIONAL \\ AMERICANA \\ Bogotá, Colombia \\ marzo 30-mayo 2 de 1948
}

\title{
ACTAS Y DOGUMENTOS
}

\author{
VOLUMEN VI
}

CONGLUSIONES

Acta Final-Instrumentos Diplomáticos

MINISTERIO DE RELACIONES EXTERIORES

DE COLOMBIA

Bogotá, 1953

DR $\odot 2017$.

Instituto de Investigaciones Jurídicas - Universidad Nacional Autónoma de México. 


\section{XXX \\ DEGLARAGION AMERICANA DE LOS DERECHOS Y DEBERES DEL HOMBRE}

La Novena Conferencia Internacional Americana,

CONSIDERANDO:

Que los pueblos americanos han dignificado la persona humana y que sus constituciones nacionales reconocen que las instituciones jurídicas y políticas, rectoras de la vida en sociedad, tienen como fin principal la protección de los derechos esenciales del hombre y la creación de circunstancias que le permitan progresar espiritual y materialmente y alcanzar la felicidad;

Que, en repetidas ocasiones, los Estados Americanos han reconocido que los derechos esenciales del hombre no nacen del hecho de ser nacional de determinado Estado sino que tienen como fundamento los atributos de la persona humana;

Que la protección internacional de los derechos del hombre debe ser guía principalísima del derecho americano en evolución; y

Que la consagración americana de los derechos esenciales del hombre unida a [248] las garantías ofrecidas por el régimen interno de los Estados, establece el sistema inicial de protección que los Estados Americanos consideran adecuado a las actuales circunstancias sociales y jurídicas, no sin reconocer que deberán fortalecerlo cada vez más en el campo internacional, a medida que esas circunstancias vayan siendo más propicias,

ACUERDA adoptar la siguiente

\section{Declaración Americana de los Derechos y Deberes del Hombre}

\section{PREAMBULO}

Todos los hombres nacen libres e iguales en dignidad y derechos y, dotados como están por naturaleza de razón y conciencia, deben conducirse fraternalmente los unos con los otros.

El cumplimiento del deber de cada uno es exigencia del derecho de todos. Derechos y deberes se integran correlativamente en toda actividad social y política del hombre. Si los derechos exaltan la libertad individual, los deberes expresan la dignidad de esa libertad.

Los deberes de orden jurídico presuponen otros, de orden moral, que los apoyan conceptualmente y los fundamentan.

Es deber del hombre servir al espíritu con todas sus potencias y recursos, porque el espíritu es la finalidad suprema de la existencia humana y su máxima categoría.

Es deber del hombre ejercer, mantener y estimular por todos los medios a su alcance la cultura, porque la cultura es la máxima expresión social e histórica del espíritu.

Y puesto que la moral y buenas maneras constituyen la floración más noble de la cultura, es deber de todo hombre acatarlas siempre.

\section{CAPITULO PRIMERO \\ Derechos}

ARTículo I. Todo ser humano tiene derecho a la vida, a la libertad y a la seguridad de su persona.
Derecho a la vida, a la libertad, a la seguridad e integridad de la persona 
ARTículO II. Todas las personas son iguales ante la Ley y tienen los derechos y deberes consagrados en esta Declaración, sin distinción de raza, sexo, idioma, credo ni otra alguna.

ARTículo III. Toda persona tiene el derecho de profesar libremente una creencia religiosa y de manifestarla y practicarla en público y en privado.

ARTículo IV. Toda persona tiene derecho a la libertad de investigación, de opinión y de expresión y difusión del pensamiento por cualquier medio.

[249] ARTículo V. Toda persona tiene derecho a la protección de la Ley contra los ataques abusivos a su honra, a su reputación $\mathrm{y}$ a su vida privada y familiar.

ARTículO VI. Toda persona tiene derecho a constituir familia, elemento fundamental de la sociedad, y a recibir protección para ella.

ARTículo VII. Toda mujer en estado de gravidez o en época de lactancia, así como todo niño, tienen derecho a protección, cuidados y ayuda especiales.

ARTículO VIII. Toda persona tiene el derecho de fijar su residencia en el territorio del Estado de que es nacional, de transitar por él libremente y no abandonarlo sino por su voluntad.

ARTículo IX. Toda persona tiene el derecho a la inviolabilidad de su domicilio.

ARTículo X. Toda persona tiene derecho a la inviolabilidad y circulación de su correspondencia.

ARTículo XI. Toda persona tiene derecho a que su salud sea preservada por medidas sanitarias y sociales, relativas a la alimentación, el vestido, la vivienda y la asistencia médica, correspondientes al nivel que permitan los recursos públicos y los de la comunidad.

ARTículO XII. Toda persona tiene derecho a la educación, la que debe estar inspirada en los principios de libertad, moralidad y solidaridad humanas.

Asimismo tiene el derecho de que, mediante esa educación, se le capacite para
Derecho de igualdad ante la Ley

Derecho a la libertad religiosa y de culto

Derecho de libertad de investigación, opinión, expresión y difusión

Derecho a la protección a la honra, la reputación personal y la vida privada y familiar

Derecho a la constitución y a la protección de la familia

Derecho de protección a la maternidady a la infancia

Derechos de residencia y tránsito

Derecho a la inviolabilidad del domicilio

Derecho a la inviolabilidad y circulación de la correspondencia

Derecho a la preservación de la saludy al bienestar

Derecho a la educación 
lograr una digna subsistencia, en mejoramiento del nivel de vida y para ser útil a la sociedad.

El derecho de educación comprende el de igualdad de oportunidades en todos los casos, de acuerdo con las dotes naturales, los méritos y el deseo de aprovechar los recursos que puedan proporcionar la comunidad y el Estado.

Toda persona tiene derecho a recibir gratuitamente la educación primaria, por lo menos.

ARTículO XIII. Toda persona tiene el derecho de participar en la vida cultural de la comunidad, gozar de las artes y disfrutar de los bene- [250] ficios que resulten de los progresos intelectuales y especialmente de los descubrimientos científicos

Tiene asimismo derecho a la protección de los intereses morales y materiales que le correspondan por razón de los inventos, obras literarias, científicas o artísticas de que sea autor

ARTículo XIV. Toda persona tiene derecho al trabajo en condiciones dignas y a seguir libremente su vocación, en cuanto lo permitan las oportunidades existentes de empleo.

Toda persona que trabaja tiene derecho de recibir una remuneración que, en relación con su capacidad y destreza, le asegure un nivel de vida conveniente para sí misma y su familia.

ARTículo XV. Toda persona tiene derecho a descanso, a honesta recreación y a la oportunidad de emplear útilmente el tiempo libre en beneficio de su mejoramiento espiritual, cultural y físico.

ARTículO XVI. Toda persona tiene derecho a la seguridad social que la proteja contra las consecuencias de la desocupación, de la vejez y de la incapacidad que, proveniente de cualquier otra causa ajena a su voluntad, la imposibilite física o mentalmente para obtener los medios de subsistencia.

ARTículO XVII. Toda persona tiene derecho a que se le reconozca en cualquier
Derecho a los beneficios de la cultura

Derecho al trabajo y a una justa retribución

Derecho al descanso y a su aprovechamiento

Derecho a la seguridad social

Derecho de reconocimiento de la personalidad jurídica $y$ de los derechos civiles 
parte como sujeto de derechos y obligaciones, y a gozar de los derechos civiles fundamentales.

ARTículo XVIII. Toda persona puede ocurrir a los tribunales para hacer valer sus derechos. Asimismo debe disponer de un procedimiento sencillo y breve por el cual la justicia la ampare contra actos de la autoridad que violen, en perjuicio suyo, alguno de los derechos fundamentales consagrados constitucionalmente.

ARTículO XIX. Toda persona tiene derecho a la nacionalidad que legalmente le corresponda y el de cambiarla, si así lo desea, por la de cualquier otro país que esté dispuesto a otorgársela.

ARTículo XX. Toda persona, legalmente capacitada, tiene el derecho de tomar parte en el gobierno de su país, directamente o por medio de sus representantes, y de participar en las eleccio-[251]nes populares, que serán de voto secreto, genuinas, periódicas y libres

ARTículO XXI. Toda persona tiene el derecho de reunirse pacíficamente con otras, en manifestación pública o en asamblea transitoria, en relación con sus intereses comunes de cualquier índole.

ARTículo XXII. Toda persona tiene el derecho de asociarse con otras para promover, ejercer y proteger sus intereses legítimos de orden político, económico, religioso, social, cultural, profesional, sindical o de cualquier otro orden.

ARTículo XXIII. Toda persona tiene derecho a la propiedad privada correspondiente a las necesidades esenciales de una vida decorosa, que contribuya a mantener la dignidad de la persona y del hogar.

ARTículo XXIV. Toda persona tiene derecho de presentar peticiones respetuosas a cualquiera autoridad competente, ya sea por motivo de interés general, ya de interés particular, y el de obtener pronta resolución.

ARTículO XXV. Nadie puede ser privado de su libertad sino en los casos y según las formas establecidas por leyes preexistentes.
Derecho de fusticia

Derecho de nacionalidad

Derecho de sufragio y de participación en el gobierno

Derecho de reunión

Derecho de asociación

Derecho a la propiedad

Derecho de petición

Derecho de protección contra la detención arbitraria 
Nadie puede ser detenido por incumplimiento de obligaciones de carácter netamente civil.

Todo individuo que haya sido privado de su libertad tiene derecho a que el juez verifique sin demora la legalidad de la medida y a ser juzgado sin dilación injustificada, o, de lo contrario, a ser puesto en libertad. Tiene derecho también a un tratamiento humano durante la privación de su libertad.

ARTículO XXVI. Se presume que todo acusado es inocente, hasta que se pruebe que es culpable.

Toda persona acusada de delito tiene derecho a ser oída en forma imparcial y pública, a ser juzgada por tribunales anteriormente establecidos de acuerdo con leyes preexistentes y a que no se le impongan penas crueles, infamantes o inusitadas.

ARTículO XXVII. Toda persona tiene el derecho de buscar y recibir asilo en territorio ex- [252] tranjero, en caso de persecución que no sea motivada por delitos de derecho común y de acuerdo con la legislación de cada país y con los convenios internacionales

ARTículo XXVIII. Los derechos de cada hombre están limitados por los derechos de los demás, por la seguridad de todos y por las justas exigencias del bienestar general y del desenvolvimiento democrático.

Derecho a proceso regular

\section{Derecho de asilo}

Alcance de los derechos del hombre

\section{CAPITULO SEGUNDO \\ DEBERES}

ARTículo XXIX. Toda persona tiene el deber de convivir con las demás, de manera que todas y cada una puedan desenvolver integralmente su personalidad.

ARTículO XXX. Toda persona tiene el deber de asistir, alimentar, educar y amparar a sus hijos menores de edad, y los hijos tienen el deber de honrar siempre a sus padres y el de asistirlos, alimentarlos y ampararlos cuando éstos lo necesiten.

\section{Deberes ante la sociedad}

Deberes para con los hijos y los padres 
Este libro forma parte del acervo de la Biblioteca Jurídica Virtual del Instituto de Investigaciones Jurídicas de la UNAM

ARTículo XXXI. Toda persona tiene el deber de adquirir a lo menos la instrucción primaria

ARTículO XXXII. Toda persona tiene el deber de votar en las elecciones populares del país de que sea nacional, cuando esté legalmente capacitada para ello.

ARTículo XXXIII. Toda persona tiene el deber de obedecer a la Ley y demás mandamientos legítimos de las autoridades de su país y de aquel en que se encuentre.

ARTículOXXXIV. Toda persona hábil tiene el deber de prestar los servicios civiles y militares que la Patria requiera para su defensa y conservación y, en caso de calamidad pública, los servicios de que sea capaz.

Asimismo tiene el deber de desempeñar los cargos de elección popular que le correspondan en el Estado de que sea nacional.

ARTículO XXXV. Toda persona tiene el deber de cooperar con el Estado y con la comunidad en la asistencia y seguridad sociales, de acuerdo con sus posibilidades y con las circunstancias.

ARTículo XXXVI. Toda persona tiene el deber de pagar los impuestos establecidos por la Ley para el sostenimiento de los servicios públicos.

[253] ARTículo XXXVII. Toda persona tiene el deber de trabajar, dentro de su capacidad y posibilidades, a fin de obtener recursos para su subsistencia o en beneficio de la comunidad.

ARTículO XXXVIII. Toda persona tiene el deber de no intervenir en las actividades políticas que, de conformidad con la Ley, sean privativas de los ciudadanos del Estado en que sea extranjero.

\section{Deber de instrucción}

Deber de sufragio

Deber de obediencia a la Ley

Deber de servir a la comunidady a la nación

Deberes de asistencia y seguridad sociales

Deber de pagar impuestos

Deber de trabajo

Deber de abstenerse de actividades politicas en país extranjero

La Novena Conferencia Internacional Americana, CONSIDERANDO: 
Este libro forma parte del acervo de la Biblioteca Jurídica Virtual del Instituto de Investigaciones Jurídicas de la UNAM

Que los derechos del hombre, internacionalmente reconocidos, deben tener protección adecuada;

Que esa protección debe ser garantizada por un órgano jurídico, como quiera que no hay derecho propiamente asegurado sin el amparo de un tribunal competente; $y$

Que, tratándose de derechos internacionalmente reconocidos, la protección jurídica para ser eficaz debe emanar de un órgano internacional,

RECOMIENDA:

Que el Comité Jurídico Interamericano elabore un proyecto de estatuto para la creación y funcionamiento de una Corte Interamericana destinada a garantizar los derechos del hombre. Este proyecto, después de ser sometido al examen y a las observaciones de los Gobiernos de todos los Estados Americanos, deberá ser remitido a la Décima Conferencia Interamericana para que ésta lo estudie, si considera que ha llegado el momento para una decisión sobre la materia. 


\section{$\mathrm{XXX}$ \\ AMERICAN DECLARATION OF THE RIGHTS AND DUTIES OF MAN}

\section{WHEREAS:}

The American peoples have acknowledged the dignity of the individual and their national constitutions recognize that juridical and political institutions, which regulate life in human society, have as their principal aim the protection of the essential rights of man and the creation of circumstances that will permit him to achieve spiritual and material progress and attain happiness;

The American States have on repeated occasions recognized that the essential rights of man are not derived from the fact that he is a national of a certain State, but are based upon attributes of his human personality;

The international protection of the rights of man should be the principal guide of an evolving American law; and

The affirmation of essential human rights by the American States, together with the guarantees given by the internal regimes of the States, establish the initial system of protection considered by the American States as being suited to the present social and juridical conditions, not without a recognition on their part that they should increasingly strengthen that system in the international field as conditions become more favorable,

The Ninth International Conference of American States AGREES

To adopt the following

\section{AMERICAN DECLaRation Of THE Rights AND Duties OF MAN}

\section{PREAMBLE}

All men are born free and equal in dignity and in rights, and, being endowed by nature with reason and conscience, they should conduct themselves as brothers one to another.

The fulfillment of duty by each individual is a prerequisite to the rights of all. Rights and duties are interrelated in every social and political activity of man. While rights exalt individual liberty, duties express the dignity of that liberty.

Duties of a juridical nature presuppose others of a moral nature which support them in principle and constitute their basis.

[298] Inasmuch as spiritual development is the supreme end of human existence and the highest expression thereof, it is the duty of man to serve that end with all his strength and resources.

Since culture is the highest social and historical expression of that spiritual development, it is the duty of man to preserve, practice and foster culture by every means within his power.

And, since moral conduct constitutes the noblest flowering of culture, it is the duty of every man always to hold it in high respect. 
ARTICLE I. Every human being has the right to life, liberty and the security of his person.

ARTICLE II. All persons are equal before the law and have the rights and duties established in this Declaration, without distinction as to race, sex, language, creed or any other factor.

ARTICLE III. Every person has the right freely to profess a religious faith, and to manifest and practice it both in public and in private.

ARTICLE IV. Every person has the right to freedom of investigation, of opinion, and of the expression and dissemination of ideas, by any medium whatsoever.

ARTICLE V. Every person has the right to the protection of the law against abusive attacks upon his honor, his reputation, and his private and family life.

ARTICLE VI. Every person has the right to establish a family, the basic element of society, and to receive protection therefore.

ARTICLE VII. All women, during pregnancy and the nursing period, and all children, have the right to special protection, care and aid.

ARTICLE VIII. Every person has the right to fix his residence within the territory of the State of which he is a national, to move about freely within such territory, and not to leave it except by his own will.

ARTICLE IX. Every person has the right to the inviolability of his borne.

ARTICLE X. Every person has the right to the inviolability and transmission of his correspondence.

[299] ARTICLE XI. Every person has the right to the preservation of his health through sanitary and social measures relating to food, clothing, housing and medical care, to the extent permitted by public and community resources.
Right to life, liberty and personal security

Right to equality before the law

\section{Right to religious freedom and worship}

Right to freedom of investigation, opinion, expression and dissemination

Right to protection of honor, personal reputation, and private and family life

Right to a family and to the protection thereof

Right to protection for mothers and children

Right to residence and movement

Right to inviolability of the home

Right to the inviolability and transmission of correspondence

Right to the preservation of health and to well-being 
ARTICLE XII. Every person has the right to an education, which should be based on the principles of liberty, morality and human solidarity.

Likewise every person has the right to an education that will prepare him to attain a decent life, to raise his standard of living and to be a useful member of society.

The right to an education includes the right to equality of opportunity in every case, in accordance with natural talents, merit and the desire to utilize the resources that the State or the community is in a position to provide.

Every person has the right to receive, free, at least a primary education.

ARTICLE XIII. Every person has the right to take part in the cultural life of the community, to enjoy the arts, and to participate in the benefits that result from intellectual progress, especially scientific discoveries.

He likewise has the right to the protection of his moral and material interests as regards his inventions or any literary, scientific or artistic works of which he is the author.

ARTICLE XIV. Every person has the right to work, under proper conditions, and to follow his vocation freely, insofar as existing conditions of employment permit.

Every person who works, has the right to receive such remuneration as will, in proportion to his capacity and skill, assure him a standard of living suitable for himself and for his family.

ARTICLE XV. Every person has the right to leisure time, to wholesome recreation and to the opportunity for advantageous use of his free time to his spiritual, cultural and physical benefit.

ARTICLE XVI. Every person has the right to social security which will protect him from the consequences of unemployment, old age and any disabilities arising from causes beyond his control

[300] that make it physically or mentally impossible for him to earn a living.

ARTICLE XVII. Every person has the right to be recognized everywhere as a per-

\section{Right to education}

Right to the benefits of culture

Right to work and to fair remuneration

Right to leisure time and to the use thereof

Right to social security

Right to recognition of juridical personality and of civil rights 
son having rights and obligations, and to enjoy the basic civil rights.

ARTICLE XVIII. Every person may resort to the courts to ensure respect for his legal rights. There should likewise be available to him a simple, brief procedure whereby the courts will protect him from acts of authority that, to his prejudice, violate any fundamental constitutional rights.

ARTICLE XIX. Every person has the right to the nationality to which he is entitled by law and to change it, if he so wishes, for the nationality of any other country that is willing to grant it to him.

ARTICLE XX. Every person having legal capacity is entitled to participate in the government of his country, directly or through his representatives, and to take part in popular elections, which shall be by secret ballot, and shall be honest, periodic and free.

ARTICLE XXI. Every person has the right to assemble peaceably with others in a formal public meeting or an informal gathering, in connection with matters of common interest of any nature.

ARTICLE XXII. Every person has the right to associate with others to promote, exercise and protect his legitimate interests of a political, economic, religious, social, cultural, professional, labor-union or other nature.

ARTICLE XXIII. Every person has a right to own such private property as meets the essential needs of decent living and helps to maintain the dignity of the individual and of the home.

ARTICLE XXIV. Every person has the right to submit respectful petitions to any competent authority, for reasons of both general or private interest, and the right to obtain a prompt decision thereon.

ARTICLE XXV. No person may be deprived of his liberty except in the cases and according to the procedures established by pre-existing law.
Right to a fair trial

Right to nationality

Right to vote and to participate in government

$$
\text { Right of assembly }
$$

Right of association

Right to property

Right of petition

Right to protection from arbitrary arrest 
No person may be deprived of liberty for Non- [301] fulfillment of obligations of a purely civil character.

Every individual who has been deprived of his liberty has the right to have the legality of his detention ascertained without delay by a court, and the right to be tried without undue delay, or, otherwise, to be released. He also has the right to humane treatment during the time he is in custody.

ARTICLE XXVI. Every accused person is presumed to be innocent until proved guilty.

Every person accused of an offense has the right to be given an impartial and public hearing, and to be tried by courts previously established in accordance with pre-existing laws, and not to receive cruel, infamous or unusual punishment.

ARTICLE XXVII. Every person has the right, in case of pursuit not resulting from ordinary crimes, to seek and receive asylum in foreign territory, in accordance with the laws of each country and with international agreements.

ARTICLE XXVIII. The rights of man are limited by the rights of others, by the security of all, and by the just demands of the general welfare and the advancement of democracy.

Right to due process of law

Right of asylum

Scope of the rights of man

\section{CHAPTER TWO \\ DUTIES}

ARTICLE XXIX. It is the duty of the individual so to conduct himself in relation to others that each and every one may fully form and develop his personality.

ARTICLE XXX. It is the duty of every person to aid, support, educate and protect his minor children, and it is the duty of children to honor their parents always and to aid, support and protect them when they need it.

ARTICLE XXXI. It is the duty of every person to acquire at least an elementary education.

\section{Duties to society}

Duties toward children and parents

Duty to receive instruction 
ARTICLE XXXII. It is the duty of every person to vote in the popular elections of the country of which he is a national, when he is legally capable of doing so.

[302] ARTICLE XXXIII. It is the duty of every person to obey the law and other legitimate commands of the authorities of his country and those of the country in which he may be.

ARTICLE XXXIV. It is the duty of every able-bodied person to render whatever civil and military service his country may require for its defense and preservation, and, in case of public disaster, to render such services as may be in his power.

It is likewise his duty to hold any public office to which he may be elected by popular vote in the State of which he is a national.

ARTICLE XXXV. It is the duty of every person to cooperate with the State and the community with respect to social security and welfare, in accordance with his ability and with existing circumstances.

ARTICLE XXXVI. It is the duty of every person to pay the taxes established by law for the support of public services.

ARTICLE XXXVII. It is the duty of every person to work, as far as his capacity and possibilities permit, in order to obtain the means of livelihood or to benefit his community.

ARTICLE XXXVIII. It is the duty of every person to refrain from taking part in political activities that, according to law, are reserved exclusively to the citizens of the State in which he is an alien.

\section{Duty to vote}

Duty to obey the law

Duty to serve the community and the nation

Duties with respect to social security and welfare

Duty to pay taxes

Duty to work

Duty to refrain from political activities in a foreign country

\section{XXXI \\ INTER-AMERICAN COURT TO PROTECT THE RIGHTS OF MAN}

\section{WHEREAS:}

The internationally recognized rights of man should be properly protected;

Such protection should be guaranteed by a juridical organ, inasmuch as no right is genuinely assured unless it is safeguarded by a competent court; and 
Where internationally recognized rights are concerned, juridical protection, to be effective, should emanate from an international organ,

The Ninth International Conference of American States RECOMMENDS:

That the Inter-American Juridical Committee prepare a draft Statute providing for the creation and functioning of an Inter-American Court to guarantee the [303] rights of man. Such draft, after being submitted to the Governments of all the American States for examination and comment, shall be transmitted to the Tenth Inter-American Conference for study, if it is felt that the moment has arrived for a decision thereon. 


\section{ÍNDICE TEMÁTICO}

Los números hacen referencia a las páginas señaladas en los documentos originales. Para evitar confusiones, se señala el documento en cada uno de los casos, según las abreviaturas indicadas al comienzo de este libro.

1. Conferencias Internacionales Americanas. Segundo Suplemento, en adelante CA

2. Anteproyecto de Declaración de los Derechos y Deberes Internacionales del Hombre e Informe Anexo, en adelante AD

3. Novena Conferencia Internacional Americana. Actas y Documentos. Vol. 1, en adelante NCI

4. Novena Conferencia Internacional Americana. Actas y Documentos. Vol. 5, en adelante NCV

5. Novena Conferencia Internacional Americana. Actas y Documentos. Vol. 6, en adelante NCVI

A

Academia Internacional de Derecho Comparado NCV 544

Agravio AD 4, 30-31; NGV 451, 463

Analfabetismo

Analfabeto AD 46; NCV 451, 459, 603

Apátridas AD 33-34; NCV 465

Arbitrariedad AD 7, 10, 26, 38, 48-49;

NCV 452, 469, 473, 501, 514, 600

Detención Arbitraria AD 18, 36- 37, 455

Prisión arbitraria AD 36

Derecho de Protección contra la

Prisión Arbitraria AD 7; NGV

452, 482, 498, 507; NCVI 251
Asilo NGV 468, 482, 499, 508, 514, 545, 551, 595, 617, 618; NCVI 252

Derecho de Asilo NCV 468, 499, 508, 514, 545, 551, 595, 618; NCVI 252

B

Bienestar CA 20-21; AD 1, 8, 14, 18-21, 28, 33, 35-36, 38, 40-41, 44, 46; NCV 452, 456, 476, 480, 483, 496, 499, 505, 508, $511,541,579-580,596-597,599,624,626$

Bienestar social AD 30, 33, 36

C

Carta del Atlántico AD 44, 51

Carta de Filadelfia AD 18, 41

Carta Económica de las Américas AD 42

Censura AD 3, 13, 22-23, 26; NGV 450, 457, 579 
Este libro forma parte del acervo de la Biblioteca Jurídica Virtual del Instituto de Investigaciones Jurídicas de la UNAM

De la Cinematografía

Véase Cinematógrafo

De la Correspondencia

Véase Correspondencia

De la Imprenta NCV 467

De la Prensa AD 3, 13, 23, 26; NGV 450

Cinematógrafo AD 2-3, 23, 25, 26; NCV 449, 457-458, 467

Censura de la Cinematografía AD 3, 23; NGV 450, 457, 458

Colonias CA 111; AD 40; NCV 437, 503, 510-511, 516, 535, 608

Comisión Interamericana de Mujeres CA 24, 110

Comité Jurídico CA 33; NCV 464, 486

Compañías AD 30; NGV 591

Competencia internacional NCV 463, 546$548,556,613$

Conferencias Internacionales Americanas

Conferencia de Bogotá CA V; NGV 454

Conferencia de Buenos Aires AD 45

Conferencia de Chapultepec CA V;

NCV 461,476-477, 513, 569- 570, 627

Conferencia de la Habana AD 44, 49

Conferencia de Lima CA 109; NCI 6-7; AD 45; NCV 510, 616

Conferencia de México AD 52- 53, 57; NCV 455, 570
Conferencia de Montevideo AD 44

Conferencia de Petrópolis CA V; NGV 456, 618

Conferencia Interamericana de Seguridad Social AD 45

Conferencia sobre Problemas de la Guerra y de la Paz CA 3, 20, 24, 52, 109; AD 12, 15, 19, 23, 26, 28, 36, 39, 42, 48, 53, 55; NGV 456, 458, 484

Novena Conferencia Internacional Americana AC 22-23, 107, 109; NCI 6-7, 81-82; NCV 456, 462, 464-465, 474, 478, 485, 494, 513, 519, 550-551

Octava Conferencia Internacional Americana CA 23, 109, NGI 6, 7; NCV 39

Quinta Conferencia Internacional Americana AD 44

Séptima Conferencia Internacional Americana CA 23; NGV 466

Sexta Conferencia Internacional Americana NGV 477

Consejo Directivo de la Unión Panamericana CA 21-24, 53; AD 53-55 109-111; NGI 6-7; NCV 559

Constitución $\mathrm{AD} 7,15,31,36-39$; NCV 452, 459, 504, 551, 600

Constitución Argentina NCV 541

Constitución de Brasil NGV 457

Constitución de Colombia NCV 457

Constitución de los Estados Unidos AD 31, 38, 48; NCV 551 
Este libro forma parte del acervo de la Biblioteca Jurídica Virtual del Instituto de Investigaciones Jurídicas de la UNAM

Constitución Francesa AD 41

Constitución de Panamá NCV 457

Constitución del Perú AD 37-38

Constitución de Uruguay NCV 457

Constitución de Venezuela NCV 457

Correspondencia AD 1, 21-22; NCV 449, 480, 496, 505, 579; NCVI 249

Censura de la Correspondencia AD 22

Derecho de la Correspondencia NCV 480, 579

Corte Interamericana de Justicia NCI 236; NCV 464, 485-486, 494, 503, 514, 556560, 568, 571, 596-597, 616-617. Véase también Tribunal Interamericano

Corte de Justicia Internacional NGI 202; NCV 463, 465, 547-548, 550, 551, 616-617. Véase también Tribunal Internacional

Cristiandad AD 35

\section{Cristo NGV 566}

Disciplinas cristianas NGV 560

Era Cristiana AD 44

Moral cristiana CA 23

D

\section{Deberes}

Deber de Abstenerse de Actividades Políticas en País Extranjero NCV 484, 500, 501, 509, 574, 606-607; NCVI 253

Deberes de Asistencia y Seguridades Sociales NCV 500, 509, 605; NCVI 251
Deberes para con los Hijos y los Padres AD 6, 35, 36; NCV 499, 508, 602, 603; NCVI 251

Deberes de Instrucción NGV 484, 500, 508, 603

Deber de Obediencia a la Ley NGV 483, 500, 509, 600, 604; NCV1 252

Deber de Pagar Impuestos Véase Impuestos

Deber de Servir NGV 483, 500, 509, 604; NCVI 252

Deber de Prestar Servicio de Armas NGV 483, 574, 604

Deberes ante la Sociedad NGV 483, 499, 508, 602; NGVI 251

Deber de Sufragio Véase Sufragio

Deber de Trabajo NCV 484, 500, 509, 606; NGVI 253

Declaraciones

Declaración Americana de los Derechos y Deberes Esenciales del Hombre NCI 129, 235-236; NCV 476, 479, 495, 503504, 513, 516, 577, 594; NCVI 248. Véase también Declaración de Derechos y Deberes

Declaración de Derechos y Deberes CA 23; AD 16, 32, 51-53, NGV 456, 475-476, 539, 624

Declaración de los Derechos del Hombre y del Ciudadano AD 13, 15, 17, 19, 47; NCV 558

Declaración de Independencia de los Estados Unidos AD 21, 38, 47, 51

Declaración de México AD 45, 48 
Declaración de los Principios Sociales de América AD 45

\section{Defensa Nacional AD 22; NGV 457}

Democracia CA 111; AD 15, 32; NCI 129; NCV 301, 437, 456, 460, 503, 510, 512, 516, 519, 539-540, 589-590, 600, 619-621

Estado Democrático AD 14-15, 19-20, 39, 42-43, 46, 50, NGV 472

Gobierno Democrático AD 17, 19

Derechos

Alcance NCV 596

Derecho Anglo-Sajón AD 32

Derecho de Asilo Véase Asilo

Derecho de Asociación AD 4, 29-30;

NCV 450，482，498，507，589-592;

NCVI 251

Derechos de Autor AD 43; NCV 481, 497, 506, 583; NCVI 250

Derecho a los Beneficios de la Cultura NCV 480, 497, 506, 514, 582-583

Derecho de la Correspondencia Véase Correspondencia

Derecho al Descanso y a su Aprovechamiento NCV 481, 497, 506, 584; NCVI 250

Derechos Económicos AD 16, 19-20, 40, 46, 51; NCV 545

Derecho de Educación AD 9-10, 4647; NCV 471, 480, 496, 505, 506, 573, 579, 581; NGVI 249
Derecho a la Familia y su Protección NGV 480, 496, 505, 578

Derecho Fundamental AD 10-17, 1922, 26, 29-30, 32, 35, 37, 41, 47-51, 5357; NCV 453-454, 464, 481, 497, 501, 507, 544, 550, 558, 571, 599, 624, 626; NGVI 250

Derecho de Igualdad ante la Ley AD 10, 18, 47, 48, 50, NGV 455, 460, 472, 479, 495, 505, 578; NGVI 248

Derechos Intelectuales NCV 582

Derecho Internacional CA 2324, 52; AD 13, 18, 49, 52-53, 5556; NGI 129; NGV 455-456, 461, 467, 511, 515, 600, 608, 617, 620

Derecho Internacional Privado AD 49

Derecho Internacional Público NCI 129

Derecho de Inviolabilidad del Domicilio NGV 480, 496, 505, 579

Derecho de Justicia NCV 481, 501, 507, 587-588, 599, 601; NCVI 250

Derecho de Libertad de Investigación, Opinión, Expresión y Difusión NGV 479, 495, 505, 578; NGVI 248

Derecho de la Libre Investigación NGV 545

Derecho a la Libertad Religiosa Véase religión

Derecho a la Nacionalidad Véase nacionalidad

Derecho de Petición AD 4, 31; NGV 451, 458, 482, 498, 507, 594; NGVI 251 
Derechos políticos AD 19-20, 41, 48; NCV 545, 613, 622

Derecho a la Preservación de la Salud y al Bienestar NGV 496, 505, 541, 579, 598, 599; NCVI 249

Deber de Prestar Servicio de Armas Véase Deber de Servir

Derecho a Proceso Regular AD 7, 37; NCV 452, 482, 498, 507, 594 NGVI; 251

Derecho de Propiedad Véase Propiedad

Derecho de Protección contra la Detención Arbitraria NCV 482, 498, 507, 594; NCVI 251

Derecho de Protección a la Honra, la Reputación Personal y la Vida Privada y Familiar NCV 479, 496, 578

Derecho de protección a la Maternidad y a la Infancia NCV 480, 505, 578; NGVI 249

Derecho de Reconocimiento de la Personalidad Jurídica y de los Derechos Civiles Véase Personalidad Jurídica

Derechos de Residencia y Tránsito Véase Residencia

Derecho de Resistencia NCI 235; NCV 477-478, 501-502, 515, 543, 544, $596,599-600$

Derecho de Reunión AD 4, 27, 2931; NGV 450, 482, 498, 507, 590-592; NCVI 251

Derecho Romano AD 32; NGV 586

Derecho a la Seguridad Social NGV 453, 460, 472, 481, 497, 506, 541, 585, 586, 598; NCVI 250
Derechos Sociales AD 19-20, 40, 51; NGV 545, 547, 556, 613

Derecho de Sufragio y de Participación en el gobierno Véase Sufragio

Derecho al Trabajo y a una Justa Retribución AD 7, 40-43; NCV 452, 456, 460, 471, 481, 497, 506, 583; NCVI 250

Derecho a la Vida, a la Libertad, a la Seguridad e Integridad de la Persona NGV 578; NGVI 248

Dictadura NCV 546, 549

Gobiernos Dictatoriales AD 36

Dignidad AD 5, 15-16, 19, 31, 34, 36, 41, 44, 47-48; NGV 451, 455, 466, 477, 479, 482, 495, 498-499, 504, 507, 513, 544, 564, 576, 580, 601-602, 620-621, 624, 626; NGVI 248, 251

Dominio AD 13, 32

Dominación NGV 511

E

Estados Americanos AD 34, 37- 40, 42, 44; NGV 478-479, 494-495, 504, 573

Estado Judío AD 15

F

Fanatismo AD 25

Fascismo NCV 625

Fascistas AD 25

Función Social AD 32-33 
Este libro forma parte del acervo de la Biblioteca Jurídica Virtual del Instituto de Investigaciones Jurídicas de la UNAM

G

Gasto Público NGV 605

Gobierno de Facto NGV 437, 466, 503,

510-512, 516, 539-540, 608

Golpe de Estado NCV 512

Guerra CA 109, AD 13, 18, 22, 25, 27, 33, 44, 56; NGV 457, 569-570, 574, 604, 626

Conferencia sobre Problemas de la Guerra y de la Paz Véase Conferencias Internacionales Americanas

Guerra de los 30 años AD 27

Primera Guerra Mundial AD 33, 34; NCV 454

Segunda Guerra Mundial CA 109; AD 15; NGV 624

$\mathrm{H}$

Habeas corpus AD 37; NCV 587, 624

Humanitaria AD 13, 15, 17, 55; NCV 457, 617

Intervención Humanitaria AD 13

I

Idioma $\mathrm{AD} \mathrm{17,} \mathrm{45,} \mathrm{48;} \mathrm{455,} \mathrm{479,} \mathrm{495,} \mathrm{505,}$ 575, 587; NGVI 248

Individualismo $\mathrm{AD} 14$

Industrialismo $\mathrm{AD} 14$

In fraganti $\mathrm{AD} 16,36,37$; NGV 452

Inmigración NGV 595

Inmigrantes $\mathrm{AD} 34$
Inmunidad CA 21

Impuestos AD 32, 48; NCV 483, 500, 509, 605-606; NCVI 252

Deber de Pagar Impuestos NCV 500, 509, 605-606; NCVI 252

$\mathrm{J}$

Jurisprudencia AD 37

Jus sanguini AD 34; NCV 459

Jus soli AD 34; NGV 459

Justicia distributiva AD 20, 32

Justicia Social AD 5, 19, 20, 31, 33, 51;

NCV 541, 621, 622

$\mathrm{L}$

Laissez faire $\mathrm{AD} 20$

Legislación Interna NGV 595, 607

Leyes Fundamentales AD 36; NGV 620

Ley Natural NGV 544

Libertad de Enseñar NGV 579

Libertad Personal AD 22, 35-37, 42; NCV 449, 457

Libertad Religiosa Véase religión

Liga de las Naciones AD 34

M

Medios de Comunicación NGV 457, 470

Menores AD 34; NGV 483, 499, 508, 602;

NGVI 252 
Este libro forma parte del acervo de la Biblioteca Jurídica Virtual del Instituto de Investigaciones Jurídicas de la UNAM

Mercancía AD 18

Monopolio AD 13, 23, 43, 47; NCV 453 457-458

Moral CA 23; AD 1, 3, 13, 15, 19, 21, 2628, 35-36, 39-41, 44-45, 55; NCV 449,-450, 456, 458, 477, 480- 481, 496-497, 499, 506, 509-510, 514-516, 541, 559-560, 589, 602, 605, 609, 619, 621, 626; NCVI 248-250

Mujer AD 6, 16, 35-36, 39, 45; NCV 451, 455, 459, 480, 496, 505, 544-545, 589, 621; NCVI 249

$\mathrm{N}$

Nacer AD 1, 20, 21; NGV 449

Nacimiento DA 5, 33, 34; NCV 596

Nacionalidad CA 22; AD 5-6, 17, 21, 33, 34, 49; NGV 451, 455, 459, 467, 481, 497, 507, 575, 588, 626; NGVI 250

Derecho a la Nacionalidad AD 34; NGV 451, 459, 481, 497, 507, 588; NCVI 250

Nacionalismo AD 13

Naciones Unidas CA 52; AD 11, 14, 16, 18, 20, 50, 53-54; NGI 7, 200; NGV 455, 462, 475-477, 513, 541, 544, 546-547, 550, 562, 576, 580, 589, 591, 596, 613, 617, 626

Asamblea General de las Naciones Unidas AD 34, 40; NGV 513, 591

Carta de las Naciones Unidas AD 45, 51, 52, 55; NGV 454-455, 466, 544$546,550,621$

Consejo Económico y Social AD 54; NCV 546, 547, 613, 626, 627

Secretaria General de las Naciones Unidas NCI 7-8
Naturaleza AD 19, 32, 35, 48; NCV 477, 479, 495, 504, 513; NGVI 248

\section{Nazismo NGV 625}

Novena Conferencia Internacional Americana Véase Conferencias Internacionales Americanas

$\mathrm{O}$

Octava Conferencia Internacional Americana Véase Conferencias Internacionales Americanas

Organización de los Estados Americanos NGV 512, 514

Carta de la Organización de los Estados Americanos CA V, 109

\section{$\mathrm{P}$}

Pacto Constitutivo AD 13, 52, 57; CA 23, 109- 110; NGV 539, 553-554, 564-565, 571 , 613-620, 625-627

Panamericanismo NCV 455, 528, 541, 619

Partidos Políticos AD 7, 28, 30, 38; NCV 452, 590

Paternidad NCV 582

Personalidad Jurídica AD 30; NGV 481, 497, 506, 514, 586; NGVI 250

Derecho de Reconocimiento de la Personalidad Jurídica y de los Derechos Civiles NCV 481, 497, 506, 586; NGVI 250

Poder Público AD 38

Política Interna AD 30, 33; NCV 466, 606, 608

Prensa AD 3, 13-14, 23, 25-27; NCV 450, 457-458, 545, 581 
Este libro forma parte del acervo de la Biblioteca Jurídica Virtual del Instituto de Investigaciones Jurídicas de la UNAM

Conferencia sobre Problemas de la Guerra y de la Paz Véase Conferencias Internacionales Americanas

Procedimiento Legal AD 32, 34

Procedimiento Sumario Véase Sumario

Propaganda AD 3, 13-14, 23, 26-27, 35;

NGV 450, 458

Propiedad

Colectiva AD 32

Derecho de Propiedad AD 5, 18, 3133; NCV 451, 455, 459, 470, 482, 498, 507,592

Particular AD 32

Privada AD 5, 31-33, 36; NGV 451, 482, 498, 507, 593; NCVI 251

$\mathrm{R}$

\section{Raza AD 39; NCV 472}

Divergencia racial AD 33

Minoría racial AD 14

Refugiados AD 34; NCV 454, 595

Religión AD 7, 16-18, 28, 38-39, 45, 48; NGV 452, 455, 473, 479, 495, 505, 575, 589,626

Religiosa AD 13, 18, 26-28; NCV 454, 458, 467, 479, 495, 505, 578; NGVI 248

Minoría Religiosa AD 13

Propaganda Religiosa AD 3, 27-28

Libertad Religiosa AD 28; NCV 470
Derecho a la Libertad Religiosa AD 3, 26; NCV 450, 458, 467, 479, 495, 505, 578 NCVI 248

Residencia AD 1, 21-22; NGV 449, 480, 483, 496, 500, 505, 509, 513, 578, 605, 606; NCVI 249

Derechos de Residencia y Tránsito NGV 480, 496, 505, 578; NGVI 249

\section{Residente NGV 588}

Residir AD 34; NCV 454, 528

Retroactividad AD 38

Revolución Francesa AD 47; NGV 551

S

Salud Pública AD 1, 3, 21, 27, 28, 44, 45; NGV 450

Seguridad CA 20; AD 1, 3, 9, 19, 22, 25, 27-28, 41, 44-45; NGI 8; NGV 449, 450, 453-454, 469, 512, 524, 528, 541

Servicio Militar NCV 574, 604

Sistema Interamericano CA V, 3, 20-23, 52, 109; AD 13, 52, 54-55, 57, 109; NCI 202; NCV 617- 618, 622, 625-626

Sufragio AD 7, 36, 38-40, 49; NCV 452, 458-459, 481, 483, 498, 500, 507-508, 514, 588, 603; NGVI 250-251

Deber de Sufragio NCV 509, 603; NGVI 252

Derecho de Sufragio y de Participación en el gobierno NGV 481, 498, 507, 588; NCVI 251. Véase también Voto Secreto

Sumario NCV 587 
Este libro forma parte del acervo de la Biblioteca Jurídica Virtual del Instituto de Investigaciones Jurídicas de la UNAM www.juridicas.unam.mx

http://biblio.juridicas.unam.mx/bjv

$\mathrm{T}$

Tortura AD 37-38

Totalitarismo NGI 235; NGV 590, 622, 625

Estado Totalitario AD 34

Gobierno Totalitario AD 13, 1726

Totalitarias AD 26; NGI 235; NGV 542

Tradición AD 22, 35-36, 81; NGV 518, $528,573,625$

Tratado Interamericano de Asistencia Recíproca NGV 456, 466, 619

Tribunal Interamericano NCV 557, 571. Véase también Corte Interamericana

Tribunal Internacional AD 56; NCV 460, 465, 570, 620. Véase también Corte Internacional

Tribunal Moral NCV 559

$\mathrm{U}$

Unión Panamericana CA V, 21-24, 53, 55;

AD 13, 53, 55; NCV 485, 510, 559

Utilidad pública AD 32; NGV 451, 471

V

Voto Secreto NCV 481, 498, 507, 588, 589-

590; NGVI 25. 
Los trabajos preparatorios de la Declaración Americana de los Derechos y Deberes del Hombre y el origen remoto de la Corte Interamericana, editado por el Instituto de Investigaciones Jurídicas de la UNAM, se terminó de imprimir el 24 de octubre de 2017 en los talleres de Impresos Chávez, S. A. de C. V., Valdivia 31, colonia María del Carmen, delegación Benito Juárez, 03540 Ciudad de México, tel. 5539 5108. Se utilizó tipo Baskerville en 8, 9, 10 y 11 puntos. En esta edición se empleó papel cream book 70 × 95 de 60 gramos para los interiores y cartulina couché de 250 gramos para los forros.

Consta de 300 ejemplares (impresión offset). 
ste libro pone de relieve la importancia de la Declaración Americana de Derechos y Deberes del Hombre, que pronto celebrará sus setenta años; lo hace mediante el análisis de la declaración y la publicación, en un texto único y sistemático, de los trabajos preparatorios de la misma.

Este libro comienza por analizar la relevancia jurídica y práctica de esta primera declaración integral a nivel internacional en torno a los derechos humanos. Describe su aplicación por los órganos del Sistema Interamericano de Derechos Humanos, y hace particular referencia a sus trabajos preparatorios. Éstos son de importancia para la interpretación de los instrumentos internacionales, especialmente si son aplicados por órganos internacionales.

El anexo de este libro publica los trabajos preparatorios de la declaración. Esta es la primera vez que son editados en forma ordenada, sin que se encuentren confundidos entre los trabajos de otros instrumentos. Además, esta edición facilita enormemente su consulta, al contar con un índice temático y títulos que identifican las discusiones generadas al interior de la Novena Conferencia Internacional Americana, donde consta la mayor parte de estos trabajos. El anexo también incluye documentos en los que se recomienda crear una futura corte de derechos humanos para la región.
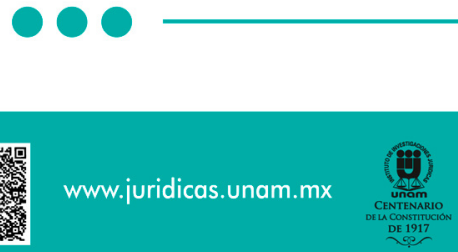